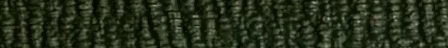

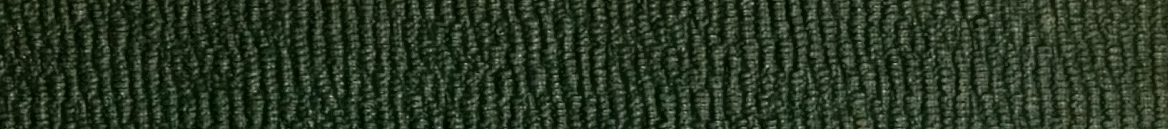

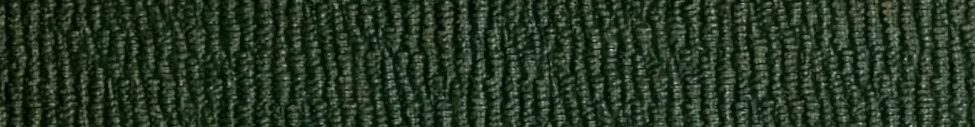

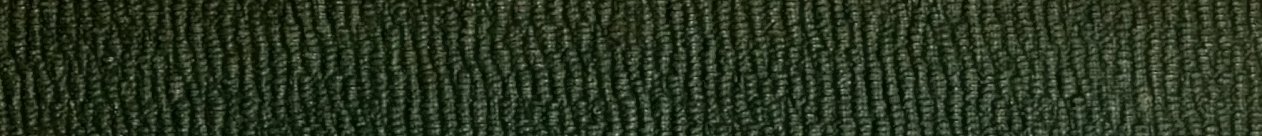

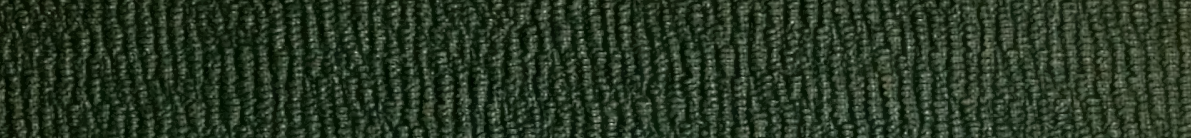
13 (1)
13)
든 I

(4)

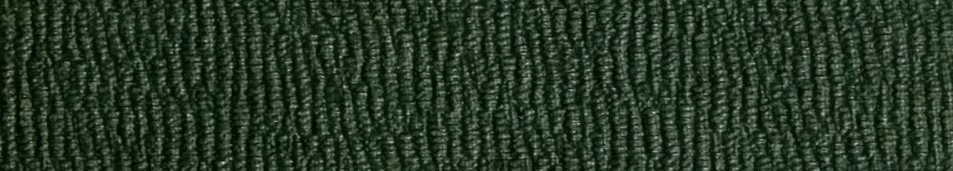

(2) 1.20

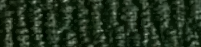

(3)

12 1)

ate

d)

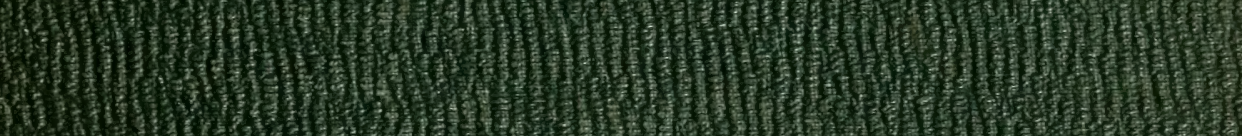

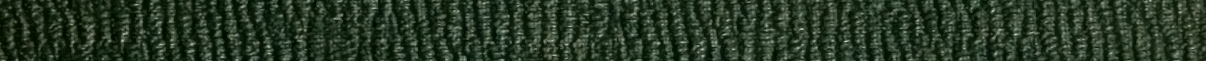

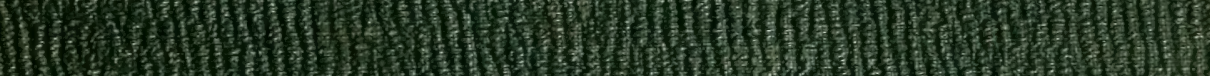
13.

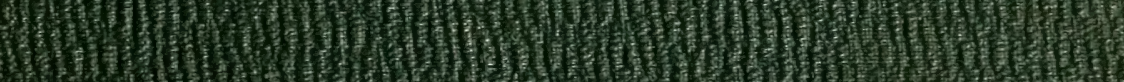
10.600

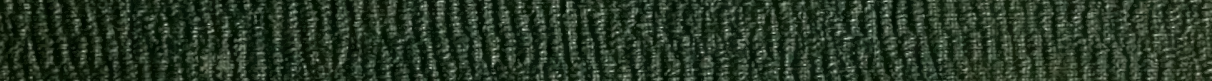

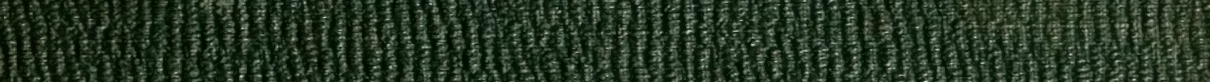
H.

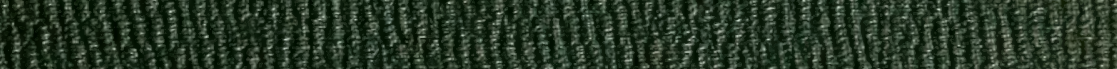

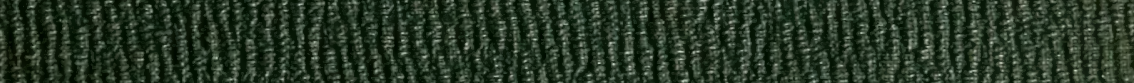

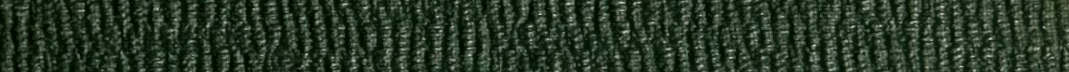

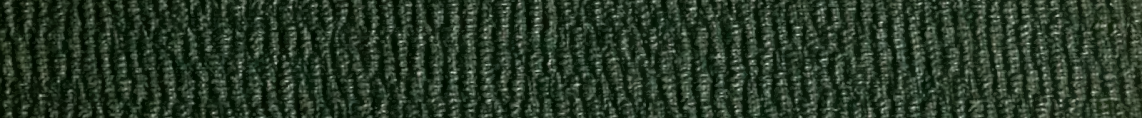

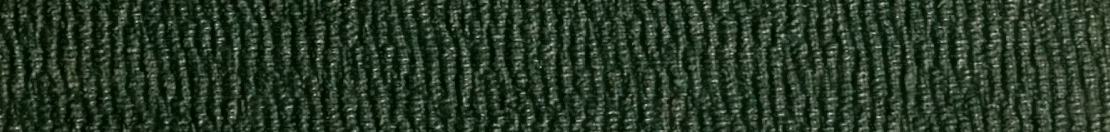

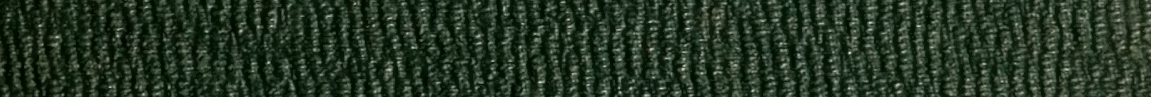

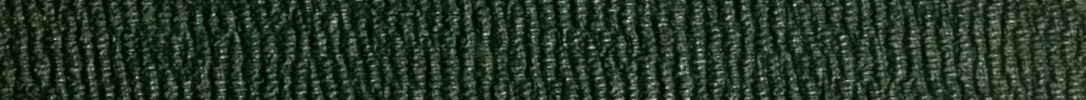
1.10

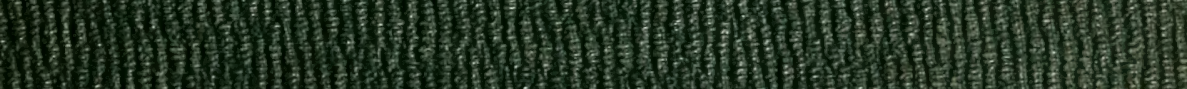

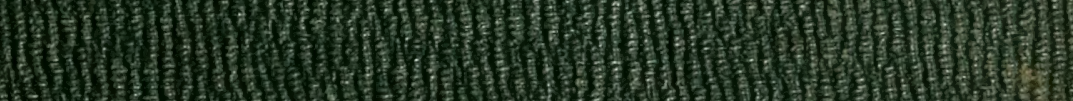
1960) (1) 
$95.3 u y$

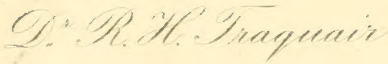





$$
\{x \mid 3
$$




\title{
HOU.ROM A H
}

\section{TI T IV O T O O N}

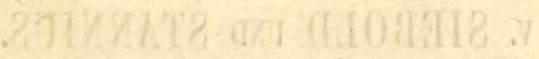

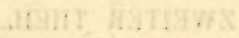

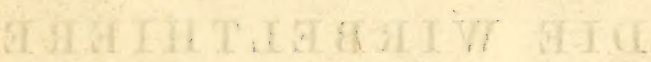

$70 \%$

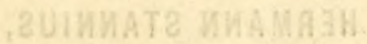

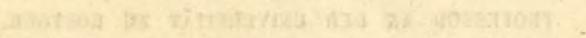

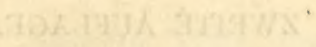

.7w Tstage

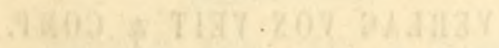




\section{HANDBUCH}

DER

Z O O T O M I E

voN

v. SIEBOLD UND STANNIUS.

ZWEITER THEIL.

DIE W I R B E L T H ERE

voN

HERMANN STANNIUS,

PROFESSOR AN DER UNIVERSITÄT ZU ROSTOCK.

ZWEITE AUFLAGE.

\section{BERLIN.}

VERLAG VON VEIT \& COMP.

1854. 


\title{
HANDBUCH
}

DER

\section{ANATOMIE DER WIRBELTHERE}

voN

\author{
HERVANN STANNIUS,
}

PROFESSOR AN DER UNIVERSITÄT ZU ROSTOCK.

ZWEITE AUFLAGE.

\section{BERLIN.}

VERLAG VON VEIT \& COMP.

1854. 


\section{H०)}

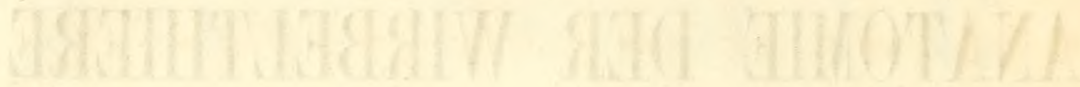




\section{Vor w o r t.}

Als vor etwa vierzehn Monaten die Aufforderung der Herrn Verleger zu Besorgung einer neuen Auflage des „Lehrbuches der vergleichenden Anatomie der Wirbelthiere" an mich gelangte, war ich einerseits erfreuet über die sich bietende Gelegenheit, die Umgestaltung einer an so vielen Mängeln leidenden Druckschrift vornehmen zu können, während andererseits die lebhaftesten Zweifel mich beherrschten, ob es mir auch jetzt gelingen werde, eine, mässigen Ansprüchen genügende, Uebersicht der Organisationsverhältnisse der Wirbelthiere zu liefern. Der Umstand, dass schon der erste Versuch Manchem nützlich geworden ist, und dass das Bedürfniss einer neuen übersichtlichen Darstellung allgemein empfunden wird, wurde entscheidend für mich. Die Arbeit, deren erste Abtheilung ich hiermit dem Publikum übergebe, will nur ein Leitfaden sein für den Lernenden und ihm durch Andeutung der Quellen den Beginn eigener Studien erleichtern. Wenn sie auf eine unendliche Fülle der Bildungsverhaltnisse ihn hinweiset, die als Variationen Eines Planes erscheinen, so mag Ehrfurcht in ihm geweckt werden vor dem 
schöpferischen Geiste von dem Solches ausging, und wenn sie in Männern, wie Georg Cuvier, Carl Ernst v. Baer und Johannes Müller die Genien nennt, denen es oftmals gelungen, den grossen Gedanken dieser Schöpfungen nachzudenken, so zeigt sie ihm die Vorbilder, denen er nachzueifern trachte. - Was den Umfang der gegenwärtigen Arbeit anbetriff, so wird er den der vorigen Auflage nur um ein Geringes überschreiten, da nicht die Aufzählung aller bekannten Einzelheiten, sondern nur eine übersichtliche Darstellung des Ganzen beabsichtigt ist. Meinerseits möchte ich für diese neue Bearbeitung eine ähnliche Nachsicht wünschen, wie sie der ersten Auflage zu Theil geworden ist.

Rostock, Ende Juli 1853. 
ERSTES BUCH.

\section{I E F I S C H E.}




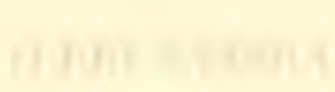

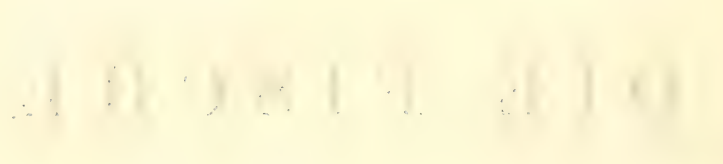




\section{Frstes Buch.

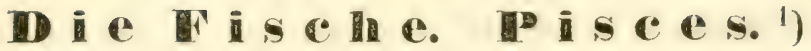

\section{Uebersicht der Gruppen. ${ }^{2}$ )}

\section{Subclassis I. LEPTOCARDIY ${ }^{3}$ ).}

\section{Ordo: Amphioxini. Branchiostoma.}

1) M. E. Bloch, Naturgeschichte der ausländischen Fische. Thl. 1-9. Berlin, 1785-1794. 4. Mt. Kpfrn. in fol. - M. E. Bloch, Oekonomische Geschichte der Fische Deutschlands. Thl. 1-3. Berlin 1782-1781. 4. Mit Kupfrn. in fol, Rein zoologisch, doch, der Abbildungen wegen, zu consultiren. - Cuvier et Valenciennes, histoire naturelle des poissons. Vol. 1-22. Paris. 182S-1849. Leider al)gebrochen, ohne vollendet zu sein. Behandelt nur die Acanthopteri und einen Theil der Malacopteri nach der Cuvier'schen Anordnung. Eine classische Uebersicht der Anatomic der Fische, wesentlich gestüzt auf eine durchgefïlirte Anatomie der Perca fluviatiiis, findet sich im ersten Bande. Zahlreiche anatomische Notizen sind der Charaliteristik der einzelnen Gattungen und Arten beigegeben. - Ileinrich Ir röyer, Danmark's Fiske. Kiöbenhavn. $1838 \mathrm{sqq}$. Noch nicht vollendet. Enthält sehr genaue anatomische Detail-Angaben. - Alexander llonro, The structure and physiology of fishes explained and compared with those of man and other animals. Edinb. 1786. fol. Uebersetzt von Schneider. Leipz. 1787. 4. - Richard 0wen, Lectures on the comparative anatomy and physiology of the vertebrate animals. Part 1. Fishes. Lond. 1846. 8. - $\boldsymbol{A}$ gassiz, Recherches sur les poissons fossiles. Neuchatel 1833 - 1544. 4. Mt. Tfln. in fol. - Ueber Entwickelungsgeschichte der Fische handeln: II. Rathke, Abhandlungen zur Bildungs - und Entwickelungsugeschichte des Menschen und der Thiere. Thl. 2. Leipz. 1833. 4. Entwickelung von Zoarces viviparus. - C. E. von Baer, Untersuchungen über die Entwickelungsgeschichte der Fische. Leipz. 1835. 4. - C. Vogt, Embryologie des Salmones. Soleures. 1841. Mt. Kpfrn. in fol. - de Filippi, Developpement des poissons. Annali universali di medicina di Milano. 1841. Revue zoologique. Paris. 1842. p. 45. - Duvernoy, (ïber die Entwicklung der Poecilia surinamensis). Annales des sciences naturelles 1844. 1. p. 313. - Comptes rendus. Vol. 18. 1844. p. 667. 720. - Rathke, Beiträge zur Entwickelungsgeschichte der Haie u. Rochen (Schriften d. naturf. Gesellschaft zu Danzig. Bd. 2. Ilft. 2.

2) Ich folge der Cuvier'schen, durch M̈̈ller modificirten Eintheilung.

3) II einrich Rathke, Bemerkungen über den Bau des Amphioxus lanceolatus. liönigsb. 18+1.4. - Goodsir, in den Transactions of the foyal society of Edinburgh. 
Erstes Buch, Die Fische.

Subclassis II. Marsipobranchit s. Cyclostomi.

Ordo 1.: Hyperotreli ${ }^{4}$ ).

Fam.: Myxinoüdei. Myxine. Bdellosioma.

Ordo 2.: Hyperoartii ${ }^{5}$ ).

Fam.: Petromyzonini. Petromyzon. Ammocoeles.

Subclassis III. Exasmobranchit s. Selachii ${ }^{6}$ ).

Ordo 1.: Holocephali.

Fam.: Chimaerae. Chimaera. Callorhynchus.

Ordo 2.: Plagiostomi.

Subordo 1.: Squalidae.

Familiae: 1. Scyllia.

Scyllum. Chiloscyllium. Pristiurus.

2. Nictilantes.

Carcharias. Splayrna. Galens. Mustelus.

3. Lamnö̈dei.

Lamna.

4. Alopeciae.

Alopias.

5. Cestraciones.

Cestracion.

6. Rhinodontes.

Rhinodor.

Vol. XV. Part 1. - J. Müller, Ueber den Bau und die Lebenserscheinungen des Branchiostoma lubricum. Berlin. 154\%. Itt. 5 Kpfrtlln. Aludruck aus den Abhandlungen der Königl. Academie der Wissenschaften zu Berlin. Berl. 1844. 4. - Quatrefag es in den Annales des sciences naturelles. Nouv. série. T. XVIII. p. 193. - Costa Storia e Notomia del Branchiostoma lubrico. Napol. 1843. fol.

4) J. Müller, Vergleichende Anatomie der Myxinoìden, 5 Bde. Berl. 1835-45. Enthält, neben der Anatomie der Myxinoïden zahlreiche und schöne vergleichende Excurse über die Anatomie der Cyclostomen, der Elasmoliranchii, des Störs und auch Jer Knochenfische.

5) Heinrich Rathke, Bemerkungen üher den inneren Bau der Pricke, Danzig. 1825. 4. - Ueber den Bau des Querders (Ammocoetes) in seinen Beiträgen zur Geschichte der Thierwelt. Bd. 4. IIalle. 152\% 4. - Ueber Ammocoetes: Quatrefages Journal de l'institut. 1849. p. 220.

6) Müller u. Il e n l e, Systematische Beschreibung der Plagiostomen. Berl. 18 \$1. fol. - Retzius, Observationes in anatomiam chondropterygiorum. Lund. 1819. 4. J. II enle, Ueber Narcine, eine neue Gattung electrischer Rochen. Berl. 1834. 4. John Davy, Researches physiological and anatomical. Vol. I. Lond. 1839. 8. Experiments and observations on Torpedo. p. 1-94. u. Vol. II. p. 436. sqq. II ̈̈ller, Vergleichende Anatomie der Myxinoïden. - Duvernoy, Sur la chimère arctique in d. Annales des sciences natur. 1837. 8. p. 35. - Leydig, Beiträge zur mikroskopischen Anatomie 1. Entwickelungsgeschichte der Rochen u. Iaie. Leipzig. 1852. 8. - Leydig, Uewer Chimaera in Müller's Archiv. 1851. 
7. Nolidani.

Hexanchus. Heplanchus.

8. Spinaces.

Acanthias. Spinax. Centroscyllium.

9. Scymnoïlei.

Scymurs.

10. Squalinae.

Squatina.

Subordo 2.: Rajidae.

Familiae: 1. Syuatinorajae.

Pristis. Rhinobahus.

2. 'Torpedines.

Torpedo. Narcine. Astrape.

3. Rajae.

Raja.

4. Trygones.

Trygon.

5. Myliobalides.

Myliobatis. Aielobatis. Rhinoptera.

6. Cephalopterae.

Cephaloplera.

Subclassis IV. GANotDET ${ }^{7}$ ).

Orilo 1.: Chondrostei.

Familiae: 1. Accipensevini.

Accipenser. Scaphirhynchus.

\section{Spalulariae.}

Spatularia.

Ordo 2.: IIolostei.

Familiae: 1. Lepidosteini.

Lepidosteus.

2. Polyplerini.

Polypterus.

3. Amiae.

Amia.

7) Ueber Accipenser: Karl Ernst von Bacr, Berichte von der Königl, anatomischen Anstalt zu Königsberg. Zweiter Bericht. Leipz. 1819. 8. - J. Müller, Ueber den Bau und die Grenzen der Gamoĩden und das natür. System der Fische. Berl. 1846.4. - S. auch Wiegmann-Erichs on's Archiv für Naturgesch. 11. Jahrg. 1845. S. 91. ff. - Vogl, in den Annales des sciences natur. 1845. - Franųue, Nonnulla ad Amiam calvam accuratius cognoscendam. Berl. 10 4 . fol. - A. Wagner, de Spatulariarum anatome. Berol. 1848. 4. 
Subclassis V. TELBOSTEI ${ }^{8}$ ).

Ordo 1: Acanlhopleri.

Familiae: 1. Percoüdei.

Perca. Lucioperca. Aspro. Serranus. Plectro. poma. Acerina. Myripristis. Holocentrum. Priacanthus. Uranoscopus. Polynemus.

2. Calaphracli.

Coltus. Agonus. Synanceia. Trigla. Platycephalus. Sebastes. Plerois.

3. Sparoïdei incl. Maenides.

Sargus. Pagellus. Box.

4. Sciaenoüdei.

Sciaena. Corvina.

5. Labyrinthici.

Ophicephalus. Anabas, Helostoma. Osphronemus. Macropodus.

6. Mugiloüdei.

Mugil. Dajaus.

7. Nolacanthini.

Nolacanthus. Rhynchobdella.

8. Scomberoüdei.

Caranx. Scomber. Cybium. Vomer. Argyreiosus. Zeus. Thynnus. Xiphias. Stromateus. Seserinus. Kurlus.

9. Squamipennes.

Brama. Chatodon. Holacanthus. Plalax.

10. Taenioüdei.

Cepola. Trachypterus.

11. Gobioïdei el Cyclopteri.

1) Gobioüdei: Gobius Schn. Sicydium Valenc. Anarrhichas.

2) Discoboli: Cycloplerus. Liparis. Syciases Miill. Cotylis Miill.

3) Echeneïles: Echeneis.

12. Blennioüdei.

Blennius. Zoarces. Lycodes. Callionymus.

13. Pediculati.

Lophius. Chironectes. Batrachus. Mallhaea.

\section{Theutyes.}

Amphacanthus. Acanthurus.

8) Das reichste Detail bei Cuvier und Valenciennes. 


\section{Fistulares.}

Fistularia.

Ordo 2.: Anacanthini.

Familiae: 1. Gadoüdei.

Gadus. Lola. Raniceps. Lepidoleprus. Motella. Phycis.

2. Ophidini.

Ophidium.

3. Pleuronectides.

Pleuronecles. Rhombus. Solea. Achirus.

Ordo 3.: Pharyngognathi.

Subordo 1.: Pharyngognalhi acanthopteri.

Familiac: 1. Labroïdei cycloödei.

Labrus.

2. Labroüdei clenoüdei.

Amphiprion. Glyphisodon.

3. Chromides.

Cichla Cuv.

Subordo 2.: Pharyngognathi malacopterygii.

Familiae: Scomberesoces.

Belone. Exocoelus. Hemiramphus.

Ordo 4: Physostomi.

Subordo 1.: Physostomi abdominales.

Familiae: 1. Siluroïdei.

a) Siluri.

Silurus, Aspredo. Malapterurus. Bagrus.

b) Loricarinae (Goniodontes Agass).

Loricaria. Itypostoma.

2. Cyprinoüdei.

Cyprinus. Alramis. Calastomus. Tinca. Colitis.

3. Characini.

Macrodon. T'etragonopterus.Serrasalmo.Anodus.

4. Cyprinodontes Agass. Poeciliae Valenc.

Anableps. Poecilia. Fundulus.

5. Mormyri.

Mormyrus.

6. Esoces.

Esox.

7. Galaxiae.

Mesyles. 


\section{Eistes Buch. Die Fische.}

8. Salmones ${ }^{9}$ ).

Salmo. Osmerus. Coregonus. Mallotus. Argrentina.

9. Scopelini.

Aulopus.

10. Clupeïdae $\left.{ }^{10}\right)$.

Clupea. Alosa. Nolopterus. Myodon. Mlegalops. Elops. Lutodeira. Butirinus. Chirocentrus.

IIeterotis. Osteoglossum.

11. Heteropygii ${ }^{11}$ ).

Amblyopsis.

Subordo 2.: Physostomi apodes.

12. Muraenoüdei ${ }^{12}$ ).

Anguilla. Muraenophis. Aplerichthus. Ophisurus.

13. Gymnolini.

Gymnolus. Carapus. Gymnarchus. (?)

14. Symbranchii.

Symbranchus. Monopterus. Amphipnous.

Ordo 5.: Plectognathi.

Familiae: 1. Bulistini.

Balistes. Aluleres.

2. Ostraciones.

Ostracion.

3. Gymmodon(es ${ }^{13}$ ).

Diodon. Triodon. Telrodon. Orthagroriscus.

9) Agasiz et Vogt, Anatomic des Salmones. In den Mémoires de la société d'histoire naturelle de Neuchatel. Tome 3. Neuchatel. 1545. 4. Ein ausgezeichnetes Werk.

10) Die von II üller den Clupeïdae zugerechnete Gattung Hyodon gehört, in sofern der Bau der weiblichen Geschlechtstheile für ihre Stellung entscheidend sein soll, anscheinend nicht in diese Familie. Hyodon clatudulus hat die Eierstochsbildung der Salmones. Jie Verhältnisse der Schwimmblase sind von Valenciennes durchaus verkannt worden. -- Valenciennes, (Vol. XXI. p. 138.) gibt auch für Notopterus an, dass seine Eier in die Bauchhöhle fallen, eine Thatsache, die mir an einem schlecht conservirten Exemplar nicht klar geworden ist.

11) Tellk ampf, in Müller's Archiv. 1844. S. 38\%. - Wyman, in American Journal of natural sciences. Octob. 1843.

12) J. Mc. Clelland, Apodal fishes of Bengal, in: Calcutta Journal of natural history. T. V. Nr. 18. Juli 1844. - Erdl, Ueber Gymnarchus niloticus in d. gelehrten Anzeigen, herausgegeb. v. d. k. Baierschen Acad. d. Wissensch. 1८4t. Nr. 202. 203.

13) Camille Dareste, (über die Osteologie des Triodon) in d. Annal. des scienc. natur. T. XII. p. 68. - Wellenbergh, Observationes anatomicae de Orthagorisco mola. Lugd. Bat, 1840. 4. 
Ordo 6.: Lophobranchii.

Syngnathus ${ }^{14}$ ).

Subclassis V1. Drexor ${ }^{15}$ ):

Lepidosiren. Rhinocryptis.

\section{Erster Abschnitt.}

Vom Skelete.

\$. 1.

Der ganze Körper der Fische, wird, gleich dem der Wirbelthiere überhaupt, durchzogen von einem soliden Gerüste: dem Wirbelsysteme im weitesten Sinne des Wortes. Dies Wirbelsystem zerfiillt in ein Axensystem und in zwei an cnigrgengesetzlen Punkten diesem angefügle, culgegengesetzte Richtungen verfolgende Bogensysteme. Das obere Bugensystem ist das über alle Regionen des Axensystems hin am weilesten ansgedehnte, indem es über lelzterem in seiner ganzen Länge sich hiuzicht. Das untere Bogensystem ist von beschränkterer Ausdehnung.

Da der vorderste Abschnill des Wirbelsystemes fast immer durch beLäichtlichere Weite des oberen Bogensystemes sich auszcichnet, anch in der Regel von dem übrigen Wirbelsysteme abgegliedert erscheint, wird er, in sciner constanten Verbindung mit gewissen dem reinen Wirbelsysteme fremden Fortsïlzen und angefügten Theilen, von der eigentlichen Wirbelsiinle als Schedel unterschicien.

Unterhalb der vorderen Regionen des Wirbelsystemes, und zwar sowol unterhalb des Schedels, als anch unterhalb eines beträchlichen Theiles der Wirbelsäule, liegen angefügt Systeme der die Ernährung und den Sloflweehsel des Individunms besorgenden Organe, sowie anch. hlos unter der Wirbelsänle, das System der Generations-Organe. - Diese Organcomplexe pflegen ron eigenen Bogensystemen versehierlener Weile unfasst zu werden. Dic Gilieder des den Aufang des Tractus intestinalis unmittelhar umfassenden bogensystemes bilden das Visecralskelet; die die gesammte Viseceralhöhle auswendig in weiterem Umfange umschliessenden Bogen gehören dem

14) Retzius, (ïber Syngnathus) in Kongl. Vetenskab. Acad. IIandling. f. 1 $\$ 33$.

15) R. 0 wen, (über Lepidosiren annectens) in den Transactions of the Linnean society. Vol. XVIII. Lond. 1 39 . - B isch off, Lepidosiren paradoxa, anatomisch untersucht und beschrieben. Leipz. 1840. 4. - J. Il yrt!, Lepidosiren paradoxa. Monographie. Prag. 18ł5. H. - Peters, (über Rhinocryptis) in II üller's Archiv für Anatomic. 1845. S. 1. 
Rippensysteme an. Beide cben genannten Systeme treten zu dem Wirbelsysteme und dessen genuincn bogenelementen in die mannichfachsten Beziehmigen. Acussere Umgürtungen des gesammten Wirbelsystemes sind ausgebildet im Schultergerüst, angedeutet im Becken.

[Das Fischskelet ist Gegenstand vieler Bearbeitungen gewesen. Man vergleiche über dasselbe vorzugsweise: Cuvier, Hist. nat. des poiss. Vol. I. p. 301. sqฯ Rosenthal, Ichthyotomische Tafeln. Hft. 1-5. Berl. 1812-1822. - van der If oeven, de sceleto piscium. Lugd. Bat. 1822. 8. - Bakker, Osteographia piscium Groning. 1822. 8. - J. F. Meckel, System d. vergl. Anatomie. Thl. 2. IIalle. 1824. S. 170. sqq. - Cuvier, Leçons d'Anatom. compar. 2. édition. Tome 1. 2. Müller, Vergleichende Osteologic u. Myologie d. Myvinoïden. Berl. 1837. - A gas siz, Recherches sur les poissons fossiles, - 0 wen, Lectures on comparat. anatomy. Lond. 1846. 8, - B. C. B rüh l, Anfangsgründe d, vergl. Anatomie aller Thicrclassen. Lieferg. 1-3. Mt. 19. lith. Tafeln. Wien. 1847. 8. - Ferner einige Monographien: Zacringer, Quacdan de historia naturali atque deseriptio sceleti Salmonis farionis. Friburg. 1829. 8. - Erdl, über das Skelet des Gymnarchus in d. Abh. d. Münchener Acad. d. Wiss. 1846. - Agassiz et Vogt, Anatomie des Salmones. p. 36. sqq. Franque, Nonnulla ad Amiam calvam acc. cognsc. Berl. 1847. - Ueber die Textur des Skeletes handeln: J. M üller, Myxinoîd. - Leydig, Unters. über Rochen und IIaie. - Agassiz u. Vogt, Anat. des Salmones, - Vogt, Embryol. d. Salmon. C. Bruch, Beiträge zur Entwickelungsgesch. d. línochensystems, in den Neuen Denkschriften d. Schwciz. naturh. Gesellsch. Bd. XI.]

\section{Von der Wirbelsäule.}

\$. 2.

Die cigentliche Wirbelsäule der Fisehe erscheint als ein durch die Linge des Körper's sich ziehendes Axcusystem, von welchem aus aulsteigende und, wenigstens eine Slrecke weit, absteigende Fortsätze zur Bildung oberer und unterer Canäle verwendet werden. Die physiologische Verwerthung der ersteren geschicht in Aufnahme des Rückenmarksystemes und einer Fettmasse oder eines fibrösen Lïngsbandes; die des letzteren in Aufnahme grösserer Blulgefässe des Körperstammes. Die Fischwirbelsïile besteht also in einem $A$ xensysteme und in zwei, entgegengesetzte Richtungen verfolgenden Bogensystemen.

Das Axensystem erscheint bei den meisten Fischen, gleich wie bei den höheren Wirbelthieren, gebildet aus einer Summe eng an ciuander gereiheter, discreter, eylindrischer Stücke von derberer Textur. Jedes dieser cylimdrischen Segmente ist ein Wirbelkörper.

Bei vielen Fischen erseheint das Axensystem aber in Gestalt eines ungegliedcrten, zusammenhangenden, von eigener Scheide umsehlossenen Stranges.

Zum nïheren Verstänlnisse dieses Verhältnisses sei Folgendes bemerkt: 
Ein eigenthümlicher Entwickelungsvorgang der hisher geneliseh miersuchten discreten Wirbelkörper aller Wirbelthiere, mit Einsehluss der Fische, ist der, dass ihrer definitiven Ausbildung das Erscheinen eines ans Zellen oder Fasern bestehenden, continuirlichen, von eigener häuliger Scheide umschlossenen Stranges vorausgeht. Dieser Strang ist, sobald er im Verlaufe der individuellen Entwickelung versehwindet, physiologisch als cin provisorisches Blastem für die spätere Wirbelkörperreihe aufzufassen. Er führt den Namen der Wirbelsaite, Chorda dorsalis.

Bei vielen Fischen erhält sich nun ein solcher ununterbrochener Strang daucrud, ohne jemals durch sich entwickelnde Wirbelkörper verdrängt zu werden. Diescr Axenstrang, der gleichfalls den Namen der Chorda dorsalis führl, ist also bei gewissen Fischen nicht ein provisorisches Blastem für definitive Wirbelkörper, sondern cin perennirendes Element, demnach nur ein morphologisches, aber kein physiologisches Aequivalent der transitorischen Chorda. Er ist, olne in Wirbelkörper sich zu gliedern, im Verlanfe der individuellen Entwickelung versehicdenartiger histologischer Veränderungen fähig ${ }^{1}$ ).

Bei der Mehrzahl der Fisehe, welche diserete Wirbelkörper besitzen, erhalten sich auch Elemente, analog denen der ursprünglichen Chorda perennirend, als ein im Verlaufe der epigonalen Entwickelung theilweise für die Vergrösserung der Wirbelkörper verwendbares, theilweise überschüssiges Blastem. Zu ihrer A ufuahme dienen kegelförmige mit ihren Grundflächen an einander stossende Aushöhlungen je zweier an einander gereiheter Wirbelkörper ${ }^{2}$ ).

Diese doppelten conischen Vertiefungen, welche die Wirbelkürper der

1) Die perennirende zusammenhangende Chorda zeigt bei Petromyzon marinus 1) cinen centralen Axenstrang, der lose in einem Canale der übrigen (hordu liegt und vorwaltend faserig ist und 2) eine viel beträchtlichere peripherische Masse. Diese peripherische Ilasse hat im Ganzen ein lamellöses oder blätteriges Gefüge. Die Blätter gehen von der Circumferenz der Scheide des medianen Axencanales aus, sind aber nicht regelmässig transversal gestellt. Bei Versuchen sie abzutragen entstehen oft conische Vertiefungen, ähnlich denen, die die Wirbelkürper charakterisiren. Sie hangen nach aussen auf das innigste zusammen mit der, namentlich im vordersten Theile des Rumpfes, dicken und knorpelharten, aber aus dichtem Fasergewebe bestehenien Scheide. - Dies stimmt im Wesentlichen mit Müller's Beohachtungen. Osteol. d Myx. S, 25. 26. 140. an Petromyzon u. Myxine. - Der differente Axenstrang der Chorda ist auch bei anderen Fischen zu erkennen, wenn auch im Detail anders heschaffen als bei Petromyzon; z. B. bei viclen Teleostei in den Ueberresten der Chorda und im Axenkanale der Wirbel. - In ihren verschiedenen Lagen von Innen nach Aussen ist die Chorda meistens histologisch ungleich. Man unlersucht bei den Teleostei am besten das freie conische Schwanzende der Chorda z. B. des Lachs. - Ueber die Gewebsclemente der Chordas. Müller I. c. u. Schwann Mikroskop. Untersuchungen Berl. 1839. 8. S. 15. 16. Tb. 1. f. 4.

2) Diese conischen Aushöhlungen mit ihrem Inhalte kann man mit Bacr als Repräsentanten der Zwischenwirbelkörper auffassen. 
meisten Fische charakterisiren, sind bisher nur bei Reprïsentanten aus der Familie der Symbranchii und bei der Gruppe der Lepidostini an allen Wirbehn vermisst worden. Hier besilzt jeder Wirbelkörper entweder vorne cinc Fläche und hinten eine conische Vertiefung oder vorne einen runden Gelenkkopf und hinten eine entsprechende Gelenkhöhle ${ }^{3}$ ).

Das Axensystem der Fischwirbelsänle erseheint dennach perennirend unler zwei verwandten Formen: cntweder als ein ungegliedertes oder als ein aus einer Summe von discreten Segmenten bestehendes Rohr. Ls stell, wie man sich anszudrücken pflegt, eine Chorda oder eine Wirbelsäule im engeren Wortsinue dar.

[Man vergleiche über die Wirbelsäule der Fische C. L. Schulze, in Meckel's deutschem Archiv für Physiologie. Thl. 4. Halle, 1818. S. 340. ff. - C. E. v. Ba er, Untersuchungen über Entwickelungsgesch. d. Fische. S. 36. - J. Müller, Vergleichende Anatomie d. Mysinoiden. Thl. 1., welcher den durch B a er gegebenen Andeutungen folgt.]

\section{\$. 3 .}

Von den nächsten Umgebungen des Axensystemes oder von ihm selhst in aufsteigender und absteigender Richtung ausgehende paarige Theile constituiren die Wirbelbogensysteme. Elemente beider Bogensysteme sind in der Regel lïngs der ganzen Ausdehmung des Axensystemes vorhanden. Viejenigen des oberen Bogensystemes bilden einen über der granzen Lïnge des Axensystemes geschlossenen doppelten oder cinfachen Canal. Der stets vorhandene dem Axensysteme zunächst liegende Canal ist zur Aufnahme des Rückenmarkes bestimmt; der miuder bestindige, lı̈̈her liegende, zweite euthält eine Follmasse oder cin clastisches Längsband (Ligamentum longiludinale superius). Jeder dieser Canïle wird häulig bald durch eigene, bald wenigstens genelisch discrete Stüche umschlossen. Wie das obere Bogensystem zwei Canäle umschliesst, so besitzt dasselbe also auch häufig jederseiis zrvei diserefe Bogenelenente. Die Elemente des unteren Bogensystemes grelangen meistens nur in einer bestimmlen Strecke des Körpers zur Einschliessung eines einfachen oder doppelten Canales. J)er selten selbststïndig vorhandene höhere nimmt die Aorta, der liefere die Vena caudalis auf; meist sind beide Canïle zu einem rinzigen verschmolzen, der aber noch weitere functionelle Verwerthung dadurch erfahen kann, dass gevisse andere Eingeweide, namentlich die Nieren und die Schwimmblase in ihn aufgenommen werden. Auch im unteren Bogensysteme erscheimen bisweilen zwicfache Elemente, entsprechend der Bildung zweier Canäle. Bei den meisten Fischen geschieht die Schliessung der paarigen Elemente des unteren Bogensystemes nur in derjenigen Re-

3) Bei anderen Fischen z. B. hei Cobitis fossilis, kommen dieselben Bildungsverhältnisse an den beiden vordersten Wirbelkörpern vor. 
sion, welehe jenseits oder hinter der, der Ventralseile des Wirbelsystemes angefïgten lumpfhöhle liegt; lings letzterer selbst zichen damn die paarigen Elemente des unteren Bogensystemes unvereinigt und meist selhst ohme zu convergiren sich hin. Sobald die Canalbildung erst unmittelbar hinter der linteren Grenze der Rumpfhölıle beginnt, stellt in den Bildungsverhailtuissen der der Rumpfgegend und der der Schwanzgegend angehörigen unteren Wirbelbogentheile und also des Wirbelsystemes überhaupt. cin scharf ausgeprägler Gegensatz sich herans; Rumpfogegend und Schwanzgegend sind dam deutlich geschieden. Aber bei viclen Fischen geschicht die Schliessung der paarigen Elemente des unteren Bogensystemes nicht blos in der Schwanzgegend, sondern anch schou oberhall, der Rumpfhöhte: also in der Rumpfgegend, bald eine kurze Strecke weit, bald in grösserer Ansdehnung, ja bei einzelnen Fischen selbst bis in die Nähe der Grenze des Schedels. Das Vorkommen eines dureh die Elemente des unteren Bogensystemes gebildeten Canales längs bestimuter Regionen oder an einzelnen Segmenten der Wirbelsänle dentet also keinesweges entscheidend darauf hin, dass diese letzteren nicht der Rumpfgegend, sondern der Schwanzgegend angehörig sind.

Da die die Bogensysteme bildenden aufsteigenden und absteigenden Elemente durch ilıre Ausgangspunkte vom Axensysteme einander symmetrisch entsprechen, so wird ein Gegensatz und eine Symmetrie zwischen einer dorsalen und ventralen IIälfte des ganzen Wirbelsystemes begrindel, welehe freilich niemals allseitig und imnerhalh aller Regionen des Körpers in das kleinste Detail durchgeführt erseheint. So pflegt sie, wegen der zuvor angedenteten Verhältnisse, in der Schwanzgegend vollkommener ausgeprägt zu sein, als in der liumpfgegend, wo sie gewöhnlich nur in eingesehräukterer Weise erkembar ist. Dic Mittellinie jeder Seite des Axentheiles bitdet den Indifferenzpunkt zwischen oberer und unterer Itailfte, welcher häufig durch den Abyang medianer, von den Wirbelkörperm abgehender, Q uerfortsätze bezeichnet wird. Ausschliesslich bei der Mehrzahl der Fische erscheint die Symmetrie zwischen dem dorsalen und ventralen Wirbelbogensysteme nicht auf die Schwanzgegend besehü̈nkl, sondern anch auf die Rumpfgegend, wem auch stets unvollkommener. ansgedehnt. eben w eil nur bei Repräsentauten dieser Thierelasse das Vorkonmen paariger absteigender Wirbelbogenelemente nieht blos anf die Schwanzgerend beschränkt ist, sondern meistens auch in der Rumptgegend Statl hat. - Durch die beiden Wirbelbogensysteme kömmt auch, mit Ausnahme der Rumphöhlengegend, cine symmetrische Theilung des Körpers in zwei Seilenhälften zu Stande. Dies geschicht, indem meistens von den Schliessmugsstellen des ganzen dorsalen und des Schwanztheiles des ventralen Wirbelbogencanales je eine mediane Verlingerung in Gestalt eines Septum ausgeht, das von dem oberen Canale aus aufsteigt, von dem unteren aus absteigl. 
Diejenigen Elemente der ventralen 11 ilfte des Wirbelbogensystemes, zwisehen wchehen dieses Septum eingeschoben ist, gehören der Schwanzgegend an. - Innerhalb der Septa entwickeln sich oft eigenthümliche solide Stützen der Flossen (Flossenträger).

S. 4 .

Das nähere Verhältniss der Bogensysteme zu dem Axensysteme zeigi sich in den verschiedenen Reihen der Fische verschiedentlich eingerichtet. Was zunächst die Verbindungsweise beider anbetriff, so crfäht dieselbe folgende Modificationen:

1. Jedes der beiden Bogensysteme bildet ein der Axen-Scheide blos äusscrlich angefügtes, durchaus selbstständiges Rohr. Die beiden Röhren: das obere und das untere stehen unter cinander nicht in unmiltelbarer Verbinduug. Accipenser ${ }^{1}$ ).

2. Jedes der beiden, von einander getrennt bleibenden Bogensysteme liegt dem Axensysteme an, bildel aber, statt eines allseitig greschlossenen Rohres, nur die Seitenwand und, mit Ausnahme ciner Strecke des muleren Canales, auch die Schlusslinie eines oberen und unteren Canales. Der Boden des oberen und das Dach des unteren Canales werden von der Srheide oder der eigentlichen Substauz des Axensystemes gebildet. Squalidae. Holocephali. Esox. Salmo.

3. Die beiden Bogensysteme gehen an den beirlen Ausscuseiten des Axencylinders, von dessen Scheide und sonstiger Substanz ihre Crrundlage jedoch wesentlich versehieden ist, ununterbrochen in einander ïber. Jedes Bogensystem bildet nur die Seitenwand und bewirkt an den meisten Stellen auch die Schliessung seines Canales. Marsipobranchii.

4. Die beiden Bogensysteme erseheinen als ummittelbare, anf- und abwärts greriehtele Canal-bildende Fortsetznngen der Grundlage des Axencylinders. Viele Teleostei.

Andere Modificationen werden durch die versehiedene Beschaffenheil der Texturverhältnisse herbeigeführt.

1. Die Grundlagen der beiden Bogensysleme können. gleich dem ununterbrochenen Axencylinder, cingefïgter solider Theile, welche eine Gliederung bewirken, sïnzlich ermangeln. Branchiostoma. Myxine. Ammocoetes.

2. Es kömmen in der übrigens ununterbrochenen Continuilät der Bogensysteme solide, eine Gliederung bewirkende Leisten vorkommen, ohne dass der Axencylinder gleichfalls gegliedert wïre oder discrete solide Theile enthielte. Petromyzon. Accipenser. Chimacra.

3. Es kann die Entwickelung solider Stücke in der zusammenhangenden Grundlage jedes Bogensystemes mit einer solehen im Axensysteme zu-

1) Vgl. \$. 8. 
sammenfallen. Beide Systeme erseheinen daher durch Anwesenheit discreter solider Stücke gegliedert. Es kommen also zugleich, mil soliden Bogentheilen. solide Wirbelkörper vor, ohne dass jedoch beide von gleicher Texturbeschaftenheit immer zu sein brauchten (manche Squalidae). - Die eben genaunte, am häufigsten vorkommende Anordnung erfihrt durch die weehselnde Lage und Zahl der soliden Bogeutheile folgende Modificationen:

a. Die einzelnen soliden Theile des Axensystemes und der Bogensysteme entsprechen einander der Lage nach so, dass auf jeden Wirbelkörper ein Paar oberer und ein Paar unterer solider Bogenslücke kümml. Letztere hangen in der Regel durch ihre Basis mit einem Wirbelkörper zusammen. Sie heissen dessen genuine auf- und absteigende Bogenschenlicl:

\section{Crura dorsalia et ventralia.}

b. Im Bogensysteme kommen solide Stücke vor, welche, ilner Lage nach, nicht einem Wirbelkörper, sondern zweien zugleich entsprechen, indem ihre Basis die Verbindungsstelle zweier Körper berührt.

Bei den Fischen kommen so gelegene Bogenstïcke nur sehr selten, unter Mangel genuiner Bogensehenkel an denjenigen Wirbelkörpern, zwischen deren Verbindungsstellen jene liegen, vor, wie dies z. B. an einigen Stellen der Wirbelsiule von Amia der Fall ist ${ }^{2}$ ). Häufiger erscheinen solche Stïcke unter gleichzeitiger Anwesenheit genuiner solider Bogensehenkel. Deshalb heissen sie Partes intercalares, Crura intercalaria. Diese Zrvischenbogenschenkel sind dann also solide Stücke, die an sonst gewöhnlich membranös bleibenden Strecken des Wirbelbogensystemes sich entwickelt haben. Sie kommen bei den Elasmobranchiii vor.

c. Es sind in gewissen Streclien des Körpers eines Fisches (Amia) Wirbelkörper gefunden, denen beine solide Bogenschenkel entsprechen. Sie bilden ein System sogenanuter Schaltwirbelkörper.

d. Es liömen endlich, ausser den genuinen Bogenschenlieln und den Zwischenbogenschenkeln, noch andere dem Wirbelsysteme sellst fremde solide Stïcke den Grundlagen des Wirbelbogensystemes eingeschoben sein. Namentlich ereiguet sich dies oft in den an der Dorsal- und Ventralseite des Wirbelsystemes auf- und absteigenden Septa, in so ferne diese die Ossa interspinalia cinschliessen.

Indem nun das am häufigsten realisirte Verhältniss das ist, dass einem disereten Wirbelkörper ein Doppelpaar solider Bogensehenkel entspricht. indem letztere ferner gewöhnlich als unmittelbare Fortsätze des ersteren sich zeigen, erscheinen die so verbundenen Theile als ein Ganzes, als eine Linheit, bilden einen Wirbel. Der Wirbel ist demnach ein Axensegmenl, dem planmilssig mehr oder minder histologisch gleichartig differenzirte Bogenstüeke in verschiedenem Grade der Innigkeit verbunden sind. Ge-

2) Vgl. \$. 9. 
leitet durch die bei den Fischen in der Znordnung zweier nach entgegengesetzten Richtmgen strebenden Bogenschenkelpaare zu einem Wirbelkïrper sich linndgebende Symmetrie hat man den doppelschenkeligen Wirbel als typisch aufgefasst. An dem ans seincu natürlichen, meist histologisch differenten Verbindungen herausgelöseten Wirbel werden also, niichst dem Körper, zwei aufsteigende und zwei absteigende Bogensehenkel untersehieden.

\section{\$. 5 .}

Eine auswendige Umgürtung der der Rumpfgegend des Wirbelsyslemes angehörigen, die Eingevveide cinschliessenden Höhle geschicht hä̈fig durch paarige solide Bogen-Elemente: die Rippen, Costae. Dieselben sind unheständig vorkommende 'Theile. In iltren Ausgangspunkten vom Wirbelsysteme, mit dem sie bei den Fischen anscheinend nie ausser Verbindung bleiben, verhalten sie sich nicht ganz gleich. Nur sehr selten überschreilet ihre Anheftungsstelle an den Wirbelkörpernderenventrale II alfte nach oben, in welchem Falle sie dicht neben den oberen Bogenelementen sich anlehnen, wodurch (wie z. B. bei Cotylis) ilne Insertionsverhältnisse cbenso, wie bei höheren Wirbelthieren sich gestalten. - Dagegen befestigen sie sich gew öhnlich an den in der Rumpfgegend vorkommenden Elementen des unteren Bogensystemes; unter Mangel der letzteren, schliessen sie (z. B. bei Polypterus) auch an die untere ventrale IÏ̈lfte des Axen- und Wirbelkörpersystemes sich an. Diese beiden Weisen der Anheftung fallen in die nämliche Kategorie, indem es die ventrale Iralfte des Wirbelkörpersystemes ist, welele den, in dem letzteren Falle unmittelbaren, in dem ersteren mittelbaren, Ausgangspunkt der Rippen bildet. Dieser Ausgangspunkt der Rippen von der ventralen IIälfte des Axen- und Wirbelkörpersystemes charakterisirt die meisten Fische, im Gegensalz zı den höheren Wirbelthieren, bei welchen diese Theile von der dorsalen II:̈lfte des Wirbelkörpersystemes, sei es ummittelbar, oder durch Vermittelung von secundären Entwickelmugen des oberen Bogensystemes (Processus transversi), ansgehen. Vermöge dieses sehr allgemeinen, wenngleich nicht ausnahmslosen, Ausgangspunktes der Rippen kam bei den Fischen eine ummittelbare Verlïngerung der ventralen Muskelmasse des Schwanzes (der unteren IIïlfte der Seitemmuskeln) auf ihnen ruhen und sie bedecken, während bei den höheren Wirbelthieren Verlängerungen der ventralen IIälfte der Schwanzmuskeln, sobald sie in die Rumpfregend sich erstrecken, wie z. B. bei den Cetaceen, ron den Rippen, welchen hier die dorsale Hialfte des Wirbelsystemes Ursprung gibt, answärts nugürtet werden. - Dic Rippen der Fische können aber keinesweges als solehe Elemente angesehen werden, deren wesentliche architelitonische und morphologische Bestimmung es wirre, Erweiterungen und Ergänzungen der Elemente des nuteren Wirbelbogensystemes in der Rumpfgegend zu bilden, um diese letzteren dadurch zur Aufuahme der Eingeweide der Rumpfhöhle geschicht zu machen. Die 
Rumpfhöhle sellst, gleich den zu ihrer Umgürtung verwendelen Rippen. ist nämlich ein dem Wirbelsysteme und namentlich anch dem Systeme der unteren Bogenelemente blos äusserlich angefügtes System. Dies ergib sich darans. dass die Elemente der unteren Wirbelbogen längs einer Strecke oder fast lings des ganzen Bereiches der Rumpfgegend zu einem selbstständigen Canale sich sehliessen liönnen, der dann, seine in der Schwanzgesend immer hervortretende Beslimmung beibehaltend, die Aufuahme der Aorta oder dieser und der Fortsetzung der Schwanzvene besorgt. Sobald dieser Canal längs der Rumpfgegend geschlossen vorkömmt, liegt er über der Rumpfhöhle. Geschieht die Umgürlung der Ietzleren damn dureh Rippen, so gehen diese von Apophysen der Seitentheile der Canalwrandungen wie z. B. beim Sẗ̈r, oder von der ventralen IIälfte des Wirbelkörpersystemes aus. Hieraus ergiebt sich, dass es unrichtig wäre, in Folge einseitiger Berü̈ksichtigung derjenigen Fälle, wo die Rippen den freien Enden der untereinander unvereinigt bleibenden unteren Bogensehenkel sich anschliessen. ilmen die generelle architectonische Bedentung unterzulegen, dass sie den Schwanzeanal der letzteren in die Rumpfgegend erweitert fortzuselzen haitten.

Es liegt weder in dem generellen architectonischen Plane der unteren Bogenschenkel, dass sie die Rumpfhöhle umgürten. noch in dem der Rippen. dass sie, als adjungirte Elemente, die unteren Bogenschenkel darin unlerstiitzen. Die architectonische Bedeutung der Rippen bleibt immer die äussere Umgürtung der Rumpfhöhle und ihrer Fortsetzumgen; darin künnen sie unterstïtzt werden von den unteren Wirbelbogenelementen. Geschieht diess, so tritt eine Fusion der Gefïsshöhle und Rumpfhöhle ein, wic diess bei der Mehrzahl der Fische sich ereignet.

$$
\text { S. } 6 \text {. }
$$

Die wesentlichsten Modificationen im Baue der Wirbelsäule bei den einzelnen Gruppen sind folgende:

Bei den Leptocardii ${ }^{1}$ ) und Marsipobranchii besteht das Axensystem in einer von eigener Scheide umschlossenen faserigen oder gallertarligen Chorda, welche von einer zweiten Gewebsschicht scheidenartig umhällt wird. Diese Schicht - häufig als äussere Scheide der Chorda bezeichnet -, verlängert sich jederscits aufwärts zur Bildung eines das Rückenmark umschliessenden Rohres, worauf sie einen zweiten, über jenem gelegenen, mit fethalligen Gewebstheilen erfüllten Canal bildet. Von der Schlussstelle des letzteren aus erhebt sich oft, als Fortsetzung jener Schicht. ein fibrüses Septum zwischen den Seilenmuskeln. Das untere Bogensystem

1) Vergl. ausser den Schriften von Rathke u. Müller, die Abhandlung von Quatrefages in den Ann. des scienc. natur. u. Schulze in Siebold u. Kölliker's Zeitsch. f, Zool. Bd. 3. Ilft. 4. 1851. S. 416. 
wird am Rumpfe durch eine mehr oder minder bedeulende Verdickung derselben ïnsseren Scheide, welche leistenartig und bisweilen mit Andeutungen einer Längsgliederung längs jeder Seile der Basis des Axeneylinders sich hinzieht, repräsentirt. In der Schwanzgezend umschliessen abwïrts gerichlete Verlïngerungen der äusseren Scheide einen die Arteria und Vena caudalis aufnehmenden Canal.

Bei Petromyzon ist die Masse der äusseren Scheide an zwei Stellen bedeutend verdickt: eimmal da, wo sic als Element des unteren Bogensystemes vom Axencylinder aus leistenartig absteigt und damm, obschon in schwächercm Maasse, da, wo sie vom Axencylinder zur Bildung des oberen Bogensystemes sich erhebt. In der Masse der äusseren Scheide, die dureh cingesprengte Knorpelsubstanz überhaupt als Blastem für Knorpel- und Knochenbildungen sich zu erkennen gibt, erheben sich in vordersten Segmente des Wirbelsystemes paarige Kuorpelleisten, ohne zur Umschliessung der oberen Canäle wesentlich beizntragen und ohue zu convergiren oder sich zu vercinigen. - An den Seiten des vordersten Abschnittes des Axencylinders hat die Befestigung der Knorpel des äusseren Kiemenkorbes Statt. -

Rippen fehlen den Marsipobranchii allgemein.

Unter den Dipnoi besteht bei Lepidosiren die von einer fibrösen Seheide umschlossene, das Axensystem darstellende Chorda aus einer peripherischen Schicht, welche zu wirklichem Knorpel sich umzubilden scheint, und aus einem gelatinösen Centralcylinder. Aufsteigende ossificirte Bogenstücke sind in die Scheide der Chorda dergestalt eingepflanzt, dass sie mit ihren knorpeligen Grundfl̈̈chen in ihre IIöhle hineinragen und mit der Oberfläche der Chorda in Zusammenhang stehen. An der unteren Fläche der Chorda-Scheide haften in einer Strecke rundliche ossificirte Scheiben. Ansserdem sind paarige knöcherne Rippen mit ihren überknorpelten Köpfen in die Scheide der Chorda eingepflanzt. Sie berühren jedoch die Oberfliche der eigentlichen Chorda nur, ohne mit ihr verwachsen zu sein ${ }^{2}$ ).

\$. 7.

In der Ordnung der Elasmobranchii ${ }^{1}$ ) stellen die beiden Bogensysteme als discrete, dem Axensysteme blos aufgeselzte oder eingekeilte Elemente sich dar. Nicht allein die Elemente des oberen, sondern auch die des unteren Bogensystemes sind his zur vordersten Grenze des Wirbelsystemes zu verfolgen. Die des unteren bilden nur in der Schwanzge-

2) Vergl. die Schriften von Bisch off u. 11 y rtl.

1) Ueber die Wirbelsäule der Elasmolranchii vergl. besonders: Müller, Vergl. Osteol. d. Myxinoïd. S. 91. - Ueber den Bau der Wirbelsäule der Squalidae: II äller's Aufsatz in $\Lambda$ gassiz hist. nat. d. poiss. fossiles. Vol.3.p. 360. nebst den Abtrild. Tb. 40.1. 
gend einen Gefässcanal und erseheinen am Rumpfe als dem Axensysteme angefügte, bisweilen der Länge nach versehmolzene Leisten. - Die IIolocephali und die Rajidae hahen das Gemeinsame, dass das vorderste, den Sehedel zunächst liegende Segment der Wirbelsäule als ein äusserlich ungegliedertes Rohr erscheint, welehes dem Schedel, und, bei einigen Rajidae, auch dem Schultergerïsl, sowie dorsalen Gliedern der Kiemenbogen, einen festen Stützpunkt gewảhrt ${ }^{2}$ ).

Das Axensystem besteht bald in einer ungegliederten Chorda, bald in discreten Wirbelkörpern. In ersterer Gestalt erscheint dasselbe bei den Holocephali, bei den Notidani und der Gattung Echinorhinus. - Dic Chorda der Chimären ${ }^{3}$ besitzt in ihrer Scheide zarte ossificirte Ringe, deren Anzahl diejenige der Bogenschenkel weit übertrift. Uebrigens ist die Scheide sehr dick, bestelıt nach imen hin aus einem atlasglïnzenden Fasergewebe und umschliesst eine gallertartige Masse, welehe einen Centralcanal enthält.

Bei den Gattungen Ilexanchus und Heptanchus ${ }^{4}$ ) umhüllt die ungegliederte Scheide der Chorda eine gallertartige Masse. Eine Theilung in Wirbelkörper ist dadurch angedeutet, dass quere, häutige, mit einer Centralöfnumg versehene Septa die Gallertmasse von Stelle zu Stelle durchsetzen und so die Mitlellinie eben so vieler Wirbelkürper bezeichnen. Bei Echinorhinus ist der Inhalt der Scheide chondrificirt.

Die discreten Wirbelkürper der übrigen Elasmobranchii besitzen an jedem ihrer Enden eine conische Aushöhlung und einen Centralcanal, durch welchen der Centralstrang der Chorda sich hindurchzicht. Ihre Texturverhältnisse bieten in Bezug auf die ossificirten oder knorpeligen Antheile bei den IIaien ${ }^{5}$ ) grosse Verschiedenheiten dar; bei den Rajidae scheinen die Wirbelkörper besländig ossificirt zu sein.

Die Bogensysteme erscheinen dem Asensysleme bald blos aufgesetzt,

2) Dieser vorderste zusammenhangende Abschnilt der Wirbelsäule ist bei den verschiedenen Rajidae sehr verschieden entwickelt. Bei Raja stellt er eine das Rückenmark einschliessende Capsel mit dünnem Boden dar. Die dünne Basis enthält keine Spur von Wirbelkörpern und auch nicht einmal einen Kiern von harter Knochensubstanz. M ïller fand, dass sellsst bei einem Rochenfütus von 2 " Länge die Säule der Wirbelkörper vor diesem Rohre fadenfürmig aufhörte. Nyxinoüd. Thl. I. S. 94. Schon bei Rhinobatus, mehr noch bei Trygon, bei Aëtobatis, bei Torpedo u. A. ist dor Boden minder dünne und es zeigen sich deutliche Spuren von Wirbelkörpern.

3) S. Ilüller, Vergl. Neurol. d. Myxinoïden. S. 71.

4) In Bezug auf die Notidani und Echinorhinus folge ich Müler, da zu ihrer eigenen Untersuchung keine Gelegenheit war.

5) Bei Acanthias und Centrina beschränkt sich die Ossification nur auf die unmit. telbare Umgebung der conischen Aushöhlungen. Bei Lamna sind an der Aussenfläche der Wirbelkürper vorkommende Vertiefungen und Rinnen mit Knorpelmasse erfült. Bei Squatina bestehen die Körper aus alternirenden Schichten von linochen und linerpel. S. d. Abb. b. M üllex, Vergl. Neurol. d. Myxinoïd. Tb. IV. F. S.

Handb, d, Zoolomie v, Siebold u. Stannius, II. 
wie bei den eine ungegliederle Chorda besitzenden Elasmobranchii, bei den Rajidae und manchen Squalidae, oder sie sind mit ihren Grundlächen in die Masse der Wirbeliörper bis zu deren centraler Ossificationsschicht hin, tief eingekeilt, wodureh dann, bei differenter Texlur dieser eingekeilten Elemente, in den Wirbelkörpern auf Durchschnilten die Figur eines Kreuzes erscheint ${ }^{6}$ ).

Was die Textur der genuinen oberen Bogensehenkel anbetrift, so bleiben sie entreder ganz knorpelig, oder erhalten eine oberfächliche Kno. chenkruste, übereinstimmend mit derjenigen, welche andere Theile des Skeletes überzieht ${ }^{7}$ ), scheinen aber in spüiterem Alter vollstïndiger ossifieiren zu können.

In Betrefl ihrer Bogensysteme haben die Elasmobranchii das Eigeuthümliche, dass diejenigen soliden Glieder dersilben, welche - weil jedes mit seiner Basis einem Wirbellïrper aufsilzt - als genuine Bogenschenkel sich charakterisiren, nicht durch häutige Interstitien geschieden, sondern durch zwischengekeille discrete Stücke (Cartilagines intercruales), deren oft mehre neben einander vorkommen, zu ciner allscitig soliden Wand des Canalis spinalis ergänzt werden. Vervollstänrligt werden die soliden Begrenzungen des genannten Canales noch hänfig, obschon keinesweges beständig, durch eigene unpare obere discrete Stücke, welehe meistens den Cartilagines crurales und intercrurales gleichmässig entsprechen und als Cartilagines impares bezeichnet werden ${ }^{8}$ ).

Der Authcil, welchen die einzelnen geuannten Stücke, die, wenn man von der Vorausselzung ausgeht, dass die Cartilugines crurales allein typisch sind, als accessorisch bezcichnet werden müssen, an der Umschliessung des Canalis spinaüis nehmen, ist bei verschiedenen Gruppen der Elasmobranchii verschieden 9). - Während hei den Holocephali und Srqualidae, von den oberen Schlussstellen des soliden Canalis spinalis aus, fibrüse Sepla zur Rïckenkante sich erheben, verhalten sich die meisten Rajidae dadurch abweichend, Chass bei ihnen sehr hïufig solide Verlängernngen der Wirbelsäule bis unmiltelbar zur Rückenhaut hinauf reichen. Es sind nämlich den

6) Diesen den Carchariae cigenthümlichen Ban fand Il üller nicht nur bei allen Nictitantes, sondern auch bei Scyllium, Lamna, Alopias. S. auch d. Abb. Vergl. Osteol. d. Myxin. Tb. IX. Fig. 6.

7) Sie heiben ganz knorpelig bei Chimacra, bei den Notidani, bei Echinorhinus, Acanthias, Centrina. Eei den übrigen IIaien erhalten sie eine oberllächliche Knochenkruste oder ossificiren auch in ihrer ganzen Substanz.

8) Diese Cartilrgines impares sind beobachtet unter den Ilaien bei Scyllium, bei den Nictitantes u. bei Squatina, wo sie aber, ilirer Zahl nach, den Cartilagines crurales entsprechen. Bei Chimaera finden sich ebenfalls discrete obere Schlussstucke.

9) Oft, wie z. D. bei Chimaera, bei Acanthias, Iragen die Carlilagines intercrurales am meisten dazu bei, welche, wemn die Cartilagines impares fehlen, bei den Haien auch die obere Schliessung des Canalis spinalis bewirken. 
Cartilagines intercrurales noch discrete obere Schlnssstïcke angefïgt, welche die obere Grenze des Wirbelsystemes vervollständigen. Sie entsprechen, ihrer Lage nach, bald je zwei Zwischenschenkelstücken, bald mehren zugleich, wie z. B. bei Rhinobalus. Achnliche unpaare Schlussstücke kommen auch einzeln am unteren Bogensysteme vor. Das Schwanzende der Wirbelsänle ist hänfig, namentlich bei den Squalidae, aufwärts gekrümmt, wie z. B. besonders stark bei der Gaftung Pristiurus; bei den Rajidae ist die Krümmung nicht deutlich.

Die Elasmobranchii ermangeln entweder der Rippen gänzlich, wic dies der Fall ist bei den Chimären und manchen Rajidae, oder besitzen dieselben in verhältnissmässig unbeträchtlichen discreten Stücken. Die Anheftung der Rippen hat an den Carlilagines crurales des unteren Bogensystemes Statt; bei cinigen Squalidae aber auch zugleich in dem $Z_{\text {wischen- }}$ raume zwcier solcher Bogenstücke ${ }^{10}$ ).

\section{\$. 85 .}

Was die Ganoüdei chondrostei anbetrifft, so kann Arcipenser als Repräsentant gelten. Das Axensystem wird durch eine von einer dicken fibrösen Scheide umhïllte Chorda dorsalis reprïisentirt. Dieser ist oben, wie unten, ein discretes Begensystem von wesentlich knorpeliger Textur angeschlossen. Jedes derselben bildel einen Ring. Acussere einfache Verlängerungen der Grundlage jedes der beiden Ringe bilden seilliche Bekleidungen der Chorda-Scheide. Diese äusseren Verlängerungen oder Ausläufer der Substanz jedes der beiden Ringe bleiben, mit Ausnahme eines vorderen Abschnittes des Wirbelsystemes 1), in welehem sie sich berïhren, durch eine zwisehenliegende, von Knorpel unbedeckte Strecke der ChordaScheide von einander getrennt. Der dorsale Ring bildet zucrst den Boden, die Seitenwandung und das Dach des Canalis spinalis. Durch mmittelbare Verlängerung seiner Kuorpelsubstanz entsteht über dem Cana. lis spinalis ein zweiter Canal zur Aufnahme eines elastischen Längsbandes (Ligamentum longiludinale superius). Die Elemente des obereu Ringes bestehen in discrelen knorpeligen Stücken verschiedener Art. Die beträcht. lichsten sind parrige obere Bogensehenkel. Jeder derselben bildet nit seiner breiten nach innen und anssen erweiterten Basis inwendig die Hälfie des Bodens des Spinalcanales und auswendig eine Bekleidung des oberen Segmentes der Chorda-Seheide. Von dieser breiten Basis erhebt sich ein schmalerer aufsteigender Schenkel, der, nachdem er sich erhoben, mit einem

10) So bei Carcharias, Heptanchus, Alopias, nach NI üller's Angaben.

1) In vordersten, dem Schedel zunächst gelegenen Abschnitte des Wirbelsym stemes liegen die verkümmerten Elemente des unteren Bogensystemes als Rippentragende, knorpclige $\Lambda$ pophysen auf $d \mathrm{~cm}$ Seitentheile des nach hinten verlängerten $O_{s}$ basilare des Schodels. 
inneren Aste die Hälfte des Daches des Spinaleanales und des Bodens des zwreiten Canales, mit seinem äusseren Aste eine Seitenwandung dieses zweiten Canales bildet ${ }^{2}$ ). Die obere Sehliessung dieses Canales erfolgt streckenweise dureh Convergenz und Verbindung der parigen Seitenwandungen, streckenweise unter Ilinzutritt eines oberen Schlnssstückes ${ }^{3}$ ). Nächst diesen paarigen oberen Bogenschenkeln tragen zur Begrenzung der Seiten und zur Bildung des Bodens des Spinalcanales noch Intercruralknorpel bei, welche mit ihrer Basis der Chorda-Scheide anliegen und zur Bildung der Austrittscanäle der Spinaluerven concurriren. -- Der untere, der Chorda-Scheide angefügte Ring bildet das Dach, die Seitenwandung und den Boden eines Aortencanales. Nur in der Schwanzgegend liegt unter diesem Aortenringe ein zweiler, bestimm zur Aufnahme der Caudalrene. - Die Bildung des Aortencanales geschieht in der Rumpfgegend vorzüglich durch einfache, abwärts völlig geschlossene Kuorpelbogen, dic anfwär's in zwei, unmittelbar unter dem Bauchtheile der Chorda-Scheide zwar zusammenslossende, aber durch ein zwischengeschobenes elastisches Ligamentum longitudinale inferius getrennt bleibende Schenkel ausgehen. Der Boden des Aortencanales und zum Theil auch seine Seitenwaudungeu werden aber noch durch zwischengesehobene discrete Schaltknorpel vervollstïndigt. Aeussere einfache Ausläufer der Substanz des Hauptbogens bilden für die untere Seitenhälfte der Chorda-Scheide eine auswendige Belegung; dieselbe geht jederseils in eine Apophyse aus, welche vorne kurz und schwach, weiterhin stark und als Querfortsalz entwickelt, zur Befestigung einer Rippe dient. Jede Rippe besitzt nur an ihren beiden Enden und zwar an ihrem oberen in kurzer, an ihrem unteren in langer Strecke freic Knorpelsubstanz. In ihrem Körper ist der centrale Knorpel immer von einer corticalen Ossification scheidenartig umgeben. - Erst in der Schrvanzgegend bildet der Boden des Aortentanales das Dach eines tieferen zur Aufuahme der Caudalvene bestimmten Canales; derselbe erhält anfangs durch Knorpelleisten, welche jederseits absteigen, nur solide Seitenwände; erscheint also in Gestalt einer unten offenen Rinne; weiterhin, und zwar da, wo die Schwanzflose beginnt, ist er auch unten völlig geschlossen, indem die absteigenden Seitenwandungen durch unpaare, in der Milte von einer Knochenscheide umgebene, untere Schlussstücke ergänzt werden. An diesen unteren Schlussstücken hat die Befestigung der

2) Dieses obcre Segment des genannten Schenkels besitzt eine_corticale Irnochenscheide in einer Strecke seiner Länge.

3) Dieses obere Schlussstück zeichnet an vielen Rumpfivirbeln sich aus durch seine Form, indem es schräg und cylindrisch aufsteigt und dann an seinem freien Ende eine nach vorn und hinten gerichtete Verlängerung besitzt, also T förmig erscheint. Seine Knorpelsubstanz wird immer in einer Strecke ron einer corticalen Ossification scheidenförmig umgeben. 
Schwanzflossenstrahlen Stall. Das Schwanzende der Wirbelsäule ist stark aufvärts gekrümmt.

[Man vergleiche über die Wirbelsäule von Accipenser: C. E, von Baer, im Zweiten Berichte von der anatomischen Anstalt zu Königsberg. Kibg. 1819. 8. In den wesentlichsten Verhältuissen zeigt Spatularia sich übereinstimmend mit Accipenser; nur fehlen die Rippen, oder werden vielmelır durch ligamentöse Stränge vertreten, die an der Basis knorpelige Elemente enthalten.]

$$
\text { S. } 9 \text {. }
$$

Bei den Ganoidei holostei ist das Axensystem in discrete ossificinte Wirbelkörper zerfallen ${ }^{1}$ ). - An den einander in der Jängsrichtung entsprechenden Enden jedes Wirbelkörpers finden sich bei Polypterus und Amia conische Vertiefungen, währent bei Lepidosteus jeder Wirbelliörper vorne einen convexen Gelenkiopf und hinten eine entsprechende Gelenkhöhle besitzt. - Nur bei Polypterus kommen lïngs der Wirbelkörperreihe des Rumpfes mediane Querfortsätze vor, an welchen Muskelgräthen befestignt sind. - Gelenlfortsätze zur Verbindung der einzelnen Wirbelkörper fehlen allgemein. - Das System der ossificirten oberen Bogen bielet in scinem Verhalten zu den Wirbelkörpern Versehiedenheiten dar. Bei Polypterus und Lepidostens sind sie Fortsätze der Wirbelkörper, bei Amia discrete, von letzteren durch Zwischenkuorpel getremute Theile. - Bei Polypterus bilden dic oberen Bogenschenkel nur einen Canal: den Canalis spinalis. Daher sind die beiden, von den Seiten eines Wirbelkörpers aus, aufsteigenden Schenkel kurz; oben gehen sie ununterbrochen in einander über. Die vorderen und hinteren Räuder der einzelnen oberen Bogen stossen, ohne zwischenliegende membranöse Interstitien und nur durch Bindegewebsstreifen getremnt, zur Bildung einer festen Seitenwand des Canalis spinalis an einander. Aufwärts ist jedem Bogen ein diseretes ossificirtes Dornstück angefügt. - Bei Lepidostens und Amia finden sich im Bereiche des Systemes der oberen Bogen zwiefache Elemente, indem die Bildung zweier übereinander gelegener Canäle zu Stande kömunt. Bei Lepidosteus hat der von jedem Wirbelkörper anfsteigende, zur. Umschliessnng des Canalis spinalis

1) Die Galtung Amia bietet die merkwürdige Erscheinung dar, dass gewisse, der Schwanzgegend angehörige Wirbelkörper keine entwickelte unteren und oberen Bogrnschenkel besitzen, sondern oben und unten nur solche schmale Kinorpelstreifen tragen, welche an anderen Stellen zwischen jedem Wirhelkörper und jedem seiner línochenbogen liegen. Ein solcher Schaltwirbelkörper liegt zwischen zwei anderen vollstandig entwickelten Wirbeln. J)er crste Schaltwirbel kömmt vor hinter dem fiten Schwanzwirbel; der letzte zwischen dem 21sten und 22sten. Merkwürdig ist der Umslind, diss an einigen Stellen der Schaltwirbel mit dem genuinen Wirbel zu einem Stiicke verschmolzen ist; z. B. zwischen dem 11ten und 12ten Schwanzwirbellörper findet sich kein Schaltstück, aber der 11 te Wirbelkörper ist sehr lang und trägt in seiner hinteren Hälfte die die Schaltwirbel charakterisirenden Knorpelapophysen; der 21 ste ist wieder sehr lang und verhält sich in seiner Vorderhälfte wie ein Schaltwirbel. - An einem zweiten Exemplare kommen solche Verschmelzungen an anderen Stelien vor. 
bestimmte Bogen, indem seine Schenkel oben munterbrochen in einander übergehen, die Gestalt ciner Röhre. - Von jeder Aussenseite dieser geschlossenen Röhre steigt ein, an der Basis mit ihr verschmolzener, später freier, schmaler rippenartiger Bogenschenkel anfwärts und hinterwärts, der mit dem ihm paarig. entsprechenden zwar convergirl, aber nicht rerschmilzt und zugleich mit ihm das oberhalb des Canalis spinalis gelegene fibröse Längsband einschliesst. Je zwei ossificirte Bogeu sind durch fibrös-häulige Interstitien von einander getrenut. - Bei Amia entspricht meistens jedem Wirbelkörper - in cinzelnen Regionen der Wirbelsäule anch den Verbindungsstellen zweier derselben - ein discreter, durch eine knorpelige Epiphyse von ihm getremter oberer Bogen, der, in den Grundzügen seiner Anordnung, mil dem des Lepidostens übereinstimml. - In dem zur Rückenkante aufsteigenden fibrösen Septum finden sich bei den Ganoïlen verschicden enwickelte Ossa interspinalia.

Das System der unteren Bogen verhält sich nicht bei Allen ganz gleich. Bei Polypterus fehlen in der Rumpfgegend die unteren Bogenstücke. In der ganzen Schwanzgegend des Polypterus geschicht die Bildung cines mteren Gefässcanales dadurch, dass an die Unterfliche jedes Wirbelkürper's zwei Schenkel eines discreten Knochens sich anheften, die abwärts in einen einfachen Dorn zusammenfliessen. 1)ic glciche Bildung fundet sich bei Amia in der hinteren IIalfte und bei Lepidosteus am ïussersten Ende der Schwanzgegend. Weiter vorwirrts hat bei Lepidosteus die Bildung des Gefässcanales durch untere, von den Wirbelkörpern an!sgehende Bogenfor'sätze Statt, welche abwärts durch die bei Polypterus vorkommenden Y förmigen Kuochen ergänzt werden; bei Amia geschicht sie nur durch discrete, von den Wirbelkörpern durch Zwischenkuorpel getrennte Bogenschenkelpaare, an deren unterer Schlusslinie einfache, aber discrete Dornstücke ${ }^{2}$ ) angefügt sind. - In dem in der Schwanzgegend, von der. Wirbelsäule aus, absteigenden Septum finden sich $\boldsymbol{O}_{\text {ssa }}$ interspinalia. - Die Rippen inseriren sich bei Amia und Lepidosteus an den freien Enden der unteren Bogenschenkel, bei Polypterus dagegen unmittelbar an den Wirbelkörpern unterhalb der medianen Querfortsätze. - Die Grenze von Rumpfund Schwanzgegend wird durch einen Wirbel bezeichnet, an dem entweder eine abortive Rippe, oder weder eine Rippe, noch das die Schwanzgegegend charakterisirende untere Schlussstück vorkömmt. - Das letzte Schwanzende der Wirbelsäule ist bei allen Ganoïdei holostei aufwärts gekrümmt; die Chorda dorsalis verlängert sich ungegliedert über die hinterste Grenze der abortiven letzten Wirbelkörper weit hinaus, nach oben gerichtet.

2) Dass alle diese unteren Stiicke aus der Vereinigung von Rippen entstehen, wic $\|$ üller vielfach hervorhebt, davon habe ich an keinem Skelete der von mir unsersuchten Ganoïden mich überzeugen können. 
[Man vergieiche über die Wirbelsanle der Ganoidei holostei: Geoffroy Si. II ilaire in der Vescription de l'Egypte. Histoire niturelle des poissons. PI. 3. - Agassiz, Poissons fossiles. 1. c. - Müller, Bau u. Grenzen der Ganoĩden, - Franque, de Amia calva, Mt. Abb. der Wirbelsäule der Amia].

\$. 10 .

In der grossen Gruppe der Teleostei crscheint das Axensystem dadurch, dass es in cine Reihe discreter ossificirter Wirbelkörper 1) zerfallen ist, gegliedert. Verhälnissmissig selten bleibt cine Strecke des Axensystemes: namentlich in der Nähe des Schedels, ungegliedert ${ }^{2}$ ), ist jedoch ossificirt. Einem jeden Wirbelkörper entspricht in der Regel cin Paar ossificirien wberer nud ein Paar glcichfalls ossificirter unterer Bogenschenkel.

Das nähere Verhalten der Wirbelkörper ist in der Regel Folgendes: Man hann jeden Wirbelkörper als ans zwei, mit ihren Spilzen in einauder übergehonlen llohlikgeh zusammengeselzt, sich vorstellen. Jeder Wirbelkörper besilzt daher an seinem vorderen. wie an seisem hinteren Ende eine nach seiner Mitle zu sich verjüngende Vertiefung. An den Stellen, wo zwci Wirbelkörper sich an einander reihen. begrenzen einander nur die weitesten Umgebungen zweier Hohlkegel. In der Circunferenz diesen conischen Anshohlungen zeigen sich ringförmige Streifungen, welche von des Milte des Wirbelkörpers aus, nach jedem seiner Euden hin, an Weite ailmälich zunehnen. In dem Centrum des Wirbelkörpers findet sich meistens cin die beiden conischen Aushöhlungen verbindender sehr kurzer Canal. Die conischen Aushöhlungen enthalten eine Masse, analog derjenigen der perennirenden unmuterbrochenen Chorda anderer Hische. Diese Hasse besitzt häufig einen discreten, durch abweichende 'Textur ausgezcielneten

1) Bemerkenswerth ist die grüne Färbung der Wirbel und anderer Kinochen ciniger Teleostej, z. B. bei Belone, bei manchen Arten von Cheilinus. - Die Wirbel von Cyclopterus zeiclinen, gleich anderen Skelettheilen, durch ihre weiche Beschaffenheit sich aus; die hnochensulstanz bildet dünne Lamellen, deren Interstitien durch cine weiche llasse ausgefült werden. Aehnlich verhalten sich, nach Cuvier, einige Tänioĩden, z. B. Trachypterus.

2) Beispiele bieten, ausser Fistularia, viele Siluroïden dar. Bei Aspredo z. B. artirulint der Schedel mit einem ossilicirten, die Halfte der Rumpfgegend cinnchmenden ungegliederten Segmente der Wirbelsäule. Yon seiner Basis alsteigende paarige Leisten bilden cinen knöchernen Ilabcanal für die Aorta. Eine von jeder seiner Seiten abgehende gewölhte breite Knochenplatte bildet ein Dach oberhalb der Schwimmblase, gibt vorne auch einen Stïtzpunkt ab für den Schultergürtel und das $O$ s occipitale externum des Schedels. Eine von dem ungegliederten Canalis spinalis aus aufsteigende einfache linochenleiste befestigt sich vorne an das Ende des Bogentheiles des Hinterhauptes und dient hinten noch dem breiten Träger der Rückenflosse zur L'nterstutzung. Der Basilartheil des ungegliederten Segmentes ist vorne dem Os busilare occipitis, hinten dem Irörper des ersten discreten Wirbels verbunden. 
Axencylinder, der durch die Oeffnung im Centrum und dureh die übrige Masse der Chorda sich hindurchzieht 4). Diesen Axencylinder der Chorda umgiebt oft eine zarte Hülle, von deren Circumferenz aus Blätter oder Lamellen nach der Peripherie der Iöhle. sich erstrecken und nicht selten so innig an den ringförmigen Streifungen haften, dass sie als deren Fortsetzungen erscheinen. - Ausnahmen von dieser Regel bilden solche Fische, bei denen die Vorderseite des Körper's flach oder fast flach ist und nur die hintere Seite eine tiefe Höhle besitzt ${ }^{4}$ ) und andere, obei denen wenigstens der Körper der vordersten Wirbejs nach dem Schedel hin, statt einer conischen Aushöhlung, einen rundlichen Gelenkkopf trägt ${ }^{5}$ ). - Die einzelnen Wirbelkörper desselben Thieres sind bisweilen vou verschiedenem Umfange, auch, je nach Verschiedenheit der Körperregionen, inniger oder loser mit einander verbunden ${ }^{6}$ ).

Bei vielen Teleostei gehen von den Seiten der Wirbelkörper mediane Querfortsätze ab; sie kommen besonders häufig in der Schwanzgegend vor, erstrecken sich aber nicht selten längs der ganzen Wirbelreihe nach vorne ${ }^{7}$ ). - Die untere Fläche der Wirbelkörper besitzt oft Aushöhlungen, die hänfig zur Aufnahme von Fett dienen; hei Esox wird aber die Aorta von den medianen Aushöhlungen oben umfasst.

Engere Verbindungen der Wirbel unter cinander werden bei den meisten Teleostei durch Gelenkfortsätze vermittelt, welche aber genetisch nicht dem Axensysteme, sondern den Bogensystemen angehören. Meistens trägt jeder Wirbel an seinem vorderen, wie an seinem hinteren Ende zwei Paare solche Fortsätze: ein obercs und ein unteres Paar, so dass jedem acht Gelenkfortsätze zukommen. Die von der Vorder-Greuze jedes einzelnen Wirbels ausgehenden beiden Paare von Gelenkfortsätzen sind vorwärts, die von seiner hinteren Grenze ausgehenden hinterwärts gerichtet. Sie umfassen einander wie sich kreuzende Arme zweier Zangen oder es legt der eine sich über den anderen. Wenn die Gelenkfortsätze stark entwickelt sind, wie bei den meisten Scomberoüden, werden sie häufig zur Um-

3) Z. B. bei Scomber scombrus, bei den Cyprinen u. A.

4) Diese Bildung finde ich an den meisten Wirbeln mehrer untersuchten Symbranchii, wo der vorderste Wirbelkörper aher einen wirklich runden Gelenkkopf trägt.

5) Z. B. bei Cobitis fossilis besitzt derjenige Wirbel, dem unten die Knochenblase, welche die Schwimmblase enthält, angefügt ist, vorn einen runden Gelenkkopf; der Körper des nächsten Wirbels isł vorne flach, verhält sich also ähnlich, wie bei Symbranchus.

6) Z. B. bei Ostracion fest in der Rumpfgegend; durch laxere Bandmasse in der beweglichen Schwanzgegend.

7) Sie kommen z. B. vor bei allen einheimischen Pleuronectes, bei den Syngnathus, bei Fistularia, Paralepis, an den Schwanzwirbeln von Esox, von Negalops und vielen anderen Fischen; bei mehren Thynnus nur an den letzten Schwanzwirbeln, 
schliessung des Spinalcanales und Gefässcanales mit verwendet. - Oft sind auch nur zwei Paare von Gelenkfortsätzen vorhanden: ein vorderes Paar, das, von der Basis der oberen Bogensehenkel aus, vor- und aufwärts gerichtet, den nächst vorderen oberen Bogen umfasst und ein hinteres Paar, das, von den Seiten des Wirbelkörpers aus, ab- und hinterwärts gerichtet, den Körper des nächst hinteren Wirbels umfasst. Indem jeder vordere Fortsatz bisweilen, z. B. bei Lophius, Batrachus u. A.. mit dem hinteren Fortsatze des nächst vorderen Wirbels durch ein straffes Ligament verbunden ist, erhält die Wirbelsäule einen äusserst festen Zusammenhalt.

Die Verbindungsweise der einzelnen Wirbelkörper mit ihren soliden Bogenschenkeln zeigt sich in so ferne verschieden, als letztere entweder perennirend discrete Stücke sind, oder als ununterbrochene Fortsälze und Ausläufer der Grundlage der Wirbelkörper erscheinen. Leiztere ist die häufigste Verbindungsweise; die erstere wird bei Esox, bei den Salmones, bei vielen Cyprinen und Characinen angetroffen, indem bei ihnen bald alle, bald die meisten Bogenschenkel der Wirbelkörpersubstanz mit ihren Grundflächen eingekeilt erschcinen. Auch bei viclen anderen Teleostei verhalten sich die Grundflächen einzelner Bogenschenkel, namentlich der unteren, in der hintersten Schwanzgegend ${ }^{8}$ ) und der oberen des ersten ${ }^{9}$ ) Wirbels hiermit übereinstimmend.

\section{\$. 11.}

In Plane, der bei Anlage des Systemes der oberen Bogenschenkel der Teleostei beobachtet ist, liegt, wenigstens häufig, deren Verwendung zur Bildung zweicr über einander gelagerter Canäle, von denen der untere zur Aufnahme des Rückenmarkes, der obere zur Einschliessung eines elastischen Längsbandes: Ligamenlum longifudinale superius bestimmt ist. - Bei einigen Teleostei sind die soliden Elemente, welche die Bildung des Spinalcanales besorgen, von denen des höher liegenden zweiten Canales einigermaassen discret; bei anderen dagegen sind beide confundirt. Zivei verschiedene Elemente im Systeme der obcren Bogen sind bei den Salmones, bei Hyodon, bei Esox, bei Paralepis, bei vielen Clupeïden wenigstens in der Rumpfgegend deutlich zu unterscheiden. Beide gehen von gemeinsamer Basis aus, die dem Wirbelkörper nicht ununterbrochen verbunden, sondern eingekeilt ist. Eine breitere, dickere, inwendige Chondrification oder Ossification erhebt sich zu geringer Höhe und geht oben ununterbrochen in diejenige der entgegengeselzten Seite über. So kommen Seitcnwandungen

8) Z. B. die interen Bogen der letzten und vorletzten Schwanzwirbel von Synanceia horrida, Vomer Brownii, Argyreiosus vomer, Macrodon, Anarrhichas, Echeneis, Brama Raji; bei letztgenanntem Fische sind in die Masse der letzten Wirbelkörper die an der Basis verbundenen, also hier einfach gewordenen Grundlächen der beiden correspondirenden unteren Bogenschenkel eingekeilt.

9) Z. B. bei Synanceia horrida, Lota vulgaris. 
und Dach des eigentlichen Canalis spinalis zu Stande. Ueber seinem Dache liegt das elastische Jängsband, eingeschlossen zwischen zwei schmaleren, meist dïmeren, hoch aufsteigenden, aber unter einander unvereinigt bleibenden rippenartigen Knochenschenkeln. An ihrer Basis sind letztere mit den imneren zu. Unschliessung des Canalis spinalis bestimmten Bogenschenkeln iunig verwachsen; verlängern sich aber über jene weithin selbstständig aufrärts. - In der Schwanzgegend der genaunten Fische sind diese zwiefachen Elemente des oberen Bogensystemes nicht mehr nachzurveisen ${ }^{1}$ ). Verwandt ist die Bildung der oberen Bogenschenkel bei den Plectognathi Gymnodontes. An den vorderen Rumpfivirbeln liegt das niedrige, oft nicht eimmal ossifieirte Dach des Canalis spinalis, an dem keine Spuren der Bildung aus discreten paarigen Seitenstüclien erkaunt werden, freizu Tage. Aber von jeder Seitenvandung des Canalis spinalis erstrecht noch ein freier Knochenfortsatz sich aufwïrls. Anstatt, wie gewönlich, zu convergiren, divergiren diese über den Canalis spinalis hinaus sich erhebenden Elemente der beiden Seiten eines Wirbels. In der Schwanzgegend erhebt sich jedoch ron der oberen I) ecke des Canalis spinalis ein cinfacher Dorn. - Bei vielen anderen 'T'eleostei kommen anf einen Wirbelkörper zwei hinter cinander liegende Bogen von versehiedeuer Ilöhe. Bei Belone, bei manchen Cyprinen 11. A. ist der vordere Bogen niedriger und dient vorzugsweise zur Bedachnng und Umgürtumg des Canalis spinalis. Der hintere Bogen brägt wenig dazu bei. Aufsteigend und convergirend nchmen die Schenkel des lełzleren ein fibröses lä̈ngsband zwischen sich; dann schliesscn sic sich, und bilden einen einfachen oberen Dorn. - Bei anderen. z. B. bei manchen Scomberoüden erhebi sich in der Länge des ganzen Wirbelkörpers jederseits ein Bogensehenkel zu geringer Höhe; dic beiderseitigen Bogenschenkel, welche den Canalis spinalis seitwärts umschliessen, werden oben durch Knochenmasse nicht vereinigt. In die Knochensubstanz jerles Bogenschenkels eingetragen ist aber noch eine schmale Knochenleiste, welche

1) Bei Salmo salar gelangt man unwillkührlich dahin, die zur Umschliessung des fibrösen Längsbandes verwendeten äusseren oberen Bogenschenkel als den die Rumpfhöhle umgürtenden Rippen analoge Elemente zu betrachten. Die am Rumpfe vorlsommenden eingekeilten Elemente der unteren Bogenschenkel entsprechen, ihren Lagenverhältnissen nach, genau den zur Bildung des Canalis spinalis verwendeten genuinen oberen Bogenstücten; die jenen angefïgten Rippen, den das fibröse Längsband einschliessenden Theilen. Charakteristisch ist, dass letztere nur in der Rumpfgegend mit den gegenübersthenden der anderen Seite nicht zu einem oberen Dorn sich vereinigen. Einer generellen Durchführung jener Vergleichung, die dahin führen könnte, in dem von dem Ligamentum longitudiaale superius eingenommenen Raume ein Analogon der Rumpfhühle zu finden, stellen grosse Schwierigkeiten sich entgegen. Aber angedeutet ist eine solche Symmetrie zwischen unten und oben immerhin, wenn auch nicht iberall durchgeftihrt. Schon beim Hecht sind die Verhältnisse minder rein, als beim Lachs. 
die obcre Grenze desselben weit überselweitet. mit der gegenuiberstehenden convergirt und zu einem cinfachen processus spinosus superior versehmilzt. - Bei vielen anderen z. B. bei den Gadviden. bei Syelopterus ist dagegen die Zusammenselzuns des oberoil liogensysteunes eines Wirbels ans verschiedenen Elementen nicht zu crkenuen. Die von den Wirbelkörpern aufsteigenden Bogenschenkel bilden slarke vordere Golenkfortsälze, convergiren und schliessen sich.zu einem einfachen Dorn. - Die Zahl der untergeordueteren Tariationen in der Anordnungsweise des oheren Bogenschenkelsystemes ist sehr gross 2). Vou der oberen Schlussitelle des Canalis spinalis kam sogleich cin rufacher oberen, nit derselben in ununterbrochenem Zusammenhange stehender Jorn sich erheben. Ist ein solches aufsteigendes Element plattenförmig so solu verbreitert, dass es die gleichnamigen Elementc des nädhst vorderen und nächst hinteren Wirbels in ganzer Höhe becührt. so werden die beiden oberen Seilcuhälften der Muskeln durch eine ganz solide Stheidewand von einander gelremt ${ }^{3}$ ). - Bei ringen Teleostei gehen von den knöhhernen Elementen Acr oberen Bugen noch accessorische Fortsitze ah: solche kommen z. I3. bei Ilypostoma an mehren Wirb.ln ror und sind zur. Untersiülzung der Knochenschilder der Haut bestimmit. - Bei demseblen Thiere sind die sonst gewöhnlich, als Ossa interspinalia. zwischm den häuligen Interstitien der Processus spinosi gelegenen, Flossenträger den letzteren durch Naht verbunden.

\$. 12.

Das Sysfem der unteren Wirbellogen zeigh nicht minder grosse Verschiedenheiten in seiner Anorelnungsweise, als das der oberen. Das gerohnlichste und darum als lypisch angesprochene Verhälniss ist das, dass das untere Wirbelbogensystem. rom Schwanze aus, lïugs der ganzen Rumpfgegend sich fortsetzl, dass seine prariggen Sehenkel dort zur Schliessung cines die Aorla und dic Venc crudalis umfassenden Gefässcanales und dann zur Bildung eines cinfachen unteren Dornfortsalzes grelangen, hier aber in Gestalt - meist Rippen tragender - von hinten atus nach vorne hin mehr und mehr divergirender unterer $Q$ uerfortsätze erscheinen. Obgleich das obere Wirbelbogensystem in der Sohwanzegend zwei Gefïsse: dic Aorte und Fena curdulis einschliesst. sind doch die Elemente zwiefacher Bogenschenkel in sciner Zusammasudzung nicht nateh. zuweisen. Ilörhstens funden sich schwarhe Sprren cincr discreten Entstehungsweise des unteren Dorues ror, wie z. 1). an dem (rsten Sehwanz-

2) Bei Callionymus lyra divergiren die als fielenkfortsätze verwendelen Elemente der Bogenschenlicl an ihren freien Enden. Diese Divergenz hezweckt die Schaffung cines Raumes zur Aufnahme der Träger der Afterllosse, die von jenen paarigen Fortsătzen seitwärts umfasst werden.

3) Z. B. In der Schwanzgegend von Ilypostoma. 
wirbel des Lachs. Zahl und Art der Abweichungen von dem typischen Verhalten sind gross. Bei manchen Teleostei zeigen sich, längs der Rumpfgegend keine Spuren von Elementen der unteren Bogen:11). Bei anderen sind sie hier mindestens ganz abortiv ${ }^{2}$ ). - Die Vereinigung der patrigen knöchernen unteren Bogenschenkel längs der Schwanzgegend kann fast ganz ausbleiben ${ }^{3}$ ). - Sehr häufig kommt dagegen auch in der Rumpfgegend eine Vereinigung der paarigen unteren Bogenschenkel zu Stande. Bald werden sie, olne eigentlich zu convergiren, unterhalb des Axensystemes durch knöcherne Querbrücken verbunden ${ }^{4}$ ); bald sind sie ganz nach dem Typus derer der Schwanzgegend gebildet, indem sie, convergireud und sich vereinigend, Spitzbogen bilden, die aber nicht so tief abıärts steigen, um den Raum für die unterhalb ihrer gelagerte Rumpfgegend zu beengen ${ }^{5}$ ); bald bilden sie unter dem Axensysteme, in grösserer Breite und geringerer Tiefe in einander übergehend, nur einen engeu Gefässcanal ${ }^{6}$ ). Diese Vereinigung und Schliessung der paarigen Elemente des unteren Bogensystemes in der Rumpfgegend beschr:̈nkt sich bald nur auf wenige der letzteren angehörige Wirbel, bald erstreckt sie sich auf viele derselben ${ }^{7}$ ). - Statt einen engen, blos zur Aufuahme der Caudalgefïsse bestimmten Canal zu bilden, kömnen die paarigen unteren Bogenschenkel der Schwanzgegend vor ihrer Vereinigung stark divergiren, um cinen weiteren zur Nlitaufuahne der hintersten Enden der Nieren und der Schwimmblase bestimmten Canal cinzuschliessen ${ }^{8}$ ). - Anstatt, wie gewöhnlich, als schmale Leisten von der breiteren Basis des Wirbelkörpers alzzusteigen ${ }^{9}$ ), können die absteigenden ossificirten Elemente von der ganzen Länge cines Wirbelkörpers ausgehen. Dabei kann die Bildung eines absteigenden einfachen unteren Dornes ganz ausbleiben; oder es kann, statt eines schmalen Doru-

1) Dahin gehören z. B. Syngnathus, Cotylis, Fistularia.

2) Z. B. bei Diodon, Tetrodon, Lophius.

3) Z. B. bei Gymnotus electricus, wo sie von oben einen fibrösen Sack decken, welcher die Schwimmblase einschliesst; ferner bei Ophicephalus striatus, wie Cuvier gezeigt hat.

4) Z. B. einer bei Synanceia horrida, vier bei Sebastes norwegicus, sechs beim Lachs, neun bei Zeus faber, Vomer Brownii, Cybium regale, acht bei Alosa vulgaris zwölf bei Lutodeira chanos, fünfzehn heim Häring u. s. w. - Bei Malacanthus Plumieri nehmen die drei hintersten vereinigten Bogenschenkel die Schwimmblase auf.

5) So bei Blennius gunnellus nach Cuvier u. Valenc. (Vol. XI.) wo ihr Canal von vorne nach hinten sich erweitert zur Aufnahme der Nieren. Ebenso finde ich sie geschlossen bei Liparis barbatus, wo aber die Nieren ausserhalb ihres Canales liegen.

6) Z. B. bei IIypostoma.

7) Fast längs der ganzen Wirbelsäule, mit Ausnahme der vordersten Wirbel bei Blennius gunnellus und Liparis barbatus.

8) Z. B. bei Exocoetus.

9) Auch solche Leisten können stellenweise in Platten sich verbreitern, die aneinander stossen, wie z. B. an einigen Schwanzwirbeln von Vomer Brownii. 
ganz entschieden auf die ursprüngliche Anwesenheil, einer solchen Krümfortsatzes, eine die ganze Lünge des Wirbelkörper's besitzende verticale Platte von der unteren Wand des Gefässcanales absleigen. Indem dann die einzelnen absteigenden Platten der, der Länge nach, auf cinander folscnden Wirbel einander unmiltelbar berühren, entsteht unterhalb des Axensystemes der Wirbelsäule ein ganz ossificirtes, die beiden unteren Seitenhälften der Caudalgegend tremnendes Septum 10). - Die unteren Bogen. elemente zeigen noch manchmal andere Eigenthümlichkeiten. ${ }^{11}$ ).

\section{\$. 13.}

Das Schwanzende der Wirbelsäule bietet bei den Ganoïdei und Teleostei beträchtliche Verschiedenheiten in Betreff des Verhaltens der letzten Wirbel. der Permanenz des Endes der Chorda dorsalis, der An- oder Abwesenheit einer zur. Unterstützung der Schwanzflosse bestimmten verticalen Platte und einiger anderer Verhältnisse dar.

Bei solchen Fischen, denen eine eigene verticale Schrvanzfosse mangelt, nehmen die Wirbel der Schwanzgegend von vorne nach hiuten an Umfang und namentlich an Länge ab und der letzle Wirbel endet etwas zugespitzt. Dahiı gehören die Blenniö̈den, die Ophidini, die Täniö̀len, die Muränoïden, Fistularia u. A.

Bei anderen, die eine ausgebildetere Schwanzflosse besitzen, verflacht und verjüngt sich das Ende des letzten Wirbels und zieht in eine von der Basis nach dem freien Ende hin allmälich sich verbreiternde verticale Platte sich ans, welche zwei ganz symmetrische Hälften, eine obere und eine untere besitzt. Un die Ränder dieser Platte legen sich die an der Basis auseinander weichenden Hälften der Flossenstrahlen. So z. B. bei Cyclopterus, Callionynus, bei den Pleuronectes, den Plectognathi. - Was die Bildung der verticalen Platte aubetrifft, so entsteht sie entweder aus den in ihrer Form modificinten oberen und unteren Bogeuschenkeln; oder aus diesen nnd aus eingeschalteten accessorischen Stäben, wie man dies z. B. bei Belone erkennt.

Bei anderen erhält sich eine aufivärts gerichtete Krümmung der letzten Schwanzwirbel perennirend, oder die Anordnung des Schwanzendes deutel

10) Z. B. bei Hypostoma.

11) Bei einem Scomberoiden (Scomber seminudus Ehrenb.) gehen, wie $\|$ üll or (Vgl. Osteol. d. Myx. S. 76.) angibt, die Rippentragenden Fortsätze der hinteren Bauchwirbel von der unteren Mittellinio der Wirbelkörper unpaarig aus, treten gerade abwärts, weichen dann zur Bildung eines Canales auseinander und gehen dann erst seitlich abwärts in zwei Schenkel aus, -an denen die Rippen hangen. - Bei Thynnus brasiliensis (Mus. Hafniens.) liömmt an mehreren Schwanzwirbeln folgende Bildung vor: der vordere und hintere Gelenkfortsatz jeder Seite eines Wirbels verhinden sich, nachdem sie steil abgestiegen, durch eine Brücke, von deren Jitte aus der Canalbildende untere Bogenschenkel absteigt und mit dem der entgegengesetzten Seite sich yereinigt. 
mung hin. Bei den Salnones krümmen sich die vier oder fünf letzten Schwanzwirbel zuerst allmälich, zulelzt steiler aufwärts und bilden so einen Bogen, dessen Convexilit abwïrls gerichlot ist. Die Körper dex vorletzten Wirbel sund noch ossificist und besitzen ihre conischen Ilöhlungen; der letafe ist aber nur ein hohler Knochencylinder, aus welchem hinten das conische Ende der Chorda dorsalis hervorgeht, um, aufwärts gerichtet, zwischen den an ihrer IVurel auscinander gewichenen Schwanzfossenstrahlen sich zu verlängern. - Vou dem dorsalen Rande der letzten drei Wirbelkörper ans erhebt sich jederseits eine allen gemeinsame unregelmässig gestaltete knochenplatle, welkhe, nach hinten verjüngi, nu einen Theil des Chorda-Endes cine Scheide bildel. Zwischen diesen beiderseitigen Knochenplatten sind aborlive Schlussstüclic des oberen Wirbelbogencanales cingekeilt. - Der ventrale Rand der heiden letzten aufwärts gekrümmten Wirbelkörper, ist von mehren, namentich nach ihren freien Enden hin, platleuförmig verbreiterten Forlsätzen umsäimt, welehe dadurch, dass sie sich mit ihren Rïudern an cinander legen, cine verticale Schwanzflossemplatte bilden. Diese dem Systeme unterer Bogenschenkel angehörigen Fortsälze gehen in grösserer Zahl von einem Wirbelkörper aus.

Dieselbe Bildung fundet sich, oft noch ausgeprägter, als bei den Salmones, bei den Ganoïlei; fermer, unler den Teleostei, bei Esox, bei Hyodon n. A. In derselben crhalten sich nelor orler minder lange perennirend solehe Verhältnisse, die bei anderen Teleostei blos transilorische Entwickelungsphasen sind 1) und die asymuetrischen Bildungsweisen ihrer letzten Sehwanzwirbel, wie sie z. B. bei den Cyprinen, den Characinen und vielen anderen, in dem Vebergewichte dex undexen Fortsätze iber die oberen hervortreten, aufklären.

Es ist also die Schranzilosse bei vielen Fischen wesentlich solehen Fortsïtzen angefïgl, die von dev ventralen Seite der Wirbelkörper ausgehen. Wenn man dic Fische, bei denen diese asymmetrische Anfügungsweise der Schwanzfosse recht aulfallend hervortrilt, als Helerocerci scharf von anderen zu unterscheiden bestrobt ist, bui denen die Schwanzflosse aus zwei gleicheren Ilälften bestcht (Ilomocerci), so hat man zu bedenken, dass ganz allmäliche Ueberginge zwischen beiden Anodunngsweisen vorkommen und dass viele als homocerk gellende Fische unverkennbare Spuren ursprünglicher IIeterocercic an sich tragen.

Bemerkenswerlh ist am letzen viler rorletzlen Schwanzwirbel vieler Teleostei ein jerlerseils vorhaulener ctwas hakenfürnniger Fortsatz der über

1) S. z. B. Baer, Entwickelungsgesch. d: Fische. S. 36, der beobachtete, wie bei Cyprinus blicca, vom fünften. Tage an, die hintere Spitze des Stammes der Wirbelsanle nach ohen sich lirünmt, so dass die Schwanzflosse, die nun anfüngt, mehr sich auszubilden, nicht symmetrisch an der spitze sitzt, sondern mehr abwärts der unteren Hălfte der Jetzten Wirbel angefügt ist. 
einer Oeffnung vorragt. Es ist dies diejenige Slelle, wo durch die bezeichnete Oeflnung eine Communication zweier Sinus lymphtulici caudales Statt hat. \$. 14.

Die meisten (anoüdei ${ }^{1}$ ) und Teleostei besilzen Rippen. Dieselben fehlen manchen der letzteren vollständig; dahin gehören die Lophohranchii, die mẹisten Plectognathi Gymnodontes ${ }^{2}$ ), die Ostraciones, Fislularia und einzelne Gattungen anderer Familien ${ }^{3}$ ). Bei den meisten Fischen beschränkt sich ihr Vorkommen auf die Rumpfgegend. Bei anderen sind aber noch in der Schwanzgegend den zu Spitzbogen gesehlossenen oder unvereinigt gebliebcnen unteren Bogeuschenkeln in längerer oder kürzerer Strecke Rippen angefïgl, welche meistens die Bestimmung haben, die nach hinten sich verlingernde Schwimmblase zu umschliessen "). - Die Rippen sind bei der überwiegenden Mehrzahl der Fische den unleren Bogenschenkeln des Wirbeisystemes angefügt; meistens seitwärts, in welehem Falle sie noch mit den Wirbelkörpern in Berührung zu kommen pflegen, oft auch an ihren freien Euden. Wenn in der Rumpfhöhle die unteren Bogenschenkel in Spitzbogen oder dureh Querbrüeken verbunden sind, tragen sie gewöhnlich noch Rippen, falls deren Vorkommen ïberhaupt in dem individuclten Plane der betreffenden Species liegt 5). Bei Polypterus liegen die Rippen, unter Abwesenheit muter: Bogensehenkel in der Rumpfgegend, dicht unter den medianen Querfortsätzen đer Wirbelkörper. - Die Gattung Cotylis bietet das einzige bis jetzl bekannte Beispiel einer noch höher autwäts reichenden Anheftur: der Rippen dar. Sie inseriren sich bei Cotylis Stannii, dem untere Bogensehenkel in der Rumpfgegend ganz fehlen, seitwïrts an den Wirbel. körpern, dicht unter den Gelenkfortsïzen der oberen Bogensehenkel. Die hippen sind von verschiedener Ansdehnung und Stärke; sehr slark 7. B. bei viclen Cyprinoüden; klein und düm bei vielen anderen Fisehen, Sic umgürten die Rumpfhöhle und dienen zugleich den Ligamenta intermuscularia des Seitenmuskels zur Befestigung ${ }^{6}$ ).

1) Harte Rippen fehlen bei Spatilaria. S. S. 21.

2) Dic ihnen angehörige Gattung Triodon besitzt Rippen, nach den Angaben von Dareste.

3) Z. B. bei Lophius, Malthaea.

4) Z. B. Lei Butirinus vulpes, bei einigen Mormyri sind sie den abwärts geschlossenen Bogenschenkeln angefügt; bei Ophicephalus striatus tragen die in der ganzen Länge des Schwanzes (mit Ausnahme der vier letzten Paare) unvereinigt bleibenden Bogenschenkel Rippen, welche die verhingerte Schwimmblase einschliessen. S. Cuvier et Valenc. VHI. p. 420 .

5) Z. B. bei den Salmones, bei Zeus faber, Vomer Brownii, vielen Clupeïdac z. B. Clupea, Alosa, Lutodeira u. $\Lambda$.

6) Eigenthümliche Bildungen, welche durch die Aufuahme der Schwinmhlase bedingt scheinen, schildert Cuvier (hist. nat. d. poiss. Vol. IX. p. 425) bei Kurtus Blochii und cornulus, bei Malacanthus Plumieri, Vol, XIII. p. 526. 
Bei einigen Teleostei zieht unter der ventralen Mittellinie des Rumpfes, an der Bauchkante eine äusserlich nur von der Haut überzogene Reihe von IIarlgebilden sich hin, welche deshalb einem Sternum ähnlich sind ${ }^{7}$ ). Dergleichen kommen namentich bei manchen Clupeïden z. B. bei den Gattungen Clupea, Alosa, Notopterus vor, erseheinen jedoch auch bei anderen Fischen, z. B. bei Zeus unter den Scomberoïden. Bei Clupea sind es unpare Stïcke, von deren mittlerem Schilde ans, jederseits ein verjüngter Schenkel aufsteigt; bei Notopterus sind paarige Stücke vorhanden.

\section{Vom Schedel und den ihm verbundenen skelettheilen.}

\$. 15.

Der vorderste Theil des Wirbelsystemes, welcher, mit einer einzigen bekannten Ausnahme (Branchiostoma) durch eine beträchtliche Erweiterung des vom oberen Wirbelbogensysteme gebildeten Canales sich auszeichnet, weil es um Aufnahme des umfänglichen vordersten Abschnittes des centralen Nervensystemes sich handelt, ist der Schedel.

Seine Grundlage bildet ein Axcnsystem, das in längerer oder kürzerer Strecke, sei es perennirend oder wenigstens genetisch und vorübergehend, als unmiltelbare Fortsetzung der Chorda dorsalis der Wirbelsäule sich zeight, meist aber in seinem vordersten Abschnitte von der Chorda unabhängig entstanden zu sein scheint. Oberhalb des Axensystemes des Schedels und in versehiedenem Grade der Innigkeil ihm verbunden, liegt ein System oberer Bogen, das, wenigstens eine Strecke weit, zur Bildung eines ununterbrochenen Canales: der Schedelhöhle verwendet wird, die durch beträchtlichere Weite vor lem Canalis spinalis sich auszeichnet. Die Ausdehnung dieses Canales nach dem vorderen Schedelende hin ist bei den verschiedenen Fischen sehr ungleich, je nachdem die Geruchsnerven in einer unmittelbaren weitereu Verlängerung der Schedelhöhle vom Gehirne aus zu dem mehr oder minder weit vorwärts gerückten Geruchsorgane sich begeben oder nicht ${ }^{1}$ ). - Gegen ihr vorderes Ende hin bilden die Elemente des oberen Bogensystemes keinen Canal mehr, sondern gehen in einen soliden einfachen und mparen Fortsatz von sehr verschiedener Ausdehnung über, zu dessen Seite vorne die peripherischen Ausbreitungen der Geruchsnerven zu liegen pffegen. - Eine Fortsetzung des Systemes der unteren Bogen der Wirbelsïule ist am Schedel gar nicht, oder

7) Dies Sternum darf indessen nicht als Aequivalent desjenigen höherer Wirbelthiere angesehen werden.

1) Zu den Fischen mit langem Geruchsnervencanale gehören z. B. Lepidosteus unter den Ganoiden, Gadus, sowie Silurus und Cyprinus. Die Bildungsweise dieses Canales ist aber bei fast allen genannten Fischen verschieden. 
höchstens sanz abortiv nachzuweisen ${ }^{2}$ ). - Unterhalb des Axensystemes des Schedels liegt, als Mund- und Rachenhöhle, der Anfang des Trachus intestinalis.

Der Schedel würde als reine und ungemischte Fortsetzung der Wirbelsäule erseheinen, wenn nicht seine Elemente bald besländig, bald bloss in gerrissen Gruppen der Fische, noch andere Verwendungen erführen und in Beziehungen zu anderen Skeletsystemen träten. Sie unterstützen bestïndig die Organe der höheren Sinne. Sie besitzen gewöhnlich enge Bezichungen zu einzelnen Gliedern des Visceralskeletes, das die unmittelbare Umschliessung der unterhalb des Schedels gelegenen Mund- und Rachenhöhle besorgt ${ }^{3}$ ). Thnen verbunden siud häufig Glieder eines Skeletsystemes, das eine weitere mehr mittelbare Begrenzung des vorklersten Abschnittes der Visceralhöhle bildet ${ }^{4}$ ). Sie sind endlich eben so" oft verbunden oder verschmolzen mit einer dem äusseren IIantsysteme primitiv angehorigen Skeletschicht ${ }^{5}$ ). Endlich gewähnt der Schedel in der Regel dem sich anheftenden Schultergürtel, oder selbst anderen Theilen der Vorderestremitäteu und bisweilen auch der vorwärts verlängerten Rückenflosse Stützpunkte.

Während der Schedel in der Regel symmetrisch gebildet ist, stellt eine Asymmetrie desselben in der Gruppe der Pleuronectides sich heraus, welche überhaupt durch die mannichfachsten asymmetrischen Bildungen sich auszeichnet.

Die Verhälnnisse der Elemente des Schedels zu den drei höheren Sinnesorganen, im Wesentlichen ähnlich, sind im Einzehen verschieden. Die Gehörorgane liegen am meisten nach hinten; das Labyrinth ist bald auf einen kleineren Raum concentrirt, der, in Gestalt einer Capsel, den Seilenwandungen der Schedehhöhle gewissermaassen eingeschoben ist ${ }^{6}$ ); bald breitet es in der Substanz der ungegliederten oder gegliederten Sehedelwandungen weiter und oft sehr weit sich aus $\left.{ }^{7}\right)$. - Mehr nach vorne licgen die Gesichtsorgane, welche, indem sie meistens in einen verengten und hinten und vorne durch einen oft abgegliederten Vorsprung begrenzten $\Lambda$ bschnitt des oberen Bogensystemes aufgenommen werden, eine Modification in den Formverhältnissen der Schedeleapsel zu bedingen pflegen. Die beiden Augen werden bald durch eine zwischenliegende weitere Verlängerung der Schedellü̈hle, bald durch cin eiufaches Seplum interorbitale, bald durch cine vermöge Combination beider Verhältnisse gebildete Scheidewand ge-

2) IÜ̈chstens an der unteren IJäfte des Os orcipifule basilure in den schwachen Spuren von absteigenden Seitenfortsätzen, zwischen denen das Ligumentum longiludinale inferius vorne anfängt, bei Esox, Salmo, Clupea $u, \Lambda$.

3) Vgl. \$. 16. - 4) Vgl. \$. 18. - 5) Vgl. \$. 19.

6) Z, B. bei den Marsipobranchii. - 7) Z. B. bei den meisten Teleostei. 
trennt. Ein 'Theil des Bervegungsapparates der Augen wird, wenigstens häufig, in Canïle anfgenommen, zu deren Bildung Schedelelemente verwendet werden ${ }^{8}$ ). - Noch weiter vorwärts liegen die Geruchsorgane, entweder dem Vorderende der Schedelhöhle, mag diese kurz, oder als Geruchsncrvencanal schr verläugert sein ${ }^{9}$ ), numittelbar augefügt, oder von letzterer dadurch mehr oder minder weit entfernt, dass die Geruchsnerven nur an einem, der Schedelhöhle vorne angeschlossenen, unpaaren Septum zu ihren Endausbreitungspnnkten treten ${ }^{10}$ ). Diese leteteren werden bald von discreten Geruchscapseln umschlossen ${ }^{11}$ ), bald bieten die vorderen Augenhöhlenvorsprünge des Seherlels ihnen Stützen ${ }^{12}$ ), bald können sie vor den Oberkiefer-Apparat uach vorne gerückt selbst von Kiefertheilen umgeben werden ${ }^{13}$ ).

su Fr-der mnter iher gelagerten Mund-und Rachenhöhle treten die Sehedelelemente ebenfalls in mannichfache Verhältnisse.

\section{\$. 16.}

Unter dem Schedel liegen nämlich die vordersten Visceralbogen und die den Gaumen-Apparat constiluirenden IIartgebilde. Beide Gruppen von Skeletheilen gehören einem gemeinsamen Systeme von Hartgebilden au, das die unmittelbare Umgïrtmg des vordersten Abschnittes des Darmrohres besorgt mol das, obschon seine primitiven Anlagen mit denen des Schedels ein Continum bilden kömnen, dem architectonischen Plane des eigentlichen Wirbelsystemes fremd ist.

Dic Summe der zu unmittelbarer Unterstülzung des Darmrohres bestimmten Hartgebilde macht das Visceralskelet aus. Da eine Sonderung gewisser, dem Viseeralskelet primitiv angehöriger Glieder von anderen Slieletformationen überhaupt und vom Schedel insbesondere schwierig ist, mud da wegen der vielfachen secundären Verwendungen und imigen Verbiudungen, die dieselben erfahren, eine in dem Sime ihres arehitectonischen Planes abgefasste Darstellung derselben der erforderlichen Klarheit crmangeln wïrde, ist hier zunächst über dic Anlagen der vordersten Glieder des Visceralskeletes und ihr Verhältniss zı den übrigen Bestandtheilen desselben Systemes zu handeln.

Bei den meisten Fischen erhält eine mehr oder minder lange Strecke der Racheuhöhle an ihren Seiten und an ihrer ventralen Schlusslinic eine unmittelbare Umgürtung durch convergirende Bogenschenkelpaare, welche abriirts zu Bogen sich schliessen. Die meisten dieser Bogen liegen in der Kiemengegend und werden, weil sie gewöhnlich die Kienenspalten begrenzen und meistens zugleich die die Kiemenblätter oder Kiemenstrahlen

8) Vgl. \$. 29. - 9) Z. B. bei Lepidosteus. - 10) Z. B. bei Cottus.

11) Z. B. bei den Marsipobranchii. - 12) Z. B. bei vielen Teleostei.

13) Z. B. bei Lepidosteus. 
tragenden Iilphragmata stützeu..ihrer functionellen Verwendung wegen, als Kiemenbogen bezeichnet. Jenseits derselben, nach der Speiseröhre hin gelesene Bogen erhalten, weil ihnen die eben genante Funclion in der Regel nach absodvirtex embryonaler Entwickelung mangelt, sic digegen den Schlundkopf unterstützen, die Benennung unterer Schlundkiefer. Ossa pharyngea inferiora. Ueber die Gleichartigkeit der archilectonischen Bedentung von unteren Schlumbliefern und Kiemenbogen waltel, trotz ihrer verschiedenen funclionellen Verwendung und daraus resultirender Verschiedenheiten in der Form und Ausdehnung, um so weniger Zweifel ob, als die Schlundkiefer während früherer Lebensstadien mancher Fische als Kiementragende Theile erkannt sind und ${ }^{1}$ ) wahrseheinlich allgemein primitiv diese Function besitzen. Die Kiemenbogen und Schlundliefer gehören in ein System: das der Visceralbogen. Die eben genannlen Glieder des Visceralbogensystemes stehen zu dem Schedel nach absolvirter Entwickelung in keiner unmittelbaren Bezichung. Vor dem vordersten Kiemenbogen liegst aber cin anderer Bogen, welcher, wenigstens bei vielen Fischen in ihren ausgebildeten Zuständen, keine Kiemen trägt, dagegen meistens zur. Unterstïlzung cines Zungeniudimentes vervendet wird und, dieser lelzieren Function wegen, den Namen: Zungenbein führt. Indem dasselbe wenigstens primitiv die Function der Kiemenbogen theilt ${ }^{2}$ ), auch bei manchen Fischen, z. B. vielen Rajidae ${ }^{3}$ ) perennirend in fast allen Verhältnissen einem Kiemenbogen entspricht, hat man es als unvesentlich angesehen, dass es bei Anderen dureh seinen Ausgangspunkt von einem ilum und dem Untertiefer gemeinsanen Suspensorium, so wie durch andere in seiner cigenthümlichen funclionellen Verwendung begründete Momente von den übrigen Bogen sich unterscheidet, und mit allem Rechte das Zungenbein, als ihnen arehitectonisch äquivalent, dem Systeme der Viscerallogen zuge. rechnet. Schwieriger wurde die Einreihng eines noch weiter vorwärts gelegenen Bogens in das System der Visecralbogen. Die genetisehen Verhälthisse des Unterkiefers bei hïheren Wirbelthieren waren es vorzuğsweise, die in ihm oder vieluchr in gevissen, in seine Zusammenselzung einghehenden Theilen ein Glied des Visceralbogen-Systemes vermuthen liessen.

1) Bacr, (Ueber Entwickelungsgeschichte. Thl. 2. S. 300.) scheint selbst noch jenseits des $O$ s pharyngeum einen Kiemenbogen gesehen zu haben. ,In Güstern, die vor zwei Tagen ausgeschlüpft waren, sah ich die Gefässbogen bis auf 7 gesteigert, so dass hinter den letzten Kiemenbogen noch zwei Paare lagen."

2) Nach den Beobachtungen von C. Vogt, Embryolog. des Salmones, p. 226, ist der Zungenbeinkiemenbogen anfungs vorzugsweise entwickeit. Ueberrest seiner Kieme ist die Pseudobranchie.

3) Dieselbe Aehnlichkeit tritt auch, freilich unter ganz anderen Bedingungen, bei anderen Fischen z. B. bei Iuraenophis hervor. 
Der Unterkiefer der Fische besteht meist aus einem Paare von Schenkeln, welche einen Bogen bilden. Dieser Bogen ist gewöhnlich, zugleich mit dem Zungenbeine, durch einen besonderen Skelettheil: das Suspeusorium am Schedel befestigt. Bei vielen Rajidae haben Zungenbein und Unterkiefer kein gemeinsames, soudern discrete Suspensorien am Schedel. Dasjenige des Unterkiefers entspricht yenau dem des Zungenbeines. Dic Suspensorien beider entsprechen gewissen oberen Segmenten der folgenden Kiemenbogen. Dies fülnt dahin, in dem gemeinsamen Kiefer- und Zun. genbeinsuspensorium, speciell in dem Os temporale der Teleostei, eine Verschmelzung der bei den Rajidae getrennten Suspensorien beider zu vermu. then. Diese Vermuthung gewinut eine Stütze in dem Umstande, dass das Os temporale der Teleostei an zwei Knochen und meist mit zwei, elwas getrennten Gelenkköpfen articulirt, und in der zweiten Thatsache, dass in dem Os temporale einzelner Teleostei zwei, durch eine dünne Knochenplatte verbundene, stärkere Knochenstäbe sich erkennen lassen. Diese Thatsachen deuten darauf hin, dass dies Os temporale die Elemente zweier Suspensorien enthalte, die ihrerseits wieder den obersten Segmenten der folgenden Kiemenbogen, d. h. denen, welche auf die Ossa pharyngea superiora folgen, entsprechen. Von einem unteren Ende dieses Os temporale geht nicht nur der Zungenbeinbogen mittelst des $O$ s slyliforme ab, sondern er setzl auch in einen anderen kleinen stabförmigen, meist discreten Knochen sich fort, den $\mathrm{C}$ uvier als Os sympleclicum bezeichuet hat.

Dieser letztere Kuochen selbst lässt bei mehren Ganoïdei holostei, namentlich bei Amia und Lepidosteus, ein von ihm ausgehender abortiver, faserhiutiger Strang aber bei den meisten Teleostei bis zum Unterkiefergelenke sich verfolgen. Von dem Gelenkstücke des Unterkiefers aus zieht num nach vorne an der Innenseite jedes soliden Unterkieferbogens, der; wie eine Schale, ihn umgibt, der Meckel'sche Knorpel sich hin. Dieser Knorpel ist der Unterkiefertheil desselben Kuorpels, der bei Embryonen hïherer Wirbelthiere unzweifelhaft als Anlage des vordersten Visceralbogens sich zu erkenuen gibt. Es geht also hieraus hervor, dass bei den Ga. nö̈den und den Teleostei das Os temporale, abgeschen von seiner weiteren functionellen Verwendung, seiner architektonischen Anlage nach, wesentlich als gemeinsames oberes Glied zweier Visceralbogen: des Zungenbeines und Unterkiefers aufzufassen ist; dass ferner gewisse Elemente des sogenanuten Kiefersuspensorium und des Unterkiefers, namentlich das $\boldsymbol{O S}_{\boldsymbol{s}}$ symplecticum und der Meckel'sche Knorpel, als weitere Glieder des ersten Visceralbogens betrachtet werden müsseu. Der Unterkieferknorpel der Fische ist, gleich dem der Reptilien und Vögel, der Unterkiefertheil des Mcckel'schen Knorpels der Säugethiere, dessen aufwärts gelegener Theil bei den Fischen das Os sympleclicum bildet. Der dem Schedel zunïchst gelegene Theil erhält, je nach den Thierclassen, eigenthümliche sccundäre 
Verwendungen; bei den Säugethieren ist er durch den IIammer repräsentirt; bei den Fischen wird er ein Element des Os temporale.

Nächst den die Seiten und die untere Schlusslinie der Mund- und Rachenhöhle umgürtenden Visceralbogen kommen die an der Decke derselben Höhle gelegenen Theile, als gleichfalls dem Visceralskelete angehö. rig, in Betracht. Zwischen den parigen Seiten-Schenkeln eines Kicmenbogens sind, als obere Schlussstücke der Rachenhöhle, sehr häufig die Ossa pharyngea superiora eingeschaltet. Ihre Stelle scheint im vordersten Abschnitte der Visceralhöhle vertreten zu werden durch die soliden Gaumenstücke, welche insbesondere in Gestalt der Ossa plerygoidea und palalina ausgebildet, vorzukommen pflegen.

In Bezug auf seine Verbindungsweise mit dem Schedel zeigt das Visceralskeletsystem in den cinzelnen Gruppen Verschiedenheiten. Nur bei cinzelnen erhält sich perennirend eine temporär vielleicht allgemeiner vorkommende, ununterbrochene Verbindung des Schedels mit Elementen des Visceralskeletes; meistens sind letztere gesondert. .....

1. Bei Branchiostoma stehen Glieder des Visceralskeletes anscheinend nieht in Beziehung zum Schedel.

2. Bei den Marsipobranchii erscheint cin zusammengesetztes, auf den Typus der einzelnen Glieder des Visceralskeletes höherer Wirbelthiere nur unvollkommen reducirtes dorsales und seitliches, den vordersten Abschnitt der Visceralhöhle umgürtendes Knorpelgerüst in ununterbrochener Continuitit mit der Schedelcapsel.

3. Bei den Plagiostomen sind vom Gaumentheile des Visceralskeletes hïchstens einzelne Glieder entwickelt. Die discreten oder zu einem Stücke verschmolzenen obersten Glieder der beiden vordersten Visceralbogen lehnen seitlich an den Schedel sich an.

4. Bei den Chimären stehen der Gaumenapparat und die als Unterkiefersuspensorium fungirende, obere IÏ̈lfte jedes ersten Viscerallogonensehenkels in ununterbrochener Continuität mit dem Schedel.

5. Bei den Dipnoi gehen die Gaumentheile und der, auch hicr wahrscheinlich Elemente des ersten Visceralbogens enthaltende, Unterkiefer von einem Schedelfortsatze aus, an den anch das oberste Glied des zweiten Visceralbogens angelehnt ist.

6. Bei den Ganoïdei chondrostei lehnen die zu einem Stücke verschmolzenen Endglieder der beiden vordersten Visecralbogen seitwärts an den Schedel sich an. Die Gaumenhartgebilde bleiben ausser unmiltelbarcr Verbindung mit dem Schedel oder fehlen.

7. Bei den Ganö̈dei holostei hat die Anlehmung der unter der Benennung des Os temporale belianuten, zu einem Slïcke verschmolzenen Endeylinder der beiden vordersten Visceralbogen steichfalls seitlich am Schedel statt. Bei mehren Ganoüdei holostei geschieht die Verbindung dieses 
Os temporale mit dem Unterkiefer durch das Os symplecticum. Bei den meisten Teleostei ist die Verbindung des unleren Endes des Os symplecticum mit dem Unterkiefer unvollkommen. Die parigen IIartgebilde des Ganmens liegen unterhalb der Schedelbasis, und sind vorne oft dem $\boldsymbol{O}_{\boldsymbol{s}}$ frontale anterius mehr oder minder innig angeheftet.

\$. 17.

Diejenigen Stellen des Sehedels, an welehen solehe Skelettheile, die dem Wirbelsysteme fremd sind, sich anfüşen sollen. pllegen ursprüugglich durch Apophysen der zusammenhangenden Grundlage der Schedeleapsel bezeichnet zu werden. Bei denjenigen Gruppen der Fische, in deren Schedelgrundlage im Verlaufe der individuellen Entwickelung discrete Ossifieationen sich bilden. pflegen diese Apophysen sich abzugliedern tind eigene Knochen darzustellen. So entstehi neben den soliden Bogenstücken der Schedelcapsel bei den Teleostei und einigen Ganoïdei ein System von Randknochen in den Ossa occipilalia externa, mastoïdea frontalia posteriora und anteriora. An Ossa occipilalia externa und mastoïdea heften dic Zinken des Schultergürtels, an die Ossa mastoüdea und frontalia posteriora das oberste Stück des Kiefersuspensorium, an die Ossa fronlalia anteriora Kuochen des Gaumen- und Kieferapparates sicl an. Bemerkenswerth ist, dass die meisteu genamnten Randknochen danchen noch zur Aufnahme von Gliedern der Sinneswerkzeuge verwendel werden, indem wenigstens die Ossa occipitalia externa und mastoüdea Ausbreitungen des Labyrinthes in ihre Masse aufnehmen und genetisch als Abgliederungen ciner Gehöreapsel crscheinen, wïhrend die Ossa frontalia anteriora oft den Geruchsnerven Durchtritt und den Nasengruben Stützpunkte gewähren könneu.

Diese Randknochen dienen theilweise anch noch zu Stützen eines sehr verschieden entwickelten Apparates anderer Knochen, die einen änsseren Gesichtspanzer bilden oder als Andeutungen eines solehen zu betrachten sind.

\section{S. 18.}

Bei den meisten Fischen schliesst sich an den Schedel ein System von Knochen, die, ähnlich wie die Rippen im Bereiche des Rumpfes, einen weiteren :̈usseren Gürtel um die Visceralhöhle und die dieser anģehörigen Slieletheile zu bilden bestimmt sind. Sie legen zum Theil anch an cinzelne Glieder des Visceralskeletes eng sich an und sind mit ihnen verschmolzen, wie dies namentlich von den Belegungsknochen der visceralen Elemente des Unterkiefers und des Os temporale gilt, wodurch denn eine Fusion zweier, dem Plane nach diverser, Slieletsysteme, von denen das eine dem Visecralskelet angehört, das andere aber zur weiteren Unschliessung der Visceralhöhle bestimmt ist, entsteht.

Bei cinigen derjenigen Fische, deren Kiemenhöhle jenseits des Schedels muler der Wirbelsäule gelegen ist, künuen analoge äussere Slicletheile 
im Berciche der ganzen Kienenhühle vorkommen. Dies ist der Fall hei den Petromyzonten und den Squalidae, welehe einen eigenthïmliehen äusseren Kiemenkorb besizen, der bei jenen sehr entwickelt, bei diesen reducirt ist.

Am Schedel erscheinen diese Knochen als ein System von Gesichtsknochen. Fin Theil derselben lïst auf analoge Knochen hïherer Wirbelthiere sich reduciren, während ein anderer aussehliesslich den Fischen eigenthümlich erscheint. In die Kategorie dieser Gesichtsknochen gehören: der Oberkiefer-Apparat, der Unterkiefer, so weit er Belegungstheil oder Schale des Meckel'sehen Knorpels ist, die secundäre Belegungsmasse der oberen Glieder der beiden crsten Visceralbogen im Ostemporale Cuv., das Os quadrato-jugale (jugale Cuv.), das von ihm aus längs der Aussenseite der Gaumenknochen vorwärts steigende Os transversum, das Praeoperculum. Zu ihnen kommen, als den Fischen ganz eigenthümlich: das Os tympanicum und der Apparat der Opereularknochen.

\$. 19.

Endlich tritt bei viclen Fischen noch ein System von Knochen mit den bisher genannten in Verbindung, das da, wo es vollstïndig entwickelt ist, einen :usseren Gesichtspanzer darstellt, indem es alle bei anderen von der Haut bedeckten Theile bekleidet und Lücken zwischen den eigentlichen Gesichtsknochen ausfüllt. Dasselbe ist selten rollstïndig, meist nur in einzelnen Gliedern entwickelt. Es setzt häufig ununterbrochen in andere, jenseits des Schedels am Rumpfe gelegenen Ossifieationen sich fort.

Die Theile dieses Gesichispanzers sind ihrerseits Ablösungen oder Glicder ciner eigenthümlichen, der Ossification fähigen Schicht odcr Lage der Cutis, die mit den freien Aussenflächen aller Kopfknochen und des Schultergürtels sehr hüufig in imnigster Verbindung steht. Fine vollstinndige und ununterbrochene Trennung der unteren Schicht der Cutis von den durch sie bedeckten Knochen gelingt oft so schwer, es behalten nach versuchter Entfernung derselben die Knochenoberflïchen das nümliche äussere Ansehen, wie die Oberfläehen der Sehuppen und anderer IIartgebilde, welehe längs der Culisansbreitung des lumpfes rorkommen, dass in vielen Fällen nothwendig die Annahune sich aufdrängt, das Blastem der oberflithlichen Schichten der Kopflinochen liabe ursprünglich wesentlich der Cutis angehört und die Theile des Gesichtspanzers seien Fortsetzmngen dieser Schicht in Bereiche der nicht von Knochen bedeckten Theile des Kopfes 1).

\section{S. 20.}

Der eigentliche Schedel der verschiedenen Fische stellt eine zusammenhangende Capsel dar, deren Wandungen bald yöllig ungegliedert, bald gegliedert erscheinen.

1) Man vergleiche z. B. den Schedel eines Lepidosieus. 
Zur Einsicht in dic, trotz dieser anscheinend grossen Verschicdenheit, beobachtete Einheit des Planes in der Construction des Schedels führt ein Blick auf die Entwickelungsgeschichte. Es stellt sich der Schedel bei den Fisehen, wie bei allen Wirbelthieren, ursprünglich als eine aus weichem, zusammenhangendem Blasteme gebildete Capsel dar und wo Gliederungen in derselben eintreten, sind diese erst Folgen eigenthümlicher, planmïssiger, secundärer histologischer Differenzirungen. Unter den Fischen giebt es nun Gruppen, in deren Plane es liegt, dass ihr Schedel in Gestalt einer ungegliederten Capsel peremirend sich erhält, und andere, in deren Anfangs ungegliederter Schedelcapsel durch locale histologische Differenzirungen eine Gliederung eintritt.

Der ungegliederte Schedel erscheint, abgesehen von der in seinem Axentheile vorhandenen Chorda durch Umwandlung seines primitiven Blastemes, blos häutig bei Branchiostoma; scine häutigen Bestandtheile werden durch Strecken von knorpeliger Textur unterbrochen bei den Marsipobranchii; cin knorpeliges Material ist rorherrschend bei den Elasmobranchii, wo es jedoch in gewissen Regionen durch fibrös-häutige Elemente unterbrochen wird. Bei ihmen tritt noch, trotz des permanenten Mangels von Gliederung der Schedeleapsel, eine weitere histologische Differenzirung dadurch ein, dass sowol die knorpeligen, als die häutigen Regionen der Schedeleapsel von einer eigenthümlichen dünnen Knochenkruste überzogen werden 1). Selten nur, wie z. B. bei Squatina in der Ilinterhanptsgegend, kam diese Knochenbildung von der Oberfläche des Knorpels mehr in die Tiefe schreiten. Aber trotz der partielleu Umvandlung in Kuocheusubstauz, deren die knorpelige Grundlage des Sehedels fähig ist, liegt eine durch Bildung discreter Ossificationen erfolgende Glietlerung desselben nicht im Plane dieser Thiergruppe. -

Bei Accipenser können in vorgeschrittenem Alter an der äusseren Oberfläche gewisser Schedelregionen dünne Knochenscherben und später zusammenhangende Knochenplatten sich bilden ${ }^{2}$ ), doch ohne dass cine wirkliche Gliederung des Schedels einträte. Nur in seinem Basilartheile cntwickelt sich typisch eine definirte Ossification.

Eine wirkliche Gliederung ist zunächst da angedeutet, wo die Grundlage der Seitenwandungen der Schedeleapsel zu discreten Ossifieationen verwendet wird. Die Dipnoi, die Ganoïden-Gattungen Polypterus bieten Beispiele von Bildung schr vereinzelter Gliederungen dar. Unter den Teleostei finden sich einzelne Gruppen, bei welchen die die Gliederungen bezeichnenden $\mathrm{O}$ ssificationen gevissermaassen nur verstrent in der den $\mathrm{Zu}$ sammeuhang erhaltenden, weicheren Grundlage der Schedeleapsel vorkom-

1) Vgl. über diese Kruste der Plagiostomen und Chimaeren Mlüller, Myxinoïd. Thl. 1 - 2) Ich habe eine Reihe der verschiedensten Stadien beobachtet. 
men und andere, bei welehen die weichere Grundlage, als Blastem für die cinander unnittelbarer berührenden Ossificationen, fast vollständig absorbirt ist.

Es erhält sich also bei vielen Gruppen der Teleostei durch Permanenz eines weicheren, knorpeligen, überall brückenartig zwifekes geschobenen und durehgezogenen Blastemes ein ununterbrochener Zusammenhang zwisehen den einzelnen, localen, eine überall typische Gliederung der Schedeleapsel andeuterden Ossificationen, und letztere bildet, neben ihrer Gliederung ein Continum. $\mathrm{Z}_{4}$ diesem Continuum stehen die einzelnen, äberhaupt in den Bereich des Schedels gehörigen, Ossificationen in einem verschiedenem Verhältnisse. Einige kömnen ohne Unterbrechung der Continuität der Schedelcapsel durchaus nicht gelöset werden, während es andere gibt, deren Entfernung den Zusammenhang der Schedeleapsel nicht unterbricht. Dieser Umstand deulet jedenfalls auf ein verschiedenes Verlüiltuiss hin, daş zwischen den einzelnen, in den Bereich des Schedels gehörigen Ossificationen einerseits und der als Blastem dienenden Grundlage andererscits obrvaltet. Diese Verschiedenheit findet ihren Ausdruck in der Bezeichnung der einen Gruppe von Ossificationen als integrirender Schedelknochen und der anderen als Deckknochen. Jede Ossification, welche, ohne die Continuilit der Schedeleapsel zu unterbrechen, entfernt werden kann, heisst Deckkuochen. Ein solcher ist entweder Hautknochen allein, oder entsteht in einer ossificirenden Schicht, die die zusammenhangende Schedeleapsel bedeckt, oder bildet sich wenigstens primitiv auf Kosten der oberfliichlichen Sehicht letzterer, um später in die Tiefe fortzuschreiten. Oft zeigen die als Deckinnocheu anzusprechenden Ossificationen, Combinationen aller dicser Entstehungsweisen.

Als Decklinochen erscheinen z. B. die die Oberflïche der knorpeligen Schedelcapsel des Störes bedeckenden Knochenschilder. Da diese - ganz abgesehen von der Unmöglichkeit, auf die typischen Scheitel- und Stirnbeine anderer Fische zu reduciren - auch an ihrer Basis in ganz gleicher Ebene liegen mit unzweifelhaften IIautknochen anderer Körperregionen z. B. des Rumpfes, auch nirgend in die dicke Knorpelsubstanz der Schedeloberflïhe sich einsenken, so werden sie als Ossificationen der Cutis betrachtet. - Werden mit ilınen die in derselben Schedelregion vorkommenden Ossificationen von Amia verglichen, welche in Bezug auf Zahl und Anordnung den typischen Scheitel-Stirnbeinen entsprechen, so stellt sich heraus, dass ihre oberfächlichste und dickste Schicht wiederum cine Ossification der Cutis ist, während sie doch zugleich tiefer reichen, als hinter ihnen liegende IIautknochen und mit corticalen Ossifieationen der Schedeldecke auf das Innigste versehmolzen sind. Hier finden sich also in derselben Region des Schedels, die beim Stör nur von IIautknochen belegt war, Ossiffeationen gemischten Ursprunges: deren oberflächliche Schicht einer 
histologischen Differenzirmg der Cutis ihre Entstehung verlankt, deren tiefere Schicht in einem der Grundlage der Schedeleapsel näher liegenden odler ihr selbst angehörigen, der Ossification fähigen Blasteme entstanden ist. Dieses lefztere Blastem braucht anseheinend nicmals knorpelig gewesen zu sein. - Es können aber die nämlichen Knochen, die bei vielen Fischen z. B. bei Esox, Salmo, die knorpelige Schedeloberffäche blos lose bedecken, auch wirklich von oben nach unten in sie cindringen, wie dies z. B. rüeksichtlich der Stirn- und Seheitelbeine von Belone der Fall ist, wo ihr Blastem also ganz entschieden nicht nur von Theilen, die oberhalb des Schedelknorpels liegen, sondern zugleich auch von diesem letzteren stanmmt. Ls können, wie dies z. B. bei den Malacopterysgii apodes und den Plectognathi gymnodontes vorkömmt, die Scheitel-Stirnbeine anscheinend sanz ohne allen Antheil einer ossificirenden Culis-Schicht entstehen. Aus Vorstehendem ergibt sich, lass die die gleiche Sehedelregion eimehmenden Ossifieationen in Bezug auf ihre Histogenie und den Antheil, welchen die rerschiedenartigen, der Ossification fähigen Blasteme in Lieferung ihres Materiales haben, sehr divers sich verhalten kömnen, wihhrend sie doch, vermöge ihrer architektonischen Beziehungen, gleichnamig bleiben. Fast alle bezeichneten Uebergänge zwischen reinen Hautossificationen einerseils und solehen Ossificationen, welche einen anfliegenden Knorpel von aussen nach imnen verdrängen, wiederholen sich an den die Schedelgrundfläche einnehmenden Ossificationen des Sphenoïdeum basilare und des Vomer, nur dass hier die Schleimhaut des Rachens und nicht die Cutis die äusserste skeletbildende Schicht ist ${ }^{1}$ ).

\section{\$. 21.}

Die wesentlichsten Modificationen der Schedelbildumg sind in Folgendem kurz geschildert.

Bei Branchiostoma, wo der vorderste Theil des centralen Nervensystemes als selbstständiges Gehirn noeh in keiner Weise vom Rückenmarke gesondert ist und vor ihm sich auszcichnet, ermangeln anch dic ihn umschliessenden :insseren Umhüllungen jeder Erweiterung. Sie bilden cine ununterbrochene Fortsetzang des Rückgrathsrohres und sind, gleich diesem, häntig. Dic Chorda erstreckt sich in diesem Rolhre weiter, als das centrale Nervensystem vorwärts. - Unter der Chorda stossen vorne, also in der Schnanzengegend, die verdünnten Enden eines den Hund umgebenden Reifens an einander. Dieser Reif ist aus vielen einzelnen Glicdern zusammengeselzt, von denen jedes in einen cigenen Knorpelfaden sich fortsetzt, der in der Axe der Mundcirren verläuft ${ }^{1}$ ).

1) Aus allen diesen Thatsachen ergibt sich, dass eine durchgreifende Classificirung der Knochen in integrirende Knochen und Deckknochen nicht stathaft ist.

1) Vgl. namentlich die oben citirte Schrift von Müller mit den Abbildungen. 
Bei den Marsipobranchii findet sich eine erweiterte Schedeleapsel, welche mit der Wirbelsäule unberveglich rerbunden ist. In den Axenoder Basilartheil dieser Schedeleapsel setzt die Chorda nur eine kurze Strecke weit sich fort und endet rorne zugespitzt. Eine linorpelige oder linochenharte Basis cranii umgibt die Chorda. Sie besteht bei Ammococtes atis zwei getremuten, bei Myxine aus einem gespaltenen, bei Bdellostoma und Petromyzon ans einem unparen Slïcle. Bei Petronyzon seht der knorpelige Basilartheil des Sehedels linten in zwei Knorpelstreifen iiber. welche eine Strecke weit an der Unterseite der Wirbelsänle sich fortsetzen. - Immer gehen von dem harten Basilartheile nach vorn zxvei divergirende Forfsitze ab, welche einen vorderen häutigen Theil der Scherlelbasis umfassen. - Von dem Basilartheile aus anfsteigende Schenkel bilden das Sehedelgewölhe, das entweder, wie bei Myxine und Ammocoetes blos knorpelhäutig, oder wie bei Bdellostoma und Petromyzon theilweise rerknorpelt ist. Bei Petromyzon sind die Seitenwände des Sehedels knorpelig und wird aueh das Ilinterhanptsgewöhte durch einen Knorpelhogen gebildet. Eine an jeder Seite des Basilarknorpels gelegene, auswärts gerichtete, blascuförnige, derbe Capsel nimmt das fichörorgan auf. An die vordere häntige Wand der Schedeleapsel schliesst sich die sehr rerschiedenartig gestaltete Naseneapsel. Unterhalb dieser beginnen die eigenthümlichen Sehnanzen- und Lippenknorpel 2), welehe bei Ammocoetes, unter Anwesenheit einer blos weichen Lippe, fehlen. -

Bei allen Marsipobranchii steht mit der Grundlage des Schedels cin rersehiedentlich entwickeltes System ron Gaumenfortsätzen in ununter. brochener Verbindung, aber ein eigener Kieferapparat, namentich auch ein Unterkiefer fehlt.

Bei Ammococtes erstreckt sich von der Innenseite jeder Gehörcapsel eine gebogene Kurpelleiste rorwärts. Die Leisten beider Seiten gehen vorne, ohne das Vorderende der Schedelcapsel zu erreichen, hogenförmigg

2) Diese Kinorpel sind sehr eigenthümlich. Bei Petromyzon liegt unmittelbar unter und vor der Naseneapsel, so wie vor dem harten Gaumen ein unfängliches hinteres Mundschild. Dieses üherwölht zum Theil ein zweites Vlundschild, das weiter vorwirts und etwas tiefer liegt und nach hinten jederseits mit dem Gaumenbogen durch einen eigenen Knorpel in Verbindung steht. Am weitesten vorwïts liegt ein zalntragender, ringfürmiger Ylundlhorpel, von welchem an jeder Seite ein griflelfürmiger linorpel nach hinten abgeht. - Bei Bdellostoma geht von der vorderen Commissur der Gaumenleisten ein unpaarer mittler Schnatuzenknorpel aus. Jieser stutzt einen queren Lnorpel, der in Verbindung mit zwei inderen seitlichen, gieichfalls von der Vordergrenze der Gaumenleisten ausgehenden linorpein ein Gerisst bildet, von welchem zur Unterstützung der Tentakel dienende Fortsätze abgehen. - S. Abb. bei ll üller, Myxinoïd. Thl. 1. Tb. 3. Fig. 5. 6. u. Tb. 4. Fig. 1. 2. - Die speciellen Configurationen dieser linorpel sind den verschiedenen Gruppen der Marsipolranchii durchatss eigenthümlich, gleich wie dies auch von der Art ihrer Verwerthung gilt. 
in einander über. Ihre Innenränder sind durch eine mittlere fascrknorpelige Platte vereinigt, welche der häntigen Basis cranii hinten angewachsen, vorue aber von ihr durch den blinden Nasengaumengang getrennt ist.

Bei Petromyzon steigt von den Seitenrändern des Schedels eine Knorpelmasse abıärts, die unterhalb der eigentlichen Schedelbasis und von ihr durch den Nasengaumengang getrennt, eine zusammenhängende Platte bildet, welche vorn über die häutige Wand der Schedelbasis hinausreicht. Von dem Vorderende jedes Seitenrandes dieses harten Gaumens geht ein Seitenfortsalz aus, der mit einem zweiten hinteren, unter der Gehörcapsel abgehenden Fortsatze zusammenstosst und so mit ilım einen sehief nach unten und vorne absteigenden, die Seitenwand des Rachens stützenden Bogen bildet. Der Innenrand dieses Bogens schliesst mit dem Seitenrande des harten Gaumens eine von fibröser Ilaut ausgefüllte Fontanelle ein, auf welcher das Auge ruhet. - Der hintere Fortsatz gibt an seiner Wurzel cinen dem Zungenbein-Apparate functionell angehörigen Knorpeltheil ab, an welchen wieder ein Knorpel des äusseren Kiemenkorbes sich anlegt.

Bei den Myxinoïden geht vom Vorderrande jeder Gehörcapsel ein Seitenfortsatz und von diesem eine lange knorpelige Gaumenleiste aus. Beide Leisten sehmelzen vorne, weit vor dem vorderen Schedelende, bogenförmig zusammen. Zwischen ihnen, seitlich nur dureh fibröse IIaut verbunden und nur vorne an die Commissur der Leisten angewachsen, liegt eine mittlere Gaumenplatte, auf weleher vorne die lange Nasenröhre ruhet und welche weiterhin durch den zwischenliegenden Nasengaumengang vom Schedel getrennt ist. Zwischen einem vorderen Schenkel des Scitenfortsatzes und der Gaumenleiste bleibt eine blos dureh Aponcurose geschlossene Lücke zur Grundlage für das Ange. Nach hinten verlïngern sich die Ganmenleisten und sind mit queren Knorpelauswüchsen versehen, wodurch ein solides Schlundgerüst entsteht, das den häutigen Wandungen der Schlundhöhle auf das engste verwachsen ist ${ }^{3}$ ).

\section{\$. 22.}

Der Schedel der Plagiostomen bietet rücksichtlich seiner Verbindungsweise mit der Wirbelsäule Verschiedenheiten dar. Gemeinsam sind Allen zwei seitliche, den Bogentheilen angehörige Gelenkflächen, denen solche, die vom Bogentheile der Wirbelsäule gebildet werden, entsprechen. Bei den Squalidae ist der Schedel aber, ihnlich wie bei den Teleostei, unbeweglich mit der Wirbelsäule verbunden und zwar so, dass sein Basilarknorpel nach hinten cine mehr oder minder tiefe conische IIöhle besitzl,

3) Vgl. namentlich die sorgfältigen Beschrcibungen von . üller, in seiner Vergl. Osteologie d. Myxinoiden, wo auch der Zungenbeinapparat dieser Thiere genau geschildert ist. 
die einer anderen des ersten Wirbelkörpers entspricht ${ }^{1}$ ). Bei den Rajidac aber articulirt er dureh eine dem Basilartheile der Hinterhauptsgegend angehörige Vertiefung beweglich mit einem in diese aufgenommenen Gelenkkopfe am Vorderende des Axensystemes der Wirbelsäule. Dic Schedelcapsel bildel ein Continumm. Am Aussenende der Seitenwandung des Schedels ist hinten das Kiefersuspensorium beweglich angefügt. Die Andeutung einer Scheidung der Schliffengrube von der Augenhöhle ist durch cinen mehr oder minder stark vorspringenden Processus orbilulis posterior gegeben. Die beiden Orbilae werden durch eine Fortsetzung der Schedelhöhle und nicht durch ein verengtes Septum interorbitale getrennt ${ }^{2}$ ). Ein solider Augenhöhlenboden fehlt meistens; doch nicht immer, wie z. B. die Gattung Seyllium beweiset. An der vorderen Begrenzung der Augenhöhle bildet die Knorpelsubstanz des Sehedels einen mehr oder minder betrïchtlichen, nach der Augenhöhle zu undurchbohrten Processus orbitalis anterior. Von seiner vorderen Circumferenz geht eine abwärts gerichtete Kuorpelglocke aus, die zur Bildung der an der Ventralseite offenen Nasengrube bestimmt ist. Seitwïrts, aber vor der Augengrube und von ihr durch eine Knorpelwand getrennt, liegt die Austrittsöffnung des Geruchsnerven. Zwischen den beiden Nasengruben bildet eine häutige oder knorpelhäutige trausversale Scheidewand die vordere Begrenzung der eigentliliehen Gehirneapsel des Schedels. Die Knorpelsubstanz des Schedels setzt aber sowol von den Innenseiten der Nasencapseln aus, als auch vorzugsweise von seinem Basilartheile aus, noch mehr oder minder weit nach vorne sich fort und bildet in dieser Fortselzung die solide Grundlage der weichen Schnauze. Ausbreitung und Form dieses vordersten Schnauzentheiles sind bei den einzelnen Gruppen der Plagiostomen in hohem Grade veränderlich und namentlich bei den verschiedenen Squalidae sehr individualisirt. Während bei Squatina dieser Schmauzentheil des Schedelknorpels kaum angedeutet ist, erscheint er bei den Carchariae, bei den Spinaces schon beträchtlich in Form dreier, unter einander vorn verbundence Schenkel und verlingert sich bei Rhinobatus, und namentlich bei Pristis, als einfaches Knorpelstück ganz ausserordentlich.

Bei allen Plagiostomen ist die Schedeloberfläche mit einer eigenthümlichen chagrinartigen Knochenkruste überzogen. Diese bildet auch einen

1) Der Basilarknochen des Ilinterhauptes erscheint überhaupt oft ganz wic ein Wirbelkörper gebilıtet z. B. bei den Prionodon. Bei einem ziemlich grossen Prionodon sah ich die Ueberreste der Chorda bis zur Grube fir die Iypophysis reichen und dic Schedelbasis in zwei Seitenhälften theilen.

2) Auf ganz eigenthümliche IVeise bildet bei Sphyrna der Processus orbilalis posterior einen langen dünnen, nach auswärts gerichteten Stiel, der hinter dem Bulbus in eine Platte sich verbrcitert, von der aus ein Fortsatz schräg zum Processus orbitalis anterior sich erstreckt, und ein zweiter einen oberen Augenhühlenbogen bildet. 
Ueberzug über blos fibröshäutige Fontanellen, welche in Mitlen der Knorpelsubstanz des Schedels und namentlich des Sehedelgewölbes bei vielen Plagiostomen ${ }^{3}$ ) typisch vorkommen.

Bei allen Rajidae findet sich ein von dem Processus orbilalis anterior aus hinterwärts gerichteter, discreter Knorpelbogen, welcher, als Schedelflossenkinorpel, zur Fixirung der vordersten Ossa carpi der Brustllosse bestimm! ist. Nur bei einer Gruppe der Rajidae: den Myliobatides, wird auch der Vorderrand des Schedels ron Flossenknorpeln und Flossen rahmenartig umzogen.

\section{\$. 23.}

Das Kiefersuspensorium der Plagiostomen ist seitwïrts unterhalb der Schlïfengegend des Schedels berweglich befestigt. Es steigt schräg ab. und vorwärts, um den Unterkiefer zu unterstützen. Rücksichtlich sciner weiteren Beziehnngen walten zwischen den Rajidae und den Squalidae Verschiedenheiten ob.

Bei den Rajidae dient es häufig nur dem Unterhiefer zur Einlenkung, indem das unterste Glied des Zungenbeinbogens dicht noben seiner Seliedelinsertion selbstständig am Schedel sich befestigt und mit dem oberen Ende des Suspensoriums nur durch Faserband in Verbindung steht ${ }^{1}$ ). - Bei den Squalidae dagegen ermangelt das Zungenbein eincr selbststïndigen Befestiguns am Schedel und sein oberstes Ende tritt rom unleren Ende des Suspensoriun neben der Einlenkung des Unterkiefers ab, - Mit dicsem Unterschiede fillt ein zweiter zusammen, der darin besteht, dass bei deu Squalidae die untere Hälfte des Kiefersuspensorium mit ähnlichen Knorperstrahlen besetzt ist, wie solehe an der convexen Seite aller Kiemenlogen vorkommen, dass dagegen das Kiefersuspensorim der Rajidae dieser Knorpelstrahlen durehaus ermangelt. Dafür kommen bei den Rajidac diese Knorpelstrahlen am zweigliedrigen Zungenbeinschenkel bis zu dessen Sehedelinsertion hinauf vor, wihrend dic an eingliedrigen Zungenbeinschenkel der Siqualidae vorhandenen nur die lieihe der am Kiefersuspensơ̌min vorkommenden fortsetzen. Es enthält also das Kiefersuspensorium der Squalidae Elemente des Zungenbeinbogens, withrend bei den Rajidae dies nicht der Fall ist.

Bei den Rajidae besteht das Kiefersuspensorimm bald ans zwei discreten Kuorpelstieken ${ }^{2}$ ), ron welchen das obere mil seinem dorsalen Eude

3) Z. B. unter den Rajidae bei laja, Rhinobatus, Aêtobatis, Trygon, Narcine; nicht aber bei (dem jungen) Pristis.

1) So nach Untersuchung von Raja, Trygon, Pristis, Rhinobatus, Aëtobatis, bei Torpedo und Narcine ist das Zungenbein oben mit dem Suspensorium des Unterkiefers verbunden.

2) Das Vorkommen dieses zweiten, wahrscheinlich einem Os symplecticum entsprechenden Stückes habe ich bei einigen, wit rather IJautoberikclie verschenen Arten 
an einer Apophyse des Schedels angeheftet ist, während das untere mit seinem ventralen Ende den Unterkiefer trïgt; bald wird es nur dureh ein cinziges Stück gebildet. - Bei den Squalidae besteht es, anscheinend bestäudig, nur aus einem einzigen Knorpelstïcke.

Das den meisten Plagiostomen zukommende, unmittelbar vor der dorsalen IÏ̈lte des Kiefersuspensorinm gelegene Sprilzloch erhält sehr häıfig eine Unterstützung in einem gewöhulich mit seiner Convexität vorwärts gerichtelen Spritzlochsknorpel 3). Die Formverhälnisse desselben, die Art semer Verbindung mit dem Kiefersuspensorium, welchen er meist durch eine Sehne oder ein Band, selten durch ein Gelenk verbunden ist, variiren; er kann selbst in eine Kette discreter Knorpel zerfallen.

Sowol der Unterkiefer ${ }^{4}$ ), als der $\mathrm{Oberkiefer}$ bestehen bei den Plagiostomen aus zwei, in der Mittellinie verbundenen, einfachen Scitenschenkeln, welche meist von derselben oberflächlichen Knochenkruste überzogen werden, die die übrigen Skeletheile bekleidet. Der Oberkiefer articulirt eigentlich nur mit dem Unterkiefer und wird daher nur miltelbar vom Suspensorium getragen. Auffallende, mit ciner eigenthünlichen Einrichtung des Gebisses zusammenfallende Formmodificationen bieten die Kiefer bei den Gattungen Aëtobatis und Myliobatis dar. Ein gesonderter Zwischenkiefer fehlt beständig. - Die mechanischen Einrichtungen der Kiefer und die Anordnung ihrer Bänder bieten mannichfache Verschiedenheiten dar.

Als accessorisches Element reihet sich dem Kiefer-Apparate vieler

der Gattung Trygon, namentlich bei T. hystrix, T. Sayi beobachtet. Der obere lïngere, breitere, dünnere Kinorpel ist mit dem unteren kürzeren, solideren, stabförmigen durch ein Gelenk verbunden. In diesem findet sich bei T. hystrix noch ein ganz kleiner Knorpel. Bei glatten Trygones habe ich das Suspensorium einfach gefunden. Dem Unterkiefer zunachst liegt aber bei ihnen Faserbandmasse, indem der obere Knorpel nicht ganz bis zu ihm reicht. - Bei Aëtolatis Narinari reicht das knorpelige Suspensorium ebenfalls nicht zu den Kiefern; in der ergänzenden Bandmasse liegt ein discreter linorpel, aber rundlich und nicht so geformt, wie ihn Müller bei Rhinoptera und Myliobatis beschreibt und Tb. IX. Fig. 13. von Myliobatis abbildet. Müller vergleicht den von ihm entdeckten linorpel mit dem Os quadrato-jugrale höherer Wirbelthiere.

3) Er scheint allen Rajidac zuzukommen z. B. auch bei Aëtobatis, auch manchen Squalidae z. B. bei Squatina. Abl, bei llenle, Narcine. Tb. IV. Fig. 3. bei Il üller, Myxin. Tb. V. Fig. 3. Ilenle nennt ihn Cartilago pterygoïdea und vergleicht ihn dem Os tympanicum der Teleostei. Ër dürfte auch wohl den convexen Knorpeln zu vergleichen sein, welche bei vielen Rajidae z. B. bei Myliohatis, Aëtobatis и. A. die Stuitzen zweicr Diaphragmata an der dorsalen und ventralen Girenze eines Kiemensackes veribinden. - In mehre Stücke zerfallen ist der Kinorpel, wie schon II enle angibt, bei Torpedo. -

4) Bei Scyllium Edvarisii zieht lïngs dem unteren Rande jedes Unterkieferschenkels ein schmales fibrüses Band mit eingesprengten linorpelstuclichen sich hin. 
Plagiostomen ein System verschiedentlich entwickelter Labialknorpel 5) an, die durch einen eigenen Muskelapparal bewegt werden. In der Gruppe der Rajidae sind sie nur bei den Gattungen Narcine und Rhiuoptera beobachtet worden. Bei den Squalidae kommen sie in der Regel, obsehon sehr verschiedentlich entwickelt, vor, als Stücke, die im Mundwinkel an einander stossen.

Ein discreter Gaumenapparat mangelt den meisten Plagiostomen spurlos. Indessen kommen Andentungen desselben vor. Bei der Gattung Narcine ${ }^{6}$ ) unter den Rajidae liegen unmittelbar unter dem Schedel, über den IIäuten des Schlundes vor den vorderen Rändern des Kiefersuspensorium paarige Carlilagines palatinae. Unter den Haien bieten einzelne Carchariae ${ }^{7}$ ) ein anderes Beispiel dar, indem von dem vorderen Rande des dorsaleu Endes des Kiefersuspensorium ein Knorpel ausgeht, der seitwärts an dic Schedelbasis sich anlegt, ihren Bereich nach aussen hin erweitert und bis unter die vordere Grenze der Augenhöhle reicht. Hier setzt er sich nach vorne fort in ein Band, welchem cinzelne Knorpelstückchen eingesprengt sind. Dieses Band endet an einem aufsteigenden Oberkieferaste, der den meisten Haien eigenthümlich ist.

\section{\$. 24.}

Der Schedel der Chimären articulirt beweglich mittelst einer dem Basilartheile und zwei den Seitentheilen der Hinterhauptsgegend angehöriger Gelenkvertiefungen mit dem Vorderende der Wirbelsäule. Die Sche delcapsel bildet ein Contiuum. Von der unbetrïchtlicheu Schläfengegend geht eine vorspringende, nach unten allmälig abgedachte hintere Augenhöhlenwand aus, welche die Augenhöhle vou der Schläfe scheidet. Das Seplum interorbilale ist faserhäutig. Eine vom Vordertheile des Schedels jederseits absteigende Knorpelglocke umschliesst das Geruchsorgan. Der Vorderraud des Schedels ist zahntragend und gibt durch sein Verhältniss zu der Apophysis mandibularis, deren Vorderrand unmittelbar in ihn sich fortsetzt, als Gaumengegend sich zu erkennen. - Eine schrïg auswärts gerichtete Abdachung der hinteren Augenhöhlenwand hangt ohne alle Unterbrechung zusammen mit einer gleichfalls auswärts und etwas abwärts

5) Dies System der Labialknorpel ist mit besonderer Sorgfalt von J. II üller studirt worden. Die Labialknorpel von Narcine hat Ilenle (Ueber Narcine S. 13.) sehr genau beschrieben und abgebildet; die von Rhinoptera hat M üller Tb. IX. Fig. 12. abgebildet. - Unter den Ilaien kommen sie z. B. bei Squatina äusserst gross vor. Abb. b. Müller, Tb. V. Fig. 5. 6. Auch bei Scyllium Edwardsii stark entwickelt. Spinax niger, dem mit Unrecht nur ein Knorpel zugeschrieben ist, besitzt gleichfalls einen oberen und unteren.

6) S. H enle, Ueber Narcine. Tb. IV. Fig. 1. 2. M üller, Myxin. Tb. V. Fig. 3. 4.

7) Meine Beschreibung stützt sich auf Untersuchung junger Exemplare von Prionodon glaucus. 
gerichteten Knorpelansbreitung der Schedelbasis und bildet mit ihr den Boden der Augenhöhle und zugleich das Gewölbe des Gaumens. Diese Kuorpelausbreitung läuft vor der Angenhöhle in eine kurze Apophysis mandibularis ans, weleher der einfache, einen unmerbrochenen Bogen bildende, Unterkiefer beweglich eingelenkt ist und welche mit ihrem Vorderrande in den, das Gaumenbein der Teleostei repräsentirenden zahntragenden, Schedelrand sich fortsetzt ${ }^{1}$ ). - Ein eigener Oberkieferapparat fehlt; dem es ist mindestens sehr ziveifelhaft, dass er durch die, die weichen, vor dem Gaumenrande gelegenen Lippen stülzenden Knorpel repräsentirt sein sollte. Ausser diesen eigenthümlichen Knorpeln, kommen, den Lippenknorpeln der IIaic analoge Knorpel, so wie auch solehe vor, die von der Nasencapsel zur weichen Schnauze treten 2), - Diese weiche Schnauze erhält Unterstïtzung durch einen vom Vorderende des Schedeldaches bogenförmig absteigenden medianen discreten Schnauzenkuorpel ${ }^{3}$ ).

\section{\$. 25 .}

Bei den Dipno i ${ }^{1}$ ) ist der Schedel fest mit der Wirbelsäule verbunden, indem zugleich das vordere Ende der Chorda dorsalis, zugespitzl, in seine Basis sich verlängert. Die knorpelige Schedelcapsel ist stellenweise durch einzelne Ossificationen belegt oder verdrïngt. Bei Rhinocryptis sind, im Gegensatze zu einer zusammenhangenden Kuorpelmasse, die Ossificationen mehr untergeordnet; bei Lepidosiren sind letztere vorherrschend. Die Gehörorgane liegen in der Substanz des Schedelknorpels. Unterkiefer und Zungenbein articuliren unmitelbar mit continuirlichen Apophysen der knorpeligen Schedelmasse. Ein unpaares Os basilare, unten concav, das unter den vorderen Abschnitt der Wirbelsänle sich verlängert, bildet bei beiden Gattungen die Schedelbasis. Paarige Ossa occipitalia lateralia umschliessen das Foramen occipitale und bilden die lintere Schedelwand. Sie sind bei Rhinocryptis nur inwendig verknöchert, aussen knorpelig, bei Lepidosiren ganz verknöchert.

Fin dachartiger einfacher Schedeldeckenknochen, Os parielale, aus zwei nach oben verschmolzenen Seitenhälften bestehend, bildet das Schedeldach. Vor ihm finden sich paarige, ihn mit zwei, nach hint:n verlïngerten, Zinken unschliessende, Ossa frontalia. An das Vorderende des

1) Man könnte sagen, bei den Chimaeren finde sich das ganze Kiefersuspensorium der Teleostei, sammt den Gaumentheilen derselben, mil dem eigentlichen Schede! in ununterbrochenem Zusammenhange.

2) Ueber diese Iinorpel der Holocephali s. Müller, Myxin. 1. S. 138. Abbild. Tb. V. Fig. 2 .

3) Dieser Schnauzenknorpel ist bei Callorhynchus anders gebildet; als bei Chimaera. S. die Abbildg, bei Müller, l. c.

1) In Betreff aller Details ist auf die Schriften von 0 wen, lischoff, Ilyrtl und Peters zu verweisen.

IIandb, d, Zootomie vo Siebold u, Staunius, II. 
Schedeldeckenknochens oder, bei Rhinocryptis, der ossa frontalia schliesst sich ein unpares $\boldsymbol{O}$ s nasale, das die mittlere verbindende knorpelige Grundlage der, an jeder seiner Seiten frei zu Tage kommendrn, helmartigen, vierfach gefensterten Nasenhöhlen bedeckt. Am vorderen Ende trägt das Os nasale zwei Isabialzähne.

Bei beiden Gattungen verlängert sich die in der Gegend des Gilhörorganes liegende Knorpelmasse in eine Apophysis mavillaris, deren Gelenkkopf den Unterkiefer aufnimmt; cine hinter dieser gelegene Gelenkläehe dient zur Articulation des Zungenbeines. Auswendig ist die Apophysis maxillaris mit einer Ossification belegt.

Der Oberkiefer-Gaumen-Apparat stellt einen von dem Gelenkkopfi des Unterkiefers der einen Seite zu demjenigen der anderen Seite reichenden unpaaren, das vordere Ende des Os basilare rahmenfürmign unfassenden Knochenbogen dar, der unterhalb der Schedelbasis gelegen ist. An seinem vorderen Mitteltheile ist er zahutragend. Ueber diesem rorderen Mitteltheile liegt der unpare Vomer. - Der Unterkiefer besteht bei Lepidosiren aus zwei, in der vorderen Mittellinie in einander übergehenden, Seitenschenkeln und besitzt, ausser seinem knöchemen Antheile, rinn invendigen Knorpelbogen. Auch Labialknorpel kommen den Dipnoi zu ${ }^{1}$ ).

\section{\$. 26.}

Die Ganoïdei chondrostei haben das Gemeinsame, dass die Chorda dorsalis in ihre Schedelbasis sich fortsetzt, dass eine bewegliche Terbindung zwischen Schedel und Wirbelsänle mangelt, dass ihr Schedel eine zusammenhangende knorpelige Grundlage besizt, weleher die meisten einzelnen Ossificationen bloss aufliegen und dass ihr Kieferapparat, gyleich dem Zungenbeine, an einem von der Schedeleapsel abgesetzten Suspensorium hangt.

Bei den Stören ist der ganze Schedel, bald vollständig. bald mil Ausnahme ciner über dem verlängerten Marke in der Itinterhauptsgegend gelegenen Lïcke 1) verknorpelt. Eine hintere Apophysis dient den Extremitätengürtel zur Anheftung. Ein knorpeliger Processus fronlalis poste rior, unterhalb dessen die Befistigung des beweglich nit dem Seliedel articulirenden Kiefersuspensorium Statt hat, grenzt hinten die gemeinsane Schläfen- und Augenhöhle von der Kiemenhöhle ab. Ein stïker entwiklielter Processus frontalis anterior bildet die Grenze zwischen der Augenhöhle und der Nasengrube. Diese liegt an der Basis der starki nach vorne

2) S. über die von Lepidosiren 1 yrtl, Tb. 1. Fig. 1, über die von Rhinocryptis Peters in Müller's Archiv. 1845. Tb. 2. Fig. 1-3. I.

1) Diese Lücke finde ich beständig bei den von mir allein und ausschliesslich berïclisichtigten Acc. Sturio der Ostsec. Brandt und Müller haben sie bei Acc. Ruthenus nicht gefunden. 
verlïngerten Schnauze. In der Schedelhöhle findet sich eine beträchlliche Vertiefung zur Aufualume der Iypophysis. Das Gehörorgan ist theils innerhalb der Schedelhöhle, theils in der zusammenhangenden Knorpelmasse des Schedels gelege'n. - Das knorpelige Schedeldach, sammt der Lücke, so wie auch die Schedelfortsätze werden von Ossificalionen bedeckt und zum Theil überragt, die, in einzelne, dicht an einander stossende Felder gruppirt, ausschliesslich der Cutis auzugehören scheinen. Zwischen Angen - und Schläfenhöhle absteigende und sie tremnende gleichartige Ossificationen setzen in einen Unteraugenhöhlenbogen sich fort. Eine sthon unter dem vorderen Abschnitte der Wirbelsäule begimnende, dem Os sphenö̈deum anderer Fische analog gebildete Ossification (Os basilare) liegt unter der knorpeligen Schedelbasis. Von ihr steigen Seitenfortsätze an den knorpeligen Processus frontales posteriores auf. Unterhalb der Augruhöhlengegend erseheint das Os basilare abwärts von Knorpelsubstanz umhüllt, and liegt erst an der Basis der Schnauze wieder frei zu Tage. An den Seitenvandungen der Kiemenhöhle kommen bei älteren Thieren oberflächliche, den Knorpel auswendig überziehende, dünne zusammenhangende Ossificationen vor.

Bei den Spatularien ${ }^{2}$ ) bilden die an der Schedeloberflichn gelegenen, nur theilweise und approximativ denen des Knochenfisch-Schedels vergleichbaren Ossificationen keine unnnterbrochene Fläche, sondern sind durch knorpelige Schedelsubstanz von einander gesehieden. An der Unterfläche des Schedels erscheint eine oberflähliche Basilarossification, deren Ausdehnung derjenigen des Sphenö̈deum basilare und Vomer der Teleostei entspricht. Die Knochen der Schedel-Oberflich", gleich wie die der Basis, setzen an die merkwürdige, słark verlängerte, spatelfürmige Schnanze sich fort und bilden gewissermaassen ihren linöchernen Slamm, der seitwärts von den Strahlen sternförmiger, in der hïutigen Grundlage der Schnauze gebildeter Ossificationen begrenzt wird.

\section{S. 27.}

Das Kiefersuspensorium besteht bei Accipenser und bei SpaLularia ans zwei Stäcken 1), welche durch Bandmasse mit cinander verbun-

2) Eine Abb. s. b. Wagner, de Spatulariar. indole,

1) Diese Angabe steht in entschiedenem Widerspruche zu derjenigen, welche von J. Müller ausgegangen ist. In seiner vergl. 0steol. d. Myxinoỉden. S. 145. unterscheidet derselbe am Suspensorium der Störe drei Stricke, nämlich cin knöchernes, das mit

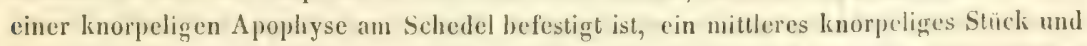
ein drittes linorpeliges Stïck, an dem das Zungunbein befestigt ist. Diese drei Stïcke lässt auch die auf Tb. IX. Fig. 10. gegebene Abbildung wieder erkennen. Meine Unterscheidung von nur zwei Stücken stitzt sich wesentlich auf Untersuchungen über die eigenthümliche Ossification der knorpeligen Theile des Stürskeletes. linorpel von linglicher Form erbalten beim Stör eine knocherne Scheide, wie die Betrachtung und Naceration der einzelnen Segmente der lïiemenbegen, der lippen, 
den sind. Das obere grössere Stück (Os temporale) articulirt berveglich mit dex Schäfengegend des Schedels. Das zweite, ihm angeschlossene entspricht dem Os sympleclicum. Bei Accipenser geht von seinem oberen, hei Spatularia von scinem unteren Ende das, dem $O s$ styloüdeum der Teleostei entsprechende, oberste Glied des Zungenbeinbogens ab. Scin unteres Ende hangt durch Bandmasse mit dem Os quadrato-jugale zusammen.

Der eigentliche Kiefer-A pparat nebst seinem Trügrer verhält sich bei beiden Gruppen verschieden ${ }^{2}$ ). Bei Spatularia liegt unmittelbar unter der Schedelbasis und zwar ganz vorne cin weiter, aus zwei in der MitIellinie getrennt bleibenden Schenkeln gebildeter Bogen, durch Haut fixirt, nicht vorstreckbar, den weiten Eingang in die Rachenhöhle begrenzend. Jeder Schenlicl besteht aus zwei Elementen: einem inneren, beträchtlichen, das den Gelenkkopf für den unter ihm gelegenen Unterkieferbogen bildet und der Ausbreitung des M. temporalis zu Grunde liegt, also wesentlich einem Os quadralo-jugale entspricht, und cinem zweiten äusseren, ihm eng angehefteten, das vielleicht den Oberkiefer repräsentirt.

Accipenser besitzt ein eigenthümliches gleichfalls unter der Schedel-

der Processus spinosi der Wirbel Iehrt. Diese knöcherne Scheide bildet sich nicht um den ganzen Knorpel, sondern nur um einen Theil desselben und zwar nicht genau im Umkreise seines mittleren Theiles, sondern mehr nach seinem einem Ende hin, so dass sie zwei knorpelige Apophysen von ungleicher Länge frei lässt; die obere, kleinere Apophyse ist als solche von $\mathbf{M}$ üller richtig aufgefasst worden; die untere, grössere ist von ihm dagegen als eigenes Stück bezeichnet. Nit demselben Rechte künnten an dem zweiten und dritten, also den beiden mittleren Segmenten des ersten Kiemenbogens, zwei oder drei Stücke unterschieden werden, nämlich ein knöchernes und zwei knorpelige von sehr ungleicher Länge. Bei Zählung der einzelnen Skelettheile des Störes hat man nicht sowol die Zahl der durch knöcherne und knorpelige Textur unterschiedenen, als die der durch Gelenke oder zwischenliegendes Bindegewebe von einander getrennten Stïcke ins Auge zu fassen. Durch Gelenk getrennt sind aber am Kiefersuspensorium nur zwei Stücke. - Ich lege deshalb besonderes Gewicht auf meine strengere Unterscheidung, weil Mäller seine Zählung zur Begründung comparativer Consequenzen benutzt hat. S. Myxinoïd. Thl. 1. S. 14\%. und bes. Archiv 1843. Jahresbericht S. CCLVII. - Zur Erläuterung der eigenthümlichen Ossificationsvorgänge beim Stör sei noch bemerlit, dass eine Ossification, welche einen Innorpel ringfürmig umschliesst, wiederum von dicker Kinorpelschicht auswendig umgeben werden kann, wie ich dies z. B. am Os temporale cines schr grossen Stüres sehe. Es wiederholt sich hier die bekannte Erscheinung am Vordertheile des $\boldsymbol{O}_{s} b a$ silare des Schedels.

2) Meine Deutung weicht von der durch Müller gegebenen vollständig ab und beruhct wesentlich auf einer Berücksichtigung der sonst so constanten Verhältnisse des $O s$ quadrato-jugale zum Unterkiefer. - Das $O$ s quadrato-jugale besteht aus cinem linorpel und einer Irnochenbelegung, die indem sie jenen nur partiell umgibt wieder cben so eigenthümlich sich verhält, wie an anderen Theilen z. B. den Rippen, den Gliedern der Kiemenbogen u. s. w. - Auch der. Unterkiefer besteht aus einem Knorpel mit Knochenbelegung. 
basis gelegenes cinfaches vorstreckbares Schild, dem der Unterkieferbo. gen angefügt ist. Der betrïchtlichste Theil des Schildes wird dureh die beiden in der oberen Mittellinie durch Faserband innig zusammengefïgten Ossa quadrato-jugalia gebildet. Jedes derselben gewihirt dem Sehläfenmuskel eine breite Ansatzfiache. Hinten schliesst den beiden genannten Hauptknochen des Schildes, als Repräsentant des Gaumenapparates, rine unpaare, rhombisch gestaltete Knorpelplatte sich an. Jedem Os quadratojugale ist ein Unterkieferschenkel beweglich eingelenkt. Jedem Unterkicferschenkel entspricht, als Oberkiefertheil, ein dem Schilde angehöriges oberes ossificirtes Randstück, an dessen äusseres Ende eine schräg hinterrvïrts gerichtete, mit ihren Enden auf dem Os quadrato-jugale ruhende Knochenleiste sich ansehliesst ${ }^{3}$ ).

\section{\$. 28.}

Der Schedel der Ganoïdeih ol ostei und der Tele ostei besitzt discrete Ossificationen, zwischen und unter welehen die Ueberreste des ursprünglich eine ungegliederte Capsel bildenden, knorpeligen oder faserhäutigen Blastemes bei vielen sehr vollständig sich erhalten, während dieselben bei anderen nicht in gleicher Ausdehnung oder fast gar nicht nachweishar sind 1). Wie für die Zählung der die Wirbelsäule bildenden Segmente in

3) Was diese beiden Ossificationen anbetrifft, so repräsentirt dic erste entweler einen Zwischenkiefer oder einen Oberkiefer; die zweite entweder den Oberkiefer oder ein Jochbein (Os jugale); oder die erste ist ein Gaumenbein und die zweite cin Os pterygoïdeum.

1) Dic Verschiedenheiten, welche in dieser Beziehung obwalten, sind sehr gross. Diejenigen Fische, bei denen die linorpelige Grundlage des Schedels am vollständigsten sich erhält, sind Esox und die Salmones. In dieselbe líategorie scheinen die Ganoïdei holostei zu gehören. - Auf ganz eigenthümliche Weise verhält sich die überall zusammenhangende weichere Schedelgrundlage bei Cyclopterus lumpus. Alle einzelnen ülrigens typisch gelagerten Ossificationen erscheinen nämlich als ganz dünne, zum Theil blos aufliegende, zum Theil in jene weichere Grundlage sich bineinzichende Blälter. - Grosse Verschiedenheiten bietet das Verhalten des Schedeldaches dar. Bei Esox findet sich vom Hinterhaupte an bis zur Schnauzenspitze hin ein unnnterbrochenes lückenfreies knorpeliges Schedeldach, das nur bei äteren Thieren vorne zwci kleine Fontanellen besitzt. Bei Salmo salar und anderen Salmones kommt vor der Squama occipitalis jeder Seite an der Şchedeldecke eine beträchtliche Lücke vor; die beiden Lücken werden durch einen mittleren, in den Vordertheil des Schedels übergehenden Knorpelstreifen getrennt. - Bei Clupea und Alosa findet sich, ausser den bciden hinteren Lücken, noch eine unpaare vordere, die von jenen durch eine Querlirïclie geschicden ist. Uebrigens verbinden seitliche Knorpelstreifen das eigentliche Schedeldach mit der Oberflache des Segmentum septi narium. - Bei Scomber sind die beiden hinteren Lücken vorhanden und werden vorne durch eine Querbrïcke begrenzt; aher die seitlichen Verbindungsbrïcken mit dem Segmenlum septi narium fehlen. Bei anderen, wie z. B. hei Collus ist unterhalb der Stirnleine eine vollstindige Lüclse. Während uteistens die Stirnbeine lose aufliegen, lassen sie sich bisweilen z. B. bei 
solchen Fällen, wo cine Gliederung des Axeneylinders fehlt, wie z. B. bei manchen Squalidae, die Anzahl der soliden obereu Bogensehenkel maassgebend ist, so lässt auch die Zahl der in den Scitenvandungen der Schedeleapsel vorkommenden meist in sehräger oder verticaler Richtung aufsleigenden integrirenden Ossificationen cine bestimmle Summe von SchedelSegmenten unterscheiden 2). Soleher Segmente gribt es fünf: das des IInterhanptes, angedentet durch die Ossa occipilalia lateralia; das des hinteren Keilbeines durch die Alae temporales; das des vorderen Keilbeines durch die Alae orbilales; das des Siebbeines durch das Os ethmoïdeum, das des Septum narium durch ein Nasenbein. welehem endlich selbst noch ein accessorisches Schmauzenelement sich amschlicssen kann.

Nur bei einzelnen Gruppen der Teleostei, wie z. B. bei den Cyprinen, bei Silurus, Loricaria, sind diese einzelnen Sermente dureh die Anwesenheil seharf geschiedener und einander unmitlelbar berührender Ossificationen in dem als Fortsetzung des oberen Wirbelbogensystemes erscheinenden Sehedclbogentheile völlig ausgeprägt; bei Vielen fïllt ihre Unterscheidung wegen ausbleibender Ossification, namentlich in dem Ethmö̈dalsegmente, schworer. Bei verhälinissmässig wenigen Teleostei verlängert sich die Schedelhöhle ${ }^{3}$ ) bis an oder in das vorderste Segment, wie z. B. bei Cyprinus, Loricaria, Silurus; bei sehr vielen bildet nïmlich schon das $\boldsymbol{O} s$ ethmö̈deum, statt einer Höhle, als verticale Platte von knöcherner, knor-

Belone nicht ohne Zerreissung hegrenzender knorpeliger Elemente abheben. - Am häufigsten erhalten sich die knorpeligen Elemente in der Gegend des Segmentum septi narium, sowol über dem Vomer, und selbst über dem Sphenoïdeum basilare, als in der: Umgebung des Nasenbeines und an der Basis der Ossa frontalia anteriora, wie z. B. bei Belone, Cottus, Perca, Lucioperca, Callionymus, Ammodytes, Zoarces, Ophicephalus u. s. w.; selhst bei sehr alten Silurus glanis kommen zwischen den Knochen dieser Gegend breite Knorpelstreifen vor. - Am vollständigsten ossificirt, und am seltensten mit linorpeligen Elementen gemischt sind im Allgemeinen die Schedel der Gadoïden, Siluroïden, Cyprinoïden und vor Allen die der Physostomi apodes; eine Eigenthümlichkeit des Aales ist allerdings die, dass sein Processus orbitalis anterior knorpelig bleibt. Die Plectognathi bieten grosse Verschiedenheiten dar.

2) Eine merkwürdige Ausnahme hiervon macht Polypterus bichir. Seine llinterhauptsgegend wird von einem einzigen Knochen eingenommen. Die Alae tomporales und orbitales, so wie cin discretes Siebbein sind nicht entwickelt. Ein einfacher Knochen: Os mastö̈deum Agass, aufsteigende Flïgel des $O$ s sphenoïdeum basilare und absteigende Fortsälze des Stimbeines bilden die Seitenwand des Schedels. Vgl. Agassiz, Poiss. foss. Vol. II. Tb. B. C. und Müller, über Bau und Grenzen der Ganoìden. Th. 1.

3) Beträchtliche Verlängerungen der Schedelhöhle zur Aufnahme der Geruchsnerven bestimmt, kommen auch bei den Ganoïdei holostei vor. S. über die des Polypterus und Lepidosteus, A gassiz l. c. - Es gehören hicher auch die unteren, nur hüutis geschlossenen Verlängerungen der Schedelhöhle zur Aufnahme der Geruchsnerven bei fien Gadus, die ganz anders sich verhaltenden im linorpel liegenden bei Esox u. s. w. 
peliger, knorpel- oder faserhäutiger Textur, nur ein einfaches Septum interorbilale.

Das Axensystem des Sehedels wird gebildet: 1) durch das in jeder Bezichung rinem Wirbelkörper entsprechende Os basilare occipitis; 2) duch das $O s$ sphenoüdeum basilare, das, so writ es ossificirt ist, häufing fast nur oder un als discrete Fortsetzung der corticalen Ossificalionsschicht des Os basilare occipilis erscheint und als abortiver Auslinfer des Axensystemes unter den drei mittleren Schedelsegmenten sich hinzicht; 3) durch den an dieses $O s$ sphenö̈deum basilare vorne sich anschliessendnn, dem Septum narium angehörigen Vomer, der als vorderstes Endglicd des ver. kümmerten Axensystemes erseheint.

Es cutspricht demnach die Anzah! der die Schedelhöhle umschliessenden und nach vorne fortsetzenden Segmente nicht derjenigen des Axensystemes. Das Occipitalsegment hat sein cigenes Schlussstück in dem Os basilere oc. cipilis; das Sphenoüdeum basilare gehört den drei mitheren Schedelsegmenten gemeinsam an; der Vomer isl dem vordersten Segmente angefügt.

Auch sonst gestalten sich die Verhïltnisse der oberen Bogentheile oder Segmente zu den basilaren Knochen rersehieden. Das Occipitale basilare ist meistens zwischen den beiden aufsteigenden Sehenkeln des Hinterhaupt. segmentes eingekeilt; den unter cinander verbundenen aufsteigenden Schenkehn des hinteren Keilbeines liegt das Sphenoüdeum basilare unten blos an; mit den Schenkehn des vorderen Keilbeinsegmentes und mit dem Ethmoïdalsegmente kömmt letzterer Knochen meist nur durch absteigende einfache Sepla in Berührung, während der Vomer gewöhnlich un als corticale Ossification seines vordersten Schedelsegmentes erscheint.

Wenn eine nähere Verghlichmog sämmtlicher einzehen Schedelsegmente mit discreten Wirbeln überhaupt gefordert verden dürfte, so würde sie abgesehen ron der mangehden Wiederholung unterer Wirbelbogenschenkel, - ergeben, dass das Occipitalsegment mit Einschluss des Occipilale basilare und des Occipilale superius einen vollstïndigen Wirbel wiederholt; dass die Segmente der beiden Keilbeine durch den beständig wiederkehrenden Be silz oberer Bogensehenkelpaare in so ferne ohne Zwang auf den Wirbellypus sich reduciren lassen, als es überhaupt nicht selten vorkömml, dass ein Wirbellërperstück den abwärls mit cinander verbundenen und bereits geschlossenen Bogensehenkehn unten blos angefü̈gl ist 4); dass das Ethmoüdeum, wemn es vinen einfachen Canal oder IIalbcanal bildel, chenfalls sein Vorbild in manchen oberen Wirbelbogen findet, dass andlich das Ethmö̈deum, als einfaches Septum, sowie auch das Segment des Seplum narium, mit abortiven Schwanzwirbeln allenfalls verghichen werden können. - Eine detaillirte

4) Z. B. bei $\Lambda$ ccipenser unter den Fischen; unter den Süugethieren bei Coelogenys paca an cinigen Ualswirbeln. 
Durchführung solcher Vergleichung würde, da der Wirbel selbst höchst mannichfach construirt sein kaun, immer nur ein subjectives Gepräge tragen und zu den Anforderungen der Wissenschaft nicht gehören.

[Ueber den Schedel der Knochenfische und Ganoïlei holostei vergl. man, ausser den IIandbüchern von Cuvier und Il eckel, so wie Cuvier's berïhmter Einleitung zur Uistoire naturelle des poissons. Vol. I. p. 3ł3., in welcher auch die ältere Literatur sehr vollständig und kritisch aufgeführt ist, folgende Schriften: A gassiz, Poiss. foss. Vol. V. part. 2. - Agassiz et Vogt, Anatomie des Salmones p. 2. sqq. - II allmann, vergleichende 0steologie des Schläfenbeines. Iannover. 1834. 4. - I Ï̈stlin, der Bau des knöchernen Kopfes in den vier Classen der IVirbelthiere. Stuttgart 1S44. 8. - Arendt, de capitis ossei Esocis lucii structura. Regiom. 1824. 4. (Die Entdekkung der knorpeligen Grundlage des IIechtschedels). - E. J. Bonsdorff, Speciel jemforrande bescrifning af hufvadskals - benen hos Gadus lota. Helsingfors 1847. 4. Auch in Finska Vetenskaps-Societetens Handlingar für i̊r 1547. (Versuch einer speciellen Reduction des Fisch-Schedels auf den des Menschen). - Ueber den Schedel einheimischer Fische findet sich genaues Detail bei B. C. Brühl, Anfangsgründe der vergleichenden Anatomie. Wien 1847, 8. - Von den Schedeln der Lepidosteus u. Polypterus handelt Agassiz, Poiss, foss. T. II. p. 1. sqq. Tb. B ${ }^{\text {, C }}$ ' $^{1}$ u. J. M äller, Bau und Grenzen der Ganoïden. Tb. 1. u. Tb. 4.

Die Entwickelungsgeschichte des Schedels beschreibt C. Vogt: Embryologie des Salmones. Neuchat. 1842. 8. p. 109 sqq.]

\section{\$. 29.}

In die Zusammensetzung des hintersten Seledelsegmentes oder des IInterhauptsgürtels gehen in der Regel vier typische und discrete, bald durch Knorpelstreifen aus cinander gehaltene, bald enger mil cinander verbundene Knochen ein. Diese sind das Körperstück: Os basilare; zwei aufsteigende Bogenschenkel: Ossa occipitalia lateralia und ein oberes Schlussstïck: Os occipitale superius s. Squama occipilalis. Zu ihnen kömmt meistens jederseits ein Randknochen: das Os occipitale externum. Sämmtliche Knochen werden oft noch zur Aufnahme von Theilen des Gehörlabyrinthes verwendet.

Das Os basilare, durchaus Wirbelkörper-ähnlich, besitzt meistens Iinten cine conische Vertiefung, welche in der Regel derjenigen des ersten Wirbelkörpers entspricht und die gevö̈hulichen Ucberreste der Chorda dor. salis enthäl. Selten, wie bei mehren Symbranchi, correspondirt ihr ein conischer Gelenkkopf des ersten Wirbels. - Die Stelle der conischen Vertiefung des $O$ s basilare wird bei der Gattung Fistularia vertreten durch einen einfachen rundlichen Gelenkkopf der in eine Vertiefung des ersten Wirbelkörpers aufgenommen wird. - Von sciner muteren Fläche steigen oft Seitenfortsätze zur Vervollständigung des unter der Schedelbasis liegenden Augenmuskelcanales ab. - Scine der Schedelhöhle zugewend te Flïche dient oft, jedoch nicht immex der Medulla oblongata zur Grundlage, indem bisweilen, z. B. bei den Cyprinen, die in der Nittellinie äber ihm 
zusammenstossenden Ossa occipitalia lateralia den eigentlichen Schedelbo. den bilden. Zwei Vertiefungen, welche an scincr Immenseite hïnfig sich finden, dienen zur Aufnahme des Saccus vestibuli.

Die aufsteigenden Bogen: Ossa occipilalia lateralia besitzen Oeffunngen zum Durehtrilte der Nervi ragi und glossopharyngei; bisweilen z. B. bei Salmo, gewähren sie auch dem ersten Spinalnerven Durchgang. Bei vielen Teleostei kömmt jedem dieser Knochen eine etwas vertiefte Gelenkfläche zu, welehe derjenigen des mit ihm arliculirenden ersten Rumpfwirbels entspricht. Seltener, wie bei den Cyprinus, Silurus, Esox fehlt sie. Nur bei cinzelnen Fischen sind diese Knochen mit den oberen Bogenschenkeln des ersten Rumpfwirbels durch Naht verbunden 1). - Dem Os occipitale laterale schliesst sich bei einigen Fischen eine kleine oberflïchliche, nirgend in die Tiefe dringende Knochenlamelle an, welehe $\mathbf{C u -}$ vice als $O s$ petrosum bezeichnet hat - eine Bezeichnung, die, wenn sie anch nur irgend eine Analogie mil dem Felsenbeine höherer Wirbelthiere andeuten soll, unstatthaft ist ${ }^{2}$ ).

Das Os occipilale superius ${ }^{3}$ ) bildet das obere Schlussstück des Ilinterhauptgürtels. Seine Knochensubstanz geht oft ummittelbar in den unter den nächst vorderen Deckknochen (Ossa frontalia principalia) gelegenen Knorpel über. Es ist schr häufig in eine starke senkrechte Leiste (Crista occipitalis superior) ausgezogen, die bald nach hinten gerichtet ist, wie bei viclen Cyprinen, bald in eine mehr orler minder hohe stark vorwärts verlingerte Crisla sich fortsetzt, wie bei vielen Squamipeunes, Scomberoïden, Sciänöden u. A. In beiden Fällen gewährt sie dem Vorderende des Dorsaltheiles des Seitenmuskels Unterstülzung. - Das Os occipilale superius enthält in scincr tiefen knorpeligen Grundlage bisweilen, z. B. bei Salmo, einen unbeträchtlichen Theil der äusseren und hinteren halbeirkelförmigen Canäle.

Als Randknochen neben dem Occipitale laterale jeder Seite zcigt sich gervöhnlich das $O s$ occipitale exlernum ${ }^{4}$ ). Auf Kosten der dicken knorpeligen Grundlage des Schedels gebildet, nehmen diese Knochen Theile des Gehörlabyrinthes auf. Sie sind ïbrigens von versehiedener Ausdehnung und gewïhren, meist durch einen versehiedentlich stark entwickelten Fortsalz, der oberen Zinke des Schultergürtels Stülzpunkte.

Das zueite Schedelsegment ist reprïsentirt durch das hintere

1) So z, B. selie ich es bei Synanceia horrida.

2) Es ist das Occipitale posterius Agassiz.

3) Os interparietale Agass. - An der Spina hat es bei Platax arthriticus und Ephippus gigas, gleich vielen Ossa interspinalia, eine eigenthümliche rundliche Auftreibung. S. Cuv. u. Valenc., Poiss. Tome VII. Th. 204. Bell in d. Philosoph. transact. 1793. Tb. VI. B. Wolff, de osse peculiari Wormio dicto Berol. 1824. 4.

4) Ossa occipitalia externa Auct. Ossa petrosa Bojanus. 
Keilbein. Dasselbe besteht aus zwei aufsteigenden Bogen: Alae temporales und einem muter der. Verbindungsstelle beider liegenden Basilarstücke: Os sphenoüdeum basilare Auct.

Die a ufsteigenden B ogen dieses hinteren Keilbeines (Ala e tempovales ${ }^{5}$ ) sind immer in der unteren Mittellinie, der Lïnge nach, unter einander verbunden. Sie slossen mit ihren hinteren Rändern an die Vorderränder des Occipilale basilare und der Occipilalia lateralia. - Der Vorderrand des unteren, zur Unterstülzung der Medulla oblongata dienenden Theiles der beiden Alae temporales bleibt ausser unmitlelbarer Berührung mit anderen Sehedelknochen, endet frei und bildet die hintere Begrenzung einer Lücke, welche vorn gewöhnlich durch das solide Mitlelstück des drilten Schedelsegmentes (das $O$ s sphenoüdeum anterius) begrenzt, abwiirts aber durch das schuppenförmige $O s$ spheneïdeum basilare verdeclst wird. In diese Lüche senkt sich die Iypophysis cerebri nebst dem Saccus vasculosus. -- An der Innenfläche der Ala temporalis zeight sich eine zur Aufnahme der vorderen IÏ̈lfte des Vestibulum bestimmte Grube, deren hintere Fortselzung dem Os occipitale laterale angehört. Der obere Theil der Grube der Ala temporalis nimmt auch den Anfang des Canalis semicircularis anterior und externus auf. - Sobald ein Augeumuskelcanal rorhanden ist, liest er unterhalb der Alae temporales, die zur Bildung seiner Seilenwände durch absieigende Fortsätze oft beilragen. Diese letzteren sehliessen dann an entsprechende kurze aufsteigende Fortsätze des Os sphenö̈deum basilare sich an. - An der Bildung der Gelenkgrube für das Kiefer-Suspensorium hat die Ala temporalis nur selten, wie z. B. bei Cyprinus, Abramis I. A. geringen Antheil. - Durch Oeffnungen oder Canïle dieser Knochen verlassen die Schedelhöhle in der Regel: die Nervi abducentes, 10 in den Augenmuslielcanal zu treten, die meisten Elemente des $\boldsymbol{N}$. trigeminus und des $\boldsymbol{N}$. facialis. Die beiden letzlgenannten Nerven treten mindestens durch vordere Ausschnitte der Alae temporales hiudurch, wie bei Gadoïden und bei Lophius.

Die beiden Alae temporales des Keilbeines erhalten eine untere Belegung durch einen basilaren Knochen: Os sphenoïdeum basilare, der ihre vordere Grenze immer un ein Betrïchlliches überschreitet. Diese gewöhnlich dünne lange Ossification liegt mit ihrem hinteren Rande oft schuppenartig unter dem vorderen Theile des Occipilale basilare oder greift mit Zacken in dessen Riudensubstanz cin, setzt sich dann unterhalb des durch die zusammenstossenden Alae temporales gebildeten Bodens der Hirncapsel nach vorne fort, überschreitet ihre Grenze und erstrecht sich meist unterhalb der beiden näehst vorderen Schedelsegmente, doch gevöhnlich tief abwärls von der unteren Schlusslinie der Hirncapsel, nach vorn bis an die

5) Alue magnae Cuvier, Bakker, Agassiz; Os petrosum Meckel, ITallmann; Os tympanicum Bojanus. 
Grenze der Schnauze, wo er in einen anderen basilaren Deckknochen: den Vomer mit seinen vorderen Zacken eingreift. - Auf ihm ruhet hitufig der Körper des dritten Schedelsegmentes, des Sphenoüdeum anterius, meist mit rincm absteigenden Stachel, wie bei Clupea, Salmo u. A. In Ermangelung cines Körperstückes senken sich auf ihn zwei schmale znsammenstossende Fortsïtze seiner ossificirten Flügel oder membranös cutwickelte, ihre Stclle vertretende, ein fibröses oder knorpelhïuliges Septum interorbilale darstellende, Theile. Auf iln senkt sich ferner das Septum interorbilale herab. - Oft besitzt das Os sphenoüdeum basilare an der vorderen Grenze der Alae temporales seicht anfsteigende mehr oder minder kurze Flïgelfortsätze; seltener wie bei Anabas, Pleuronectes u. A., cine absteigende Crista; noch seltener verlängert es sich vor den Alae temporales in verticaler Richtung etwas aufwärts zur Vervollständigung des Seplum interorbitale, wie bei Notopterus. - Bei einigen Familien z. B. bei den Gadoïlen, Silnroïlen, Mü̈noïden, Plectognathi Gymnodontes u. A. legt er sich unmittelbar unter die Alae temporales; bei anderen ist er theils unter, theils selbst zwischen ihnen eingekeilt, wic z. B. bei einigen Pleuronectes; meistens bleibt er von ilnen entfernt, wie z. B. bei den meisten Clupeidae, Salmones, Esoces, Cyprini und vielen Acanthopteri. Bei diesen nämlich bildet die obere Fläche des Sphienoüdeum basilare den Boden eines nuterhalb der geschlossenen Hirncapsel gelegenen, oft durch ein medianes Septum getheilten (Cyprinus), zur Aufnahme melrer Augenmuskeln, namentlich der M. M. recti externi, bestimmten Canales, dessen obere Wandungen von den unteren Schlussknochen der Hirneapsel, dessen Seitenwandungen von absteigenden Fortsätzen der letzteren allein oder zugleich von aufsteigenden Seitenfortsïtzen des Os sphenoideum basilare gebildet werden.

Dass dies $O s$ sphenoüdeum basilare ausschliesslich auf fibrös-häntiger Grundlage entstehe, darf um so weniger behauptel werden, als es hïufig, wie z. B. bei Salmo, Esox, Clupea einen Knorpelsticl halb umfasst, der von der Unterseite des vordersten Theiles der knorpeligen Grumdlage des Schedels bis zux Gegend der Alae temporales hin hinterwäts sich erstreckt. - Seine untere Fläche steht, gleich derjenigen des Vomer, nicht selten in enger Verbindung mit der unterliegenden Schleimhaut der Mundhöhle, zeiggt, ilı zunichst, bisweilen cine eigenthümliche Ossificationsschicht, welcher die tieferen Lagen der Schleimhant zum Blastem gedient zu haben scheinen, trägt auch nicht selten Zühne ${ }^{6}$ ).

Wenn man den Ausgangspunki dieses Knochens festh:ilt, der eben die corlicale Ossificationsschicht des $O s$ occipilale basilare ist, das er umunterbrochen bis zur Gegend des Septum narium fortsetzl, ron wo aus der

6) z. B. bei Anabas scandens, Ophicephalus striatus und anderen Labjrinthiformes, dann bei Notopterus, Ostcoglossum, Sudis. 
Vomer, als vorderes Endstück, ihn verlängert, so drängt sich nothwendig die Ansicht auf, es möchten diese Knochen: das Sphenoïdeum basilare und der Vomer als vordere, mehr oder minder abortive Endverlängerungen des Axensystemes der Wirbelsäule zu betrachten sein ${ }^{7}$ ).

Das dritte Schedelsegment entspricht dem Os sphenoïdeum anterius höherer Wirbelthiere. Es bildet die hintere Wand der Augenhöhlen und cine Strecke ihrer Inmenwand. Seine Elemente tragen zur unmittelbaren Begrenzung des vorderen Theiles der Schedelhöhle, namentlich, so weit lelztere die Hemisphären des Gehirnes einschliesst, bei. Zwisehen seinem Körperstücke und dem Vorderrande der Alae temporales des hinteren Keilbeines liegt die Grube für die Hypophysis. Es gewährt dies Schedelsegment, gevöhnlich in Gemeinschaft mit den Alae temporales, oder in scinen häutigen Antheilen, selten mit seiner ossificirten Grundlage, dem Orbitalaste des $\boldsymbol{N}$. trigeminus, den $\boldsymbol{N}$. $\boldsymbol{N}$. oculorum molorius und trochlearis, - so wic allein durch seine unteren hïutigen Theile dem $\boldsymbol{N}$. oplicus Durchtritt. Die Verschiedenheiten, welche die Betrachtung dieses Schedelsegmentes, namentlich an getrockneten Schedeln, erkennen lässt, beruhen hauptsächlich eincrseits auf der verschiedenen Entwickelung seiner ossificirten Bestandtheile im Gegensatze zu den fibrös-häutigen und andererseits auf der bei manchen Fischen z. B. bei den Gadoïden, so schwierigen Fixirung seiner vorderen Grenzen. Was die Ossificationen dieses Segmentes anbetrifft, so bestehen dieselben, falls solche überhaupt vorhanden sind, aus zuvei Alae orbitales ${ }^{8}$ ), welche an den oberen Theil des Vorderrandes der Alae temporales sich anschliessen. Diese ossificirten Alae orbilales bcsilzen eine schr verschicdene Austehunng. Sie sind ganz unbeträchllich und oft kaum als discrete Stücke zu erkennen bei den Gadoüden; sie gewimnen an Umfang bei Esox, Salmo, Macrodon, Lepidosteus und Amia, wo sie in das den Orbitaltheil des Schedels bedeckende Knorpeldach con. tinuirlich übergehen; noch weiter vorwärts reichen sie bei Clupea, Alosa, Megalops. Am beträchtlichsten aber sind sie bei vielen Siluroïden und Cyprinoïden. Sie bilden hier die Seitenwandungen der hinteren IÏ̈lfte einer weit nach vorne reichenden Verlïngerung der Schedelhöhle. Während nämlich bei sehr vielen Teleostei die Schedelhöhle oberhalb der Orbilae sich sehr verengl, behauptet sie beiSilurus, Loricaria, Cyprinus, sowie bei Notopte-

7) Wenn gegen diese aus Auffassung der architectonischen Verhältnisse der Fische, wie der höheren Wirbelthiere, hervorgegangene Anschauung eingewendet wird, die Chorda dorsalis reiche ursprünglich nicht bis an das vorderste Schedelende, so beweiset einmal Branchiostoma, dass sie in der That so weit sich verlängern kann und andererseits fragt es sich, ob es ein nothwendiges Requisit der Axentheile der Wirbelsäule ist, aus dem ganz ununterbrochenen Blasteme der Chorda hervorzugehen.

8) Alae orbitales s. parvae Cuvier, Bojanus, Rosenthal; Alae magnae Meckel, llallmann; Alae orbitales posteriores Brühl. 
rus auch hier, gleich wie in dem nächst vorderen Schedelsegmente, eine gewisse Weite und wird bis zur Grenze des Körpers des Ethmoülalsegmentes von den Alae orbilales seitlich begrenzt. Ja diese können wie z. B. bei Abramis brama, unmittelbar hinter dem Körper des $O$ s elhmoideum mil cinander in der unteren Mittellinie zusammenstossen. Es sind also Silurus glanis und die Cyprinen, bei welehen, unter den cinheimischen Fischen, eine scharfe vordere Begrenzung dieses Schedelsegmentes vorzugsweise zu klarer Anschauung kömmt. -

Bei den meisten derjenigen Teleostei, welchen ein Augenmuskeleanal zukömmt, besitzt das dritte Schedelsegment cin eigenes Körperstück in dem Os sphenoïdeum anterius $C_{\text {Cuv }}{ }^{9}$ ). Er besteht gewöhnlich in zwei convergirenden, absteigenden und mit cinander verschmelzenden Leisten, die in einen einfachen unteren Fortsatz anslaufen, hat also meistens die Form eines Y. Jeder seiner Seitenschenkel pflegt von dem unteren Rande einer Ala orbilalis auszugehen und sein unpaarer unterer Sticl ruhet gewöhnlich auf dem Os sphenoïdeum basilare. - Bei jüngeren Ilechten ist dieser Knochen knorpelig und sein einfacher, oben in zwei Schenkel ausgehender, Stiel ist eine unmittelbare aufwärts gerichtele Fortsetzung des vom fünften Schedelsegmente ausgehenden, nach hinten verlaufenden Knorpelsticles. Der Körper des Os sphenoideum anterius bildet die vordere Begrenzung der zur Aufnahme der Hypophysis bestimmten Grube, gehört also der Schedelcapsel selbst an. - Bei denjenigen Fischen, die eines Augenmuskelcanales ermangeln, fehlt er als selbstständiger Knochen.

Als Randknochen des zweiten und dritten Schedelsegmentes erscheinen die discreten Elemente der Schläfengegend. Dieselben bestehen in zwei Knochen, welche vorzugsweise auf Kosten des zusammenhangenden Schedelknorpels entstanden sind, meist aber zugleich eine änssere corticale Ossificationssehicht besitzen. Einer dureh beide Knochen zugleich gebildeten, meist langen Gelenkgrube ist das Kiefersuspensorium eingefügt.

Der hinterste dieser Knochen ist das Os mastö̈deum ${ }^{10}$ ), das zur Aufnahme des Canalis semicircularis externus mit verwendet wird und, gevöhnlich mittelst einer Apophyse, zur Anheftung ciner der Zinken des Schultergürtels dient.

9) Os sphenö̈deum anterius Cuvier, Agassiz; Os sphenoüdeum superins Hallm. - Cuvier bezeichnet nicht nur diesen Knochen, sondern auch das Os ethmoüdeum der Cyprinen und Siluroiden als Os sphenödeum anterius I. c. pag. 325. - Es kömmt z. B. vor bei Perca, Lucioperca, Acerina, Scomber, Salmo, Clupea, Ammodytes. Gänzlich vermisst habe ich diesen Knochen bei Cottus, Pleuronectes, Gadus, Cyclopterus, Diodon, Tetródon u. A.

10) Os mastö̈deum Cuvier, Neckel; Os petrosum Gionfroy, Baliker, Bojanus, Squama temporalis s, Os temporale Agassiz. 
Der vordere Randknochen ist das Os frontale posterius ${ }^{11}$ ), das den oberen Umfang der Augenhöhle hinten begrenzt und zur Anlage des hinteren Sckenkels des Infraorbital-Knochenbogens dient.

Das vierte Schedelsegment: das Siebbein, Os ethmö̈deum ${ }^{12}$ ) bielet in Betreff der histologischen Differenzirung seiner Grundlage sehr grosse Verschiedenheiten dar. Es besteht wesentlich aus cinem unpaaren, vertical gestellten Kürperstücke, das, wenn es knorpelig oder ossificirt ist, einen nicht unbeträchtlichen Theil der Augeuhöhlen-Scheidervand bildel. Bei vielen Fischen wird seine Stelle nur dureh ein knorpelhäutiges oder fibröses Septum vertrelen. Bei anderen ersfheint es als cine verticale Knochenplatle, die oben in die knorpelige Grundlage des Schedeldaches, unten in die das $O s$ sphenoïdeum basilare ühcrgeht und nach hinten von den Alae orbitales ebenfalls durch Zwischenknorpel geschicden ist. So zeigt es sich z. B. bei Lepidostens, Amia, Megalops, Salno, Esox - Fischen, bei welchen es verschieden weit vorwïrls ansgedehnt, das Septum interorbilale bildet ${ }^{13}$ ). - Bei Clupea und Alosa, wo er fast ganz linorpelhïutig ist und nur in geringer Ausdehnung aus dickerem Knorpel besteht, bildet sein hinterster, an die Alae orbitales sich anfïgender Theil eine kurze abwärts geschlossene Höhle, die weiter vorwärls in ein cinfaches, hnorpelläuliges. jeder Ilöhlung crmangelndes sephum interorbitale sich umwandelt. - Eigenthümlich gestaltet es sich bei Folopterus, bei den Siluroülen und Cyprinoïlen, wo es zugleich durch sehr vollständige Ossification sich auszeichnet, durch Bildung einer viel weiteren Höhle, die die Schedelhöhle nach vorne beträchtlich verlängert. Bei Silurus glanis verbinden sich mit den beiden Alae orbilales die Seitenschenkel eines abwärts geschlossenen, also cine IÏ̈lle bildenden unparen Knochens, der zwischen den paarigen Ossa frontalia anteriora bis zur Grundlage des fünften Schedelsegmentes sich fortsetzt. Dieser, einen unten geschlossenen IIalbcanal darstellende mpaare Knochen reprïisentirt den Körper des Siebbeines. Ganz analog verhailt sich das Os ethmö̈leum bei den Cyprinö̈len, wo seine Seitenschenkel jedoch nach oben unter der knöchernen Schedeldecke durch Knor-

11) Os frontale posterius Auct. Squama temporalis Meckel, Geoffroy, Rosenthat; Os parietale Bojamus. Es entspricht der Squama tomporalis höherer Wirbelthiere.

12) Os ethnö̈deum Spix, Agassiz; Ala orbitalis Meckel, Hallmann. Cuvier erwähnt dieses Knochens in seiner am häufigsten vorkommenden Form nicht; das Os ellemö̈deum der Cyprinen und Siluroïden verwechselt er aber mit seinem Sphenoüdeum anterius. - $\mathrm{Brühl}$ nennt dies Os ethmoüdeum Alu orbitalis anterior.

13) Bei Salmo salar ist es sehr weit vorwärts bis zwischen die Basis der Ossa frontalia anteriora ausgedehnt und trägt hinten now zur vorderen Begrenzung der Schedelhöhle bei. Bei Esox enthält es, wie man auf Querdurchschnitten sieht, eine bis in dic Gegend der Ossa frontalia anteriora fortgesctzte enge Ilöhle, welche, als Verlängerung der Schedehöhle, die Geruchsnerven aufnimmt. 
pelleisten verbunden werden. - Wo und so weit der Siebbeinkörper cine IIöhle einschliesst, die die Schedehöhle nach vorne verlïngert, verlaufen in dieser die Geruchsnerven; von dem Punkte an, wo der Siebbeinkörper ein einfaches Seplum darstellt, verlanfen die Geruchsnerven gewöhnlich an dessen Ausseuflïche bis zu ihren Austrittsstellen in der Nähe der Basis der Ossa frontalia anteriora. Bei den Gadö̈den ist die Grundlage der Siebbeingegend häutig, der Geruchsnerven-Canal liegt hier unter den Stirnbeinen und wird nach unten durch die aufwïrts divergirenden Lamellen des häutigen Septum interorbitale gebildet. Alle genannten Bildungsformen des Siebbeines kehren bei anderen Wirbelthieren wieder; die Ilöhlenbildung durch den Knochen selbst zur Verlängerung der Schedelhöhle bei vielen Batrachiern; die Form eines verticalen knöehernen Septum interorbitale bei der Mehrzahl der Vügel; die Reduction auf ein faserhäutiges und knorpelhäutiges Seplum bei vielen Sauriern.

Als Randknochen, welche die Grenze dieses und des folgenden Schedelsegmentes bezeichnen, erscheinen die Ossa frontalia anteriora ${ }^{14}$ ). Diese Knochen, welche gewöhnlich durch perennirend ungegliederte Knorpelsubstanz von cinander getrennt bleibeu, bilden den vorderen Augeuhöhlenrand; bei der überwiegenden Mehrzahl der Fische finden sich in ihrer Basis, die der gemeinsamen linorpeligen Schedelgrundlage noch angehört, bisweilen in ihrer Substanz selbst, Oeffnumgen zum Durchtrilte der Geruchsnerven ${ }^{15}$ ). Die Kuochen selbst unterslützen mit ihren vorderen Flächen sehr häufig die Ausbreitung des Geruchsorganes.

Die obere Bedeckung des zweiten, dritten und vierten Schedelsegmentes geschieht durch Knochen, weiche als Ossa parietalia und Ossa frontalia anzusprechen sind.

Der Bereich der Ossa parietalia ${ }^{16}$ ) ist ein viel beschränkterer, als der der vor ihnen gelegenen Ossa frontalia, indem sie meistens nur so weit, als die Innenränder der Ossa mastoidea reichen. das Sehedeldach bilden. Bei den meisten Telcostei werden sie durch die zwischengeschobene

14) Os frontale Auct. Ethmoïdeum laterale Meckel, Bojanus. Lacrymale Geofroy, Carus.

15) Diese Oeffnungen fir die Geruchsnerven werden bald von ihnen allein, bald unter Theilnahme benachbarter Knochen gebildet. Bei Gadus callarias werden die beiden Ossa frontalia anteriora durch eine discrete linochenbrïcke verbunden. Der mittlere Theil derselben liegt unmittelbar unter der hinteren stielförmigen Verlängerung des $\boldsymbol{O}$ s nasule. Von ihm aus erstreckt sich zu jedem Os frontale anterius ein Schenkel. Jeder Schenkel bildet ein Dach über der Austrittsstelle des $\boldsymbol{\Lambda}$. olfactorius, die auswärts vom vorderen Stirnbeine begrenzt wird. Darf dieser discrete unpaare línochen als Repräsentant cines Siebbeines angesehen werden?

16) Durch eine Oeffnung jedes Os parietale tritt bei viclen Fischen der Famus lateralis $N$. trigemini. 
Squama occipitalis, dic dann in ummittelbare Berührung mit den Ossa frontalia kömmt, von einander getrenut. Seltener berühren sich dic beiden sleichnamigen vor den Vorderrand der Squama occipitalis geschobenen Knochen mit ihren Inneuräudern, wie z. B. bei den Cyprinen, bei Mlacrodon ${ }^{17}$ ).

Die beiden Ossa frontalia ${ }^{18}$ ) erstrecken sich bei den meisten Fisehen bis zur hinteren Grenze des cinfachen Nasenbeines; wenn doppelte Nasenbeine vorhanden sind, wie z. B. bei Esox, können sie sich noch eine betrïchtliche Strecke weit zwischen sie schicben. Sie besitzen demnach immer einen sehr beträchtlichen Bereich ihrer Ausbreitung auf dem Schedel. Absteigende Fortsätze derselben können, wie bei einigen Ganoüden, zur Bildung eines die Geruchsnerven aufnehmenden und die Schedehöhle nach vorn fortsetzenden Canales beitragen.

Das fünfte Schedelsegment bildet gewöhnlich cin mehr oder minder weit über die, durch dasselbe getrenuten, Nasengruben hinaus verlïngertes Septum narium. In Behell sciner Ausdehnung, sciner Formverhältnisse, seiner Sonderung verhält es sich äusserst verschieden. Es gehören demselben zwei Ossificationen an: der einfache oder doppelte Vomer und das einfache oder doppelle Nasenbein. - Bei manchen Teleostei z. B. den Cyprinen, den Gadoïden, auch bei den Siluroüden und Loricarinen ist dies Schedelsegment vollstïndig ossificirt. Bei sehr vielen Anderen bleibt seine Grundlage aber knorpelig und steht in diesem Falle in vollkommenerem ${ }^{19}$ ) oder unvollkommenerem ${ }^{20}$ ) Zusammenhange mit der übrigen gemeinsamen Schedelgrundlage. Wichtig ist der Umstand, dass ron der Basis dieses Segmentes sehr allgemein ein, von vorne nach hinten gerichteter Knorpelstiel abgeht. Dieser liegt abwärts von der Basis des vierten und dritten Schedelsegmentes und erstreckt sich bis in die Gegend des Vorderendes der beiden zusammenstossenden Alae temporales. Bis in die Gegend des vor-

17) Vor dem Vorderrande der Squama occipitalis, zwischen ihm und den Ossa frontalia, liegt bei Hormyrus ein beträchtliches unpaares, in der Nitte durch eine schwache Leiste ausgezeichnetes $\boldsymbol{O}_{s}$ interparietale. Die zu seinen Seiten liegenden Deckknochen bedecken einen Hohlraum, welcher, ohne von Knorpel äberzogen zu sein, einen grossen Theil des Gehörlabyrinthes einschliesst. Dieselbe Lücke, wie bei den Mormyri findet sich bei Notopterus u. Hyodon, wo sie aber nur von Haut bedeckt ist.

18) Ossa frontalia principalia Cuvier. Bei sehr vielen Siluroiden lassen dic beiden Knochen vorne in der Hittellinie eine häutig geschlossene Lücke zwischen sich. So z. B. bei Silurus, Aspredo, Loricaria u. A. - Bei Cobitis findet sich ebenfalls eine Lücke, nur weiter nach hinten, und auch die Ossa parietalia trennend. - Bei Thynnus vulgaris sind Lücken vorhanden, sowol vorne als hinten, zwischen Os frontale und $\boldsymbol{O}$ s parietale.

19) z. B. bei Esox, bei den Salmones.

20) z. B. bei Cottus, Cyclopterus, Callionymus, Belone. 
deren freien Randes der Alae temporales, also bis zur Grenze der Hypo. physis hin, ist nümlich in frühesten Stadien der Entwickelung das Vorderende der von der Wirbelsäule aus in die Schedelbasis forlgesetzten Chorda dorsalis erkannt worden. - Der genannte Knorpelstiel wird in seiner hinteren IIälfte von der vorderen IIäfte des Os sphenoüdeum basilare, weiter vorwärts aber vom Vomer umfasst. Beide Knochen erscheinen meist als corticale Ossificationen dieses Knorpels.

Was die Ossificationen dieses Schedelsegmentes anbetriff, so ist der Vomer fast immer einfach; bei Lepidosteus wird er jedoch durch zwei seitliche, in der Nittellinie einauder berührende Ossificationen repräsentirt. Der Vo. mer greift gewöhulich mit Zacken in das Vorderende des Os sphenoideum basilare ein und stellt, ganz abgesehen von seinen genetischen Verhältnissen, das äusserste Eude des abortiv gewordenen Wirbelkörpersystemes dar. Er ist bald eine ganz dünne Ossification, bald stärker und dicker, bisweilen an seinem Vorderende verbreitert, wie z. B. bei Silurus. Bei den Cyprinen trägt er an seinem freien Ende zwei starke Apophysen. - Der Vomer kömmt an seiner unteren, der Mundhöhle zugewendeten Fläche in innige Berührung mit der Schleimhaut derselben, die nicht selten ein Blastem für seine Verdickung liefert. Er gehört daher auch zu denjenigen Knochen, die am häufigsten zahntragend sind.

Oberhalb des Vomer liegt meistens ein einfaches Nasenbein (Os nasale $\left.{ }^{21}\right)$. Bei solchen Fischen die durch vollstïndigere Ossification dieses Sehedelsegmentes sich auszeichnen, z. B. bei Gadus, Cyprinus, Silurus, Macrodon liegt das Nasenbein dicht oberhalb dem Vorderende des Vomer und schliesst unmittelbar an den Vorderrand der Ossa frontalia principalia sich an, ein einfaches Septum narium bildend. Seine Form kann dabei höchst mannichfach sein, wie eine Vergleichung der eben genannten Fische lehrt. - Bei anderen, wo dieses Schedelsegment unvolliommen ossifieirt ist, wie z. B. bei Cottus, Callionymus, Belone, liegt oberhalb des Vomer fast nur Knorpel; aber cine kleine in diesen Knorpel eindringende unpare Ossification bezeichnet das Os nasale. Bei anderen, wie bei den Salmones ist diese Ossification sehon betrïchtlicher und, je nach Verschiedenheil der Arten, bald ganz cortical, bald tiefer eindringend. Bei Clupea dringt der Vordertheil der Ossification tief in die Knorpelsubstanz, während zwei nach hinten abgehende getrennte Fortsätze cortical sind. - Paarige Nasenbeine sind nur bei wenigen Fischen beobachtet. Solche schliessen sich bei Lepidosteus vorne an die Stimbeine und bedecken oben, wie der Vomer unten, den Canal, in welchem die Geruchsnerven, von dex Schedelhöhle

21) Als Os nasale haben Spix, Bojanus und $\mathbf{A g a s s i z}$ diesen Knochen mit Recht bezeichnet. - Es ist Cuvier's Os ethmoüdeum; II eckel, Bakker, Ge offroy deuten ihn wie Cuvier. 
aus, zu den weit vorwärts gerückten Riechorgancu treten. Bei Esox sind sie ebenfalls vorhanden. Jeder beginnt ein wenig vor dex Nasengrube, noch cinvärts vom $O$ s terminale und erstreckt sich answärts vom $O s$ frontale seiner Seile, als Deckknochen bis zum Vorderende der Schnauze.

Bei einzehen Teleostei erscheint dem Schedelsegmente des Sepım narium noch ein Schuauzentheil vorne angefügt. Bei Manchen kömmt er nicht zu Tage. Dies ist z. B. der Fall bei Cottus, bei Belone, wo ein dem vorderen Schedelende angeschlossener disereter kleiner Knorpel von den Zwischenkiefern bedeckt wird. Bei anderen, wie bei Agonus, finden sich mehre in Stacheln ausgezogene Ossificationen dem Torderende des Schedels angefügt. Bei Malthaea bildet der discrete Schnauzentheil eine beträchtliche freie Vorragung am Schedel. - Bei Esox findet sich kein abgegliederter discreter Schmauzentheil, aber vorne, zu jeder Seite des stark verlïngerten Schedelknorpels, zeight sich eine discrete Ossification, die in die Tiefe des Kuorpels eindringt; sie gehört dem Systeme der Randknochen an, indem das $O s$ palatinum an diese Stelle sich anlegt.

\section{S. 30 .}

Eigenthümliche oberflächliche Gesichtskuochen oder Gesichtspanzerknochen kommen den Ganoïden und den Teleostei in der Regel zu. Sie fehlen selten ganz 1). Bei einigen ist dies System von Knochen blos angedeutet, bei anderen sehr ausgebildet vorhanden.

Bei den Teleostei erseheinen sic gewöhnlich in derjenigen Reihe von Knochen, welche als Ossa nasalia, infraorbilalia, supratemporalia bekannt sind. Der vorderste dieser Knochen: Os terminale ${ }^{2}$ ) liegt als mehr oder minder schuppenförmige Platte oder als Rime oder Röhrchen einvärts von der Nasengrube oder über ihr und reicht bis zum Zwischenkiefer. Bei Bedeckung der Nasengrube bleibt er gewöhnlich unbetheiligt, kamn aber auch eine Art von Dach über dem einwärts gelegenen Theile derselben bilden ${ }^{3}$ ). - An dieses Os terminale schliesst sich melr oder minder unmittelbar der vorderste der Ossa infraorbitalia. Dieser vorderste Infraorbitalknochen, welcher gewöhulich dem durch das $O s$ frontale anterius gebildeten vordersten Augenhöhlenfortsalze eng anliegt, bildet den vordersten Theil eines Unteraugenhöhlenringes, der durch mehre, nach hinten successive anf cinander folgende Ossa infraorbitalia vervollständigt wird, deren hinterster gewöhulich an dem durch das $O s$ frontale posterius gebildeten hinteren Augenhöhlenfortsatze befestigt ist. - Neben den Infraorbitalknochen kom-

1) Unier den Teleostei, bei mehren Pediculati, z. B. Lophius, Chironectes, bei den Plectognathi Gymnodontes und 0straciones.

2) Cuvier's Bezeichnungsweise beizubehalten war nicht müglich, weil sein $O s$ ethmoïdeum als $O$ s nasule erkannt und aufgeführt ist.

3) Z. B. bei llacrodon, Polypterus, Amia. 
men ofl noch eigene Supraorbitalknochen Ossa supraorbitalia vor ${ }^{4}$ ). - Die Infraorbiallsnochen, gew uhnlieh in der Zahl vou vier vorhanden, bieten rücksichtlich ihres näheren Verhaltens sehr grosse Versehiedenheiten dar. Oft stellen sie einen schmalen, die Augenhöhle unten und seitlich begrenzenden Bogen dar. Bisweilen erlaugt einer derselben cinen beträehtlichen Umfang ${ }^{5}$ ). Bei anderen Teleostei mehre derselben. So bilden z. B. bei Macrodon die hinteren Infraorbitalknochen eine breite Platte, welehe, wie ein äusserer Gesichtspanzer, den Gaumen-Apparat und das Kiefersuspensorium auswärts bedeckt. Bei manchen Teleostei wird der Infraorbitalring durch einen absteigenden Knochen mit dem Praeoperculum verbunden, wie z. B. bei Cottus. Bei den Triglae kömint eine Verwachsung ihres ventralen Randes mit den Praeoperoulum zu Stande und sie breiten auch vor der Augenhöhle schildförmig sich aus. Auf diese Weise bilden sie einen sehr vollständigen äusseren Gesichtspanzer. Bei einigen Teleostei verlängeru sie sich einwärts in die Augenhöhlen und bilden einen unvollstïndigeu Augenhöhlenboden ${ }^{6}$ ). - Andererseits könneu sie ihre Verbindung mit dem Os fronlale posterius aufgeben, wie 7. B. bei Pterois volitans, bei $\mathrm{Li}$ paris, wo, von der Mitte des Praeoperculum aus, eine aus zwei Knochen

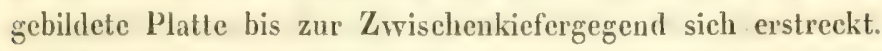

Fast beständig schliessen mehr oder minder unmittelbar an den hintersten Infraorbilalknochen ein oder mehre Knochen sich an, welche, der Reihe der vorderen im Ganzen conform gebildet, den in der Schläfengegend gelegenen Randlinochen, namentlich dem Os frontale posterius und dem Os mastoüdeum auf- und anliegen und selbst über die obersten Glieder des Schultergürtels sich fortselzen. Diese Knochen sind, wegen ihrer bezeichneten lagge, als Ossa supratemporalia ${ }^{7}$ ) und die letzten derselben, in so ferne sie die Zinken des Schultergürtels betlecken, als Ossa extrascapu. laria bezeichnet worden ${ }^{8}$ ):

Alle genannten Knochen kömnen ihre platte Form anfgeben und durch Röhren und Ilohlräune vertreten werden, die bestimmt sind zur Anfnahme peripherischer Nervenkuäucl. Enge Röhren kommen z. B. vor bei

4) Z. B. einer bei Cyprinus nach aussen "vom Os frontule principale, der vorwärts auch an das $O$ s frontale anterius stosst.

5) Z. B. bei Callionymus lyra der vorderste.

6) Bei Normyrus erstreckt sich von der Circumferenz der Ossa infraorbitalia eine fibröse Membran in die Orbitu, welche einen sehr scharf begrenzten Boden derselben bildet und ihr eine trichterförmige Gestalt verleihet. Ein unvollkommener knöcherner Augenhöhlenboden findet sich z. B. bei Uranoscopus.

7) Diese Bezeichnung hat Bakker ilhen zuerst gegeben.

8) Ich habe sie früher Ossa suprascapularia genannt, aber, um einer Verwechselung mit so benannten Elementen des Schultergärtels vorzubeugen, die Bezeichnung geändert. 
Silurus glanis; weite Hohlräume bei den Gadoïden ${ }^{9}$ ), bei den Sciänoïlen ${ }^{10}$ ), bei Acerina cernua u. A.

Sehr entwickelt erscheinen die oberflächlichen Gesichtsknochen bei den Ganoüdei, mit Ausnahme von Spatularia, wo sie ganz aborliv sind. Bei Lepidosteus bilden sie, mosaikartig an cinander gefügt, nicht nur eineu oberflächlichen Panzer über der ganzen Schläfengegend, sondern setzen auch über und unter der Augenhöhle, so wic vor derselben ziemlich weit vorwärts sich fort. Bei Polypterus verläuft eine Reihe solcher Knochen quer über der Hinterhauptsgegend und erstreckt sich dann jederseits oberhalb des Kicmendeckelapparates und der Schläfengegend, das Spritzloch bedeckeud, zur hinteren Grenze der Augenhöhle hin und vou hier aus weiter vorwärts. Eine vom Praeoperculum aufsteigende Knochendecke ergänzt den äusscren Panzer. Bei Aceipenser und bei Amia verhailt sich ihr Verlauf wesentlich, wie bei den 'Teleostei.

Bei vielen, aber nicht bei allen Fischen (z. B. anscheinend nicht bei Lepidosteus, bei IIypostoma) enthalten diese Kuochen ein System von Rinnen und Canälen, mehr oder minder aualog denen, die die Schuppen der Seitenlinie des Rumpfes vor anderen Schuppen auszeichnen. Dabei können sie aber doch cinen mehr oder minder vollständigen Hautpanzer bilden.

Bei anderen Fischen bilden sie nur noch ein System von solchen Rinnen und Canälen und verlieren fast jeden Antheil an der Formation eines äusseren Panzers.

Unter allen Verhältnissen erscheinen diese Knochen als ein System vou Hartgebilden, welche der Haut angehören. Bald sind sie Glieder eines den ganzen Kopf oberflächlich überzichenden Hantpanzers; bald sind sie ausschliesslich Glieder eines der llaut angehörigen, aber selbstständig gewordenen Systemes von Hartgebilden, die die Bestimmung haben, peripherische Hautnerven aufzumehmen und zu stïtzen. Unter beiden Bedingungen erstrecken sich ihre Fortsetzungen auch über typische Schedel- und Gesichtsknochen.

1. Sie sind Glieder eines den ganzen Kopf oberflïchlich überziehenden IIautpanzers. An den Schedeln der genannten Ganoïden, so wie auch mancher Teleostei, z. B. der Triglae, der Loricarinen, der Syngnathi, ciniger Siluroïden erkeunt man leicht, dass sie Fortsetzungen ciner corticalen Ossificationsschicht sind, welche auch die sämmtlichen typischen Schedelund Gesichlsknochen auswendig überzieht. I)iese letztere findet gewöhn-

9) Besonders ausgezeichnet ist die Bildung bei Lepidoleprus.

10) Albildungen davon finden sich bei Cuvier u. Valenciennes, Hist. nat. des poiss. Tb. 140. Sie stellen weite IJ̈̈hlen dar, die nach aussen theils durch zierliche Knochenbrücken überspannt, theils häutig geschlossen werden. Nach Valenciennes (Hist. nat. des poiss. T. XIX, p. 279.) sollen diese Knochen bei einigen Mormyri, ähnlich wie bei den Sciänoiden ausgehohlt sein; so namentlich bei M. bane. 
lich Wiederhohlungen und Fortsetzungen in Ossificationen, welche die Rumpfgegend bedecken und entschieden der Cutis angehören. Sie sind demnach diejenigẹ Glieder eines den ganzen Kopf überziehenden IIautpanzers, welche die von typischen Schedel- und Gesichtsknochen entblüssten Kopfstellen bekleiden. Charakteristisch ist der Umstand, dass sie als selbstständige Knochen solehen Fischen spurlos fehlen, bei denen ein äusserer zusammenhangender Hautknochenpanzer die unterliegenden Kopfknochen, so wie deren freie Interstitien, ohne dass eine eigentliche Verwachsung Statt fände, loser umhïllt, wie bei Diodon und den Ostraciones.

2. Sie sind ausschliesslich Glieder eines selbststïndigen, aber der Haut angehörigen Systemes von Hartgebilden, die häufig und vielleicht immer zur Aufnahme von peripherischen Hautnerven bestimmt sind; also Glieder cines Hautnervenskeletes. So erscheinen sie z. B. bei den Aalen, bei den Gadoïden, bei einigen Siluroïden. Sie setzen bei diesen Fischen, nament. lich bei vielen Repräsentanten der erstgenannten Gruppen, sich fort in ein System von Knochen, das längs dem Rumpfe sich hinzieht und dem näm. lichen $\left.Z_{\text {wecke dient }}{ }^{1}\right)$. Wie aber diejenigen Knochen, welche als abgelösete Glieder eines zusammenhangenden Kopfhautpanzers erscheinen, über die Schedel- und Gesichtsknochen sich fortsetzen, so auch diese Glicder des Hautnervenskeletes. Bei den Aalen finden sich über den Schedel und in Gesichtsknochen for'gesetzte Röhren; bei den Garlö̈en sind ihnen analoge Schuppen den Schedel- und Gesichtsknochen eng aufgesetzt 12). - Was speciel ihre Beziehungen zur Iaut anbetrifft, so liegen sie in eincr aponeurotischen, fibrösen Schicht, die stellenweise von der Cutis getrennt ist, aber weiterhin ganz allmälich in sie übergeht.

3. Sie combiniren meistens beide Bestimmungen, bilden einen mehr oder minder vollständigen Gesichtspanzer und zugleich ein peripherisches IIautnervenskelet, verhalten sich demnach analog den Schuppen der Seitenlinie, welche gleichfalls beide Bestimmungen erfüllen und in die sie nach hinten unmittelbar sich fortsetzen. In dieser Art der Verwendung finden sie sich bei der Mehrzahl der Teleostei.

Analoge Glieder cines Kopfhautpanzers, die die Augenhöhlen ungürten, kehren in anderen Thierclassen wieder; dahin gehören z. B. die Supraorbitalknochen der Crocodile, der Eidechsen. - Auscheinend ist auch die Gruppirung dieser Knochen um die Augenhöhle der Ausdruck eincs allgemeineren architektonischen Planes, den dic Natur in den verschiede-

11) Diese Fortsetzung längs dẹn Rumpfe unter Gestalt einer eigenen linochenreihe kömmt auch bei solchen Fischen vor, wo die Gesichtsknochen zugleich plattenfürmig verbreitert sind, wie bei Cottus scorpius. Auch bei einer Synanceia habe ich diese Knochen am Rumpfe gefunden.

12) Unter den Gadoïden ist besonders instructiv der Schedel von Raniceps fuscus. 
nen Thierelassen hier und da, unter Verwendung rersehiedener Elemente, ausführt.

\section{\$. 31 .}

Das Kiefersuspensorium der Ganoïdei holostei und der Teleostei ein Complex von Elementen der beiden vordersten Visceralbogen und ron Gesichtsknochen - erstreckt sich von der Schläfengegend des Schedels, welcher er beweglich eingelenkt zu sein pflegt, in einem meist weiten Bogen bis zu dem, ihm durch Gelenk verbundenen Unterkiefer und steht zugleich mit den Gaumenkuochen in Verbiudung. Das Zungenbein haftet. an ihm und es dient dem Opercular-Apparate zur Stütze. Abgesehen von den beiden unzweifelhaft dem Gaumen-Apparate angehörigen Knochen: dem Os pterygoiddeum und palatinum, ist hei den meisten Teleostei der Knochencomplex des Suspensorium aus sechs discreten Ossificationen zusammengesetzt.

Das eben angedentete gewöhnliche Verhältniss erfähnt jedoch bisweilen bedentende Abweichungen, begründet in der Vereinfachung des ganzen $A_{p}$ parates unter gleichzeitigem Hangel der Gaumenkuochen, wie dies z. B. bei Muraenophis hervortritt.

Die das Kiefersuspensorium gewöhnlich zusammensetzenden Knochen sind: 1. das die Verbindung mit dem Schedel bewirkende Os temporale Cuv.; 2. cine stabförmige, meistens clwas einwïrts gelegene Verlängermug desselben: das Os symplerlicum Cuv.; 3. das das Gelenlistïck des Unterkiefers gewöhnlich allein aufnehmende Os quadrato-jugale, Os jugale Cuv.; 4. das dem Aussenrande des Os temporale und quadrato-jugale angefügte Praeoperculum; 5. das Os tympanicum Cuv., welehes eine Verbindung zwischen dem Os temporale, Os quadrato-jugale und Os plerygoödenm bewirkt; 6. cin Randknochen des Os pterygö̈deum: das Os transversum Cuv. ${ }^{1}$ )

Das Os temporale ${ }^{2}$ ) ist meistens beweglich und nur bei den Familien der Plectognathi unbeweglich mit dem Schedel verbunden. In ersterem Falle greift es gewöhnlich mit doppeltem Gelenkkopfe in zwrei der Schläfengegend angehörige, durch das Os mastoideum und Os frontale posterius gebildete Gelenkgruben ein. Bei cinzelnen Teleostei sind in dem Os temporale zwei durch dümere Knochensubstanz vereinigle dieliere Knochenleisten zu erkennen ${ }^{3}$ ). - Am oberen Theile seines Ilinterrandes be-

1) Bei Mormyrus, wo, nach anderen Angaben, die Zahl der Knochenstücke verringert sein soll, finde ich sie sämmtlich; die Anheftung des ein sehr vollständiges Gewölbe bildenden $\Lambda$ pparates am Schedel ist aber inniger als sonst und gestattet weniger freie Bewegung.

2) Os temporale Cuv., Os quadratum Bojanus, Os mastoïdeum Agassiz. Vgl. \$. 16. - Einen eigenthïmlichen inwendigen Vorsprung besitzt es bei Ophicephalus; cr steht in Beziehung zu den accessorischen Respirationsorganen der Schlundkiefer.

3) Z. B. bei Batrachus surinamensis. 
sitzt es einen gewölunlich runden Gelenkikopf, bestimmt zur Einlenkung des Operculum, des obersten Stückes des Kiemendeckels. Nur selten liegt dieser Gelenkkopf tiefer abwärts, wie z. B. bei Muraenophis.

Eine stahförmige untere Verlängerung des $O$ s temporale ist bei jungen Thieren knorpelig, bei ilteren ganz oder theilweise ossificirt, durch Zwischenknorpel von ihm gesondert und darum als eigener Kuchen: Os symplecticum ${ }^{4}$ ) erscheinend. Dicht neben der Stelle, wo das Os symplecticum vom Os temporale sich abscheidet, liegt das oberste Stück des Zungenbeinbogens: das Os slyloüdeum an letzterem Kuochen, der also anfangs die gemeinsame Grundlage zweicr Visceralbogen sebildet hatte, die an diesem Punkte sich treunen. - Nur bei wenigen der hier abzuhandelnden Fische, unter denen Amia und Lepidosteus hervorzuheben sind, erstreckt sich das $O$ s symplecticum bis zum Unterkiefer und bildet einen eigenen Gelenkkopf für seine Aufnahme, so dass also hier das Os arliculare des Unterkiefers zwei Gelcnkwerbindungen eingeht: eine mit dem Os sympleclicum und die andere mit dem Os quadrato-jugale. - Meistens erstreckt sich das Os symplecticum einwïrts vom Praeoperculum nach vorne und cudet unterhalb des Os quadrato-jugale; dann aber lässt sich oft ein Faserband von seinem Ende bis an das Os articulare, denjenigen Knochen des Unterkiefers, ans dessen Substanz heraus der Meckel'sche Knorpel sich fortsetzt, verfolgen. Die genaunten Verhailtnisse charakterisiren das $\boldsymbol{O} s$ sympleclicum als obere Fortsetzung des Unterkieferknozpels, als Sehlïfentheil des Meckel'schen Knorpels. - Ein Mangel des Os symplecticum, unter Anwesenheit des Unterkieferknorpels, lë̈mmt bei erwachsenen Telcostei selten vor; er ist beobachtet worden bei vielen Siluroüden und Loricarinen.

Das Praeoperculum lehnt sich meist lose und elwas beweglich an den Aussenrand des Os temporale und Os quadrato-jugale. Seltencr, wie z. B. bei den Siluroïlen, den Plectognathi Gymnodontes u. $\Lambda$. ist es demselben ganz imigg und unbeweglich verbunden. Sein vorderes Ende crreicht fast immer das Unterkiefergelenk. Ls enthält in der Regel einen bogenförmig zum Unterkiefer hin sich erstreckenden IIauptarm der Knochenrinnen oder Knochenschuppen des Seitencanalsystemes. Eine solehe Reihe von Knochenrinnen kam das Os temporale an seinem Aussenrande begleiten, ohne dass ihn ein entwickeltes Praeoperculum angefügl wäre, wie dies z. B. bei Muraenophis der Fall ist.

Nicht selten verlängern sich die Ossa infraorbilalia abwärts in einem mit dem Ausscurande des Praeoperculum auf das Imnigste rerbundenen Knochenpanzer, der daun schildartig über den Schläfenmuskel wegseht. Das Pracoperculum gehört zu denjenigen Knochen die besonders häufig in

4) Tympano-malléal Agassiz. 
harte, stachelförmige, nach der freien Oberfläche des Körpers gerichtete Fortsätze auslaufen.

Das dem Os temporale unten sich anschliessende Os quadratojugale ${ }^{5}$ ), durchaus bestïndig in seinem Vorkommen, nimmt das Unterkiefergelenk auf und entspricht, nach Lage und Function, dem gleichnamigen Kuochen der Reptilien und Vögel. - Ein dem wirklichen Os jugale entsprechendes, von ihm zum Oberkiefer gelangendes discretes Knochenelement scheiut den Fischen allgemein zu fehlen; indessen hangt der Oberkiefer bisweilen z. B. bei Muraenophis dureh ein starkes Ligament mit dem hier selr kleinen Os quadrato-jugale zusammen.

Das Os tympanicum, eine meist dünne, platte Ossification, welche eine Verbindung des Os temporale mit dem Os pterygoiddeum bewirkt, das Gaunnengewölbe erweitert und dem Schliifemmuskel breitere Grundlage gewährt, ist der am häufigsten fehlende Bestandtheil dieses Knochenapparates.

Das Os transversum Cuv. ${ }^{6}$ ) s. pterygoödeum externum ist cin gewöhnlich von der vordersten Grenze oder dem Vordertheile des os quadralo-jugale ausgehender, nach der Oberkiefergegend hin vorwärts gerichteter Randknochen des Os plerygoüdeum. Cuvier's Vergleichung desselben mit dem Os transversum der Reptilien hat Anstoss gegeben, weil letzteres ein Verbindungsglied zwischen dem Os pterygödeum und dem Oberkiefer darstellt und das Os transversum in solcher Function bei den Fischen nicht bekannt war. Indessen findet sich bei Macrodon taraira, die Stelle des Os transversum der übrigen Teleostei vertretend, ein vou der Verbindungsstelle des Os pleryggideum und palalinum ausgehender, quer auswärts serichteter, mit dem Oberkiefer ganz eng verbundener Knochen, welcher also auf das Entschiedenste dem $O s$ transversum der Reptilien entspricht. \$. 32.

Ein eigener knöcherner Gaumen-Apparat fehlt selten. Er wird z. B. vermisst bei der Gattung Muraenophis, unter gleichzeitiger Verkümmerung des grössten Theiles des Visceralskeletes. - Den Gaumen-Apparat bilden gewöhnlich zwei parige Knochen: die Ossa pterygö̈dea und palatina. Jene sind weiter hinterwïrts, diese, an sie sich anschliessend, ganz vorne unter dem Schedel gelegen. Die paarigen Knochen beider Seiten werden durch den zwischenliegenden $\boldsymbol{V}$ omer und einen Theil des $\boldsymbol{O} s$ sphenoïdeum basilare getrennt. Ihre Verbindung mit dem Kiefersuspensorium wird hinten gewöhnlich durch das zwischen dem Os pterygö̈deum

5) Os jugale Cuvier, Os quadratum Agassiz. - Nüller hat das Verdienst, diesen Knochen dem Os quadrato-jugale vicler Reptilien und der Vögel verglichen zil hahen.

6) La caisse Agassis, Pterygoïdeum posterius Hallmann, Bojanus. 
und temporale gelegene Os tympanicum vermittelt; vorne begrenzt das $O s$ pterygoüdeum gewöhnlich das Os quadrato-jugale; nach aussen vom $O_{s}$ plerygoiddeum liegt das Os transversum. - Das Os palatinum ist vorne gewöhnlich an dem Os frontale anterius, häufig auch an lem Vomer befestigt. - Beide Knochen des Gaumen-Apparates sind gewöhnlich Zahntragend.

\section{\$. 33 .}

Der Unterkiefer articulirt meistens nur mit dem Os quadrato-jugale; selten wie bei Amia, Lepidosteus, besitzt er zwei Gelenkvertiefungen, von denen die eine zur Verbindung mit dem genannten Knochen, die andere dagegen zur Einlenkung an dem Os sympleclicum bestimmt ist. Er besteht aus zwei convergirenden und in der vorderen Mittellinie in sehr verschiedenem Grade der Innigkeit verbundenen Bogenschenkeln. Jeder Schenkel wird, mit seltenen Ausnahmen, mindestens aus zwei Knochen zusammengesetzt. Diese sind: 1. das dem Os quadrato-jugale beweglich cingelenkte Gelenkstïck: Os arliculare und 2. das den beträchtlichsten Theil des Unterkiefers bildende, in der vorderen Mittellinie mit dem gleichnamigen Knochen der entgegengesetzten Seite verbundene, gewöhnlich Zahntragende $O s$ dentale. Das $O s$ articulare zeichnet gewöhnlich durch beIrächtlichere Dicke vor dem zweiten Knochen sich aus. Von seiner Substanz aus erstreckt sich inwendig, als deren unmittelbare Fortsetzung, der Meckel'sche Knorpel 1) längs der Innenfläche des ganzen $O s$ dentale bis zur vorderen Mittellinie. Das Os dentale, von beträchtlicherem Umfange, als das vorige Stück, erseheint als äussere Schale, als Belegungsknochen des Meckel'schen Knorpels. - Bisweilen bildet er eine IIöhle, indem sein Knochenblatt nach innen sich umkrempt.

Die Aussenfläche des Os dentale ist oft mit denselben kleiven Knochenrinnen besetzt, wie das Praeoperculum, indem der Arm des Seitencanales der längs dem Praeoperculum sich erstreckt, über der ganzen Aussenfläche des Unterkiefers, der Länge nach, bis vorn sich fortzusetzen pflegt.

Bei den meisten Teleostei kömmt eine Vermehrung der Zahl der den Unterkiefer zusammensetzenden Knochenslïcke vor. Es liegt nämlich gewöhnlich unterhalb des $O$ s articulare, aber an der Anssenflïche des Unterkiefers erkennbar, cin liteines Eckstück: Os angulare, das sowol mit dem Os arliculare, als mit dem Os dentale verbunden ist. An diesem Knochen pflegt das Interoperculum mit seinem vordersten Ende entweder durch Bandmasse angeheftet zu sein oder es articulirt selbst mit ihm durch eine Gelenkverbindung. - - Ein anderes, seltener vorkommentes Knochenstück ist das Os operculare, an der Innenseite des Os articulare gelegen.

1) Der Knorpel kann auch streckenweise ossificiren, wie ich dies z, B, bei Caranx trachurus sehe. - 
Bei Lepidosteus und Osteoglossum 2) steigert sich die Anzahl der jeden Unterkieferschenkel zusammensetzenden Knochenstücke auf sechs, indem für die Gegend des Processus coronoüdeus noch zwei accessorische Knochen hinzukommen: das auswendig gelegene Os supraangulare und ein inneres Deckstück : das Os complementare. Noch grösser wird ihre Anzahl bei Amia, indem nicht nur die eben aufgezählten Knochenstücke vorhanden sind, sondern auch das die Innenwand des Unterkieferkanales bildende und oben die Reihen kleiner inwendig stehender Zähne tragende beträchtliche Os operculare vorne durch vier kleine zahntragende Knochenstücke fortgeselzt wird.

Der Unterkiefer, in seinen Formverhältnissen ausserordentlich variirend, besitzt häufig einen eigenen Processus coronoïdeus ${ }^{3}$ ).

An seiner Aussenfläche befestigt sich häufig cin eigener Mundwin. kelknorpel ${ }^{4}$ ), der bogenförmig zum Oberkiefer-Apparate hinaufreicht und selten einem eigenen oberen Knorpel dersclben Art entspricht. Er unterstïtzt auswendig die zwischen dem Oberkiefer-Apparate und dem Unterkiefer gelegene Mundwinkelhaut oder Falte.

Bei einigen Fischen trägt der Unterkiefer a ce ssorisehe Knochen. So ist jedem Seitenschenkel desselben bei Polypterus eine kiemendechelartige Knochenplalte angefïgt, welche den Zwischenram zwischen beiden Unterkieferschenkeln auswendig bedecken. Bei Amia geht eine unpaare mediane Kuochenplatte, analoger Function, von dem Vereinigungswinhel der beiden Unterkieferschenkel ab.

Ein unpaarer Knochen, der bei Megalops und Elops ron derselben Stclle abgeht, wiederholt für den Unterkiefer, indem er tiefer gelegen ist, den Kiel des Zungenbeines.

\section{\$. 34 .}

Der Oberkiefer-Apparat, bestehend aus dem Oberkiefer (Maxilla superior) und dem $\mathrm{Z}$ wisehenliefer (Os intermaxillare), begrenzt den oberen Rand des Einganges in die Mundhöhle. Die gegenseitigen Lagen- und Verbindungs-Verhältnisse der beiden genannten, meist paarigen Knochen zeigen sich sehr verschieden. Einigen Teleostei z. B. den Plectognathi Gymnodontes, der Gattung Scrrasalmo u. A. kömmt cine innige ausgedehnte Verbindung und Versehmelzung des Zwischenkiefers, der aber nur bei Diodon unpaar ist, mit den Oberkieferstücken zu.

Bei der Mehrzahl der Teleostei, namentlich bei den Acanthopteri, den

2) Bei letztgenanntem Fische nach Müller's Angabe.

3) Derselbe ist z. B. stark bei Mormyrus, Cyprinus u. A.

4) Z. B. bei Polypterus, Megalops, Gadus, Chironectes, Cyclopterus, Caranx, Zeus, Ophicephalus, Fistularia und vielen Anderen. Es sind diese Ilundwinkelknorpel, worauf bereits $M$ iiller, der sie bei Trigla zuerst auffand, aufmerksam gemacht hat, Analoga derjenigen der Plagiostomen. 
Anacanthini, den Pharyngognathi acanthopteri, den Cyprinoïdei, den Cyprinodontes, den Scopelini, den Symbranchii, bei Syngnathus liegen die beiden Elemente des Oberkiefer-Apparates so hinter einander, dass der Zwischenkiefer den ganzen äusseren Kieferrand bildet und der Oberkiefer einen hinter ihm gelegenen, ilm parallelen, ihn auswärts jedoch nicht überragenden Bogen darstellt. - Bei anderen Fischen z. B. bei Macrodon ${ }^{1}$ ) ist diese Anordnung so modificirt, dass der Oberkiefer nur eine kurze Strecke weit hinter dem Zwischenkiefer liegl, alsbald aber an den nur kurzen und wenig nach aussen verlängerten Zwischenkiefer herantritt um, seinen Bogen verlängernd, mit ihm den Aussenrand des Maules zu bilden. - Bei anderen Gruppen z. B. den Ganoïdei holostei, bei Esox, den Salmones, den Clupeïdae, bei Gymnotus, Muraenophis u. A. fehlt der hinter dem Zwischenkicfer und ihm parallel laufende Abschnitt des Oberkiefers. Letzterer schliesst an den äusseren Rand des Zwischenkiefers sich an und bildet mit ihn cinen gemeinsamen Bogenschenkel zur äusseren Begrenzung des Maules. - Bei einigen Gruppen, z. B. den Siluroïden, den Loricarinen, bildet der Zwischenkiefer deshalb die Begrenzung des Maules, weil der Oberkiefer ganz abortiv ist.

Wenn die beiden Bogen cinander parallel laufen, kömmt beiden, vorzugsweise aber dem Z $\mathbf{w i s c h e n k i e f e r , ~ m e i s t e n s ~ e i n e ~ g r o s s e ~ F r e i b e w e g l i c h k e i t ~}$ zu. Jeder Schenkel des Zwischenkieferbogens besitzt dann yुewöhnlich einen anfsteigenden $A$ st, welcher mit dem Schedel durch elastische Bänder verbunden zu sein pflegt ${ }^{2}$ ). Die Länge dieses aufsteigenden Astes und versehiedentlich getroffene mechanische Einrichtungen gestatten manchen Fischen, z. B. den Labrö̈den, den Cyprinodonten, das Maul stark ror"zustrecken. - Die Freibeweglichkeil des Zwischenkiefers wird aber bedeutend beschräukt oder aufgehoben, wemn seine beiden Hälften in grösserer Ausdehnung, sei es durch feste Bandmasse, wie z. B. bei Cybium, sei es durch in einander greifende Kuochenzacken, wie bei Belone, mit einander verbunden werden. Sie fïllt chenfalls dann weg; wenn der Zwischenkicfer dem Vorderende des Schedels durch Naht fest rerbunden ist, wie z. B. bei den Ganö̈dei holostei, hei Maerodon, bei Muraenophis, - Bei einigen Fischen bildet der stark verlingerte Zwischenkiefer den Sehnabel, wie bei Belone, oder das Sehwert, wie bei Xiphias ${ }^{3}$ ). - Bei mauchen Fischen

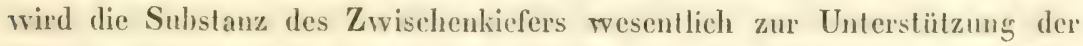
Nasengruben mil rerwendet, wie z. B. bei den Ganoüdei holostei, bei Mnracnophis.

1) Aehnlich bei den verwandten Gattungen: Tetragonopterus, Anodus u. A.

2) Interessant ist unter vielen anderen z. B. die mechanische Einrichtung bei Callionymus lyra, wo die enorm langen aufsteigenden Zwischenkieferäste unter einer häutigen und einer ossificirten Brïcke hingleiten.

3) Abgebildet bei Cuvier u, Valenc. Tb. 231. Vgl, Vol. VIII. p. 266. 
Was die Zusammensetzung des Zwischenkiefers anbetrifft, so besteht er meistens aus zwei discreten Seitenschenkeln; selten sind diese zu einem unpaaren Stücke verschmolzen, wie z. B. bei Diodon und bei Mormyrus.

Jeder Oberkieferschenkel besteht bald aus einem einzigen Stïcke, bald tragen mehre ${ }^{4}$ ) oder selbst sehr viele discrete Ossificationen zu seiner Bildung bei. Das merkwürdigste Beispiel der letzteren Art bietet Lepidosteus dar, wo jeder Schenkel des sehr langen zahntragenden Oberkiefers aus zahlreichen an einander gereiheten Knochenstücken besteht.

Während der Oberkiefer meist von beträchtlichem Umfange ist, erscheint er bei einigen Fischen z. B. bei Belone im Vergleiche zum Zwischenkiefer sehr klein und bei Auderen z. B. den Silnroïden, den Loricarinen, ganz reducirt, oder fehlt, wic beim Aal. - Der Oberkiefer ist häufig dem Vomer, den Ossa frontalia anteriora und auch den Gaumenbeinen in verschiedenem Grade der Innigkeit verbunden ${ }^{5}$ ).

\section{Vom Skelet des Respirations-Apparates.}

\section{\$. 35 .}

Die Skeleltheile, welche zu dem Respirations-Apparate der Fische in cngere Beziehung treten, orduen sich in zwei Gruppen. Die der einen Gruppe angehörigen Theile bilden eine unmittelbare Umschliessung desjenigen Segmentes des Darmrohres, welches von den engeren oder weiteren Pori branchiales interni durchbrochen ist, und dienen gewöhnlich den Kiemenblattreihen zur mittelbaren Stütze und Grundlage. Sie constituiren das innere Skelet des Respirations-Apparates, das, mit Ausnahme der Marsipobranchii, allgemein entwickelt ist. - Die in der anderen Gruppe zu vereinigenden Theile bilden blos äussere Stützen oder Bedeckungen der von den Kiemen eiugenommenen Höllen und constituireu das äussere Skelet des Respirations-Apparates. Sie erscheinen nach zwei Richtungen hin entwickelt: entweder als solide Stützen der zwischen den einzelnen Kiemensäcken und zwischen den Pori branchiales externi bis zur äusseren Haut sich erhebenden Brücken, wie bei den Marsipobranchii hyperoartii und den Squalidae, bei welehen Thieren sie zu den Kiemenhöhlen ähulich sich verhalten, wie Rippen zur Rumpfhöhle; oder als äussere meist von Theilen des Kiefersuspeusorium ausgehende Deckplatten der gemein-

4) Z. B. bei Esox, bei vielen Clupeìden (Clupea, Alosa, Mlegalops, Butirinus u. A.) Salmones: (Salmo, Coregonus), manchen Scomberoìden (Caranx, Cybium, Vomer, Argyreiosus u. A.) manchen Percoïden (Myripristis, Ilolocentrum, Serranus, Plectropoma). Man hat diese Knochen als Ossa supramaxillaria bezeichnet.

5) Ein eigenthümliches Verhalten schildert Valenciennes bei Chirocentrus. Hist. nat. des, poiss. Vol. XIX. p. 154. 
samen Kiemenhöhle, wie in dem Opercularapparate der Ganoïdei, Teleostei, wo sie die Elemente des Opercularapparates bilden.

[Ueber das Skelet des Respirations-Apparates vergleiche man: Geoffroy Sain Ililaire, Philosophie anatomique. T. I. Paris, 1818. 8. - Duvernoy in Cuvier Leçons d'Anat. compar. 2. édit. T. VII. p. 220 sqq. - Rathke, Anat. philos. Untersuchungen über den Kiemen-Apparat und das Zungenlıein der Wirbelthiere. Riga, 1832. 4.]

A. Vom äusseren Skelet des Respirations-Apparates.

S. 36 .

Dasselbe ist am vollkommensten ausgebildet bei Petromyzon und Ammocoetes.

Bei Petromyzon 1) setzt eine dorsale fibröse Decke des Herzbentels in das hintere Ende eines ïusseren knorpeligen Kiemenkorbes sich fort, der zuerst hinten, seitwärts und unten eine zur Aufnahme des Herzens bestimmte Capsel bildet. Indem dieser knorpelige Kiemenkorb vom Herzen aus vorwärts sich verlängert, bildet er ein oben jederseits mit der Wirbelsäule zusammenhangendes, an der ventralen Seite durch ein ununterbrochenes Sternum geschlossenes Gilterwerk, welches mit dem Wirbelrohr, die Aorta, die Speiseröhre, den Bronchus, die Kiemensäcke, die Kiemenarterie und mehre Muskeln einschliesst. Dieser äussere Kiemenkorb wird, mit Ausnahme der Pori branchiales externi, von absteigenden Fortsetzungen der Rumpfmuskeln auswendig bedeckt.

Die Anordnung der knorpeligen Elemente dieses Kiemenkorbes ist wesentlich folgende:

Von der den Herzbentel unten und seillich umschliessenden Knorpelcapsel treten jederseits 4 Knorpelleisten vorwärts, welche durch eine Querleiste verbunden werden. Diese zwischen den Insertionsstellen zweier Knorpelleisten ausgeschweifte und daher unregelmässig gestaltete Querleiste ist nach aussen und oben am Wirbelrohre befestigt; nach innen und unten stosst sie mit der der enlgegengesetzten Seite in einem medianen Brustbeinartigen Knorpel zusammen. Solcher Systeme von unregelmässig gestalteten Querleisten, welehe oben an der Axe des Wirbelsystemes befestigt sind und an der Veutralscite in einem ununterbrochenen langen Sternum zusammenstossen, gibt es sieben, oder, mit Einschluss der vordersten, die einerseits dem Gaumenbogen des Schedels und andererseits

1) Abbildungen dieses Apparates geben Rathke, Müller in den citirten Schriften; Mayer, Analecten f. vergl. Anatomic. Bonn, 1835. 4. Tb. 1. - Carus und 0 tto, Erläuterungstfln. z. vgl. Anat. Hft. 7. Tb. \&. Bei Ammocoetes ist, wie bereits Rathke (Ueber den Bau des Querders) Schrift. d. naturf. Gesells, zu Danzig. Bd. 4. angegeben (Seite 71. Tb. 3. Fig 15.) derselbe im Ganzen ählich gebildet, doch fehlt die Knorpelcapsel um das IIerz. 
mit dem Stemum verbunden ist, acht. Jede der sieben eigentlichen Querleisten wird mit der ihr zunïchst liegenden durch zwei unregelmässig ausgeschweifte linorpelige Längscommissuren verbunden. Der von letzteren, in Gemeinschaft mit ersteren umsehricbene Raum dient zum Theil zur Umschliessung der Spiracula extema des Kiemensystemes. Ausser diesen Lüngscommissuren ragen von jeder Querleiste aus noch einige hakenförmige freie Fortsätze in das zwei Querleisten trennende Interstitium hinein.

Bei den Squalidae ${ }^{2}$ ) erstrecken, sich jederseits in die Interstitien der Kiemenspalten Knorpelstreifen; bald finden sich dorsale und ventrale Streifen, bald nur letztere; diese gehen aus von der unteren Seite der Copulae der Kiemenbogen, denen sie bisweilen durch Ligament angeheftel sind mol erstrecken sich durch das Muskelfleisch nach aussen. Ihre Formen sind mannichfach; sie finden sich bei manchen Haien nicht zwischen den Interstitien aller Kiemenspalten.

\section{\$. 37.}

Der Apparat von Kiemendeckelkuochen, welcher den Dipuoi ${ }^{1}$, Ganoïdei und Teleoslei eigenthümlich ist, lat, sobald er nicht blos abortiv erscheint, gleich den ihn nahe verwandten Radii branchioslegi, die physiologische Bestimmung eine änssere bewegliche Bedeckung der Kiemenhöhle zu bewirken. Dic Kiemendeckelknochen erscheinen meist dem Kiefersuspensorium und dem Unterkiefer verbunden; künnen aber auch ohne solche feste Anhaltspunkte vorkommen, wie dies bei Accipenser der Fall ist.

Der Apparat der Kiemendeckelknochen besteht in der Regel aus drei discreten Elementen, von denen das oberste als Operculum, das mittlere als Suboperculum und das dritte, von der Unterkieferecke ausgehende, als Interoperculum bezeichnet wird.

Bei Accipenser bleiben drei, der Lage und Fumetion nach, ihnen durchaus entsprechende Ossificationen ganz ausser Verbindung mit dem Kiefersuspensorimm und dem Unterkiefer, stecken vielmehr in der Cutis. Bei Spatularia ist ein einziger Kiemendeckellinochen am Os temporale befestigt, der durch Ilautausbreitung nit der Platte der vom Zungenbeine ausgehenden Radii branchiostegi znsammenhangt. Sonst ist allgemein das Operculum einem rom Os temporale ausgुehenden Gelenkikopfe, und zwar gewöhnlich sehr beweglich, angefügt. Ihm schliesst abwärts das meistens kleinere ${ }^{2}$ ), eigener Gelenkverbindung crmangelnde Suboperculum sich an,

2) S. eine Abb. bei Rathke, Untersuch, über d. Zungenbein - und Kiemenbogen-Apparat. Tb, 2. 3.

1) Rhinocryptis besitzt zwei Opercularstücke, von welchen eines dem Kiefersuspensorium, das andere dem Zungenbeine, als Repräsentant der Radii, angehürt. S. d. Abb. bei Peters in II üller's Archiv. 1845. Tb. 2. Fig. 2.

2) Es ist hisweilen ausnahmsweise beträchtlicher als das 0perculum, z. B. bei Callionymus lyra. 
welches durch Faserhaut ihm und dem Interoperculum verbunden ist. Das Interoperculum nimmt gewöhulich den Raum zwischen dem Suboperculum und dem Os angulare des Unterkiefers ein und liegt dabei nach innen und hinten vom Praeoperculum und Os quadrato-jugale. Es ist dem Os angulare des Unterkiefers durch Fascrband verbunden. Bei den Pleclognathi Gymnodontes und Ostraciones ${ }^{3}$ ) erstreckt es sich von der Unterkieferecke vorwärts zum Zungenbeinbogen, legt sich verbecitert an diesen und verlïngert sich daun, bald ossificirt, bald als Ligament zum Operculum, mit dem es sich verbindet. Indem das Interoperculum, vom Unterkiefer ausgehend, an der Aussenseite einer Stelle des Zumgenbeiubogens und weiterhin am Suboperculum angeheftet ist, bewirkt es die Combination der Bewegungen sämmtlicher genannter Hartgebilde.

Bei manchen Teleostei, z. B. Cotylis, bleibt es jedoch, vom Os angulare des Unterkiefer's ${ }^{4}$ ) zum obcrsten Theile des Zungenbeinbogens sich erstreckend, ganz ausser Verbindung mit den vom obersten Theile des Os temporale ausgehenden zwei Elementen des Kiemendeckels. Eben so verhält es sich, unter Erreichuug einer ausserordentlichen Länge, bei Fistularia.

Die Anzahl der Kiemendeckelknochen erscheiut häufig reducirt. Nicht selten fehlt ü̈mlich das Interoperculum, indem es nur durch ein vom Unterkiefer zum Zungeubeine sich erstreckendes straffes Faserband vertreten wird, wie z. B. bei Liparis, Mormyrus, Nolopterus, den Siluri. Bei den Loricarinen hat der ganz abortive Opercularapparat seine Freibeweglichkeit eingebüsst. Sehr unbeträchtlich sind die tief am Os temporale angehefteten Opercularknochen bei Muraenophis ${ }^{5}$ ), wo das Interoperculum ebenfalls fehlt.

B. Vom Systeme der inneren Kiemenbogen.

S. 38 .

Bei allen Fischen, mit Ausnahme der Marsipobranchii, erhält eine mehr oder minder lange Strecke der Rachenhöhle eine unmiltelbare Unschliessung durch solide, bald vollständige, bald unvollständige linge bildende Bogeu, welche bald temporär, bald perennirend, den Kiemeublattreihen mittelbare Stützpunkte gewähren.

Bei Branchiostoma erscheinen sie, innerhalb der liumpfhöhle gelegen, als solide Gerüste desjenigen zwischen Mundhöhle und Speiserölue gelege-

3) Aehnlich verhält es sich bei Callionymus.

4) Es erscheint bei manchen Fischen als Ossification eines Ligamentes, Bisweilen hat es dagegen unverkennbare Achnlichkeit mit einem Zungenbeinstrahl, gleich wie dies auch von den übrigen Gliedern des 0 percular- $\Lambda$ pparates nicht selten gilt.

5) Beim Aale sind die gewöhnlichen drei linochen vorhanden. 
nen sehr langen Segmentes des Visceralsystemes, das als Kiemenhöhle fungirl, sind also ihrer physiologischen Verwendung gemäss, solide Stützen der Kiemenhöhle. Sie erscheinen an jeder Seite als ein System von Knorpelleisten, die oben bogenförmig mit einander verbunden sind, unten aber frei enden. Je zivei auf einander folgende Leisten zeigen ein verschiedenes Verhalten. Immer theilt sich nïmlich die eine Leiste in zwei Gabeln, während die nächst folgende einfach bleibt. Indem nun der Ast der einen Gabel dem vorderen Asle der nächsten Gabel entgegentritt, entsteht ein System von Spitzbogen, deren jeder eine einfach und ungetheilt gebliebene Leiste einschliesst. Es geschieht also die Bildung eines solchen Bogens auf Kosten dreier Leisten. Diese drei Leisten sind noch durch Querbalken verbunden. Die Anzahl der Spitzbogen beläuft sich auf 40 bis 50 . Die jeder Seitenhälfte angehörigen Stäbe sind obeu durch ein an die Chorda dorsalis sich anschliessendes Längsband, unten durch ein analoges freies Band verbunden 1 ).

\section{S. 39.}

Bei den Elasmobranchii, Ganoïdei, Teleostei und Dipnoi erscheint ein ganz analoges System von Bogen, das, nur in geringerer Ausdehnung, die Umgürlung des vorderen vor der Speiseröhre gelegenen Abschnittes des Darmrohres besorgt. Je nach ihrer verschiedenen Function crhalten die einzelnen Bogen verschiedene Benennungen.

Diejenigen, welche die Kiemenspalten begrenzen und meist zugleich die die Kiemenblätter tragenden Diaphragmala stützen, werden als Kie. menbogen, Arcus branchiales, bezeichnet. Die jenseits derselben uach der Speiseröhre hin gelegenen, erhalten, weil sie den Schlundkopf unterstüten, die Benennung: unterer Schlundknochen, Ossa pharyngea inferiora. Derjenige Bogen, welcher vor dem vordersten Kiemenbogen liegt und theilweise zur Unterstützung eines Zungenrudimentes verwendet wird, dem gewöhnlich auch keine, häufig nur cine Kiemenblattreihe entspricht, heisst Zungenbein.

Mit wenigen Ausnahmen besteht jeder dieser Bogen ans zwei paaripen Seitenschenkeln, die an der ventralen Mittellinie durch ein System vou Copulae oder Körperstücken unter einander verbunden zu werden pflegen. An den meisten Bogen besteht jeder Seitenschenkel aus mehren discreten Slücken oder Segmenten.

\section{S. 40 .}

Das $\mathrm{Zungenbein} \mathrm{verhält} \mathrm{sich} \mathrm{in} \mathrm{Bezug} \mathrm{auf} \mathrm{seine} \mathrm{dorsale} \mathrm{Anheftung}$ bei den einzelnen Ordnungen der Elasmobranchii I) verschieden. Bei

1) S. Müller, Bau und Lebensersch. d, Branchiost. S. 89. Abb. Tb. 4.

1) Abbildungen finden sich: von Callorhynchus bei Müller, Myxin. Tb. 5. Fig.2. von Narcine bei Henle. Tb. 4. Fig. 1.4. 
den IIolocephali ist es dureh fibröse Haut an die Apophysis articularis des Schedels angeheftet; bei den Rajidae ist es entweder unnittelbar hinter dem Kiefersuspensorium am Schedel eingelenkt und mit der Basis des letzteren nur durch Faserbandmasse verbuuden, oder, wie bei den Torpedines, dem Schedelende des Kiefersuspensorium angefügt; bei den Squalidae ist es dagegen an das untere Ende des Kiefersuspensorium angefïgl. Gemeinsamer Charahter des Zungenbeines aller Elasmobranchii ist der, dass es in einer Strecke seines änsseren Randes mit freien Kuorpelstrahlen besetzt ist ${ }^{2}$ ), analog denjenigen, die bei den Plagiostomen von der Mitte jedes eigentlichen Kiemenbogens viel höher sich erheben, als bei den Chimären. Bci allen Elasmobranchii liegt die crste Kiemenblattreihe an der hinleren Seite dieser Ausbreitung von Knorpelstrahlen, welehe also auch die functionelle Bestimmung der Strahlenreihen der eigentlichen Kiemenbogen dadurch theilt, dass sie der Vorderwand des ersten Kiemensackes eine solide Unterstützung gewährt.

Jeder Seitensehenkel des Zungenbeines besteht bei den IIolocephali aus drei Stüeken, von denen das oberste ganz klein ist; bei den Rajidae nur aus zwei unter einem Winkel zusammenstossenden Stücken ${ }^{3}$ ) und bei den Squalidae aus einem einzigen. - Bei den Holocephali und den Squalidae werden die beiden Schenkel des Zungenbeinbogens durch ein mittleres, dickes, nach vorne vorspringendes, zur Unterstützung der Zunge dienendes Körperstück verbunden. Bei den Rajidac geschieht ihre Verbindung meistens durch einen einfachen weiten schmalen Knorpelbogen; bei der Familie der Torpedines aber vereinigen sie sich in der vorderen Mittellinic gar nicht, sondern jeder Seitenschenkel lehnt nur nach hinten an den des ersten Kiemenbogens sich an.

Die Anzahl der hinter dem Zungenbeine gुelegenen Bogen, welche meistens sümmllich nicht unterhalb des Schedels, sondern des vordersten Abschnittes der Wirbelsänle gelegen sind, beliunt sich hei den Holocephati und den Rajilae auf fünf; bei den S(qualidae findet sich allgemein hinter dem fünften noch die Andeutung eines sechsten t) und wahrscheinlich ist

2) Diese freien Knorpelstrahlen des Zungenbeines der Chimären sind an ihrer Basis theilweise zu einer linorpelplatte verwachsen. Aehnliche Verwachsungen kommen bei einigen Squalidae an den Strahlen des Kiefersuspensorium vor.

3) Die zwei Stücke des Zungenbeines der Rajidac, so wie der grösste Theil der beiden untersten Stücke desjenigen der Chimären entsprechen den beiden Mittelstücken eines Kiemenbogens.

4) Ich habe dieses tisher nicht bekannte Glied gefunden: bei Prionodon glaucus und einigen anderen Prionodon, bei Scoliodon aculus und einer zweiten Art, bei Sphyrna, bei Galeus canis, bei Sppinax niger, Acanthias vulgaris, Pristiurus melanostomus, Scyllium Edwardsii, ('hiloscyilium punctatum, Centroscyllium Fabricii, Siquatinat vulgaris und cinem Scymmus. Es liegt hinter dem langen ventralen segmente des sogenannten 
ihre Anzahl bei den Notidani noch grösser. Yon den fünf Bogen entspricht der hinterste den Ossa pharyngea inferiora der T'eleostei; bei den Rajidae stosst jeder Schenkel des letzteren mit dem Winkel, den seine beiden Segmente bildeu, unmittelbar an den Schultergürtel; bei den Sqgualidae geschieht seine Verbindung mit demselhen durch ein straffes Band.

Jeder Bogenschenhel besteht aus mehren mit einander articulirenden Segmenten oder Gliedern. Die Anzahl 5) der Glieder jedes der fünf ausgebildeten Bogen belïult sich bisweilen auf vier; oft ist aber die Zahl der Glieder einzelner Bogen, namentlich des letzlen und vorletzten reducirt. Zwischen cinzelnen Segmenten findeu sich bei den Squalidae oft noch kleine rundliche Knorpel eingeschaltet ${ }^{6}$ ).

Die eigentlichen Kiemenbogen sind an ihrer convexen Seite mil Kicmenhautstrahlen besetzt. Jiese sind bei den Holocephali niedrig und kurz, bei den Plagiostomen oft sehr lang. Inden sie die Beslimmung haben, die häntigen Kiemenbeutel zu unterstützen, kann es nicht auffallen, dass die Strahlen nicht nur längs dex Kiemenbogen vorkommen, sondern auch an der dorsalen und ventralen Scite zweier auf einander folgender Bogenschenkel, also entsprechend den beiden Commissuren eines Kiemensackes, verbreiter in einander übergehen können ${ }^{7}$ ). - Sobald ein Bogensehenkel aus vier Segmenten besteht, sind nur die beiden mittleren mit diesen Strahlen besetzl. Das oberste ${ }^{8}$ ) legt sich dachartig über den Schlundkopf und das unterste bewirlit die Verbindung mit dem System der Copulae oder mit an. deren Bogen.

Dies System der Copulae bietet wieder eine grosse Mannichfalligslieil der Anordnungsweisen dar.

Os phuryngeum inferius, beginnt an dem Punkte, wo das dorsale Segment mit ihm zusammenstosst, ist meist länglich und erstreckt sich mehr oder minder weit cinwärts zur Gegend der Copulae hin. Oft ist diese seine Verlängerung blos ligamentos. Bei den meisten Ilaien ist ein einziger Knorpel vorhanden, der z. B. bei einem erwachsenen Galeus canis sehr gross ist; bei cinigen Fütus, namentlich von Prionodon glaucus, und bei jungen Exemplaren ron Sphyrna und von Scoliodon acutus liegt dem eben beschriebenen ein zweiter, ihm parallel laufender, ganz ahortiver kínorpel hinten an. Bei einem grösseren Scoliodon ist nur einer vorhanden. Seine Form weicht am meisten von der beschriebenen ab bei Squatina.

5) Jeder Bogen hat z. B. 4 Segmente bei Squatina vulgaris.

6) Z. B. bei Galeus canis, Prionodon glaucus u. A.

7) Diese öfter vorkommende Bildung erscheint vorzugsweise ausgeprägt bei $\Lambda$ ëtobatis, wo die letzten Knorpelstrahlen, mit welchen die einzelnen Bogen besetzt sind, ohen sowol, als unten, zu breiten Knorpelblättern werlen, die von einem Bogen zum anderen hinüber sich erstrecken und dorsale und ventrale Begrenzungen der Kiemensäcke bilden.

4) Diese olscrsten Segmente entsprechen den Ossa pharyngea superiora der Teleostei. Bei den Rajidae fehlen sic oft dem ersten Kiemenljogen. Bei vielen Elasmol)ranchii auch den unteren Schlundkiefern. 
Charakteristisch für alle Elasmohranchii ist der Besilz einer an der Ventralseite des Kiemenbos disystemes gelegenen und über dessen hintere Grenze meist weil hinaus verlïngerten, unparen, oft in eine, bald unabgeselzte, bald discrete Spitze anslaufenden Knorpelplatte: Cartilago subpharyngea impar. Diese Knorpelplatte ist der unteren Wand des Schlundkoples engr angeheftel und bildet eine solide Bedachung des Ilerzbeutels. Bald ist sie breit, bald schmäler. Sie selzt sich bisweilen unmulerbrochen von hinten nach vorne forl; als Copula sämmtlicher Bogenschentiel, mil Einschluss derjenigen des Zungenbeines, erscheinend, die an ihren Seitenrändern sich inseriren wie bei Pristis, bei Aëtobatis u. A.; oder ihre Ausdehunng ist blos auf den hintersten Abschnitt des Kiemenkorbes beschrankl wie bei anderen Rajidae, den meisten Squalidae und den Chimären. In diesem lelzleren Falle lehmen bei den Squalidae und den Chimären nur die ventralen Glieder des Schlundkiefers und des hintersten Kiemenbogens an sie unmitlelbar sich an. Bei vielen Rochen z. B. den Torpediues, bei Rhinobatus u. A. hat nicht cine successive Einlenkung der einzelnen Glieder Statt, sondern die eines gemeinsamen Stückes, das die Summe der ventralen Segmente der meisten Kiemenbogen repräsentirt. - Die beiden vom Schultergürtel aus an die den Herzbeutel bedeckende Carlilago impar tretendeu rentralen Glieder der Ossa pharyngea inferiora bilden bei den Rajidae oft solide Seitenleisten für den Herzbeutel ${ }^{9}$ ). - I) ie ventralen Glieder der drei vordersten Kiemenbogenschenkel der Squalidae und der Chimären, welche nicht nmmiltelbar an die Carlilago impar sich anlehnen, werden gewöhnlich dnreh eigene unpare Copulae mit cinander verbunden, deren Anzahl aber nicht immer geuau derjenigen der Bogen entspricht, die auch nicht miter einander der Länge nach verbunden zu sein pflegen.

Bei Pristis, wo die Cartilago subpharyngea impar als geneinsame Copula zwischen den beiden Schenkelreihen der Kiemenbogen nach vorne sich verlängert, trilt sic in ein eigenthümliches Verhältniss zum Kiemenarterienstamme; ein von ihren Seitenrindern absteigender und nuten geschlossener Knorpelbogen bildet nämlich den Boden eines soliden, zur Anfnalume des Kiemenarlerienstammes bestimmten Camales. Dieser erstreckl sich weit vorwïrts und besitzt Seilenörhnugen zum J)urchtritte der einzelnen Kiemenarterien; bei Trygon, bei Aëlobatis u. A. ist dieser Canal nur durch eine schmale untere brïcke angedentel, dic anch unien nicht immer knorpelig, sondern nur häutig geschlossen sein kann.

\section{\$. 41 .}

Das Zungenbein und dic Kiemenbogen der Ganoïlei und Teleostei ermangeln selten der die paarigen Schenlel unter cinander und die ganze Boggenreilie verljindenden unteren Schluss- oder Körperstüche (Copulae).

9) Am deutlichsten bei Pristis, minder ausgeprïgt bei anderen Rajidac. 
Das Zungenbein haftet mit seinem obersten Segmente an dem unteren Ende des Os temporale oder an dem Os symplecticum ${ }^{1}$ ). Sein Bogen ist in der Regel weiter, als der der folgenden Kiemenbogen. Jeder seiner Schenkel besteht gewöhnlich aus vier Gliedern, von welchen das mittelste am längsten zu sein pflegt ${ }^{2}$ ). Das oberste derselben, das die Anheftung an das Kiefer-Suspensorium besorgt, ist bei den Teleostei unter dem Namen des Os stylö̈deum bekannt, bleibt oft knorpelig und verkïmmert selbst nicht selten. Das unterste, gleichfalls kurze Segment lest sich meist an dasjenige des ersten Kiemenbogens und an die vorderste Copula. Dies unterste Segment besteht bei vielen Teleostei aus zwci über einander liegenden Kuochenstückeu. Mit sehr wenigen $\Lambda$ usnahmen, zu denen namentlich dic Ganoüden, unter Ausschlnss von Lepidosteus, so wie die Gattung Muraenophis gehören, geht vou der Verbindungsstelle der beiden Bogenschenkel ein vorwärts gerichtetes Knochenstück: Os linguale s. entoglossum ab, das der Zunge zur Grundlage dient. - Von der unteren Seite jedes Endgliedes tritt meistens eine Sehne ab. Die Selnen beider Seiten dienen zur Befestigung eines unpaaren, verschicden gestalteten Knochenstücks: des Zungenbeinkiels, der die Bestimmung hat, die beiden zun Zungenbeine tretenden M. M. sternohyoüdei zu trennen und ihre Ansalzflächen zu vergrössern. Dies nicht selten fehlende Knochenstück ist bei Polypterus durch paarige Stücke vertreten, deren jedes von dem Ende eines Schenkels ausgeht.

Mit Ausnahme einiger Ganoïden haftet an dem mittelsten Segmente ein verschiedentlich entwickeltes System von Knochenstrahleu: Radei branchiostegi ${ }^{3}$ ). - Gewöhnlich durch eine Hautverdoppelung, zwischen welcher Muskelfasern verlaufen, zusammengehalten (Membrana branchiostega ${ }^{4}$ ) tragen sie zur Unschliessung der Kiemenhöhle wesentlich bei. Jiese Function tritt am entschiedensten da herror, wo die Kiemenhöhle, sehr weit ausgedehnt, nur dureh eincn engen Spalt sich öfnet, wir z. B. bei Muraenophis, wo anch dieselbe fast allseitig von den langen dïnnen Strahlen umschlossen wird, die übrigens hier ansnahmsweise des un-

1) Bei Accipenser geht es vom oberen Theile, bei Spatularia vom unteren Ende des Os symplecticum aus.

2) Be: Accipenser sind nur drei Segmente vorhanden; bei Polypterus, Lepidosteus, Amia, bleibt das oberste linorpelig; äberhaupt ist die Anzahl der Segmente bei den Teleostei nicht constant.

3) Diese Strahlen sind sehr verschieden ausgebildet, daher von der systematischen Zoologie zur Charakteristik der Fische vielfach benutzt. Bei den Aalen sind sie stark gekrümmt und geschwungen. Bei Tetrodon ist der erste von enormem Umfange. Bei Lophius sind sie sehr lang.

4) Die Membranae branchiostegae beider Seiten stehen in der ventralen Mittellinie gewölınlich durch einen schmalen Isthmus mit einander in Verbindung. Bei den Mormyri lilessen sic in ihrer ganzen Breite in einander, so dass cin unpaarer Vorhang entsteht der bis zum Schultergürtel hinreicht. 
mittclbaren Zusammenhanges mit den Zungenbeinbogen crmangeln. Bei Spatularia werden die Strahlen dureh eine dem Kiemendeckel ähnliehe Platte repräsentirt und bei Polypterus geht vom Zungenbeine ${ }^{5}$ ) cine der Strahlen ermangelnde Membrana branchiostega ab.

\section{\$. 42 .}

Die dem Zungenbeine nach hinten sich anschliessenden Bosen liegen meistens unterhalb des Schedels, seltener, wie bei vielen Malacopterygii apodes, weiter nach hinten gerïckt unter dem vordersten Abschnitte dev Wirbelsiule. Die Anzahl dieser Bogen beläuft sieh gewöhnlich auf fünf, von welchen die vier vordersten die eigentlichen Kiemenbogen, Arcus branchiales darstellen, der hinterste aber, weil er bei vorgesehrittener Entwickelung der Fische in der Regel keine Kiemenblätter stützt, sondern nur zur U'mgürtung des unteren Theiles des Schlundkopfes verwendet ist, als unterer Schlundkiefer: Os pharyngeum inferius bezcichnet wird. Bei Polypterus fehlt dieser fünfte Bogen ganz; bei Rhinocryptis kommen percunirend sechs Bogen ror, und bei Lepidosiren fungirt der fünfte und letzte als Kiemenbogen.

Sämmtliche Bogen umgürten die Schlcimhaut der Rachenhöhle auswendig unmittelbar. Nur sehr selten stehen die Kiemenbogen mit der die Rachenhöhle auskleidenden Schleimhaut ausser eigentlicher nächster Verbindung. So erscheinen sie bei Muraenophis als zarte Stäbe, welche zwischen der Muskelschicht der Rachenhöhle, deren Schleimhaut bis auf kleine runde, die Stelle der sonst langen Interbranchialschlitze rertretende Oeffnungen undurchbohrt ist, gelagert sind. Bei den meisten Fischen sind Fortsetzungen der Rachenschleimhaut, wenigstens längs bestimmter Segmente der Kiemenbogen, mit der soliden Substanz der letzteren ganz innig verwachsen. Wenn bei ihnen gewisse Segmente der Bogen die weiten Interbranchialschlitze ummittelbar begrenzen, so kamn es den Anschein gewinnen, als würde die Continuität der Rachenwände von diesen Itartgebilden durchbrochen. Dies ist aber nicht der Fall, dem die gewöhnlich aus Stacheln, Tuberkeln, zahnartigen Gebilden bestehenden imneren Ueberzüge der die Brücken zwischen den Interbranchialschlitzen bildenden Segmente der Kiemenbogen sind die cigentlichen Fortsetzungen der Rachenschleimhant, welche selbst. brückenartig zwischen den Interbranchialschlitzen sich hindurchziehen und von den Kiemenbogen, mit denen sie oft sehr innig verwachsen sind, nur eine feste Unterstützung erhalten.

Die Zahl der Segmente, welche cinen einzelnen Kiemenbogensehenlicl bilden, ist nicht gleich; für die letzlen Bogensehenkel pflegt sie geringer zu sein, als sie für die vorderen es ist. Jeder Schenkel der drei rordersten

5) Abbild. des Zungenlıcines und Kiemenbogengerüstes von Polypterus, s. b. Miller, Bau und Grenzen der Ganoỉden. Tb. 1. 
Kiemenbogen besteht sehr allgemein ans vier Segmenten, jeder Schenkel des vierten Bogens besitzt meist nur drei Glieder und der untere Schlundkiefer hat gewöhnlich nur eingliedrige Schenkel.

Jedes cinzelne Segment eines Schenkels erhält seine eigenthümliche Verwendung. Die obersten oder dorsalen Segmente der vorderen Bogenschenkel bilden eine äussere Belegung der Rachenhöhle und dienen dorsalen Muskeln des Kiemenapparates zur Anheftung, ohne dass jemals das Diaphragma der Kiemenblätter an ihnen sich fortsetztc. Selten nur zeigen sie sich unter der stabartigen Form der übrigen Segmente. Wenn dicser Fall aber bei manchen Fischen, namentlich am obersten Segmente des crsten Kiemenbogens eintritt, so ist letzteres meistens dem Os sphenö̈deum basilare mit seiner oberen Spitze durch Ligament rerbunden und besorgt also eine Anheftung des knöchernen Kiemenbogenapparates an den Schedel. Seltener convergiren die entsprechenden Segmente des ersten Bogens beider Seiten mod schliessen sich an einander 1). - Bei sehr vielen Fischen zeichnen die obersten Segmente der Bogenschenkel durch umregelmässige Gestalt, durch Verwachsung oder sonstige innige wechselseilige Verbindung der Segmente derselben Seite zu breiteren Platten und durch den Besitz von Zähnen, welche von ihnen $a b$ in die Rachenhöhle hincinragen, sich ans. Thre von denen der übrigen Segmente so häufig abweichenden Gestaltungsverhältnisse und Functionen gaben Veranlassung zu einer besonderen Bezeichnung derselben als Ossa pharyngea superiora.

Die beiden mittelsten Segmente der Kiemenbogen besitzen aussen, an ihrer convexen Seize gewöhnlich eine Rinne oder Aushöhlung, bestimmt zur Aufuahme der Gefïsse und Nerven der Kiemen; zu jeder Seite derselben haftet anch die Grundlage, von welcher die soliden Stützen der Kicmeublättchen ausgehen. Das zweite Segment ist kürzer, als das dritte, welches alle übrigen an Länge übertrifft. Jenes besitzt an scinem dorsalen Ende gewöhnlich zwvei Zinken, von denen die eine, als Processus articularis, zur Anheftung an das Os pharyngeum superius bestimmt, die andere, als Processus muscularis, aber frei ist.

Eine eigenthümliche functionelle Verwendung erfährt das zweite dem Os pharyngeum superius zuniichst liegende Segment des ersten Kiemenbogens, in der Familie der Pharyngii labyrinthiformes, indem es an der den Kiemenblïttern entgegengesetzten inneren Seite in dünne Blätter sich theilt, welche von Schleimhaut überzogen, Aushöhlungen bilden, in welchen Wasser eine Zeillang für die Bedürfnisse der Respiration aufbewalnt wird, eine Einrichtung durch welche diese Fische in den Stand gesetzt werden, ihren gewöhmlichen Aufenthalt im Wasser auf längere Zeit zu

1) Z. B. bei Clupea harengus; hierdurch krommt dann cine vollständige Umgürtung der Rachenhöhle zu Stande. 
verlassen tund anf dem Erdboden sich forlzuberegen. Diese blatlrerigen Theilungen sind bei den versehiedenen Gathungen der genamuten Familie verschiedentlich entwickelt; vorzugsweise ausgebildet sind die mehrmals gekrümmten zarten Lamellen bei Auabas ${ }^{2}$ ).

Das rierte oder vorderste meist umbetrïchtliche Segment, welches in der Regel den Schenkeln des vierten Kiemenbogens fehll, besorgt wesentlich die Anheftung an das System der die Bogenschenliel beider Seiten unler cinander vereinigenden Copulae. Es erfïhrt dasselbe aber häufig noch eine eigenthümliche Verwendung. Unterhalb der Reihe der Copulae zeigt sich nämlich bei viclen Teleostei ein rerschiedentlich entwickelter Canal, zur Aufuahme der Arteria branchialis communis und bisweilen auch der Thyreoüdea bestimmt. Dieser Canal hat gevöhnlich ossifieirte Stiutzen. Bei den meisten Teleostei besitzt das letzle Segment einzelner Kiemenbogensehenkel einen absteigenden Fortsatz zur seillichen Unterstïtzung desselben. Vorzugsweise oft geht derselbe vom letzten Segmente jedes Sehenkels des dritten Kiemenbogens ab. Die Fortsätze beider Seiten neigen sich convergirend zu cinander und bilden, in der Mitte durch fibrös-häutige Theile verbunden, einen abwïirts gerichteten Spilzbogen ${ }^{3}$ ). - Oft wiederholt sieh die nämliehe Bildung, wenn gleich weniger deutlich, anch am letzien Segmente des zweiten Kiemenbogens. - Bei den Plectognathi 4) werden aber nicht Knochenfortsïtze, sondern ganze Knochen zur Bildung eines unterhalb der Copulae gelegenen Knochencanales verwendet. Bei Ostracion z. B. steigt von den Aulchnungsstellen der Schenkel des dritten Kiemenbogens an dic hinterste Copula ein Paar soleher Knochen ab. Da hier jedem dieser Schentel das sonst gewöhnlich vorhandene vierte Segment fehlt, so wird es wahtuscheinlich, dass dasselbe durch den renannten absteigenden Knochen ausschliesslich repräsentirt ist.

Der fünfte, das Os pharyngeum inferius constituirende Bogen besteht gुewöhnlich aus zwei eingliedrigen Schenkeln. - Bei den Chromiden sind dieselben durch eine mittlere Naht innig vereinigt. - Bei den Labroïden und den Seomber-Esores fehll eine solche und so werden die sonst vor handenen Bogen durch ein unpares mittleres Knochenstïck vertreten.

Bei wenigen Teleostei liegen dic entsprechenden Schenhel der cinzolnen Kiemenbogen in der ventralen Miltellinie neben einander, ohue durch eigene Körperstïcke oder Copulae verbunden zu sein ${ }^{5}$, - - J)en meisten

2) Diese richtigere Bezeichnung der Lage der sicbheinförmigen Labyrinthe verdanken wir Peters, der nächstens darüher nähere Mitheilungen machen wird.

3) Z. B. bei allen Clupeĩden (Megalops, Butirinus, Alosa etc.), bei Esox, bei Cyprinus u. s. w. Diese Bildung fehlt anderen Fischen ganz, z. B. den untersuchten Cyclopoden, Gobioïden, Blennioîden, Cataphracten.

4) Aehnlich wie Ostracion verhält sich Tetrodon.

5) Z. B. Jei Lophius piscatorius, Cotylis Stannii, Muraenophis helena, punclata. 
Ganoïden und Teleostei kömmt dagegen ein System ventraler Körperstücke oder Copulae zu, das ein Verbindungsglied zwischen den beiderseitigen Bogenschenkeln darstellt. - Nur bei einigen Ganoïden ${ }^{6}$ ) erstreckt sich dasselbe zwischen alle Bogensehenkel hindurch und verlängert sich selbst über die hintere Grenze des Os pharyngeum inferius hinaus. - Bei den meisten Teleostei werden dagegen die Sehenkel des unteren Schlundkiefers und meist auch des vierten Kiemenbogens durch mittlere Körperstücke nicht verbunden. - Dic Anzahl der letzteren schwankt 7), beschränkt sich jedoch meistens auf drei, von denen das erste unmittelbar an das Os entoglossum des Zungenbeines sich anzuschliessen pflegt. An das erste lehnen meist die Endglieder des Zungenbeines und des ersten Kiemenbogens, an das zweite die des ersten und zweiten Kiemenbogens und an das dritte die des zweiten und dritten Kiemenbogens sich an. Die des vierten Bogens pflegen nur durch Knorpelhaut verbunden zu sein.

\section{Von den Extremitäten.}

\section{\$. 43.}

Nur wenigen Fischen fehlen die Vorderextremitäten und mit ihnen zugleich ein Schultergürtel. Dahin gehören die Leplocardii und Marsipobranchii.

Bei den Elasmobranchii ist der Schultergürtel hinter dem Schedel an dem vorderen Abschnitte der Wirbelsïule gelegen; am weitesten nach hinten gerückt in der Familie der Torpedines.

Bei den Squalidae besteht er aus einem, vom Rücken aus, jederseits vorwärts und abwïrts gerichteten Bogenschenkel. Die Schenliel beider Seiten gehen in der ventralen Mittellinie olne alle Unterbrechung und ohne Naht in cinander über. Jedes dorsale Ende trägt oft einen lileinen discreten Knorpel, der als Schulterstück sich zu erkennen gibt ${ }^{1}$ ). - Mit der Wirbelsänle steht der Schultergürtel der Squalidae nirgend in unmittelbarer Verbindung, liegt vielmehr theils oberhalb der Rückenmuskeln, theils in die Muskelsubstanz cingesenkt, durch welche er fixirt wird. - In der Gegend, wo der Bogenschenkel jeder Seite von oben nach unten sich umbiegt, besitzt er an seinem hinteren Rande drei Gelenkköpfe zur Articulation dreier Knorpelstücke: Ossa carpi. An die beiden äusseren Stücke schliessen oft

6) So bei Accipenser und bei Amia. Beim Stör haften das Zungenbein und die drei vordersten Kiemenbogen an einem einzigen Körperstücke; zwischen den beiden Schenkeln des dritten und vierten Bogens, ferner zwischen denen des vierten und fünften liegen discrete Copulae; endlich liegt noch jenseits der Schenkel des fünften oder des Os pharyngeum inferius ein mittlerer Endknorpel. - Bei Amia sind an der jenseits des unteren Schlundkiefers liegenden Endverlängerung des Systemes der $\boldsymbol{C o}$ pulae noch zwei kleine zahntragende Knochenplatten befestigt.

7) Bei einigen Fischen werden sic sehr abortiv. Bei Batrachus, bei Uranoscopus u. A. findet sich nur eine die heiden ersten Bogen verbindenue kleine Copula.

1) Z. B. bei Squatina, Scyllium. 
vorne und hinten sucecssive noch accessorische Knorpel sich an. Die Ossa carpi tragen die Phalanges digitorum entweder unmittelbar, oder durch eine zwischengeschobene zweite Reihe von Knorpeln, welche breiter sind, als die Phalanges ${ }^{2}$ ). Letztere bestehen aus mehren Reihen länglicher Cylinder, welche aber nicht bis an das freie Flossenende reichen. Denn im ïusseren Segmente der Flosse finden sich zwischen den beiden Lamellen der Cutis feine gelbe Faserstreifen von hornartigem Ansehen', welche mit ihrer Basis die freien Enden der knorpeligen Phalanges umfassen.

In den wesentlichen Verhältnissen, namentlich auch in Betreff mangelnder unmittelbarer Verbindung mit der Wirbelsïule übereinstimmend, zeigt sich der Schultergürtel der Chimären. Er bildet einen einfachen, nirgend unterbrochenen Knorpelbogen, dessen dorsales Ende in einen hinterwärts gerichteten, an der Kante der Wirbelsäule unbefestigten Knorpelfaden sich verlïngert. $1 \mathrm{hm}$ unmittelbar eingelenkt sind nur zwei Ossa carpi. Die äussersten Phalanges sind sehr kurz. Die gelben Faserstreifen bilden, beträchtlich ausgedehnt, den grössten Abschnitt der Flosse.

Was die Rajidae aubetrifft, so gestaltet die Art der Fixirung ihres Schultergürtels sich sehr verschieden. Bei Einigen, z. B. bei Raja, sind die beiden dorsalen Enden des Gürtels an einen, von der oberen Kante des ungegliederten Segmentes der Wirbelsäule ausgehenden, dümnen Querfort. satz befestigt. Bei anderen, z. B. bei Trygon, sind sie den Seiten desselben Segmentes in ganzer Höhe dureh Syndesmose verbunden; bei anderen, z. B. bei Aëtobatis, den Seiten des ungegliederten Segmentes durch Gelenke eiugefiigt; bei anderen, z. B. bei Torpedo, steht der weit nach hinten gervickle Schultergürtel ausser unmittelbarer Verbindung mit der Wirbelsäule und verhält sich in dieser Hinsicht, wie bei den Srqualidae. Aber er bildet einen a!Iseitig geschlossenen Ring. Jeder Seitenbogen dieses Ringes besteht aus zwei Abschnitten: einem oberen transversellen, der der Scapula angehört, und einem absteigenden, der Clavicula entsprechenden. Die ossificirten Clavicular-Segmente beider Seiten werden in der ventralen Mittellinie durch cine Knorpelleiste verbunden. Jedes Scapularsegment steht mit dem der entgegengeselzten Seite gleichfalls durch eine knorpelig bleibende Pars suprascapularis in Verbindung. - An jeden Bogenschenkel lehnt sich, anscheinend bei allen Rajidae unmittelbar und durch Syndesmose das Os pharyngeum inferius. - An die beiden äusseren der mil dem Schultergï̈rtel verbundenen Ossa carpi (deren Zahl oft drei beträgt) reihen sich nach rorne und hinten successive sehr viele zur Stälzung der Phalanges digitorum dienende ähnliche Stïcke an. Das vordere Ende der Reihe dieser Knorpel steht ferner mit dem Scherlel bestïndig durch einen eigenen Sehe.

2) Z. B. bei Scyllium Edwardsii. Die Iland der Scyllien erimnert lebhaft an diejenige der Cetaceen. 
(lelflossenknorpel ${ }^{3}$ ) in Verbindung. Dieser ist dem Processus frontalis anterior neben der Nasencapsel cingelenkt und von ihm aus hinterwärts gerichtet, um mit den Carlilagines carpi eine Reihe zu bilden. Durch diese Ausdehung der Ossa carpi nach hinten und nach vorne, und die Menge der an sie angehefteten Phalangen gewinnt der ganze Körper der Rochen seine eigenthümliche scheibenförmige Gestalt 4). - Eine Eigenthümlichkeit der Familie der Myliobatides ${ }^{5}$ ) ist noch die, dass die Elemente ihrer Vorderextremität in einem, aus zwei ganz discreten Seitenschenkeln bestehenden, Bogen, der vom Schedelflossenknorpel der einen Seite zu dem der anderen Seite reicht, vor dem Schedel, so wie vor und über den Naseneapseln sich fortsetzen. Jeter dieser Bogen ist mit gegliederten Flossenstrahlen beselzt. - Die in vielfachen Reilien stchenden Phalanges digilorum der Rajidae zerfallen gewöhnlich in zwei Abtheiltungen; die der ersten sind einfach; in der zweiten finden sich mehre Reihen gespaltener oder doppelter Phalanges. - Die gelben Faserstreifen der Sqqualidae und Holocephali sind ganz abortiv oder fehlen vollständig.

\section{S. 44 .}

Was die übrigen Ordunngen der Fische anbetrifft, so ermangeln wenige unter ihnen der Vorderextremititen; unter denen, welehe keine Brustflossen besitzen, wohin namentlich die Symbranchii, die Gattung Muraenophis, die Syngnathi ophidii, die Pleuronectiden-Gattung Achirus gehören, kömmt den meisten aber ein Schultergürtel zu. Dieser ist bald slark entwickelt, wie bei Achirus, Symbranchus 1), bald auf zwei ïusserst feinc Grïthon reducirt, wie bei Muraenophis ${ }^{2}$ ). Fische, welche im ausgewachsenen Zustande der Brustflossen ermangeln, kümen solche in früheren Ent.

3) Bei Narcine liegen zwischen dem Schedelflossenknorpel und der schnauzenförmigen Verlängerung des Schedels noch zwei kleine linorpel. S. Il enle, l. c. Tb. IV. Fig. 1.

4) Dass die Vorderflossen der Torpedines in einem gewissen Entwickelungsstadium, als vorne freie, unangewachsene, hlos mit dem Schultergürtel verbundene flügelfürmige Anhänge erscheinen, geht hervor aus den Mittheilungen von J. Davy, Philosoph. transact. 1534. p. 531. Tb. XXII. und I.euckart in Siebold Zeitschrift f. wisssens. Zoologie, S. 259. Tb. XVI. Fig. 1. 2.

5) Eine Abb. s. b. Müller, Myxinoüd. Tb. IX. Fig. 13. S, 174. Müller hat diese Bildung bei Hyliohates und Rhinoptera beschrieben. Meine Darstellung beruhet auf Untersuchung von Aëtobatis Narinari.

1) Bei Symbranchus ist die Scapula klein; die Claviculı gross; die beiden Claviculae convergiren und verbinden sich, wie gewöhnlich, mit einander. Merkwürdig ist die Anwesenheit eines der Hinterhauptgegend des Schedels eingelenkten stielförmigen línochens, der nach hinten gerichtet, dennoch die Scapula nicht erreicht und auch ausser mittelbarer Verbindung mit ihr bleibt.

2) Cuvier hat auf diese Gräthen, die den Rudii branchiostegi an Feinheit nicht nachstehen, bereits aufmerksam gemacht. Sie beriihren sich in der ventralen Mittellinie nicht. 
wickelmgsstadien besitzen ${ }^{3}$ ). - Ein Beispiel auffallender Asymmetrie gibt Solea monochirus ab, wo nur rechterseits eine Flosse entwickelt ist. Bei den Ganö̈dei und den meisten Teleostei hat die Anheftung des Sehultergürtels am Schedel Słatt; bei den Symbranchii, Muracnoülei und Notacanthini ist er indessen weiter hinterwärts an Querfortsätzen der Wirbelsäule suspendirt.

Der Schultergürtel der Ganoïdei und Teleostei besteht aus paarigen Seilenschenkeln, welehe in der ventralen Mittellinie meist durch Ligament, selten durch Naht unter cinander verbunden sind ${ }^{4}$ ). Die Zusammensetzung jetes Bogenschenkels geschicht meistens durch drei Kuochenstücke, von denen das oberste oder dorsale eine Omolita ${ }^{5}$, das mittlere eine Scapula ${ }^{6}$ ) und das ventrale eine Clavicula ${ }^{i}$ ) darstellt. Diese Knochen sind gewöhnlich durch Faserbänder unter cinander verbunden.

Die Omolita lehnt sich in der Regel mit zwei Zinken an den Schedel; die obere Zinke ist dem Os occipilale externum, die untere dem Os mastö̈deum angeheftet. Seltener fehlt die Spaltung in zwei Zinken und der ungetheilte Knochen bewirkt die Fixation am Schedel ${ }^{8}$ ).

Die Scapula setzt, vom vorigen Knochen aus, den Gürtel abrvärts fort.

Die Clavicula ist immer das beträchtlichste Segment und verbindet sich in der ventralen Mittellinie des Körpers mit derjenigen der anderen Seite, meist durch Ligament, selten durch Naht, wie z. B. bei Platycephalıs, bei vielen Siluroüden und Loricarinen ${ }^{9}$ ). - Indem sie sehr häufig in zwei Knochenblätter sich spaltet, bildet sie eine nach hinten seöffnete Rinne zur Aufnalume von Muskeln. Von ihrer Verbindungsstelle mil der Scapula aus, crstreckt sich häufig zum Os occipilale basilare ein straffes cylindrisches Faserband, das eine feste Anheftung derselben an den Basilartheil des Schedels bewirkt ${ }^{10}$ ).

Vomoberen Theile der Clavicula geht gewöhnlich ein hinterwïrts und abwärts gerichteter Knochen ab, der bisweilen fehlt ${ }^{11}$ ) und bei anderen Fischen

3) Nach den Beohachtungen von Fries gilt dies von sehr jungen Individuen von Syngnathus lumbriciformis (s. Wiegmann's Archiv 1838. 1. S. 252. Tb. VI. Fig. 7. .

4) Bei Acripenser liegt über der Verhindungsstelle der beiden Claviculae eine eigenthümliche unpaare 0ssification, welche, wol mit Unrecht, einem Sternum verglichen ist.

5) Omolita Geoffroy; Omoplata Bakker; Suprascapulare Cuvier.

6) Scapula Cuvier; Omoplata Geoffroy; Acromion Bakker.

7) Claviculn Gouan, Geoffroy, Meckel, Agassiz. Coenosteon Bukker; Humerus C'uvier.

8) Z. B. bei Chironectes, Cyclopterus, Liparis, Pterois.

9) Z. B. bei Aspredo, Iypostoma.

10) Z. B. bei Nacrodon, Tetragonopterus, Megalops.

11) Z. B. bei Silurus, Anguilla, Symbranchus, Cotylis. 
durch einen Fortsalz vertreten wird ${ }^{12}$ ). Er bleibt selten einfach ${ }^{13}$ ); indem frühır oder später gewöhnlich ein zweiter Knochen ihm sich anschliesst. Diese Kuochen betrachtet $\mathrm{Cuvier}$ als analog dem Os coracoideum ${ }^{14}$ ). Sie bieten, in Betreff ihrer Ausdehnung und Verbindungen, grosse Verschiedenheiten dar. Ḧ̈ufig sind sie nur kurz und enden frei, eingesenkt in dic Masse des Ventraltheiles des Seitenmuskels oder oberflächlicher unter der Haut. Bei einigen Teleostei sind sie aber lang, reichen weit nach hinten und stehen selbst mit dem Beckenknochen in Verbindung ${ }^{15}$ ); bei anderen erstrecken sie sich sogar bis zu den Trägern der Afterflosse ${ }^{16}$ ) und sind damn oft nicht platt, sondern cylindrisch oder prismatisch.

Die eben geschilderten Verhältnisse des Schultergürtels erfahren mannichfache Modificationen, welche sowol die Anzahl der ihn zusammensetzenden Knochen, als anch die Art ihrer Verbindung mit dem Schedel und der Wirbelsänle betreffen. Bei Silurus liegt oberhalb der Clavicula nur ein cinziger Knochen ${ }^{17}$ ), der durch zwei Zinken mit dem Schedel und durch einen dritten Fortsatz mit einem Processus transversus des ersten Wirbels in Verbindung steht. - Bei Batrachus ist die Clavicula jeder Seite durch zwei discrete cylindrische Knochen an dem Schedel befestigt; der vordere bewirkt ihre Verbindung mit dem Os mastödeum; der hintere und tiefere mit der Seite der Crista occipitalis. - In sehr eigenthümlicher Weise bilden bei den Loricarinen die Claviculae beider Seiten, ein nur in der Mitte offenes linöchernes Septum zwischen der Kiemen- und Runpfhöhle.

Bei den meisten Fischen folgen auf die Clavicula zwei Reihen vou Knochen, welche in ihren näheren Verhältnissen ausserordentlich zahlreiche Verschiedenheiten darbieten und die mannichfachsten Deutumgen erfahren haben, insgesammt aber nur die II and der Fische zu repräsentiren scheinen. Diejenigen der obersten Reihe, welche unmittelbar der Clavicula sich anschliessen, entsprechen den Ossa carpi; die der zweiten Reihe aber den Ossa metacarpi. Ein der Regio carpi angehöriges Element erstreckt sich schr häufig ${ }^{15}$ ) längs jeder Clavicule bis zur Vereinigungsstelle

12) Z. B. 'bei Hypostoma.

13) Z. B. bei Chironectes, Batrachus, Liparis, Cyprinus.

14) Os coracoïdeum Geoffroy.

15) Diese Thatsache ist zuerst durch Geoffroy hervorgehoben (Philosoph. anatomique p. $460 \mathrm{sqq}$.). Bei Mugil cephalus schliesst an den obersten schuppenförmigen Knochen ein zweiter, langer cylindrischer Knochen sich an, der an das hintere Ende des Beckenknochens sich anheftet.

16) Z. B. bei den Arten der Gattung Amphacanthus, bei Argyreiosus u. A.

17) Die Omolita fehlt überhaupt häufig als discretes Stück z. B. bei Lepidosteus.

18) Z. B. bei Balistes, bei Silurus glanis, bei Zeus faber. 
dieses Knochens mit dem der enlgegengesetzten Seite, steht auch nicht selten, wie z. B. bei Loricarinen und Siluroülen dureh Naht mit der vor ihr gelegencu Clavicula in Verbindung. Die Anzahl der Ossa melacarpi belïuft sich nicht selten auf fünf, wodurch dem numerisehen Typus der höheren Wirbelthiere entsprochen wird. Doch ist die angegebene Zahl bei weitem nicht für alle Fische normirend. Form und Austehnung dieser Ossa metacarpi sind ebenfalls sehr vielen Variationen unterworfen; durch Länge und etwas cylindrische Form ähnelı sie denen der höheren Wirbelthiere am meisten bei den Pediculati und bei Polypterus. Die Regio melacarpi bleibt unentwickelt bei den Siluroïden und Loricarinen. - Den Enden dieser Ossa melacarpi sind, als den Fischen durchaus eigenthümliche Elemente, welche die Stelle der Phalanges digitorum functionel vertreten, ohme ihnen morphologisch irgend zu entsprechen, die Flossenstrahlen ${ }^{19}$ ) augefïgt. Diese Flossenstrahlen verhalten sich ihrem Baue nach, durchaus wie die der unpaaren Flossen, welche eben den Fischen eigenthümliche Elemente sind; ihre Grundlagen, werden, gleich deneu der unpaaren Flossen, von einigen Fischen in frühen Lebensstadien, abgeworfen; sie erhalten bei anderen, gleich den unpaaren Flossen, nicht von den zulnächst gelegenen Spinalnerven, sondern aus der Bahn des Ramus lateralis $\boldsymbol{N}$. trigemini ihre Hautuerven ${ }^{20}$ ). - Dass die soliden Elemente der IIand ausgebildet sind, und unmittelbar ohne vermittelnde Verbindung durch Vorderarm- und Oberarmknochen an den Schultergürtel sich anschliessen, darf, Angesichts vieler Thatsachen aus der Entwickelungsgeschichte der höheren Wirbelthiere, nicht befremden.

Was die Flossenstrahlen anbetrifft, so erseheint als Eigenthümlichkeit der meisten Siluroïden und Loricarinen die ungemeine Stärke und die bisweilen vorkommende zahnarlige Bewaffinng des, auch wegen des Mechanismus seiner Einlenkung beachtenswerthen ersten Flossenstrahles 21). Abweichend von den Flossenstrahlen verhalten sich die sogenannten fingerförmigen Anhänge der Triglae und Polynemus dadurch, dass sie nichı, wie die übrigen, durch eine zusammenhangende Itant verbunden werden. - Wenn, wie dies bei den meisten Fischen der Fall ist, jeder Strahl aus zwei parallelen Stücken oder IIälften besteht, so lï̈mmt es oft ror, dass die äussere IIälfte des einen Strahles mit der imneren IIälfte eines zmmïchst gelegenen Strahles durch ein an der Basis beider verlaufendes Ligament in Verbindung steht ${ }^{22}$ ).

19) Diese letzteren entsprechen demjenigen Segmente der Flosse der Chimären und Squalidae, das durch die gelben Faserstreifen eingenommen wird.

20) Z. B. bei den Gadoïden.

21) Eines der cigenthümlichsten Bildungsverhältnisse zeigt er z. B. bei der Gattung Aspredo.

22) Z. B. bei Coltus, Synanceia, 
Unter den Dipnoi hat bei Lepidosiren die Terbindung des Sehultergürtels mil dem Schedel durch Band Statl; der Schultergürtel wird durch zwei aus Knorpel und Knochensubstanz 23) bestehende, unien ununterbrochen in einander übergehende Scheuliel gebildet. Fin conischer Knorpel der von der Convexität jedes Schenkels ansgeht, gewähnt der eigenthümlichen pfriemenförmigen Kuorpelgerte, welche die Flosse repräsentirt, cinen Stützpunkt. Bei Rhinocryptis ${ }^{24}$ ) findet sich zur Suspension des sonst übereinstimmend gebildeten Schultergürtels am Sehedel eine eigene Omolita, so wie ein accessorischer vom Schedel ausgehender Knochen, der hinter dem Schultergïrtel im Fleische liegt und mit ihm durch fibröse IIant in Verbindung steht. Der anch hier in einfacher Zahl vorhandene gegliederte Flossenstrahl ist in ganzer Länge mit knorpeligen Nebenflossenstrahlen besetzt. Auf sie folght noch ein feiner Flossenbart, bestehend aus verklebten Fasern.

[Ueber die Vorderextremitäten der Fische vergleiche man: Carolus Mettenheimer, Disquisitiones anatomico-comparativae de membro piscium pectorali. Berol. 1847. 4. Von der Richtigkeit der abweichenden Deutungen der von mir als Ossa carpi und metacarpi bezeichneten Elemente habe ich mich nicht zu überzeugen vermocht.]

S. 45.

Der Hinterextremitäten oder $\mathbf{B}$ auchflosen ermangeln sehr vicle Fische und zwar sowol solche, welche keine Vorderextremitaten besitzen, als auch solche, denen diese zukommen. Sie fehlen namentlich Branchiostoma, den sïmmtlichen Marsipobranchii, den Malacopterygii aporles, den Plectognathi Gymnodontes und Ostraciones, den Ophidini, den Lophobranchii und einzehen Repräsentanten anderer Familien z. B. Anarrhichas, Xiphias, Ammodytes. Die Iage der Hinterextremilaten ist sehr verschieden. Sie sind bald den Vorderextremitälen unmittelbar angefügt, bald elwas cntfernter von ihnen gelegen, bald an die Grenze der Schwanzgegend gerüclit. Die Fische heissen, je nach der Lage derselben: Pisces jugulares s. suh)brachii, Pisces thoracici und Pisces abrlomiuales. - Das Becken der Fische ermangelt jeder Verbindung mit der Wirbelsäule. Bei den Elasmobranchii liegen die Hinterextremititen immer am Banche vor dem After. Bei den Plagiostomi besteht das Beckengerüst in einem einfachen queren Knorpelbogen. Dieser trïgt jederseits ein Os tarsi, an welchem die Flossenstrahlen, gewöhnlich mil Ausuahme eines einzigen, der unmittelbar an Becken haftet, befestigt sind; leiztere sind bei den Haien in wenigen, bei den Rochen in zahlreicheren Reihen vorhanden. Bei deu mänulichen Elasmobranchii befestigen sich an den hinteren Enden der beiden Ossa tarsi eigenthümliche

23) Abb. bei Bisch off. Tb. 2. Fig. 4.

24) Abb, b. Peters, Müller's Arch. 1845. Tb. 2. Fig. 2. 
zangenartige :iussere Begattungsorgane. Bei den Chimären besteht das Becken, das auch durch seine Form verschieden ist, aus zwci Seitenhälften. Als Os tarsi erscheint ein rundlicher Kuorpel, an dem dann die knorpeligen Flossenstrahlen befestigt sind. Am freien Ende finden sich wieder die gelben Hornstreifen.

Bei den Ganoïden, welehe gleichfalls sïmmlich Pisces abdominales sind, besteht das Becken aus paarigen Seitenstückeu. Bei Aceipenser und Po. lypterus sehliesst sich an dasselbe eine Reihe ron Ossa metatarsi. An diesen haften die Flossenstrahlen.

Was die Teleostei anbetrift, so besteht ihr in seincn Formverhïlnissen sehr variurendes ${ }^{1}$ ) Beclien gewöhnulich aus zwei in der Mitlellinie in mehr oder minder weiter Ausdehnmng durch Syndesmose bald loser, bald imniger verbundenen Seitenhälften. Selten sind diese Seitenstücke in der Mitlellinie unverbunden und weiter von cinander getremul ${ }^{2}$ ). Nur bei den Loricarinen (Hypostoma) kömmt eine Zusammenselzung jeder Beclienhälfte aus zwei Stücken dadurch zu Slande, dass seillich cin schrïg vorwärts zur Seitenwand des Bauches gerichteter Knochen von dem Hauptstückic abgeht. Bei den Balistes ist das Becken durch einen einfach, mit seinem Torderrande zwischen den beiden Claviculae eingekeilten, unpaaren, säbelförmigen Knochen vertreten, der keine Spuren einer Enlstehung aus paarigen Seitentheilen zeigt, auch am freien Ende keine Flossenstrahlen, sondern nur einen von Hautincrustationen überzogenen kurzen Zapfen trägt ${ }^{3}$ ). Bei allen Teleostei sind die Flossenstrahlen dem Bechen unmittelbar angefügt.

Das cigenthümliche Bauchschild der Cyclopoden entsteht entweder allein durch die beiden Beckenknochen und die diesen angefügten Flossenstrahlen, wie z. B. bei Cyclopterus und Liparis oder unter Theilnahme der Vorderextremitäten, und wird hinten durch die in Form eines Bogens angeschlossenen Schenliel des Becliengerüsles ergänzl. So bei Cotylis, wo den Schenkeln des Beckengerüstes nur sehr foine und durch einen häuligen Saum verbundene Flossenstrahlen angefügt sind.

Bei den Dipnoi sind die von einem einfachen Beckenstütele ansgehenden beiden Strahlen ähnlich gebildet, wie an den Vorderextremiliaten; bei

1) Bei Zeus faber besteht er z. B. aus zwei verticalen, eng an einander gefïgten Ilälften; bei IIypostoma, Loricaria u, $\Lambda$. aus zwei breiten, horizontalen, zu ciner beträchtichen Platte verbundenen Stücken.

2) Z. B. bei Belone, Exocoetus, Anableps, Lophius.

3) Der lange, vorne zwischen den Claviculae eingekeilte, hinten vor dem After frei vorragende Knochen der Balistes ist vielfach als ein Brusthein gedeutet worden. Da die ilinterextremitäten der l'lectognathi, sobald sie überhaupt vorhanden, wic bei Triacanthus, nicht abdominal sind, so ist mir die beutung jenes linochens als BechenInochen sehr wahrscheinlich. Beobachtungen über die L̈ntwickelung der Balistini müssen ergeben, ol) derselbe transitorische Flossen trägt, oder nicht. 
Lepidosiren ist ein einfacher gegliederter Knorpelstrahl vorhanden, bei Rhinocryptis besilzt er cine Streche weil Nebenstrahlen und einen IIautsaum.

\section{Von den unpaaren Flossen.}

S. 46 .

Das System der unparen Flossen, dessen einzelne, meist unterbrochene Segmente, unter den Benennungen der Rückenflosse, Schwanzflosse und Afterflosse bekannt sind, würde, bei mangelnder Unterbrechung und bei weil vorwärts gerücktem After, eine freie und zusammenhangende Umgürtung der Kanten des ganzen Körpers, mit Ausnahme der Kiemenhöhlengegend, bilden. Die Betrachtung der perennirenden Verhältuisse einzelner Fische z. B. vieler Pleuroncetides, die Wahrnehmung ${ }^{1}$ ), dass bei manchen anderen, die nur einzelne Glieder des Flossensystemes besitzen, diese dic allein vollstïndig entwickelten Ueberreste einer in der Anlage vorhanden gewesenen Flosse von der angegebenen Ausdehnung sind, unterstützen die Auffassung, dass die Bildung einer zusammenhangenden, die äussersteu Kanten des Wirbelsystemes frei umgürtenden Flosse wesentlich im architectonischen Plane der. Fische liegt.

Perennirend erscheint sie in solcher Ansdehnung nur selten z. B. bei Branchiostoma, einigen Blennioidei, Pleuronectides, Muracnoïdei; bei den meisten Fischen ist sie in einzelne, wenigstens äusserlich getrennte Segmente zerfallen. Nur bei Wenigen, z. B. bei Cristiceps, bei Lophius und einigen Pleuronectes erheben sich Flossenstrahlen auch noch von der Oberfläche des Schedels.

Die unpaaren Flossen besitzen anseheinend immer mehr oder minder solide Elemente. Bei Branchiostoma silzen auf dem vom Wirbelsysteme senkrecht aufsteigenden fibrösen Blatte hinter einander gestellte Strahlen,

1) Vgl. hierüber C. E. v. Baer, Entwickelungsgeschichte der Fische. S. 23. 1. 37. B. Fries, in Wiegmann's Archiv f. Naturgesch. 183S. 1. S. 256. C. Vogt, Embryol. des Salmones. p. 134. - Baer beobachtete bei jungen Cyprinen nach dem Ausschlüpfen eine zusammenhangende Flosse, die vom Nacken um die Schwanzspitze bis zum After und sogar vor diesem weg am Bauche hin sich erstreckt. Sie hat an der Stelle, wo der After sich bildet, eine Kerbe. Die einzelnen perennirenden Flossen entstehen so, dass in der primären zusammenharigenden häutigen Flosse für jene Knorpelstrahlen sich bilden, während in den Intervallen die Ilaut schwindet. - Fries machte die interessante Beobachtung, dass bei ganz jungen Individuen von Syngnathus lumbriciformis eine Schwanzflosse vorhanden ist, die ganz dieselbe Bildung und Form, wie beim Aal besitzt und als eines ihrer vorzïglichsten Bewegungsorgane dient. Vogt fand, dass die einzelnen Flossen bei Coregonus, mit Einschluss der Fettlosse, aus einer zusammenhangenden embryonalen Flosse durch secundäre Gliederung entstehen. 
beshehend ans röhrigen Capseln, die in zwei symmetrischen Seilenhïlften

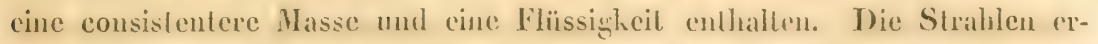
reichen das freie Ende dex Flosse nicht 2). -- Bei Pedronnyon bestelen die soliden Elemente in dïmnen, biegsamen, am Ende gabelfömigg gespaltenen Strahlen.

Bei den Elasmobranchii, Ganoüdei und Teleostei besilzen dic Filossen nichl nur selbst solide Grundlagen in ihren Strahlen, sondern diese erhatlen, wenigrsteus so weit sic der Rücken- und Afterflosse angehören. noch rigenc, dem Wirbelsysteme angefïgle solide Stälzen in den Flossentriaseru, während die Strahlen der Schwanzfosse den ron den Wirbelkörperu ausgechenden, meist platlenförmigg verbreiterten Forisiilzen ummillelbar angefiight zu sein pllegen. Die versehiedene Art der Anfï̈zung der Flossenträger an das Wirbelsystem erscheint meist dureh das verschiedene Verhalten der soliden auf- und absteigenden Elemente der Wirbelbogen bedingal. Wem die letzleren in gुanzer Ilöhe und Tiefe, ohne dureh häulige Interstilien ron cinander getrennt zu scin, sich ummiltelbar an cinander fügen. liegen die Flossentrïger jenseils ihrer freien Enden; wenn dic cinzehen Wirbelhogenelemente dagegen dureh membranöse Interstilien yon einander ge-

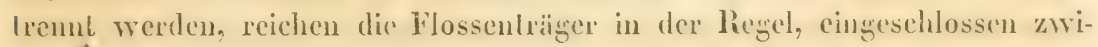
sehen den hänligen Blällern, meh oder minder weil in die Zwisehenräume der Wirbelbogenstüclie hinab und erhalten die Benemmms: Ossa interspinalia ${ }^{3}$ ). - Wenn bei den fianoïdei mul Teleostei solche Ossa interspinalice hïnfig ohne entsprechende Flossenstrahlen beobachtel werden, so crklärt sich dies mit Wahrscheinlichleit ans der, dem individuellen Plane soleher There angुemessenen. blos parliel erfolgten, volbsindign Lintrichelunщ der ursprönglich weit ausgedehnten Anlage des Flusisensystenes.

Bei den klasmohranchii mul bei Aceipenser liegen die filossenträger am Lï̈clien ïber, an der rentralen Seile unter den feeien Enden der Wirbelloggen, durch fibröses fiewelbe an dicselben eng angelneflet. Jerler wirkliche Flossenträger besteht antweder ans einem einzigen Knorpelstëtle, wie bei Chinacra, oder aus mehren ïber einander gelagerlen Stïclien. wie bei den Elasmobranchii mud bei Aceijenser. Bei den Teleostei sind die Flosscuträiger scllen den leeien Enden der Wirbelhogenelenente angefiigl, wic bei einigen Siluroüden und Loricarinen $\left.{ }^{1}\right)$. Meist liegen sic. als Ossa interspinalia, mehre oder minder lief hinabedehend, zwischen den, in Gostall dinfacher Jornen verlängerten, Bogenschenkehn, cingeschlossen von den beiden

2) VgI. II üller, Abh. d. Berl. Acad. d. Wissensch. Berl. 184t'. S. 85. Tb. 1. Nicht ganz übereinstimmend äussedt sich Quatrefages (I.c.)

3) Dass dicse Ossa interspinalia nicht dem Wirbelsysteme, als solchem angehüren, hat Cuvier gegen fe offroy und Andere, die diesem gefolgt sind, nachgewiesen. Ilist, natur, d. poissons. T. 1. p. 365.

4) Z. B. bei Aspredo, bei Ifypostoma u. A.

llandb. d, Zootomie y. Sicbold u. Stanniugs. II. 
Lamellen der diese trennenden fibrösen Membran. Oft liegen mehre Flosseulräger zwisehen je zwei Wirbelbogenclementen ${ }^{5}$ ). - B Bei einzelnen Teleostei, deren After mehr oder minder weit vor dem Anfange der Schwanzgregend gelegen ist, erscheinen auch vicle Träget der Afterflosse nichl zwischen die vereiniglen absteigenden Bogensehenhel geschoben, sondern vor ihnen liegend 6). - Sehr häufig hommen Flossenträger ohne entsprerhende Flossenstrahlen vor; sie haben dann oft, wenn gleich nicht immer, die, auch wirklichen Flossentrïgern biswcilen zukommende, Beslimmung `), Kuocheuschilder der Inat zu stïlzen. - In Bezug auf ihre Formen, ihre Ansdehmung und ihr niheres Verhalten zu den Bogenelementen verhalten sich die Flossenträger äusserst versehieden.

Bisweilen sind sie den Bogenclementen durch Naht verbmolen ${ }^{8}$ ). Bisweilen bilden die unleren Flossenträger dureh gegenseilige Anlagerung ein festes Sepım zwischen den beiden Kürperhällten lïngs der Sehwanzgegend ${ }^{9}$ ).

Eine Vervachsung mehrer Flossenträger mil cinander zu einem slarken abwärts und bogenformig vorwärts geriehleten Knochen findet häufig. besonders bei Fischen mil schmalem, seitlich comprimirtem Körper, an der unmiltelbaren hinteren Grenze der Rumpfhöhle Stall, welehe durch ihı von der Caudalgegend geschieden wird ${ }^{10}$ ). - Eine Verwendung dieses Flossentrïgers zur Bildung einer die Aufuahme des hintersten Lndes der Schwimmblase besorgenden IJ̈hle lïmmt bei cinigen Arten der Galtung Pagellus vor 11). - Eigenthümlich sind die bei cinigen Squamipenues und Scomberoüden vorkommenden Auftreibungen cinzelner Ossa interspinalia ${ }^{12}$ ). - Bei der Galtung Echencis werden die Flossentrïger, nebst ihren

5) Z. B. bei Pleuronectes platessa; bei Zeus faber; bei Notopterus Bontianus die Träger der Afterflosse. - In Bezug auf die Ossification der Flossenträger mag beilaufig bemerkt sein, dass bei Pleuronectes platessa eine corticale Knochenscheide um einen centralen Knorpel vorhanden ist.

6) Z. B. bei Pleuronectes, Brama Raji, bei welchem letzteren Fische diese vordersten Flossenträger durch unregelmässige Lage und theilweise Verschmelzung noch sich auszeichnen.

7) Bei Ilypostoma gehen für diesen Zweck eigene Seitenfortsätze von den Flossenträgern ab. - Flossenträger, in Gestalt einfacher Kinorpelstïclie kommen auch bei IIaien ohne entsprechende Flossen vor, $z$. B. bei Squatina vor der ersten und zwischen beilen Rückenflossen.

8) Z. B. bei IIypostoma. - 9) Z. B. bei Vomer Brownii.

10) Z. B. bei Zens faber, wo drei Flossenträger vollstïndig verschmolzen sind und auch die nächst hinteren verschmolzenen Flossenträger diesen sehr innig sich anschliessen.

11) Z. B. Pagellus calamus, penna. (Cuv. et Valenc. Vol. VI. p. 2019. Tb. 152.

12) Z. B. bei Ephippus gigas (S. Cuv. et Valenc. Vol. VII. p. 124.), bei Platax arthriticus, (ibid. VII. p. 230.), Hynnis goreensis (ibid. IX. p. 196.). 
Strahlen, zur Bildung des zum Ansangen hestimmlen Kopfochildes repwendet $\left.{ }^{13}\right)$.

Zweets Linlentumg der Flossenstrahlen besilzen die Flossentrigger an ihren freien Enden passende mechanisehe Vimrichlungen, die wieder mannichfach sind. Der Flossentrigger ist, in so ferne er der Einlenkung eines Flossenstrahles dient oft. z. B. bei Cyprinus, aus zwei. durch Symphyse verbundenen, trembaren Stücken gebildel. Eine an Ende des oheren Stïckes befindliche Gelenkgrube nimmt ein ans zwei Seitenhailften bestehendes Gelenklinö̈helehen auf, dessen obere rundliche Erhabenheiten den Verliefungen an der Basis des Flossenstrahles cutsprechen. - Ein Flossenstrahl kann aber auch an zwei Flossenträgern zugleieh eingelentit sein. wic das oft rücksichllich der harten, einfachen Strahlen vorkömmt. -

Die Flossenstrahlen ${ }^{14}$ ) selbst sind verschicden gebauet. Entwe. der sind sic durchyingig einfache spilze Knochen; oder sie besilzen zwei seilliche Ifilfien, deren Basis hnöchern zu sein pllegt. Während sie weiterhin ans geshliederten, weichen, oft ramificirten IIornstreifen bestchen. Die Grundlage der bei den Salmones, bei vielen Claracini, bei den Siluroüden u. s. w. vorkommenden Fettflosse bilden zu Faden eng verbundene Fasern.

13) S. Abb. bei Rosenthal, Ichthyotomische Tafeln. Das Schild besteht aus Querstäben (Flossenträgern) und zwischen diese eingeschobenen Stüclen (Flossenstrahlen).

1.t) Auf diesen Verschiedenheiten in der Bildung der Flossenstrahlen beruhet die Sonderung der Ínochenfische in Acanthopteri unil Nalacopteri. Die letztere Benenung erhalten dicjenigen Fische, deren sämmliche Flossenstrahlen gegliedert sind, währeud bei den Acanthopteri, nehen solchen, auch einfiche, ungegliederte stachelförmige Strahlen vorkommen. Müller hat die herkömmliche Unterscheidungsweise zwischen Acanthopteri und Malacopteri modificirt und zähit zu den Acanthopteri auch diejeniggen Fische, welche einen ungegliederten ersten Strahl der Bauchllosse besitzen. Bei manchen Ganoīden, z. B. bei Lepidosteus ist der vordere Rand der Flossen oder der erste Strahl mit stachelartigen Schinith (Fulera) besetzl. - S. darüber Il äller, Gamö̈len. S. 25. - Bei P'olyplerus sind die alegesonicrten Rückenliossen sehr merkwardig gebildet, indem sie aus einem flossenstrahle und ans einer falmenartig davon ausgelienden Reihe von Nebenstrahlen bestehen. 


\section{Zweiter Abschnitt. \\ Von den ïusseren Handecken und dem peripherischen Nervenskelet.}

\$. 47.

Die äusseren IIautdecken bieten eine ïusserst reiche und bunte Mannichfaltigkeit der Bildungsverhältnisse dar, welehe bedingt wird theils dureh die verschiedene Dicke der Cutis und der unter ihr abgelagerten Blasteme theils durch die An-oder Abwesenheit von IIartgebilden, welche oft zu einem mehr oder minder dicken Panzer zusammengefïgt sind. Zu lelzteren gehören namentlich: die Schuppen, die, oft mit schmelzilunlichen Schichten überzogenen, Ossificationen, die verschiedenen Stacheln und Tuberkehn, welehe sämmtlich rïcksichllich ihrer architectonischen Anordnung, ihrer

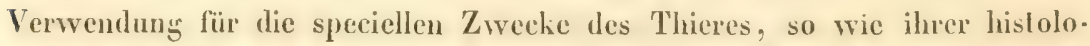
gischen Differenzirung wieder eine unabschbar grosse Mannichfaltigkeil des Verhaltens darbicten.

Die Dicke der Cutis, welche von den unterliegenden Mnskeln gewöhnlich durch eine silberglänzende und pigmentirte Gewelssschicht getrennt wird, ist nicht nur bei den verschiedenen Gattungen und Arten der Fische, sondern häufig anch an verschiedenen Stellen der änsseren Oberfläche desselben Thieres sehr verschieden. - Ein aufallendes Beispiel des Unterschiedes zwischen zwei Seiten des Körpers, in Bezuga aul Pigmentirmug und andere Verhältuisse, liefern die Pleuronectiden und besonders die Gattung Solea. - Die gewöhnlichen Bildungselemente der Cutis sind Fasern, dem Bindegewebe und dem elastischen Gewebe angehörig; meistens finden sich zwischen diesen, oder auch unter ihnen, in eigener S chicht, mit Fetl, Lymphe, Elementarzellen, Pigmentzellen, mehr oder minder gefüllte Räume. In diesem subcutanen Blasteme, das oft auffallend dick ist, gleichwie in der $\boldsymbol{C u}$ tis selbst, vertheilen sich Blutgefässe. Bedeckt wird die Cutis meistentheils von einer Schicht Pigmentzellen. Oberflächlich liegt endlich die, ans verschiedenartig gestalteten Zellen, welche gewöhnlich nicht pflasterartig an einander liegen, gebildete Epidermis ${ }^{1}$ ). Interessant siud die temporären Verschiedenheiten, welche das IIaulsystem mancher Fische, in Bezug auf Färbung und Exsudationen, daxbietet. Bei manchen Cyprinen, bei Cottus und

1) $\mathrm{Abgebildet}$ bei $\mathrm{Agassiz}$ et Vogt, Anatomie des Salmones. Tb. 0. Fig. 12. 13. Vogt hat 1. c. p. 107. mit allem Rechte darauf aufmerksam gemacht, dass der die Hautoberlläche der Fische bedeckende Schleim aus dieser abgestossenen, beständig sich erneucrnden Epidermis besteht. - Nan sieht z. B. bei Petromyzon diese Zellen in .den verschiedensten Entwickelungsstadien in dem Hautschleime. 
anderen Knochenfischen mämlichen Geschlechles erseheint die IIaut zur Begatlungszeil schön pigmentirl; zugleich erheben sich bei manchen männJichen Cyprinen um dieselbe Zeit unter dem Epidermial-Ueberzuge der Schuppen Exsudationen, um derentwillen diese Fische als Perlfisehe bezeichnet werden.

Die am häufigsten vorkommenden derberen, der Cutis angchörigen Elemente sind die Schuppen ${ }^{2}$ ). Diese hinsichtlich ihrer Formen, ihrer Ausdehmung, ihrer Ausbreitung in der Cutis unendlich variirenden IIartgebilde liegen cingebellet innerhalb geschlossener Capseln oder Säcke, die von Fortsetzungen der Cutis gebildet werden. Dic Haut, welche den CutisSack bildet ist an ihrer freien Oberfliche oft iusserst zart und an der Schuppe angewachsen. Das Wachsthum der Schuppen geschieht theils von der Peripheric der ganzen Schuppe aus, theils an den Grenzen der einzelnen, durch Nïhte ron cinander geschiedenen Stüclic der Sehuppen. Diese, wachsen auf Kosten des in den Nähten zwischen ihnen liegenden Blastemes. Die Nähte zeigen sich bald als vom Centrum gegen die Peripherie auslaufende Linien, bald quer verlanfend. An der Oberfliche der Schuppe gervahrt man oft, in dünner Schicht, cin vou der Cutis gesondertes membranartiges Blastem, welches Erhabenheiten und Vertiefumgen besitzt, dic den eben so gerichteten Unebenheiten der Schuppe selbst entsprechen; an ihrer unteren Flïche zeight sich ebenfalls hïnfig cine weichere Substanz von der Textur des Faserknorpels; beide oberflïhlichen Lagen gehen an den Rïndern der Schuppe bisweilen in cinander über, sind auch von der eigentlichen Substanz der Schuppe an deren Riudern kaum zu sondern. - An den Flächen der Schuppen haftet schr gerwöhnlich eine aus mikroskopischen flachen, länglichen, zugespilzten Plättehen bestehende Materie, welehe der IIaut der Fische ihren Metallglanz verleihet. - Was die elementare $Z_{\amalg-}$ sammenselzung der Schuppen aubelangt, so kommen unter und in ihnen oft eigenthümliche clliptische und auch viereckige Körper: die sogenannten Schuppenkörperchen vor.

Seltener lassen in ilnen strahlige Knochenkörperchen sich nachweisen ${ }^{3}$ ). In diesem Falle, wo sie also wirklich ossificirt sind, besitzen sie an ihree Oberfliche oft eine härtere schmelzähnliche Schicht. Rïcksichalich ihres Vorkommens und ihrer Anordnung verhallen sich die Schuppen verschicden. Sic liegen bald verstreuet und cinzeln in der Culis, bald, mol zwar

2) Bei den meisten Fischen decken sie einander Dachziegelfürmig; bei manchen sind sie in der Cutis mehr verstreuct, wie bei den Aalen. Bei den Suquamipennes sind Ruicken - und Afterflosse fast vollständig mit Schuppen bekleidet. - Die Schuppen des Seitencanales sind vor den übrigen durch aufgesetzte, bisweilen ossificirte Röhren, durch ramificirte Canäle, bisweilen durch die Bildung von Cristae und dergl. mehr ausgezeichnet.

3) Z. B. bei Polypterus, Lepidosteus, Thynnus vulgaris U. A. 


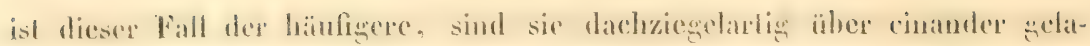

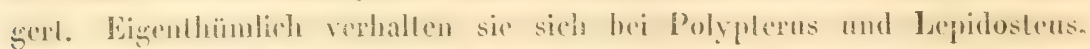
wo sie in schicten Binden stehen und wo die, cine Binde bildenden, Sehuppen durch Gelenkfortsätze mit einauder verbunden sind 4). - - Der freic Rand der Schuppen ist entweder munterbrochen, oder gezähnelt und gewimpert. Jieranf beruhet die Uniersehedihng der Sehmpen in Cy clö̈lSchuppen oder ganzrandige Schuppen und in Clenoid-Schuppen oder Kammschuppen.

Die Stelle der Schuppen wird bei vielen Fischen vertreten dureh Ossifieationen und Knochensehilder, welche z. B. bei den Aecipenserini, bei cingen Calaphacli, cinigen Silnoülei, den Loriearini, bei vielen Plectosnalhi und b: i den Jophohranchii angugtroflen werten. Solche Ossifieationen bilden oft cinen zusammenhangenden IIaulpanzer. Sic kömnen aber auch blos rinzeln und spärlich verslrenet in der sonst cinfachen Cutis vorhommen. - Die Knochensehilder sind sehr ga wähnlich von einer harten, shlalten, schmelzähnlichen Schicht an ihrer freien Oberfäehe bedeckl. Die Art ihrer gegenseiligen Verbindung ist versehirden. Bisweilen, wie z. B. bei Oslracion, sind dic polygonalen Knochen mosaikartig mit cinander verbunden; bei Diodon sind es rertikale Stachehn die von horizontalen, in der dicken Cutis haftenden Grundlagen ausgehen. Beri manchen Rajidae liommen cinzelne Stacheln ror, die in Bat und Entrickelung volle Uebereinstimmung mil den Zähnen besitzen. - Manche Fische sind mit cigenthümlichen Bewaffunngen versehen, welche ïber die IIautoherflïche hinansragen; so z. B. besitzen mehre Thentyi am Schwanze jeder Seite cinen Stachel, der bei den Arten der Gattung Acantlurus beweglich ist.

[Die Ilaut der Fische und namentlich die Schuppen derselben sind Gegenstand vicler Forschungen gewesen. Schon Leeuwenhoek hatte mit derselben sich beschäftigt. S. Anatomia Lugd. Bat. 1687. 4. p. 56. p. 104 sqq. - Baster, Opera subseciva. I. III. Tb. 15. - Heusing er, Histologie. Bd. 2. S. 229. - I untzmann, in den Verhandl. d. Gesells. naturf. Freunde in Berlin. Thl. I. S. 269 ff. Mt. Abb. Mlandl, in den Ann. des scienc. natur. 1839. XI. p. 347. und.XIII. p. 62. Agassiz, ebendaselbst. XIV. p. 97. - Peters in 11 üller's Archiv. 1541. p. CCIX. - Reiches Detail bei Agassiz, Poissons fossiles. - Alessandrini de intima squamarum textura piscium in d. Novi commentarii Acad. scientiar. Instit. Bononiens. 1849. Vol. IX. p. 371. (Cyprinus Carpio und Labrax lupus). - Williamson, On the microscopic struchure of the scales and dermal theth of some Ganoïd. and Placoìd. fishes. Philos. Transact. 1849. Part II. 1. 43. - Ueber Ilautknochen : II ïller, Myxinöd. Thl. I. s. 63.1

$$
\text { 5. } 48 .
$$

Dom äusseren Haulsysleme imig rerbunden ist cin System von Sïckden, Canälen, Röhren, welehe an bestimmlen Stellen der Hautoberllache

4) Z. B. Lota vulgaris. Ophidium. - 5) Alggebildet bei $\Lambda$ gassiz, Poiss. fossil. 
nach aussen münden. Sie bilden das Seilenporensystem oder Seitencanalsystem. Dasselhe ist bei den meisten Fischen vorwallemb an Kopfe antwiekell. Weil die diesem Systeme angehörigen Gebilde häufien einen mehr oder minder llïssigen Inhall besitzen und feei nach anssen münden, hat man sie lange Zeit für secernirend gehalten und sie als Schleimsiacke oder Schleimröhren bezeichnet. Bei dem ihnen zukommenden Reichthume an Nerven, welche aus den Bahnen des $\boldsymbol{N}$. trigeminus und $\boldsymbol{N}$. ragus hervorliommen, ist es schr wahrscheinlich gevorden, dass ihre wesentliche Bestimmung die sei, peripherischen Nerrenausbreitungen eine Unterlage und Slütze zı gewihren. In Rüclisicht hicranf könnten sie als ein peripherisches Nervenskelet aufgefasst werden. Die Anvesenheit dieses Systemes von peripherischen Gehilden gehört in den allgemeinen Bauplan der Fische und so verschiedenartign dieselben sowol in arehitectoniseher, als in histologischer Bezichung angelegt sein mïgen, so sind doch die Hauplghlieder dieses Systemes auf bestimmte, in ihren Grundzügen in allen Fischstuppen gleichatig wiederkehende Bahnen angewiesen. Diese Bahnen sind folgende: Von dem Vorderende der Kopfoberfläche aus erstrecken zwei Arme, welche serwöhnlich die Nasengrube ihrer Seite unfassen, sich hinterwïrts; der cine liegt oberhalh; der andere mulerhalb jerler Angenhöhle. Beide Arme vereinigen sich und setzen verbunden lïngs der Schläfengegend nach hinten sich fort, um hier durch eine quere Brïcke mil denjenigen der enfgegengeselzten Körperhailfte verbunden zu werden. Jedes Seitensystem erstrecht sich längs jeder Seite des Rumpfes, als eigentlich sogenamuter Seitencanal, von rorne nach hinten und zwar meist bis zum Ende des Schranzes. D) be den einzelnen Gruppen der Fisehe vorkommendin Abreichungen ron diesem typischen Verhalten beruhen: 1. auf mangeluster Entwichelung cinzelner Arne; 2. in der Zugabe of mächtign, selbststïndig und eigenthümlich entwickelter accessorischer Elemente zu den typischen; 3. in Modificationen, die durch eigenthümliche Anordnung oder Entwickelung gewisser Körpertheile, z. B. in abveichender Stellung der Nase, in slarker Entwickelung der Extremitälen. begründet sind.

Bei den Myxinö̈den I) scheint nur der Rumpftheil dieses Systemes entwickelt zu sein; er begimul entfernt ron der Schnauze. Auf den Zwischenraum zweier Ligamenta intermuscularia, von dem 9 ten an, bis zum Schwanzende hin, kömmt rin nach aussen mündender, runder, plalter Sack. - Bei Petromyzon is nur der vordere Theil entwiclielt. Ein Bogen von

1) S. d. Abb. bei J. Müller, Myxinoïd. I. Tb. 1. Jeder Sack ist nach J. M ïller von eigener muskulüser IIaut ungeben. Die innere Oberlliche ist glatt. Die Säcke enthalten cine grosse Anzahl ovaler lïrper, welche cincu in unzälligren Windungen aufgewickelten Faden bilden. S. Mäller, Eingeweide der Fische. S. 11. 
Poren 2) zicht hinter der moleren IItille des Maules sich hin; von jedem seiner Enden aus erstreckt sich ein Arm über, der andere unler der $\mathbf{A u -}$ grmhöhle nach hinten; letzlerer setzt unterhalb der Poribranchiales bis zu deren hinterem Ende sich fort.

Bei den Elasmobranchii erfïhrt unter allen Fischen dies ganze System seine grösste und, je nach Verschiedenheit der grö̈seren Gruppen und Galtungen, am meisten individualisirte Ausbilulung. Da die Nasengruben nach unten sich ëfuen, haben auch die zu ihrer Umgïrtumg beslimmten Schenkel ihre Lage nicht an der Oberfläche, sondern an der Unterfläche des Kopfes; für die meist stark enlwickelte Schnauze crstrecken sich Fortsetzungen des Apparates bis zu deren Vorderende; mit der von oben nach unten plaltgedrückten Körpergestalt der Ro. chen und der enormen Entivickelung ihrer Extremitaten lrangt es zusammen, dass bei ilnen der Rumpflheil des Seitencanales lïngs der Rïelicnflïche des Körpers nach hinten rerlänft. Das tranze System von Gebilden zerfillt bei den Plagiostomen: 1. in Centralröhren und deren Acste, ansgezcichnet dureh Dicke ilurer Wandungen, und 2. in meist dümmwandige Gallert-Röhnen. Beide plleggn nach aussen zu münden. Ton beiden kön nen noch 3. Systeme ron Blïschen untersehieden werden, die mit ihnen nicht communiciren und anch licine nach der Oberfliche hin frei ausmündende Oeffumgen besitzen.

Die dichwandigen Centralröhren bilden das eigentliche Sciteneanalsystem. Sic sind meistens ron fibröser, bisweilen von linorpelihulicher oder wirklich knorpeligger Textur mol haben im Ganzen den typisehen Verlanf. An der Oberflïche des Kopfes liegen sanz vorne Schenkel für die Solmauze oder die häntigen Bedectungen anderer vor dem Selıchel gelegenen Theile, ein unterer und oberer Augenhöhlenring: cin Schlïfenfortsatz und cine Quercommissur in der Ifinterhauptsgegend. Bald liegen sie Ioser muter der IIant, bald in liefer eingelurehten Stellen der Schedeloberfläche, bald etwas vergraben in seiner Knorpelsubstanz. Der Rompftheil ist eine Forlselzung des Schläfentheiles. Dic iusseren Pori sind, wie man namentlich bei den Rajirlae sieht, nicht Oeflnungen der Ilaupteanïle selbst, sondern die Enden von ihnen ausgehender Querschenkel. Stärliere, rom Rumpftheile ausgehende Seitensehenkel sind hei den Rajidac ausserdem fïr. die Oberfläehen der Brustflossen bestimmt ${ }^{3}$ ).

2) Die Poren führen in enge häutige Säckchen. Ihr Bau und die Beschaffenheit ihres Inhaltes sind mir nicht ganz klar geworden.

3) Eine gute Abb. des Verlaufes bei Torpedo findet sich bei Davy, Researches. Vol. I. Plate XI. Es ist wol ein Irrthum, wenn II. Müller (in Würzburg) S. 141. dieses System bei den nicht electrischen Rochen für unbekannt hält. Es ist dies dasjenige Rohrensystem, das, wie ich schon S. 51. der ersten Auflage bemerkt, bei einigen Rochen in ktirzer Strecke durch den Schedelknorpel tritt, das den allgemeinen 
An der meren Fläche des Kopfes I) liegen die Bogensehenkel für dir Nase mod fïr die untere Fläche der Schmauze, welehe sowol unler cinanfer, als mil den dorsalen Röhren zu communiciren pflegen. Bei Acanthias z. B. erstreckl sich ein von der Schlifengegend absteigender Schenkel lïngs der Aussenseite der Kiefergegend vorwiets und spaltet sich in zwei gewumblene. in Unkreise der Nase sich hinziehende Aeste: einen inneren und cinen äusseren. Die immeren Aeste beider Sciten Iegen sich in der Mitle der Unternïche der Schnauze dicht an einander; der äussere zieht sich um den liand der Schnauze herum nach oben. Bei den verschicdenen Rochen ist dies System in seinen Grundzïgen ähnlich, im Einzelnen sehr variabel ausgebildet. Die Fortselzungen der Supraorbitalschentiel erstrecken sich vor dem Sehedel z. B. bei mehren glatthïutigen Trygones in die Tiefe und communiciren so mit dem unter dem Kopfe gelegenen Röhrensysteme. Dies bildet reiche gewundene Geflechte unter dex IIant der Nasenklappe, dam zwischen der Nasengrube und der Spilze und den Seiten der Seheibe. Forlselzungen dieser gewundenen Canäle erstrecken im Umkreise des ganzen Bogens der Ossa carpi, also auswärts von der Kiemengegend und deu Banchhöhle, nach hinten. Secundäre beträchtliche Aeste verlaufen unler der IIant der Mitte der Flossengegind. Die cinzelnen Gattungen und selbst Arten bieten gervisse Eigrenthümlichkeiten des Terlanfes der Röhren dar.

Die dünnwandigen Gallertröhren ${ }^{2}$ ) münden cinerseits frei an der IIautoberfläche und enden andererseits mit einer Impulle, in welche cin Nervenstïmmchen cintritt. Die dünnwandigen Röhren selbst sind mil ghlasheller Gallerte erfüllt. Die blinden Enden der Gallertröhren liegen in Päichehen gesammelt, die oft von eigener Faserhaut umhïllt werden. Sie finden sich vichleicht bei allen Plagiostomen. Am deullichsten und reichlichsten sicht man sie bei den Ilaien, sowol in der ganzen Schnauzengegend, als auch längs dem Verlaufe der Centralröhren.

Verlauf des Seitencanalsystemes aller Fische theilt, dessen Verlauf denjenigen der Aeste der Seitennerven bei haja modificirt (Periph. Nervensyst. d. Fische. S. 10.., ) das, meines Wissens, seit langer Zeit allgemein bekannt war. Müller's Citate aus der ersten Auflage dieses Buches dürfen nur auf dies System bezogen werden.

1) Die grösseren Canäle und einzelnen Gallertröhren der unteren Fläche von Liaja sind alıgeb. bei Monro, Vergleichung des Baues der Fische. Tb. 5. u. 11. (11. u. 12. des Originales). - S. über die grösseren Canäle II. Müller, S. 140 ff.

2) Es sind dies Savi's Organes muciféres, p. 329. Abbildungen des Verlaufes dersclben s. b Savi. Tb. 3. Fig. 10, einzelne Röhren mit ihren Ampullen, Fig. 11. Fig. 15. - Abbildungen der Ampullen bei verschiedenen Plagiostomen bei Leydig, Beiträgc. Tb. 2. Fig. 1-6. - Ein Conglomerat solcher Gallertröhren am Unterkicfer von lhaja ist, wie ich gezeigt habe, Periph. Nerv. d. Fische. S. 66., von Swan für ein Ganglion gehalten. (Illustrations of nervous system. p. 66.). S. II. Nüller, I. c. S. 13t-139. 
Jie. Bläschen ${ }^{3}$ ) sind von $\mathrm{S}$ avi als Appareil folliculare nerveux bei den Torpedines besehrieben worden. Sie liegen hier reilenweise anf sehnigen Strïngen an der muteren Flïche des Kopfes, in der Cirenmferenz der Nasenswuben, an der Nasenhlappe, zwischen den Flossendinorpeln und dem chetrischen Organe. Sie umschliessen gुleichfalls eine glashelle Flüssigkeil und graue scranulirte, Zellen und Kerne enthaltende amorphe Masse, in welche ein Nerv cintritt und aus welcher Nervenfasern wieder anstrelen, $10 \mathrm{~m}$ in cin benachbartes Bläschen sich zu begeben.

Alle diese verschiedenen Gebilde dienen zur Aufnahme peripherischer Vervenausbreitungen; diese stammen aus ciuer gemeinsamen centralen Quelle: den Corpora restiformia. Diese Nerven besitzen breite Primitivühren welehe Inslïufer hipolarer Ganglienkörper sind. Sie verlanfen in den Bahnen des $\boldsymbol{N}$. trigeminus und facialis, so wie des $\boldsymbol{R}$. lateralis $\boldsymbol{N}$. vagi $\left.{ }^{`}\right)$. - Die zur Anfuahme der Enden dieser Nerven bestimmten Gebilde haben sïmmllich mehr oder minder den oben geschilderten typischen Verlauf, dem derjenige der peripherischen IIautnerven accommorlirt ist. Sie rlürften als histologisch rerschieden differenzirte Antheile des nïmlichen Apparates zu betrachten sein.

Bei den Chimären crhält sich der typische Verlanf der dickwandiggen Centralröhren an Kopfe und am Rumpfe. Ilinter dem Unterkiefer funden sich zwei quere absteigende Bogen. Vorne an der Schnauze kommen deren mehe vor. Die Röhren gुehen an einigen dieser Bogen in weitere nach aussen geöthnete Habcanäle ïber. Diese sind von Stelle zu Stelle weiter geöfnet und besitzen solide Grundlagen in knöeheruen ${ }^{5}$ ) Reifen. Die weiter geöffneten erhabenen Stellen werden durch niedrigere, nicht so unterstützle nuterbrochen. - In der Schnanzengegend finden sich den dünnwandigen Gallertröhren analoge Gebilde in reichster Zahl, welche die nämlichen Nerren aufnehmen ${ }^{6}$ ). - Bei Accipenser und Spatularia liegen letzleren entsprechende Gruben, eigenthümlich gruppirt, unter der Sehnamze und am spatelförmigen Schedelfortsatze.

Bei den Teleostei liegt das vorderste Ende des peripherischen Nervenskeletes ${ }^{7}$ ) gewöhnlich an der Innenseite jeder Nasengrube; scin unterer

3) S. Savi, 1. c. 332. Tb. 3, Fig, 10. 12. 13, - Leydig, Tb. 3. Fig. 6. VgI. II. II üller I. c. S. 139-140.

4) S. meine Schrift über d. periph. Nervensystem d. Fische an viclen Stellen. S. 30. 38, 108 u.s.w. - S. über die Eintrittsweise der Nerven Savi; über diesellbe und ilır weiteres Verhalten besonders II. Il üller.

5) Auf diese histologische Eigenthümlichkeit hat Leydig aufmerksam gemacht. Il ïller's Archiv 1851. S. 241.

6) S. meine Schrift üb. d. periph. Nervens. d. Fische u. d. Aufsatz v. Leydig.

7) Es gibt Fische, bei denen solide Grundlagen für die Nervenausbreitung nicht aufzufinden sind. Dahin gehören Lophius, Chironectes, Malthaca, die meisten Plectognathi. Bei Batrachus sind sie abortiv vorhanden. - 
Arm bilded einen Infraothitalbowen; sein oberhalb der Ansentiöhle rerlanfimder A:m folut dem os frontale mol selat längs dem Os parielale nach hinlen sich lort, mu mit dem der anderen Seite dureh cinen längs der hinferen Grenze der Ossa parielalia verlaufenden Querarm sieh zu verbinden s). Ein tieferer unterer Arm besinnt an der Verbindumsstelle der beiden Unterkieforhälften, erstreckt sich am Unterkiefer hinterwïrts zur Grenze des Pracoperculum, verlïuft in diesem aufirïls zur Schlifengegend und von hier aus zur Omolila, wo der obere Arm in iln cinmündet, damit beile vereinigh lïngs dxm Rumple, als Scitenlinie oder Seiteneanal zum Schrranzende sich fortsetzen. - Das peripherische Nervenslicled besilzt hisweilen theilweise selbstslindige Röhren oder IIabean̈lle, welehe nanentlieh ron der Nasengegend an. als Tnfraorbilalbogen, und in ihrer bis zum Schultregtirtel hin gerichteien und weiter lings dem Rumpfe verlaufenden Forlstzung, weder anderen Skoldtheilen, noch auch den Schuppen eingefïg sind. In diesem Falle haben die seibstsländigen Röhren und IIalhrantile meistens eine knöcherne Textur 9); seltener bestehen sic aus einem derben, eng in die Cutis eingebeltelen faserigen fewebe, dem bisweilen etwas Knochensubstanz eingesprengt ist ${ }^{10}$ ). - Meistens aber hat das periplierisehe Nervenskelet der Teleoslei seine Selbstständigkeit verloren und erseheint durchgängig als ein Röhren- und Canalsystem, das am Kopfe dessen Knochen, am Rumpfe den Schuppen cingefïgt oder innig und fest aufgeselzt ist "1). Folgende Kopflinochen werden geviohnlich zu scincr Auf-

8) Es findet sich bisweilen eine vordere Quercommissur und eine hinter der Grenze des Schedels gelegene zweite wie z. B. bei Muraenophis.

9) Dies ist namentlich der Fall bei vielen, aber nicht bei allen Gadoüden. Vorzüglich schön ausgebildet in Gestalt selbstständiger subcutaner Ifalbcanäle, die am Rumple längs eincr Strecke sich wiederholen, erscheinen sie bei Lepidoleprus und bei Raniceps; namentlich sind sic bei letzterem Fische am Kopfe ebenso, wie am Rumpfe gebildet; doch setzt sich bei diesen beiden Gattungen das System der in einer ticferen fibrösen Cutis-Schicht gelegenen Kinochen nicht weit nach hinten am Rumpfe fort. Viel weiter mach hinten reicht es bei Gadus und Lota; vorne sind sie grösser und dichter, hinten stehen sie entfernter und werden abortiv. Vermisst habe ich sie bei Plycis und Motella, - Beim Aal und bei Muraenophis ersclicinen sie als sulscutane Knochenrühren, die in fibröser Ilautschicht sich entwickelt haben. Beim $\Lambda$ al kannte sie schon Stenonis (.Myologiae Specimen. Amstel., 1669.). Bei diesen Aalen sind die Grundlagen der lä̈hren aber am Kopfe theilweise plattenförmig ausgebreitet. - Als in der Ilaut gelegene linochenrobren kommen sie auch am limmple soleher Fische vor, bei denen sie am Kopfe nicht selbststiundigr, sondern den Kuochen des Gesichtspanzers eingefiigrt sind. So z. B. bei Cottus scorpius und anscheinend mehren anderen Catiphhracti, unler denen ich sic bei einer Synanceia gefunden habe.

10) So bei Silurus unter den Teleostei; bei Spatularia unter den Ganoïden.

11) So wenig als in den linochen, namentlich denen des Infraorbitalbogens, als in denen der Schuppen kommen immer einfache Canale vor; dieselben sind vichehr hiulig stark ramificirt. - Die den Schuppen zur Canalbildung aufgeselaten kleinen Bogen enthalten bisweilen Iinochemsulstanz. - Die Canalhiddenden Schuppen der 
nahme verwendet: scin vorderes Ende an der Oberflïche des Kopfes liegt im Os terminale; sein Unteraugenhöhlenarm vird von den UnteraugenhühIenknochen des Gesichtspanzers, sein oberer Kopfarm rom Stirnbeine und Scheitelbeine, sein tiefster Arm vom Os dentale des Unterliefers und ferner vom Praeoperculum aufgenommen; die Fortsetzung zum Schultergürtel liegl entweder im Os mastö̈deum oder ist selbstständig, als $\boldsymbol{O}$ s supratemporale und Os extrascapulare. - Mag das peripherisehe Nerrenskelet selbstsländig oder bestimmten Knochen und Schuppen eingefügt sein, fast immer sind nach aussen mündende Oeffnungen seiner cinzelnen Glieder sichtbar; besonders deutlich und weit erscheinen dieselben gewöhmlich längs dem ganzen Kopftheile. Oft liegen die Mündungen dicht unter der Ilaut, bisweilen tiefer; dann führen, von der Hautoberflïche aus, Günge zu ihnen, deren ïnssere Circumferenz aus fibrösen Gewebstheilen gebildet ist ${ }^{12}$ ). Ebenso finden sich in beiden Fïllen an der Innenseite derselben Oefrnungen, bestimmt zum Durchtritte von Nerven und von Gefässen.

[Dies Seitencanalsystem der Fische ist Gegenstand vieler Untersuchungen gewesen. Stenson, Redi, Lorenzini, Perrault, II onro, Camper sind die alteren Naturforscher, die ihm ihre Aufmerksamkeit zuwendeten. Der Umstand, dass es gewöhnlich nach aussen geöfnete Mündungen besitzt, liessen in ihm einen Secretionsapparat vermuthen, und zwar um so mehr, als es oft gelingt eine Flüssigkeit aus den äusseren Poren desselben hervorzudrücken. Der eigentliche Inhalt erschien mehren Naturforschern und zwar selbst solchen, die den Nervenreichthum und die Gefïsse dieser Gebilde kannten, wie namentlich mir sellst bei früheren, lange Zeit hindurch nicht wiederholten, Untersuchungen drüsig und gleich Cuvier, Wagner, Savi, die von denselben Voraussetzungen ausgingen, hiclt ich diese Anschauungsweise fest. Blainville hatle sich schon nicht zu Gunsten derselben ausgesprochen; Jacobson und Treviranus hatten den Apparat bei den Plagiostomen für ein besonderes Sinnesorgan gehalten; Vogt hatte dann bei Knochenfischen seinen Zusammenhang mit Lymphgefässen nachgewiesen, auch die Ansicht, dass er Schleim absondere, bekämplt. Leydig ist endlich, nachdem ich wiederholt auf den Nervenreichthum der damals sogenannten Schleimröhrenknochen und der Theile des Seitencanales aufmerksam gemacht, in der Eeschreibung des Verhaltens der Nerven innerhalb derselben mir zuvorgekommen, indem er zeigte, dass die in den Schleimröhrenknochen und in den Theilen des Seitencanales vorkommenden von langen Zellen bedeckten Bläschen Schlingenformig verbundene und sich theilende Nervenfibrillen enthalten. Diese Nervenfihrillen werden im Zustande der vollen Entwickelung der Organe von lymphatischer Flïssigkeit umspült. Bemerkenswerth ist meine Erfahrung, dass beim Ilechte diese Blasen während

Scitenlinie folgen bald der Grenze zwischen Dorsal- und Ventralmasse des Seitenmuskels, hald liegen sie oberhall, z. B. hei Ammodytes, bald (wie bei den Scomberesoces, weit unterhalb derselben. Diese Schuppen bilden bald ein Continuum; bald ist ihre Reihe so unterbrochen, dass die der Schwanzgegend in einer tieferen Reihe stchen, welche die des Rumpfes nicht continuirlich fortsetzt, wie bei vielen Chromiden.

12) Z. B. bei Motella an Kopfe, bei Muraenophis am Rumpfe. 
strenger Winterkälte ganz anders sich verhalten, indem die Nerven zu atrophiren und zum grossen Theil zu zerfallen scheinen. - Da nun die vermeintlichen Drüsencanale nicht existiren, schliesse ich mich der Ansicht an, dass die wesentliche Bedeutung dieses der llaut adjungirten mehr oder minder soliden Systemes darin bestehe, peripherische Nervenaubloreitungen zu unterstützen. Dass sie ein besonderes, nur den Fischen eigenthümliches Sinnesorgan heherbergen, möchte ich darum noch nicht annehmen, denn es liegen auch bei anderen Thieren die Enden der IIautnerven in häutigen Bläschen, welche eine helle Flüssigkeit enthalten. In wie ferne die in den Iohlräumen enthaltenen lymphatischen Flüssigkeiten als Blasteme für die Neubildung von Nervenfibrillen sich erweisen möchten, bleibt noch zu erforschen.

Han vgl. üher diese Gebilde bei den Plagiostomen: Blainvilles, Principes d'Anatomic comparée. Paris, 182\%. T. I. p. 152. Jacobson, Isis 1843. p. 406. S avi bei ll atteucci, Traité des phénomenes èlectro-physiologiques des animaux. P’aris 1844. Leydig, Beiträge z. mikroskop. Anatomie d. Rochen u. Iaie. Lpz. 1850. II. Il üller, in d. Verhandlungen d. med. phys. Gesellschaft zu Würzburg. 1851. S. 13ł. bei den finochenfischen: meine Jitheilung in Froriep's Notizen. April 12t2. Nr. 469. bezïglich der Schleimröhrenknochen, der Agassiz, Owen u. Andere unbedingt gefolgt sind, freilich ohne llinweisung auf die Quelle; über die Verbindung mit Lymphgefãssen: Vogt und Agassiz Anatomie des Salmones p. 137, über die Nerven dieser Theile: meine Schrift uber d. peripherische Nervensystem der Fisclie: iiber das Verhalten der Nerven in diesen Gebilden: Leydig und Müller's Archiv. 1850. S. 170. und 1851, S. 235. Nt. Abb. - Alle speciellen Erörterungen müssen, so mancher Stoft immer vorliegt, hier ausgeschlossen bleiben.]

\title{
Dritter Abschnitt.
}

\section{Vom MHslielsysteme und den electrischen Organen.}

\section{Uebersicht der Ninskeln.}

\author{
5. 49.
}

Die gesammie Muskelmasse, welehe das Skelet der Fische auswendig bedeckl, zerfillt - abgesehen von der Muskulatur der Gesichlsknochen mud des Visceralskeleles - mindestens in Musheln des Wirbelsystemes mol solche des Flossensystemes. Die Muskehn des Wirbelsystemes kïmnen bald zugleich zur. Umschliessung der liumpfhöhle verwendet werden, bald kënnen, lïngs dem Verlaufe dieser lelzteren, eigene Systeme von Bauchmuslieln. welche nur am Schwanze fehlen, eingeschallet sein.

Dic Musluulatur des Wirbelsystemes zeigh bei dex Mchrahl der Fische cinc cigenthümliche Anordnung. Diese besteht darin, dass von dem Wirbelsysteme und sinen Fortsätzen, so wie fermer fon den lippen oder den fibrësen ïusseren Bekleidungen der Rumpliühle aponeurotische Ausbreilun- 
gen ausgehen, welehe von vorne nach hinten und von imen nach anssen so gerichtet sind, dass ihre änsseren freien Enden nach Entfernung der Culis in Gesialt von schmalen Streifen, die die Muskehnasse durehzichen. zu Tage liommen. Indem die Aponenrosen sehief ron vorne nach hinten und von innen nach aussen durchtreten, müssen auf (uerschnitlen mehre Systeme der Streifen, die ihre Enden bezcichnen, in cinander geschachtelt erseheinen. Diese aponeurotischen Ausbreitungen, deren Anzahl derjenigen der Wirbelkörper entspricht, von deren Milte je cine ausgeht, bilden sehief durchtretende Sepla, welehe die der hinteren IIïlfte des cinen und der vorderen des folgenden Wirbels entsprechenden Muskiclfasern seharf von einander sondern. - Das System dieser aponeurotischen Ausbreitungen ist gevöhnlich so angeordnet, dass rine Symmetrie zwischen dem Systeme der dorsalen und der ventraken Muskinatur des Wirbelsystemes hervortrill. Dies geschicht dadureh dass cine miltlere vom Schwanz nde bis zum Kopfe sich hinzichende Furche, deren Richtung bei manchen Fischen genau dem Verlaufe der medianen Querfortsätze der Wirbellë̈rper ritspricht, osuc Theilung in eine dorsale mol ventrale Mälfte der Muskelmasse und ihrer Aponeurosen bewirlit. Die Mehrzahl der Teleostei bielet Beispiele dieser medianen Sehcidung der dorsalen und ventralen IIälfte des vertebralen Muskelsystemes dar, dureh welehe eine der Anordnung des Wirbelsystemes cutsprechende, selten vollkommene, Symmetrie zwischen oben und unlen bewirkt wird. Diese Scheidung beider Muskelmassen liegt aber nicht unab:̈nderlich im architeclonischen Plane aller Fische, dem sie mangell z. B. bei Pelromyzon 1), obschon hier noch keine selbstsiandigen Banchmuskeln zur Umsehliessung der Rumpfhölıle auftreten. - Diese letzleren erscheinen als nene Elemente für die Rumpfgegend aber schon bei den Myxinö̈den.

Doch bei weitem nicht bei allen Fischen erhält sich die erwälnte lypische Anordunng des vertebralen Muskiclsystemes vollständig und rein ausseprägt; unter den Teleoslei trilt z. B. bei d'n Aalen, cine Sonderung seiner Dorsalhïfte in eine tiefere und eine oberflichlichere Mushulatur cin. Bei den Plectognathi Gymmodontes und Ostraciones wird das vertebrale

1) Bei Petromyzon erstrecken sich von einer solchen Aponeurose zur anderen zahlreiche, dicht an einander liegende Scheidewände, welche also den Zwischenraum zweier Intermuskularbänder in gerader Richtung durchsetzen. Zunächst jedem Septum liegt etwas fett - und gefissreiche Muskelsubstanz; im inneren Raume jedes durch die Septa umschlossenen Kästchens aber liegt eine muskulöse Schicht, welche das Eigenthümliche besitzt, dass sic in zahlreiche ganz dünne Lamellen oder Blättchen zerlegt werden kann. Die ganze Einrichtung zejgt eine unverkennbare Analogie mit der Bildung des electrischen Organes der Torpedines. Nerven und Gefässe hale ich zwischen diesen Muskelblättchen nie wahrgenommen. S. meine Mittheilungen üher den Bau d. Muskeln bei Petromyzon fluviat. in d. Nachrichten d. königl. Gesells. d. Wissensch. z. Göttingen. No. 17. 1851. 
Muskelsystem, im Gegensatze zu den ïusserst stark entwickelten Muskelu der Rücken-, After- und Schwanzllosse, ganz abortiv mud dïmne Banchmuskelu slejgen rom Rücken zur Umschliessung der Rumpfhöhle abwärts. - Bei den Elasmobranchii begegnet man ciner Sondermug der vertedralen Muskulatur in einzelnen Muskeln, welche, obschon mannichlach mnta. rinander durch ihre Schnen verflochlen, ciner Reduclion anf die Rüblacnmul Sehwanzmuslieln höherer Wirbellhiere fïhig zu sein scheinen.

[Man vergl, über die Anordnung der Muskeln bei den Myxinoiden: Mïller, Vgl. Anat. d. Myx.; bei Petromyzon: Rathke, Ban der Pricke; über die Rëicken - und Schwanzmuslich von Raja: Robin, Annales des sciences natur. 1847, auch als besonderer Abdruck: Theses de zoologie. Recherches sur un appareil qui se trouve sur les poissons du genre des Raies. Paris, 1847. 8.; über die Muskeln von Perca: Cuvier, in der llist. nat. d. poiss. Vol. I.; über dic des Coregonus: Vog t et $\mathbf{A g a s s i z}$ Anatomie des Salmones; über die der Orthagoriscus: Goodsir, in den Annals of natural history. Vol. VI. p. 522.; üher die des Lepidosiren: Il y $\mathrm{HI}$, Lepidosiren. S. 13. - Ausserdem s. die grösseren Handbücher von Cuvier und Meckel. - Die verhältnissmässig sparsamen Vorarheiten gestatten noch lieine vergleichende Uebersicht der Muskeln von Fischen aller Gruppen; deshath beschränke ich mich auf eine liurzo Charakteristik der Iluskulatur der typischen Teleostei.]

\$. 50 .

Bei den Ganoüden und denjenigen Teleostei, deren Wirbelsäule in ihrer ganzen Lïnge durch entwickelte obere und untere Bogenstïclie mehr oder minder entschicden symmetrisch in eine dorsale und entsprechende ventale IÏ̈lfte zerfïll, is die das Wirbelsystem aussen bedechende Muskelmasse gewöhnlich in eine dorsale und ventrale Porlion von mehr oder minder symmetrischer Anordnung geschieden.

Jede Seilenhälfte des Rumples wird nimlich von einer starken MusLichasse, deu Seitenmuskel, cingenommen, welcher vom Ende des Schwanzes aus oben zum Hinlerhaupte, unten zum Schultergürtel sich erstreckt. Eine mittlere Lingsfurche theilt die jede Seilenhälfte des Rumples einnchmende Muskehmasse in eine dorsale und ventrale IIalfte. In der Gegend dieser Lïngsfurche erhebt sich gewöhnlich die ausgebildete Masse des eigenflichen Seitenmusliels am wenigsten nach aussen; viehmehr entsteht hier, inden die dorsale, wie die ventrale IIïlfte des Muskels nach der sie tremenden Furche hin sich abdachen eine mehr oder minder seichte Verliefung, welche häufig von Muskelfasern ausgefüllt wird, dir cincu mehr embryonalen Charakter tragen und oft sche fettreich, gefüssreich und röblelich sefärbt sind ${ }^{1}$ ). An der Oberfläche des Scilenmushels erscheinen zahleciche.

1) Agasiz und Vogt, 1. 60, bezeichnen diese Muskelmasse als IIautmuskel. Indessen hat schon Leydig, (Beiträge zur mikrosk. Anit. d. Rochen U. IIaic, S. 77.) auf den embryonalen Charakter der Primitivbündel dieser Muslecllage bei Abramis brama 
im Ganzen parallele, sehnige Streifen. Jeder Streifen verläuft von der Milte der Gegend eines Wirbelliörpers aus in seiner grössten Streclie schrä̈g hinterwïls und bildet dam einen mehr oder minder spitzen Winkel, indem er die Richtung nach vorn eimnimmt. Dieser Winkel pflegt in der Sehwanzgegend spitzer, als in der Rumplgegend zu sein. Die an der äusseren Oberflïche der Muskulatur erscheinenden Streifen sind die Säume dureh die eigentliche Muskelmasse durehtretender und sie in einzelne $\Lambda \mathrm{b}$ theilungen sondernder Ligamente. Ein solehes Ligament ggeht rou der Mitte jedes Wirbelkürpers aus mod ist zunächst längs der ihm angehörigen mteren und oberen Bogensehenlel, in der liumpfogegend auch längs fler jenen angefïgten Rippen befestigt, biegt sich aber am Ende jeder dieser Wirbelfonlsätze gewöhnlich unter mehr orlex minder spitzem Winkel nach vorme um. Solide Stützen erhalten diese Ligamente sehr häufig in den bei den verschiedenen Fischen verschiedentlich entwickellen Floischgु ren Richtung am Shelete den Verlaul der Ligamente pezeichnet. Es zere fällt also der Seitemmuskel in so viele Abtheilungen als Wirbelkërper und Spinaluerven vorhanden sind. Vermöge ihrer Anhefturgstreise an den von jedem Wirbelkörper aus hinterwärts gerichteten oberen und unteren Bogenschenkeln sind dir an den Bogensehenheh und Rippen sich befestigenden Segmente jedes Ligancules oben, wie unten, nach hinten gerichtet. Beide Segmente ;ossen also convergirend an ihrem mitlerem, dem Wirbelkörper angehefteten Theile in einem vorwärts gerichtelen Bogen zusammen. - Jedes Ligament durchsetzt aber von inmen nach anssen die MusJelmasse nicht in verlicaler Richtung. Viehmehr arscheint das den Wirbelfortsätzen angehörige obere und untere Segment jedes Ligamentes, während es von der linöchernen Wirbelsäule nach der Ilaul hin aufsteigh, nach der Kopfseite hin convex, nach der Schwanzscile hin ansgehöhlt, bilded also gewissermaassen eine rom Millelpunkte der Wirbelsäule aus sehräg hinlerwärts gुerichtete, nach vorn convexe, nach hinten ausgonöhlte Rime. Jede mehr vorn gelegene Rimne ist weiter, als die nächst hinlere und umfasst diese zum grossen Theile. Wenn nun die schnigen Bänder, genan

aufmerksam gemacht. Wic bei diesem Fische, verhalten sich nach meinen Untersuchungen die Primitivbündel dieser Muskellage bei Salmo salar und bei Belone. Sie stimmen auch mit denen der Augenmuskeln von Petromyzon überein. - Gieich wic an den Augenmuskeln von Petromyzon, sieht man auch in dieser Muskulatur namentlich derjenigen der Schwanzgegend des Lachs - die Umwandlung von capillaren Blutgefässen in Muskelelemente. - Ich möchte, nach Maassgabe meiner bisherigen Beobachtungen, dies rothe, fett- und gefassreiche Fleisch fur in der Bildung begriffene Muskelsubstanz erklären. Zugleich ist es mir wahrscheinlich geworden, dass die oft vorkommenden ramifieirten, mit querovalen fiernen und feinliörnigem Inhalte versehenen Muskelrühren blos provisorische Bildungen sind, deren Intergang der definitiven Bildung von Muskelsubstanz vorausgeht. 
dem Verlaufe der Wirbelfortsätze folgend, da aufhörten, wo diese endigen, so wïrden die beiden von der Mitle eines Wirbelkörpers ausgehenden Ligamente: das obere und das untere zusammen einen Hohlkegel darstellen, mit nach vorn gerichteler Spilze und mit später divergirenden auf-und abwiirts gerichtelen Schenkeln. An Eude jedes Wirbelfortsatzes nimml aber jedes Band, unter Bildung eines hinterwärts gerichteten Winkels, eine, der bis dahin verfolgten, entgegengesetzte Richtung an. Seine hinterrärts gerichtete Concavitït war schon, je mehr es vom Wirbelkürper sich entfernte, allmälich immer flacher geworden, zuletzl verschwanden und in einc vorwïrts gerichtele IÏhlung übergegangen; diese zeigh sich auch an dem, als zweitem Winkelschenkel, von ihm ausgehenden vorwärts gerichteten Blatte. Durch diese Verhältuisse kömmt es, dass jedes Ligament an der Stelle wo der äussere Winkel erscheint, einen hinterwïrts gerichteten IIohlkegel oder Iohlkegelabschnitt bildet, der den Iohliegel des nächsL vorderen Ligamentes aufnimmt. Auf diese Weise bildet jedes Querband drei zusammenhangende Hohlkegel oder Iohlkegelabschnitte; die Spitze des mittleren ist nach vorne, die Spitzen des oberen und unteren sind nach hinten gerichtet. Von hinten nach vorne stecken die Hohlkegel aller einzelnen Querbander successive in einander, in der Weise, dass die hinteren die spitzesten sind, während die vorderen allmälich immer stumpfer und weiter werden. Der Zwischenraum zwischen zwei solchen Querbïndern wird durch Muskelfasern ausgefüllt. Die so eben gesehilderten Verhältnisse des Seitenmuskels erfahren häufige Modificationen. Die Symmetrie zwisehen der ventralen und dorsalen Ï̈̈lfte desselben erscheint meistens nur in der Schwanzgegend vollstïndig ausgeprägt; in der Rumpfgegend, wegen der durch die Rippen bedingten Erweiterung der Bauchhöhle und wegen der oft überwiegenden Kürze der oberen Bogensehenkel, mehr verwischt. In der Rückengegend des Rumpfes sind die hinterwärts convexen Hohlkegel des sie bedeckenden Segmentes des Seitenmuskels oft sehr viel stärker rückwärts gerichtet, als in der Bauchgegend.

Der Dorsaltheil des Seitenmuskels befestigt sich vorn an dem Schedel, und zwar meistens mil eiuem Hauptschenkel an dem Schedeldache, weleher bei den mit stark entrvickelter Crista occipilalis versehenen Fischen auswärts derselben sich anlegt. Der Ventraltheil des Sritenmuskels sendet gleichfalls ein Fascikel zum Schedel, der an dem Seitentheile desselben endet. Er befestigt sich jedoch wesentlich an der muteren IIälfe des Schultergürtels, und von der Vereinigungsstelle der beiden Claviculae aus erstreckl sich seitwärts, an den Zungenbeinkiel angelegrt, eine unter dem Namen des MI. sternohyoüdeus bekamule Fortselzung zum Zungenbeinkörper. 


\section{\$. 51 .}

Das ganze System ron Visceralbogen versehiedener Weile ist bei den Teleostei in hohem Grade beweglich und die verschiedenen Muskeln jedes cinzehen Gliedes lassen sich in gerrisse, wesentlich nach gleichem Plane gebildete, Systeme bringen.

Ein System dieser Muslielu zieht die cinzelnen Bogensehenkel aufwirts gegen den Schedel; diese Muskeln steigen rom Sehedel oder ron festen Punkten, die ihren Endansätzen näher liegen, in schä̈ger odex garader Richtung abrärts und befestigen sich an den Anssenseiten der durch sir anzuziehenden Schenkel, erweitern daher den von letzleren umsehlossenen Raum. Uebrigens wirken sie in resschiedenen Riehtungen, indem die Einen ihre Schenkel aul- und vorwïrts, dic anderen sie anf- und rüchrö̈ls zichen.

Zu diesem Systeme gehört: 1. der gemeinsame Kiefermuskel ${ }^{1}$ ). Er nimmt die obere Fläche der das Kidersuspensorium bildenden und einwïrts erweiternden Knochengruppe ein. Er besteht gewöhnhich ans mehren, in ihren Ursprüngen differenten Portionen. Eine derselben liegst oberflïchlich und haftet of wesentlich dicht unter der Haut; rine zweite starke Portion nimmt rom ganzen äusseren Umfange der Knochengruppe und namentlich rom Praeoperculum ihren Ursprung; cine dritle, von der vorigen biswcilen durch cinen zwischengeschobenen Levator suspensorii getrennt, entsteht vom $O s$ frontale posterius, mastö̈deum und temporale. Diese ver. schiedenen Portionen laufen vorne in zrrei durch eine Aponeurose ${ }^{2}$ ) rerbundene Schnen aus, von denen dic obere, dümncre, längere am Oberkiefer, die andere kürzere, dickere am Unterliefer und zwar vorzugsweise an seinem Os arliculare sich befestigt.

2. Der M. levalor suspensorii ${ }^{3}$ ). Er entspringl vom Os fronlate posterius und zerfillt bisweilen in zwei diffrente Portionen: einc obere stïrkere, die am Praeoperculum und cine liefere kürzere, die an Os temporale sich befestigt. Der Muskel hebt das Suspensorium gegen den Schedel.

3. Der M. levator operculi ${ }^{4}$ ), bald cin einfacher Mustel, ball cin System mehrfacher Bündel, die, vou dem Os maslö̈deum aus, an den Aussenrand der Oberfläche des Operculum sich begeben.

1) Cuvier u. Agassiz, No. 20. M. masseter Ag. Bei Coltus sind seine drei Portionen scharf unterschieden; die oberflächlichste geht wescntlich in die für den Oberkiefer bestehende Sehne über. Die zweite Portion entspricht mehr dem M. masseter, die dritte dem M. temporalis höherer Wirbelthiere.

2) Diese Aponeurose verliert sich in der die Kiefer verbindenden Membran.

3) Cuvier und Agassiz, No. 24.

4) Cuvier und Agassiz, No. 25. Mehrfache Fascikel in einer Reihe z. B. bei Cottus; die vorderen sind länger, als die hinteren; jene ziehen das operculum zugleich aufwärts, diese quer an den Schedel. 
4. M. M. levatores arcuum branchialium ${ }^{5}$ ). Sie erstrecken sich, vou der unteren Seite der Gelenliverbindung des Os temporale mil dem $\boldsymbol{O}$ s frontale posterius und $O$ s mastoüdeum aus, an die Seiten der oberen Glieder der Kiemenbogen.

5. M. M. levatores ossium pharyngeorum superiorum ${ }^{6}$ ), zwei MLusliehn, die ron den Alae temporales zu den crsten Ossa pharyngea superiora fast gerade absteigen und sie heben.

6. Verwandt diesen Muskeln ist ein anderer, bei vielen Fischen sehr mïchtig ausgebildeter Muskel, der die Ossa pharyngea superiora gegen die Wirbelsänle zicht. El wirkt weniger als Iteber, wie als Zurückzicher des Kiemenapparates und verdient daher die Bezcichnung eines $\boldsymbol{M}$. retractor ossium pharyngeorum superiorum ${ }^{\top}$ ).

Ein zweites System von Muskch zicht den Bogenapparat abwärts gege'n das Schultergerüst oder auch gegen das Zungenbein, erweitert aber chenfalls den von ihn eingeschlossenen Raum. Es gehören dahin die Senker des Kiemengerüstes:

1. Lin Muskel, der von der Mitte jedes Schenkels des Schultergürtels schräg zum Os pharyngeum inferius sich erstreckt ${ }^{8}$ ).

2. Ein Musliel, der, von der Vereinigungsstelle der beiden Claviculae aus, schrïig von hinten nach vorne verlaufend, an das System der Copulae der Kiemenbogen sich befestigt ${ }^{9}$ ).

3. Ein Musliel, der von der Unterflïche des Zungenbeinkörpers aus schrïg nach hinten sich erstreckt um an die Unterfliiche des Os pharyngeum inferius sich zu' inseriren ${ }^{10}$ ).

4. Ein sehr kurzer Muskel der, von derselben Stelle ans, an die $C_{\boldsymbol{o}}$ pulae der Kiemenbogen trilt ${ }^{11}$ ).

Ein zweites System von Mnskeln zicht die cinander correspondirenden Bogensehenkel an einander oder einen Bogen an ein gemeinsames Mittelslied. Es wirken also diese Muskeln als Constrictoren. Sie sind sowol an der dorsalen, wie an der ventralen Seite der Knochengruppe entwickelt. Diesem Systeme gehören folgende Muskeln der dorsalen Seite an:

5) Cuvier, (No. 30.) beschreil)t bei Perca vier solchex Muskeln; bei Cottus finde ich drei; einen für jelen der drei vorderen Kiemenbogen; der vierte erhält einen cigenen, weiter hinterwärts entspringenden Muskel. Jene entsprechen der No. 30., dieser den No. 32. und 33. der Cuvier'schen Abbildungen.

6) Cuvier erwähnt ihrer unter No. 30. p. 411. A gassiz, No. 31.

7) Cuvier, No.41. Er ist bei Cottus, Cyclopterus, Gadus u. A. viel stärker, als bei Perca. - 8) Cuvier und Agassiz, No. 37.

9) Cuvier und $\mathbf{\Lambda}$ gassiz, No. 36. Die beiden oben genamuten Muslieln liegen immer seitwärts vom Pericardium, das sic unmitlelbar berühren.

10) Cuvier und Agassiz, No. 35.

11) $\mathbf{\Lambda}$ gassiz erwähnt diesen Muskel unter No. 35.; bei Cottus $\mathbf{u}$. $\mathbf{\Lambda}$. ist er gesondert. 
1. Als Constrictor wirkt ein von dem Seitenrande des Os sphenoüdeum basilare ausgehender, quer nach aussen an das Os tympanicum und pterygoüdeum seiner Seite tretender mächtiger querer Gaumenmuskel 12).

2. Als Senker des Suspensorium wirkt cin kleinerer, hinter diesem gelegener, von der Ala temporalis zur Inmenseite des Os temporale tretender Muskel 13).

3. Als Senker des Operculum virkt ein, von demselben Knochen ansgehender an die Innenseite des Operculum sich begebender Muskel 14).

4. Zwischen den beiden Reihen der Ossa pharyngea superiora finden sich gleichfalls quere, sie an einander ziehende, als Constrictoren wirkende Muskeln ${ }^{15}$ ).

An der ventralen Seite gehören diesem Systeme an:

1. Ein querer Muskel, der, an der Innenseite des Unterkieferbogens gelegen, dessen beide Seitenschenkel an einander zieht. M. transversus mandibulae $\left.{ }^{16}\right)$.

2. Zarte Muskelbündel, die von der Imenflïche des Opercular-Apparates der cinen Seite, längs der Imnenfläche der Radii branchiostegi beider Zungenbeinschenkel, zu der entsprechenden Stelle der entgegengesetzten Seite sich hinziehen ${ }^{17}$ ).

Diesem Systeme von Muskeln angehörig sind kleine Muskeln, wclehe von der Basis des einen Radius zu der des anderen treten ${ }^{18}$ ). - Dic genamnten Muskehn liegen eingeschlossen zwischen den Blättern der Membrana branchioslega.

3. Ein kleiner Muskel erstreckt sich vom Körper des Zungenbeines zur Imnenseite jedes Zungenbeinschenkels ${ }^{19}$ ).

4. Quere Muslieln, welche zwisehen den beiden Ossa pharyngea inferiora vorkommen ${ }^{20}$ ).

5. Quere Muskeh, welche zwischen den einander entsprechenden Schenkehn der letzten Kiemenbogen vorkommen ${ }^{21}$ ).

Das ganze System oberer und unterer Quermuskeh lässt als eine vor-

12) Cuvier und Agassiz, No. 22.

13) Cuvier erwähnt ihn unter No. 22. - 14) Cuvier und Agassiz, No. 26.

15) Agassiz, No. 38,; sehr stark bei Cottus, unmittelbar unter dem Os sphenö̈deum basilare. - 16) Cuvier und Agasiz, No. 21.

17) Cuvier, No. 28., Diesen Muskel, den Herr Remack (Müller's Archiv 1843. p. 190.) für unbekannt hielt, hat gerade Cuvier auf das Sorgfältigste beschrieben, wie schon Agassiz mit vollem Rechte bemerkt. S. Cuvier I. c. p. 409. und auch p. 408. und Agassiz, 1. c. p. 67. Er ist z. B. bei Cyclopterus, Cottus, Lophius sehr entwickelt. - 18) Agassiz, No.28.

19) A gassiz, No. 44, - 20) Cuvier, No. 40.

21) Ein sehr starker Quermuskel dieser Art liegt bei Collus zwischen den Endglicdern der beiden letzten einander entsprechenden Bogenschenkel unterhalb der Copulae. 
dere Forlselzung der den Schlundkopf und die Speiseröhre ringförmig umgürtenden Schicht quergestreifter Muskelbiundel sich aufrassen.

Ein driltes System von Muskeln hat das Gemcinsame, dass es aus paarigen Muskeln besteht, deren jeder von der Aussenfïiche hinlerer Bogenschenkel beginnt, um an nächst vordere Bogen sich anzuselzen. Dahin gehören an der Ventralseite:

1. Die Musculi geniohyoüdei ${ }^{22}$ ). Jeder Muskel erstreckt sich von der Aussenseite cines Zungenbeinbogens, an welchem er, lïngs der Basis der Radii branchiostegi, sich hinzicht, schrïg vorwärts und cinwïrts zum Unterkiefer.

2. Die sich kreuzenden Zumgenbeinmuskeln ${ }^{23}$ ). Jeder dieser Muskelı erstreckt sich, von einem Radius branchioslegus des einen Zungenbeinsehenkels schrig rorwärts rerlaufend, zum vordersten Segmente des Zungenbeinschenkels der entgegengesetzten Seite.

3. Von dem untersten Gliede des letzlen Kiemenbogens erstreckt sich von aussen nach innen verlaufend, ein Muskel zu dem unten vorspringenden Gliede des dritten Bogens; er crhält cin Verslïriungsbïndel von dem unteren Gliede des dritten Kiemenbogens, das denselben Endansatzpunkt am zweiten Bogen hat. Ein analoger Muskel erstreckt sich vom unteren Gliede des zweiten Kicmenbogens vor- und einwärts zur Grenze der Copula der' ersten Glieder ${ }^{21}$ ).

Auch an der Dorsalseite ist dieses System reprïisentirt in Muskeln, die von den oberen Gliedern der hintersten Kiemenbogen, schräg vor- und einwirts verlanfend, an dic Ossa pharyngea superiora sich anheften ${ }^{25}$ ).

Abgesehen von diesen Muskeln, ist noch ein muskclhïutiges Diaphragma hervorzuheben, das wesentlich von der Ausbreitung jedes Os pharyngeum inferius und weiter aufivïts von dem Schlundkopfe aus zu dem ganzen vorderen Umfange des Schultergïrtels sich hinzicht und so cine hintere Begrenzung der Kiemenhöhle bildet.

22) Cuvier und $\mathbf{\Lambda}$ gassiz, No. 2\%. Dieser Muskel zeigt bei den einzelnen Fischen manche Eigenthümlichkeiten. Bei Cottus vereinigen sich beide Muskeln bevor sie zum Unterkiefer treten und bilden zwei Bäuche: einen unteren und einen oberen, von denen jener an dem inneren und oberen, dieser an dem unteren und äusseren Rande der Verbindungsstellen der beiden Unterkieferhälften sich inserirt. Zwischen der von diesen beiden Bäuchen gebildeten Schlinge verläuft der mittlere Theil des M. transversus mandibulac. Da die sich kreuzenden Zungenbeinmuskeln fehlen, die unteren Bauche des Muskels aber sich krenzende Fasern enthalten, auch eine theilweise Tremung des Gesammtmuskels in zwei Schicbten gelingt, so findet hier offenbar cine Verschmelzung der M. M. geniohyö̈dei mit den sich kreuzenden Zungenbeinmuskelu Statt, welche letzteren aber einen weiter vorwärts gerückten Ansatzpunkt besitzen.

23) Cuvier, No.29. - 24$)$ Nach Untersuchungen bei Cottus und Cyclopterus. - 25) So namentlich bei Cottus. 


\section{S. 52.}

Die verschiedenen Flossensysteme dei Knochen-Fische crhalten ihre eigenen Muskchn. Längs den Kanten des Rücliens und des Banches erstrecken sich, von vorne bis hinten, über und unter dem Scilenmuskel grelegen, eigene oberfä chliche Längsmuskeln der un paren Flossen ${ }^{1}$ ), deren Continuitat durch die Flossen selbst unterbrochen ist. Sie liegen auswärts von denjeuigen Flossenträgern, welche kejne Strahlen tragen. Das vorderste Segment des oberflïchlichen Flossenmusliels der Rückenseite erstreckt sich, sobald nur eine ciuzige Rückenflosse vorhanden ist, welche entfernter vom Kopfe begimnt und nicht zur Schwanzflosse sich ausdehnt, vom Os suprascapulare zum vordersten Strahle der Rïckenflosse, an den ex sich befestigl: das zweite Segment vom letzlen Flossenträger zu demjenigen oberen Strahle der Schwanzflosse, der noch dem Rïckenflossensystem angehört. - Wemn mehre von cinander getrennte Rï̈kenflossen vorhanden sind. liegen die Muskelbäuche längs ihrer Zwischenräume; wird aber der Rücken von einer cinzigen Flosse eingenommen, wic bei Pleuronectes, so fehlen diese Muskeln.

Längs der Bauchkante erseheinen diese Muskeln wieder. Ihre unterlıalb der Rumpfhöhle verlaufenden Segmente sind bei den Banchflossern nu schwach gesondert von den Bauchtheilen der Seitenmuskeln und befestigen sich an den Aussenseiten des Beckens. Vom Ilinterrande jedes Beckenknochens geht, sowol bei den Pisces jugulares, als bei den P. abrominales, ein gewöhnlich den After umfassender Muskelbanch ab. Die Endschnen beider Muskeln befestigen sich am Gelenkende des vordersten $\boldsymbol{O}$ s inter. spinale inferius. Zwisch:n dem hinteren Ende der Afterflosse mol dem ersten Schwanzflossenstrahl liegt wieder cin Muskelbauch.

Verschieden von den genannten Muskeln sind die in gerader oder elwas schriger Richtung auf-oder absteigenden cigenen Muskeln der cinzelnen Flossenstrahlen, welche wieder in oberflichliche und in tiefe zerfallen. Die oberflächlichen ${ }^{2}$ ) solien vou der Aponcurose des Seitenmusliels aus und befestigen sich auswärts vom Gelenlikopfe cines Flossenstrahles. Die tiefen ${ }^{3}$ ) gehen von den Ossa interspinalia aus, um vorne und hinten am Gelenkkopfe jedes Flossenstrahles sich zu fixiren. Sie liegen gevöhnlich zum grössten Theile unter den Enden der Scitenmuskeln verborgen.

Die für die Schwimmberegungen so wichtige Schwanzflosse besitzt ihre eigenen Muskeln, die ihre cirzeluen Strahlen von cinander entfernen. Sie zerfallen in oberfiachliche ${ }^{4}$ ) und liefe ${ }^{5}$ ). Zu ihnen kommen bei manchen Fischen noch Muskeln, welche die einzelnen Strahlen

1) Cuvier und Agassiz, No.6.7.8. - 2) Cuvier und Agassiz, No. 2.

3) Cuvier und Agassiz, No. 3. u. 4. - 4) Cuvier und Agassiz, No: 11.

5) Cuvier und $\mathrm{Ag}$ assiz, No. 9.10.13. 
an einander ziehen ${ }^{6}$ ). Zwei oberfliehliehe M uskeln strahlen von der Mille des Sehwanzlheiles der Wirbelsäule nach oben und unten zu den einzelnen Strahlen der Schwanzflosse aus. Sie liegen unmiltelbar nuler der Ilaut und haften an ciner fibrösen Decke des Seitemmuskels. Sie zichen die Strahlen gegen die Axe der Wirbelsäule und nïhern sie einandes. Zwei tiefe seitliche Muskeln, in ihrem Verlaufe analog, vou dem Schwanzheile der Wirbelsäule selhst entspringend, sind vom Seitenmustiel beinale berleckl. Sie befestigen sich an die Basis der gespaltenen Flossenstrahlen, mit Ansuahme der beiden oberen Strahlen, welehe dem Systeme der Rïckenflossen angehören. Ein dritter mittlerer Muskel befestigt sich an einen Theil der dorsalen Schwanzflossenstrahlen. Diese Muskeln entfernen die einzelnen Strahlen von einander und beherrschen die Seitenbervegungen der Flosse.

Die Strahlen der Brust- und Bauchflossen besilzen gleichfalls cigcne, meist stark cntrickelte Muskeln ${ }^{7}$ ). Sorrol dic Vorder-, als die Ilinterflïche der Brustflosse besitzt zwei Systeme derselben, welche ausschliesslich für die Flossenstrahlen bestimmt sind. Was zuerst die dem Kopfe zugewendete Fläche der Brustflossen anbelrift, so entspringt von der Claricula cine schrigg absteigende Muskelmasse, die in so viele Bäuche zerfäll, als Flossenstrahlen vorhanden sind. An dem aufirirts gelegenen Rande jedes Flossenstrahles befestigt sich ein Muskelhanch. - Ton dieser Muskelmasse bedeckt, liegl cine zweite, von den Ossa carpi ansgehende, deren Fasern eine mehr aufsteigende Richlung haben. An dem abwärts gelegenen Rande jedes Flossenstrahles befesligt sich cine ihrer Endselnen. - Eine analoge Einrichtung wiederholt sich an der Ilinterseite. Tou der Scapule ans steigt eine Mushelmasse schrïg abwïrts. Sie zerfïll in so vicle Bänche als Flossenstrahlen vorhanden sind. An dem anfrärts gelegenen Rande jerles Strahles befestigh sich die Selne cines dieser Muskelbäuche. Ton der Innenseite der Clavirula geht cine andere schrïg anfwärls geriehtete Musliehmasse ans. Jeder ihrer Bäluche befestigt sich an dem abwärts gelegenen Rande der Basis rines Flossenstrahles. - Bisweilen crhiilt der erste Flossenshahl noch einen cigenen Muskel. - Gleich den Brustlossenstrahlen, besilzen auch die Banchflossenstrahlens) an ihree vorderen Seite zwei Systeme von Muskeln; an der hinteren Fläehe sind dieselben bisweilen nicht gesondert.

Der Sclutlexgürtel selbst wird dureh die Fortselzungen des Seitenmushels fixirt. Bei manchen Fiselen wird ex dureh einen eigenen, von dem Os masloüdeum ausgehenden Muskel an den Sehedel gezosgn ${ }^{9}$ ).

Das Becken wird besonders durch die oberflïhlichen Läugsmusliehn

6) Cuvier, No. 11.12. - 7) Cuvicr und Agassiz, No. 14, 15. 16.

S) Cuvier und Agassiz, No. 17.18. - 9) Cuvier, No. 10. 
der Flossen und die Seitenmuskeln fixirt. Die heiden Beckenhälften werden, besonders da, wo sie nicht mit einander verbunden sind, sondern cutfernter von einander liegen, durch einen Qucrmuskel an cinander gezogen.

\section{S. 53.}

Ein sehr merkwürdiges Bildungsverhältniss besitzen einige Rochen. An der unteren Fläche des Schwanzes der Rochen kömmt jederseits von der Wirbelsäule ein langes spindelförmiges elwas transparentes, lichtgrau. liches Gebilde vor, das etwa zwei Dritheile bis drei Viertheile der Schwanzlänge einnimmt. Es liegt hinten ummitlelbar unter der Haut und geht vorne fast unmerklich in die Masse des Schwanztheiles des Musc, sacrolumbalis über. Sein Uebergang in den genannten Muskel geschieht so, dass seine Spitze in die Ilohlkegel, welche von dessen Iamellen gebildet werden, zugespitzt sich hineinerstreckt und ron ihnen umfasst wird. Wie an jeden dieser Hohlkegel des Muskels eine vou der IIautfascic ausgehende Aponeurose übergeht, so fundet sich auch ein fortlaufendes System ïhnlich gerichteter Aponeurosen, die successive an die Aussenvand dieses Gebildes herantreten.

Jas Gebilde wird sowol oberflïchlich, als auch in der Dimension der Dicke von queren Bindegervehsscheidewänden durchsetzt, die von unregelmässigg gestellten Lüngsscheidewänden wiederum durchkreuzt werden. Durch diese Scheidewände zerfällt es in eine sehr grosse Anzahl von unregelmässigen, polygonalen, wesentlieh quer gerichteten, von einander getreunten Rïumen. An den Längsscheidewïnden verlanfen groössere Gefässe und Nerven, an den Querscheidewïnden die jedem geschlossenen Raume bestimmten feineren Verzweigungen beider nud zwar vertheilen sich die Nerven an der Vorderwand, die Gefïsse an der Hinterwand jedes Septum. Der Inlıalt der Räume besteht aus einer gallertartigen durchscheinenden Grundmasse, rvelche besonders in der hinteren II:̈lfte des polygonalen Raumes cin unregelmässig gestaltetes, von grösseren und kleineren Hohlräumen vielfach durchbrochenes Maschenwerk darstellt. In diesen Iohlrïumen oder Alveolen, welche, von der Gefïsswand aus, nach der Nervenwand hin an Umfang abnehmen, hat die Ausbreitung der Capillargefïsse Statt, welche büschelweise in sie sich einsenken. - An vielen Stellen der Grundmasse sieht man runde Keruhaltige Elementarzellen eingelagert; in der vorderen Iïlfte jeder Capsel des vordersten Theiles des Gebildes findet man ferner quergestreifte Muskelsubstanz, welche theils in sehr dümnen zarten BlätIcrn, bisweilen wie ein Anflug, die Alveolen überzieht, theils breitere Bündel bildet.

[S. J. Stark, in den Annals of natural history. XV. p.121. - Ch. Robin, in den Annal. des scienc. natur. 1847; Froriep's Notizen, 1847. Octob., No. 78. Bd. IV. N. 12. S. 179 ff. - Die Beschreibung von Robin ist sehr genau. Derselbe hält dies 
Dritter Abschnitt. Vom Muskelsysteme u. d. electr, Organen. 121

Organ für ein electrisches. Er hat es angetroffen bei Raja clavata, Raja rubus und Raja batis.

Der Robin'schen Deutung möchte ich nicht, oder höchstens sehr bedingt beistimmen. Meiner Ansicht nach, verhält sich dies Organ zu dem Muskel, den es fortsetzt, ungefähr wie die Chorda dorsalis zur Wirbelsäule. Es ist die primordiale Anlage eines Schwanzmuskels, welche perennirend sich erhält. Als Fortsetzung des Muskels charakterisirt es sich, theils durch seine Continuität mit demselben, theils durch seine gleiche Anheftungsweise mittelst fortlaufender Aponeurosen. Entscheidend ist jedoch für mich der Umstand, dass ich in dem vordersten, dem wirklichen Muskel zunächst gelegenen Theile quergestreifte Muskelelemente in Gestalt von schr zarten quergestreiften Blättern und selbst von Faserbündeln getroffen habe.]

\section{Von den electrischen Organen.}

\$. 54.

Sowol bei der Familie der Torpedines unter den Rajidae, als bei einigen Teleostei, kömmt ein merkwürdiger Apparat vor, der unter Einfluss der ihm angehörigen Nerven Electricität frei werden lässt.

Bei der Torpedines erstreckt sich dieser Apparat zu beiden Seiten des Kopfes und des Kiemenapparates nach aussen zu dem vorwärts zum Schcdel verlïngerten Flossenknorpel und liegt unmittelbar unter der äusseren glatten Haut. Nach Entfernung der letzteren gelangt man auf eine Aponeurose, unterhalb welcher die electrischen Organe gelegen sind. Jedes Organ besteht aus einer beträchtlichen Anzahl meist sechsseitiger, vertikal oder etwas schräg gestellter Säulen. Jede Säule besitzt eine aus Bindegewebe und elastischen Fasern oder ausschliesslich aus ersterem gebildete Umhüllung. Letztere umschliesst eine anscheinend gallcrtartige Masse; diese besteht aber aus zahlieichen queren Sepla, welche in der Richtung der Säule über cinander geschichtet sind. In sic trennenden $Z$ wischenräumen findet sich eine helle, feine Körnchen haltige Flüssigkeit. Mit seinen Rändern ist jedes Septum angewachsen an der Umhüllung jeder Sïnle, als deren Fortselzung es zu betrachten ist. Jedes Seplum erhält wieder einen eigenen imneren Ueberzug. An jedem Seplum verästeh sich zahlreiche Capillaren. Die Nervenfibrillen verzweigen sich unter vielfacher Theilung wobei sie sehr fein und blass werden, an der verlicalen Wand der Säulen und an den Sepla. Jedes Organ erhält vier Nervenstämme, von denen der vorderste in der Bahn des $\boldsymbol{N}$. facialis und die drei anderen in der des $\boldsymbol{N}$. glossopharyngeus austreten. Die Nerren nehmen ihren Ursprung aus den Lobi electrici; ihre Primitivfasern erscheinen als Ausliufer der in diesen enthaltenen multipolaren Ganglienkörper. Sie crmangeln nach ihrem Austritte aus dem Centralorgane eigener gangliöser Elemente durchaus.

Gymnotus electrieus besitzt zwei parige electrische Organe. Jedes grössere obere Organ liegt unmittelbar unter der äusseren Haut, über den 
Muskelu und erstreckt sich längs des ganzen Schwanzes nach hinten. Das mulere kleinere wird von den Muskeln der Schwanzflosse bedechl. Die Nerven diescr Gebilde (jederseits über 200) sind Fortsetzungen der Rami anteriores der Spimalnerven.

Malapterurus electricus besilzt cin einziges, über den ganzen Körpel sich ausdehuendes, electrisches Organ. Unter der äusseren Haul liegt eine starke schuige; atus sich krenzenden Fasern bestcheude Aponcurose; zwischen dieser und einer zweiten Aponeurose, die über dem die Muskeln deckenden laxen Bindegewebe sich ausbreitet, liegt das electrische Organ, das am Banche die grösste Dicke besitzt. Es besteht aus rhomboüdalen Zellen, welehe, von einem feinen IIButchen ausgekleidet, eine gallertartig durchschcinende Masse von speckartiger Consistenz enthalten. In dieser Masse finden sich runde mikroskopische Körnehen. Die Nerven des Oreganes stammen aus dem $\mathbf{N}$. vagus und den Rami anteriores der Spinalnerven.

Während die electrische Natur der eben bezeichneten Organe der Torpedines, des Gymmolus und des Malapterurus dureh Beobachtungen und zum Theil sehe instruclive Versuche ganz ausser Zweifel gestellt ist, haben rein anatomische Unlersuchungen zu der Ansicht gefüht, dass auch cinige andere Fische im Besitze elechrischer Organe sein müchlen. Abgesehen von den im vorigen $\$$. crwähnten Gebilden der Gattung Raja, hat man anch bei melien Arten der Gattung Mormyrus, so wie dem Gym. narchus niloticus solehe zu finden seglaubt. Früher wurden noch zwei andere Fische: Trichiorus indicus und Tetrodon (lectricus 1) als electrisch bezeichnet.

[Die elektrischen Organe der Torpedines waren bereits den Alten bekannt. Eine Zusammenstellung der Kenntnisse derselben gilt: E. du Bois, Quae apud veteres de piscibus electricis exstant argumenta. Berol. 1S43. \&. Später haben Borelli, Redi, Lorenzini, Kaempfer, Réaumur, J. II unter, (Philos. Transact. 1773. T. II. p. 481. u. 1775. P. 2. p. 395.), Geoffroy u. A. mit den anatomischen, Walsh, (Phil. Transact. abridged. Vol. XIII. p. 475.) mit den physicalischen Verhältuissen sich beschäftigt. - Dann haben die Gebrüder Dary (S. J. Davy, Researches physiological and anatomical. Vol. I. Lond. 1839.) und I atteucci (Traité des phénomìnes électrophysiologinues des animaux. Paris, 18tt. 8.) die physicalischen Untersuchungen fortgesetzt, während Delle Chiaje (Anatomiche disamine sulle torpedini Napoli 1839. 4.), Valentin (in den Neuen Denlsschrift. der allgem. Schweiz. Gesellsch. für die ges. Naturwiss. Bd. 6. Neuchat. 1841.), Savi, (in den der Schrift von Matteucci angefügten Recherches anatomiques sur le Système nerveux et sur l'organe électrique de la torpille. Par. 1844. 8.) Wagner, (Ueber den feineren Bau des electrisehen Organes im Zitterrochen. Gött. 1847. 4.) die histologischen Verhältnisse wesentlich erörterten. Nachdem Savi die Theilungen der Nervenfibrillen, und dic Abwesenheit gangliuser Elemente an den Nerven des electrischen 0rganes gefunden (1. c. p. 31s squ), auch

1) Vgl. Patterson, Philosoph. Transaet. Vol. 76. 


\section{Dritter Abschnit. Vom Muskelsysteme n. d. electr, Organen. 123}

die Ganglienkürper in den Lobi electriri nachgewiesen (I. c. p. 2! 8.), wurden die l'rsprungs - und Endigungsweisen der Nerven näher studirt ron Wagner, der durch den Nachweis, dass Ganglienliörper in Nerven sich fortsetzen und Ganglienkürper mit cinander sich verbinden können, so wie durch richtigere Auffussung der Theilungsverhältnisse peripherischer Nerven Savi’s Arbeiten ergünzte. Ecker endlich gab eine dankenswerthe Arbeit über die Entwickelung der Nerven des electrischen Organes. (Sicbold und Kölliker's Zeitschrift. Bd. 1. S. 38.)

Was Gymnotus electricus anbetriff, so wurden seine electrischen Eigenschaften bekannt durch Richer (Mẻm. de l'acad. roy. d. scienc. Par. 167\%.). Walsh, II umboldt, Faraday, Schoenbein haben dieselben näher studirt. Il unter, (Philos. Transact. Vol. V.), Rudolphi, (Ahh. d. Acad. d. Wissens. z. Berl. 1520-21. S. 229.) u. Valentin I. c haben die anatomischen Verhältnisse des electrischen Organes exponirt. - Das electrische Organ des Malapterurus ist in seinen Wirkungen durch Adanson bekannt geworden; Ge offroy, (Annal. d. Mus. d'hist. nat. T. I. p. 3.), Rudolphi, (Abh. d. Acad. d. Wissensch. zn Berlin. 1524. S. 137.) und zulctzt Peters (Müller's Archiv f. Phys. 1845. S. 375. Tb. 13. lig. 8-11.) haben seine anatomischen Verhältnisse aufgeklärt. - Nachtriglich verweise ich auf die interessanten Beobachtungen des Dr. Bilharz in den Nachrichten von der Königl. Ges. der Wiss. zu Göttingen. No.9. 1 $\$ 53$. Der electrische Nerv entspringt aus dem Rückenmarke, steht mit Ganglien nicht in innerer Verbindung und besteht aus einer einzigen colossalen Primitivfaser, welche im electrischen Organe erst einfache, dann mehrfache Zweige abgibt, die wider sich theilen.

Was Mormyrus longipinnis anbetrift, so hat $\mathbf{R} u ̈ p p e l l$ (Fortsetzung der Beschreibung und Abbildung mehrer neuer Nifische Frankfurt. 1832. p. 9.) zwei Paar längliche gallertartige Yassen erwähnt, welche unter den Sehnen der Schwanzflossenmuslicln liegen. Feine verticale weissliche Linien durchkreuzen den Längendurchmesser dieser Gallerte. Sie veranlassen eine Verdicliung des Schwanzendes, welche allen Mormyri eigenthümlich ist. - Gemminger und Erdl haben diese Organe für electrische erklärt (Gelehrte Anzeigen d. Königl. Baiers. Acad. d. Wissens. Bd.23. Münch. 1846. S. 405.). Kölliker, (Bericht von d. Königl. zootom. Anstalt zu Würzlurg. Leipz. 1849. 4. 1. ๆ.) hat diese Organe als electrische beschrieben und Tb. 1. alugebildet. Jedes Organ stellt eine lägliche Capsel dar, welche durch zahlreiche senkrecht stehende, quere Srheidewände in Fächer getheilt wird. Nach mir gewordenen Witheilungen won R̈̈ppell hat dieser verdiente Forscher niemals electrische Schläge von einem Mormyrus erhalten. Sollte dies Organ nicht dem der Rochen an die Seite zu stellen sein? An einem Mormyrus, den ich vor mir habe, fällt mir die Unregelmässigkeit des Organes und sein anscheinender Uebergang in benachbarte Muskeln auf.

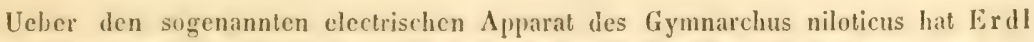
(Gelehrte Anzeigen der küniglich Baiers. Academie der Wissenschaften. No. 73.

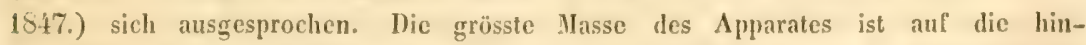
tere Inalfte des langen Schwanzes angewiesen; ein Theil davon begleitet noch die Wirbelsäule bis zum hopfe hin. Er wird gebildet aus vier häutigen köhren, die lurze prismatische Körper enthalten, welche, wie Perlen an einer Schnur, hinter einander gereihet sind. Dic häutigen Röhren sind durchsichtign und hangen mit den sie 
ıungebenden Muskeln und Intermuskularbändern so innig zusammen, dass es schwer hält, sie in ihrer Integritat darzustellen. - So gewagt es ist, diese Organe functionel den electrischen Organen der Torpedines u. s. w. gleich zu stellen, so ist ihre Kenntniss doch höchst interessant, weil sie mindestens Uebergangsbildungen zwischen cigentlichen electrischen Organen und der Muskelbildung bei Petromyzon darstellen.]

\section{Vierter Abschnitt.}

\section{Vom Nervensysteme und von den Sinnesorganen.}

\section{Vom Nervensysteme.}

\section{\$. 55 .}

Die Centralorgane des Nervensystemes bestehen aus dem im Canale der oberen Wirbelbogenschenkel liegenden Rückenmarke und dem von der Schedelhöhle umschlossenen Gehirne, welche mittelst des rerlängerten Markes in cinander übergehen. Nur Branchiostoma macht von dieser Regrel in so ferne cine Ausnahme, als bei diesem Fische der vordere Theil des centralen Nervensystemes vor dem Rückenmarke durch eigene Anschwellangen nicht ansgezcichnet ist, jencs vielmehr nach rorn allmälich sich verdünnt und endlich vorne abgerundet, als Hirn endet.

[Die Centralorgane des Nervensystemes sind Gegenstand vielfacher Untersuchungen und Deutungen gewesen. - Die wichtigsten früheren Arbeiten sind namhaft gemacht bei Cuvier (llist. nat. d. poiss. I. p. 415.) und bei Gottsche in dessen an Beobachtungen sehr reichhaltigem Aufsatze: Vergleichende Anatomie des Gehirnes der Gräthenfische in Müller's Archiv 1. Anat. u. Physiol. 1835. - Eine liritische Analyse sämmtlicher über die Deutung der einzelnen Gehirntheile vorgetragenen Ansichten hat geliefert: Nüller in seiner Vergleichenden Neurologie der Myxinoüden. Berlin, 1840. - Die Entwickelung des Gehirnes des Coregonus ist mit besonderer Sorgfalt studirt worden von: C. Vogt, Embryol. des Salmones. p. 52. Dem genannten Beobachter zufolge, sind bei Coregonus bereits ursprüngtich die drei auf einander folgenden Erhabenheiten vorhanden, welche das Gehirn der erwachsenen Teleostei auszeichnen. Er nennt sie Prosencephalon, Mesencephalon und Epencephalon. Vogt stimmt mit seinem grossen Vorgänger B aer, (Entwickelungsgesch. der Fische S. 14.) sowol über diesen Punkt, als in Betreff des zweiten überein, dass die Augen eine Entwickelıng der primitiven mitteren Hirnblase sind. - Anders verhält es sich, nach den übereinstimmenden Beobachtungen anderer Forscher, bei den höheren Wirbelthieren, indem bei ihnen die Augen aus der vordersten der drei primitiven Ilirnblasen sich entwickeln und zwar aus der der Regio ventriculi tertii entsprechenden hinteren secundären Abschnürung derselben. Ich verweise z. B. auf die ausführlichen Angaben von Bisch off, Entwickelungsgeschichte des Itundeeies. S. 81. 84. 91. 96. 103. 111. Iliernach würde also die vorderste primitive llimblase der Fische kein vollständiges physiologisches Aequivalent derjenigen der beschuppten Reptilien (s. R a th k e Entwickelung der Schildkröte. S. 15.), der Vögel und der Säugethiere sein können; die primitive vordere IIirnblase der Teleostei bleibt einfach und zerfällt nicht in zwei 


\section{Vierter Abschnitt. Vom Nervensysteme u. d. Simnesorganen. 125}

şcundäre Blasen; aus ihr entwickeln sich nicht die Sehnerven; die primitive vordere llirnblase hüherer Thiere zerfält secundär in zwei Blasen, von welchen die hintere, als Regio ventriculi tertii, die hohlen Augenblasen hervortreten lässt. -

Die histologischen Verhältnisse der Centralorgane des Nervensystemes scheinen bei den höheren Fischen ziemlich gleichartig und mit denen höherer Wirbelthiere übereinstimmend zu sein. Nicht so verhalten sie sich bei niedriger organisirten Fischen. Bei Petromyzon besteht wenigstens das Rïckenmark aus Fasern, welche mit den Elementarbestandtheilen desselben bei höheren Wirbelthieren fast jeder Aehnlichkeit ermangeln und nur mit dem sogenannten Axencylinder, der gewöhnlich im lebendigen Nerven in derjenigen Form, unter welcher er nach dem Tode sich darbietet, nicht existirt, verglichen werden kann. Es sind platte bandartige, von hüllenlosen Ganglienkörpern ausgehende Fasern, von theilweise colossaler Breite, die allmälig oder plützlich in die allerfeinsten kaum messbaren Fibrillen zerfallen, deren Aehnlichkeit mit den feinsten elastischen Fasern nicht zu verkennen ist. - In dem Gehirne mancher Fische kommen neben kleinen Zellen oder Zellenkernen und einer feinkörnigen Medullarsubstanz, grosse und zum Theil colossale Ganglienkürper ohne eigene IIüllen vor. NÏ̈ller hat sie zuerst bei Petromyzon geschen von dem ich sie näher beschrieb; Valentin im Gehirne von Chimären; Savi und Wagner in den Lobi electrici der Zitterrochen; Leydig im Cerebellum von Sphyrna; ich in der Medulla oblongata von Raja clavata; neuerdings habe ich in der Medulla oblongata von Esox und Salmo einzelne gefunden, gleichzeitig mit $\mathrm{W}$ agner, der sie im Lolus vagi von Cyprinus antraf. Ein Resultat von Wagner's Studien ist die durch Leydig bestätigte Thatsache, dass Fortsitze dieser Ganglienkugeln unmittelbar in peripherische Nerven übergehen. Eine andere Thatsache ist die, dass solche cen trale Ganglienkürper unter einander verbunden sein lönnen. Wagner fand dies bei Torpedo; ich bei Petromyzon. Meine Studien an letzterem Thiere haben von der Variabilität der Grössenverhältnisse der Ganglienkürper und der Zahlverschiedenheit der von ilınen abgehenden Fortsätze mich üluerzeugt. Als Ergebniss anhaltender Forschungen möchte ich aussprechen: dass bei manchen Fischen die grossen Ganglienkürper der Centralorgane blos temporär vorhandene Gebilde mir zu sein scheinen, hestimmt zu weiterer Differenzirung in molekulare Körner. und sehr kleine Zellen, welche letzteren dann in Nervenfasern sich fortsetzen. - S. über diese Ganglienkörper: Wagner, in den Nachrichten von der künigl. Gesells. d. Wissens. zu Göttingen. 1850. No.4. und in Ecker's Icones physiologicac. Lips, 1852. IIft, 2. Tb. 14. und meine Abh. in den Nachrichten von der königl. Gesells. d. Wissens, zu Göttingen. 1850. No. 8.

Der Verlauf der Nervenfasern in den Centralorganen ist bisher noch nicht mit Erfolg studirt worden. - Einen eigenthümlichen Weg hat eingeschlagen: Nat. Guillot, Exposition anatomique de l'organisation du centre nerveux dans les quatre classes d'animaux vertébrés. Paris, 1844.

Das peripherische Nervensystem der Fische ist gleichfalls vielfach untersucht. Ausser den Schriften über die vergleichende Anatomie des gesammten Nervensystemes, vergleiche man: Stannius, das peripherische Nervensystem der Fische. Rost. 1849. 4., worin die frühere Literatur möglichst berücksichtigt ist und die Verdienste, welche vor Allen E. II. Weber, ferner J. Müller, (Vgl. Anat. d. Myxinoïd.); S chlemm u. d'Alton, (über Petromyzon, Müller's Archiv 183๖.); B üchner, (über Cyprinus, 
Mém. de la société d'hist nat. d. Strasburg. T. II.); II yrtl, (Ueber Lepidosiren); S w a n, (Illustrations of the nervous system. Lond. 1838. 4.) und Andere sich erworben, hervorgehoben sind. Man vergl. ausserdem: Agassiz und Vogt, Anatomic des Salmones; Bonsdorff, Disquisitio anatomica nervum trigemin. partemule cephalic. Gadi Lotae cum nervis Mammal. comparans, Helsingf. 1846, 4.]

\section{\$. 56 .}

Das Rückenmark der Cyclostom(n ${ }^{1}$ ) ist bandartig, platt, clastiseh und dehubar. - In seiner Ungebung findet sich im Canalis spinalis ron Petromyzon eine grauliche, weiche, sulzige Masse ${ }^{2}$ ). - Auch bei den Chimären bleibt es, unter Anwesenheit ähnlicher Bildungselemente elastisch und zeigt sich im hintersten Theile bandartig ${ }^{3}$ ).

Bei den Ganoïden, Teleostei und Plagiostomen ist es gewöhnlich von rylindrischer Form, besitzt eine hintere liefere und eine rordere saichtere Längsfurche und cinen mehr oder minder weiten Mediancanal. - Gewöhnlich ist das Rückenmark schr lang, indem es die ganze Lïnge des Wirbelcanales einzunchmen pflegt; dabei verlierl es gewöhnlich von vorne nach hinten almälich an Dicke. - Nur wenige Fische machen, so weil bekannt, von dieser Regel eine Ausnahme. Dahiı gehört zunïchst Lophius pisealorius, wo das anfangs ziemlich dicke Rüekenmark, von dem die langen Wurzeln der Spinahnerven entspringen, sich plötzlich sehr verdümut und zwischen jenen im Canalis spinalis gelegenen Wurcln fadenfömig nach hinten sich fortsetzt d). Hier sind ferner namlaft zu machen mehre Plectognalhi Gymmodontes, uamentlich Orthagoriseus, Diodon ${ }^{5}$ ), Tetrodon, wo das Rïckenmark cinen ganz kurzen conischen Zapfen darstellt und der Canalis spinalis durch die, eine lange Cauda equina bildenden, Spinalnersenwurzeln ausgefüllt wird. - Das Rüclienmark endet bei viclen Teleostei mit ciner scharf hesvortretenden rundlichen oder ovalen Anschwellung ${ }^{6}$ ),

1) Bei Branchiostoma soll es nach Quatrefages aus hinter einander liegenden Anschwellungen bestehen.

2) In einer zähen formlosen Grundmasse finden sich grosse blasse liugcln von $x_{0}^{1}-y^{\prime}=$ "'Durchmesser. Sie sind sehr scharf conturirt, kugelrund oder elliptisch, sehr clastisch, mattweiss. Sie enthalten bald einen grossen Kern mit Kiernkörper, bald feinkörnige gelb oder schwarz pigmentirte Substanz orler grössere Tropfen, wie Oeltropfen aussehend. In der Grundmasse entwickeln sich in spindelförmige Fasern ausgezogene körnchenhaltige Kerne.

3) So nach den Angaben von Valentin, Müller's Archiv. 1842.

4) So ist Arsaky's (de piscium cerebro et medulla spinali. Hal. 1813.) nicht genaue Angabe durch Valenciennes, llist. nat. d. poiss. T. XIl. p. 35\%. verbessert worden, wie ich durch eigene Untersuchung mich überzeugt habe.

5) Dies Verhalten, das ich bei Diodon glaubte zuerst erkannt zu haben (Nervensyst. d. Fische. S. 114.), finde ich schon von 0 wen (Comparative anatomy. p. 173), gekannt. Ueber Orthagoriscus s. Arsaky, Tb. 3. Fig. 10.

6) S. darüber E. II. Weber in Meckel's Archiv f. Anat. u. Physiol. 1827. 
welche bisweilen noch in einen unparen Faden sich auszicht. - An den Ureprungsstellen cinzelner slïrkerer Nerienwuzeln aus den hinteren Strängen erheben sich diese bisweilen zu rundlichen Ansehwellungen. Am bekamntesten sind die bei den Triglae vorkommenden, ans welehen diejenigen Wurchn hers orgehen, deren Elemente peripherisch für die sogenannten fingerförmigen Anhänge der Brustlossen bestimmt sind. Bei Trigla gurnardus erheben sich ron der oberen und hinteren Fliche des Rä̈ekenmarkes, znnïchst der Medulla oblongata, jederscits hinter cinander fünf granlich-weisse. solide, rundliche Anschwellungeu, von denen die beiden vordersten nur durch eine sehr seichte Einschü̈rung von cinander geschieden, die hinteren aber ganz discret sind. An der Basis dieser Anschwellungen und in iltren Zrvischenräumen treten successive fünf hintere Spinalnervenwurgeh hervor ${ }^{7}$ ).

Die Umhüllungen des Rückenmarkes verhalten sich im Allgemeinen übereinstimmend mit denen des Gehirues. Beim Stör werden die vorderen und hinteren Wurzeln der Spinalnerven innerhalb des Canalis spinalis durch ein, der Länge nach, an jeder Seite desselben befestighles elastisches mit Zalmfortsälzen versehenes Ligamentum denticulatum getrennt.

\$. 57.

Das Gehiru der Marsipobranchii zeichuel sich durch den Umstand aus, dass vor der Gegend des Cerebellum an der Oberfliche drei discrete, hinter einander gelegene, einfache oder paarige Erhabenheiten oder Lappen vorhanden sind, wihthend bei den ïbrigen Fischen, nach dbzug der Tubercula olfactoria, nu zwei solcher Lappen vorkommen. Bei den Myxinö̈den entsprieht das vorderste Paar, von dem die Nerri olfaclorii aussehen, den Tubercula olfactoria und den Hemisphären zugleieh. Dic nïchstfolgende parige Abtheilung repraisentirt die Lobi ventriculi tertii; von ihree Basis nehmen die Sehnerven ihren Ursprung; hinter der Ursprungsstelle der Sehnerven liegl, an ilırer Basis, die Iypophysis; zwischen dem hinteren Theile der die beiden Lappen oberflichlich trennenden Furche liegt die Eppiphysis. Die nächst folgende paarige Abtheilung, welehe ïber und zwisehen den Anschwellungen der Medulla oblongala eingekeill liegl, ist vorlinfig als Cerebellum zu denten. Biese sämmtlich paarigen Abtheilungen erscheinen an der Basis liaum gevondert. Sie sind durchaus solide und ohne innere Iföhlen gefunden worden. Nur zwischen dem C'ezebellum und der Medulla oblongata liegt cin sinus rhomboüdalis. - Das verlingerte Mark zecigt sich, im Vergleiche zum Rë̈chemmarke, in der Dicke und Breite angeschwollen. Es besitzl seitlich zwei divergirende lïngliche Anschwellun-

7) Diese bereits Collin's bekannten Anschwellangen sind von drsaky, Tiedemann, (Meckel's deutsches Archiv f. Phys. Bd.2. S. 103.), Cuvier, Gottsche und mir untersucht worden. (Periph. Nervens. d. Fische. S. 111.). 
gen (Lobi medullae ollongatae), welche zur Seite der hintersten Ilirnabtheilungen vorne frei und stumpf enden. Aus diesen Lobi medullae oblongalae nehmen die meisten Hirnnerven ihren Ursprung ${ }^{1}$ ).

Das Gehirn der Petromyzonten unterscheidet sich von dem der Myxinoïden in mehren wesentlichen Punkten. Nächst den Tubercula olfacloria und von ihuen sehr unvoltkommen gesondert, zeigen sieh die vorne durch eine Spalte getrennten, hinten verbundenen soliden Iemisphären. Auf letztere folgt der unpare, hohle Lobus ventriculi terlii, welcher unten in die Höhle der Iypophysis sich fortselzt. Aus ciuer oberen, von wulstigen Lippen begrenzten dreieckigen Oeffunng dieses Lobus treten feine Gefässe hervor, an welchen die Epiphysis ${ }^{2}$ ) befestigt ist. Vor der Hypophysis kommen die Sehnerven hervor. An den Lobus ventriculi terlii schliesst sich ein gleichfalls hohles, den Corpora quadrigemina entsprechendes Paar von Erhabenheiten ${ }^{3}$ ). Als Cerebellum endlich kann höchstens eine schmale Querleiste gedentet werden, welche über dem vordersten Theile des Sinus rhomboüdalis ausgespannt ist und nur eine Commissur der seitlichen oberen Theile der Medulla oblongala darstellt. Die untere Fläche des Gehirnes zeigt sich ziemlich chen; nu am vorderen Theile der Basis des verlängerten Markes befindet sich cine unbelrächlliche unpaare Vorragung. - Dic Medulla oblongata gewiunt nach dem Hirne zu an Breite und besitzt einen weiten Sinus rhomboüdalis, der unter dem Cerebellum in die IIöhle der Vierhügelmasse sich fortsetzt. - Die den Myxinoüden eigenthïmlichen Lobi medullae oblongatae fehlen.

Die vaskulösen Gebilde des Gehirnes bilden an der Oberflïche des vierten Ventrikels eine gefaltete Gefässhaut ${ }^{4}$ ).

$$
\text { S. } 58 .
$$

Das Gehirn der 'Teleostei unterseheidet sich durch den Besitz von nur drei auf cinander folgenden oberen Erhabenheiten ${ }^{1}$ ), von welchen die beiden vorderen parig sind, während die letzte unpaar ist.

Meistens liegen unmittelbar vor den Hemisphärenlappen die den Riechnerven angchörigen Anschwellungen, die selten erst, unter Anwesenheit

1) Das Gehirn der Myxinoïden ist von Müller: Vergl. Neurol. d. Myxinoid. geschildert; die Abbildungen finden sich in 1 üller's Schrift: Ueber den eigenthümlichen Bau d. Gehörorganes bei d. Cyclostomen. Berl. 1838. Tb. 2. 3.

2) Die Epiphysis crscheint oft als ein rundes, wcissliches, aus Molekularkörnern bestehendes sackförmiges Gebilde hoch aufwärts in der Schedelhöhle und bisweilen in Communication mit einer gallertartigen hinter dem Geruchsorgan gelegenen Masse, welche oberilächlich nur von der Haut bedeckt ist.

3) An der Oberlläche der Vierhügelmasse liegt vorne ẹine weite unpaare Oelfnung, die in ihre Höhle führt.

4) Dieselbe bedarf noch näherer Untersuchungen.

1) Es sind Vogt's Prosencephalon, Mesencephalon und Epencephalon. Embryol. d. Salmon. p. 152. 
längerer Tractus olfactorii, ummiltelbar vor der Austrittsstelle der Riechnerven aus der Schedehöhle sich rorfinten ${ }^{2}$ ). Auf die Itemisphïrenlappen folgen dam, als partige, hohle Anschwellungen, die sogenannlen Lobi oplici, deren Deutung verschiedenarlig ausgefallen ist. Der Umstand, dass die: Irypophysis an der unteren vorderen Grenze dieser Lappen sich befestigl mnd dass die Sehnerven ans ihrem grössten oberdlächlichen gewölhten Theile hervorgehen, deutel cutschicelen darauf hin, dass die Lobi optici fhysiologisch zum Theil den Miltelhirne oder der Gegend des drilten Ventrilicls höherer Wirbelthiere entsprechen, während die zweite Thatsache. dass zwrischen ihnen und der hinfersten Hirnanschwellung die Nervi trochleares enlspringen, in ihnen zugleich die Elemente der Corpora quadriescmina dew höheren Classen erkemnen lïsst. Auf die Lobi optici folght das unpaare Cerebellum, und dann die Medulla oblongala, welehe hänfig dureh den liesitz eigenthümlicher, mil stïlierer Entwichelung gewisser Nerven in Bexichmog stehender, Anschwellungen (Lobi posteriores Auct.) ausgerechnet isl. An der Basis des Gehirnes liegt die Irypophysis, hinter welcher die Sehnerven herrorkommen und damn folgen, als untere Anschwellungen der Gegend der Lobi optici, die Lobi inferiores.

Die parigen, soliden IIemisphärenlappen der Teleostei haben gewöhnlich in frischem Zustande eine blälich-grane Farbe und besitzen hänfige cinige sche schwarhe Erhabenheiten und Vertedungen an ihrer Ober1!iche ${ }^{3}$ ). Sie besteben grossentheils aus grauer Masse, culhallen aber zuutrich weisse Fascin. mit welchen die Pyramidalstränge als Pedunculi ceredri in sie ansstrahlen. Die beiden Lappen der Ifemisphitren sind dureh cine weisse schmale Commissura interlobularis, deren Fasern aus den $\boldsymbol{P}_{e}$ -

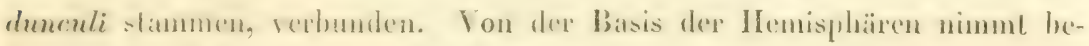
stïndig der Gernelisnerv seinen Ursprumg.

In der Regel sind die IIemispluären minder umfänglich, als die Lobi optici ${ }^{4}$ ), seltener gleieh gross odler grösser. Bei den durch asymmetrische

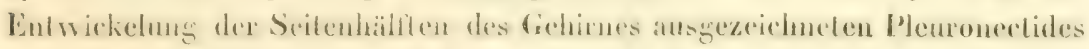
ist der aufwärts gelegenen Lobus umfïnglicher, als der untere, ihm cntsprechende.

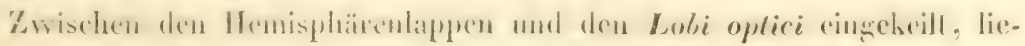

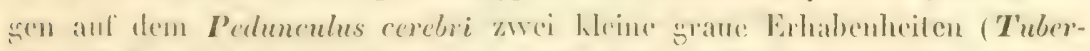
cula intermedia) wetehe bisweilen durch eine feine (Gorcommissur (Com-

2) Y.S. \$. T\%.

3) Bei Coltus theilt eine schräge Furche jede ffemisphïre sehr unvollkommen in zwei Lappen; hei fiadus callarias sind mehre nach vorne convergirende Lingsfurchen vorhanden.

4) Bei Alosa z, B, verhältnissmässig selır klein.

Handb. d. Zoolomie va Sichold u. Stannius, II. 
missura tenuissima ${ }^{5}$ ) verbunden erscheincn. Ein hinter und zum Theil zwischen ihnen gelesener Spalt führt in das Infundibulum. Von ihnen aus erheben sich zwei Gefässe in der Sehedelhöhle, welehe in Zweige sich anflïsen, in deren (iremuferenz biswcilen mil lymphatiseher Flïssigkeit gefïlle Blischen sich fuden. Die Stelle dieser Blïschen wird bei anderen Fischen durch eine feinkörnige Epiphysis vertreten ${ }^{6}$ ).

Jie zun̈ichst folgenden, oberflichlichen, parigen, meist sehr mufinglichen Erhabenheilen bilıen ein Gewölbe ïber anderen, von ihnen bedecklen, Theilen, in deren Grumblage sie seilwärts ïberecelien, von deren Oberflïche sie jedoch dureh cinen Hohlraum oder Ventrikel (Ventriculus loti oplici) getrennt werden. Sic bilden zusammen mit den von ihnen über-. wöbten Theilen die Lobi oplici und reprïscntinen, mil Ënschluss lelzterer, die Gegend des dritten Ventrikels und die dex Corpora quadrigemina. D)er

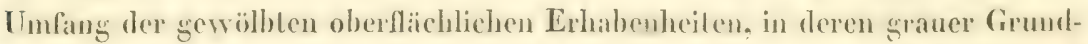
masse weisse liasern eingetragen sind, die, nach vorne convergirend mol gervissermaassen sich abschnühend, in den beiden Sehnerven sich sammeh mod concentriren, stehl anscheinend immer in getadem Verhiblinisse zur Slärke der Sohneven und zum Unfange der Augen. Es erseheinen also diese Decken der Lobi optici als oberfichliche Ausbreitungen der Anfïnge: der Sehnerven. An der Stelle, wo die Sehnerven selbstständig werden, sind dieselbun durch eine Commissur (die Commissura transversa IIalleri) under einander verbunden. - Die genamulen beriden oberdlïchlichen Decken der Loli optici, welehe in der oberen Mitlellinic cinander oft nicht ummitlehbar berïhren, werden dureh ein in ihre imnere Schicht sich fortselzendes, zwischen ihnen blalkarlig ausgespanntes System von queren, weissen. in srane Grmolsubstanz cingelnagenen Marlsasem verbunden `). - Ein unLer dieser Commissur gelegrenes, mil zwei Schenkeln aus der Tiefe des vorderen Theiles der Robi entspringendes, meist dreicekiges Marliblatt bedecht hänligg die in der Höhle der Lobi ggelegenen Erhabenheitens). - Da wo die gewö̈bien Decken seitlich in den Grund des Ventrikels übergehen, liegr jerlerseits ein verschiedentlich gestalteter, oft betrïchtlicher Wulst ${ }^{9}$ ), von

5) Ob sie beständig vorkömmt, ist mir sehr zweifelhaft geworden; bei Cottus scorpius z. B. habe ich sie im Mai spurlos vermisst.

6) Die Epiphysis gehört, wic bercits Gottsche bemerkt, zu den sehr variabeIen Gebilden. Beim Lachs erheben sich, wie beim Stör, Gefüsse und Nervenschenkel von den Tubercula intermedia aus, weit aufwärts in dic linorpelsubstanz des Schedels.

7) Es ist dies Gottsche's Corpus callosum. Bei Clupea harengus und Alosa vulgaris liegt dies Querfasersystem oberfächlich zu Tage, da die beiden ausseren Lappen hinten aus cinander weichen.

8) Gottsche hat es als Fornix bezcichnct. Es ist vorzüglich ausgebildet bei $\Lambda$ losa und bei Esox.

9) Dies ist der Thalamus opticus Auct. Er ist z. B. selir stark bei Belone. Dic ausstrahlenden Fasern bilden den Stabkranz: Corona radiata. 
dem ans zahlreiche weisse Fasern, in Gestall eines Plitlehens, in die Innentlähe der Dechen der Tobi optici ansstrahlen. - Eine tiefe, weisse, beträichlliche Commissur ${ }^{10}$ ) zwischen beiden Lobi finded sich vor dem Adius ad infindibulum, den sie vorue begrenzt und clwas bedeckt. Ilinten erhchen sich rom Boden des Ventriculus lobi optici, unnitlelhar vor dem Vordertheile des Cerebellum, mit dem sie in Verbindung stehen, zwei oder häufiger vier graue Erhabenheiten "). Sie liegen aul ciner Markplatle, unter welcher ein Ilohlram ${ }^{12}$ ) verläuft, der eine Communicalion zwisehen dem vierten und dritten Ventrikel bewirkt. - Dic Grundlage der Lobi optici besteht wesentlich aus den zu den Ilemisphären sich forlsetzenden Itimschenkeln. An der Basis ihrer hinteren IJïlte zeigen sich zwei mehr oder minder ovale, nach hiuten juxtaponirle, nach rorne elwas aus rinander weichende Erhabenheiten: die Lobi inferiores. Of lindel man sie hohl. Eieber ihrem hinteren Theile liegt cine, die hinteren Seilentheile der Cobi optici verbindende, weisse Doppeleommissur: Commissura ansulata. Sic steht durch seitliche Fasem mit der den Sehnerven angehörigen Commissura transversa in Vexbindmog. - Da, wo die Lobi inferiores vorne ans cinander weichen, findel sich ein grance liaum mit zwei wnlstigen Lippen (Trigonum fissum), welche cinen Spalt begrenzen, aus dem das Infundibulum hervortrit, dureh den anch die dieser Gegend angefïgle Ge. lïsshaul des Succus rasculosus in den gemeinsamen Ventrikel sich fortsetat. - Dem Trigonum fissum angefügt liegl auch die Mypophysis ${ }^{13}$ ). Dies sche betrïchlliche Gebilde ist gewöhnlich eingesenkt in eine mels oder minder fiede Grube, deren hinlere Grenze durch den freien Vorderrand der verciniglen Alae temporales des Keilbeines gebilda wird. Sie zoigh, zu versehiedenen Jahreszeiten und in versehiedenen Lebensaltern bei der gilei-

10) Es ist dies Gottsche's Commissura anterior.

11) Corpora quadrigemina Anct. Merkwürdig ist das Schwankonde in der Anzahl dieser Körper bei Thieren derselben Art. Schon Gottsche hat bei cinen Plenronectes darauf aufmerksam gemacht. Ein Gadus callarias, den ich vor mir habe, besitzt, statt der gewöhnlich vorkommenden zwei Körper, vier. Bei Esox sind vier vorhanden; bel Belone zwei, deren jeder unvollkommen getheilt ist.

12) Aquaeductus Sytuii, Gottsche.

13) Gottscho's gegen einige seiner Vorganger ausgesprochener Tadel, dass sie in ibren Beschreibungen der Hypophysis ungenau gewesen, weil sie sie, als bisweilen ans zwei hinter einander liegenden liörpern bestehend, geschildert, scheint mir nicht gerechtfertigt. Ihr Zustand ist einmal sehr ungleich. Gottsche selbst gibt dies zu, wenn er sagt, dass man sie bisweilen vergrössert findet, dass sie dann von Blutgefässen strotzt, dass sic in einem Falle bei cinem Pleuronectes sogar die Grösse des lobus opticus hatte. - Sie wird meistens solide gefunden, doch anscheinend nicht immer. - Anch die Art ihrer Verbindung mit den angrenzenden Theilen mörhts ich nicht als immer gleichartig bezeichnen. Kinen Theil ihrel Substanz findel man oft ganz schneeweiss, während der andere bläulicher gefürbt ist. 
chen Species mnlersucht, Verschiedenheilen in Betreff ihrer Anfügung und Ausdehnung. Der Umsland, dass bisweilen ein schon dureh versehiedene Farbe ansgezeichneles Blastem ihr angefügl ist, hat zur Amnahme zweier hinler cinander liegender Itypophyses Anlass gegeben. Ifinter der IIypophysis liegl, gleichlalls dem Trigonum fissum und len Lobi inferiores m. len angefügt, ein (Gefïsssack: Succus vasculosus ${ }^{14}$ ), sehr variabel hinsichtlich seiner Ausdehnmgs und speciellen Beschaflenheil. Es besteht ans Läppchen, in welche Gefässschlingen ïbergehen.

Die letze der oberdïchlichen Ansehwellungen bildet das mpane C $\varepsilon$ rebellum, ein in seinem Utmfange bei den verschiedencn Treostei selnr variabeles Gebilde. Klein ist es z. 13. bei Gobius niger, Cyelopterus lumpus, Collus scorpins, grössel bei Belone, hei Alusa, bei Clupea larengus, noch grösser bei Gadus callarias, wo sein Vordertheil in die Höhle der Tobi optici himeinragt, ferner bei Scomber scombrus, bei Thymms vulgaris. bei Silurus glanis, wo es die robi oplici zum grossen Theile bedecht. Fis zeigt bisweilen Querfurchen und anch die Andenhng cince längsofurehe. Seitwärls geht die Masse des Cerebellum über in die Auschwellungen der Corpora resliformia, von denen cin Theil der Wuzchn des $\boldsymbol{N}$. trigeminus rnlsteht ${ }^{15}$ ). Inwendieg erstrechl sich in die Substanz des Cerebellum eine Höhle, welehe mit dem vorteren Abselnitle des vierten Ventribels com. municirt.

Die Medulla oblongala, vor dem Rückenmarke durch überwie-

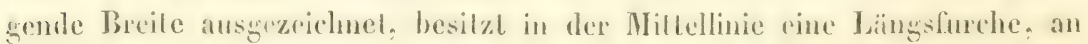
deren Seiten die weissen vorderen Pyramiden, als Fortselzungen der vor-

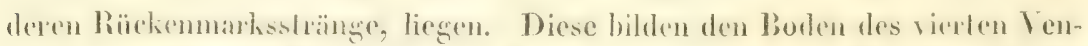
trikels, an Irssen Oberlläche cin Syshen weisses quecer Markasmbümdel verlïuft. Die auscinander weichenden hinteren oder oberen Rïckenmarksstränge lassen zum Ursprunge des Nervus trigeminus hin sich verfolgen. Ein driltes Paar ron angesehryollenen Strängen liegl zwischen beiden; es sind die Corpora restiformia; sie bilden die Pedninculi cerebelli.

Diese Strähge umschliessen den viecten Ventrikel, dessen Höhle nach hinten in die des Rïckennarkes sich fortsetzl. Am hinteren Ende des vierten Ventrikels. also an dex Grenze des Rüclicumarlies, nud cigentlich dicsem angehörig, findel sich stets eine, dic aus emander weichenden hiuteren lähkenmarksstrïnge rerbindende. woisse Markeommissur: Commissura spinulis. Selten liegt der vierte Ventrikel frei mol oflen zи 'Tage. Bei sehr. rielen Fischen nämlich wird derselbe efwa in der Milte seiner Länge oder

14) Ich habe ihn nicht selten ganz vermisst, namentlich bei Esox.

15) In der grauen Substanz des Cerebellum finden sich beim Dorsch weisse Markstrïnge, welche vollstïndig sich kreuzen und nach hinten in dic graue Sulstanz des Cerebellum austrahlon. 
anch, wie hei einisen Clupeölen, weiler vorwïls von zwei, in des Millellinic zdsammenstossenden. Erhabenheilen (tobi posteriores) berdeclit und

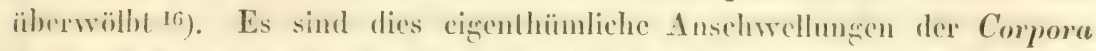
resliformia, ans welchen hintere Wurzeln des $\boldsymbol{N}$. trigeminus und des Sei-

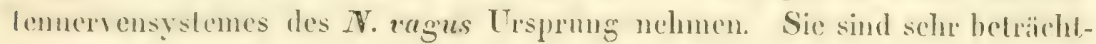
lich bei Clupea harengus, Alosa vulgaris, Garlus callarias, Esox, mässig stark bei Belone, schwach bei Coltus, Perca, Pleuronectes.

Andere duschwellungen liegen seitwïrts an den Crura cerebclli ad medullam oblongatam; sie stehen dureh eine an der Unterfläche der Medulle oblongata verlaufende Commissur mil cinander in Verbindmug und geben den Elementen des $\boldsymbol{N}$. ragus Urspung. Bui viden Cyprinen sind diese sonst unbedententen, als Lobi vagi behamten, Anschwellumgen, ans denen hier die, für das contractile Gaumenorgan bestimmlen, Nerven hervor. gehen, sehr entwickelt.

Bei Cyprinen und Silurus crhebt sich vom Gronde der vierten Ilirnhöhle noch eine muare rundliche Ansehwellung (Lobus impar), velehe zwischen jenen seitlichen gelegen. gewissen Elementen des $\boldsymbol{N}$. triggeminus Ursprung gibt.

Das Cehirn der Teleoslei fïllt die Schedelhöhle, wenigstens bei :illcren Fischen, fast niemals rollstïndig aus, viehnele bleibt zwischen ihm und den Wandungzen der Schedeleapsel gewöhnlich ein sehr beträchtheher Zwisflenram. Als Dura mater ist die die Innenwand der Schedeleapsed ans kiledende, bisweilen pigmentirle Membran zu betrachlen. Eine, in Bezug

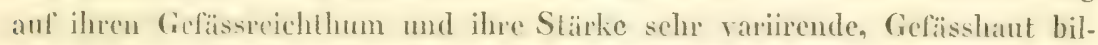
det den Ueberzus des Gehirnes, selzt ïber die Zwischenräume seiner einzelnen grösseren Ahtheilumen sich fort und biliet nichl sellen, namenllich über dem vierten Ventrikel, cinen Cicfisssack. Zwisehen ihe und der Dutra mater finden sich mehr oder minder reichlich Gallert- mi Fellmassen. Pigmentzellen, Gefïse und Subtanzhrielen. Bei einigen Fisehen z. B. beim Lachs sind dic Fellmassen gen ̈̈hnlich änsserst slark mnd reichlich. bei auderen, wie bei Collus seorpius viel spätlicher. Bei manchen z. B. bei Esox. Gadus u. 1. findel sich: stall der Fetlmassen, lymphatische oder sallertartige Flüssigkeil. in releher jedoch Felltröpfehen rorzukommen peflegen.

[Unter den zahlreichen Arbeiten über das Gehirn der Gräthenfische sind hervorzuheben: der schon \$. 55. genannte Aufsatz ron Gottsche; die Schilderung des Gehimes von Coregonus palaca in $\mathrm{Agassiz}$ und $\mathrm{V}$ ogt, Anatomie des Salmones und

16) Bei Trigla gurnardus, Alosa vulgaris und anderen Fischen werilen diese Lobi postcriores-vom Cerebellum fast ganz verdeckt. - I usconi hat darauf aufmerlisam "rimacht, dass bei Tinca die Lobi medullue oblongutue des cinjährigen Thieres noch kaum entwickelt sind. S. Müller's Arch. 1846. S. 478. Tb. 15. Fig. \%.8. 
cine Monographie des Gehirnes cinheimischer Süsswasserfische vou II. M. A. Ki la a tsch: de cerehris piscium ostacanthorum aquas nostras incolentium. IIalis. 1850. 4. Sie sind sämullich durch Abbildungen erläutert. - Merkwärdige Abweichungen vom gewöhnlichen ilirnbau zeigt, nach Erdl (Gelehrte Anzeigen, hersgl, v. d. k. baiers. Acad. d. Wissensch. 1816. No. 179. S. 4013.) die Gattung Mormyrus, so wie nach demselben (s. cbendaselbst 1846. No. 202. S. 599.) Gymnarchus niloticus.]

\section{\$. 59.}

Das Gehirn der Ganoïlen $\left.{ }^{1}\right)$ stimmt, mit Ausnahme sü̈sserer Ansdehnung dex Pedunculi cerebri zwischen den Ilemisphä̈en und den Lobi optici, in seiner wesentliehen ïnsseren $A$ nordnung nenit demjenigen der Toleostei übcrein. Bei Accipenser folggen anf die, durch den Besitz cines an ilnem Ausgangsspunkte oben gö̈fneten. Ventrikels ansgezeichicten Tubercula olfactoria die durch eine Spralle getremuten, aber durch rine wreisse Commissura interlobularis verbmdenen Hemisphären. Jerler Hobns derselben besteht aus zwei. Jurch eine quere Furche seschedenen. inwendig soliden, Erhabenheiten. An sie schliessen sich die Pedunculi cerebri, eine oben geöflnete Rinne darstellend, welche scillich von schwachen Erhabenheilen begrenzt wird. Sie sind oben von den Forlsclzungen der gemeinsamen Ilimhaut überwölht, welehe vor ihnen in einen langen, ronischen,

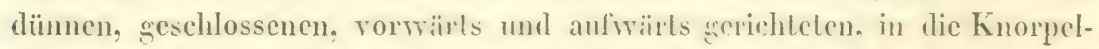
substanz des Sehedels weit hineinragenden Sack sich zuspitzen. Diese änsseren Membrancn aber umschliessen einen zweilen oben geschlossenen. hinten mit dem Infundibulum communieirenden Gefïssatk, weleher Iymphatische Jlïssigkeit cnthïl. Dieser Gefïsssack ist ähulich gehiddet; wie der Saccus vasculosus. Von seinen Gefässhäulen aus crheben sich mehre gestreckle, parallel laufende Gefaisse in den conisehen Sack der gemeinsamen Gefässhatut und von diesem aus in dic Knorpelsubstanz des Schedels. An der Basis dieser Gefïsse entwicheln sich dic Bhiischen der Epiphysis ${ }^{2}$ ).

1) S. über Accipenser meine Abhandl. in Mäller's Archiv. 1843. - Die wesentliche Uehereinstimmung des Gehirnes der Ganö̈dei holostei mit dem von mir geschilderten Baue desselben beim Stör hat nachgewiesen: J. Müller, Ueber Bau und Grenzen d. Ganoïden, wo auch die erforderlichen Abbildungen gegeben sind. Von den ursprünglich gegebenen, anch durch Huller acceptirten Deutungen, weiche ich in dieser Darstelluug, die auf fortgesetzte Untersuchungen sich stützt, ab. Busch, De Selachiorum et Ganoïdeorum encephalo. Berol 18\$8. 4. hat mit Recht auf dic Inconseyuenz ciner Annalme cigener Lobi ventriculi terlii aufmerksum gemacht, bei seinem über mich ausgesprochenen Talel aber thersehen, dass sein grosser Lehrer mehrfach die gleiche Deutung ausgesprochen hatte.

2) Der Zustand dieser Epiphysis ist höchst verschiedenartig. Biswcilen sicht man nur Gefïsse und Blïschen, Bei anderen Thieren, und zwar gewühnlich, Folgendes: die "uberculı intermedia werden durch eine graue Brïcke verlunden. Ihre Bestandheile simd lï̈nchenhaltige Zellen, die in feinkörniger (irundsubstanz liegen. Von dieser Brücle geht nun cin weisser, bei grossen Stören bis 3 Zoll langer, bisweilen 


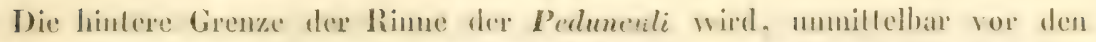

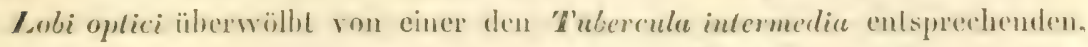
zwei Erhabenheilen bilenden Commissur. - Die zunichsl folgenden sewöblen, weissen, ohcrlïchlichen, paarigen Lappen der Lobi optici, ron welehen die Terri optici ausgehen, verhallen sich, in ihrer Verbindungsweise durch ein granes Gewälbe und cine vordere weisse Commissur, wie bei den Teleostei. Sie bedecken eine Iröhle, welehe nach rorne mit dem Ramme zwischen den Pedunculi cerebri, nach muten mit der IIöhle der eng verbundenen Lobi inferiores und mit dem Infundibulum, nach hinten mil dem Sinus rhomboüdalis communicirt. - Das Cerebellum ragl zapfenförnign hinein in die Iöhle der Sobi optici mol empfïngt hier, von jeder Seite der Wandungen dieser IG̈hle ans, einen starlsen weissen Markischenkd. Mil diesem, von den Yobi optici überwübten eigenllichen Cercbellum hangl eine selur entwickelle. hinter jenen Zobi gelegene, steile: gewundene grane Commissur der Corpora restiformia imnig zusammen. - Die nach dem Hirne zIl an Breite beträthtlich gewimnende Medulla oblongala bildet einen weiten offenen Sinus rhomboüdalis. Zur Seite seiner Längsfurche liegen die weissen Pyramidalstrïnge zu Tage: unmiltelbare Forlsetzungen der gleichen an der Basis der Rückenmarkshöhle bedindlichen Stränge. An Vorderende des sinus rhomboidalis astreckt sich ron jedem derselben ein weisser Querstrang in die nugebende Markmasse. Diese (aerstränga sind es, welehe in den, von den Lobi oplici ïberwöblen, Theil des Cerebellum spailer eintrelen. - Weiter nach aussen folgen die in zwei parallele Läugsbiindel zerfallenen. aus cinander gewichenen Forlsetzungen der hinderen ohler oberen Rï̈chenmarkshäuge. Ihnen aussen und oben angefügl crscheinen die granen gelräuscllen Corpora resliformia, deren Commissur den frei zu Tage liegenden Theil des Cerebellum bildet.

Was die Umhällungen anbelrift, so ist der hinlerste weite Theil der Scherlehöhle; welcher noch einen Theil des Rë̈chemmaties anfuimml, mit.

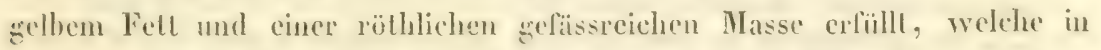
ihren miliroskopischen Beslandtheilen mil der, die grossen Vonenstïmme umgebenden, Gedissdrïse wesentlich äbereinstimmt. J)ic Mcdulla oblongala. nebst dem Gehine, werden ron einem, stellenwerise dunkel pignentirten Sacke mmhïll, dessen IÏ̈ute in mehe Schichten sich sondern lasien. Die änsseren Schichten stohen dureh Brächen mil eincr, die anstrelenden Ner-

doppetter Faden aus, der in dem conischen Sacke und später ausserhall, desselben in einer eigenen vorderen, vorn algerundet endenden Aushöhlung der linorpelsulstanz des Schcrlels nach vorn verläuft und hier endet. Dieser weisse Faden besteht aus einem mit dunkelen Molekularkömchen, mit hirmzellenartigen und anderen Theilen und fiernen gefillten Ilohlraume, nehen welchem Blulgefisse verlaufen. Sein vorderes Linde enthalt bäld hasse runte \%ellen, bald Detrilus: dunlele Molekularmasse und Felt. 
ven und zum grossen Theil anch die innere Schedellählenwand ibberatehen-

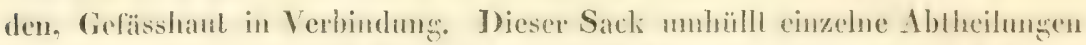
des Gehimes, namentlich die Gegenden der Sinus gुmz lose, andere innigg. Fir wird wesentlich gebildel aus Gefässhänlen. Zur Seile der Corpore resliformir bildet die hier der Ilirnsubstanz anf das ensole anliegende innerste Platte des Sackes zahlreiche, parallele, liammartige, Lansverselle Falıen, in welehen die Gefïsse verlaufen. Wähend seiner Anstehnumg ïber dem Sinus rhomboüdalis und über dem Sinus der P’cdunculi mulnüllt er mit lymphatischer Flïssigheil erfüllte Sitclie. Der in fiestall cines Ilornes verlïngerte, ron der II ̈̈hle der Pedunculi auszehende Lymphsack rö̈̈lt ron den Fortsätzen der Gefässhant ebenfalis eine äussere Bekleidung.

Mit der Anordnung der Ilirnabtheilunger bei den Ganoiden scheint diejenige der Dipnoi grosse Aehnlichkeit zu haben ${ }^{3}$ ).

$$
\text { \$. } 60 \text {. }
$$

Die wesentliche Anordnnng der Hirutheile bleibt bei den Elasmohranchii $\left.{ }^{1}\right)$ dieselbe, wie bei den Teleostei und fanö̈lci; doch zeichnel sich das Gehirn immer dureh viel beträchllichere Enlwickelung senuer Masse. so wie durch mehre andere Umshände aus. Dahin gehören: 1) die schon bei manchen Teleostei angetrotlene Entfrumg der 'Lubercula olfactoria von den Ilemisphärenlappen dureh die zwischengeschohenen. oft sehr lan. gen Tractus olfactorii; 2) die anch den Ganoìlei im Ganzen cigenthümliche, aber bei manchen Elasmobranchis, und zum Theil in auffallender Weise, hervortretende Entfermung der fobi oplici von den Ilemisphärenlappen durch die zwischen selegenen lïngeren l'cdunculi cerdri; 3) des schr bedeutende Umfang des Cerebellum.

Die Hemisphären ${ }^{2}$ ) zeiggen rerhälnissmässig cinen beträchlichen Un-

3) S. vorzüglich Peters in MülIer's Archiv. 1845. Tb. 3. Fig. 6. 7.

1) Das vielfach untersuchte Gehim der Elasmobranchii ist, in Betreff seiner morphologischen Verhältnisse, am ausfihrlichsten und errimilichsten crürtert von Busch, De Ganoïdeorum et Selachiorum encephalo. Berol, 1848. 4. mit trefflichen Abbildungen. - Andere Abbildungen von Gehirnen der Plagiostomen finden sich z. B. bei Carus Zootomie. T'b. 9.; Carus, Darstellung des Nervensystemes. Tb. 2.; Kuhl, Beiträge z. Zool. u. vergl. Anat. Frkf. 1820. T'b. 1.; bei Weber, de aure et auditu hom. et animal. Lipz. 1520. 4. Tb. 10.; bei W agner, Icones physiol. Tb. 23.; bei Davy, Physiolog. researches. Vol. I. Tb. 1.; bei Swan, Illustrat. of the comp. anat. of the nerv. Syst. T'b. 10, bei Savi in Matteucci, Traité d. phénom. electro-phys. Tb. 2.3. - Ueber den elementaren Bau s. Savi, Wagner und Leydig. - Rücksichtlich aller speciellen Verhältnisse muss auf Busch verwiesen werden.

2) Warum Busch 1. c. p. 10, nach dem Vorgange von Rolando, dic Hemisphinren als Lobi communes d. h. als Lobi olfuctorii und hemisplenerici zugleich denten will, ist mir unklar. S. meine Schrift äber d. periph. Nervensyst. d. Fische. S. 3., wo ich aus cinander gesetzb, dass die Tractus olfuctorii der lïsche immer llimröhren enthalten, mögen sie lang oder lurz sein, während die $\boldsymbol{N}$. N. olfuctorii immer 


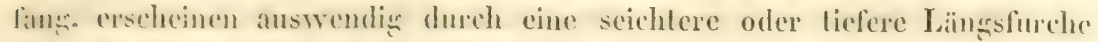

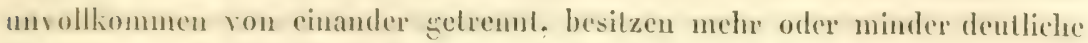

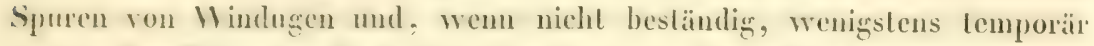
eine innere IIöhlung: in wolcher bisweilen den Streifunhïgehn vergheichbare Erhabenheilen beobachtet werten. Aus den Seitentheilen dieser Ifemisphiiren eschen die Tractus olfactorii hervor, nm vorn, oft weit vom Gehirne enternt. ilue Anschwellnugen zu bilden. Diese Truclus werden ebenfalls häufigy hohl angetrofin und commmieiren dam mit dem Ventrikel der IIenisphäı'ch.

Die Hemisphären schlicssen sich bald ummittelbar an die oberflïchlichen Wälbungen der Lobi oplici. bald werden sie durch die beiden längeren. frei zu Tage liegenden, seillich durch graue Masse belegten. in der Mille cine Rimne bildenden, also cinen Simus besitzenden Pedunculi cerebri ${ }^{3}$ ) von ihnen getrent An der hinteren Grenze dieser liegen die Tubercula intermedire und minterhalb lelzlerer der Aditus ad infundibulum, welehem die solisle, bei den Squalidae viclfach gelappte IJypophysis, nebst dem mit ilım communicirenden Saccus vasculosus angefügt sind.

Die Gegend der Lobi optici besilzt oberflïchlich zwei convexe, millelst eincr Lïngsfurehe unvollkommen von cinauder getrennte Gewölbe, deren Umfang meist geringer ist, als derjenige der Hemisphären und im Ganzen anch, als der der gleichnamignen Gebilde bei den Teleostei. Aus ihnen entstehen die meisten Fasern der Sohnerven. Sic werden meistens mehr orlen minder vollstïndig äberrast und bedeckt ron dem Vordertheil des Cerebellum. An der Basis dex Lobi oplici liegen. etwas rorwärls serücht, die hald hohicn, bald soliten robi inferiores, zwischen denen die Hypophysis und der fiaccus rasculosus cingelieilt sind. Vor den Lobi inferiores findet sich das Chiasma nervorum opticorum.

Das sehr umfängliche Cercbellum, dessen Ilöhle mil dem Aquactuch Syleii in Verbinduns steht, erstrecht sich vorne gew öhnlich äber eincu schr beträchllehen Theil fler Docken der Lobi optici nut bedeckl hinten in ciner nicht minder bedentenden Streche den Sinus rhomboüdalis, besitzl bisweilen cine Längsfurdte, zeight häufig transverselle Streifen, oder wie hei

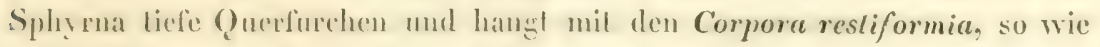
mit der Fortsetzung der hinteren Rückenmarksstrünge zusammen.

rinen anderen Ban zeigen, sobald sic die Tuberula olfactoria verdassen, mögen dicse unmittelbar vor dem Gehirne oder weit nach vorne gerückt liegen.

3) Ein Theil der Stränge der Pedunculi steht mit den Sehnervenursprüngen hinten in Verbindung. Cuvier und Gottsche haben diese Communication richtig crkannt und ich habe geirrt, wenn ich sie zu vermissen glathte. (s.. meine Schrift S. 8.). Sollten diese ron den Sehnervenursprüngen zu den Ilemisphitren trotenden Strainge bestimut sein, lichtemplindungen zum Sensorium zn ubertragen, um zu willwihrlichen Actionen anzuregen? 
Die umfängliche Medulla oblongala besteht jederseits ans drei Strïugren: den vorderen Pyramiden, den Fortselzungen der hinleren Rüblenmarksstränge und den Corpora restiformia. Letzlere bilden vielfach gewuudene Wülste zur Seite des Cerebellum: die Lobi posteriores s. Lobi nervi trigemini. An Boden des Sinus shomboüdalis erheben sich bei den Haien 4-6 perlschnurfürmig an cinander gereihete Erhabenheiten, welche den Rochen allgemein zu fehlen scheinen.

Bei den Torpedines wird der Sinus medullae oblongatae fast granz bedeclit durch die in der Mittellinie an cinander stossenden, einwïrts von den Corpora restiformia gelegenen, seh" belridehtlichen Lobi electrici " $)$, welehe reichlich multipolare Ganglienlï̈rper enthalten, deren Pole in Nervenfascrn sich fortsetzen ${ }^{5}$ ).

In seinen wesentlichsten Terhiltnissen stimmt das Gehirn der Holoce. phali mit dem der Plagiostomen überein ${ }^{6}$ ).

Das Gehirn der Elasmobranchii fäll bei ganz jungen Thicren die Schedellöhle ziemlich voliständig aus; bei äteren Thieren gevöhnlich - aber nicht immer 7) - nur theilweise. Abgesehen von der harten Ilimhaul, die die Schedelhöhle ummittelbar auskleidet, verdient die dias Gehim überzichende Gefïsshant Beachtung. Sie hildet gefässreiche Falten, die den Corpora resliformia eng anliegen, und Fortsätze, die in den Sinus rhomboüdalis übergehen und wahre Plexus choriö̈dei darstellen. Zwischen ilı und der harten Hirnhant funden sich sehr oft zellenähnliche Räume, von Ballen der Gefïsshaut durelizosen, mit lymphatiseher, sallerdartiger Substanz erlïllt. Eine dritte zarte Membran hildet die das Gehirn dicht ïberziehende lia mater.

\section{\$. 61 .}

Jeder Spinalnerv entsteht in der Regel mit zwei Wurzeln: einer vorderen und einer hinteren; eine Ausnahme von diescm Gesetze macht nicht selten der erste Spinalnerv. Die vordere Wurzel cntsteht ans dem vorderen, die hintere aus dem hinteren Strange des Rïchenmarles. Gewöhnlich, doch nicht ganz bestïndigs, z. B. nicht bei Diodon, übertrifft die hintere Wurzel die rordere an Stïke. Die Dielie der einzelnen Wurzelı kann an verschiedenen Stellen des Rückenmarkes rersehieden sein. Besonders stark sind z. B. cinjeg der ersten Spinahervenwurzeln bei den Trighe 1) und bei Polynemus, vvo sie zugleich von cigencu Anschvellungen

4) Die genauesten Abbildungen des Gehirnes der Torpedines verdanken wir Savi, l. c. Tb. 3. - 5) Diese Thatsache ist durch Wagner ermittelt.

6) S. das Speciellere bei Busch, 1. c. nnd dessen Abbildungen. Tb. 2. Fig. 7-9.

7) Eine Ausnahme bildet z. B., wie auch Busch angibt, Zygaena.

1) S. über diese Anschwellungen $\$$. 56. An der Basis dieser Anschiwellungen und in ihren Zwischenräumen treten suecessive fünf hintere Spinalnervenwurzeln hervor. Die beiden Stränge, welche die hintere Wutzel des dritten Spinalnerven con- 
des Rï̈ckenmathes ilnen Ursprumg nehmen. - Die vordere IVurzel eines jeden Spinahnerven verlisst dis Röckenmark gewöhnlich als einfacher Strang. Bei Aceipenser, Spinax ${ }^{2}$ ) und Carcharias tritt dagegen die vordere Wurzel in der liegel mil zwei disereten Strängen aus dem Rïchenmarke herror. - Eine Eignenhümlichlieit der bisher untersuchten Gadoïlen ${ }^{3}$ ) ist die, dass jede hintere Wurzel einiger oder vieler der Spinalnerven der Rumpfgregend zwei gesonderte Stränge und jeder dieser letzteren sein eigenes Spinal ganglion besilzt. Die cine dieser Wurzeln ist für den $\boldsymbol{R}$. dorsalis, die andere fïr den $\boldsymbol{R}$. ventralis eines Spinalnerven bestimmt. - Die hintere Wurzel enthïlt vorzugsweise feine, die vordere, ansschliesslich orler vorwaltend, breite Primiliväiten. - Bisweilen haben die Wurzeln der Spinalnerven von ilnrem Ut'sprunge ans rlem Rückenmarke bis zu ihrer Austriltsstelle aus dem Spinaleanale eine write Sirecke zurïchzulegen, sind daher schr lang. Besonders ist dies bei extrenner Kürze des ganzen Rückenmarlies, wie bei mehren Plectognalhi Gymnodontes oder bei grosser Dümne seines hinleren Theiles, z. B. bei Idophins der Fall, wo die Nervenwurzcln cine starke Cauda equina bilden.

stituiren, sind von sehr betrïchtlicher Stärke. Auch findet man fir diese Wurzel zwei unvollıommen getrennte Spinalganglien. Jiese hinteren Wurzeln enthalten grüsstentheils feine Primitivfäden. Auch die vorderen, von den vorderen Rückenmarkssträngen cntstehenden Wurzeln sind stark. - Die beiden ersten hinteren Wurzeln treten mit drei vorderen W'urzeln zur Bildung des ersten Spinalnerven durch eine gemeinsame schedelöfnung aus. Die beiden ersten hinteren Wurzeln bilden nach ihrem Austreten aus der letzteren zwei dicht neben einander liegende Ganglien. - Die Rami anteriores der beiden ersten Spinalnerven sind, nach Abzug des Ramus pro musculo sternohyoüleo und des starken Nerren für den Scitenmusliel der Schwimmblase, bestimmt für die Vorderextremität; der dritte Spinalnerv alıer begibt sich, nach Abgabe cines $\boldsymbol{R}$. communirans zum Plexus brachialis, ausschliesslich an die fingerförmigen Organe und deren Muskeln.

2) Bei Spinax hat der eine Strang, indem er der Austrittsstelle der ganzen Wurzel gecrenuber aus dem Räckenmarke kümmt, einen sehr kurzen queren Verlauf im Cunalis spinalis, während der andere Strang, weiter vorwärs entspringend, im Sprinalcanale eine Strecke weit hinterwärts verlaufen muss.

3) Gefunden hale ich diese Eigenthümlichkeiten bei Gadus callarias an 31 Spimalnerven, bei G. aeglefinus und G. minutus an vielen, ferner hei Raniceps fuscus, Lepidoleprus norwegicus, Lota vulgaris, Brosmius vulgaris und Motella mustelus. - Die fír den ra, posterior s. dorsalis hestimmte hintere Wurzel verlässt den Canalis spinalis zwischen den oberen Bogenschenkeln je zweier Wirlel, stcigt aufwïls und bildet in einiger Entfermung von der Austrittsstclle rin eigenes kleines Ganglion. Entweder sogleich nach der (ianglienbildung, oder etwas spater, legt an sic das dünne für den liucken bestiumte motorische Wurzelelenent des nächst hinteren Spinalnerven sich an. So entsteht der $\boldsymbol{R}$. dorsulis aus den heterogenen Elementen zweier auf einander folgender Spinalnerven. - - Die fir den Bauchast bestimmte hintere Wurzel bildet mach ihrem Austritte aus dem Foramen intervertelorale ihr spinalganglion und darauf legt die ihr entsprechende vordere Wurzel an sic sich an. 
Dic Austrillsweise der beiden Wurehn aus dem Canalis spinalis verhitl sich in so ferne versehieden, als sie den lelzleren bald durch eine ge-

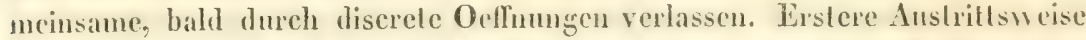
haben die Elemente der vorderen Spinalnerven vieler, die aller Spinalner. ven mancher Teleostei. Bei den Elasmolranchii, bei Aceipenser, bei einižen Taleostei, z. B. bei Perea, Pleuroncetes, Silurus, Cyprinus, Esos, Salmo lat jede Wurzel ihre diserete Austriltsstelle. Bei den Pagiostomen trill die rosdere Wurzel durch die Cartilago cruralis, die hintere durch die Carlilago intercruralis ${ }^{4}$ ). - Bei den Teleostei liegen die Anstrittsöflnumgen bald in den ossificirten Elementen, bald in den häuligen Theilen der oberen Bogen, bald in beiden zugleich.

Die Spinalganglien entstehen auf Kosten der hinteren Wurch. Für einzelne Nerven hamn das Ganglion noch in Canalis spinalis liegen. wie dies namentlich in Betreff der vordersten bisweilen vorkïmmt. Wenn cin Nerv zwei hintere Wurzeh erhält, bilden diese gewöhnlich zwei juxlaponirte Ganglien. - Die Ganglien cinzelner Spinalnerven sind oft besonders stark.

Sehon vor der Vereinigung der beiden Wurzeln eines Spinalnerven können Zweige ans einer oder aus beiden derselben hervortecten, wie dies namentlich bei Plagiostomen, bei Accipenser, bei $C_{y}$ prinen, Salmonen 1 . s, w. beobachtel ist ${ }^{5}$ ).

Jeder vollstïndige Spinalnerv besilzt resentlich cinen dorsalen und einen ventralen Ast. Am vollkommensten ist die Symmetrie Beider da ausgepräigt, wo jeder dieser Aeste seine cigene rorkere und hinlere Wurzel besilzt, wie bei den Gadö̈len an vielen Nerven. Ein zweiter BildunssIypus ist der, dass die hintere Wuzel cin cinfaches Spinalganglion bildel, aber die rordere Wurzel sogleich nach ihrem Austrelen in zwei Schenkel sich theil, von denen eincr fïr den $\boldsymbol{R}$. dorsalis, der andere für den $\boldsymbol{R}$. ventralis bestimmt ist. Endlich kïnnen die Elemente beider Acste ans cinem indifferenten Vereingungspunkle aler vorderen und der hinleren Mirzel entstehen.

1. Der Ramus dorsalis erstreckt sich längs dem oberen Bogen seines Wirbels und später auf den tiefen Flossenmuskeln anfwïts zum Rïcken, inden er seine Zweige abgibt sowol für den Rïckentheil des Ścitermmskels, als auch für die tiefen Flossenmuskehn. - Wïluend seines Ver. lanfes nach oben empfängt er cinen $\boldsymbol{R}$. communicans aus dem Rt.edorsalis der nä̈hst vorderen Spinaluerren. Dieser R. communicans, weleher hisweilen stärker ist, als der eigentliche $\boldsymbol{R}$. dorsalis, tremut sich ron eincm

4) In Folge eines Irrthums des Correctors sind in Texte meiner Schrift über das Nervensystem die Bezeichnungen Cartilago cruralis und intercruralis verwechselt.

5) S. Näheres in meiner Schrift. S. 118. 
solchen bald sogleich bei oder nach seinem Entstehen, bald erst viel späler. In ersterem Falle steigh. er gewöhnlich längs dem oberen Bogenschenhel des nïchst hinteren Wirbels schü̈g anfwärts zum Rïchen, um mit dem nächst folsenden $\boldsymbol{R}$. dorsalis sich zu verbinden ${ }^{\circ}$ ). In zweilen falle slellt cr zwischen scinem ursprünglichen $\boldsymbol{R}$. dorsalis und dem nïchst hinteren cinen mohr queren Verbindungsast dar. Auf diese Weise kam also durch sïmmlliche cinzelne $\boldsymbol{R}$. $\boldsymbol{R}$. communicantes ein auf den tiefen Flossenmuslichn liegender, die einzelnen $\boldsymbol{R}$. $\boldsymbol{R}$. dorsales verbiudender Längsslamm entstehen, wie z. B. bei Cottus, bei den Gadoïden.

Bei ilenjenigen Fischen, welche cinen $\boldsymbol{R}$. lateralis $\boldsymbol{N}$. Irigemini besilzen, gुcht der vereinigle Slamm des eigentlichen $\boldsymbol{R}$. dorsalis und des $\boldsymbol{R}$. communicans oben an Rücken, cinfach oder in zwei Zweige gespallen, in die Bahu dieses Collector's über. Aber auch da, wo ein $\boldsymbol{R}$. lateralis fehlt. können die oberen Enden der dorsalen deste an dor Grenze der eigenlliduen Flossenmuskeln noch dureh sehr feine, in der Längenrichlung des Rumpfes gelegene Rr. RR. communicuntes verbunden werden. Die von den dorsalen Aesten ausgehenden Musliclzweige enthallen vielfach sich theilende Fibrillen.

2. Der Ramus ventralis ist bestiundig umfänglicher, als der $\boldsymbol{R}$. dorsalis. Er erstreckt sich an scinem Wirbelkö:per etwas abwäris, gibl gewöhnlich eine cinfache oder doppelte Wurzel zum Grenzstrange des $\boldsymbol{N}$. sympathicus und culsendet andererseits cinen, sewöhnlich von seinem vorderen Rande ausgehenden, Ramus medius, um dann abwïls zu lreten. Der 18. medius trill in den Zwischentam zwischen Dorsalmasse und Ventralmasse des Seilemmuskels und begibl sich in demsclben nach anssen. Fo verlheilt sich in den Scilmumbled und besonders in dessen dorsale II:ille. Seine Endzweige trelon, anscheinend immer. unter die Ilant, ohue in die Bahn des $\boldsymbol{R}$. lateralis vagei ïberzugehen. Nach Abgabe des $\boldsymbol{R}$. medius trill der vinlache Slamm des $\boldsymbol{R}$. ventralis als Ramus intereostalis oder $\boldsymbol{R}$. in. tercruralis abwïts, wobei ex oft zugleich stark hinlerwäts gerichtet ist. E. hrill immer am lordereande des dem nächst hinteren Wirbel angehöri-

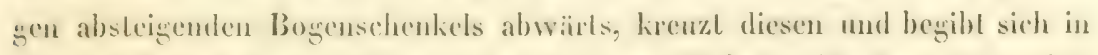
das Spretium intercostale des närhst hinteren Wirbels. IE liegl dieht äber drun Peritonenm, gibl aber anch Muskelzweige ab. In der muteren Banchgegend spaltet er sich oft. in zwei Lweige von denen der Eine vorwärts, der Andere hinterwärts gerichtel ist.

Bei cinigen T'eleostei und den Rajidac stehen in der Schwanzgegend die $\boldsymbol{R}$. $\boldsymbol{R}$. ventrales zweier Spinalnerven, hald höher, hald liefer, dureh einen Lransversellen $\boldsymbol{R}$. communicans mit cinander in Verbindung.

6) Br kann aber mehr als ein blosser 12. communicans sein, indem er, mach Alogabe eines solchen, noch selibststiudig sich verlängert, wie z. B. bei lisox. 
Bei Gadus und Raniceps grehen in der Caudalgegend die R. R. intercrurales inferiores über in den ventralen Stamm des R. lateralis trigemini, der schon bei seinem Absteigen länss dem Rumpfe feine Verbindungszweige von den $R$. $R$. intercostales erhalten hatte.

Einige Eigenthümlichkeiten bietet der erste Spinalnerv ( V. hypoglossus Auct.) dar; die Zahl seincr Wurzeln ist schwanliend ${ }^{\top}$ ); er lrill häufig aus durch das $O s$ occipitale laterale. Sobald der erste Spinalnerv, sei es allein, sei es in Verbindung mil dem zweiten, einen $R$. anterior besilzl. gibu dieser letztere cinen Strang ab zum Plexus brachialis mol sclyt damm sich fort in den zwischen Schultergïrlel und Zungenbein selegenen $\boldsymbol{H}$. sternohyoüdeus. Bei den Haien erhalten die viel zusammengeselzteren Muskeln, welche zwischen dem Schultergüntel und dem Zungenbeine oder Lnlerkiefer gelegen sind, ihre Nerven ans den R. R. anteriores der beiden arslen Spinalnerven. Ebenso bei den Rochen dureh einen. von dem, durrh Vereinigung vicler Spinalnersen, gebildelen Stamme, sich ablüsenden As. Den Fischen mangelt demuch cin selbstständiger $\mathbf{V}$. hypoglossus s), der vielmehr noch in den Elementen ihres ersten Spinalnerven culhallen ist.

Bei Trigla erhalten die starken Seitenmusken der Schwimmblase ihre Aeste aus den ersien Spinalnerven. Diese Aeste steigen analog dem $\boldsymbol{N}$. phrenicus der Säugethicre ab.

Bei solchen Fischen, deren Rückenflosse ${ }^{9}$ ), sei es in cinzelnen, oder in zahlicichen verschmolzenen Strahlen, am Sehedel sich befestigh sind es dorsale Aeste der ersten Spinalnerven, welche rorrwärts sich crstreckend. diese Flossen mit Nerven versehen.

Zur Vorderextremitit der Teleostei treten meistens Elemente dex lami anteriores dreier Spinalnerven, nämlich ein Zweign vom $R$. anterior des ersten, der ganze R. anterior des zweiten und ein Ast vom R. anterior des drillen Spinalnerven; bei einigen Teleostei könmul noch ein Ast vom $R$, anterior des vierten hinzu. Bei Accipenser begeben sich zu ilu Aeste vom sechsten, bei Acanthias Aeste vom elften Spinalnerven. Bei den Rochen ist, wegen Ausdehumg der Flossen, die Anzahl der für sie beslimmten Nerven ansserordentlich vermehrt. Bei $R$. clavata sammeh sich die 16 Spinalnerven in einen Längsstamm, der zuerst den $R$. hypoglossus abgibt und dann zur Extremitat tritt. Zu der Flosse treten ausserdem noch cinzeln die $R$. R. anteriores von 30 Spinaluerven.

Bei denjenigen 'Telcostei. deren Becken am Schultergerïste befestigl ist, erhalten die Bauchlossen ihre Nerven hïufie von den R. R. anteriores

7) S. Näheres in meiner Schrift. S. 121.

8) S. Näheres in meiner Schrift. S. 124, wo riber die Elemente des N. Typoglossus und accessorins Bemerkungen gegelsen sind.

9) Z. B. bei Lophius, Pleuronectes, Echencis. S. Näheres in meiner Schrilt. S. 123. 
des vieplen und fünften Spinalnerven. Doch kommen cinzelne Abweichungen rom dieser liegel ror. - Bei den Pises abdominales empfangen die Bauchllossen ihre Aesle aus denjenigen Spinaherven, welchen sie zunächsl liegen.

$$
\text { \$. 62. }
$$

Die Verhälnisse des $\boldsymbol{N}$. sympathicus ${ }^{1}$ ) der Marsipobranchii sind noch nichl schörig aufgehlärt. Während die meisten Anatomen deuselhen rinen sympathischen Nerven absprechen, ist es mir wahrscheinlich geworden, dass derselbe bei Potromyzon repräsentirt sei in Fasern, weldhe aus den die I'enae verlebrales bigleitenden Fettkërpern hervorkommen, und ron diesen ans, einerscits an die Gefïsstämme und andererseits an 'die unter ihnen frelogenen lieimbereitenden Geschlechlstheile sich begeben. Diese Annahme slïlzl sich rolzugsweise anf der Beobachtung, dass in den genannlen Fellkörpern sehr heine Cysten oder Sehlänche sich bilden, in denen Fasern sich entwickeln oder mit denen Fasern in Virbindung stehen: dass ferner anch den, in gervissen Ganglien von Petromyzon angeLroflenen granulirten Körperchen analoge Gebilde in der Ungebung und namentlich am Ursprunge dieser Fasern wahrgenommen sind. Wem allerdings die langen, wellenförmig stekrüselten Fasern mit Bindegewebsfibrillen nnd mit elastischen Fasern die grössle Aehnlichkeit haben. so ist zu bedenken, dass anch die Elementartheile des Rï̈ckenmarkes bei Petromyzon und die im Sympathicus anderer Thiere vorkommenden Remakschen Fasern viel Abweichendes von dem Baue der sewöhnlichen NervenElemente besitzen.

Auch bei den Plasiostomen bietel der $\boldsymbol{N}$. sympathicus manche Eignthïmlichkeiten dar. - Ein Kopftheil desselben ist bisher vermisst worken. Längs der Wirbelsïnle rieht bei Leanthias, noben jeder Vence vertebralis, von ihrer Ausgangsstelle aus der Schwanzvene an, eine Reihe von Ganglien sich vorwïrts, welche zum Theil durch einen Grenzstrang unter cinander der Länge nach verbunden sind. Zwei obcre oder vordere Ganglien sind st:̈̈ker, als die übrigen. In jedes der letateren treten Rami communicantes ron Spinalnerren; das rordersle hangt auch mit einem Faden des $\boldsymbol{N}$. vagus zusammen. Das erste oder rorderste Ganglion ist das belräichllichste nurl liegt im Jamen des Truncus transtersus venarum zur Seite de's Oesophagus, dicht ̈̈ber rler Wirbelsäule. D) vordersten Ganglien berder Scilen stehen durch cinen queren Zweig mil cinander in Verbindung. Aus diesen vordersten Fanglien gehen die Wurzeln des die Arteria coeliaca begleitenden schwachen $\boldsymbol{N}$. splanchnicus ab. - Aus den nächst hinleren Gans-

1) Man vgl. über den N. sympathicus der Fische: E. I. Weber, Anatomia comparata nervi sympathici. Lips. 1818. 8. - C. It. Giltay, de nervo sympathico. Lugd. Bat. 1-34. - - 0. E. A. IIjelt, In systema nervorum sympathicum Gadi I.otae observationes. Halsingfors. 1847. 8. 
lien entstehen behrächtliche Nerven für die Geschlechtstheile ${ }^{2}$ ). - Dic Ganghientietlen und die Nerven selbst seheinen in steter mol vieldeicht periodischer Ernenerung begriffen zu sein. Keimstïlten der Ganglienkïrper sind theils rundliche nit Blastem erfïllte an den grossen Venenstämmen

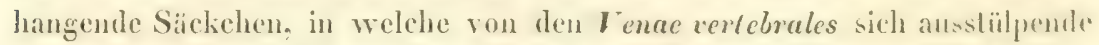
Gefïsse hineintreten, theils die als Nebennieren angesprochenen Körper. Auf Kosten der grossen Ganglienkörper selbst cutwiekeln sich die Kernfasern, aus denen namentlich dic zu den Geschlechtstheilen thelenden Norven oft ausschliesslich bestehen ${ }^{3}$ ).

Kaum ausgebildeter. als bei den Plagiostomen, ist das sympalliselue Nervensystem bei Accipenser. Der Grenzslrane liegt in der Substanz ciner die Fena rertebralis jeder Scite ungebenden Gefiissdrüse verbergen reicht, gleieh dieser, bis zu den Sciten der Schedelinasis. Er ist von graner Fabe und besteht wesentlich ans Kernfasm. Tnuerhalh der lianchhöht entlïsst er: - ausser den für die- Niere und die Geschlechlstheile beslimmLen Elementen - an beträchtlichen Zweigen zwei, von welchen der hinterste der Arteria mesenterica posterior folgt, der vordere aber cine Wurat des der Averia coeliaro-mesenterica sich ansehliesscuden Ramus splanch. nicus ist. Weiler nach dem Kopfe hin treten Zwveige ab, die die Kiemenvenen begleiten. Scine Endauslïufer anf der Sthedelbasis werten sohe frin und communiciren mit dem austretenden $\boldsymbol{N}$. vagus.

Sämmtliche Telcostei stimmen darin übcrein, dass sic nicht blos in

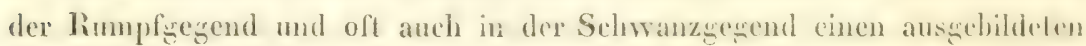
Grenzstrang des Sympathere besilzen, somblem dass lelzicrem anch ein Kopftheil zulömmil Der Grenzslrang des Rumpres liogl immer han an

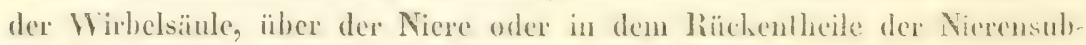
stanz eingebeltet. Der Schrvanztheil desselben selzt mehr oder minder weit nach hinten sich fort in dem die Aorta und die Vence cardalis anfnehunenden Canale der unteren Wirbelbogenschenkel.

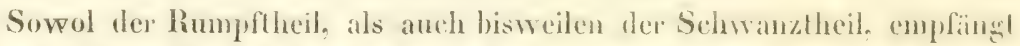
Thami communicantes von den Rami anteriores aller Spinalnerren. An der Uebergangsslelle der Rami communicantes in den Grenzstrans finden siel. anscheinend beständig, Ganglien, die bald mit mulewafinctem Anger, bald! mikroskopisch wahrnehmbar siud.

Der Kopftheil des Grenzstranges selat immer unter den Arstrillsstellen der $\boldsymbol{N}$. N. vagus, glossopharyngeus und facialis sich fort und liegt.

2) Diese Nerven bilden zum Theil Stränge, deren jeder in sehr feine Fasem sich zerlegen läst. Diese feinen, geschwungenen fibrillen lassen sich meist als Ausläufer spindelförmiger mit feinen Körnchen gefüllter Zelten erkennen.

3) Eine genaucre Beschreibung des sympathischen Nervensystemes der Plagiostomen, über das noch Vieles zu sagen wäre, liegt ausser dem Plane dieser Schrift. 
ausserhalb der Seliedelhöhle. An seinen Verbindungsstellen mit den genannten Hirunerven finden sich Ganglien, deren Lage, Zahl und Anordnung bei den einzelnen Fischen manche Verschiedenheiten darbicted, gewöhnlich aber der Zahl und Lage der genamnten Nerven entspricht. Ort gelingl der Nachweis seiner Verbindung mit dem $\boldsymbol{N}$. trigeminus; endlich sind anch sympathische Fïden zmm Ganglion ciliare und zu dem $\boldsymbol{N}$. abducens verfolgt worden. Die specielle anatomische Anordnung des Kopftheiles entspricht wesentlich derjenigen der Aortenwurzeln. Sobald die Kiemenvenen jeder Seite in einen Bogenabschnitt zusammentreten und die beiden Seitenbogenabschnitte erst nach Aufnahme sämmtlicher Kiemenvenen zur Aorta sich vereinigen, ist der Verlauf des sympathisehen Kopftheiles, der dann gewöhnlich den austretenden Hirnuerven eng anliegt, analog; liegt zwischen den Insertionen vorderer und hinterer Kiemenvenen aber schon cin unparer Aorten-Anfaug, so folgen die beiden, dann cuger an cinander gerïck ten, Kopfgrenzstrünge diesem und stehen duxch längere R. R. communicantes mit den einzelnen Hirnnerven in Verbindung. - Die aus dem Kopftheile des Grenzstranges entstehenden Zweige sind, - mit Ausnahme der bei einzehnen Fischen beobachteten Fïden für den Gefïsscanal des Os sphenödeum busilare, für das Ganglion ciliare, für den $\boldsymbol{N}$. abducens und für die Pseudobranchie - feine in der Rimne der Convexität jedes Kiemenbogens verlaufende, die Gefïsse begleiteude Kiemenuerven.

Indem die beiden Grenzstrïnge am Anfange des Rumples nahe an einander rücken, pllegen die Rami communicantes der crsten zwei orler drei Spinaherven lang zu sein und in ihrem speciellen Verhallen manche Versehiedenheiten darzubielen. Am Anfange seines Rumpftheiles bildel jeder Grenzstraug, sei es unter der Schedelbasis oder an Anfange der Wirbelsäule eine, oft beträchtliche, Anschrvellung (Ganglion splanchnicum). Diese Ganglien sind wesentlich ${ }^{4}$ ) die Ursprungsstellen der die Arteria coeliacomesenterica begleitenden N. N. splanchnici und durch den versehiodenarligen Ursprung dieser Arterie ist die verschiedene Lage der grenamblen Ganglien wesentlich bedingt. Aus jedem Ganglion geht eiganllich ein Truncus splanchnicus hervor; entspoingt aber die Artcria coeliaco-mesenterica rechterseits, so ist scheinbar oft das rechte, daun grewöhnlieh stirkere oder anch allein vorhandene, Ganglion die Ursprungstitte dex genamulen Nerven und ein zu ihm tretender Verbindungsast ans dem linken Ganglion oder dem linken Grenzstrange ist Repräsentant dex linken Wnrzel. - Was die N. N. splanchnici anbetrift, so folgen sie in der liegel wesentlich dem Verlaufe des Arteria coeliaco-mesenterica. Bei viclen Kuochenfischen bil-

4) Auch untergeordnete Zweige für die Nierensulstanz, fiir die letzte liienen-vene, für die absteigende Aorta, für das Vorderende des Ovarium liünnen alus ihm hervorgehen.

Handb, d. Zootomie $v$. Sicbold u. Stannius, 11. 
den die N. N. splanchnici an der genannten Arterie alsbald zwei unvollkommen verschmolzene Ganglien oder eine einfache stärkere gangliöse Anschwellung (Ganglion coeliacum), das bei Belone in directer Verbindung steht mit len Ganglion eines jeden R. intestinalis N. vagi. Das Verhallen der N. N. splanchnici zu den R. R. inieslinales $N$. ragi biclet sonst mannichfache Verschiedenheiten dar. Bei einigen Knochenfischen bleiben dic Stämme beider Nerven von einander gesondert und nur untergeordnete Zweige derselben frehen Verbindungen ein; bei anderen verbindet sich ein sympathischer Ast innig mit dem rechten R. intestinalis $N$. vagi oder rerschmilat mit ihm, wie bei den Cyprinen. - Die Zweige der N. N. splanchnici, welche wesentlich dem Verlaufe der Gefässe zu folgen pflegen, begeben sich zur Leber, zur Schwimmblase, zum Pancreas, zur Milz, zum Magen und Darmeanal und in das Mesenterium.

Die Fortselzungen der beiden Grenzstränge am Rumpfe stehen bisweilen dureh feine, die Aorta umspiunende Fidden mit cinander in Verbindungs. Zweige ron ihnen begeben sich in die Nierensubstanz, anch an die Geschlechtsthcile. Ist eine Arteria mesenterica posterior vorhanden, so erhaill auch diese cinen begleitenden Ast ans jedem Grenzstrange oder cinen cinfachen Ast ans cince unpaaren Anschwellung, die aus jeden Grenzstrange eine Wurzel empfängt.

Die bemerkenswerthesten Aeste, welche ans dem Rumptheile ihren Ursprung nehmen, sind die Nerven für die Ovarien und Horlen, so wie füı die Harnblase. Die Zweige für die Geschlechlshlueile treten bald einzelı und successive ans der Nierenmasse hervor, wie z. B. bei Zoarces, bei Cyclopterus; bald sind es venige atustrelente Aeste die sie zusammensetzen, wie z. B. bei Lueioperca und Silurus. Bei manchen Fisehen z. B. bei Gadus, Plenronectes liegen die Nerven für die Ovarien und die IIarnblase am ïussersten Eude der Rumpfhöhle und bilden sehr betrïchlliche Stïmme. deren Umfang, in Vergleich zu den Wurchn, enorn zu nennen ist. Eine wichtige Thatsache ist die, dass diese starken Nerven nur dureh ïusserst feine Rami communicantes oder Wurzeln mit den Grenzstringen des $N$. sympathicus in Verbindung stehen. The Masse besteht z. B. bei Gadus grossentheils ans den sogenamten hemak'schen Kernfasem. Nester von Ganglienkürpern sind ihuen an versehiedenen Stellen reichlich eingelagert. Das Blastem für diese Gauglienkörper, die, gleich den Nerren selbst, in beständiger Neubildung begriffen zu sein scheineis, geben, obschon nicht ausschliesslich, doch zum grossen Theile, dic in die Nierensubstanz cingebelteten Nebennieren ab.

Die Grenzstränge sind bei mehren Knochenfischen in den Canal der unteren Wirbelbogeuschenkel verfolgt worden, wo sic die Schwanzgefïse begleiten. Sie verhalten sich hier rerschieden und verschmelzen häufig zn cinem einfachen Stamine. 
S. 63.

Die Anzahl der sogeuannten spinalartigen . Iirunerven 1) beschränkt sich bei den Fischen gewöhnlich anf rier; diese sind die $N$. $N$. vagus, glossopharyngeus, facialis und trigeminus. - Elemente des N. hypoglossus sind im ersten Spinalnerven enlhalten; ein durch seine charakleristischen Ursprmugsverhälnisse bezeichneter $N$. accessorius schein dagegen allgemein zu fehlen. - Der $N$. glossopharyngeus zeigt durch Verschmelzung, cuge Anlagerung und Austausch von Fasern oft eine innige Beziehung zum $N$. vagus; der $N$. faciulis desgleichen zum $N$. trigeminus. - Die Aualogie der genamnten llirmerven mit Spinalnerven erscheint nur durch das Verhalten einzelner Zreige angedeutet, ist dagegen lieine vollstiundige und ins Einzehe durchgeführte. Der Verlauf vieler ihrer Aeste ist nämlich der architectonischen Anordnung derjenigen IIartgebilde accommodirt, welehe der eigentlichen vorderen Fortsetzung des Wirbelsystemes angefügt sind. Wie in den unterhalb des Schedels liegenden IIargebilden cine Fusion zweier ideel zu tremender Skeletsysteme Statt hat, so cnthalten auch die ventralen Aeste der Ilimnerven Elemente zwiefacher Arl: solehe die den Skelettheilen des eigentlichen Visecralsystemes folgen und soleh̀, welche an den die gesammte Visceralhöhle auswendig ungürtenden Theilen sich verbreiten. Ihre Hanptiste folgen dem Verlaufe der eigenllichen Visceralbogen und zwar wid jeder Visceralbogen vou zwei, aus versehiedenen ventralen Stämmen abgehenden, Aesten begleitet. - Die dorsalen Aeste der Ilimnerven steigen da, wo sie vollständig entwickelt sind, nicht an den Aussenwandungen des Schedels auf, wie dic der Spinalnerven an den Ausseuseiten der oberen Wirbelbogen, sondern treten dureh die Sehedehöhle nach oben und dann nach ansen. Sie entsprechen, abgesehen ron ihren in der Schedelhöhle selbst sich vertheilenden Fäden, wesentlich nur denjenigen dorsalen Elementen der Spinalnerven, die fïr das Flossensy stem bestimmt sind. Aber aus der Bahn der Hirmnerven können auch solehe Aeste abgehen, die an dem ventralen Flossensysleme und selbst an den Flossen der Extremitïlen sich vertheilen. -- Indem der dorsale Flossenuervenstamm des N. Irigeminus oft zu cinem Collector von dorsalen Zweigen aller Spinalnerven wird, ïhnelt er dem Grenzstrange des $N$. sympathicus, der aus den ventralen

1) Die Texturverhältnisse der peripherischen Nerven der Fische sind nicht aiberall dieselben. Während bei den höheren Fischen bisher keine wesentliche Abweichung in dem Bate ihrer Nerven von dem den höheren Wirbelthieren zulommenden wahrgenommen ist, zeichnen die Nerven der Gattung Petronyzon durch den Besitz glasheller, scharf conturirter, platter lasern sich aus, welche keine Varicositaten bilden, jedes gerinnenden Inhaltes ermangeln und eine Substanz (nthalten, die in ihrem iusseren Verhalten derjenigen entspricht, welche dem Axencylinder anderex Nerven cigen ist. S. meine Mittheilung in den Naclirichten von d. liünigl. Gesellsch. d. Wissensch. zu Göttingen. 1850. No, 8. 
Aesten der Spinalnerven successive Elemente empfängt. - Aus der Bahn des $N$. vagus entsteht ferner gerwöhnlich ein Nerv, welcher lïngs des ganzen Körpers bis zum Schwanzende hin unter der Haut sich vertheilt. So wiedcrholt sich an der äusseren Körperoberfläche diejenige weite Ausdehnung der Elemente dieses Nerven, welehe in der Rumpflöhle Statt hat, indem sein $R$. intestinalis mindestens bis zum Magen und bisweilen längs des ganzen Darmes sich erstreckt. - Wïhrend der Grenzstrang des $N$. sympathicus vorne uuterhalb der Austriltsstelle des N. trigeminus endet, ersetzt ein ans der Bahn dieses Hirnnerven hervorgegangenes Element (der N. palatinus) die mangelnde Fortsetzung des Grenzstranges unterhalb der vordersten Hälfte des Schedels.

\section{\$. 64 .}

Bei allen Teleostei, den Ganoïdei und den Plagioslomi besitzt der Nervus vagus, mit Einschluss des Seitemerven, zwei ganz discrete Wurzelportionen von beträchtlicher Stärke. -.. Dic erste der beiden Wurzelportionen, welche den Ranus lateralis bildet, besteht immer aus cinem cinzigen Bündel. Sie enthält immer breite oder sehr breite, doppelt und dunkel conturirte Primitivfäden, mit flüssigem leicht gerinnendem Inhalte, welehe als Pole bipolarer Ganglienkörper sich zu erkemen geben. Thre Reizung sollicitirt niemals Berregungen. Sie entsteht ganz allgemein, nebst der dritten Wurzel des $N$. trigeminus, aus den Anschwellungen der Corpora resliformia, mögen diese als Anschwellungen deu Sinus rhomboiddalis brüekenarlig eine Strecke weit üherwölben, wie bei vielen Teleostei, odler an der Seite der Medulla oblongata schwïchere Anschwellungen bilten, wie bei den Cyprinen und bei Silurus, oder gekräuselte und gekrümmle Wülste zur Seite des Sinus rhomboidalis und des Cerebellum darstellen, wio bei Accipenser und bei den Elasmobranchii.

Die zweite Wurzelportion, welehe den eigentlichen Nervus branchiointestinalis constituirt, gerwöhnlich bedeutend stärker, als die erste, trilt bei den Teleostei tiefer abwärts zwischen den Sirängen der Medulla oblongala hervor. Bei allen Cypriuen findet sich an ihrer Austrittsstelle eine beträehtliche graue Anschwellung in welcher die Elemente der für das contractile Gaumenorgan bestimmten Nerven wurzeln. Bei allen Teleostei sind in diesex. Wurzel die feinen Primitivfibrillen ror sparsam vorhandenen breiteren vorherrschend; nicht in gleichem Maasse bei den Plagiostomen und bei Accipenser. Bei einigen IIaien treten an diese Wurzel dureh einen eigenen Knorpelcanal ein Paar, vorderen Spinaluervenwarzcln analoge, Fibrillen-Complexe heran, welche spüter sich ablösend, in Schultermuskeln sich vertheilen.

Bei allen Fischen enthält dieze Wurzelportion functionel verschiedene Elemente; die motorisehen beherrsehen die die Kiemenbogen an- und abzichenden Muskeln, das muskulöse Diaphragma der Kiemenblïtter, die Mus- 
lichn des Schlundliopfes, ferner die Speiseröhre und den Magen, so wie entlich dic Rumi cardiaci den von Weber entdeckten, die Bewegnngen hemmenden, Einfluss anf das Herz kund geben.

Bei Accipenser, Raja und einigen Gadoïden ist diese zweite Wurzelporlion von der des $N$. glossopharyngeus in so ferne unvollkommen geschicden, als ein Austausch von Fasern zwischen beiden Statt findet.

Noch inncrhalb der Schedelhöhle sondert sich von einer oder von beiden Wurzelportionen des $N$. vagus häufig; doch bei weitem nicht beständig, cin dorsaler Schedelhöhlenast ${ }^{1}$ ). Er vertheilt sich entweder im Fette der Schedelhöhle und an den häutigen Umhüllungen des Gehirnes und der Medulla oblongata, wobei er mitunter mit cinem analogen Zweige rom N. trigeminus sich verbindet, und kamn selbst die Schedeldecken durchbohren, um unter der Kopfhant sich zu verzweigen, oder er geht, sei es theilweise orler vollstïndig, in die Bahn des nach hinten sich erstreckenden $R$. lateralis $N$. trigemini über.

Die beiden IIauptportionen des $N$. vagus verlassen dic Schedelhöhle durch eine gemeinsame Oeffuung, welche bei den Teleostei im Os occipitale laterale gelegen ist. Während ihres Durchtrittes sind beide Portionen eng an cinander gefïgl. Während des Durchtretens und gleich nach demselben bildet die zweite Portion eine cinzige grössere oder melne kleinere, bald vollkommener, bald unvollkommener mit cinander zusammenhangende Anschrellungen, mil denen die Elemente der austretenden crsten Portion, deren bipolare Ganglienkörper hier gleichfalls gelegen sind und mitunler ebenfalls eine leicht erkennbare discrele Auschwellung bilden, bald schwach, bald gar nicht verbunden sind.

Die erste Wurzelportion des $N$. vagus constituirt demuach das Seitennervensystem. Dasselbe enthät wesentlich breite Primitivfiden, denen aber auch, wenigstens secundïr, meist schmale beigemengl sind. Diese stammen bei vielen Telostei aus Elementen, die an der Austrilts. stelle aus dem Schedel von der zweiten Wurzelportion des $N$. vagus abgegeben werden, bei vielen Cyprinen aber aus dem $R$. recurrens, der aus der Wurzelmasse des $N$. trigeminus cum faciali hervorgegangen ist.

Mit Ansuahme des abortiven Scitemerven von Petromyzon, der ans zwei Zweigen des $N$. vagus und einem rïcklanfenden Asle des $N$. facialis gebildet wird und noch eine Verbindung mit dem ersten Spinalnerven

1) Er kömmt, mit Ausnahme von Silurus, allen denjenigen kinochenfischen zu, welche einen ausgebildeten $\boldsymbol{R}$. lateralis $\boldsymbol{N}$. trigemini liesitzen, doch auch bei anderen. So kümmt er vor bei P'erca, Acerina, Cottus, Trigha, Caranx, Zoarces, Cyclopterus, Labrus, Belone; den Gadoïlen, Cyprinoilden, Esox, Accipenser. S. Nïheres in meiner Schrift. S. 85. 
eingehı, sind keine Verbindungen des Rumpftheiles der Seitennerven mit Spinalnerven erkannt worden.

Bei den Teleostei sondert sich von dem gemeinsamen Stamme des Seitennervensystemes alsbald ein dorsaler Ast; dieser bleibl selten cinfach, zerfällt rielmehr meistens in zwei Zweige, von denen der $R$. opercularis an der Innenfläche des Opercuhem sich vertheilt, während der zweite, als Ramus supralemporalis oder R. extrascapularis, in die Hölen der in der Schläfen - und Schultergegend vorkoinmenden Ossa supratemporalia und extrascapularia eintritt. - Bei Raja begibt sich ein aufsteigenter Ast zum Anfange des Rumpftheiles des Seitencanales aufwärts.

Der Seitennervenstamm tritt unter dem obersten Theile des Schullergïrtels hindurch, um einfach, oder in stärkere Aeste getheilt, an der Seite des Rumpfes gerade hinterwär's bis zur Sclivanzflosse oder selbst zwischen deren paarigen Strahlenwurzeln verlängerl, zu verlaufen und nimmt, von vorne nach hinten, an Umfang allmälich ab.

Er ist in der Regel von beträchtlicher Stärke; nur bei solehen Fischen, denen ein Seitencanal mangelt, denen zugleich harte Haubedeckungen zukommen, wie bei den Plectognathi Gymuodontes, zeigt er sich auf einen geringen Unfang reducirt oder ganz abortiv.

Er besteht entweder ans einem einfachen Hauptstamme und verläuft dann gewöhnlich oberflïchlich an der Grenze der Dorsal- und der Ventralmasse des Seitenmuskels ${ }^{2}$ ) muter der Ilaut, oft anch ganz in der Tiefe unler den Rïchenmuskeln dicht an der Wirbelsïule oder den Rippen; oder er zerfällt in zwei parallele Hauptstämme; oder der Ilauptstamm gibt starke, seitliche, ihm nicht parallele $\mathrm{Z}_{\text {weige }}$ ab ${ }^{3}$ ).

Sobald der Stamm der Seitemerven oberflächlich an der Grenze der Seitenmustelmassen liegt, begleilet er das Seitenlymphgefïss. Bei den eines Seitencanales ermangelnden Fischen gibt er Fiden ab an die Hant; sonst gelingt es oft solche in den Seitencanal zui vèrfolgen.

Eine, wenn gleich nicht mumgïnglich erforderliche, Bedingung der Theilung der Seitennerven in zwei parallele Aeste: einen R. superficialis und einen R. profundus, gibt die Abweichmng des Seilencanales von der

2) Meine in der Abhandlung über das peripherische Nerveusystem der Fische ausgesprochene Ansicht, dass das Vorkommen der Seitennerven durchaus an eine Trennung der Seitenmuskelmasse in eine dorsale und ventrale llälfte gebunden sei, habe ich, neueren Studien gemäss, aufgegeben.

3) Ein einfacher Stamm ist vorhanden z. B. bei Spinax, Carcharias, Chimacra, Accipenser, Syngnathus, Anguilla, Diodon, Tetrodon, Ilypostoma, Cyclopterus. In der Tiefe, an der Grenze der Wirbelsăule, verläuft er z. B. bei Carcharias,-Spinax, Chimaera, Anguilla. In zwei parallele llauptäste zerfällt er bei den meisten Knochenfischen: zwei starke seitliche, dem llauptstamme nicht parallele Zweige gibt er als bei Raja. S. Näheres in meiner Schrift. S. 99. ff. 
Grenze der Ilauptmuskelmassen des Rmmpfes ab. Verläuft der Seitencanal oberhalb der genamnten Grenze, so gibt der Seitenuerv dorsale oberflichliche Aeste ab, verläuft er unterhalh jener Grenze, so werden mehr ventrale oberflïchliche Acste abgegeben. Bald sind dies mehre, successive zum Scitencanale tretende, Acste; bald ist es ein cinfacher Ast, der dann oft nach mud nach Verstïlinngsfäden aus dem Stamme selbst cupfïngt. Sobald der Scilencanal an der Grenze ron Rumpf und Schwanz oder weiterhin in der Schwanzgegend auf die Grenzlinie zwischen Dorsal- und Ventralmasse des Seitenmuskels tritl. geht der dann schon auf ein dünnes Fädchen reducirte oberflichliche Ast der Seitemerven in den eigentlichen Slamm vieder über, welcher letztere ron jetzt an, selbst wenn er anfangs tiefer lag, oberflïchlich dicht unter dem Seitencanale nach hinten zur Schranzflosse zu verlaufen pflegt.

Die feineren Zweige des Seitemerven t) treten da, wo Knochen des Seitencanales vorbanden sind, durch eine an deren convexer Fläche be. findliche Ocfluung in die von derselben gebildete Rimne; da, wo den Schuppen solidere IIalbeanäle anfgesetzt sind, durchbohren sie die Basis der Schuppen. Bei den eines Seileneanales ermangelnden Fischen vertheilen sic sich unter der IIaut.

Bei Polypterus und einigen derjenigen Teleostei ${ }^{5}$ ), dic eines R. lateralis $N$. Irigemini ermangeln, giht der R. lateralis vagi einen zum Rïcken aufsteigenden feinen Ast ab, der in dem Zwischenraume, weleher die den Flossenträgern angehörigen Muskeh von dem eigentlichen Seilemmuskel tremnt, von vorne cine Strecke weit nach hinten sich begibt und feine Zveige für dic Flossenhäute entlässt.

Der aigentliche $N$. vagus s. N. branchio-intestinalis giht zunächst Kiemenbogenäste ab. Jeder Kiemenbogen, mit Ausnahme des ersten, dem, als schou rom $\Lambda$. glossopharyngeus versorgl, nur cin Ast zukömml, erbïlt zwei Aeste vom $N$. vagus und zwar gehen immer der hintere Ast emes Bogens und der rordere Ast des nächslstehenden Boyens aus cincu gemeinsamen Truncus branchialis hervor. Diese Trunci sondern sich suecessire aus dem gemeinschaftichen gangliösen Plexus, mil $\Lambda$ usuahme des crsten, der immer cin melu oder minter discreles Ganglion besitzl. Jeder R. Granchialis gुbl zuniehst einen Zweig ab für die die Kiemenbogen an den Schedel ziehenden Nuskchn, sendet dann cinen Zwoig an dic änsseren häuligen Belileidungen seines Kiemenbogens, hill daranf in die Rimne der Convexilat desselben, umspinnt die Gefässe, gibt Fïlen an das muskulose Diaphragma der Kiemenblitler und strebt zur Ventralseite des

4) S. meine Schrift. S. 105.

5) Dahin gehören namentlich die bisher untersuchten ('yprinoïden und Clupeïden. S. meine Schrift. S. 107 . 
Kiemenbogens, wo er an den Copulae und an den hier gelegenen Muskeln sich vertheilt.

Analog in ilnem Verlanfe sind die Rami pharyngei inferiores, welche den Schlundkopf umstricken und seine dorsalen und ventralen Muskeln versorgeu.

Untergeordneler sind die, bisweilen von den Trunci branchiales abgehenden, hiswcilen selbstständigen Zweige für die Ossa pharyngea superiora, welehe an den ihnen angehörigen Jäuten, Zähnen und Muskeh sich vertheilen. Verlängerungen dieser Zweige sind es, welehe bei den Cyprinen reichlich in das contractile Gaumenorgan ausstrahlen.

Einige feine Zweige sind bestimmt für das die Kiemenhöhle hinten begrenzende muskulöse Diaphragma.

Ein Ramus cardiacus tritt von einem R. pharyngeus oder oesophageus ab) und begiht sich an dem Truncus venosus transversus s. Duchs Cuvieri seiner Scite zum Vorhofe des Herzens.

Der Truncus intestinalis verbreitet sich allgemein an der Speiseröhre und dem Magen, bisweilen auch an einem Theile des Darmeanales und, sobald eine Schwimmblase vorhanden ist, auch an dieser. Jeder Truncus intestinalis begibt sich zur Seite der Speiseröhre, ihrer Aussenwand mehr oder minder imnig angeheftet, unler Abgabe zahlreicher Rami oesophagei, in der Bauchlıöhle hinterwïrls. Der Verlauf beider Trunci ist in der Resel nicht ganz symmetrisch. Der rechte folgt gewöhnlich dem Verlaufe der meist rechterseits absteigenden Arteria coeliaco-mesenterica. Scin Stamm bleibt entweder von demjenigen des sie begleitenden R. splanchnicus $N$. sympalhici gesondert und es gelien dann untergeordnete Zweige beider Nerven Verbindungen mit einander ein; oder er erhält einen $R$. communicans von ihm; oder beide verschmelzen vollständig mit einander. Dic so gemischten Aeste sind oft auch noch am Duodenum zu verfolgen.

Bei Belone bildet jeder $R$. intestinalis eine starke gaugliöse Anschwellung. Bei Diodon vertheilt sich der $R$. intestinalis vorzugsweise an dem Schlundsacke. - Der Schwimmblasenast, bald einfach, bald doppell, oft zumeist aus dem linken Truncus intestinalis entstehend, tritt meist mit den Gefïssen zur Schwimmblase, bisweilen auch längs ihres Ductus pneumaticus. - Bei Lepidosiren gibt der Truncus inteslinalis cinen Irauptast zur Lunge ab.

Bei den Myxinö̈den verbinden sich die beiden $R$. R. intestinales an der himteren Seite der Cardia unter spitzen Winkel zu cinem unpaaren Nerven, weleher längs der Anheftungsstelle des Mesenterium bis zum After verfolgt ist.

\section{\$. 65 .}

Der Nervus glossopharyngeus, bei den Cycloslomen und bei Lepidosiren noch Theil des $N$. vagus, ist bei den 'Teleostei, Ganoïdei und 
Elasmobranchii ein selbststïndiger Nerv, wemn sehon zwischen ihm und dem $N$. vagus bei einigen Teleostei noch innige Beziehnngen obwalten. Sein meist einficher, selten doppelter Wurzelstrang verlïsst die Medulla oblongala seitwïts zwischen den Wurzeh des $N$. acusticus und $N$. vagus. Er enthält motorische Elemente neben anderen, die keine deutlichen Bewegungen sollicitiren. Bei den Teleostei verlïsst er die Sehedelhöhle durch cine Oeflunng im Os occipitale laterale; bei den Ganö̈dei holostei tritt er vor diesem aus. Bei Accipeuser und bei den Plagiostomen besitzt er zum Durchtritt cinen eigenen Knorpelcanal, während er bei Chimacra mit dem N. vaguus vereint austritt. Er verlässt die Schedelhöhle immer in der Kiemenhöhlengegend. Nachdem er dieselbe verlassen hat, bildet er allgemein cine gangliöse Anschwellung, welche bei den Teleostei immer in imniger Verbindung mit dem Grenzstrange des $N$. sympathicus steht.

Bei den Knochenfisehen besitzt er gewöhnlich zwei Haupläste: 1. einen $R$. anterior s. hyoüdeus posterior, der an der Schlcimhaut des Gaumens und meist auch an der Pseudobranchie sich vertheilt und in seinem Verlanfe wesentlich dem hinteren Rande des Zungenbeinbogens folgt. - Bei den Cyprinen erweilert sich sein Bereich dadurch, dass er auch Zweige für das contractile Gaumenoryan abgibt. 2. einen stärkeren Ast, der für die Muskulatur, für die vordere häntige Bekłeidung und für die die Gefïsse aufnehmende Rinne der Convexität des ersten Kiemenbogens bestimmt ist. Seine ventralen Endzweige verbreiten sich in der Zunge oder unter der Schleimhaut des Zungenbeinkörpers.

Bei $A$ ccipenser, wo wesentlich dieselben Aeste vorhanden sind, kömmt noch ein vorwärts gerichteter Ast hinzu, welcher mit dem R. palatinus und R. maxillaris superior $N$. trigemini Verbindungen eingeht und mit ihren Elementen unter der Schleimhaut des Gaumens sich vertheilt.

Bei den Elasmobranchii versorgt er die am Zungenbeine befestigte halbe Kieme und gibt, wie gewöhnlich, einen zweitrn Ast für den ersten Kiemenbogeu ab. - Bei 'Torpedo verlaufen in seiner Bahn die Ilauptïste des electrisehen Organes.

\section{S. 66.}

Die Wurzeln des Nervus trigeminus cum. Nervo faciali, entspringen und liegen nahe neben cinander; eine derselben geht nach der Peripherie hin in Stränge über, welche ausschliesslich dem $N$. trigeminus angehören; die Fortsetzung einer anderen ist ein blos dem $N$. facialis bestimmtes Element; andere Wurzeln sclzen in Stränge sich fort, die in die Zusammensetzung beider Nerven eingehen. Die Zahl der Wurzelu beider Nerven belïuft sich bei den untersuchten Elasmobranchii, und bei den meislen Teleostei auf vier; sie steigt bei manchen der letzteren, so wie bei Accipenser, auf fünf und sinkt bei einigen Knochenfischen selbst auf drei. Bei Anwesenheit ron rier Wurzehn enthïlt die erste, unmittelbar unter 
dem Cerebellum, von der Seite der Medulla oblongala ansiretende, neben motorischen, namentlich für den Kiefermuskel und den IIcbemuskel des Kiefer-Suspensorium bestimmten, Elementen, solche, die nicht motorisch wirken, ist demmach als gemiseht zu bezeichen. Die von iln ausgehenden Nerven bleiben ausschliesslich in der Bahn des $N$. trigeminus. - Eine zweite Wurzel, welche elwas weiter aufwith, als die erste, aus der Medulla oblongala hervortritt und in der Regel primär blos feine Primitivröhren führt, bildet immer eine grane Anschvellung, aus wcleher wesentlich die Elemente des Nervus palatinus hervorgehen. - Eine drille Wurzel, muter allen die dünnste, verlässl dic Medulla oblongala unmittelbar vor der ersten Wurzel des $N$. acusliens, welcher sie eng anliegt, führt nur breite Primitivröliren, bildet keine gangliöse Anschwellung, onthält nur motorische Elemente und ist blos dem $N$ - facialis angehörig. - Zu den genannten Wurzeln kömml eine cinfache oder ursprünglich in zwei Schenkel gespaltene Wurzel hinzu, welche mil derjenigen des $R$. lateralis ragi aus dem durch das Corpus restiforme gebildeten Lobus medullae oblongalae hervorgeht. Sic führt ansschliesslich breile, doppelt conturirte Primitiv. röhren, welche als bipolare Ganglienkürper sich zn erkennen geben. Ihre Fäden gehien sowol in die Bahn des $N$. trigeminus, als in die des $N$. facialis über und enden in den verschiedentlich entwickelten Elementen des am Kopfe vorkommenden peripherischen Nerrenslieletes, in welchen sie oft die von Leydig beschriebenei Nervenknäucl bilden:

Bei ihrem Austreten aus der Schedelhöhle bilden die Wurzeln des Nerven-Complexes bei manchen Teleostei, z. B. bei Lophius, bei den Gadoüden, bei Silurus, so wie auch ferner bei Accipenser einen semeinsamen gangliösen Plexus; bei anderen, wie bei den Cyprinen, sind zwei unvollkommen getremte gangliöse Geflechte vorhanden. Meistens. bildul jedoch diejenige Wurzel, deren Elemente den $N$. palatinus constituren, ein diseretes Ganglion, wïhrend auch dic erste, dem N. trigeminus ausschliesslich angehörige Wurzel ihre eigene gangliöse Anschwellung besitzt. Bei Triggla bildet ein Strang dieser Wurzel, ans welchem die Ciliarnerven hervorgehen, eine discrete Anschwellung.

Die Austrittsstelle des ganzen Nerren-Complexes liegt bei den Gadoïden in ainem Aussehnitte des Vorderrandes der Ala temporalis des Keilbeins. Bei den ührigen Fischen frelen die Stïmme cinzeln, und zwar die ventralen, grë̈sstentheils oder sïmmtlieh, durch Oefhungen der Ala temporalis des Keilbeines aus.

Dem Nervus trigeminus ausschliesslich angehörig sind folgente Acste: 1. der R. ophthalmicus; 2. die Rami marillaris superiores, buccalis und maxillaris inferior; 3. der R. communicans ad $R$. hyoüdeo-mandibularem des N. facialis.

Der R. palatinus behauptet bald cine gewisse Selbstständighicil; bald 
ist er dem $N$. trigeminus, bald, und zwar häufiger, dem $N$. facialis imniger verbunden.

Ihm verwandt ist der $R$, recurrens vieler Cyprinen.

Dorsale Scherlelhöhlenzweige und der $R$. lateralis zeigen sich gemeinsamen Elementen beider Nerven angehörig.

Der Nervus, facialis gibt Zweige an die Muskeln des KiemendeckelApparates und des Kiefer-Suspensorium und zerfällt dam in einen $R$. mandibularis und einen $R$. hyoideus.

Ein accessorisches Element desselben ist der erste $R$, electricus der Torpedines.

Bei der Mehrzahl der Teleostei sind dorsale Zweige des $\boldsymbol{N}$. trigeminus beobachtet worden, welche aus dessen Wurzelgeflechten entstehend, im Fette der Schedelhöhle oder an deren Seitenvandungen aufsteigen. Sie verhalten sich, hinsichtlich ihrer Stärke und der Weite ihres Bereiches, sehr rersehieden. Oft vertheilen sie sich blos im Fette der Schedelhöhle und an den Umhïllungen des Gehimes; bei anderen durchbohrt zugleich ein Zweig dieser aufsteigenden Nerven die knöcherne Schedeldeclic, um unter der Kopfhaut sich zu verbreiten; mitunter hat zugleich eine Verbindung mit einem analogen dorsalen Zweige des N. ragus Statt. Vorzüglich ausgebildet ist das System dieser für die Schedelhöhle bestimmten Nerven bei den Cyprinen und bei Silurus. - Bei vielen Fischen gehen diese Schedelhöhlen-Nerven aus vom Ursprunge des $R$. lateralis, der im Allgemeinen als weitere Ausbildung der dorsalen Aeste des $\boldsymbol{N}$. trigeminus zu betrachten ist, aber auch zu cinem, allen Flossen, die den Körper umgürten, bestimmten Nerven sich entwickeln kann.

Dieser R. lateralis, (ler bei weitem nicht allen Teleostei zukömml 1) und anch bei Fischen aller übrigen Ablheilungen spurlos vermisst ist. er. streckt sich, sobald er vorhanden, in der Schedelhöhle anfivärls und hinterwïrts, um, nach Aufnahme eines $R$. communicans $V$ agi, dieselbe durch das Os parielale oder durch die llinterhauptsgegend zu verlassen. $A$ bweichend verhält er sich in dieser Bezichnng beim Aal. - Nach seinem Austritle aus der Sehedelhöhle stellt er entweder einen Rückenkantenast dar, oder er gibt zurgleich ventrale Aeste und namentlich anch solche ab, die für die Extremitäten bestimmt sind. Unter beiden Bedingungen erhält er verstärliende Elemente aus dem dorsalen Aste cines jeden Spinalnerven. Sobald der R. lateralis cinen einfachen Rückenkanlenast darstell, tritt er

1) Er ist namentlich beobachtet worden bei Perca, Acerina, Cottus, Zoarces, Cyclopterus, Labrus, Belone, allen Siluroïden und Gadoỉden, Anguilla, fehlt aber sehr vielen Teleostei, gleich wie auch den Elasmobranchii und (ianoidei spurlos. E. II. Weber hat ihn bei Silurus glanis entdeckt. S. Meckel's Ans. f. Anat. und Phys. 1527. S. 303. MIt. Abb. Tb, IV. S. Näheres in meiner Schrift. S. 49. ff. u, Abb. Tb. 3. 
zum Rücken und verlänft längs desselben gerade hinterwärts bis zum Schwanze; da, wo Rückenflossenmuskeln vorhanden sind, unter diesen, wo sie mangeln, unmittelbar unter der Cutis gelegen. Auf diesem ganzen Wege empfïngt er von dem $R$. dorsalis eincs jeden Spinalnerven cinen gewöhulich einfachen, seltencr doppelten R. communicans und wird so zu einem Collector von Elementen aller Spinalnerven. Aus dem so gemischIcn Stamme gehen feine Fälen ab für dic Muskcln der Flossenstrahlen, für die IIaut der Rückenkante und für die der Flossenstrahlen.

Bei manchen Teleostei beschrïnkt sich der $R$. lateralis nicht auf die

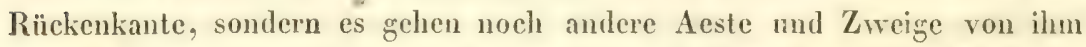
ab. Dahin gehören: 1. nach rorn gerichtete Zweige für die IIaut des Kopfes, in verschiedener Stärlic und Austehnung beobachtet bein Aal und mehren Gadus. 2. Aeste für die Flossen der an der Kehle gelegenen Itin. terextremiläl, gefunden bei allen untersuchlen Gadoüden. 3. Acste für Ilaut- und Flossenstrallen der Vorderextremität, beobachtet beim Aal and allen Gadoïden. 4. Starke Ilantzwcige für verschicdene Gegenden des Rumpfes, wahrgenommen bei allen Gadoïden. 5. Ein starker ventraler Ast, der in der Schwanzgegend zur Afterflesse ebcuso sich verhailt, wie am Rücken zur Rückenflosse, ist beobachtet bei Gadus callarias, aeglefinus und Raniceps fuscus.

Der Ramus primus s. ophthalmicus, anf desseil Reizung nicmals Zuckungen in willkïhrlich beweglichen Muskehn beobachtet werden, führt Elemente, die aus der ersten Wurzel entstehen, neben solchen, die ans derjenigen Wurzel hervorgehen, welche vom Lobus posterior Medullae oblongatae entspringend, Fortsetzungen bipolarer Ganglientörper als Elemente enthailt. Bei manchen Fischen besitzen einer oder beide Wurzelstränge des Nerven diserete gangliöse Anschvellungen; auch dem Stamme des Ciliarnerven kömmt bisweilen eine solche zu.

Der $\boldsymbol{R}$. ophthalmicus besteht bald aus zwei gesonderten Strängen, bald aus einem einfachen Stamme. Bei den Plagiostomen und den Ganoïdei holostei verlïuft der obere Strang ummittelbar unter dem Dache der $\Lambda$ ugenhöhle vorwïrts, während der andere, viel schwïchere, unter den $\boldsymbol{M}$. $\boldsymbol{M}$. rectus und obliguns superior, dicht an dem Bulbus gelegen, dieselbe Richtung nimmt. Immer vereinigen sie sich, bevor sie die Angenhöhle verlassen. Bei den meisten Teleostei verlïuft der einfache oder zweischenkelige Nerv unter dem Dache der Augenhöhle vorwärts. Während dieses Verlaufes treten von dem oberflichlichen Aste oder von dem gemeinsamen Stamme versehiedentlich starke Rami frontales ab, welche in die Canäle des peripherischen Nervenskeletes sich begeben oder unter der Haut der Slirngegend sich vertheilen. Andere untergeordnetere $\mathrm{Z}$ weige sind für die hïuligen Bekleidungen der Augenhöhle und lie Umgebungen des Bulbus bestimmt. Immer werden in der Augenhöhle die Ciliarnerven abgegeben. 
Bei den Plagiostomen gesehieht die Vereinigung der beiden Stränge erst, nachdem der $R$. superficialis einen nach aussen und unten tretenden R. nasalis entsendet hat, der theils an den Umgebungen der Nasengrube, theils in der Gegend der Mundwinhellnorpel sich verzweigt. Bei Accipenser verlisst der Inaptstamm des Nerren die Augenhöhle in zwei Aeste gespalten, ion denen der Eine oberhalb des Geruchsorganes miter der IIaut sich vertheilt, wïhrend der Andere, als $R$. nasalis, in der unmittelbaren Umgebung des Riechorganes sich verzweigt.

Nachdem der eiufache Stamm bei den Teleostei die Augenhöhle verlassen, gelangt er, oft nach Abgabe von dorsalen für die Kopfbedeckungen bestimmten Zweigen, hinter der Nasengrube unter die äussere Haut. Sein Ende zerfïllt gewöhnlich in mehre feinere $Z$ weige, welche theils das $O s$ terminale durchbohren, theils an der Schleimhaut der Nasengrube, theils unter der z̈usseren Haut in der Umgebung des Riechorganes - sich vertheilen und häufigg Verbindungen mit Eudzweigen des $R$. maxillaris superior, selten auch mit solchen des $N$. palatinus eingehen. Bei Belone verlängert sich der Nerv bedeutend, als Zwischenkieferast. - Bei den Elasmobranchii verlïngert sich die vereinigte Fortsetzung beider Stämme, nachdem sie die Angenhöhle verlassen, lïngs der Schnauze und strahlt in eine Menge von Zweigrn aus, die bei den Ilaien und Chimären in die zur Aufnahme der Nerven bestimmten eigenthümlichen Röhren und Ampullen sich brgeben.

Dem $R$. ophthalmicus mehr oder minder entschieden angehörig sind Ciliarnerven. Bei den Triglae und, in geringerem Grade, bei vielen anderen Teleostei besitzt der Truncus ciliaris communis cine gewisse Selbststïndigkeit; bei anderen Teleostei, so wie auch bei Accipenser und den Plagiostomi löset er sich vom $R$. ophthalmicus und zwar bei letzteren von dessen R. profundus. - Verbindungen des Truncus ciliaris mil sympathischen Fädchen sind bei manchen Teleostei beobachtet.

Das Ciliarnervensystem ${ }^{2}$ ) besteht wesentlich aus Elementen des $N$. trigeminus und des $N$. oculorum motorius. Dem N. trigeminus ausschliesshich angehörig ist ein $R$. ciliaris longus, welcher neben der Insertion de's M. rectus superior die Sclerotica durchbohrt und dann zur Chorioidea und Iris sich begibt. Ein zweiter $R$. ciliaris brevis welcher selten vermisst ist, gelnt eine Verbindung ein mit dem Ciliarnerven des $N$. oculorum motorius und oft anch mit cinem sympathischen Fädchen. Nach der Verbindung dieser Nerven zeigt sich ein Ganglion ciliare.

Aus diesem Ganglion geht cin cinfacher oder doppelter Nerv hervor, welcher neben dem $N$. opticus, mcist angeheftet an der Arferia ophlhalmica, in den Bulbus tritt. Die Fïden dieses Nerven begeben sich zur. Iris.

Das Ciliarnervensystem der Plagiostomen zeichnet durch einige Ver-

2) S. Näheres in meiner Schrift. S. 38. 
hältnisse sich ans. Der $R$. ciliaris ex Oculomolorio tritt isolirt, in Begleilung eines Blutgefässes, zwischen den Insertionsstellen der M.M. rech internus und rechus inferior in den Bulbus. Ausser ihm begeben sich in den letzteren zwei bis vier aus dem Ramus ophhalmicus profundus stammende Fädchen.

Die Ramimaxillares und der R. buccalis gehen auf verschiedene Weise, meist einen gemeinsamen Stamm bildend, seltener melı oder minder isolirt, aus dem gangliösen Plexus des $N$. trigeminus hervor. Sie begeben sich unter der den Boden der Orbila bildenden fibrösen Membran vorwärts, um früher oder später sich zu trennen.

Der Ramus maxillaris superior, wesentlich den R.R. infraorbitalis und alveolaris der Säuger entsprechend, meist von nicht behrïchllicher Stärke, vertheilt sich bei den Teleostei besouders in den vordersten Infraorbitalknochen, an Zwischenkiefer und Oberkiefer und zwar sowol an den häutigen Bedeckungen, als in Canälen derselben, so wic an der den Eingang der Mundhöhle bekleideuden Schleimhaut. - Bei Accipenser nimml er eincu Verbindungszrveig vom $N$. glossopharyngeus in seine Bahn anf und vertheilt sich unter der Schleimhant des vorstreckbaren Kieferapparates, an der Hant des Kieferwinkels und an der Oberlippe. - Bei Spinax vertheilt er sich in der Gegend des oberen Labialknorpels, am Oberkiefer und Mundwinkel.

Der Rumus buccalis, dem R. subcutaneus malae höher'i Wirbelthiere vergleichbar, ist bei den Teleostei bestimmt für die ITöhlen und häntigen Ungebungen der Infraorbitalknochen, mit deren Entwirkelung sein Umfang correspondirl; bei Accipenser, wo er zwei Stränge besilzl, fïr die weiche untere fiäche der langen Schnauze, an welcher er in die Ampullen des Nervenskeletes sich vertheilt.

Der Ramus maxillaris inferior, sehwächer bei Aceipenser und besonders bei den Plagiostomen, als bei den Teleostei, wo er unter allen Aesten des $N$. trigeminus der stärkste zu sein pllegt, ist vorzugsweise Muskeherv, verzweigt sich aber auch an häutigen Theilen, an den Lippen, den Unterkicfer-Bartfiden, in der Knochensubstanz und an der Matrix der Zühne des Unterkiefers.

Bei den Teleostei tritt er unterhalb: der Augenhöhle ab- nnd vorwärts zum Unterkiefer. Er gelangt zu diesem nach Abgabe von Zweigen für den IIebemuskel des Kiefergaumen - Suspensorium und für den gemeinsamen Kiefermuskel. Am Unterkiefer gibt er cinen für Ilaut uud Zähne bestimmten äusseren Ast ab und dann zwei an dessen Innenfläche verlaufende Aeste, von denen der cine über, der andere unter dem Meckel'scken Knorpel einwïrts sich erstreckt. Der obere tritt in einen Knocheneanal des Unterkiefers und ist bestimmt für Haut und Zähne; der untere, welcher beständig Verbindungen ringeht 
mil dem $R$. mandibularis des $\Lambda$. facialis, sendel Fäden zur Unterlippe, so wie in den die heiden E'nlerkieferïste an einander zichenden Quermuskel und in den M. geniohyoüdeus. J)ie etwa vorhandenen Barlfïlen erhalten z. 13. bei Silurus, Gadus u. A. ilure Nerven gleichfalls aus Zweigen des R. maxillaris inferior. - Bei Accipenser ist sein Verlauf, so wie seine Vertheilung in den Muslieln wesentlich äbereinstimmend; nur erhäll der starke Ifebemuskel des Kiefersuspensorium einige direct aus dem ganghiösen P'lexus des $N$. trigeminus herrorgehende Fïlen. - Bei Chimacra sind Elemente für die Iaut der weichen Schnauze in der Bahn des Nerven molhalten, der zuletzt auch an IIaul und Muskeln der Labialknorpel sich vertheilt. Bei den Plagiostomen ist seine Vertheilungsweise wesentlich analog:

\section{S. 67.}

Der Ramus palatinus behauptet in der Regel, den übrigen Elementen des $N$. trigeminus und denen des $N$. facialis gegenïber, eine gewisse Selbststindigkeit. Bei den meisten Teleostei stammt der grüsste Theil seiner Elemente aus der die schmalsten Primitivfäden führenden, gerwöhnlich eine noch in der Schedelhöhle gelegene, discrete gangliöse Anschwelung hildenden Wurzel. Er verlässt dann die Schedelhöhle anch gerwöhnlich durch rinen eigenen Canal der Ala temporalis des hinteren Keilbcines. Bei den Gadoüden, bei Silurus, bei Accipenser und bei den Plagiostomen lassen sich dagegan seine Beziohungen zu einer bestimmten Wurzel des NervenComplexes weniger dentlich nachreisen. Bei den Gadoüden und bei Silurus rerlïsst or die Schedelhöhle mit den ührigen Elementen des $N$. trigeminus; bei den Elasmobranchii geht er aus einer dem $N$. facialis anliegnenden Anschredlung hervor. Er enthïl immer vorwaltend schmale, oder schmalere Fibrillen als die übrigen Nerven und ist wesentlich fïr die Ganmenschleimhaut bestimmt. Bei allen Teleostei erstreckt er sich - den vordersten Ausläuforn des Wirbelsystemes folgend, und also wie ein vorderer Endtheil des Sympathicus in seinen wesentlichen morphologisehen Bezichungen sich verhaltend - lïngs dex Aussenseite des Sphenoüdeum basilare und des Vomer, meist ummittelbar unter der das Gaumengewölbe auslileidenden IIant, sellener ïbre oder zwischen den Fasern drs queren Gaumenmuskels vorwärts, vertheilt sich an der Gaumenschleimhant und den etwa vorhandenen Zähnen der Gammenknocheng goht vorn Verbindungen ein mil Fïden des $R$. maxillaris superior und verzweigh sich an $V_{0}$ mer; an den Rändern der Mitte der Kieferknochen unter Haul und Schleinlaut. Bei Cobitis, wo ex an den Stamm des Oberkiefernerven sich anlegt und mil dessen Elementen sich mischl, gibt ar Zweige für Oberlippe und Bartfäden ab. - Bei Accipenser geht er mit einem rorderen Aste des N. glossopharyngens seflechlarlige Verbindungen cin und vertheilt sich mter der IIant des vorstreckbaren Kieler-Apparates. - Bei den Selachiern 
giebt er einen Ast zur Pseudobranchie und vertheilt sich dann unter der Schleimhaut der Rachenhöhle.

Ein merkwürdiger, nur bei einigen Cyprinen beobachteter, Ast ist der R. recurrens, welcher nur feine Primitivfäden und zahlreiche gangliöse Elemente führt. Aus dem gangliösen Plexus des Nerven-Complexes hervorgehend, stehen die $R$, recurrentes beider Seiten durch quere in der Schedelhöhle gelegene gangliöse Schlingen mit cinander in Verbindung. Jeder Nerv verläuft innerhalb der Schedehöhle mach hinten, umfasst einen Ast des Acusticus und geht später cine Verbindung mit dem R. lateralis vagi und eine andere mit dem $R$. anterior des ersten Spinalnerveu ein ${ }^{1}$ ).

\$. 68.

Der Nervus facialis der Teleostei besilyt stets cine liscrete, nicht gangliöse, dicht vor den Elementen des $\boldsymbol{N}$. acusticus austretende, molorische Wurzel, an welche bald aus zwei verschiedenen Wurzeln des $\boldsymbol{N}$. trifूeminus stammende Bündel, in Gestalt eines kurzen $R$. communicans ad $\boldsymbol{N}$. facialem sich anzulegen pilegen, wodurch er dam zu einem gemischten Nerven wird. Der letztgenamnte Ast wird nur dann vermisst, wemn der $\boldsymbol{N}$. facialis aus dem gemeinsamen gangliösen Plexus des $\boldsymbol{N}$. trigeminus hervorkömmt und keine gesonderte Austrittsstelle ans der Schedelhöhle besitzt, wie bei den Gadoïden und bei Lophius, in welehem Falle die Verbindung mit Elementen des $\boldsymbol{N}$. trigeminus schon beim Austritte aus der Schedelhöhle Statt hat.

Der $\boldsymbol{N}$. facialis ist allgemein bestimmt zur Beherrschung der die äusseren Eingänge in den Respirations-Apparat offuenden und schliessenden Muskeln. Er besitzt ausserdem zwei absteigende Hauptäste, von denen der vordere den hinteren Ast des Unterkieferbogens, der hintere deu vorderen Ast des Zungenbeinbogens bildet.

Der erste Ast des $\boldsymbol{N}$. facialis, welcher gewöhnlich vor Hinzutritt des R. communicans $\boldsymbol{N}$. trigemini sich sondert, ist der für die das Operculum an den Schedel ziehenden Muskeln bestimmte, hinterwärts gerichtete $R$. opercularis. Bei Accipenser vertheilt sich ein, stärkerer Ast in den betrïehtlichen, das Kiefersuspensorium an den Schedel ziehenden Mnskel; bei den Elasmobranchii wird er durch $Z_{w e}$ ige vertreten, die an den Constrictoren der vordersten Kiemensäcke sich vertheilen.

Ein anderer vorwärts gerichteter $\boldsymbol{A}$ st begibt sich bei vielen Teleostei in den Musc. adductor arcus palatini, der aber bisweilen vom $R$. palalimus $\boldsymbol{N}$. trigemini aus versorgt wird. - Bei Raja gibt der $\boldsymbol{N}$. facialis Aeste in die zur IIebung und Senkung der Schnauze bestimmten Muskeln.

Die eigentliche Fortsetzung des durch Elemente des $\boldsymbol{N}$. trigeminus verstärkten Stammes bildet bei den Teleostei der Truncus hyoïdeo-mandibu-

1) Vgl, meine Schrift. S, 58 . 
laris. Dieser Stamm tritt meistens an die Innenflache des Os temporale und begibt sich damn durch einen Canal desselben nach aussen, um alsbald - häufig nach Abgabe von Elementen für die Cantile des Praeoperculum, bisweilen auch von Verbindungsfïden für den $\boldsymbol{R}$. anterior $\boldsymbol{N}$. glossopharyngei - in zwei IIaupläste sich zu theilen: einen $R$. mandibularis und einen R. hyoüdens. Jener ist das morphologische Aequivalent der Chorda tympani höherer Wirbelthiere.

Der $R$. mandibularis erstreckt sich an den Kuochen des Kiefersuspensorium und durch dieselben, zum Unterkiefergelenke und verläuft an der Innenfläche des Unterkiefers, unter dem Meckel'schen Knorpel, in der dicsen aufnehmenden Längsrinue vorwärts bis zur Verbindung beider Unterkieferhälften. Er vertheilt sich, nach eingegangenen Verbindungen mit dem $R$. maxillaris inferior $\boldsymbol{N}$. trigemini, in dem die beiden Unterki ferhälften an cinander zieheudeu Muskel, in dem $\boldsymbol{M}$. geniohyoüdeus, an der Schleimhaut der Mundhöhle und an der den Unterkiefer bekleidenden äusseren Haut. Bei Silurus und Anguilla gibt er einen beträchtlichen äusseren Hautzweig für den Unterliefer $a b$, der sonst dureh untergeordnete $\mathrm{Z}$ weige vertreten wird.

Der R. hyoüdeus tritt gewöhnlich an die Innenseite des Kiefersuspensorium; heim Aal ist er nach hinten gerichtet. Er begibt sich lïngs dem Os styloideum unter das Interoperculum an den Zungenbeinbogen. Dem Verlaufe des letzleren nach vorne folgend, gibt er Zweige ab für die hä̈tige Bekleidung der Imnenfläche des Suboperculum und des Interoperculum und für die Zwischenränme der cinzehen Radii branchioslegi, welehe sowol für deren Muskulatur, als für deren häutige Ungebung bestimmt sind. Der Nerv endet unter der äusseren IIaut der Zungenbeingegend und in Aem die Membranae branchioslegae beider Seiten verbindenden Muskel.

Bei den Ganoïden und den Elasmobranchii ist die Vertheilung der Nerven im Wesentlichen analog. Bei den Plagiostomen sondert sich der Truncus hyoideo-mandibularis von dem ilhm anfangs verbundenen $R$. pala-

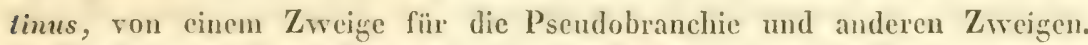
Dann begiht er sich hinter die IInterrand des Spritzloches und verlinut hicrauf lïngs dem Kiefersuspensorium, dessen Irebemuskel er mit Zweigen versorgl, abwïrls, gibt $Z$ weige an die Nerven-Ampullen ab und entsendet Zweige, welche dem $R$. mandibularis und $R$. hyoüdeus der Teleostei im Ganzen entsprechen.

\$. 69.

Was die Augenmuskelnerven anbetrift, so sind sie bei Branchiostoma und bei den Marsipobranchii hyperotreti vällig vermisst worten.

Bei Lepidosiren haben sie keine ursprüngliche Sellsslstindigheil, sondern verlaufen in der Bahn des $\boldsymbol{N}$. trigeminus. Bei Petromyzon ist ilne Anzahl verringert und auch der $\boldsymbol{N}$. trigeminus gibt Bälen an die Angenmuskeln ab. Der $\boldsymbol{N}$. trochlentis entspringt hier hinter den Lobi oftici und tritt 
mit dem N. oculorum molorius, welcher vor dem $N$. trigeminus entspringt, in die Augenhöhle. Der vereinigte Nervenstamm theilt sich in zwei Ilauptäste: cinen oberen, zum $\boldsymbol{M}$. rechus superior und einen zweiten, zum $\boldsymbol{M}$. reclus internus und $\boldsymbol{M}$. obliquus superior. Die übrigen drei Augenmuskehn erhalten ihre Zweige aus der Bahn des $N$. trigeminus.

Bei den übrigen Fischen sind bisher ausuahmslos drei Angenmuskelnerven: der $N$. oculorum motorius, der $N$. trochlearis und der $N$. abducens angetroffen worden.

Der Umfang der Augenmuskeluerven entspricht der Stïrke der Augenmuskeln; so sind sie fein bei Silurus, stark bei Gadus. Bei mauchen Fischen legen sich dem $N$. trigeminus ursprünglich augehörige Füiden sowol an den $N$. trochlearis, als auch an den $N$. oculorum molorius.

Die primitiven Nervenelemente gehören immer zu den breiten, duukel conturirten. Häufig kommen schon im Verlanfe der Nerrenstämme und

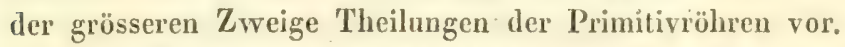

Der N. oculorum motorius, unter den Augenmuslicherven immer der starkste, entspringt beständig von der vorderen Pyramide oder dem Pedunculus cerebri, dicht hinter dem Lobus inferior und tritt bei den Teleostei zwischen den beiden Schenkeln der Commissura ansulata hervor. Die Schedelhöhle verlässt er bei den Teleostei durch die häntigen Theile oder durch die knöchernen Flügel des vorderen Keilbeines, oft auch durch den Fliigel des hinteren Keilbeines. Er vertheilt sich, nachdem er meistens in zwei Aeste zerfallen ist, in die Musculi rectus superior, rectus inlernus, obliquus inferior und rectus inferior. Ausserdem gibt er, und zwar gewöhnlich sein tieferer Ast, eine Wurzcl zum Ganglion ciliare, oder, wie bei einigen Salmones und Plagiostomi, ein die Sclerolica selbstständig durchbohrendes Fïdchen ab.

Der N. trochlearis, immer ein sehr feiner Nerv, kömmt stets mit einfachem Wurzelstrange aus der zwischen Lobus opticus und Cerebellum gelegenen, sie trennenden Furche hervor. Die Ursprünge beider Nerven sind durch eine Commissur mit einander verbunden. Der N. trochlearis verlässt bei den Teleostei die Schedelhöhle durch die häutigen oder knöchernen Theile der vorderen Keilbeingegend und vertheilt sich anssehliesslich in dem M. rectus superior.

Der N. abducens, wenig starker, als der vorige, entspringt allgemein weit hinterwärts aus den vorderen Pyramiden der Medulla oblongala dicht an deren Mittellinie und zwar meist mit zwei Wurzelsträngen.

Er tritt alsbald abwärts und verlässt die Schedelhöhle bei den Elasmobranchii und Accipenser durch einen Canal des Schedelknorpels, bei den mil ansgebildetem Augenmuskeleanale versehenen Teleoslei dureh die Ala temporalis des Keilbeines, bei anderen vor diesem, durch fibrös-häntige Theila. -- Bei wenigen Teleoslei sind Verbindungen des Nerren mit einem 
sympathischen Fädchen, das aus dessen vorderstem Kopfganglion stammt, beobachtet. - Er vertheilt $\therefore$ hh ausschliesslich in den Muse, rectus externus; nur bei den mit Nickhaut versehenen IIaien scheinen auch in den Muskel dieser Nickhaut Elemente des $N$. abducens einzutreten.

$$
\text { S. } 70 \text {. }
$$

Der Nervus acusticus, bei allen Fischen durch seine betrichtliche Stärke ausgezeichnet, verlässt die Medulla oblongala dicht hinter den letzten Wurzeln des Nervus trigeminus cum faciali, der letzterem Nerven angehörigen Wurzel eng angeschmiegt, und vor der Wurzel des $N$. glossopharyngeus. Nur bei einigen Rajidae begeben sich Fasern, die in der Bahn des letztgenanuteu Nerven austreleu, nachdem er solche vom N. acusticus empfangen hat, an Theile des Gehörorganes.

Die Elemente des N. acuslicus verlassen die Medulla oblongala bald juxtaponirt und in Gestalt eines einfachen dieken Stranges, bald in zwei und selten in drei Wurzelstränge gesondert. Im ersteren Falle spaltet sich die Wurzelmasse alsbald in zwei Stränge, welche den sonst gesondert ans. trelenden zwei Strüngen analog sind, in so ferne der erste die beiden vordersten Ampullen und das Vestibulum mit seinen Elementen versorgl, während der zweite zu der hinteren Ampulle and zum Sacke sich begibt.

Die Elementartheile des Nerven sind breite oder sehr breite Nervenröhren. Sie enthalten bei Fischen aller Ordnungen Ganglienkörper eingeschlossen, sind demnach als bipolare Ganglienkörper ${ }^{1}$ ) zu bezeichnen.

Viele Nervenröhren bilden Endschlingen; andere scheinen einfach in Terminalzellen zu enden ${ }^{2}$ ).

\section{\$. 71.}

Die Nervi optici, in ihrer Stärke je nach dem Umfange der Augen wechselnd beschaffen, nehmen ihren Ursprung wesentlich von den Lobi optici, deren Umfang wieder in geradem Verhältuisse zu demjenigen der Sehmerven zu stehen pflegt. Das Verhälniss der Sehnerven zu dem Lobus opticus ist so, dass man sich vorstellen kann, jener sei an seinem Ilirnende hohl geworden und strahle mit seinen Wurzeln in den Lobus opticus aus. Fasern des Sehnerven stehen ausserdem in Verbindung mil der Fascia lateralis und der Commissura ansulata. Bei Raja und bei mehren Gadus-Arten lassen sich dem Sehnerven angehörige Fasern mit dem $\boldsymbol{P} e$ dunculus cerebri in den IIemisphärenlappen verfolgen.

1) Sie sind yon mir gefunden bei Petromyzon, bei Acanthias und Raja, bei Accipenser, bei sehr vielen untersuchten Teleostei, z. B. Perca, Lucioperca, Acerina, Cottus, Trigla, Scomber, Pleuronectes, Gadus, Esox, Salmo, Alosa u. A.; Leydig hat sie auch bei Chimaera angetroffen. S. meine erste Mittheilung in d. Nachrichten von d. königl. Gesellsch. d. Wissens. z. Göttingen. 1850.

2) Diese Endigungsweise glaube ich in den Ampullen der hallorirkclfürmige Catnaile bei Pleuronectes platessa erkannt zu haben. 
Die beiden Sehnerven der Teleostei stehen bald nach ihrem Ursprunge durch Commissuren mit cinander in Verbindung, welche, zwei eder selbst drei an der Zahl, als weisse Querbiundel, unmittelbar vor dem als Trigonum fissum bezeichneten Theile der IIrubasis gelegen sind. Nur die vordere dieser Commissuren gehört ausschliesslich den Sehnerven an; sie ist bei einigen Clupeïden, gleich wie bei Plagiostomen, weit vorwärts gerückt, dort unter der Kreuzungsstelle der beiden Nerven, hier an der Basis des Chiasma gelegen.

Das gegenseitige Verhalten der beiden Sehnerven gestaltet sich bei den verschiedenen Gruppen der Fische verschieden.

1. Bei den Marsipobranchii ') stehen die beiden Sehnerven an ihrer Basis dnech eine Commissur in Verbindung, die dicht am Hirne liegt; von hier ans tritt aber jeder ohne weitere Kreuzung zu dem Ange seiner Seite.

2. Bei den Teleostei findel cine cinfache Kreuzung der Sehnerven Stat, in der Art, dass der rechterseits entsprungene zum linken Auge, der linkerseits entsprungene zum rechten Auge tritt. Meistens liegt dabei der linkerseits entsprungene über dem rechterseits entsprungenen; doch ist dies Verhalten nicht beständig und selbst individuellen Abweichungen unterworfen. Beim IÏring besitzt der rechterseits entsprungene Schnerv zwei Bündel, zwischen welchen der ganze für das rechte Auge bestimmte Nerv hindurchitritt.

3. Dic Anwesenheit eines Chiasma ist charakteristisch für die Elasmobranchii und die Ganö̈den. Das Ergebniss der bisher über das Verhalten des Chirema angestellten Untersuchungen ist, dass, wenigstens bei Raja, in demselben mehre Bündel der beiden Sehnerven sncessive sich kreuzen und dass ausserdem Quercommissuren in demselben vorkommen.

Gleich nach der Kreuzung tritt der Sehnerv bei vielen Kuochenfischen durch eine dem vorderen Keilbeinsegnente angehörige fibröse Membran in die Augenhöhle. Wo, wie bei den Cyprinoïden und Siluroüden, das vordere Keilbeinsegment knöcherne Flügel besitzt, trilt er durch diese hindurch. Bei Accipenser und bei den Elasmobranchii durchbohrt er die soliden Schedelwandungen. Bei seinem Eintritte in die 1)urchgangsöfinnung empfüngt er ein derbes Neurilem, das ihn zum Bulbus begleitet. Diesen

1) Innerhalb dieser Commissur verlaufen bei Petromyzon Fäden von dem einen $\boldsymbol{N}$. opticus zum anderen. Der $\boldsymbol{N}$. opticus erscheint als ein mattweisses, mit feinen Molekularkörnchen besetztes sehr elastisches Band. In diesem Bande lässt sich eine feine Lïngsstreifung erkennen. Zerfasert man es, so zeigen sich feine wellenfürmig gekräuselte Fäden oder Bänder. Jedes dieser letzteren ist in fast unmessbar feine, blasse, sehr elastische, gleichfalls wellenfurmig gekräuselte Längsfibrillen zu zerlegen. Diese werden nach der Retina hin ganz starr. Die Fibrillen gehen im Gehirne von kleinen länglichen spindelfümigen Zellen aus, welche durch zwischengelagerte feinkörnige Grundmasse zu einer Art Membran verbunden erscheinen. 
durchbohet er nicht in seiner $\Lambda x e$, somdern seine Eintrittsstelle liegt gewöhnlich etwas hinten und oben.

Was die Form des ganzen Nerven anbelangt, so ist sic anfangs gewöhnlich eylindrisch; früher oder späiler indert er jedoch bei den meisten Fischen diese Form und erseheint in Gestalt eines gefalteden Bandes, das man ans einander breilen kann. Besonders dentlich und schön ist dies Verhalten bei den Scomberoïden, Pleuronectiden und Clupë̈len ${ }^{2}$ ).

\section{S. 72.}

Die Nervi olfactorii wruzeln allgemein in den unteren Theile der Hemisphärenlappen. Sie besitzen stets eigene Anschwellungen (Tubercula olfactoria). Dic Lage dieser Tubercula olfactoria bietet Verschiedenheilen dar. Bald nämlich lieggen sie unmiltelbar vor den Hemisphären 1), als einfaches oder doppeltes ${ }^{2}$ ) Paar von Anschwvellungen, bald dagegen weit nach vorne gerückt, unnillelbar vor dem Eintritte der Geruchsnerven in das Riechorgan ${ }^{3}$ ). Nur bei lianiecps fuscus sind sie elwa in der Mitte zwischen Ursprungs- und Anstrillsstelle der Geruchsnerven angetroffen worden.

Bei den Teleostei besitzt der Tractus olfactorius zwei aus der IIemisphäre kommende Wurzelstränge, was am deullichsten da crkamnt wird, wo die Tubercula olfactoria weit nach vorne gerückt sind. Bei deu Plagiostomen entsteht der, hïufig hohle ${ }^{1}$ ), Tractus olfactorius trichterförmig im Umkreise ciner Anschrvellung an der ïusseren Seite des Ilemisphärenlappens. Die Tractus olfactorii werden, gleieh dem Gehirne, von der Pia mater umbleidet und bestehen bei ien Teleostei und Elasmobranchii ans zarten Hirmröhren. Die Tubercula olfactoria sind immer seicht gelappt, graulich-weiss, sehr" gefässreich.

Der aus cinem Tuberculum olfactorium austrelende Geruchsncrv übertrifft an Umfang nnd Masse beständig den in jenes eingetretenen Tractus. Der eigentliche Geruchsnerv unterscheidet sich von letzterem auch dureh sein Ausschen und seinen Bau. Er ist gewobnlich bläulich-weiss, hall-

2) S. Näheres in meiner Schrift über d. peripher. Nervensyst. d. Fische. S. 10. B. Eustachi hat diese Bildung entdeckt; später hat Malpighi sic heschrieben.

1) So bei allen bisher untersuchten Percoïlen, Cataphracten, Sciänoüden, Sparoüden, Mugiloüden, Squamipennen, Scomberö̈den, Täniö̈den, Theutyern, Blenniöiden, Gobioiden, Cyclopoden, Pediculaten, Labroïlen, Chromiden, Scomber-Esoces, Pleuronectiden, Fistulares, Esocinen, Salmoniden, Clupeïden, Muränoìden, Gymnotini, Lophobranchii, Plectognathi, Ganoĩdei, Marsipobranchii.

2) So bei Anguilla, Conger, Gymnotus.

3) So bei allen untersuchten Gadoîdei, Siluroüdei, Cyprinoïdei; ferner bei den Elasmobranchii holocephali und Plagiostomi.

4) Die IIohle ist bei kochen bald angetroffen, bald - und zwar bei der gleichen Species - vermisst worden. Ich habe sie bei jungen Individuen gefunden, bei älteren öfter vermisst. Ob demnach, von Lntwickclungsvorgängen abhängige Verschiedenheiten yorkommen, bleibt zu ermitteln. 
durchscheinend und elastisch. Er besteht aus bandartigen, platlen, sehr blassen Strängen von ungleicher Breite. In der Längsrichtung der letzteren verlaufen selı feine, mit feinkörnigem Aufluge belegte Fasern.

Bei denjenigen Fischen, deren Tubercula olfactoria weit nach vorne geriickl liegen, und wo zugleich die Schedelhöhle weit nach vorue sich verlängert, verlïsst der Geruchsuerv sein Tuberculum mit mehren oder vielen sehr kurzen granen Strängen, welche sogleich durch kleine Zwischenräume der hinler dem Geruchsorgane ausgespannien fibrösen Membran hindurchund in lelzteres cintreten. - Bei den meisten Teleostei ist die Schedelhöhle nicht bis zur Gegend des Geruchsorganes hin verlängert, indem früher oder später die beiden fibrösen Blätter, wclche, anfaugs von cinander abstehend, die Schedelhöhle von der Augenhöhle abgrenzten, sich dicht an einander legen und ein einfaches fibröses Seplum zwischen den beiden Augrenhöhlen bilden. Unter dieser letzlgenannten Bedingnng durchbohrt der Geruchsnerv oft, aber nicht immer, das fibröse Blatt seiner Seile und tritt an die Wand der Augenhöhle, wo er, von derberem Neurilem ungeben, über dem Musculus trochlearis vorwïrts zu der Oeffumg neben der Basis des $O$ s frontale anterius sich erstreckt, durch die er mit trichterförmig aus einander gebreiteten Fasern zum Geruchsorgane sich begibt.

\section{Von den Simnesorganen.}

S. 73.

Das Gehörorgan der verschiedenen Gruppen der Fische sleht auf verschiedenen Stufen der Ausbildung. - Das Labyrinth liegt cntweder ausserhalb der eigentlichen Schedelhöhle und zwar bald, auf engeren Raum beschrinlit, in mil ihr communicirenden, schon äusserlich erticunbaren Gehörcapseln (Cyclostomen), bald, weiter ausgedehnt, innerhalb der Knorpelsubstanz des Schedels (Plagiostomen; Dipnoi); oder es licgt theils in letzterer und theilweise auch in der Schedclhöhle selbst (Iolocephali, Ganoïdei, Telcostei). Meistens ist es nach aussen hin von den staren, ununterbrochenen Wandungen der Sehedeleapsel umschlossen, die bisweilen Ansehwellungen und Auftreibungen in der Gehörsgegend bilden, wie z. B. bei manchen Taeniö̈lei; seltener besitzen die Schedelwandungen in der Gegend, lie das Gehörorgan einschliesst, äussere Oeffnungen. Die letzteren münden bald an der äusseren Oberfläche des Kopfes und pllegen damn nur durch die ïnseren IIantbedeckungen verschlossen zu sein, bald sind sie nach der Eingerveidehöhle hin gerichtet, in welchem Falle bei manchen Teleosiei vordere Aussackungen der Schwimmblase an sie sich anlehnen oder mit ilnen durch eine Reihe versehiebbarer Knochen in Verbindung stehen. 
Bei Branchiostoma ist noch keine Spur eines eigenen Gehörorganes nachgerviesen.

Bei den Marsipobranchii ist das Labyrinth eingeschlossen in seitlichen dem Sehedel unnittelbar und innig verbundenen Knorpeleapselı. Bei den M. hyperotreli liegt das blos in einem ringförmigen, in sich selbst zurücklanfenden Rohre bestehende häutige Labyrinth, an dessen oberer Wand der Nervus acusticus sich ausbreitet, in einer ihm entsprechend gestalteten IIöhle jener Capsel. Es enthält lieine den Gehörsteinen anderer Fische analoge Concretionev. - Das häutige Labyrinth von Petromyzon wird noch durch häutige Theile ${ }^{-}$an seine umschliessende Knorpelcapsel befestigt. Es bestelit 1. aus einem Vestibulum, das drei Abtheilungen besitzt: zwei grössere, die auswendig durch eine Furche, inwendig durch einen faltigen Vorsprung getrennt sind und mit denen eine dritle unpaare sackförmige Abtheilung durch einen Stiel verbunden ist. Hierzu kommen 2. zwei halbcirkelförmige Canäle, deren jeder bei seinem Ursprunge aus dem Veslibulım eine Ampulle besitzt, in welche faltenförmige Vorsprünge hineinragen. Beide Canäle steigen an der Oberfliche des häutigen Vestibulum, welcher sie angewachsen sind, auf, um knieförmig mit einander sich zu verbinden. An dieser ihrer Verbindungsstelle communiciren sie abermals mit dem $\boldsymbol{V} \boldsymbol{e}$ stibulum durch eine Oeffunng. Das lhïulige Labyrinth enthält nur helle Flüssigkeit und lieine feste Coneretionen. Die beiden Aeste des N. acusticus umfassen die Ampullen.

Bei den Plagiostomen ist das Labyrinth, welches wesentlich aus dem Vestibulum und drei halbcirkelförmigen Canälen besteht, von der Knorpelsubstanz des Schedels ganz umfasst, ohne in die Schedelhöhle selbst hincinzuragen. Das häutige Labyriuth liegt in ihm entsprechend gestalteten, viel weiteren Aushöhlungen der Knorpelsubstanz des Schedels (dem sogenannten kuorpeligen Labyrinthe); zwischen beiden befindet sich eine Flüssigkeit und von der Innenfliche dieser Excavationen der Knorpelsubstanz erstrecken sich Füden an die Aussenfläche des häutigen Labyriuthes. Diejenige linorpelige Aushöhlung, welche das häutige Veslibulum aufuimmt: das sogenaunte Veslibulum carlilagineum communicirt durch einen, das knorpelige Schedeldach durchselzenden, Canal, der indessen hïulig geschlossen ist, mit der Schedeloberflïthe. Bei den Rochen entsprechen dem Vestibulum carlilagineum die beiden hinteren der vier an der Schedeloberlliche befindlichen Oeffnungen.

Das Vestibulum membranaceum bildet einen in drei Abtheilungen zerfallenen Sack, welcher weiche krystallinisehe Concremente enthïl. Seine mittlerc Abtheilung communicirt bei den Rochen durch cinen aufsteigenden Gang mit einem häutigen Säckehen. Gang und Säckchen sind mit einer weissen, kohlensaure Kalkerde cnlhaltenden, breigen Masse gefüllt. Das Säekchen liegt zwischen der Sehedeloberfläche und der Culis und zerfïllt 
in zwei Abtheilungen: eine untere und eine obere, von welchen die letztere durch enge, die Haut durchbohrende Canile, die indessen gegen von aussen eindringende Substanzen durch Klappen geschïtzl sind, uach aussen mündet. Im Umlireise des Säckchens findet sich cin Muskel, der ihn comprimiren kann ${ }^{1}$ ). Drei halbeirkelförmige Canäle stehen mit dem häutigen Vestibulum in Verbindung. Bei den Rochen hat dieselbe dadurch Statt, dass zwei sehr enge Oeffnungen, eine aus dem vorderen und eine aus dem hinteren Canale, die beide kreisförmig und unter cinander nicht verbunden sind, in das Vestibulum führen. Der äussere Canal verbindet sich an seinen beiden Enden mit dem vorderen Canale. Bei den Haien ist die Verbindung der halbcirkelförmigen Canäle analog der bei den Teleostei Statt findenden. - I)ie Ampullen der Canales semicirculares besitzen Septa transversa, an denen die Nerven-Ausbrcitung Statt hat.

Bei Chimacra ${ }^{2}$ ), wo das Labyrinth zum Theil in der Knorpelsubstanz des Schedels eingeschlossen, zum Theil in der Schedelhöhle liegt, setzt das häutige Vestibulum durch einen Canal zn cincr unparen, im Schedeldache liegenden Oeffnung sich fort; von ihr ans treten zwei Canäle zu zwei kleinen Oeffnungen in der Haut der Hinterhauptsgegend.

Das Gehörorgan der Ganoïdei und der meisten Teleostei liegt zum Theil innerhalb der knorpeligen oder kü̈ehernen Sehedelwandungen, zum Theil aber noch innerhalb der Schedelhöhle selbst. Es wird also nach aussen gewöhnlich allseitig von den festen Schedelwandungen, nach innen von dem halbllüssigen oder fettreichen Inhalte der Schedelhöhle ungeben. Bei Aecipenser wird indessen das Gehörorgan jeder Seite von der eigentlichen Sehedelhöhle noch abgegrenzt durch cin dünnes, membranöses, verticales Septum. Das Gehörorgan besteht aus einem die Gehörsteine aufnehmenden membranösen Sacke und aus dem Vestibulum, das gewölnlich ebenfalls ein festes Concrement enthält und in welches die drei halbeirkelförmigen Canäle cinmünden ${ }^{3}$ ).

Anı tiefsten abwärts liegt der Sack; bei den Teleostei gewöhnlich in cincr lïnglichen durch Knochen des Occipitalsegmentes und durch die Ala lemporalis des Keilbcines gebildeten Grube. Bald hangl er unmittelbar an dem Vestibulum, bald ist er von ihm elwas weiter entfernt. Obgleich er

1) Diese Verbindung des häutigen Labyrinthes mit der Schedeloberfläche wird bei Carcharias, nach Weber, vermisst.

2) S. Leydig in Miller's Archiv. 1851. S. 245.

3) Das Labyrinth von Lepidosiren, aus denselben Theilen gebildet, liegt in der Knorpelsubstanz des Schedels, mit Ausnahme des Sackes, der theilweise innerhalb der Schedelhöhle gelegen ist. Statt der Gehörsteine, sind hreige Krystallanhäufungen vorhanden. Der Canalis semicircularis externus besitzt blos an seinem vorderen Schenkel cine einfache Ampulle, während dic beiden anderen an jedem Schenkel cine Ampullé zeigen. Vgl. II yrtl, l, c. S. 51. 
mil letzterem bestindig durch eine IIautfortselzung in Verbindung steht, scheint doch eine Ilöhlenverbindung beider bei den Knochenfischen nicht immer Stalt zu finden, die jedoch beim Stör deutlich vorhanden ist. Der Sack ist bei vielen Knochenfischen durch ein Septum in zwei IIöhlen von ungleicher Grösse getheilt. Jede derselben enthält ein aus kohlensanrev Kalkerde bestehendes Conerement; das in der vorderen Ilöhle enthaltene, grössere führt die Bezeichnung Sagilla, das der hinteren IÏ̈hle Asteriscus. Diese Concretionen besitzen bei den Teleostei gewöhnlich gezackte Ränder, oft auch andere Einschnitte und Erhabenheiteu, bestimmt zur Unterstïtzung der an ilnen Statt findenden Nervenausbreitungen. Bei Accipenser, wo ebenfalls zwei Concretionen vorkommen, sind dieselben minder regelmässig geformt, an der Circumferenz weicher, auch von einer breiigen krystallinischen Masse ungeben. Die Steine werden immer von heller lymphatischer Flüssigkeit umspült.

Das höher gelegene Vestibulum membranaceum liegt nach aussen den Sehedelknochen lose an, durch Bindegewebe locker mit ihnen verbunden; nach imnen ist es der Medulla oblongata und dem Cerebellum zugewendet. Bei Esox hat es einen hinteren in den Canalis spinalis blind hineinragenden Anhang. Das Vestibulum enthält bei den Teleostei in seinem vorderen Theile ein festes Concrement (Lapillus), das beim Stör fehlt und durch etwas breiige krystallinisehe Masse vertreten wird. In dasselbe münden die drei halbeirkelförmigen Canäle gewöhnlich mit fünf Oeffnungen. Der vordere und der hintere Canal, welehe senkrecht stehen, besitzen cinen gemeinsamen Ansgangspunlit von der IIöhle des Vestibulum, indem sie zusammen münden. An seinem entregengesetzten Ende bildet der vordere eine Ampulle. Neben dieser liegt die Ampulle des äusseren oder horizontalen Canales. Neben dem eiufachen anderseitigen Ausgange des letzteren ist die Ampulle des hinteren Canales gelegen.

Die halbeirkelförmigen Canäle des Störes ${ }^{4}$ ) liegen, vollständig von der Knorpelsubstanz des Schedels umschlossen, in ihnen entsprechend geformten IIöhlungen der letzteren. Diese IIöhlungen füllen sie jedoch nicht vollstïndig aus, sondern liegen entfernt von ihren Waudungen, durch Bindegewebsbrücken angeheftet, durch Blnlgefïsse umsponnen. Bei den Teleostei sind sie oft nur theilweise in die Schedelgrundlage eingesenkt, theilweise blos von dem Inhalte der Sehedelhöhle, in die sie frei hineinragen, umschlossen. Die zu ihrer Aufuahme und Anlehnung bestimmten Knochen sind die meisten Theile des Ilinterhauptsegmentes, das Os mastoüdeum, die Ala temporalis und biswcilen auch die Ala orbitalis des vorderen Keilbeinsegmen-

4) Ihre Grundlage, welche immer solider ist, als diejenige des V beim Stör gebildet durch transparente, viclfach ramificirte Fasern und Plättchen. Inwendig findet sich eine Zellenschicht. 
tes. So weit die weichen halbcirkelförmigen Canäle von Aushöhlungen der Schedelsubstanz aufgenommen werden, liegen sie den Wandungen derselben niemals dicht an, sondern verhalten sich im Wesentlichen ähnlich wie beim Stör. In Betreff ihrer Ausdehnung, Länge und Weite bieten die Canäle manche Versehiedenheiten dar. Ihre Ampullen besitzen Sepla transversa. Die Aeste des $\boldsymbol{N}$. acusticus vertheilen sich an den Concrementen des Sackes und des Vestibulum, so wie an den Septa der Ampullen der halbcirkelförmigen Canäle, ohne in letztere selbst sich forłzusetzen, welche einen flüssigen Inhalt besitzen.

Bei der geschilderten Lage eines Theiles des Labyrinthes innerhalb der Schedelhöhle, können die, manchen Fischen eigenthümlichen, blos von Haut bedeckten Fontanellen der Schedeldecken, wie sie z. B. bei den Silurö̈lei, Loricarini, bei Cobitis u. A. vorkommen, nicht ohne Einfluss auf die $\mathrm{Zu}$ leitung der Schallwellen sein. Besonders merkwürdig sind in dieser Beziehung aber die Mormyri, wo die äussere Bedeckung des Labyrinthes durch cincu lose aufliegenden dünnen Knochen, der hinten einen kleinen nur von äusserer Haut überzogenen haum unbedeckt lässt ${ }^{5}$ ), geschieht.

Bei Lepidoleprus trachyrhynchus ${ }^{6}$ ) findet sich seitlich am Hinterkopfe über dem oberen Ende der Kiemenspalte eine trichterförmige von dünner Haut geschlossene Grube, welche in den zur Aufnahme des Gehörorganes bestimmten Theil der Schedelhöhle hineinragt. Zwischen der Innenfläche ihrer Haut und dem Labyrinthe liegt eine faserig - gallertartige Substanz. Bei Notopterus und Hyodon claudulus findet sich zwischen dem dorsalen Ende des Operculum und dem hinteren Augenhöhlenrande eine blos von der äusseren Haut überzogene Grube. Unter ihr liegen zwei weite, durch eine Knochenbrücke getrennte Oeffnungen, die in die Schedelhöhle, da wo sie das Gehörorgan umschliesst, hineinführen.

In eigenthü mliche Verbindung tritt das Gehörorgan vieler Teleostei mit der Schwimmblase ${ }^{7}$ ). Diese, auf verschiedene Weise zu Stande gebrachte, Verbindung beider Gebilde bewirkt, dass, bei Ausdehnung oder Zusammenziehung der Schwimmblase, die in dem häutigen Labyrinthe enthaltene Flüssigkeit comprimirt oder expandirt wird. Bald erscheinen, zu Erreichung dieses Zweckes, Fortsetzungen der Schwimmblase bis zum Gehörorgane selbst herangeführt, bald werden Fortselzungen des häutigen Gehörorganes durch eine Reihe von Knochen, welche den vor-

5) S. Heusinger in Meckel's Archiv f. Anat. u. Physiol. 1827. Bd. 1. S. 324. Abb. Tf. 4. Aehnlich soll, nach Erdl, auch Gymnarchus niloticus sich verhalten,

6) S. 0 tto in Tiedemann und Treviranus Zeitschrift f. Physiologie. Bd. 2. S. 86. Aehnlich verhält sich Lepidoleprus coelorhynchus, nicht aber L. norwegicus, wo diese Bildung ganz fehlt.

7) Diese Verbindungen hat kennen gelehrt E. H. Weber, De aure et auditu hominis et animalium. T, I, Lips. 1820.4. c. tab. aen. X. 
deren Wirbeln angefügt sind, mit der Wandung der Schwimmblase verbunden.

1. Am einfachsten gestaltet sich dic Verbindung bei cinigen Percoïden ${ }^{8}$ ), Sparö̈den und Anderen, wo die vorderen Hörner der Schrvimmblase an häutig geschlossene Stellen der Occipitalgegend des Schedels sich anlegen, an die von innen das hintere Eude des Vesibulum herantritt.

Complicirter sind die Verhältnisse bei manchen Clupeïdac 9). Das vordere sehr verengte Ende der Schwimmblase tritt in einen Canal der Basis des Hinterkopfes und spaltet sich hier gabelförmig in zwei sehr enge Aeste. Jeder dieser Aeste erweitert sich innerhalb des Knochens und spaltet sich wiederum in zwei Zinken, deren jede eine kugelförmige Anschwcllung bildet. In dic zur Aufnahme der vorderen dieser beiden Anschwellungen bestimmte kugelförmige Aushöhlung der Ala temporalis erstreckt sich ein Anhang des Vestibulum, der auf diese Weise mit der Schwimmblase in Berührung köınmt. Die Vestibula beider Seiten werden ausserdem durch einen in der Schedelhöhle, unterhalb des Gehirnes, verlaufenden Quercanal mit einander verbunden.

2. Eine mittelbare Verbindung des Gehörorganes mit der Schwimmblase ${ }^{10}$ ) durch eine Knochenreihe zeigt sich bei den Familien der Cyprinoïdei, Siluroïdei, Charicini und Gymnotini. - Bei den Cyprinen geht jederseits von dem den Sack und das Veslibulum verbindenden Canale ein Gang aus, der gleich seinen hinteren weiteren Fortsetzungen, mit Flüssigkeit erfüllt ist. Die beiden Gänge verbinden sich zu einem im Basilartheile des Hinterhauptes gelegenen Sinus impar. $Z_{w}$ ei hintere Oeffnungen des-

8) Z. B. bei Myripristis, Holocentrum, Triacanthus macrophthalmus; bei Sparus Salpa u. Sargus, L. von E. H. We ber entdeckt.

9) Z. B. bei Clupea, Alosa, Engraulis. - Von E. H. Weber entdeckt. - Bei Hyodon claudulus - und ganz analog verhält sich Notopterus - communicirt das vordere Ende des Schwimmblasenkörpers durch enge Oetfnungen mit zwei sphärischen dickwandigen Blasen. Jede derselben legt sich in eine Vertiefung der Knochen der Hinterhauptsgegend ihrer Seite und haftet eng an den letzteren. Dem vordersten Theile jeder dieser Blasen entspricht eine Oeffnung in den Ḱnochen, die inwendig von einem Theile des Vestibulum, auswendig aber von der innersten Haut dieser Blase bekleidet ist, indem die weisse Faserhaut derselben im Umkreise der äusseren Gehörsöffnung aufhört und nicht über leiztere selbst sich fortsetzt. Bei Hyodon und Notopterus combiniren sich also gewissermaassen die Bildungen von Lepidoleprus und Mormyrus mit denen mancher Percoïden und Sparoīden.

10) Bei den Cyprinoïden und bei Silurus glanis entdeckt von E. H. Weber, bei Pimelodus von Heusinger gefunden; in der Familie der Characini bei Gasteropelecus durch Heusinger entdeckt, von J. Müller als allgemeine Eigenthümlichkeit der drei zuerst genannten Familien erkannt; unter den Gymnotini bei Sternopygus macrourus durch C. E. v. B a er gesehen und ausführlich erörtert und weiter verfolgt durch J. Reinhard 1852. 8. 
selben führen in zwei an der Oberflïche des crsten Wirbelkörpers gelegene, theilweise nur häutig, theilweise von knöchernen Wandungen umschlossene Atria. Jedes Atrium wird durch einen eigenthïmlichen, zwisehen dem Ilinterhaupte und dem Dornfortsalze des ersten Wirbels gelegenen Knochen: Clauslrum, bedeckt. Diese Atria stehen, mittelst dreier unter cinander verschiebhar verbundener und mit den vorderen Wirbehn articulirender Knochen, mit der Schwimmblase so in Verbindung, dass der vorderste derselben das Atrium aussen bedeckt und verschliesst, und der hinterste an der Aussenwand der vorderen Schwimmblase angeheftet ist. Analog dem der Cyprinen ist das Verhalten dieser Theile bei den übrigen Familien.

[Das Gehörorgan der Cyclostomen behandelt: J. Müller über den eigenthümlichen Bau d. Gehörorganes bei d. Cyclostomen. Berlin, 1838; das der Plagiostomen Monro, sowie, mit dem der Teleostei, Weber, in ihren angefürten Schriften. S. von älteren Arbeiten auch Scarpa, de auditu et olfactu. Ticin. 1798. 4. If uschko, Beiträge zur Physiologie und Naturgeschichte. 1. Bd. Weimar, 152t. 4. - Ganz unbrauchhar ist Breschet, Recherches anat. et physiol, sur l'organe de l'ouie des poiss. Paris, 1838. 4. - Ueber die Gehörsteine rgl. Ed. Kr ri e ger, Diss. de Otolithis. Berol. 1840, 4. Ueber die Ampullen der halbcirkelförmigen Canäle: Steifensand in M üller's Archiv. 1835. S. 174.]

\$. 74.

Die Gesichtsorgane der Fische, in der Regel von beträchllichem Umfange, bleiben nur bei verhältnissmässig wenigen klein oder abortir. Bei Brauchiostoma ${ }^{1}$ ) scheinen zwei seitlich, am Vorderende des centralen Nervensystemes liegende Pigmentflecke, zu wclehen anscheinend sehr kurze Nerven treten, als Augen gedeulet werden zu müssen. Noch bei den Myxinoïden ${ }^{2}$ ) bleiben die Augen höchst unentwickelt.

Bei Myxine findet sich jederseits, von Muskeln und Haut bedeckl, ein sehr kleines, ganz abortives Auge, zu welchem ein Nerv sich begibl. Bei Bdellostoma liegt das, hinsichllich seiner immeren Organisation gleichfalls noch nicht ausreichend untersuchte, Ange oberhalb der Muskeln und wird vou einer dümnen Fortsetzung der äusseren Ilaut überzogen。 Ein muskulöser Bewegungs-Apparat des Bulbus scheint durchaus zu fehlen. - Ausserordentlich klein sind die Augen auch bei den Dipnoi ${ }^{3}$ ). Sie liegen in trichterförmigen Einstülpungen der Schedel-Aponeurose, welche dic Orbilae

1) Nach Quatrefages (Ann. d. sc. nat, 1845. p. 225. Tb. 13. Fig. 7.) sind indessen die Augen ausgebildeter, als man bisher annahm. Der $\mathbf{N}$. opticus geht in ein ringförmiges Pigment über, an dem ein hemisphärischer, durchsichtiger, das Licht stärker, als die umgebenden Theile, brechender Körper sich findet. Dieser Körper ist der Dura mater eingefügt. Er wird, gleich dem Pigmente, von einer Capsel umhüllt, die mit einer anscheinend flüssigen, schwach orange gefärbten Sulistanz gefullt ist.

2) S. II üller, Gehörorgan d. Cyclostomen. S. 23.

3) Vgl. Hyrtl, Lepidosiren. S. 51. 
bilden, sind ron den durehsichtig werdenden Handdecken überzogen, haben eine sehr dünne Sclerotica, eine schwarze Chorioüdea und eine kugelige Linse, welche mit der Chorioüden durch einen schwarzen, an dem Seitenrande jener sich befestigenden Faden zusammenhangt, ermangeln der Iris und des Ciliarkörpers und besitzen einen Bewegungs - Apparat in vier geraden Augenmuskeln. - Noch bei einigen Teleostei kümmıt es vor, dass die äussere Haul, ohne sich beträchtlich zu verdünnen oder durchsichtigg zı werden, die unter ihr liegenden, schr kleinen Augen überzicht, deren Anwesenheit deshalb, mit Unrecht, in Abrede genommen wurde. So bei Apterichthus coecus ${ }^{4}$ ), Silurus coecutieus ${ }^{5}$ ) und dem in unterirdischen IIöhlen lebenden Amblyopsis spelaeus ${ }^{6}$ ).

Bei der Mehrzahl der Fische sind die Augen verhältnissmïssig gross; bei einigen, wie z. B. bei Priacanthus, Pomatomus, Lepidoleprus, durch ungewöhnlichen Umfang ausgezeichnet; nur bei einzelnen Familien, wie bei den Sturionen, den Silurö̈den und den Physostomi apodes, besonders aber bei den vorhin namhaft gemachten Thieren, klein. Sie liegen gewöhnlich symmetrisch an beiden Seiten des Orbitalsegmentes des Scherdels, rücken seltener mehr an die Oberfläche des Schedels, wie z. B. bei Uranoscopus, und liegen nur bei den Pleuronectides asymmetrisch, beide an derselben Seite des Kopfes ${ }^{7}$ ).

Der in die Orbita eingesenkte Abschnitt des Bulbus pflegt von Fett, oder von gelatinösem Bindegewebe und von lymphatischer Feuchtigkeit reichlieh umgeben zu sein. Bisweilen steht der Bulbus auf eigenthümliche Weise mit der Wandung der Orbila in Verbindung. So besitzt bei allen Plagiostomen die Sclerolica hinten, neben der Eiutrittsstelle des Selnerven, eine knorpelige, äussere, hinterwïrts gerichtete Ansehwellung mit convexem Gelenkikopfe, weleher auf einem vom Schedel ausgehenden, aus dem Grunde der Orbita vorragenden, von einem dünneren Stiele getragenen, am Ende verbreiterten Knorpel beweglich, nur durch Bindegervebe locker angeheftet ruhcl. Bei cinigen Ganö̈den und den meisten Teleostei inserirt sich an die Sclerotica, neben der Eintrittsstelle des Nervus opticus, ein von der Orbitalıand ausgehendes fibröses T'enaculum ${ }^{8}$ ).

Die Bewegungen des Bulbus werden sehr allgemein, selbst bei den Marsipobranchii hyperoartii, durch vier gerade und zwei schiefe Augen-

4) de la Roche, Annales du Husée d'hist. nat. T. XIII. p. 326.

5) S. Rudolphi, Grundriss d. Physiologie. T. II. Abth. 1, S. 155.

6) S. Tellkampf in Müller's Archiv. 1844.

7) Merkwürdig sind die häufig vorkommenden Fälle von individuellen Abweichungen in der Lage der Augen bei den Schollen. Vgl. Schleep in Oken's Isis. 1829. S. 1049.

8) Z. B. bei Accipenser, Esox, Salmo, Clupea, Ammodyles, Fistularia, Echeneis. Dasselbe war schon Scarpa und Rosenthal bekannt. 
muskeln vermittelt, welche letzteren von der Vorterwand der Orbila, die durch das vierte, dem Siebbeine entsprechende Schedelsegment gebildet wird, ihren Ursprung nehmen. Dic geraden Augenmuskeln entspringen weiter hinten aus dem Grunde der Orbita, oder, wie bei vielen, obschon bei weitem nicht allen Teleostei, aus einem, unterhalb der Schedelbasis gelegenen, vorne in die Augenhöhle ausmündenden Knochencanale. Aus ihm gehen mehre Muskeln beider Bulbi divergirend hervor. Am weitesten nach hinten erstrecken sich in diesem Canale die Musculi recli externi; seiner Ausmündung näher entspringen der $\boldsymbol{M}$. rectus internus und rectus inferior, während die Insertion des $\boldsymbol{M}$. rechus superior meist ausserhalb dieses Canales zu liegen pflegt.

Thränenorgane feblen den Fischen allgemein.

Das Verhalten der äuseren Haut, welche, durchsichtig werdend, die Vorderfläehe des Bulbus stets überzieht, bietet manche Verschiedenheiten dar. Bald nämlich geht sie in einer Flïche über die Cornea weg; bald bildet sic im Umkreise des Bultus, indem sic vicht blos seine zu Tage liegende Oberfläche überzieht, sondern etwas in die Tiefe seiner Circumferenz sich einsenkt, eine mehr oder minder liefe, kreisrunde Einsenkung. Bisweilen kommen weitere Augenlidbildungen ${ }^{9}$ ) durch Faltungen der durchsichtigen Haut zu Stande; namentlich bei manchen Scomberoïden z. B. bei Scomber und Caranx, mauchen Chueïden, z. B. den Gattungen Clupea, Alosa, wo das vordere und hintere Augenlid durch einen verticalen Schlitz getremnt werden. Am anffallendsten ist die Bildung von Butirinus, wo ein kreisförmiges, durchsichtiges Augenlid vorhanden ist, das, der Pupille entsprechend, in der Mitle cine runde Oeflnung besitzt.

Nur den in die Gruppe der Nietitantes vereinigten Haien kömmt eine wirkliche Nickliaut zu. Sie ist eine, an ihrer äusseren Oberfläche beschuppte, Inutduplicatur, welche aus der inneren lamelle des unteren Augenlides hervorgeht und schief gegen die hängenaxe des Körpers gerichtet ist. Sie kaun bald den grössten Theil des Bulbus bedecken, wie bei den Carchariae, bald nur einen kleinen Theil desselben, wie bei den Musteli. Hhre Bewegungen stehen unter Einfluss eigcuer Muskeln. Bei Mustelus und Galeus ist nur ein Muskel vorhanden, weleher von der Seite des Sehedels entspringt, ab- und vorwärts gegen den hinteren Umfang der Orbila verläuft und hier an dem hinteren Theile der Nickhaut mit kurzer Schne sich befestigt. Bei den Carehariae nithert sich die Bildung der Nickhaut-Muskulatur derjenigen der Vögel dadurch, dass noch ein zweiter Muskel vor-

9) Augenlidbildungen sind auch anderen Gruppen der Teleostei nicht fremd, wie z. B. bei Sternopygus Marcgravii durch Reinhardt cin lireisrundes Augenlid beschrieben ist. 
handen ist. Dieser bildet eine, an dem hinteren Theile der Bedeckung des Bulbus doppelt befestigle, muskulöse Schleife, durch welche der eigentliche Muskel der Nickhaut hindurchtritt ${ }^{10}$ ).

Whas den Bulbus selbst anbetrift, so hat derselbe, wegen grosser Flachheit der Cornea, cine ungef:ihr hemisphärische Forın; sein stark gewölbter Theil liegt innerhalb der Augenhöhle.

Die Sclerotiea ist bei deu Elasmobranchii, beim Stör 11) und bei Spatularia knorpelig, hinten von Bindegervebe, imnen von einer Pigmentschicht überzogen. Bei der Nehrzahl der Teleostei enthält die zusammenhangende fibröse Grundlage derselben, zwei starke knorpelige oder ossificirte Scheiben, welche hinten einen verhältnissmässig kleinen, unregelmässig gestalteten, blos durch fibröse Haut gefüllten Raum zwischen sich lassen. Selten kömmt um diese Scheiben, statt ler fibrösen Grundlage, cine zusammenhangende Knocheneapsel vor, welehe hinten eiue zum Durchtritt der Sehnerven bestimmte Oeffnung besitzt ${ }^{12}$ ).

Die in der Mitte dümnere, nach dem Rande zu sich verdickende, durchsichtige Connea ist gewöhnlich sehr flach. Ihre äussere und innere Schicht weichen bei vielen Knochenfischen vou dex mittleren, dem Baue nach, ab. Eine der auffallendsten Bildungen bietet die Gattung Anableps 13) dar, in. dem ein horizontaler dunklerer Streif der Conjunctiva dic Cornea in zuvei Abtheilungen theilt: eine obere und eine untere. Dic Cornen selbst, die Iris, die Linse sind in ihren anaţomischen Verhältnissen gleichfails modi ficirt. - Zunächst der Sclerolica liegt gewöhulich, doch nicht durchaus beständis, eine sibergläuzende Schicht. Auf sie folgt, sowol bei vielen Elasmobranchii, als auch bei mauchen Teleostei, ein Tapelum ${ }^{\mathbf{1}}$ ).

10) S. Näheres b. Müller, Ueb. d. Eingeweide der Fische. S. 13, u. die betreffende $\mathrm{Abb}$. Tb. 5.

11) Beim Stör bildet die Sclerotica eine sehr dicke Knorpelcapsel, die hinten nur cine Oelfnung für den eintretenden Nerven besitzt. Zunächst der Cornea liegt aber ein Knochenring, gebildet aus zwei schmalen, dünnen Knochenbogen: einem oberen und einem unteren, die an den beiden Augenwinkeln einander berühren. Bei Spatularia mangelt dieser Ring; die Knorpelcapsel der sclerotica ist schr dick. (Abb. des Störanges bei Rosenthal in Reil's Archiv fur Phys. Bd. 10. Tb. 7. Fig. 3. und bei Soemmering, de ocul. sect. horizont. Tb. 3.). Dieser Knochenring entspricht, wic bereits Rosenthal bemerkt, dem der Vögel und einiger Reptilien.

12) So bei Xiphias gladius, wo, nach C'uvier (IIist, nat. d. poiss. T. VIII. p. 264.) diese Knochencapsel nicht die sonst vorhandenen Knorpelscheiben vertritt, sondern gleichzeitig mit ihnen vorhanden ist.

13) Vgl. Meckel in seinem deutschen Archiv f. Phys. Bd. 4. S. 124. und eine anscheinend sehr sorgfältige Beschreibung bei Valeneienues, hist. nat. d. poiss, T. XVIII. p. 262, wo auch die schon durch Bloch hervorgehobene Bemerkung, dass das Auge des Fö̈us diese Bildung noch nicht zeigt, bestätigt und modificirt wirl.

14) S. üher dics 'Tapetum namentlich Brüeke in 11 üller's Archiv. 1045. S. \$102. Es wurde von delle Chiaje entuleckt. Lis künmt vor bei vielen Plagiostomen z. B. 
Die eigentliche Choriö̈dea besteht aus der Gefässhaut, deren Capillaren durch spärliches Bindegewebe zusammen gehalten werden. Zwisehen den Capillaren und vor ihnen finden sich gewöhulich in beträchtlicher Menge rundiche oder polygonale, platte, mit schwarzem Pigmente gefüllte Zellen, welche membranförmig verbunden, dic Membrana Ruyschiana bilden. Bei vielen Fischen liegt in der Umgebung des eintretenden Sehnerven, zwischen der eigentlichen Chorioüdea und der silberglänzenden Schicht, ein eigenthümliches vasculöses Gebilde: die Choriö̈dealdrïse ${ }^{15}$ ), welche den Wundernetzbildungen angehört. Bei vielen solcher Fische, denen eine Pseudobranchie zukömmt, löset sich nämlich die aus derselben hervorgegangene Arteria ophlhalmica magna büschelförmig in zahlreiche arterielle Gefässe auf, welche den arteriellen Theil dieses Wundernetzes bilden, der dann die Arterien der Chorioüdea abgibt. Die aus derselben Gefiisshaut slammeuden Venen zerfallen in der Choriö̈lealdrüse ebenfalls wundernetzartig in Rïhren, aus welchen das Blat in cine Vena ophthalmica magna sich sannelt, die dasselbe in das Körpervencusystem überführl.

Die Iris, über deren Beweglichkeit ${ }^{16}$ ) noch kaum ausreichende Erfahrungen vorliegen, erscheint als Fortsetzung der Chorioïdea, welche, bei der Kleinheit der vorderen Augenkammer, der Ilornhaut alsbald folgt. Ihre Vorderfläche wird von einer eigenthümlichen silberglänzenden Schicht überzogen. Ob zwischen den Lamellen derselben Muskelfasern verlaufen, bleibt zu crmitteln 17). An ihrer hinteren Fläche liegt die aus dunkler Pigmentlage gebildete Uvea.

Bei vielen Rochen erstreckt sich vom oberen Rande der Iris ein halbmondformiger, schleierartiger Fortsatz abuärts über einen Theil der P'upille (Operculum pupillare). Vom unteren freien Rande des eigenthümlichen Fortsatzes gehen mit verdünnter Basis zahlreiche, versehiedeullich lange, nach ihrem freien Ende hiu scheibenförmig sich verbreitende, anssen goldglänzeude, an der Innenfläche schwarz piømentirte Fortsätze ab. -- Ein ahulicher halbmondförmiger, am freien Ende aber ganzrandiger Pupillar-

bei Raja batis, Torpedo, Trygon, Squatina, Spinax, Centrophorus, Carcharias, Sphyrna, Galeus, Hexanchus; ferner bei Chimaera, bei Accipenser; unter den Teleostei bei Ponatomus telescopium, Labrax lupus, Pleuronectes platessa, Thynnus und vielen Anderen. Bei Hexanchus griseus besteht, nach Brücke, das Tapefum aus. Zellen, in welchen die den Silberglanz verursachenden Krystalle abgelagert sind. Die Zellen sind durch ihre Grösse ausgezeichnet. Bei manchen Fischen geht die Gefässhaut nicht ganz pigmentfrei über dem Tapetum fort. Abramis brama besitzt cin Pseudotapelum.

15) S. J. Müller, Vergl. Anatomic d. Gefässsyst. d. Myxinoïd. S. 82., wo auch die ältere Literatur aufgeführt ist. Vgl. \$. 91. Anm. 5. und §. 105.

16) Vogt und Agassiz haben sich bei Salmonen von derselben überzeugt; dic Bewegung geschieht sehr langsam. I. c. p. 85 . Haller konnte sje nicht crkennen.

17) Die Iris der Teleostei erhält, nach 1 üller, ihre Gefasse nicht aus der Chorioïdealdrüse. 
vorhang erstreekt sich bei der Pleuroneetiden-Gattung Rhombus vom oberen Abschnitte der Iris aus über cinen Theil der Pupille. So weil dieser Pupillarvorhang reicht, ist auch die das Auge überzichende Haut undurchsichtig und pigmentirt. Diese Einrichtung bezweckt die Abhaltung des ron oben einfallenden Lichtes. - Die Pupille ist bei der Mehrzahl der Fische unvollkommen rund; bei Accipenser, so wie bei vielen Plagiostomen, länglich-oval; bei manchen in die Quere gezogen.

Die Eintrittsstelle des Sehnerven in die Sclerolica liegt ausserhalb der Axe des Bulbus. Bei vielen Knochenfischen geht von der runden oder rundlichen Eintrittsstelle des Schnerven aus, durch die Retina eine bis zu ihrem vorderen Rande hin sich erstreckende Spalte ${ }^{18}$ ). Durch diese Spalte sieht man bäufig die unter dem Namen des Processus falciformis bekanute gefässreiche Fortsctzung der Chorioülea hindurchtreten.

Die Retina selbst füllt den von der Chorioüdea gebildeten Hohlraum aus und folgt eine Strecke weit auch noch der Iris, indem sie in einiger Entfernung von der Pupille endet. Sic besteht aus meliren Schichten, deren äussere durch die Zwillingszapfen uud die Stäbchen gebildet wird, während wach imen Nervenfibrillen und eine Zellenschicht liegen ${ }^{19}$ ).

Die durehsiehtigen Medien des Auges bestehen in dem Glaskörper und der fast liugelrunden Linse, welche, hinten in eincr Vertiefung des Glaskörpers liegend, vorn an die Iris herantritt und in die vordere Augenkammer hineinragt. $\mathrm{Ob}$ eine wirkliche Linsencapsel im Leben vorhanden ist, bleibt zu untersuchen. Nach dem Tode liisst von der Linse häufig eine dickere Capsel sich ablösen, die in Betreff ihres elementaren Banes vou dem der Liuse nicht eigentlich abzurveichen scheint; doch fundet man oft in der Circumferenz derselben nur cine ganz zarte Schicht von Zellen. Die Linse ${ }^{20}$ ) besteht aus concentrischen Blätlern. Ihr, im Gegensalze zu einer viel weicheren peripherischen Masse, durch Härte ausgezeichneler Kern besitzt die bekannten sägenförmig gezackten Faseru. Nach der Peripherie hiu erblickt man melı und mehr ganzrandige Fasern. An gevisse Stellen der Circumferenz der Linse heflęn sich häufig pigmentirle gofiissreiche Falten, welche von der Chorioïder ausgehen ${ }^{21}$ ). Eine solche Falle, dic von dem Spalt der Relina aus, den Glaskürper seitwärts durchsetzt und an

18) Sic ist bei den bisher untersuchten Ganoiden veririsst worden.

19) S. Gottsche in Müller's Archiv. 1834. S. 45\%. II annover in Müller's Archiv. 1840. S. 322. II. Müller, in v. Siebold u. Külliker's Zeitschrift. Bd. 3. S. 234.

20) S. Werneck in Ammon's Zeitschrift für Ophtha?mologie. Bd. 5. - Bei Untersuchung der Augen ganz frischer oder auch lebender linochenfische ist mir die Existenz einer discreten Linsencapsel sehr zweifelhaft geworden.

21) Sic sind zum Theil als wirkliche Ciliarfortsatze beschrieben worden, wic 2. B. bei Haien, bei Thynnus, Sic kommcn anch beim Stör, beim llechte vor.

Handb, d. Zoolomic y. Siebolu u. Slannius, II. 
einen Punkt des Randes der hinteren Hemisphäre der Linse tritt, führt den Namen des Processusfalciformis ${ }^{22}$ ). An der Anheftungsstelle sowol dieser, gewöhulich pigmentirten, oft auch pigmentfreien Falte, wie anch an denen der sogenamnten Ciliarfortsätze an die Linse fundet sich nicht selten, obschon keiuesweges beständigg, cin hleines durchsichligges Knölchen ${ }^{23}$ ). Man hat diesen Gefïssfalten die Bestimmung zugeschrieben cin Suspensorium für die Linse zu bilden. Es lïsst sich aber nicht einsehen, wie ein solehes einem Fische zeitweise auf beislen Augen fehlen und zu anderen Zeiten wieder vorhanden sein soll. Allem Anseheine nach steht ihre Anvesenheit in nächster Bezichung zur Bildung und Ernenerung der Substauz des Glaskïrpers und namentlich der Linse. Dic nengebildete Linsensubstanz ungibt die hintere IIenisphäre derselben oft trichterförmig und lässt sich abschälen.

[Ueber das Auge der. Fische vgl: II aller, Opera minora. T. III. p. 250 sqq. Rosenthal, Zergliederung d. Fischanges in Reil's Archiv f. Physiol. Thl. X. S. 393. -W. Socmmerring, de oculorum sectione horizontali. Gött. 1818. fol. p. 62 squ Jurine, in den Mémoires de la société physique de Genève. Tom. I. Albers, in den Denkschriften d. Acad. d. Wissensch. z. München. 1808. - Vogt u. Agassiz, Anatomie des Salmones. p. 87. - Ueber die Entwickelung des Auges bei Coregonus handelt C. Yogt, Embryologie des Salmones. p. 73. sqq]

\section{\$. 75.}

Das Geruchsorgan der Fische besteht in einer melu oder minder faltenreichen, mit einem Epithelium belileideten Schlcinhantaushreilung, in welcher die Euden der Fibrillen der Geruehsnerven eingesentit sind. Diese Schleimhanlansbreitung liegl bald in eigenen häutigen oder knorpeligen Capseln, bald in Gruben an dem Vorderlheile des Schedels. Verhält-

22) Ich habe diesem Fortsatze seit einiger Zcit dauernde Aufmerksamkeit gevidmet und kann die aus allen vorhandenen Beschreilungen desselben sich ergebende Unbeständigkeit seines Verhaltens bestätigen。 Er kann temporär ganz fehlen. - Dic Gefässfalten bestehen bald aus Gefüsen und Pigment, bald enthalten sie zugleich Fasern, die man für Nervenfasern zu halten geneigt sein kann; hisweilen findet man darin nur P'igment und Crystalle. Iläufig liegen in der Umgehung Wasse durchsichtige, kernhaltige runde Zellen; sic finden sich mitunter der Länge nach bandförmig an einander gereihet, so dass sie eine Faser bilden. - Leydig, (Rochen und Haie. S. 26.) will in dem líütchen und in der von ihm atusgehenden Faserung einen Muskel erkennen, während ich darin nur in der Entwickelung begriffene Linsenfascrn zu erblicken vermag.

23) Bald ist diese durchsichtige l'roluheranz der Linse oder Linseneapsel, bald eine oft nicht mit der Linse zúsammenhangende, etwas rüthliche Anschwellung des Vorderrandes des Processus falciformis als C'ampanula Bulleri genommen worden, weshalb diese Bezcichnung im Texte vermieden wurde. RosenthaI, 1. c. S. 408. bezeichnet jene Protuberanz der Linse als ein hathmondförmiges Plätchen, welches der Linseneapsel anhingt und der Myaloüden des Galakörpers eine grössere Verbindungsfläche darbieted, 


\section{Vierter Abschnitt. Vom Nerrensysteme u. d. Simnesorganen, 179}

nissmässig selten findet eine Communication derselben mil der Rachenhöhle oder der Mundhöhle Statt. Das die Schleimhant auskleidende Epithelium trägt, wenigstens temporär, Cilien.

Das Geruchsorgan der L.eptocardii mol Marsipubranchii ist entweder unpaar oder wenigstens einfach.

Bei Branchiostoma ist eine über dem linken Ange liegende, ziemlich flache. becherförmigge Vertiefung beobachtet, die mit ihrem muteren spitzeren Theile dem centralen Nervensysieme umitlelhar aufsilzt. Die Concavitit des Becherchens ist mit Flimmerorganen besetzt und stehl mil der Mundhöhle in keiner Verbindung ${ }^{1}$ ).

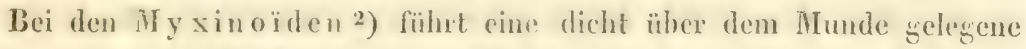
Oefhung in cine luftröhenartig von Kuorpelringen gestuilzte, lange Nasenröhre. Diese geht in eine gitterförmig vereinigle Knorpelfäden besilzende, Nasencapsel äher, welche an die vordere häulige Wand der Gehimeapse] sich anschliesst. Innerhalb dieser bildel die Schlemhanl Lïngsiallen. Vom Grunde der Nasencapsel führt sin unler der Hirneansel verlaufender häntiger Nasengammengang durch eine Oeffumng in die Mundhöhle. Hinter der

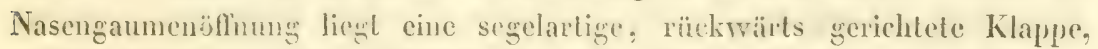
welche zur Ernenerung und Besfegung des in der Nasenhöhle cnthaltenen Wassers zü dienén scheint.

Bei Petromgzon fïhrt cin an dor Oberflïche des Kopfes mündendes, der Knorpelringe crmangelndes Nascurohe in eine cinfache, breite, knorpelige Nasencapsel, die an die vordere, häntigen. gerade Wand der Gehirneapsel sich ansehlicsst. In dieser hinteren Wand befinden sioh zwei dureh fibröse Nembran grschlossue Fontanellen, in dexen Mille die einfache Odrnung für den Eindriat der boiden Geruchsnerven liegl. wolche letzteren anch die Gehineapsel duxch vine cinfache, an deren Forderwand befundlehe, Oefl-

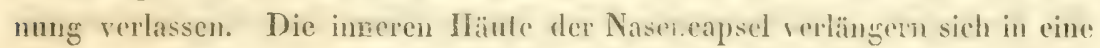
lange, an Ende blind geschlossene Röhre, welche den harlen Gammen durchbohrt, aber durch die mudurchbohrte Sinleimhant der Mundhöhle ron dieser lelzleren abgeschlossen ist.

Bei Ammoeoetes fiiht rine mit riner llanlfalle umgebene Oefinng an der oberen Seite des Kopfes in einen ror dem Vorderonde der Gohirncapsel und hinler der Oberlippe gelesenen hänligen Sack, in welehem innere Schleimhaulfalten rermisst sind, welcher aber gleichfalls in einen blind geschlossenen Naseugaumengang übergeht.

1) S. Kölliker in Müller's Arch. 1543. S. 32. Mit. Abb. - Quatrefages, in d. Ann. d. sc. nat. 1845. p. 226.

2) Abbildungen der Nase der Marsipobranchii bei Mïller, Vgl. Anat. d. Myx. Thl. I. Tb. 2. 3. 4. - In demselben Werke dic genaucsten vergleichenden Beschreibungen der Nasen disser Gruppe. 
Bei den Plagiostomen liegen die zur Aufnahme der Geruchsorgane bestimmten mit der knorpeligen Grundlage des Schedels in ununterbrochener Continuitat stehenden, theilweise durch Knorpel, theilweise durch häutige Theile gebildeten Gruben seitwärts unmittelbar vor den Augenhöhlen. Sie schliessen dem Processus orbitalis anterior und dem Boden der Hirncapsel sich an und jede besitzi eine nach der unteren Schnanzenfläche hin gerichtete einfache Oeffnung. Sie sind häufig durch häutige, von Knorpejn gestützle, durch kleine Muskehn beıvegliche Klappen verschliessbar. Der Nasenflügelknorpel ist meist mit dem Rande der Nasengrube an mehren Stellen verwachsen, seltener discret. Bei Myliobales und Rhinoptera kömmt in der Mitte einer beiden Nasen gemeinsamen Nasenklappe noch ein unpaares Knorpelstück vor.

Der Geruchsnerv tritt seitwärts, unmittelbar von der Schedelbasis aus in die Nasengrube. Diese ist ausgekleidet dureh cine Schleimhaut. Das Gerippe derselben bilden, von einer schrïg oder quer gestellten Axe oder Leiste aus, nach beiden Seiten hin auslaufende Falten.

Bei den Holocephali liegen die weiten tiefen Nasengruben numittelbar über der Oberlippe.

Was die Dipnoi anbelangt, so liegen die knorpeligen gefensterten Nasencapseln ${ }^{3}$ ), welche von viœr Längsspalten durchbrochen sind, seitlich am vorderen Kopfende. Die Schlcimhantausbreitung zeigt die Bildung der übrigen Fische, indem von einer Leiste nach beiden Seiten hin Falten ab. gehen. Jede Nasenhöhle setzt bei Lepidosiren durch zwei Oeffnungen in die Mnndschleimhaut sich fort und auch bei Rhinocryptis durchbohren die Nasenlöcher die Lippen.

Bei den Ganoïdei ${ }^{4}$ ) chondrostei und den Teleostei sind die Nasengruben gewöhnlich dicht vor dem Processus orbitalis anterior gelegen. Bei Accipenser und Spatularia liegen sie in einer Vertiefung des zusammenhangenden Schedelknorpels; bei den Teleostei in Gruben vor den Ossa frontalia anteriora. Die Eingïnge zu den Nasengruben bieten manche Eigenthümlichkeiten dar. Beim Stör und bei Spatularia ist über jete, sonst offene Nasengrube eine brückenförmige Leiste gespannt, die einen vorderen Auslïufer des peripherischen Nervenskeletes enthält. Bei den Teleostei, wo jede Nasengrube gewöhnlich von den beiden vordersten Schenkeln desselben Nervenskeletes umfasst wird, die selten ein wirkliches Dach über derselben bilden, wie bei Muraenophis ${ }^{5}$ ), führen gewöhnlich zwei

3) Vergl. Hyrtl, Bischoff u. Peiers.

1) Unter den Ganoidei holostei sind sie bei Lepidosteus ganz nach vorn an die Spitze der Kiefer gerüclit; auch bei Amia weit vorwärts. Sie werden bedeckt von Knochen, welche Röhren des Nervenskeletes euthalten. Beide Fische hesitzen die einfachen nach dem Typus der übrigen Fische gebildeten Nasenfalten.

5) Dieses Dach entstelit dadurch, dass von der äusseren, wie von der inneren 
äussere, an der Oberfläche des Kopfes gelegene Eingänge in dieselbe. Diese liegen bald sehr dicht neben cinander, bald aus cinander gerückt. Die vordere Oeffunng befindet sich nicht selten an der Spitze einer röhrenfürmigen Verlängerung, wie z. B. bei vielen Physostomi apodes. In dieser Gruppe wird die versehiedene Stelhung der Nasenlöeher für die systematische Charakteristik wichtig. Bei den Symbranchii liegt die vordere Nasenölfnumg an der vorderen Spilze des Kopfes, die hintere über dem Auge; unter den Muracnöldei ist die hiutere Oefnuug beim Aale elvas vor das Auge gerïckt, während bei anderen dieser Familie angehörigen Gathungen zvvar die vordere Oeffunng ihre gewöhuliche Lage beibehält, die hintere jedoch die Oberlippe durchbohrt und zwar entweder nach aussen mündet oder nach innen, und dann eine Communication der Nasenhöhle mit der Muudhöhle bewirkt ${ }^{6}$ ). - Die Zahl derjenigen Knochenfische, bei denen jede Nasengrube nur eine einzige, ̈̈ussere, oft weitc Oeffung besitzt, ist gering. Es gehören dahin namentlich viele Pharyngoguathi, wie die meisten Chromides, die Labroïdei ctenoïdei, nehre Scomber-Esoces. Eudlich enthält die Gruppe der Plectoguathi Gymnodontes Thiere, welche der Nasenlöcher gäuzlich ermangeln und statt der Nase, hautartige trichterförmige, oder ganz solide Tentakel besitzen, in welche (ler Geruchsuerv ausgehl ${ }^{7}$ ). Dic Ausbreitung der Geruchsnerven hat an einer Schleimhautausbreitung Statl. Diese überzieht gewöhulich eine derbere fibröse Grundlage. Idetztere bildet mil ihrem Ueberzuge Falten; diese gehen häufig von einem Centrum oder einer sehr kurzen Mittelleiste radienförmig nach der Peripherie und damn erhält das eigentliche Geruchsorgan eine mehr oder minder vollkommene Kreisfigur ${ }^{8}$ ); eben so häufig gehen die Falten auch von einer Längsrippe nach beiden Seiten hin in Reihen ab. Diese einfachen Bildungen können complicirter werden, wie z. B. bei Polypterus, wo in jeder Nasenhöhle fünf häutige Nasengänge um eine Axe gestellt sind, deren jeder in seinem Inneren die sonst einfach vorkommende Faltenbildung

Längs-Knochenröhre eine von zierlichen, queren gabelig getheilten Streifen durchzogene knorpelhäutige Membran ahgeht; beide bilden ein Gewölbe von dessen Mitte eine pigmentirte frei endende Falte in die liöhle des Geruchsorganes sich einsenlit.

6) Ueber diese bereits van Cuvier im Allgemeinen angedeutete Eigenthümlichkeit vgl. Lütken, Nogle Bemaerkninger om Naeseborenes Stilling hos dei Gruppe med Ophisurus staaende Slaegter of Aalefamilien. Abdruck aus: Videnskabelige Meddeleser fra den naturhistoriske Forening ; lijöbenhavn for 1852. Der Verfasser bildet aus diesen Aalen seine Familie der Ophisuridae. Die Communication mit der Mlundhöhle hat z. B. Statt bei Chilorhinus Suensonii, Ichthyapus acutus.

7) Ueber diese von Cuvier im Allgemeinen angedeutete Eigenthümlichkeit siehe einige weitere Bemerkungen bei Müller, Vgl. Anat. d. Gefisssyst. d. Myxin. S. 7S.

8) Beim Stör z. B. gehen die Falten, 23 an der Zahl, von einem Centrum radienartig aus, doch bilden sic keine regelmässige Kreisfigur, denn die oberen sind kiirzer als die unteren. 
zeigt ${ }^{9}$ ). - Einem anderen Typus folgt aber die Nascubildung melrer Scomber-Esoces. Bei Belone z. B. erheht sich von der Milte der ïbriģens ziemlich grlatt ausgekleideten weilen Nasengrube, cinrm Pilzhule ungefïh vershleichbar, ein anf dem cintrucuden Goruchsncrven slicharlig befestigter, unregelmässig gestalteter, etwas gelappter Schleimhautwulst.

[Ueber das Geruchsorgan der Fische vgl. II a r wood, System der vergl. Anatomie. IIft. 1. Uebers. von Wiedemann. Berl. 1799. 4. Scarpa, de auditu et olfactu. Ticin. 1798. 4. - Blainville, Principes d'Anat. comparée. T. I. - ]

\$. 76.

Als Geschm acksorgan möchle die Zunge der meisten Fische sehwerlich zu betrachlen sein, und ob äberhanpl der Geschmackssim bei diesen Thieren entwickelt ist, blcibl urst zu crmiltelu. - Besondere Tastorgane scheinen dagegen Vicle zu besilzen. D)athin mörhlen z. B. zu rechnen sein die seln empfindlichen Labialpapillen ron Pelromyzon ${ }^{1}$ ), die vielfach z. $\mathbf{B}$. bei Cyprinoïden. Silurö̈den, Gadoüden, beim Stör u. A. vorkommenden Bartäden, welche bei cinigen dieser Fische, z. H). beim Vicls, anch dureh eigene betriblitiche Muskeh bewegl werden. Ob die sogenannten fingerförmigen Anhänge der Trighac und Polynemi dahin zu rechnen, bleibl. zweifelliaft.

9) Müller hat hierauf aufmẹrksair gemacht.

1) Ihr Bau hat im Aligemeinen grosse Achnlichkeit mit den Papillen anderer Organe bei anderen Thieren, namentlich mit denen der frosclizinge. Auch das Verhalten der Gefïssschlinge ist wesentlich übereinstimmend. Sie sind mit cinem Ejpithelialüberzuge besetzt, dessen Zellen in beständiger Eneuerung begriffen zu sein scheinen.. In manche dieser gestielten Zellen ragt ein kurzer cylindrischer ziemlich starer hörper hincin. Diesen erkennt man nicht selten als zusammenhangend mit einem ausserhalh, der Zelle verlängerten, hisweilen diese sellst an Länge ühertreffenden Fädchen, das demnach in der Zelle frei endet. Nach langen vergeblichen Studien über die Endigungsweise der Nerven in den sehr emplindlichen Papillen bin ich zweimal zu Anschauungen gelangt, welche jene in Zellen endenden Fortsilze als Nervenendigungen micli ansprechen lassen. Ich erblickte nämlich melire derselben, gleich den sic umgebenden Zedlen, in Zusammenhang und als Ausliufer ciner Fibrille, die allem Anscheine nach nur für eine Nervenfibrille genommen verden konnte, wenn schon die Erkenntniss ihres Ausganges von grösseren Nervenüsten mislang. 


\section{Fünfter Abschnitt.}

\section{Von dem Verdunungsupparate und den ilme anhangुenden Gebilden.}

\section{Von den Viscerallı̈̆hen.}

\$. $7 \%$

Die Visceralhühle der Fische zerfillt in zwei grosse, hinter einander welegene Abtheilungen. Die vordere dersedben bildet die Ml und- nud Kiemenhöhle. Lelztere, unterhalh der Rachenhöhle oder selbst der ganzen Speiseröhre grelegen, communicirt mit diesen vordersten Alschmilten des Tractus intestinalis. Meistens ist diese Communication eine unmiltelbare, indem die genannten Abschnilte des Munddinmes selbst von den Pori branchiales interni durchbrochen werden; seltentr eine mittelbare, wie bei Petronyzon, wo nur eine von der Mundhöhle ansgehende, unter der rigentlichen Speiserühre hinterwärts sich epstreckende, hinten blind endende Ausstülpung (Bronchus) ron den Pori branchiales interni durchbrochen ist. - Längs der Ventralseite der Kiemenhöhle erstreckt sich, oft eigenthümlich fixirt, das gemeinschaflliche Kicmenarterienrohr, das aus dem hinter ihn gelegenen Herzen hervorgeht. Dieses liegt zwisehen den Grenzen der Kiemenhühle und Banchlı̈hle, unter dem oft, z. B. bei den Plagiostomen, duch einen die Copulue des Kienengerüstes nach hinten verlïngernden Knorpel gestiitzlen, vorderen Theile des Traetus intestinalis und zwar so, dass sein Kinmenarterientheil (Bulbus arteriosus und Kammer) zumeist eine ventrale Laige hat, wihrend sein Vorthof und der in ihn übergehende Sinus venosus, welcher dureh die quer absteigenden Duclus transversi vertebrale und in den Lebervenen visecrale Gefïsse aufnimml, mchr anfwirls liegl. Wo ein Sehultergürtel ausgehildet ist, liegt das Iterz gewöhnlich zwischen dessen Sehenkeln, sellen, wie bei manchen Physostomi apodes, besonders den Symbranchii, erst weiler nach hinten. Bei einer Gruppe der Fische, der der Marsipohranchii hyperotreti, wied das Kiemenartericnroln, nebst der Jferzliammer, von einem eigenen, hinten weiteren, vorne verenglon, unterhalb der ventralen Srite der Kiemensäcke gelegenen bäntigen Sehlauche unschlossen, welcher mil Oeflimugen zum Durchtritte der cinzehnen Kiemenarterien versehen ist 1). - Die zweile, hintere Abtheilung der Visceralhöhle ist die eigentliche Banchhöhle, von der Kiemenhühle durch das zrrischengeschobene Herz und dessen Umhüllmugen getremnt. Vom Bauchfelle umschlossen, das nur selten, wie bei den Petromyzonten, gänzlich rermisst wird, übrigens aber wieder schr grosse Terschiedenheiten

1) S. Müller, Myxinoiden Thl. 1. U. 4. 
darbietet, dient sie zur Aufnahme des beträchtlichen, jenscits des Munddarmes gelegenen Abschnittes des Darmrohres und der ihm adjungirten drüsigen Gebilde: der Leber, des Pancreas und der Milz, so wie auch der Geschlechtstheile. Eine Veriängronng der Bauchhöhle über den Bereich der Rumpfgegend hinaus, zwischen den Träigern der Afterflosse und deren Muskeln, in welcher dann das Orarium und cin Theil des Darmcanales zu liegen pflegen, kömmt in einer Familic, der der Pleuronectides häufig vor. - Bei manchen Fischen ivird dagegen eine durch eigene Oefinungen oder Gänge bevirlite Comm unication der Peritonealhöhle mit der Höhlung des das Herz umschliessenden Beutels beobachtet. Bei den Myxinoïden und bei Ammococtes wird der Herzbeutel selbst durch cine Fortsetzung des Periloneum gebildet und hangt mit der Banchhöhle offen zusammen ${ }^{2}$ ) - eine Eimrichtuug, die bei Petromyzon fehlt, weil hier cine Fortsetzung des knorpeligen äusseren Kimmkorbes den für das Herz bestimmten Raum von der Bauchhöhle abgrenzt. - Bei den Plagiostomen und bei Accipenser ${ }^{3}$ ) findet eine Communication des Herzbeutels mit der Bauchhöhle durch einen miltleren, das Diaphragma durchbohrenden Canal Statt. Dieser theilt sich in der Banchhöhle in zwei Canäle, welche vor dem Magen sich öffnen ${ }^{4}$ ).

Sowol bei cinigen der eben namhaft gemachlen Fische, als auch bei einigen Anderen, ist die Bauchhöhle frei nach aussen geöfnet durch einen einfachen, vor dem After gelegenen Porus, oder durch parige, zu den Seiten des Afters gelegene Poriabdominales, welche ausser und neben den Oeffumngen der Ausführungsgänge der Geschlechtstheile vorkommen. - Ein einfacher vor dem After, je nach Versehiedeuheit der Individuen bald rechts, bald links, immer also asymmetrisch gelegener Porus abdominalis kömmt von bei Rhinocryptis. Paarige zur Seite des Afters gelegenen Pori sind vorhanden bei allen Plagiostomen ${ }^{5}$ ) und mehren Ganoïden ${ }^{6}$ ). Sie scheinen bei jenen blos dic Bestimmung zu haben Wasser in die Bauchhöhle eintreten zu lassen, während

2) S. nähere Angaben bei Müller, Gefässsyst. d. Myxin. S. 1.

3) Nach Flimmerbewegung in diesem Canale sowol, als im Herzbeutel habe ich bei Accipenser zu verschiedenen Zeiten vergeblich gesucht.

4) Abgeb. bei Il onro, Vergl. d. Baues d. Fische. Tb. 2. Fig. 1. von Raja.

5) S. d. Abb. bei Monro, I. c. Tb. 1. Fig. 5. u. Tb. 8.

6) Bei den Ganoïlei chondrostei waren sie längst bekannt, bei Accipenser schon von Monro abgebildet; bei Lepidosteus sind sie durch II üller aufgefunden; ihres Vorkommens bei Amia und Polypterus gedenkt IIyrtl, Sitzungsber. d. Acad. d. Wiss. zu Wien. 1852. S. 179. Bei Polypterus sollen sie, nach IIyrtl's Meinung, zur Ausführung des Samens dienen. - H y rtl, (Beiträge z, Morpholog. d. Uro-Genital-Organe d. Fische. Wien, 15.9. S. 11. Tb. 2. Fig. 6. d.) hat anch bei Mormyrus oxyrhynchus innerhalb der Afterhöhle, unmittelbar über dem Afterrande ausnündende, durch Schleimhaulfalten gedeckte Pori peritoneales beobachtet. 
sie bei letzteren vielleicht auch zur Ausführung des Samens oder' auch der Eier bestimmt sind.

Eine Oeffung, welche weder in die Darmhöhle, noch in discrete Ausfühungseanäle der Gesehlechtstheile sich fort. setzt, sondern aus der Banchhöhle nach aussen führt, dient manchen Fischen zur Ausführung der Eicr und des Samens, die, unter Mangel ausführender Genitalgänge, aus den keimbereitenden Geschlechtstheilen austretend, frei in die Bauchhöhle fallen. Dahin gehört der hinter dem After ausmündende Porus genialis bei beiden Geschlechtern aller Narsipobranchii, Ob ein soleher bei den Salmones, den Galaxiae und Hyodon, wo der IIoden eigene ausführende Canäle besitz, dem weiblichen Geschlechte zugeschrieben werden darf, ist, nach neneren Untersuchnugen von Hyrtl, zweifelhaft ${ }^{7}$ ). - Verwandt ist eine bei Branchiostoma weit vor dem After, in der Mittellinie des Bauches gelegene, von zwei seitlichen Lippen eingefasste Oeffunng, welche als Porus respiratorius externus der Kiemenhöhle und zugleich zur Ausführung der Eier und des Samens dient.

\section{Vom Verdauungsapparate und seinen Auhängen.}

S. 78.

Die Mund- und Rachenhöhle der Fische bietet manche Eigenthümlichkeiten und Verschiedenheiten dar. Einige derselben sind folgende: Bei Branchiostoma ist die Mundhöhle ron der Kiemenhöhle durch eine hinten mit beweglichen Anhängen beselzte Falte abgegrenzt. Vor der Mundhöhle und im Innern derselben kommen sehr eigenthümliche fingerförmig gestellte Räderorgane vor, deren schwach vorragende Flächen mit Wimpern besetzt sind. Durch das Spiel dieser Wimper gelangen Stoffe in die Mundhöhle und aus dieser in die Kiemenhöhle.

Bei den Plagiostomen und bei Accipenser liegt die Mundöflinung unterhalb der Schnanze - ein Bildungsverhältniss, das deshalb Interesse be. sitzt, weil es bei Knochenfischen, in weleher Gruppe ein analoges Verhalten übrigens chenfalls perennirend bei den Loriearinen angetroffen wird, sonst als transitorisches Entwickelungsstadium wahrgenommen ist ${ }^{1}$ ). - In der Mundhöhle mancher Plagiostomen liegt hinter dem Kiefer-Apparate eine segelförmige Falte; bei einigen erheben sich auch hinter dem Unterkiefer

7) Beim Aal findet sich hinter dem After cine in einer Vertiefung der Ilaut liegende Oeffnung, welche nicht blos das Orificium urethrae aufnimmt, sondern in zwei trichterfürmige kurze Canile fuhrt; jeder dieser in die Bauchhühle fubrenden Canäle ist zur Ausführung der Eier bestimmt. Rathke, (Wiegmann's Archiv für Naturge sch. 1838. ThI. I. S. 302.) hat diese Canäle zucrst beschrieben.

1) S. Vogt, Embryol, d. Salmones. p. 172. Abb. Fig. 86. 154. 
eigenthümliche Papillen, - Die Rachenhöhle der meisten Plagiostomen und cinigor Ganoüden conmunicirt mit der äusseren Oberfläche des Kopfes durch parige vor der dorsaleu Insertion des Kiefersuspensorium nach anssen ge. äfnele Gïnge: die Sprilzlöeher. The äussere Oeflnung ist bei vielen Plagiostomen dureh eine Klappe verschliessbar; ihre Wand wird oft dureh cinen eigenen, meist einfachen, selten doppelten Knorpel gestützl; in ihrer äusseren Circumferenz findet sich bisweilen cin Kranz ron Zacken. Bei wenigen Plagiostomen, wie bei den Carchariae und Triacnodonles, fehleu sie ganz oder sind nur in Fötalzustande ${ }^{2}$ ) vorhanden und bei erwachsenen Thieren findet sich dann nur cin von der Rachenhöhle ausgehender, nach aussen nugeïfneter Gang. - Von der inneren Wand des Spritzlochscanales gelıt bei einigen Plagiostomen ein Seitencanal ab, dessen blind erweitertes Ende anf der Scitenwand des Schedels liegt, da wo in dessen Substanz das Gehörorgan gelagert is! ${ }^{3}$ ). - Was dic Ganoïdei anbetrift, so kommen Spritzlöcher nicht allgemein vor; während Accipenser; Spatularia. Polypterus sic besitzen, ermangeh ihrer die Gathungen Seaphirhynehus, Lepidostens, Amia. Bei Polypterus ist jedes Spritzloch von einer aus drei IIaulknochen gebildeten Klappe auswendig bedechi. Den Teleostei fehlen sie allgencin. - Bei Thieren dieser grossen Gruppe erseheint eine segelfärmige Falte hinter dem Oberkiefer-Apparate häufig wieder. Wähend Speicheldrïsen den Teleostei, gleich allen äbrigen Fischen, durehaus zu fehlen scheinen, findel sich bei der Gattung Searus zu jeder Seite des os pharyngeum inferins, eine mil Papillen reichlich beseizte taschenartige Einstülpung der Schleimhant, welehe wahrscheinlich als absonderndes Organ zu betrachten ist ${ }^{4}$ ), - Sehr bemerkenswerth ist das contractile Gaumenorgan der Cyprinö̈len ${ }^{5}$ ), unter der Schedehasis, zwischen und unter den Ossa pharyngea superiora gelegen, ans quergestreiften Muskelfasern gebihlet, welche aus den Bahnen der N. N. vaģus und gglossopharyngeus mil Nervenfïden reichlich versorgh werden. - Das hiiulig nit derber Bekleidung versehene, oft mit Zähuen beselzle, sclten weiche und - fleischige Znugenrudiment dürfte zur Vermittelung von Geschmacksenpfindung wenig geeignet sein. - Bei den meislen Fischen, na-

2) Müller hat Spuren davon gefunden hei den Galtungen Prionodon, wo ich sie ebenfalls kenne, und bei scoliodon. S. Ueber d. glatten Ilai des Aristoteles in d. $\mathbf{A b h}$. d. Berl. Acad. d. Wissens. 1840. S. 249.

3) Müller traf ihn an bei Scyllium, Pristiurus, Mustelus, Galeus, Rhinobatus und Syrrhina und meint, er müsse die Schallwellen des Wassers direct anf den Schedelknorpel leiten. Gefüsssyst. d. Myxin. S. 79.

4) S. Cuvier u. Valencionnes, hist. nat. T. XIV. p. 157.

5) S. die Bemerkungen über dasselbe von E. H. Weber in Heckel's Archiv f. Anat. u. Physiol. 1827. S. 309. und von Ed. Weber im IIandwörterl). für Physiol. Thl. III. Nhth. 2. S. 29. 
mentlich aus den Ordnungen der Ganoülei und Telcostei, ist der concave, der Rachenhöhle zugewendele Ranl der Kiemenbogen mil Knochen, Tuberkelı, Zïhnen, Borsten, die bisweilen, wie z. B. bei Spatularian eine ganz ausserordentliche Länge creichen, beselzt. Diese ansserordentlich mannichfachen Besälze der genamnlen G(bilele sind rorzüglich dazu bestimml, das Eindringen von Speisen und anderen fremden Körpern aus der Racheuhöhle in die Kiemenspalten zu verhindern.

Bei einigen Teleoslci, z. B. Coltus, findet sich, parallel dem os pharyngeum superius des ersten Kiemenbogens nud ror ilum, noch eine Reihe von Zacken, denen ein gallertartiges, Bindegewchsfibrillen cullablendes Blastem zu Grunde liegt.

\section{\$. 79.}

Während es einerseils Fische gibt, welche der zam Ergreifen und Festhalten der. Speisen dienenden Zähne gänzlich crmangeh, bieled andererseits das Zahnsystem, wo es vorhanden, eine so ansserordenlliche Mannichfaltigheit seiner auf Inserlionsstellen, Zahl, Form, Terbindung, Textur und Ersetzung beä̈glichen Verhälnisse dar, wie sie in sämmllichen iubrigen: Wirbelthierelassen nicht, wiederkehren.

Durch gänzlichen Mangel ron Zähnen ausgezeichnet sind z. B.: Branchiostoma, Ammocoetes, Accipenser. und unter den Teleostei die Familie der. Lophobranchii, die Chupëden-Gattung Chatoessus, die Salmoniden-Gatlumg Coregonus ${ }^{1}$ ), dic Siluroüden-Galtung Iypophlhahmus, dic CharacinenGattung Anodus, die Sciänoïlen-Gattiung Macquaria.

Bei einzehen Fischen liommon Zähne in solehen hänligen Gebilden ror, welche gar nieht an hinvehen sich aulehnen. Abgesehen von den auf der Schleimhaut des Oesophagus bei cinigen Scomberö̈don 2) beobathtelen zahnartigea Bildnngen, gehören dahin z. B. die Mundschleimhantzähne des Bagrus genidens ${ }^{3}$ ), die Labialzähne von Petromyzon, von Rhynocryplis, von Helostoma 'Temminckii '). Sehr häufig kommen Zaihne an solehen

1) Interessant ist für die Erkenntniss des planmässigen Vorkommens der Zähne die Beobachtung ron C. Yogt, (Embryol. d. Salmon. p. 173.) dass die Embryonen von Coregonus vorspringende conische hakenförmige Zälıne an der Basis Cranii, an den Ossa pharyngea und am oberen Anlinge der kípmenbogen besitzen, so dass also die Uebergangstelle der Hundhöhle in den Tractus intestinalis mit Zähnen besetzt erscheint. S: d. Albb. Fig 166. 167. Dies wiederholt sich ofter. Auch jüngere Individuen von Spatudaria sollen Zihne besitzen, wahemel sie bei ausgewathenen Individuen spurlos mangein.

2) Dahin gehören die Gattuingen lhombus, Stromateus, Sescrinus.. S. Cuvier et Valenc. Tom. IX. p. 406, - Ibid. p. 412. - p, 381. Solche zahnartige Gebilde hatte Cuvier auch Tetragonurus zugeschrichen; Valencicnnes, Vol. XI. p. 184. leugnet sie hier und findet im Oesophagus nur zahlreiche, Iange, weiche Papillen.

3) S. Valenciennes in d. Hist. nat. d. poiss. Vol: XIV. p. 453.

t) S. Cuvier et Valenc. Hist, nat. d. poiss; Vol. VH. p. $34 \%$. Verwand und 
häuligen Theilen vor, welche gewissen Knochen blos anliegen oder sie überziehen. So ruhen die Zähne der meisten Plagiostomen auf fibrösen Platten, welche, ohne in die Knorpelsubstanz eimzudringen, längs der Kiefer befestigt sind. So kann man auch bei vielen anderen Fischen die Schleimhautausbreitung, von welcher sie sich erheben, wegnehmen, ohne den Knochen selbst zu berïhren. Es sind nämlich alle Zähne Gebilde, welche primitiv dem IIautsysteme und zwar dem Schleimhautsysteme angehören und von diesem aus erst secundär mit den Knochen sich zu verbinden pflegen. Diese Verbindung geschicht oft dadurch, dass das Gewebe zwischen der Basis des Zahnsackes und dem unterliegenden Knochen ossificirt.

Es können nun selır versehiedene Knochen zahntragend sein; näınlich ausser dem $\boldsymbol{O}$ s denlale des Unterkiefers, der Zwischenkiefer, der Oberkiefer, die Gaumenbeine, die Ossa plerygö̈den, der Vomer, der Keilbeinkörper, die Mittelstïcke des Zumgenbeines, Theile der Kiemenbogen, die Ossu pharyngea inferiorce und superiora: also, mil Ausnahme des Keilbeinkörpers und des Vomer, nur Kuochen, welche dem Visceralskelete angehören, oder ihm rerwandt sind. Dass aber Vomer und Sphenoideum basilare zahntragend sein liönuen, ist um so weniger als Anomalie zu betrachten, als die Zühne in dem häutigen Ueberznge dieser, die paarigen Gaumenstïcke trennenden Knochen sich entwickeln und in die Corticalsubstanz lelzterer blos secundiar sich einsenken. - Bei den Cyprinen ist auch dem Os basilare occipilis cine eigenthümlich gestaltete Zahnplatle eingefügt. Die Zahn-ïnnlichen Theile der Schnauze der Gattung Pristis, welehe die Säge bilden, kann man vielleicht eben so gut, als den Zähnen, den von der IIaut so vieler Rajidae sich erhebenden Stacheln vergleichen, da diese Jetzteren, auch wenn sie am Kumpfe und Schwanze vorkommen, in ihren wesentlichen Texturverhältnissen von den Zähnen nicht verschieden zu sein pflegen.

Bei weitem nicht alle genamuten Knochen sind aber bei allen Fischen zahutragend. Bald gruppiren sich die Zähne wie z. B. bei den Plagiostomen nur um die Circumferenz der äusseren Mundöffnung, indem sie dem Verlaufe von Ober- und Unterkiefer folgen; bald kommen sie, wie bei den Cyprinen, nur an der hinteren Begrenzung der Mundhöhle vor, indem in dieser Gruppe, mit Ausnahme einer eigenthümlichen Zahnhildung am IInterhauptsbeine, Zähne nur an den Ossa pharyngea inferiora vorhanden sind. Andererseits kam fast dic ganze Mundhöhle damit besetzt sein, wie bei den Salmones, Esox uud manchen Clupeìdae, bei welchen fast alle vorhin genamiten Knochen zahntragend erscheinen.

doch wielerum ganz eigenthümlich scheint die von Valenciennes (Vol, XXII. p. 52.) uäher geschilderte Zahnbildnng der Gattung Parodon zu sein. 
Die Befestigungsweise der Zähne an den Knochen ist da, wo sie wirklich an solchen fixirt sind, und nicht blos durch fibröse 'Theile an ihnen haften, mamnichfach beschaffen; bei den meisten Knochenfischen sind sie durch ihre ossificirte Basis mit dem unterliegenden Knochen verwachsen; bei anderen erhebt sich in die Zahnhöhle ein Fortsalz oder Zapfen vom Knochen ans, wie z. B. bei Anarrhichas. Bei anderen findet eine Einkeilung innerhalb wirklicher Alveolen Statt, in welchem Falle aber wiederum ein Zapfen in die Basis der Zahmhöhle sich erstrecken kann, wie z. B. an den Schneidezähnen von Balistes. Eine eigenthümliche Bildung bieten die Myliobates dar; ihre Zähne bestehen in der Mitte aus einer Reihe von Platten mit beträchtlichem Querdurchmesser. An den Seiten greifen kleinere, viereckige, pflasterförmige Stücke in die Lücken der mittleren Platten ein.

Form und Umfang der Zähne sind ansserordentlich zahlreichen Variationen unterworfen. Bisweilen wechselt die Form nach dem Alter oder bietet, je nach dem Geschlechte, Verschiedenheiten dar ${ }^{5}$ ). Bei Arten der Gattung Chrysophrys werden z. B., nach Cuvier's Bcobachtungen, die runden Zähne in gewrissem Alter durch ovale ersetzt. - Am häufigsten haben die Zähne die Form cines Cylinders, eines Kegels oder eines mehr oder minder spitzen Hakens. Ganz kleine Zähne, zahlreich über eine Fläche verstreuet, erscheinen blos als Rauhigkeiten derselben. Wenn cylindrische oder zugespitzte Zähne, schr dümn und fein und dabei in grosser Zahl neben einander stehend, so kur'z sind, dass sie leichter durch das Getast, als dureh das Gesicht wahrgenommen werden, nennt Cuvier sie „Dents en velours" (Dentes villiformes). Sind die cylindrischen oder zugespitzten Zähne etwas länger, so ähnelt die damit besetzte Fläche einer Raspel: „Dents en rápe" (Dentes raduliformes). Verlängern sich die cylindrischen Zähne noch mehr und sind sie dabei weich und biegsam, so erseheinen sie horstenförmig: Dentes seliformes. - Zühne von conischer Gestalt sind oft so klein und so zahlreich, dass die damit besetzle Fliche cin granulirtes Ansehen erhält.

5) Bei der Gattung Raja verdienen nach Müller u. II en le (Plagiostomen p. VIII.) die Zähne nur eine untergeordnete Berücksichtigung als Art-Kennzeichen, weil sie, je nach Alter und Geschlecht, verschieden sich verhalten. In der Regel sind sie in der Jugend stumpf; manche Arten erhalten während des Wachsthumes in beiden Geschlechtern spitze Zahne; bei anderen behält das Weibchen, noch erwachsen, stumpfe Zähne, während die der Männchen zu der Zeit, wo sie geschlechtsreif werden, spitz. werden und von da an ferner spitz beiben; aber der Zeitpunkt der Verwandlung der stumprìn Zähne in spitze variirt zuweilen in Beziehung auf die Grösse der Individuen. Denn sie sahen zuweilen von einer Species männliche Individuen von gleicher Cirösse, wo die Zähne in dem cinen Falle, so weit sie nach aussen sichlbar waren, noch ganz stumpf, in dem anderen schon alle spitz und lang waren. - Altersverschiedenheiten zeigen auch die Zähne mancher Ilaic, s. z. B. die $\Lambda$ bl). derselben von Prionodon glaucus bei Miller und II enle. I. c. Tb, 10. 
Bei einigen Fischen, z. B. bei vielen Rajidae, sind die einzelnen Ziihne, Pflastersteinen ähnlich, an cinander gehagert. Bei Anderen stehen grössere conische Zïhne fiei.

Ilakenförmige Zühne kommen oft vor, z. B. stark gekrümmt bei Chauliodus; sie künnen mit Widerhaken rersehen sein, wie einige Zähne bei Trichinus.

Den menschlichen Sehneidezilhnen ähnlich sind die meisselförmigen vordersten Zähne im Zwischenkiefer und Unterkicfer von Sargus and Charax. Die Schneide kann wieder ge'zïhnelt oder gezackt sein, wie bei Acanthurus. Die Zïhne künnen an ihren Seiten gezzïhneìt und ansgezackt sein, bald eiumal, bald viellach, wie bei vielen Srqualidae und bei Serrasalmo.

Bei der Mehrzahl der Fische fundet ein fortwährender, nicht auf beslimmte Lebensstadien beschnänliter Wechsel der Zähne Statt. Gewöhnlich liegen hinter oder anch neben deil in Gebatuch begrifenen Zühnen die Ersatzzälne, welche z. B. bei manchen IIaien, noch harizontal oder abvïrts gerichtet sind. Wenn die Zähne in IÏ̈hlen cingeschlossen sind, so finden sich über oder mer diesen, die flöhlen, in denen die Entwickelung nener Zähne geschicht. Bei der Mohrzahl der Teleostei geschicht die Entwickelung der nenen Zähne in Säckchen, welehe ron der Schleimhaut der MImondhöhle gebildet werden. Bei den Plagiostomen sind es gewöhnlich freie, in ihren Umrissen den Zïhnen ähnliche Schleimhantpapillen, welche zu diesen Hartgebilden crystallisiren.

Die Textur der Ziihne ist sehr verschiedenarlig. Die Zälune der Marsipobranchii bestehen aus Ilorusubstanz. In ihrem Bane ahnlich scheinen die elastischen und biegsamen Zähne der Gathmgnn Trichodon, Chactodon und der Loricarini zu sein. Bei leizteren sind sie lang: dünne, biegsam und endigen in Maken. - Die knochenharten Zähne der Mehrzahl der Fisehe zeigen wieder cine versehiedenartige Znsammensetzung. Die Grundsubstanz der meisten bildet ein Zahnbein. mit weilen und zahlreich verästelten Rïhrehen, die oft netzartigy zusammenhangen. Die ganze Masse solcher Zailme kann ghleicharlig sein, oder sic sind auswendig von festerer, Elfenbeinarliger Substanzschicht überzogen. Eine dem Schmelze ähnliche Schicht, jedoch der Schmclzprismen ermangehnd, ist bei Sargus und Balistes wahrgenommen. An ihrer Basis besilzen manche Zilhe, uamentlich bei Balistes, eine dem Caementum der Sängethicre verwandte Substanz. Die Zähne sind entweder mil einer, die Matrix aufinchmenden, Höhle versehen, oder - häufiger - solide. In ersterem Falle strahlen von der Höhle zahlreiche Canüle ans, welche unter beständiger Verästelung nach der Peripherie hin, sich allmälich verengern. In die soliden Zälne erstrecken sich meist netzfürmigg verbundene Canïle, welche unmiltelbare Fortselzungen derjenigen der entsprechenden Kieferknochen sind. Einige Zaihne sind so angeordnet, dass Complexe ron Caniten men Gefässen iso- 
Fünfter Abschnitt. Von dem Verdanmusapparate etc. 191

Int verlaufen, jeder ron eiuer Schicht Elfenbein und Cäment umgeben, so dass ein anscheinend cufacher Zahn aus zahheichen Zühnchen zusammengesetzt ist.

[Ueber die Zähne der Fische s. reichhaltige Bemerlungen in den Schriften von Cuvier, so vie bei Agassiz in den Poissons fóssiles. Ueber ihren feineren Bau vgl. Retzius in Mïller's Archiv. 1837, so wie auch 0 wen, Odontography. Lond. 1810 sųq. E.]

\section{\$. 80 .}

Eine Uebersicht der Verschiedenheiten in der Bildung des Tractus intestinalis, welehe in Folgendem gegeben ist, fiihrt zu den Resultale, dass nicht bei allen Fischen diejenige Sonderung desselben in Speiseröhre, Magen, Dünndarm und Dickdarm, welche bei höheren Wirbellhicren vorkömmt, anzutreflen ist. - Das Rectum mündet bei den Fischen bald durch ein frei zu Tage liegendes Ostium direct nach aussen, wie bei den Cyclostomen, Ganoülei und Teleostei, hald in eine Cloake, die, ausser seiner Oeffnung, noch die Mündungen der Geschlechts- und Harnverkzenge aufnimml, wie bei den Plagiostomen und den Dipnoi. Ein durehgreifender Charakter der Fische ist der, dass die Mïndung des Mastdarmes niemals hinter der Mündung der Harnwerkzeuge liegt.

Bei Branchiostoma setzl der Kiemenschlauch in die liurze, enge canalfürmige Speiserühre sich fort, welche in den viel weiteren Darm sich öfnet. Von diesen geht sogleich ein, als Leber sich eharakterisirender, langer, grïu gefïbter, an der rechten Seite des Kiemenschlanches gelegener Blindsack ab. Der Darm verengt sich nach hinten allmilich, besonders hinter dem Porus abdominalis, wo er enger von den Leibeswänden umschlossen wird. Er hangt der Rückenwand der Visceralhöhle ohne Gekröse an. In Iunern des ganzen Darmschlanches, nit Einschluss des Blindsackes, ist Flimmerbewegung beobachtet worten. Der After lient asymmetrisch an der linken Seite.

Bei den Marsipobranchii hyperolreti liegt der vorderste $\Delta b$ schnill des Darmrohres dicht muter dem Axentheile des Wirbelsystemes, anfangs ïber dem Mushelkörper der Zunge, weilerhin ïber der Kienengegrond. Er nimmt die Duchus branchiales oesophagei der Reihe nach ant. Ilinter dem letzten derselben geht ron der Speiserihre ein cigchthinmlicher weiter Duclus oesophago-cutaneus linkerseits nach aussen und unten, der bei Bdellostoma, in Gemeinsehaft mit dem lelaten linken äusseren Kiemengange, in das entsprechende lelzte Stigma branchiale cxtermum, bei Myxino mit allen äusseren Kiemengängen in das Stigma cxlernum der linken Seite ansmündel. Dann geht dic Speiseröhre, nach eincr mbedertenden Einschnürung: in den elwas weileren, in der banchlöhle gelegrnen Ahschnill des Tructus inlestinalis üher. Dieser verlïult, an rinem Geliröse befestigl und ̈̈berall gleichnässign weil, bis zu dem, an Ende dex bauchhöhle gele- 
geneu After. Mit Ausnahme einiger niedriger Längsfalten ist seine Imnenfläche glatt und ermangelt sowol der Flimmerorgane, als einer Spiralklappe.

Bei Petromyzon liegt unter dem Axensysteme der Wirbelsäule und über dem die Ductus branchiales interni aufuehmenden, hinten geschlossenen, vorne mit der Rachenhöhle communicirenden Bronchus, den umgebenden Gebilden eng angeheftet, die lange, enge, röhrenförmige Speiseröhre, welche inwendig zahlreiche und dichtstehende, breite von rechts nach links absteigende, freic Lïngsfalten besilzt. Sie ist an der Grenze der Banchhöhle von dem übrigen, gerade hinterwïrts verlaufenden, frei in der Bauchhöhle schwebenden, durch ein Gekröse nicht befestigten, windungslosen Darmrohre mittelst einer Schleimhaulfalte abgegrenzt, welche in eine, durch den grössten Theil des letzteren bis zum kurıen Rechum sich hinziehende, Längsfalte sich fortsetzt. Diese Längsfalte zeigt bei der Lamprete einen sehr schwach gewundenen Verlauf; in ihrem freien Rande liegt die Darmvene. Der Eudtheil des hintersten, dem Rectum entsprechenden Darmabschnittes ist an einer sehr kurzen und schmalen medianen Falte suspendirt, innerhalb welcher Gefässe zu ihm sich begeben.

[S. Naheres in den oft genannten Schriften von J. Müller und Rathke.]

S. 81 .

Bei den Elasmobranchii führt die auswendig mit quergestreiften Muskelfasern belegte, inwendig bisweilen, obschon keinesweges immer, mit derberen oder weicheren Papillen ${ }^{1}$ ) besetzte Speiseröhre in einen, inwendig verschiedene Texturverhältnisse zeigeuden, Magen, der, entweder ohne Bildung eines Blindsackes oder nach Bildung eines solchen, in ein aufstejgendes pylorisches Rohr umbiegt. Dies pylorische Magenrohr, welches bald kurz, bald lang ${ }^{2}$ ) ist, macht gegen den Darm zu abermals eine Biegung und besitzt an der Uebergangsstelle in denselben eine imnere vorspringende Falte: Valvula pylori ${ }^{3}$ ). Sie bildet den lingang in eine klappenlose, bald weilere, bald röhrenförmige IÏ̈hle, in welche, meist unmittelbar nuter der Valvula, die Duchus hepaticus und pancreaticus einmünden und beim Fötus der Ductus vitello-intestinalis sich inserirt ${ }^{4}$ ). Diese, dem Duodenum entsprechende, Abtheilung führt bei den Squalidae die Beneunung der

1) Z. B. Acanthias vulgaris, bei Aëtohatis Narinari sind solche vorhanden.

2) Sehr lang und eng z. B. bei Scyllium Edwardsii.

3) Z. B. bei Rhinobatus Ilorkelii, Trygon Sayi.

4) S. eine von $1 l u ̈ l l e r$ gegebene Abbildung. Ueber d. glatten Iai des Aristoteles. Tb. 5. Fig. 2. Bei den meisten Plagiostomen erweitert sich der in der Bauchhöhle gelegene Theil des Dotterganges zu einem inneren Dottersackc. Dieser gewinnt an Imfing unter Verkleinerung des iusseren Doltersackes. Ich finde diesen inneren Dottersack z. B. noch bei einer jungen Pristis. Bei Mustelus laevis und wahrscheinlich auch bei den übrigen Vivipara colylophora, fehlt der innere Dottersack, wic Il üll er gezeigt hat. 
Bursa Entiana ${ }^{5}$ ). Auf sie folgt der sogenamnte Klappendarm, dem Dünndarme der höheren Wirbellhere entsprechend. Die in seiner IIöhle befindliche, seine inuere Oberfläche bedeutend vergrössernde, Spiralklappe ist nach zwei verschiedenen Typen gebildet. Bei der Mehrahl der Elasmobranchii ist sie in der Art sehraubenförnig gewunden, dass sowol ihr an Jer Darmwand befestigter, als auch ihr freier Rand eine Spirale bildet. Bei der Familie der Carchariae und bei der Gattung Galeocerdo, wo in ihr. wie bei Petromyzon, die Darmvene liegt, ist sie dagegen in ciner longitudinalen Linie segelartig befestigt und dabei spiralförmig gerollt 6). Auf den weiten Spiraldarm der Elasmobranchii folgt ein kurzes, von einfacher Schleimhant ausgekleidetes, dem Rectum entsprechendes Endstïck. In den Anfang des letzteren, und zwar in seine Rückseite, mündet ein längliches, hohles, drüsiges und absonderndes, am Mesorectum befestigtes Organ mit weiter Oeffnung. Das Rectum mündet in die Cloake vor den Odfinmoen der IIarn- und Geschlechtstheile. - Der Magen und das Duodenum bis zu dem vordersten Abschnitte des Klappendarmes sind an einen, bald vollständig häutigen, bald nelzförmig durchbrochenen Mesenterium befestiğl. Der Klappendarm ist frei. Das Rectum haftet wieder an cincr Perilonealfalte.

Bei Chimaera ${ }^{\top}$ ) wo der ganze Darm gerade zum Afler verlïuf, geht die inwendig mit Längsfalten besetzle Speiseröhre ohne zwischenliegenden Magen in einen erreiterten Abschnitt über, der anfangs durch den Besitz von dichtstehenden Zacken ansgezeichnet ist, die weiterhin ilue Stellung ändern. In den sehr kurzen Anfang dieses Abschnittes (Duodenum) mündet der Duchus choledochus, neben und unter dessen Oeffumng sogleich die crste Klappe abzusteigen beginnt. Die Klappe macht drei Windungen; dann folgt das mit Lïngsfalten besetzte Rechum. Zwischen je zwei seiner Falten liegt am Anfange des Reclum je eine Anhäufung von Drüsensehlänehen. Ein Mesenterium fehlt.

Nach dem Typus der Plagiostomen, indessen mit cinigen Modificationen, ist der Tractus intestinalis dex meisten Ganoüden gebildet. Bei Accipenser geht die eng an die Wirbelsänle geheftete, auswendig mit quergestreifter Muskelschicht belegte, inwendig mit dicker, weisser Epithelialschicht und mit konischen Papillen ausgelileidete Speiseröhre in den mil

5) Ueber die Unrichtigkeit dieser Bezeichnung hat sich ausgesprochen: J. Mïller, Abhandl. d. Acad, d. Wissensch. z. Berlin. 1842. S. 228.

6) Diese Einrichtung war schon P'rrault bekannt (Oeuvres de Pliysique. Vol. II. p. 435. pl. 15., der seinen Galeus glaucus dem Squalus alopecias gegenüberstellt. 1)ann hat Meckel sie beschrieben (Syst. d. vergl. Anatom. Thl IV. S. 311.); endlich auch Duvernoy (Ann. des scienc. natur. 1835. T. II. p. 275. Mit $\mathbf{\Lambda} b$ b. Tb. 10. u. 11.

7) Vgl. auch Leydig, Müller's Archiv. S. 259. Der Gallengang inserirt sich nicht unter, sondern dicht über dem Anfange der Klappe. 
weicherer, sammtartiger Schleimhaut versehenen Magen über. Dieser, anfangs am Banchfelle befestigt und in seinen ferneren Abtheilungen durch netzförmig durchbrochene Peritonealbrücken mit den benachbarten drüsigen Organen zusammenhangend, besteht aus mehren Abtheilungen. Dieselben sind: 1. ein absteigender, wenig erweiterter Abschnitt, in dessen Anfang mit kurzem, weitem Duchus pneumalicus die Schwimmblase mündet; 2. ein nach vorn anfsteigendes enges pylorisches Rohr, das 3. an seinem vorderen Ende wieder sich umbiegend zu einem dickwandigen, länglieh-runden Muskelmagen anschwillt, welcher mit seiner Muskel- und Schleimhaut einen trichterförmigen Yorsprung in die IIöhle des Duodenum hinein bildet. Dies sehr lange, aus zwei, unter spitzem Winkel zusammenstossenden Schenkehn bestehende, durch keine Bauchfellfalte befestigte Duodenum nimmt, gleich hinter dem Magen, sowol dic Appendices pyloricae, als auch die Duchus hepalicus und pancreaticus auf. Die Appendices pyloricue bilden eine beinahe nierenförmige, auswendig mit flachen Tuberositäten bescizte derbe Masse, deren Wandungen aus dicken Lagen glatter Muskelfasem bestehen. Invendig zeigen sich grössere und kleinere zellige Rïume, deren jeder die nämlichen Häute, wie der Darmeanal besiłzt. Namentlich bildet die Schleimhaut dieselben zellig-maschigen Vertiefumgen. Die Iohlränme der Appendices gehen nicht dureh einen gemeinsamen Ausführungsgang, sondern durch drei weite, brückenartig getrennte Ostia in das Duodenum über. Dieses letztere besilzt inwendig in zahlreichen, grösseren nnd kleinereu polygonalen Zellenräumen cinen sehr complicirten Secrelions-Apparat. Seine Muskel- und Schleimhaut bilden cinen trichterförmigen Vorsprung in den Klappendarm, der, gestreckt hinterwärls verlaufend, in seiner ganzen Länge durch das Bauchfell befestigt ist und vor dem After in die sehr kurze, mit glatter Schleimhaut bekleidete Andeutung eines Rectum übergeht. Der Klappendarm zeigh dieselben Zellen, wie das Duodenum und auch die die Klappe bildenden vorspringenden Wülste sind mit offen mündenden Follikeln besetzt ${ }^{8}$ ).

Von den Accipenserini unterscheiden sich die Spalulariae vorzüglich dureh abweichende Textur der Schleimhaut des Oesophagus, durch grosse Kürze des aufsteigenden pylorischen Rohres und Nangel des Muskelmagens, durch abweichenden Bau der dickwandigen Appendices pyloricae, die nicht zu einer drüsigen Masse verbunden, sondern am Ende fungerfürmig gespalten sind und durch grosse Kürze des gerade nach hinten verlaufenden Duodenum. Das Rectum ist kurz ${ }^{9}$ ).

8) Nachträglich sei in Bezug auf eine Bemerkung von Leydig (Anatomischhistologische Untersuchungen über Fische u. Reptilien. Berl. 1853. 4. S. 17.) hervorgehoben, dass diese Follikel bei $\mathbf{A}$. sturio immer vorhanden sind.

9) S. die Abb. bei A. Wagner de Spat, anat, Fig. 4. Ich finde das Rectum nicht netzförmig, sondern von glatter Haut ausgekleidet. 
Was die Gamoüdei holostei anbetrift, so fehlt bei Polypterus eine eigene Duodenal-Ablheilung des Darmes fast ganz. " Die Portio pylorica des Magens bildet einen Vorsprung in das obere Ende des Klappendarmes, ron welchem Vorsprunge die Spiralklappe ausgeht. Ueber dieser Stelle liegt ein einziger Blinddarm: Appendix pylorica. In den Anfang des Klappentarmes mündet der Gallengang. -- Verwandt zeigh sich Amia dureh den Besitz einer, rier Windmgen machenden, Spiralliappe; diese liegt jedoch nicht in dem zunïchst auf den Magen folgenden Darmabschnitte, sondern weit nach dem Ende des Tractus inteslinalis hin. Der Magen bildet einen Blindsack und besitzt ein pylorisches Rohr, das durch eine Klappe von dem weiten Duodenum geschieden ist. Dies setzt sich weiter fort in den mehre Windungen machenden Dünndarm, welcher vor seinem Uebergange in ein sehr kurzes Rectum die Spiralklappen enthält.

Bei Lepidosteus endlich fehit eine ausgebildete Spiralklappe ${ }^{10}$ ) des Darmes ganz. Der gerade absteigende weile Magen biegt sich in ein sehr lurzes dickwaudigeres pylorisches Rohr um, das, nach Bildung eines blinden Säckchens, durch ein enges Ostium in das Duodenum übergeht. In dieses inseriren sich sogleich hinter dem Pförtner mit wenigen weiten Oeffnungen zahlreiche, durch Bindegervebe zusammengehaltene, sehr kurze $A p$ pendices. Der wenig gewundene enge Darm geht, olne dureh eine Klappe geschieden zu sein, in einen weiteren Endabschnitt über.

Was die Dipnoi anbetrift, so geht bei Lepidosiren der vorderste, den Oesophagus und Magen ${ }^{11}$ ) reprësentirende Abschnitt des Darmeanales in das kurze Duodenum ïbar, von welchem er durch eine Pförtnerklappe getremnt ist; dicht neben dem Pfürtner müudet der Gallengang. Weiterhin folgt der Spiraldarm, den auch Rhinocryptis besitzt, und zuletzt ein kurzes Rectum.

\section{S. 82.}

Die anatomische Anordnung des Tractus intestinalis der Teleostei ist den grössten Verschiedenheiten unterworfen. 1)ie cinzehen Abschnitte desselben bleiben häufig durchgängig von ungefïhr gleicher Weite; in diesem Falle gibt, wenn imnere Klappen oder andere mit unbewaflnetem Auge deullich erkembare T'exturunterschiede der verschiedenen Strecken fehlen, die Insertionsstelle des Duclus choledocitus einen IIallpunkt

10) Immer bleibt es fraglich, ob nicht drei schräge Sireifen, welche in dem über dem kurzen Endabschnitte des Darmes liegenden Thoile desselben vorkommen, als Andeutungen einer solchen zu betrachten sein möchten.

11) IIyrtl fand an der dorsalen Wand des Magens zwischen Musliel- und Peritonealhaut ein drüsiges, undeutlich gelapptes, sehr gefüssreiches Organ ohne Ausführungsgang, das in den Darmcanal sich fortsetzt, und in dessen Spiralklippe aufgenommen wird. S. dessen Schrift S, 25. Vielleicht ist es die Mliz. Im Anfange des Darmcanales kommen eigenthümliche Gruben vor. 
ab zur Unterscheidung der Duodenalgegend. Fische, bei denen eine eigentliche Magenerweiterung fehlt und bei denen der Tractus inteslinalis olne deutlich unterscheidbare äusserliche Abgrenzung einzelner Abtheilungen darmartig sich verhält, sind, z. B. die Scomber-Esoces, die Labroüdei, die Cyprinoïden, die Cyprinodontes, die Loricarinen, die Symbranchii.

Bei einigen den genannten Gruppen angehörigen Fischen, wie bei Cobilis "), bei den Scomber-Esoces, den Symbranchii, verläuft der Tractus inteslinalis ganz gerade und gestreckt zum After, während er bei Anderen, \%. B. manchen Cyprinoïden (Tabeo) und Loricarinen (IIypostoma) durch beträchtliche Länge und vielfache Windungen sich auszeichnet. Bei anderen, wie bei Lsox, erstreckt sich der Magen in der Richtung der Speiseröhre abwärts und geht dann unter einem Winkel sofort in das enge Duodenum über, von dem er durch eine Klappe geschieden ist.

Bei den meisten Teleostei bezeichnen änssere Unterschiede in der Weite die einzelnen Abtheilungen des Tractus intestinalis dentlicher. Die häufigste Bildung ist die, dass eine kurze Speiseröhre gerade in eine mehr oder minder erweiterte Mageuhöhle ${ }^{2}$ ) sich fortsetzt, welche durch eine Krümmung in ein rechterseits aufsteigendes oft diekwandiges pylorisches Rohr $\left.{ }^{3}\right)$ übergeht. Dieses setzt, oft durch eine äussere Einschnürung geschieden, in das Duodenum sich fort, welches nicht nur die Ausführungsgänge der Leber und des Pancreas aufnimmt, sondern änsserst hänfig, wenn schon keinesweges immer, die in sehr verschiedener Anzahl vorbandenen, unter dem Namen der Appendices pyloricue bekaunten Ausstülpungen bildet. Das Duodenum selzt ohne weitere Abgrenzung in einen mehr oder minder langen, oft mehrfach auf- und absteigenden, Dünndarm 4) sich fort. Dieser führt endlich in ein sehr kurzes, äusserlich selten deutlich unterscheidbares Reclum.

Dieser generelle Bildungstypus erfïhrt zahlreiche und mamnichfache Modificationen, begründet in der verschiedenen Weite der Cardia-Hälfte des Magens, in der mangelnden oder vorhandenen Blindsack-Bildung derselben, in der verschiedenen Ausbildung des pylorisehen Rohres, in der Abwesenheit oder Anwesenheit mehr oder minder zahlreicher Appendices pyloricae,

1) Dieser Fisch, dessen Darmcanal durch Gefüssreichthum sich auszeichnet, schluckt atmosphärische Luft und gibt Kohlensäure von sich. Vgl. Erman in Gilbert's Annalen. Bd, XXX., 1808. S. 140.

2) Die Speiseröhre kann auch sehr lang und selbst gewunden sein, wie z. B. bei Lutodeira.

3) Reichliche Ansammlungen von Lymphe, welche ich zwischen seinen IIäuten und Gewebselementen bei mehren Gadus fund, sind von mir mit Unrecht fir ein hier normal abgelagertes Blastem gehalten worden.

4) Er ist z. B. durch seine Länge und durch vielfache Windungen ausgezeichnet z. B. bei Lutodeira chanos; ferner unter den Theutyi bei Naseus. 
in der Verschiedenheit der Weite des Rectum. Die Cardia-IIilfte des Magens ist oft eine bald lïnglich, bald rundlich oder bauchig erweiterte gerade Fortsetzung der IIöhle der Speiscröhre, die aber keinen eigentlichen Blindsack bildet, wie z. B. bei vielen Pereoïden, Cataphracten, Cyclopoden, Pediculati, Gadoïdei, Pleuronectides, Siluroïdei, Mormyri.

Bei anderen Fischen liegt dagegen der Uebergang in die IIöhle der Portio pylorica der Cardia nahe und zwischen beiden Oeffnungen verläıgert sich die Porlio cardiaca in einen mehr oder minder weit absteigenden Blindsack, wie z. B. bei vielen Clupeïdac (Clupea, Alosa), manchen Characini, bei Ammodytes, bei den Muraenö̈dei (z. B. beim Aal), bei Scomber scombrus, bei Thynnus.

Blinde Ausstülpungen des Duodenum (die sogenannten Appendices pyloricae ${ }^{5}$ ) fehleu manchen Familien der Teleostei ganz; dahin gehören: die eigentlichen Gobiöldei, mehre Cycloporles, sämmtliche Labrö̈dei, Chromides, Scomber-Esoces, die Siluroüdei und die Loricarini, die Cyprinoüdei und Cyprinodontes, Esox, die Muracnö̈dei ${ }^{6}$ ), die Symbrauchii, die Pleclognathi und Lophobranchii. Sie könuen den meisten Arten civer, Gattung fehlen und einzelnen zukommen, wie z. B. die Gattung $\left.\mathbf{O}_{\text {phidium zeigt }}\right)^{\text {) }}$. - Die Zahl dieser blinden Ausstülpungen variirt ausscrordentlich. Ammodytes besitzt einen einzigen Blinddarm; zwei cinander gegenüberstehende kommen vor bei Rhombus maximus; ihre Zahl steigh bis fünf bei anderen einheimischen Plenroneclides; zwei sind rorhanden bei Zoarces vivipatrus, bei Rhynchobdella ocellata; drei bei Perea fluviatilis, bei Aecrina cernua und meluren auderen Percoïlen; vier bei Pagellus erythrinus, bei Sargus Salviani, bei Smaris vulgaris; fünf bei Sargus Rondeletii; acht bei Chaelodon striatus; die Anzahl derselben steigt bei anderen Squamipennes, z. B. bei IIolacanthus, bei einigen Cyclopoden, z. B. bei Cyclopterus, bei den Scomberö̈den, den Gadoüden s), den Characini, Salmones, vielen Clupeïdae ausserordentlieh; bei Scomber scombrus zählte ich 191 Blinddärme. - Die Stellung derselben wechselt; oft inseriren sie sich lïngs riner Seite des Duodenum, wie bei Osmerns, bei Clupea u. A.; oft sind sie mchr ringförmig um dasselbe gestellt, wie bei Cyclopterus, den Gadus-Arlen u. A.;

5) Die Entwickelung dieser Appendices sclieint, nach der Angahe von Vogt, (Embryol. d. Salm. p 174.) bei Lachsen erst selır spät zu erfolgen. Bei Zoarces viviparus ist dies, nach Forchhammer, (de Blennii vivipari formatione et evolutione. Kil. 1819. 4. p. 17.) nicht der Fall rücksichtlich der beiden Appendices.

6) Wohin Gymnarchus gehört, bleibt immer noch ungewiss. Er besitzt nach Erdl zwei Blinddärme.

7) Ophidium blacodes Forster besitzt, nach M̈̈ller, sechs Blinddärme.

8) Raniceps fuscus, der so manches Eigenthümliche besitzt, lat indessen nur zwei Appendices. 
oft sind beide Bildangsweisen gevissermassen combinirt, wie z. B. bei Scomber scombrus, bei einigen Salmones ${ }^{9}$ ) u. $\boldsymbol{A}$.

Das nähere Verhalten dieser Apendices bictet mancherlei Versehiedenlıciten dar; sind sie in geringer Anzall vorhanden, so pflegt jeder seine besondere Eimmündungsstelle in den Darm zn besilzen; bei Anwesenheil vieler haben oft zwei oder vier eine geneinschaftliche Insertion, wie z. B. die vorderen von Scomber scombrus; oder es mïnden melne und selbst viele in einen Gang, wodurch daun die Zahl der in den Darm sich inserirenden Gänge von derjenigen der Blinddärme nm ein schr Vielfaches überirothen werden und selbst ein einziger Gang eine beträchtliche Anzahl nach ler Peripherie hin mehr und mehr sich spaltender Röhren aufnehmen kamm.

Bei manchen Fischen, namentlich aus der Familie der Scomberoüden, rerbinden sich zahlreiche Blinddämchen nicht un allmälig zu einer geringen Anzahl in das Duodenum einmündender Stämme, sondern dic Därmchen selbst werden oft noch durch Bindegewebe und Gefïsse so imigg zusammengchalten, dass ihre Masse das Aussehen einer Drüse crhält. Dies ist in versehiedener Art der Fall, z. B. bei Thynnus vulgaris ${ }^{10}$ ), Th. alalonga ${ }^{11}$ ), Auxis vulgaris ${ }^{12}$ ), Pelamys sarda ${ }^{13}$ ), Xiphias gladins ${ }^{14}$ ), Lichia amia ${ }^{15}$ ) u. A.

Das Rectum zeigt sich bald elwas verengt, bald wenig erweitert. An seiner vorderen Grenze fehlt, mit seltenen Ansuahmen, jede Spur von Blinddairmen ${ }^{16}$ ).

Der Tractus intestinalis der Plysostomi steht in Höhlenverbindung mil der Schwimmblase vermöge des bald in die Speiseröhre, bald in den Blindsack des IIagens einmündenden Ductus pmeumaticus derselben. - Bei einigen Pleclognalli (z. B. Diodon, Telrodon) geht ferner von der vorderen Wand der Speiseröhre ein eigenthümlicher Luftsack aus, der nach vorue bis an die Grenze des Unterkiefers, nach hinten bis zum Anfang der Schwanzggegend reicht. Derselbe nimmt luft auf und dient zum

9) S. über die Blinddärme der Salmones die Abhandlung von Kner in den Sitzungsberichten der Wiener Acad. d. Wissenschaften. Wien, 1852. Bd. VIII. S. 201.

10) S. Cuvier, Hist. nat. d. poiss. Vol, 8, p. 66. Hier münden die Blinddärmchen mit 5 0effnungen. Aehnlich Th. brachypterus ibid. p. 100.

11) S. Cuvier ibid. p. 126. Hier ist ein einziger Gang vorhanden, der nach seinem freien Lnde hin in einzelne Bündel von Blinddärmchen zerfällt, die alle, eng zusammengehalten, wie Drüsen aussehen.

12) S. Cuvier ib. p. 143 , - 13) S. Cuvier ib. p. 158.

14) S. Rosenthal, Abhandlungen a. d. Gebiete d. Anat. Phys. u. Pathol. Berl. 1824. 8. S. 79, Cuvier I. c. p. 262. - 15) S. Cuvier I. c. p. 354.

16) Andeufungen davon kommen nach Cuvier u. Valenc. (Vol. V. p. 354. und 361.) vor bei der Gattung Box; bei Box vulgaris einer; bei Box salpa zwei. 
Aufblasen dieser Thiere. In der Regel cine cinfache Ilöhle hildend, soll er bisweilen kammerig oder mil zelligen Wänden versehen sein ${ }^{17}$ ). Dass er als respiratorisches Gebilde zu betrachten sei, dagegen spricht der Ursprung seiner Gefässe aus den Körperarterien.

Die Lage des Afters wechselt bei den Teleostei sehr. Bei der Mehrzahl derselben liegt en nicht nur hinter den Bauchflossen, soudern auch an der hinteren Grenze der Bauchhöhle, vor dem Anfange der Sehwanzgegend. Bei Manchen ist er weiter vorwärts gerückt; in diesem Fallo rerlïngert sich die Afterflosse ehenfalls gewöhulich weit nach vorne unterhalb der eigentlichen Bauchhöhle. So liegt der After z. B. bei Cepola rubesecns in der Mitle der Banchgegend, bei Gobius lanceolatus weiler vorwärts gerüclit, bei den meisten Pleuronectes ebenfalls sehr weit nach vorne. - Bei der den Ophidini angehörigen Galtung Encheliophis ${ }^{18}$ ) Müll. nud bei den Gymnotini liegt der After, unter Mangel des Beckens, dicht hinter dem Schultergürlel. - Nur bei zrvei Fischgaltungen liegt er vor dem Becken; es sind dies die von Cuvier ${ }^{19}$ ) zu den Percoüden gezählte Gatlung Aphredoderus, wo er noch vor den Brustlossen liegt und der einzige Repräsentant der Familie der Ileteropygii: Amblyopsis 20).

Was die Texturverhälnisse des Tractus inteslinalis anbelangt, so sind in der Regel nur Schlundkopf und Speiseröhre mil quergestreiften Muskelfasern belegt; eine merkrürdige Ausnahme hienvon bildel die Gattung Tinca, indem hier in der ganzen Länge des Tractus intestinalis cine auswendige Belegung mil quergestreiften Muskelprimitivbündeln rorkönmt ${ }^{21}$ ). - Die glatte Mustelhaut rler ïbrigen Abschnitte des Darmrohres verhält sich in Bezug auf ihre Stärke in den verschiedenen Regionen äusserst verschieden. Dickwandiger als die übrigen Segmente ist gewöhnlich die Porlio pylorica des Magens; hei den Gattungen Mugil und Dajaus, bei Anodus und Hemiodus nimmt sie so an Dieke zu, dass sie dem Muskelmagen der Vögel ähnlich wird.

Das Verhalten der Höhle des Darmohres ist nicht minder variabel. Sehr gewöhnlich, obschon keinesweges bestïndig, findel sich an der Uebergangsstelle der Porlio pylorica des Magens in das Duodenum eine in Bezichung auf Ausdehnung und Dicke versehiedene Ialvula pylori; nicht

17) Vgl. über seinen angeblich zelligen Bau die kritischen Bemerkungen von Baer, Entwickelungsgesch. d. Fische. S. 47.

18) S. Müller, Ueber die Eingeweide der Fische. Tb. V. Fig. 4. 5.

19) Hist. nat. d. poiss. Vol, IX. p. 450, u p. 452.

20) S. Tellkampf in Müller's Archiv. 1844. S. 393.

21) S. Reichert, Med. Zeitung d. Vereines f. Heilkunde in Preussen. 18\$1. No. 10. und die experimentellen Beohachtungen von Ed. Weber in Wagner's Ilandwörterbuch d. Physiologic. Bd. 3. Abth. 2. 
ganz so oft hegegnet man einer zweiten Klappe an der Grenze des Dünndarmes und des Rectum ${ }^{22}$ ).

Reihen stärker vorspringender Schleimhantfalten können in verschicdenen Abheilungen des Tractus inteslinalis vorliommen, um cine Vergrösserumg der Innenflächen zu bewvirken. Sehr selten erscheinen derghleichen Bildungen schon im Oesophagus, wie z. B. bei Lutodeira chanos ${ }^{23}$ ). Es findet sich hier ein System schräg, von oben und vorne nach unten und hinten gerichleter paralleler Valvulae conniventes, deren freier Rand in die Höhle des Oesophagus hineinragt. Achnliche doch mchr runde ringförmige Qucrfalten finden sich in ganzen Dünudarm mancher Fische z. B. bei Clupea, Alosa, Chirocentrus dorab ${ }^{24}$ ). Bei anderen Fischen z. B. bei Spinachia, bei Gasterosteus, bei Salmo nehmen sie nur gewisse Strecken des Dïmudarmes ein. J) näheren Verhältnisse der Schleimhautausbreitungen sind äusserst mamichfach; nicht nur gehen die Formen, unter denen die Schleimhaut so hïufig sich erhebt, nicht selten unmerklich in cinander über, sondern auch Altersstadien und temporäre Verhälnisse der Fische scheinen Unterschiede zu begrinden. Am einfachsten ist meistens die Anordnung der Längsfallen bildenden Schleimhaut im Oesophagus, der aber auch mit Papillen, Warzen, zahuartigen Bildungen u. s. w. besetzt sein kann. Was den Magen anbetrifft, so bemerkt man in der IIöhle der absteigenden Porlion desselben gewöhnlich keine Magendrüsen, wïhrend diese dagegen bisweilen z. B. bei Cyclopterus lumpus, Zoarces vivipartus, Cottus scorpius sehr deullich sind ${ }^{25}$ ). Tie Schleimhaut erhebt sich in den Höhlen beider Magenabtheilungen häufig in Längsfalten, welche in der absteigenden Porlion zum Theil als Forlsetzungen derjenigen des Oesophagus erscheinen; die fler Porlio pylorica sind dagegen meist niedriger und stehen dichter; neben ilnen liommen sehr oft nelzförmige Bildungen vor. In Verlaufe der Schleimhautausbreitung des Dünndarmes finden sich äusserst häufig Lïngsfalten umd zwar entweder allein oder durch Querfalten verbunden, so dass die Innenflärhe ein nelzförmiges oder zellenförmiges Ansehen erhält. Diese nelzförmiggen Bildungen sind wieder einfach oder zusammengesetzt. Zivi-

22) Ich vermisse sie z, B. nicht allein bei den Cyprinen, sondern auch bei Silurus glanis. Sic findet sich dagegen sonst schr häufig z. B. bei allen einheimischen Pleuronectes.

23) S. Valenciennes hist, nat. d. poiss. Vol. XIX. p. 190. Ich möchte sic elier mit ralculae connicentes, als mit einer Spiralklappe vergleichen, wie dies durch Valenciennes geschieht.

24) Valenciennes 1, c. Vol. XIX. p. 160, welcher sie beschreibt, bezcichnet sie wieder als Spiralklappe, womit ich nicht übereinstimmen kann.

25) Bei Zoarces nehmen sie z. B. dicht unter der Speiseröhre fast die ganze Circumferenz der Nagenhöhle ein; weiterhin sind sie nicht mehr so ausgebreitet. Am zierlichsten sind sic bei Cyclopterus lumpus. 
schen ilnen kommen nicht selten lileine Cryptae vor. Auch wirkliche Zellen zeigen sich nicht selten, wie z. B. bei Anmodytes, - Die Anordmung der Selıleimhant der Ippendices pyloricae entspricht in der Regel derjenigen des Duodenum. In Rectum erhält sich bald eine ähnliche Anorduung der Schleinhaut, wie im Dünmdarm, bald, und zwar ist dies der hïufgere Fall, erscheint sie hier einfacher gebildet. - Die imncrste Auskleidung des Tractus intestinalis geschicht vielleicht immer durch cin Cylinder-Epithelium. Abortive oder in Bildung begriffene Zellen kommen neben den ausgebildeten sehr reichlich vor. Bei dem gegenwärligen Stande unserer Kenntuisse über die Lebensverhältnisse der Fische können die versehiedenartigen Anordnumgsweisen ihres Tractus intestinalis, sowol was die gröberen. als auch namentlich was die feineren Texturverhältnisse anbetrilft, noch kein bedentendes Interesse in Anspruch nchmen, da jede Einsicht in die physiologisehe Bedeutung der Formen mangelt.

Die Befestigung der in der Bauchlı̈̈hle gelegenen Abschnitte des Darmcanales geschicht durch das Bauchfell. Dies ist meisteus wirklich membranös und dann oft rerschiedentlich pigmentirt; an seinen Ausbreitungen über die Körperwandungen funden sich häufig Schüppehen, Nadeln und anscheinend erystallinische Anhäufungen, welehe ähulich den silberglänzenden Schïppchen, die die Sclerolica und die Schwimmblase inwendig auskleiden, sich verhalten; sch häufig aber ist es in einzelne Bänder, Brücken, Fäden zerfallen, zwischen und an denen die Gefïsse verlanfen. Auch hier gilt es wiederum, dass Altersverschiedenheiten bei Thieren der gleichen Species gewisse Unterschiede begründen ${ }^{26}$ ).

[Ueber die gröbere Anordnung des Tractus intestinalis findet sich reiches Detail bei Cuvier u. Valenc, Hist. nat, d. poiss. - Ueber den Traclus intestinalis einheimischer Fische vergleiche man die reichbaltige Abhandlung von II. Rathke im zweiten Bande seiner Beiträge zur Geschichte der Thierwelt. IIalle, 1524. 4., in welcher namentlich die Anordnungsweisen der Schleimhaut und des Bauchfelles geschildert sind. Rathke hat gerade diejenigen Fische geschildert, die anch mir durch die Nähe der Ostsee vorzugsweise zu Gehote stehen. Eine vieljährige Beschaftigung mit diesen Thieren lässt mich Rathke beistimmen in dem Ausspruche, dass die Summe der Variationen in Betreff gewisser feinerer Bildungsverhältnisse sehr gross ist. Dic fiir den Zweck dieses Buches erforderliche Raumbeschränkung gestattete mir kein Eingehen in das Detail, das nicht aus Mangel an Stoff, sondern absichtlich vermieden ist; Polemik lag hier, wie überall, ausser den Plane.]

\$. 83 .

Die Leber ') besteht, mit einziger Ausnahme von Branchiostoma, wo sie, ähnlich, wie bei den Anneliden, von den Darmwänden noch nicht ge-

26) Nach den Beobachtungen von Rathke (I. c. S. 10t) ist das Gekröse mancher Fische ursprünglich vorbanden, schwindet jedoch später durch Resorption.

1) Vgl. über die Leber der Fische: F. G. Mierendorf de hepate pisciun. Berol. 
sondert ist 2), und den Myxinoïlen 3), wo sie zwei völlig getrennte Drüsen darstellt, aus einem gewöhnlich beträehtlichen drüsigen Organe von ziemlich weicher Consistenz und gelblicher oder gelber, gelbbrauner, rothbrauner, rother, hellrother oder selbst schwärzlicher Färbung. Meist zeichnet sie durch sehr beträchtlichen Fettgehalt sich aus ${ }^{4}$ ). In der Regel begimnt sie im Anfange der Bauchhöhle, dieht hinter dem Ilerzbeutel; seltener erst weiter hinterwärts in der Bauchhöhle, wie bei mehren Diodon. Oft erstreckt sie sich weit nach hinten in der Bauchhöhle, wie bei Symbranchus, bei manchen Haien u. A.

Ihre Form scheint häufig bedingt durch die der Bauchböhle; so ist sie z. B. breit bei vielen Rajidae, sehr in die Länge gezogen bei manchen Symbranchii; lang und aus cinem cinfachen Körper bestehend bei Lepidosteus.

Bei den Myxinoïden findet sich eine kleinere vordere, rundliche und cine doppelt so lange hintere Leber. Zwischen beiden liegt die Gallenblase, welehe aus jeder einen Ductus cyslicus aufinimmt. - Bei den Pelromyzon begimnt die compacte, ungelappte, zusammenhangende Leber im vorderen Anfange der Banchhöhle und umhüllt hier mit einem Theile ihrer dorsalen Masse den Anfang des Darmes und des Pancreas sehr eng. Eine Gallenblase fehlt der Gattung Petromyzon, während eine solehe bei Ammocoetes vorhanden ist. - Bei den Elasmobranchii begimnt die Leber etwas hinter dem Ilerzbentel und ist dureh eine Peritonealfalte (Ligamen(um suspensorium) an der vorderen Begrenzung der Bauchhöhle befestigt. Sie bestcht bald aus zwei durch eine Commissur verbundenen Hauptlappen wic bei vielen IIaien, z. B. Scyllinn Edwardsii und einigen Rochen, z. B. Trygon Sayi, Torpedo Galvanii oder es ist zwischen diesen noch ein Mittelstück eingeschoben, wie z. B. bei Squatina vulgaris, bei Raja clavata 11. A. Enorm ist ihr Umfang bei Chimaera. Die Gallenblase liegt mehr oder minder eingebettet in die Lebersubstanz. Ein oder zwei Hauptlebergänge führen in den Duchus choledochus. Dieser, oft in einer Strecke etwas erweitert und verdiekt, inserirt sich in die Duodenalabtheilung über dem Anfange des Klappendarmes; von seinem Herantreten an den Darm bis zu scincr immeren Ausmündung auf einer kleinen Papille verlänft er oft eine Strecke weit schräg zwischen den Darmhäuten und besitzt hier Quer-

1817. 8. c. fig. - Rathke in Meckel's Archiv. 1826. S. 126. und in Müller's Archiv. 1837. S. 468.

2) S. M üller, Ueber Bau u. Lebensers. d. Branchiostoma.

3) S. Müller, Ueber d. Eingew. d. Fische.

4) Bei einigen Fischen ist er enorm, z. B. bei Chimaera, worauf schon Gunnerus in seinem Aufsatze über die Seekatze (Schriften der Drontheimer naturf. Gesellsch. Bd. 2. S. 261.) aufmerksam gemacht hat. 
falten, welche den Rücktritt der Galle verhülen ${ }^{5}$ ). - Bei Accipenser besitzl sie zwei unvolliommen getremnte, durch Einschnitte in viele untergeordnele Lappen zerfallenc Haupllappen. Die Callenblase liegt grösstentheils eingebettet in der Lebersubstanz. Die Gallencanïlchen in der Leber vereinigen sich zu mehren Stämmchen, welche nach und nach einzehn in den einerseits zum Blasenhalse und andererseits zum Duodenum tretenden contractilen Gallengang einmüuden. An ihm setzt die Lebersubstanz bis zu seiner Eimmündungsstelle in das Duodenum sich fort und sehmiegt sich noch um das letztere.

Die Leber der Teleostei ${ }^{6}$ ) bildet bald eine einzige Masse ${ }^{7}$ ), wel che, ohue in grössere Lappen zu zerfallen, doch, namentlich an ihrer concaven Seite, vielfach eingeschuitten scin kann und dann gewöhnlich mehr nach der linken Körperhälfte gerückt zu sein pflegt; bald besitzt sie zwei seitliche Hauptlappen, welche durch ein Querstück verbunden werden ${ }^{8}$ ), in welehem Falle der linke Lappen der beträchtlichere zu sein pflegt, oder drei Ilauptlappen ${ }^{9}$ ); bald besteht sic aus zahlreichen zwischen die Windungen des Darmeanales eingesenkten Lappen, wie z. B. bei Cyprinus carassius.

Anscheinend allgemein oder höchstens mit sehr seltenen Ausnahmen 10) kömmt den Teliostei eine Gallenblase zu, welche gevöhulich dicht unler der Leber mehr oder minder dentlich zu Tage kömmt, seltener fast ganz in ihrer Substanz cingebettet liegt. Bei cinigen Fischen ist sie ganz von der Leber getrennt, meist mehr rechls gelegen. Die Grösse dieser Gallenblase steht gewöhnlich in geradem Verhälnisse zu der der Leber. Ihre Gestalt ist nicht überall grleich: liugelförmig oder oval oder cylindrisch. Eine sehr viclen Scomberö̈den "1) und einigen anderen Fischen zukommende Eigenthünlichlieit ist die langgestreckte gefïssartige Form ihrer Grallenblase, die oft durch den grössten Theil der Lünge der Bauchhöhle bis in die Nähe des Afters sich erstreckt. Das Verhalten der Gallengïnge bietet manche Verschiedenheiten dar; bald münden viele einzeln, bald wenige ${ }^{12}$ ) in den gemeinsanen Gallengang, der einerseits als Ductus cysticus in die Gallen-

5) So bei Raja batis, wo Davy (Researches. Vol. II. p. 430.) bereits auf diesen Bau aufinerksam gemacht hat.

6) S. über dieselbe Rathke in Mleckel's Archiv f. Anat. u. Phys. 1826. S. 126.

7) Z. B. bei Coltus, Cyclopterus, Belone, Salmo, Esox u. n. A.

8) Z. B. bei Anarrhichas, Silurus glanis u. A.

9) Z. B, bei Thynnus vulgaris, mehr oder minder bei den Cyprinen.

10) Dass dem Cyclopterus lumpus eine Gallenhlase fehle, ist irrthümlich behauptet worlen; obgleich ich mehrmals auf ihre Anwesenheit aufmerksim gemacht, haben Nenere, wie z. B. Owen, sie dennoch greleugnet. Sie ist klein, rundlich u. enthält eine blasse Galle.

11) Z. B. Thynnus, Pelamis, Auxis, Scomber, Thyrsites, Lepidopus.

12) Zahlreich sind sie z. B. bei Anarrhichas, bei Silurus glanis; drei sind bei Salmo vorhanden, die in den Blasenlials münden u. s. w. 
blase und andererseits als Ductus choledochus in das Duodenum sich fortsetzt, ball sind noch eigene Duclus hepro-cystici oder eigene Duclus hepato-enterici vorhanden. Die Eimmündungsstelle des Ductus choledochus in das Duodenum liegt dicht ïber, unler oder zwisehen denen der Appendices pyloricae. Oft nimmt er den Duclus pancreaticus auf oder mündet dicht neben ihm. Beim Wels tritt er durch das Pancreas hindurch. Inwendig ist die Einmündungsstelle oft durch eine Papille bezcichnet.

\section{S. 84 .}

Während bei Branchiostoma und bei den Myximoïden noch nicht eine Spur des Pancreas aufgefumlen ist, zeigt sich bei Petromyzon am Darmanfange und zrvar an der Stelle, wo die Leber innig mil ibm verbunden ist, cine weisslich-graue, aus mikroskopischen rundlichen Läppchen, welche Zellen einschliessen, gebildete kleine Drïse, welche der Darmwand dicht anliegt. Obschon Ansführungsgänge derselben mit Sicherheit noch nicht beobachlet worden sind, scheint sie doch als Pancreas gedeutet werden zu müssen 1).

Alle Elasmobranchii besilzen ein verhältnissmässig sehr beträcht. liches Pancreas ${ }^{2}$ ). Dasselbe liegt unmittelbar hinter dem Magen, in unmittelbarer Nähe der Milz, bei Chimacra an ihr angerrachsen, ist von derber Consistenz, einfach ${ }^{3}$ ) oder aus zrvei brückenartig verbundene Lappen ${ }^{4}$ ) gebildet und besteht aus traubigen, fest mit einander vereinten Lïppehen. Sein Ausführungsgang mündet, oft bis zu seinem Ende von Drüsensubstanz umgeben, vor dem Anfange des Spiraldarmes.

Unter den Ganoïlen ist das Pancreas bisher nur bei Accipenser ${ }^{5}$ ) beobachtet worden. Es beginnt an Ende des Pylorus und steigt längs dem Duodenum abwärts, dem es dicht anliegt. Die drüsige, aus Läppchen bestchende Masse selzt bis auf die Insertionsstelle des Ausfülrungsganges in den Darm sich fort. Sie mündet neben dem Ductus choledochus.

Was die Teleostei ${ }^{6}$ ) anbetrifft, so scheint cin drüsiges Pancreas, wenigstens sehr häufgg, wemn nicht allgemein vorhanden zu sein. Wäh-

1) Bojanus, Isis, 1821. S. 1172. hat sie gekannt. S. auch Rathke, Ueber d. inneren Bau d. Pricke. S. 39.

2) Observat. anat. coll. priv. Amstelod. Amst. 1673. I1. p. 17. Tb. 3. Ilonro, I. c. S, 22. Tb. VIII.

3) Z. B. bei Raja clavata, bei Chimaera arctica.

4) Z. B. bei Raja batis, Acanthias vulgaris.

5) Es ist entdeckt von Alessandrini Commentat. Bononiens. Vol. II. 1836.p. 335. u. Ann. des sc. nat. XXIX, p. 193. Nach dieser von mir in der Dissertation von Brockinann bestätigten Entdeckung musste die herkömmliche Ansicht, dass die Appendices pyloricae der Fische einem drüsigen Pancreas entsprechen, aufgegeben werden.

6) S. Observationes anatomicae Collegii privati Amstelodamensis. Amstel. 1673. 12. p. 35. E. II. Weber in M eckel's Archiv. 1827. S. 28\%. u. meine in der Dis- 
rend dasselbe anfangs nur bei solchen Fischen aufgefunden war, die der Appendices pyloricae ermangeln, haben spätere Untersuchungen seine Coëxistenz mit letzteren nachgewiesen. Bei Silurus glanis, wo es sehr gross ist, tritt der Ductus choledochus durch seine Substanz hindurch; bei Esox, bei Muraena anguilla ist es beträchtlich und mündet neben dem Ductus choledochus: bei Belone besteht es aus zwei oder mehren rundlichen, weissgrauen Körpern. Unter den mit kleinen Appendices versehenen Fischen besteht es z. B. bei Pleuronectes platessa aus zwvei im Mesenterium eingeschlossenen Körperchen; der Ausführungsgang verliuft unmittelbar neben dem Ductus choledochus, ihm bis zu seiner Einmündung in den Darm eng angeheftet. Bei Gadus callarias und Lota vulgaris ist es verhältnissmässig schr klein. Bei Salmo salar stellt es eine flache gelapple Masse dar; der Ausführungsgang verläuft dem Ductus choledochus auf das engste angeheftet, so dass man erst beim Durchschneiden des anscheinend einfachen Leberganges erkeunt, dass er aus zwei Canälen besteht.

\section{S. 85 .}

Die Milz ist, mit Ausnahme der Leptocardii und der Myxinö̈den, bei allen Gruppen der Fische angetroffen worden. Bei Petromyzon liegt sie als ein hellrothes Organ linkerseits zwischen der das Jerz einschliessenden Knorpelcapsel und der Chorda dorsalis, den Magenhäuten eng angeheftet ${ }^{1}$ ). Sie besteht aus zwei durch eine Brücke verbundenen rundlichen Körperchen, und enthält runde mit körncrhaltigen Zellen gefüllte Räume. - Bei den Elasmobranchii ${ }^{2}$ ) liegt die Milz immer in der Nähe des Magens, mit dem sie durch Gefässe oder mittelst Peritoneallamellen zusammenhangt; bistveilen ist sie auch dem Pancreas innig verbunden oder angewachsen wie z. B. bei Chimaera. Bei Chimaera, den Rajidae und einzelnen Squalidae ${ }^{3}$ ) besteht sie aus cinem einfachen, verschieden gestalteten, bisweilen länglichen und gelappten Körper; bei vielen Haien ist sie jedoch in mehre discrete, an benachbarten Blutgefiissen hangende, Körper zerfallen und zwar bald so, dass neben einem IIauptorgane ein kleinerer Nebenkörper vorkümmt, oder dass mehre kleinere Körper vorhanden sind, neben denen bisweilen

sertation von Brockmann, de paucreate piscium. Rost. 1846. 4., niedergelegten Beobachtungen; ausgezogen in Müller's Archiv. 1848.

1) Ma yer (Froriep's Nolizen. Thl. 34. S. 116.) hat auf das Vorkommen dieses Organes bei Petromyzon zuerst aufmerksam gemacht. Schwager-Bardeleben Observat. mikroscop. de glandularum ductu excretorio carentium structura. Berol. 1841, 8. p. \%, hat sie genauer untersucht und ich folge seiner Beschreibung. Abb. ihres Inhaltes Tb. 1. Fig. 1.2.

2) Ueber den variabelen mikroskopischen Befund des Milzparenchymes S. Leydig, Rochen u. Haie. S. 60 ff.

3) Einfach ist die Milz unter den Iaien z B. bei Mustelus, bei Sphyrna, bei Scyllium; bei anderen zerfallen z. B. bei Lamna cornubica, bei Carcharias, bei Aranthias, bei Spinax, bei Squatina, wo schon Monro die Nebenmilz kannte. 
noch ganz kleine Organe derselben Art vorkommeu. - Unter den Ganoïden ist Accipenser ebenfalls dureh den Besitz einer variabelen Zahl vou Nebenkörpern (sie steigt auf 7), welche zugleich mit der grösseren in der Duodenalschlinge gelegenen Milz vorkommen, ausgezeichnet. - Bei den Teleostei erscheint sie in Gestalt einer cinzigen, bräunlich rothen, selten hellrothen, weichen, sehr blutreichen Masse, deren äussere Form verschiedenartig - - rundlich, länglich u. s. w. - sein kann. Ein Zerfallen in mchre Körper kömmt hüchstens ausuahmsweise vor ${ }^{4}$ ). Sie liegt in der Nähe des Magens oder des vordersten Abschnitles des Darmeanales, an Gefïssen haftend, dureh Banchfellfalten oder Bindegervebsbrücken befestigt. - Den Dipnoi kömmt ebenfalls eine Milz zul ${ }^{5}$ ).

[Ueber das Resultat der mikroskopischen Untersuchungen der Fischmilz s. besonders Schwager-Bardeleben 1. c.; Ecker in dem IIandwörteriuche d. Physiol. Bd. 4. S. 151.; Leydig, I, c. u. Kölliker Handbuch der mikroskop. Anat. Th. II. S. 269. - Die Malpighi'schen Körperchen sind bisher in der Hilz der Fische vermisst worden. Contractilität der Fischmilz wahrzunchmen, ist mir werler bei Plagiostomen, noch bei Knochenfischen gelungen. - Bemerkungen über die Lymphgefïsse der Milz s. b. Folımann, Saugadersyst. d. Wirbelth. S. 45.; wo auch der älteren Beobachtuugen von li e w son Erwähnung geschieht. - Nachträglich sei noch in Betreff des Vorkommens Malpighi'scher Körper her Milz des Störes verwiesen auf Leydig (Anat, histol. Unters. über Fische und Reptilien. Berl, 1853.]

\section{Sechster Abschnitt.}

\section{Von den Respirationsorganen und den ilmen morphologisch verwandten Gebilden.}

\section{S. 86 .}

Die Respirationsorgane, deren physiologischer Charakter der isi, dass ihnen aus venösen Bahneu Blut zugefüht wird, welehes in austretende arterielle Blutbahmen sich sammelt, erseheinen bei allen Fischen planmïssig unter der. Form inn erer Ki emen. Es bestehen diese in zarlen Schleim. hautverdoppelungen : den Ki em en b lä $t$ le r n, zwischendenen die Ausbreitung

4) Nebenmilzen habe ich einmal ausnahmsweise bei Pleuronectes maximus beobachtet.

5) Peters (Müller's Archiv. 1845. p. 8.) hat sie-Lei Rhinocryptis beobachtet, wo 0 wen sie. vermisste. 
der capillaren Gefässe, Zwecks respiratorischer Veränderung des in ilmeu enthaltenen Blutes, Statt hat $\left.{ }^{1}\right)$. Diese inneren Kiemen liegen in eigenen Räumen oder IIöhlen: den Kiemensäcken oder Kiemenhöhlen, in welche das Wasser, dessen Sauerstoffgehalt die Blutveränderung bewirkt, einzuströmen und aus welehen dasselbe auszuströmen vermag. Um dies zu erreichen, stehen die Kiemenhöhlen sowol mil dem Anfange des Traclus intestinalis, als auch mit der äusseren Hautoberfläche in Verbindung. Die Communication mit dem Anfange des Tractus intestinalis, unterhalb dessen die Kiemenhöhlen gelegen sind, geschieht immer durch zahlreiche in seine Höhle einmündende Oeffnungen: Pori branchiales interni; dicjenige der äusseren Hauloberfläche wird bald durch eben so viele entsprechende, nach aussen mündende Oeffnungen: Pori branchiales externi, bald durch eine einzige, gewöhnlich parige, selten umpaare Oeffnung bewirkt. - Die Anzahl der Kiemenblattreihen ist nicht nur, je nach Verschiedeuheit der Fischgruppen, grossen Verschicdenheiten unterworfen, sondern erfährt auch im Verlaufe der individuellen Entwickelung desselben Thieres Modificatio nen. Nicht minder verschieden zeigt sich die Ausdehnung der Kiemenblätter, indem dieselben bei manchen Fischen, namentlich den Plagiostomen, im Fötalzustande den Raum der. ihnen angewiesenen Höhlen nach aussen überschreiten und freie äussere Verlängerungen bilden, rücksichtlich welcher es noch zu ermitteln bleibt, ob sie blos respiratorischen Zwecken oder zugleich zur Absorption von Nahrungsstoffen dienen.

Nur bei einem einzigen Fische kommen neben inneren Kiemen auch äussere von der äusseren Haut überzogene Kiemen vor.

Die Lebensweise mancher Fische, welche das Wasser zeitweise verlassen, erheischt Einrichtungen, die sie in den Stand setzen, Behufs der Respiration erforderliches Wasser längere Zeit zu bewahren, um anf Kosten desselben zu athmen. Dergleichen Einrichtungen besitzen die der Familie der Pharyngii labyriuthiformes angehörigen, gleich wie auch einige andere Fische in eigenthümlichen blätterigen, von Schleimhant belieideten, Ausw üchsen, welche Behälter des Wassers und accessorische Athemorgane zugleich darstellen.

Andere Formen der Athmungsorgane, welche bisweilen neben mehr oder minder abortiven Kiemen vorkommen, sind lungenartige Auss a ckungen, die bald als Ausstülpungen der Kiemenhöhlen, bald als Bauchhöhlenlungen, welche von der ventralen Seite des Schlundes ausgehen, erscheinen.

Die verschiedenen Respirationsorgane erhalten, ausser dem ihnen vom Herzen aus zuströmeuden venösen Blute, das durch die Athmung in arte-

1) Sie sind jedoch bei Branchiostoma noch nicht nachgewiesen. 
rielles umgewandelt werden soll, ernährende Gefässe ${ }^{2}$ ) aus dem Körperarteriensysteme, deren Blut dann vieder in das Kürpervenensystem zurückgeführt wird. Bei den Teleostei treten ans den dorsalen Verlängerungen der Kiemenvenen Zweige zu dem Kiemen-Apparat, die für die Kiemenbogen und die Schleimhant derselben bestimml sind. Die Muskeln an der Basis der Kiemenstrahlen erhalten ihre Gofässe aus dem Kiemenvenenstamme jedes Bogens. Die Schleimhaut der Kiemenblättehen wird mit ernährenden Gefässen versorgt, welehe ans den am Rande der Kiemenblälchen herabsteigenden Kiemenvenen entspringen und baumartig sich verzweigen. Am äusseren Rande des Kiemenblätchens liegen die aus cinem weitmaschigen Gefïssnetze hervorgehenden Venae bronchiales, die in die Venae jugulares einmünden.

Durch ihre archilectonischen Verhältnisse sind den inneren Kiemen verwandt die Pseudobranchien, den lumgenatigen Anssackungen dic Schwimmblasen, indessen gehören beide functionel nicht in die Kalegoric der Respirationsorgane.

[Man vergleiche über die Respirationsorgane, ausser den einzelnen angefuhrten Arbeiten: du Verney, Oeurres anatomiques. Paris, 1761. 4. p. 496. - Doellinger Ueber die Vertheilung des Blutes in den Kiemen der Fische in Abhandl. d. math. phys. Klasse der Acad, der Wissensch, zu München. Thl. Ir. 1837. S. 785. Tb. 1. Alessandrini, de piscium apparatu respirationis tum speciatim Orthagorisci in Nov. comment. acad. scient. instit. Bononiens. 1839. T. HI. p. 359.; Observationes supra intima branchiarum structura piscium cartilagineorum. Comm. Bononiens. 1840. IV. p. 329. - Lereboullet, Anatomie comparée de l'appareil respiratoire dans les animaux vertébrés. Strasb. 1838. 4. - D üvernoy, in den Ann. des sc. natur. 1839. IIyrı, in den Medicin. Jahrbüchern des Oesterr. Staates. Bd. 24. 1九38. S. 232. G. R. Treviranus, Beobachlungen aus der Zoot. u. Phys. Brem. 1839. 4. S. 8.

\section{Von den Respirationsorganen.}

\$. 87.

Bei Branchiostoma ist der imnerhalb der Leibeshöhle gelegene Aufang des Tractus intestinalis, welcher hinten in die Speiscröhre sich fortsetzt, durch eine grosse Zahl von Spalten unterbrochen, die durch Knorpelstäbe gestülzl werden. Durch diese Spalien gelangt das in den Mund aufgenommene Wasser in die Leibeshöhle, die es dureh den weit vor dem Af er gelegenen einfachen Porus branchialis externus wieder verlisst. Die Schleimhaut bildet an den Mittelbalken faltenartige Lüngsleisten. Sie ist sowol an den Seitenrändern

2) S. die näheren Angaben bei J. Mäller, Vergl. Anat. d. Gefässsyst: der Myx. S. 34. nach Untersuchung von Esox u. Lucioperca. Abb. Tb. 3. Fig. 1. 
der Spalten, als auch an der Imenfäche der Leisten dicht mit Wimpern besetzt 1).

Die Myxinoiden²) besitzen jederseits platte, rund scheibenförınige, dachziegelarlig hinter cinander, unterhalb der Speiseröhre gelegene Kiemens äcke. Ihre Zahl beläufl sich bei Myxine und Bdellostoma hexatrema, sowie an der rechten Seite von Belcllostoma heterotrema, anf 6, während bei letztgeuanntem Thiece linkerseits 7 vorhanden sind. Jeder dieser Säcke besitzt cine innere Schleimhaut und eine sie auswendig dicht mmleidende fibröse Schicht. Die Schleimhaut jedes Kiemensackes erhebt sich zu Kiemenblättern. Dieselben stehen radial und gehen von der cinen Wand des platten Sackes zur anderen hinüber, bilden Septa, an deren kleinen Querfalten das Capillargofïsssystem sich ausbreitet und lassen Räune zwischen sich in die das Wasser eindringen kann. Es steht nämlich jeder Kiemensack durch zwei Gïnge: cinen Duchs oesophageus und einen Duchus culaneus sorvol mit der IHöhle des Oesophagus, als mit der ïusseren IIantoberfläche in Verbindung. Beide Gänge gehen von der Mitte jedes scheibenfürmigen Sackes aus; clras entfernt vom Umlireise der Insertion jedes Ganges enden die radial gestellten Kiemenblälter frei. - Die fibröse Schicht der Kiemenbcutel und der Gänge ist mit quergestreiften Muskeln belegt, die eine sehr bestimmte Anordnmog besilzen. - Das Verhallen der Ductus cutanei oder der äusseren Kiemengänge ist, je nach den Gattungen, wesentlich verschieden. Bei Bdellostoma besitzt jedex derselben sein eigenes Stigma externum; bei Myxine münden alle äusseren Kienengäuge, die also von verschiedener Lïnge sind, in cin einziges Sligma externum zusammen. Beide Catlungen besitzen ausserdem einen unparen, linkerseits gelegenen Duclus oesophagro-culaneus, der von der Speiscrühe unmittelbar nach aussen führt: bei Blellostoma in die letzte äussere, bei Myxine in d'e gemeinsame Kiemenülnung der linken Seite. - Jeder Kiemensack, mit seinem äusseren und inneren Gange, liegt in einem serösen Beutel, welcher iln cinmal dichı unkleidel und dann frei überzicht. Die serösen Bentel je zwei auf cinander folgender Säeke legen sich mit den entsprechenden Blïllern dicht an einander. So cutstehen aus zwei Blältern gebildete Septa. Jeder serüse Beutel communicitt durch eine Odfnung mit einem serösen Längsrohre, das rom vorderen Ende des Kiemenapparates bis zum Ilerzen reicht und den Kiemenarlerienslamm enthält. Durch seine Oeflinungen treten die cinzelnen Kiemenarterienäste. - Ausserhalb der serösen Bentel ist der ganze Kiemenapparat mil dem dazu gehörigen Abschnitte des Oesophagus von eigenthümlichen muskulösen Schleifen umgeben.

1) S. II üller, Branchiostoma. S. 98.

2) S. Näheres bei Müller, Vergl. Osteol. d. Myxinoïd, S. 198. und die Abb. Th. VII. u. dessen: Untersuchungen über die Eingeweide der Fische. S. 2.

Handb. d. Zootomie v. Siebold u. Stannius. II. 


\section{\$. 88 .}

Bei Petromyzon sind jederseits sicben häutige Kiemenbeutel, deren Verengerung durch einen besonderen Muskelapparal geschieht, vorhanden. Dureh die Terbindung der entsprechenden Wïnde zoveier hinter einander liegender Beutel entstehen quere Diaphragmata zwischen einzelnen Kiemenhöhlen. Zwïschen die Blätter zweier Sïclie trilt eine Kiemenarterie, um an den Kiemenblättern sich zu vertheilen. Die einzelnen Kiemenbentel, von elliptischer Form, sind fast quev von innen nach aussen gerichtet. An der imneren Cireumferenz jedes Beutels sind die Kiemenblälchen befestigt. Jeder Beutel besitzl zwei kurze Gänge; der eine führt in cin Spiraculum externum; dex andere in cin Spiraculum internum. Die Spiracula externa liegen der Reihe nach hinter cinander zwischen dem Gitterwerke des äusseren linorpeligen Kiemenkorbes, dem die Wandungeu der Kiemenbeutel auswärts angeheftet sind. Die inneren Gänge münden in einen medianen, unterhalb der Speiseröhre getegenen, hinten blind gegeschlossenen, vorne mit der Rachenhöhle zusammenhangenden, dünnhäutigen Bronchus. Zwei an seinem Eingange ge'egene Klappen hindern den Rücktrilt des in den Bronchus aufgenommenen Wasser's in die Rachenhöhle. Diese Klappen besizen eine solide Grundlage in zwei, vorn in Fäden auslaufenden Knorpelplatten, deren Berregungen dureh einen eigenen Muske!apparat geregelt werden.

Bei den Plagiostomen findet sich ebenfalls eine Reihe getrennter Kiemenbeutel. Die IIiute je zweier Kiemenbentel begrenzen einander aber nicht ummillebar; vielmehr liegen zrvischen iluen von den Kiemenbogen ansgeleude Knorpelstïbe, velche der Ausbreitung der IIäute zur Grundlage dienen. Diese Knorpelstäbe sind, vorzngsweise an ihrer Vorderflache, weniger an der hinteren, mit quergestreiften Muskehn belent, welche, in schrïger orler transverseller Richlung verlanfond, die Stäbe kreuzen, sowol an sie, als an das häulige Diaphragma sich befestigen und die Zusammenschnïrung der Kiemenbeulel besorgen. Jede Seite der Knorpelstabsreihe ist, answendig von der Muskulatur, durch die cigentliche Membran der Kiemenbentel belieidet. Die Membranen zweier auf cinander folgenden Kiemenbeutel bilden demnach, nebst den Knorpelstäben nud Muskeln, ein Diaplıragma zwischen je zwei Kiemenhöhlen. Die Häute sind an ihren den IJöhlen zugewendelen Seiten mit den Reihen der Kiemenblätler besetzt. An der dem Zungenbeine angefügten Vorderwand des ersten Kiemenbentels, so wie an der Wand des letzten haftet nur eine cinzige Kiemenblattreihe. Thic Höhle jedes Kiemenbentels mündet — mter Ab. wesenheit eines cigencn Bronchus - nach innen, mmiltelbar in die Raehenhöhle; nach anssen hat jede cinc freie Mündung. Die cinzelnen freien Mïndmogen werden durch schmalere ofler breitere', von der änsscren Haut ïberzogene Interstitien vou einander abgegreuzt. Bei den Squalidae wer- 
den diese Interstitien unterstützt durch äussere Knorpel, deren Summe einen abortiven Repräsentanten des äusseren Kiemenkorbes der Petromyzonten abgibt. - Die Spriacula externa liegen bei den Squalidae seitlich, bei den Rajidae an der Bauchflïche, einwärts ron den Brustflossen. Ihre Zahl beliuft sich - mit Ausnahme der Gattungen Hexanchus und Heptanchus, wo sie auf sechs und sieben steigt - joderseits auf fünf. - Die Kiemenblätler der Fötus von Plagiostomen bieten in so ferne eine bemerkenswerthe Eigenthümlichkeit dar, als sie in zarte gefässführende aus der Kiemenhöhle frei herausragende Fäden sich verlängern, die frühzeitig schwinden ${ }^{1}$ ).

\section{S. 89 .}

Bei den Holocephali, den Ganoïden, den Teleostei und den Dipnoi mangeln die äusseren Interstitien zwischen den Spiracula externa der einzelnen Kiemensäeke, unter meln oder minder bedeutender Reduction der Ausdehnung des Diaphragma zwischen den beiden cinander zunächst liegenden Kiemenblattreihen. Eine gemeinsane, durch einen Kiemendeckel geschützte änssere Oeffnung führt in die Kiemenhöhle, worin die bei den Plagiostomen je zwei Kiemenbeutehn angehörigen Kiemenblattreihen dem Verlaufe je eines soliden Kiemenbogens folgen. Zwischen zwei Kiemenbogen liegt ein, ein Spiraculum internum reprïsentirender, in die Rachenhöhle mündender Spalt oder Schlitz.

Die Chimären bilden hinsichtlich der allgemeinen Anordnung des Kiemenapparates die Uebergangsglieder zu den Teleostei.

Indem bei den Chimären das aus zwei Blättern bestehende Diaphragma bis zum freien Rande zweier auf cinander folgender Kiemenblattreihen sich erhebt und zugleich an den oberen und unteren Grenzen der Kiemenbogen in die gremeinsame Ilaut der Kiemenhöhle sich fortsetzt, besitzen sie wirkliche, wenn auch nach aussen unvollständige, Kiemenbeutel. Die zu einem, je zwei Kiemenblattreihen trennenden, Diaphragma vereinten Seilenwandungen je zweier derselben lehnen nämlich nach aussen hin, nicht mehr an Brücken der äusseren Cutis sich an. Deshalb ermangeh die Chimären anch discreter äusserer Spirssula. Ein durch die häutige Bekleidung des Zungenbeines und seiner Radii gebildeter Kiemendeclsel bildet einen beweglichen Verschluss der einzelnen äusseren Eingïnge in die Kiemenbentel. - Die Zahl der Kicmenbeutel belïuft sich auf vier. Dic erste halbe Kieme gehört dem Zungenbeine, die letzte dem vierten Kiemenbogen an. Jie halbe Zungenbeiukieme besitzt lïngere knorpelige Radii, als Grundlagen

1) S. über diese von Monro entdeckte Thatsache: F. S. Leuckart Untersuchungen über d. äusseren Kiemen der Embryonen von Rochen w. Ilaien. Stuttgard 1836. 8. Mt. Abb. Sie sind bisher angetroffen bei den Gattungen: Scyllium, Carcharias, Sphyrna, Mustelus, Selache, Alopias, Acanthias, Spinar, Scymnus, Pristis, Rhinobatus, Torperlo u, Raja. Vergl, anch J. Müller, Ucber den glatten llai des Aristoteles. Berl. 1840. 
ihrer Kiemenbentelwand; an den eigentlichen Kiemenbogen finden sich unterhalb der Insertion der Kiemenblïlter, und zwar am Hinterrande, statt der langen Kuorpclstäbe der Plagiostomen, nur sehr linrze Knorpelzaclien.

Bei Accipenser besitzt das hier dicke Diaphragma nicht medr solehe Ausdehnung, indem es, von seinem Kiemenbogen ans, nur bis zum driltein Viertheil der Länge je zweier von ihm geschiedener Kiemenblattreihen sich erhebt. J)ies Diaphragma, über dessen obere Grenze die Sehleimhaut der einen Kiemenblattreihe eines Bogens in die der zweiten Rrihe sich fortsetzl, schliesst daslische Fasern, so wie auch mehre Systeme discreter, zarter, in Sitmen anslaufender, quergestreifter Muslich, welche die Stellung der Kiemenstrahlen verändern, ein. An jeder der Aussentlïchen dirses Diaphragma ist nit dem lïngsten Theile stines cinen Randes ein solider linorpeliger oder ossificirter, oberhall, des Ditphlaragma sich verlïngernder Kiemenstrahl hefestigt. Der freie Rand desselben ist gezillnelt. Der solide Strahl dient der Ansbreitung der das respiratorische Gefiissnetz umfassenden Schleimhaut zur Grundlage.

Ihinsichnlich der Anzahl der Kiemenblattreihen bicten dic Ganoüden grosse Verschiedenheiten dar. Accipenser mul Lepidostens besitzen eine vordere, am Kiemendeckel haftende, cinfache Kiemenblattreihe und ausserdem vier Doppehecihen von Kiemenblïtern; zwischen der hintersten und dem Os pharyngenm fintel sich din Spalt. Bei Polyplerus und Spalularia 1) fehlt die Kiemendectielkiene und bei Polypterus ist anch an vierten Kiemenbogen nur eine Kiemenblattreihe befestigt; linter dieser lelzteren mangelt der Spalt. Nicht minder versehieften zeigt sich die Anordunng des Kiemendeckels.

Bei den meisten Teleostei ${ }^{2}$ ) erscheint das zwischen zwei, demselben Kiemenbogen angehörigen. Kiemenblattrihen gelegene Biophragme in der Regel viel niedriger und verkïmmerter, als bei Accipenser, indem es kaum bis an das erste Driltheil der Länge der Kiemenblätre sich zu erheben pflegt. T)asselbe schliesst häufig mehre Systeme quergestreifter lileinex Muskeh ein, welche die soliden Grundlagan der Kiemenblïlter: die Kiemenstrahlen cinander nähern und zwar theils die cinander gevenüberliegenden, theils die neben einander gelegenen.

Jedes Kiemenblattehen der Teleostei, wie auch der Ganoüdei, beshelht nämlich gewöhnlich aus einem ron Schlcimhaut äberzogenen soliden Strahle. An den doppelblialterigen hiemen erhebt sich lïngs jedem Rande der in der Convexität eines Kitmenbogens hetindlichen hime ein soleher Strahl. Alle

1) Bci Spatularia ist das ohere Drittheil des vierten Jiemenlogens angewachsen und trägt so weit nur eine Kiemenblatreihe.

2) Ueber die etwas abweichenden Verhälthisse ron Xiphias s. Rosenthal, Abh. aus d. P'hysiol. Berl. 1524. 8. Tb. 6. und Cuvier, (llist. nat. d. poiss. T. VIII. p. 263.). 
diese Strahlen sind dureh ihre Basis mit dem knöchernen Kiemenhogen nicht verwachsen, sondern ihn leicht bewreglich angerü̈gh. Sie gehören anch nicht sowol den Kuochenlogen selbst, als der sie belileidenden Menbran an, denn an der oberen und unleren Gronze cincr Kiemenblattreilhe sicht man sie häufigg gar nicht mehr an den Knochen, sondern nur an der Bekleidung der Kiemenhöhle befestigl. Hier geht auch die hinlere Kiemenblattreihe des einen Bogens in dic vordere des folgenden Bogens bisweilen bogenförmigg und ununterbrochen äber, wie dies z. B. bei manchen Ostraciones besonders denlich ist. Jeder Strahl ist von scinem freien Eude bis zu seiner Basis mit Sehleimhaul locker behleidet. Dieser Ueberzug setzt an der oberen Grenze des Diaphragma, also zwisehen je zrvei Strahlenreihen, von einer derselben auf die gegenüberliegende sich fort; an der Aussenseite der Basis verbindet er aber auch die Strahlen derselben Reihe. Die die cinzelnen soliden Strahlen bedeckende Schleimhaut haftet an denselben nicht innis, sondern bildet einen weiten Ueberzug derselben, verlängert sich namenlich seitlich über ihre Grenze und bildel äusserst zahliciche Querfalten, duch welche eine beträchtliche Fächenvermehrung zu Slande kömmi. Man sicht daher, bei passender Vergrösserung, an den Rïndern der Kiemenstrahlen zottenartige, freie, conische, bald schräg, bald quer gerichtete Fortsätze oder Aussackungen; bisweilen erscheint ein Kiemenblätchen, wie ein gefiedertes Blalt. Bei der Familie der Jophobranchii folgt auf die dïnnere Basis ein rundlich erreitertes Ende, woraus denn cine kenlenfömige frestalt resultirt. Annähernd findel sich eine solehe Bildung auch bei einigen Loricarinen.

Der Schleimhantüberzug der Kiemenstrahlen bildet die Grundlage für die Ausbreilung des respiratorischen Gefïssnetzes. Aus der. in rer Rinne der Convexitäl des Kimmenbogens verlaufenden, Arleria branchialis geht für jedes Kiemenblätehen, bald unmittelbar, bald millelbar, eine Arterie hervor. Diese Arlerir steigt längs den inneren Rande des Blällchens anf. Jede quere Falte der Schleimhaul erhält ihren eignenen Zweig ans dem Längsstïmmehen. Jeder solcher Zweig bildet, inden er plötzlich in sehr zarte Zrveige sich auflösel, ein änsserst feines und dichles, schr oberflïhlich gelegenes Capillargelïssnetz. Aus diesem sammelt sich das arteriell gewordene Blut jeder Querfalte allmïlich in cinen Kicmenvenenzweigg, welcher in den der Arteric des Blältrhens entsprechenden Jängsvenenstamm sich sammell, der an äusseren Rande des Kiemenblälchens verlïuft und in den Kiemenvenenstamm seiner Seite sich einsenkt ${ }^{3}$ ).

Bei der Mehrzahl der Teleostei ist jeder der vier rigenllichen Kiemenbogen nil zwei Reihen von Kiemenhlätern beselzl: welehe gewöhnlieh nur

3) S. Näheres über diese Gefissverhaltnisse bei Düllinger und auch bei II yrtl in den med, Jahrbüchern d. Oesterr. Staates. 1838. Bd. 15. S. 235. 
die Gegend des zweilen und dritten Segmentes des kuöcherneu Bogens einnehmen. Eine Verringerung der Anzahl der Kiemenblaltreihen kümmt indessen häufig vor. Indem nämlich der vierte Kiemenbogen einblätterig wird, besitzen viele Teleostei nur $3 \frac{1}{2}$ Kiemenblattreihen, womit denu auch Mangel des letzten Kiemenspaltes verbunden ist ${ }^{4}$ ). - Bei anderen fehlen die Kiemenblïlter am ganzen vierten Bogen spurlos, wie bei Cotylis und Sicyases unter den Cyclopoden, bei Lophius und Batrachus unter den Pediculati, bei Diodon und Tetrodon unter den Plectognathi Gymnodontes, bei Monoplerus unter den Symbranchii. - Bei der Gattung Malthaea trägt anch der dritte Kiemenbogen nur eine Reihe von Blältchen, so dass nur $2 \frac{1}{2}$ Kiemenblattreihen übrig bleiben. - Bei Amphipnous Cuchia endlich erhält sich nur am zweiten Kiemenbogen eine lileine eigentliche Kieme, indem der erste und vierte Bogen völlig liemenlos sind, der dritte Bogen aber nur eine glatte IIautleiste ohne Kiemenblättehen besitzt.

In der Regel sind die beiden Blällerreihen desselben Kiemenbogens von ungefilir gleicher Lïnge; doch kommen viclfache Ausnahmen von dicser Regel vor, z. B. an dem ersten Kiemenbogen der Cyprinen und einheimischen Salmones, wo die vordere Blätterreihe kürzer, als die hintere, ist und an dem letzlen Kiemenbogen schr vieler Fische, wo die lelzte Blätterreihe kürzer, oft abortiv isi und anch fehlen kann. - Uebrigens erreichen die Blätter bei den verschiedenen Fischen cine sehr versehiedene IIöhe orler Länge. Lang und hoch sind sie z. B. bei den Clupeïdae, Salmones, Cyprinoüdei, liurz und niedrig bei den meisten Cataphracti, Blemnioïlei, Pediculali, Pharyngii Labyrinthiformes. Bei Anabas scandens kommen lïngs dem vierten Kiemenbogen nur sehr liurze, auf einen kleinen Raum beschränkte Kiemenblälter vor.

Die Kiemenbogen sind mit den an ilmen haftenden Kiemenblïttern durch den beveglichen, die Kiemenhöhle auswendig bedeckenden, Kiemendeckel von aussen geschülzt. Den Ausgang für das durch das Maul aufgenommene Wasser aus der Kiemenhöhle bildet ein, in der Regel pariger, seitlicher, schräg von oben und hinten nach unten und vorne sich erstreckender, Spalt. Dieser ist gervöhnlich weit und bei einigen Familien, z. B. den Cyprinoülen, den Salmones, vor Allen aber bei vielen Scomberoïden und Clupeïlen sehr lang; bei anderen aber, wie bei vielen Pediculati, Mormyri, Plectognathi und Mmaenoüdei ist er seln eng und meist auf eine kleine seitliche Oeflunng reducirt. Bei den Symbranchii verschmelzen die beiden Spalten zu einer einzigen medianen Oeflnung, welche

4) Dahin gehören die Gattungen: Cottus, Agonus, Scorpacna, Sebastes, Synanceia, Synancidium, Apistes unter den Cataphracten; Cyclopterus, Liparis, Lepadogaster, Goliesox unter den Cyclopoden; Zeus unter den Scomberö̈den; Chironectes unter den Pediculati; so wie endlich die Gruppe der Labroïdei cycloĩdei. 
indessen in der Mille dureh ein Seplum gelheilt sein kann, wic z. B. bei Monopterus.

Die die Communication mit dem Schlunde bevirkenden Interbranchialspalten sind von sehr versehiedener Ausdehnung. Bei vielen Teleostei sind diese Spalten dadurch verkleinert, dass die hätligen Ueberzüge je zıvei benachbarte Bogen an ihren Grenzen eng mit einander sich verbinden, oder von cinem soliden Bogen zum benaclibarten sich hinüberzichen, wie bei vielen Cyprinen, den Plectognathi, den Lophobranchii und vor Allen bei Muraenophis, bei dem die Spalten durch kleine runde Löcher, welche den überliegenden Schlund durchbohreu, vertreten werden. - Gewöhnlich nehmen die Interbranchialspalten von vorne nach hinten an Ausdehnung allmälich ab, so dass der zwischen dem vierten Kiemenbogen und dem Os pharyn. geum inferius gelegene der kleinste wird. Sehr klein und eng ist dieser hinterste Spalt bei den Gadoüden und cinigen Cataphracten, z. B. Pterois, Uranoscopus u. A. - Nicht selten fehlt der letzte Spalt zwisehen dem vierten Kiemenbogen und dem os pharyngeum inferius, indem dic häutige Bekleidung von jenem auf diesen Knochen unmittelbar sich fortselzt. Dicser Mangel des letzten Kiemenspaltes hangt mit Anrvesenheit blos einer Kicmenblattreihe an dem vierten Kiemenbogen eng zusammen.

An der hinteren Grenze der Kiemenhöhle, längs dem oberen Theile des Schultergürtels, kommen sowol bei Accipenser, als auch bei cinigen Teleostei absondernde Follikel vor (Folliculi branchiales) die mit weiten Oclfunngen nach aussen münden. Unter den Teleostei sind sic namentlich bei batrachus tau ${ }^{5}$ ) sehr deutlich.

Was die Dipnoi ${ }^{6}$ ) aubetrifft, so besitzen sowol Lepidosiren, als Rhinocryptis eine cinfache keihe von Kiemenblättern an der Haut der vorteren Wand der Kiemenhöhle über dem ersten Kiemenbogen; bei I.epidosiren ist der zweite Kiemenbogen nur an seinem hinteren Ende mit Kiemenblältern besetzt; der dritte und vierte tragen sie nach ihrer ganzen Iänge; rler fünfte ist nackt. Bei Rhinocryptis sind der zweile und dritte Bogen liemenlos; der vierte und fünfte tragen jeder cine doppelte Reihe von Kiemenblätteru, bis zu deren Mitte ein Diaphragma sich erhebt. Ueber dem sechsten Kiemenbogen liegt eine ciufache Kiemenblatheihe an der hinteren Wand der Kiemenhöhle.

$$
\text { \$. } 90 \text {. }
$$

Was die accessorischen $\Lambda$ thmungsorgane ${ }^{1}$ ) der Fische anbe-

5) Bei Lophius piscatorius liegt an derselben Stelle der Thymus-Sack; bei Batrachus surinamensis vermisse ich die Folliculi.

6) S. das Nähere in den betreffenden Schriften.

1) Wohin ein von Ehrenberg bei Ileterotis Ehrenbergii. Va J. an dem vierten Kiemenbogen heobachtetes Organ zu rechnen, ist noch nicht ganz aufgeklärt. S. Va- 
triflt, so sind 1. ä ussere Kiemen ${ }^{2}$ ) und zwar neben inneren Kiemen und Lungen, bei Rhinoeryptis angetrollen worden. Ihrer sind jederseits drei, hinter der Kiemenöllnung gelegen, nuverästelt. T)ic Vorderseite ist vou einer Fortsetzung dex äusseren IIaut gebilded, dic Minterseile weich, sammlartig, ungefïrbt, mit feinen Zellen dicht beselzt mol zur federartigen Vertheilung der Gefïsse bestimmt. Diese sind: Arterien aus den inmeren Kiemenarterien mn Venen, die in die imneren Kiemenvenen übergehen.

2. Baumförmige Bildungen an der convexen Seite des nächst oberen Segmentes des zweiten und vierten Kiemenbogens von IIcterobranchus anguillaris, dessen Kiemenhöhle zu ihrer Aufnahme nach hinten verlïngerl ist. Der vordere, dem zweilen Kienenbogen angehörige Auswuchs ist unbetrichllicher als der hintere, weleher letzlese auch in viel zahlreichere Acste zerfällt. Das Gerïst bildet cin ziemlich weicher, knorpelartiger Kern, der vou Schleimhaut überzogen ist, unlerhalb welcher die Gofässe verlaufen. Diese slammen aus den Kiemenarterien und treten in Kiemen venen ${ }^{3}$ ). Aehnlich verhält sich die Gattung Clarias.

3. Die siebbeinförmigen Labyriuthe ${ }^{4}$ ) an dem inneren Theile des den Ossa pharyngea superiora zunäclıst ggelegenen Seguentes des rordersten Kiemenbogens bei der Familie der Pharyngii labyrinthiformes: mehrfach oder vielfach gewundene oder durchbrochene:Knochenblättchen, in ihren IIöhlungen Wasser aufnehmend, das durch eine Oeffnmog eintritt, vou Schleimhantausbreitungen überzogen, an wolche Zweige der Kiemenarterien sich verbreilen und von welehen aus andere Zweige in die Kiemenvenen übergehen. Am ansgebildetsten sind sie bei Anabas und Osphromenus, am werigsten bei Polyacanthus und Ophiecphahus. Die Kicmenhöhlen sind zu ilner Beherbergung durch starke Wälbung des OpercularApparates und andere Eimrichtungen besonders niodificirt.

4. Accessorische in eigenen Höhlen eingeschlossene Kiemenblattreihen bei lutodeira chanos ${ }^{5}$ ).

enciennes, Poiss. Vol. XIX. Vermuthlich gehört es den baumförmigen Bildungen von Heterobranchus und Clarias an.

2) Peters in Müller's Archiv. 1845.

3) Ueber Heterobranchus s. Geoffroy im Bullet. philomat. Ann. X. n. 62. p. 105. - Ileusinger im Berichte von d. zootom. Anstalt zu Würzburg. Würzburg. 1826. S. 42. - Valenciennes, Hist. nat. d. poiss. Vol. XV. p. 353. - Allessan drin in den Comment. nov. acad, scient. Bononiens. Vol. V. 1841., wo namentlich die Verhältnisse des Gefässsystemes berücksichtigt sind.

4) Vergl. über dieselben Cuvier, Hist. nat. d. poiss. Vol. VII. p. 323. mt. Abb. Tb. 205. u. 206. u. J. Taylor, on the respiratory organs of certain fishes of the Ganges in Brewster's, Edinburgh journal of science. 1831. N. IX. p. 33. Ausgezogen in der Isis, 1835. S. 308.

5) J. Müller hat zuerst auf diese merkwürdige Bildung hingewiesen. Bau u. Grenzen der Ganoïden. S. 75. Die Kieme des vierten liiemenbogens ist, soweit sie 
5. Die Kiemenhöhlenlungen. Bei Saccohranchus siugio ${ }^{6}$ ) erstrect sich, von der Kiemenhöhle aus, cin langer Sack in die Seitenmuskeln über den Rippen. Er ist von querlaufenden Muskelfasern umgeben und nimml Wasser anf. Seine Gefïse stammen ans der Jetzten Kiemenarterie und gehen in die Aorta über. - Bei Amphipnous Cuchia ${ }^{7}$ ) gelit zwischen den oberen Fuden des Zungenbeines nnd des ersten Kiemenbogens jeder Seite cine Blase ab, welehe hinter dem Kopfe, zu jeder Seite des Nackens liegt. Sie ist sehr gefüssreich und erhält ihre Gefïsse aus Kiemenarlevien; die aus der Blase austrelenden Gefässe vereinigen sich zur Bildung der Aorta.

6. Dic Rumpflı̈hlenlungen der Dipnoi. Bei Lepidosiren ${ }^{8}$ geht von der ventralen Wand der Speiscröhre, etwas nach rechts, durch eine longitudinale spaltförmige Glottis, welehe scitlich von zwei wulsligen, lippenähnlichen Schleimhaulfalten, dic einen Sphincter einschliessen, begrenzt wird, und vor der, an der unteren Wand des Schlundes, ein lileiner Knorpel liegt, cine kurze häutige Luftröhre ab, die in cine weite, invendig zellige IIöhle übergeht. Diese setzt von der ventralen Seite um die Speiseröhre tretend, an die Dorsalseite des Körpers sich fort, um in zwei, unter der Chorda, ausserhalb der Peritonealhöhle, linten über den Nieren gelegene, vom Kopfe bis zum After sich erstreckende Lungensäeke zu zerfallen. Die innere Oberfläche derselben besitzt ein Nelz ron Balken und Zellen; dies zeigt sich in der vorderen Hälfte ähulich wie in der Lunge der Ophidier, in der hinteren ähnlich wie in der der Batrachier bescliaffen ${ }^{9}$ ).

an dem Jritten Kinochenstücke desselben (von oben gezählt) befestigt ist, doppelblättrig; an dem zweiten Knochensegmente von ohen ist sie dagegen eimblätrig und der Haut der Kiemenhöhle angewachsen. Von der Verbindungsstelle dieser beiden Segmente des vierten Kiemenbogens einerseits und dem äusseren Ende des Os pharyngeum inferius andererseits, erhel, sich ein weicher halbcirkelfürmiger Canal, der hinter der Auskleidung der Kiemenhöhle nach der äusseren Schedelwand hin aufsteigt, sich dann abwärts krümmt und mit einer. Ampulle blind endigt. Seine Höhle steht da, wo er vom Ende des Os pharyngeum ausgeht, mit der Rachenhöhle durch eine Oeffnung in Verbindung. Dieser Canal enthält cine accessorisehe blättrige Kieme, deren Blättchen linorpelige Stützen besitzen; seine häutigen Theile sind eine Strecke wcit durch weichen linorpel gestützt und aussen von Muskelsubstanz an einigen Stellen umgeben, die wahrscheinlich das in ihm angesammelte Wasser auspresst.

6) Heteropneustes fossilis Müler. - S. ausser der Abhandlung von Taylor, Valenciennes in d. ilist. nat. d. poiss. XV. p. 402. u. Duvernoy im Amtl. Berichte über die Versamml. der Naturf. zu Aachen. Aachen, 1849. S. 155.

7) S. Taylor l. c.

8) Ich folge Iyrtl I. c. S. 29. Abb. Tb. 3. Fig. 1.2. Aehnlich schildert Peters (II üller's Archiv. 1845.'S. 8.) die Lungen von Rhinocryptis.

9) Ueber die noch nicht hinlänglich charakterisirten Lungen des Gymnarchus. S. $\$ 92$. Anmerk. 


\section{Von den Pseudobranchien.}

\$. 91 .

Unter der Benennung der Nebenkiemen oder Pseudobranchien werden etwas versehiedentlich gelegene Gebilde znsammengefasst, welche den meisten, obschon bei weitem nicht allen, der in die Ordnungen der Elasmobranchii, Ganoüdei und Teleostei gehörigen Fische zukommen. Diese Gebilde sind im Allgemeinen nach dem Plane der respiratorischen Kiemen gebauet; sie bilden anch Gerüste, an denen die zu ihnen tretenden Gefässe in Capillaren zerfallen, aus welchen Jetzteren wiedernm abführende Gefïsse hervorgehen. Nach absolvirter fölaler Entwickelung der Fische entstehen ihre Blut zuführenden Gefïsse nicht ans den-Kiemenarterien, sondern ans solehen Blutbahmen, welche arterielles Blut enthalten und die ans deren Capillaren sich sammelnden Stämme münden nicht direct in Venen ein, sondern fïhren ihr Blut, Arterien gleich, anderen Organen, namentlich der Chorioïdea des Anges und, beim Stör und den Plagiostomen, auch dem Gehirne zu, aus welehen Organen dasselbe erst in venöse Blutbahnen gelangt. So erscheinen sie, nach absolvirter fötalcr Entwickelung, als Gerüst für die Ausbreitung von artericllen Wundernetzen. Embryologische Forschungen $\left.{ }^{1}\right)$ machen es indessen wahrseheinlich, dass diese Gebilde, wenigstens bei Knochenfischen, in früheren Entwiclelungsstadicu, auch in Betreff des Ursprunges ihrer Gefïsse, den wirklichen respiratorischen Kiemen gleich sich verhalten. Es scheint demnach, als ob die gleichen Gebilde in versehiedenen Lebensstadien eine verschiedene physiologische Verwendung erfahren.

Bei den mejsten Plagiostomen liegt die Psendobranchie am vorderen Unfange des Spritzloches. Dic Schlcimhant der Spritzlochshöhle bildet cine Reihe senkrechter, kiemenarliger oder kammartiger Falten, welehe bisweilen Querfältchen besitzen. Bei den Carchariac, wo die eigentlichen Spritzlöcher fehlen und eine blinde Vertiefung der Rachenhöhle ihren unteren Eingang vertritt, liegen die Grfïsskörper der Nebenkiemen an deren Ende, aber nicht mehr innerhalb ihrer Itöhle, sondern auf dem Kiefersuspensorium, durch Bindegewehe verdeckt. Bei einigen Squalidac und Rajidae fehlen, trolz der Anwesenheit von Spritzlïehern, die Psendobranchien ganz 2). - Eine Analogie ihrer anatomisehen Anordnung mit der der wahren Kiemen stellt dadureh sich herans, dass die Falten oder Blätter der

1) S. Baer, Unters. über die Entwickelungsgesch. der Fische, S. 27. - Vogt, Embryol. des Salmones. p. 226.

2) Dahin gehören Scymnus (wo sie aber bei jungen Fötus vorhanden sind), Lamna, Myliobatis, Trygon, Taeniura. - Auch den Holocephali, hier aber unter Mangel der Spritzlöcher, fehlen die Pseudobranchien. 
Psendobranchien bei Embryonen einiger IIaien, als fadenförmige äussere Verlängerungen aus dèn Spritzloche frei vorragen. Diese Fäden der Nebenkiemen schwinden früher als diejenigen der eigentlichen Kiemenblätter ${ }^{3}$ ).

Was die Ganoïden anbetrifft, so mangeln die Pseudobranchicn bei Polypterus und Amia, finden sich dagegen bei Lepidosteus, so wie bei den Ganoïdei chondrostei, mit Ausnahme von Scaphirhynchus. Bei Accipenser liegt eine Pseudobranchie an der inneren Apertur jedes Sprizloches anf der Schleimhaut der Rachenhöhle, ist kammförmig und besitzt 15 Falten, welche kleinere Querfalten bilden.

Unter den Teleostei ist das Vorkommen der Pseudobranchien sehr allgemein 4). Sie finden sich gewölnlich hinter dem queren Gaumenmuskel unter dem Os temporale. Sic liegen bald unbedeckt frei und haben danu die äussere Form einer wirklichen Kiemenblattreihe, wobei sie ganz angewachsen oder frei sein kömnen oder sie sind überzogen von der äusseren IIaut der Kiemenhöhle und bisweilen versteckt unter Bindegewebe und Muskehn, in welehem Falle sic gewöhnlich als gelappte und unförmlicher gestaltete, scheinbar drüsige, blutrothe ${ }^{5}$ ) Organe sich zeigen. Die Zahl der Lappen ist verschieden; sie sind bald regelmässiger angeordnet, wie bei Tinca, bald unregelmässiger, wie bei Esox, bei Belone u. $\Lambda$. Die Pseudobranchien von beiderlei äusserer Form zeigen in den wesentlichen Verhältnissen Uebereinstimmmng ihres Baues. Jedes Blatt der kiemenartigen Pseudobranchien besteht gewöhnlich aus einem knorpeligen, bisweilen gezähnelten Strahle, der von einer gefalteten Schleimhaut überzogen ist, die

3) Vgl. Leuckart, Unters. üb. d. äusseren Kiemen d. Embryonen von Rochen u. IJaien. Stuttg. 1836. 8. S. 17. u. 34. - Sie sind uamentlich bei Embryonen von Acanthios, Spinax, Mustelus, Scyllium u. Scymnus lichia angetroffen.

4) Indessen ist ihre Abwesenheit beobachtet worden: unter den Gymnodontes bei Tetrodon testudinarius, bei sämmtlichen Physostomi apodes, bei mehren Clupeidae, namentlich den Gattungen: Stomias, Chauliodus, Chirocentrus, Notopterus, Osteoglossum, Ifeterotis, Sudis, bei den Mormyri, bei mehren Cyprinodontes, namentlich den Gattungen Poecilia, Lebias, Orestias, unter den Cyprinoïdei bei Cobitis, ferner bei den meisten Siluri, bei meliren Notacanthini, namentlich bei Mastacemblus u. Notacanthus. - Ihr Verhältniss zur Choroidealdrüse - die ihre arteriellen Gefässe durch die Vasa revehentiu der Pseudobranchie erhält, (s. \$. 105.) - ist Folgendes: Unter den línochenfischen ist kein Beispiel von llangel der Choroülealdrüse bei Anwesenheit einer Pseudobranchie bekannt. - Nur bei Ganoïlen und Plagiostomen ist letztere ohne gleichzeitige Anwesenheit einer eigentlichen Choroüdealdrüse vorhanden, indem die Fasa revehentia auch nicht ausschliesslich zur Chorioüdea treten, sondern einen weiteren Bereich haben. - Selten, wie hei Erythrinus, Osteoglossum, Notopterus, kommt die Choroïdealdrüse spurweise, ohne Vorhandensein einer Pseudobranchie, vor. - Vielen Fischen (mit kleinen Augen), fehlen Pseudobranchie u. Choroïdealdrüse zugleich z. B. den Siluroìden, den Aalen, Cobitis.

5) Die drüsige Form der Pseudobranchien kömmt z. B. vor bei den Gadoüden, den Scomber-Esoces, bei Esox. 
der Ausbreitung der Gefässe zur Grundlage dient ${ }^{5}$ ); doch kann dieser knorpelige Strahlı auch fehlen. Die Blätter der drüsigen Form sind oft kürzer, dicker und minder regelmässig gestaltet, als die der kammartigen Psendobranchien.

Ausser der in den Blätern der Pseudobranchien in Capillaren zerfallenden Arteria hyoüdea, erhalten dieselben ein eigenes System von ernährenden Gefässen, die den Vasa bronchialia der Kiemeublättehen analog sind ${ }^{7}$ ).

[Unsere Kenntnisse über die Pseudobranchien und namentlich über ihr Verhältniss zum Gefässsysteme verdanken wir J. Müller, der ihr Verhalten in seinem Meisterwerke, der "vergleichenden Anatomie des Gefässsystemes der Myxinoïden", mit bewundernswerther Genauigkeit gesshildert hat.]

\section{Von der Schwimmbláse.}

\$. 92.

Die Schwimmblase ist ein von mehren IÏ̈uten gebildetes, lohles, gashaltiges Organ, das, seinen allgemeinsten lagenverhältnissen nach, in architectoniseher Beziehung, einem Bronchialgerüst vergleichbar erseheint, den Ursprungsverhältnissen seiner Gefässstämme nach, jedoeh von den Lungen wesentlich unterschieden ist, dessen physiologisehe Verwerlhung für den Organismus der Fische in einer gasförmigen Abscheidung besleht, deren willkïrliche oder unvillkürliche Compression orler Expansion eine Veränderung des specifischen Gerrichtes des Thieres oder eine Verschiebung der Lage des Schwerpunktes in seinem Körper zur Folge haben kann.

In Betreff ihres Vorkommens gilt folgendes: Bei den Gruppen der Leptocardii, Marsipobranchii, Elasmohranchii und Sirenoülei fehlt sie durehaus, wïhrend sie allen Ganö̈dei nnd den meisten Fanilien der Teleostei zukömmt. Einzelne Familien der letzteren ermangein ilırer gänzlich; dahin gehören unter den Acanthopteri dic Blenioindei, unter den Anacanthini dic Plenronectides, unter den Physostomi die Loriearini und Symbranchii, so wie auch die noch nicht untergebrachte Gattung Ammodytes. Bisweilen fehlt sie den meisten Reprïsentanten eincr Familie und liömmt nur wenigen zu; dies ist z. B. der Fall rüclsichtlich der Gobioüdei ${ }^{1}$ ) mit Einschluss

6) Auffallend war mir die Erscheinung einzelner sehr langer, fadenförmiger Verlängerungen der Blätter der Pseudobranchie bei einem jungen, $1 \frac{1}{2}$ Fuss langen Lachs, die ich in den letzten Tagen des April wahrnahm.

7) S. Müll er Gefässsyst. d. Myxinoïd. S, 53.

1) Unter den Gobioildei fehlt sie den meisten Arten der Gattung Gohius (mit Ausnahme von Gobius guttatus), fehtt den Gattungen Trypauchen, Sicydium, Callionymus, Trichonotus, Platyptera, Comephorus, findet sich dagegen bei einigen Gattun- 
der Cycloporles und rücksichtlich der Scopelini, wo sie bei Paralepis vorhanden isl. Sonst mangelt sie oft einzelnen Gattungen, während die nächst verwandtcn, der nämlichen Familie angehörigen, sie besitzen ${ }^{2}$ ). Ja sie kam sclbst einzelnen Arten einer Gattung fehlen, anderen znkommen. - Was ihre Lage anbetrifl, so liisst sich im Allgemeinen sagen, dass sie in der Rumpfhöhle sich fundel, olne jedoch auf deren Bereich beschränkt zu sein. Sie liegt hier ausserhalh der eigentlichen Peritonealhöhle, indem nur ihre untere Flïche vom Bauchfelle belikidet zu sein pflegt, unter den Nieren und der diese unten überzichenden fibrösen Membran oder numittelbar unter den Wirbelkürpern. Je nach ihrer verschiedenen Ausdehunng, erstreckt sie sich durch die ganze Rumpfhöhle oder nimmt nur einen Theil derselben ein, wie z. B. beim Stör, bei den Pediculati, den Plectognathi Gymnodontes, bei Syngnathus u. A. - Sehr häufis überschreitet sie jedoch mit ihren Enden die Länge der eigentlichen Rumpfhöhle. Dies geschieht in Betreff ihres hinteren Eudes in verschiedener Weise: 1. Bei vielen Acanthopteri, wo sie hinten in zwei Zipfel oder IIörner sich spaltet, liegen dicse auf den Dornen der absteigenden Bogenschenkel der Schwanzwirbel und anf den Ossa interspinalia der Afterflosse und werden von deren Muskulatur bedecki. Dies ist der Fall bei vielen Squamipennes (z. B. bei Drepane punctata und longimana, bei Ilolacauthus tricolor, Psettus xhombeus, Pimelepterus marciac und longipinnis) bei viclen Sparoïdei und Maenides (z. B. bei Arten der Gattung Lethrinus, bei Cantharus vulgaris,

gen. Der kleinen Gruppe der Cyclopodes scheint sie allgemein zu fehlen, wenigstens gilt dies von Cyclopterus, Liparis, Lepadogaster, Cotylis.

2) Unter den Percoiden fehlt sie bei Cirrhites, Chironemus, Trachinus, Percis, Aphritis, Percophis, Uranoscopus, Nullus. Mehren Arten der Gattung Polynemus fehlt sie, während sie eben so vielen anderen zukömmt. Unter den Cataphracti fehlt sie bei Cephalacanthus, Cottus, Aspidophorus, Platycephalus, Hemitripterus, Scorpacna. Die Gattung Sebastes enthält Arten, denen sie zuliummt (z. B. S. norwegicus) und andere, denen sie mangelt. Unter den Sparoīdei fehlt sie bei Latilus; unter den Sciaenoïdei bei Eleginus. In der-Gattung Umbrina kommen Arten vor, denen sie fehlt, neben anderen, die sie besitzen (U, vulgaris). Unter den Labyrinthici feht-sie bei Macropodus und Spirobranchus. Unter den Scomberö̈dei folılt sie bei Scomber scombrus, während andere Arten derselben Gattung sie besitzen; bei Thynnus vulgaris und alalonga, während amderen Arten, z. B. Th. brachypterus eine Schwimmblase zukömmt; sie fehlt in Jerselben Fanilie bei Auxis, Pelamys, Elacate, Stromateus, Coryphaena, Lampugus. Unter den Squamipennes fehlt sie bei Brama Raji. Unter den Taenioïdei bei Trachypterus und Gymnetrus. Unter den Pediculati bei Lophius, bei Malthaea, bei Chironectes hirsutus, während sic den meisten Arten der letztgenannten Gallung, so wie auch den bisher untersuchten Arten der Gattung Batrachus zukümmi. Unter den Pharynognathi malacopteri fehit sie bei Sarris Raff. und bei Scomberesor Rondeletii, während S. Camperi sio besitzt. Unter den Siluroüdei fehlt sie den Gattungen IYyophthahmus, Cetopsis und Pygidium, unter den Plectognathi bei Orthagoriscus, unter den Cyprinoüdei bei Balithora, unter den Clupeidae bei Alepocephalus. 
Box vulgaris, Oblada melanura, Maena vulgaris, Smaris vulgaris), bei vielen Scomberoüdei (z. B. bei Lichia amia, Chorinemus saltans, Caranx trachurus u. A.), bei mehren Theutyi (Acanthurus, Naseus u. A.), einigen Taeniö̀dei (Cepola) und selbst bei einigen Labroïdei (Lachnolaïmus), wie anch die Percoïden in Dules maculatus u. A. Beispiele dieser Art liefern ${ }^{3}$ ). 2. Bei einigen Fischen liegt ihre über die Rumpfhöhle hinausreichende Verlïngerung in einer Höhlung des ersten Interspinalknochens der Afterflosse. So bei Pagellus calamus und P. seriba. 3. Bei auderen, wie bei einigen Exocoetus, verlïngert sich ihr hinteres Ende in den sehr erweiterten Canal der unteren Wirbelbogenschenkel des Anfanges der Schwanzsegend. 4. Bei anderen, wie bei Ophicephalus, bei Gymnotus electricus und Carapus macrurus verlängert die einfache oder die hintere Blase sich unter den nicht zur Schliessung gelanglen unteren Wirbelbogensehenkeln weit nach hinten. 5. Bei anderen, wie bei Arten der Gatlungen Butirinus und Mormyrus, bilden unterhalb der zur Schliessung gelanglen unteren Wirbelbogenschenkel befestigte Rippen eine zur Aufuahme der die Länge der Rumpfhöhle übcrschreitenden Schwimmblase bestimmte IḦ̈le. - Vordere Verlängerungen der Schrvimmblase zum Schedel hin kommen häufig vor und sind auch namentlich bemerkenswerth durch die schon früher $\mathbb{S} .73$ erwähnte Beziehung, in welche sie oft zu den Gehörorganen treten. Ja selbst in die Schedelknochen kómen vordere Ausstülpungen der Schwimmblase sich erstrecken, wie z. B. bei Clupea und Alosa.

Wahrend die Schnvimmblase vieler Fische ziemlich frei oder nur lose angeheftet in der Rumpfhöhle liegt, erscheint sie bei anderen, z. B. manchen Gadoüdei, mit den unteren Wirbelbogensehenkeln und den Rippen inniger verbunden. In ganz eigenthümlicher Weise liegt die vordere Abtheilung der Schwimmblase bei einigen Cyprinoüden (namentlich den Gattungen Cobitis und Acanthopsis) und die ganze Blase oder ein Theil derselben bei einigen Siluroüdei ${ }^{4}$ ), (namentlich den Gattungen Clarias, Ileterobranchus, Saccobranchus und Ageneiosus) nicht frei in der Rumpfhöhle, sondern wird von einer Knochencapsel umschlossen, die ron der ventralen Seite vor. derer Wirbel ausgeht.

3) Bei Alestes Hasselquistii verlängert sich die hintere Schwimmblase asymme-

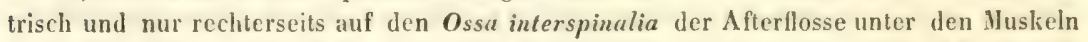
des Schwanzes nach hinten. S. Valenciennes hist. nat. d. poiss. Vol. XX. p. 184.

4) Bei den genannten Siluroüdei ist diese Einrichtung durch 1 üller aufgefunden (s. Eingeweide d. Fische. S. 40.). Bei ihnen ist diese Knochencapsel an den Seiten offen und durch eine knöcherne Scheidewand in der Mitte getheilt. Bei $\Lambda$ geneiosus militaris gehen (nach Müler 1.c. S. 49.) aus der Capsel nach hinten zwei feine blinde Zipfel der Schwimmblase als. Bei der-verwandten Gatlung Schistura N. L. (S. geta) findet sich hinter der Wirbelanschwellung, nach Mtiller, noch eine grosse, freie, häutige Schwimmblase. 
[Die Schriften über die Schwimmblase sind zahlreich. Man vergl, besonders: G. Fischer, Versuch über die Schwimmblase der Fische. Leipzig, 1795. 8. - De la Roche; in den Annales di Ylusée d'hist nat. 1809. Vol. XIV. p. 194. u. 245.II. Rathke, in den Neuesten Schriften d. naturf. Gesellschaft in Danzig. IIalle, 1825. Bd. 1. Itft. 4. - v. Baer, Untersuchungen über die Entwickelungsgesch. der Fische. Leipzig, 1835. 4. - H. Rathke, in Müller's Archiv. 1838. S. 313. - J a cobi, Diss. de vesica aërea piscium. Berol. 1810. 4. - J. M üller, Vergleichende Anat. des Gefässystemes d. Myxinoīden. Berlin, 1841. 4. - und in seinem Archiy f. Anat. u. Physiol. Jahrgg. 18ł1. u. 42. - J. Müller, Ueber die Eingeweide der Fische. S. $27 \mathrm{fr}$.

Zahlreiche specielle Angaben finden sich verstreut in Cuvier u. Valenciennes, hist. nat. d. poissonis.

Ueber die Entwickelungsgeschichte der Schwimmblase liegen nur spärliche Beobachtungen vor. Nach den an Perca durch C. E. v. Baer angestellten Forschungen (s. Wiegmann's Arch. für Naturgesch. 1837. Thl. 1. S. 248.) ist anzunehmen, dass auch die geschlossenen Schwimmblasen ursprünglich, wenn gleich nur kurze Zeit, mit dem Oesophagus in Hühlen-Verbindung stehen. - Bei den mit perennirendem Ductus pneumaticus versehenen Cyprinen stülpt sich nach B a er (Entwickelungsgesch. d. Fische. S. 32, 33.) die hintere Schwimmblase aus der rechten Seitenwand des Verdauungscanales hervor, von wo sie immer mehr nach hinten rüclst. Ihr hohler Stiel erscheint, in Vergleich zu der an Weite zunchmenden Blase allmälich immer enger. Sehr viel später bildet sich die vordere Schwimmblase und zwar anscheinend als Bläschen hinter den Gehörorganen, das erst später mit der hinteren Blase in Communication tritt. - Abweichend von den Baer'schen Nittheilungen sind die von Vogt (Embryol. d. Salmones. p. 177.) über die Entwickelung der Schwimmblase bei Coregonus palaea. Nach dem Ausschlüpfen des Embryo zeigte sich eine kieine, halblireisfürmige, solide Anhäufung von Zellen auf der hinteren Wand des. Oesophagus in der Nähe des Magens. Diese Anhäufung verlängert sich nach hinten und nimmt die Form einer erweiterten Tasche mit verengtem Halse an. Im Inneren dieser Zellengruppe bildet sich eine einfache Höhle, die anfangs blos im erweiterten Theile vorhanden ist, später auch in die Verengerung sich erstreckt. Lange Zeit ist diese Ilöhle o hne Communication mit dem Darmrohre, welche letztere erst zwei oder drei Wochen nach dem Ausschlüpfen entsteht. Dann sucht der junge Fisch die Oberflïche des Wassers und verschluckt eine Nenge Luft, worauf die Schwimmblase fast die ganze Bauchhöhle ausfüllt.

Die näheren Verhältnisse der Iläute der Schwimmblase gestalten sich äusserst verschiedenartig. Ihre Wandungen sind oft von bedeutender Dicke, wie z. B. beim Stür, bei Pogonias chromis; bei anderen Fischen sind sie zart und dünne, z. B. bei Mlormyrus, Salmo, Clupea, Ophidium; wenig dicker bei Esox, bei Belone u. A. Bei Gadus z. B. G. callarias ist die Vorderwand und die den Rippen fest angeheftete Seitenwand sehr dickhäutig, während der vor den Nieren und dem Axentheile der Wirbelsäule liegende Theil sehr dünnläutig ist. Die vordere und die hintere Blase der Cyprinen bieten, wie welter erwähnt ist, Verschiedenheiten ihrer Textur dar. - Bei einigeu Fischen z. B. bei Gadus besteht die dicke, weisse, sogenannte fibröse Haut der Schwimmblase aus geschwungenen Fasern, die bei Zcrung in schr feine, 
zum Theil zickzackförmig gebogene, grösstentheils aber nadelförmig und haarförmigg gestaltete starre Körperchen oder Fäserchen zerfallen. Zwischen ihnen findet sich bisweilen graue amorphe Substanz. - Bei anderen Fischen z. B. bei Cyprinus, bei Esox kommen in den Wandungen der Schwimmblase contractile Faserzellen vor. An der Innenfläche der Srhwimmblase vieler Fische z. B. von Clıpea, Belone, Gadus, Perca u. A. liegt eine silberglänzende Schicht. Sie besteht bekanntlich aus länglichen, verschicden geformten, scharf conturirten, platten, blassen, dünnen Schüppchen und aus sehr langen feinen, nadelfürmigen, anscheinend crystallinischen Körperchen wie sie auch im Peritoneum mancher Fische vorkommen. An der silberglänzenden Membran haften oft, z. B. bei Belone, milchweisse, aus Fett und Elementarkörnchen bestehende Punkte oder Flecke. Bei manchen Fischen findet sich an der Innenwand ein Pflasterepithelium.

Was den architectonischen. Werth der Schwimmblase anbetriff, so darf man sic, namentlich in Betracht der Unbeständiglieit ihrer Eimmündungsstelle, als ein Bronchialgerüst auffassen, wenn auch eine physiologische Verwendung zu Lungen bei dorsaler Insertion ihres Ductus pueumuticus, nicht vorzukommen scheint, es sei denn, dass Erdl's Beobachtungen an Gymmarchus niloticus (Münchener gelehrte Anzeigen. 1Si6. Bd. 23. S. 592.) sich bestätigten, wonach diesem Fische, an der Stelle der Schwimmblase, eine in die obere Wand des Schlundes mündende Lunge zukommen soll. An der Einmündungsstelle der Luftröhre bildet der Schlund rechts und links eine Longitudinalfalte zur willkürlichen Oellnung und Verschliessung derselben. Diese angebliche Lunge bestcht aus einer äusseren sehr zarten Wandung und aus zahlreichen Parietalzellen, welche zierliche Maschenwerke bilden und besonders im vorderen, dickeren Theile der Lunge in mehren Schichten über einander liegen. Um Erdl's Ansicht beizutreten, vernothwendigt sich eine Untersuchung des Gefässsystemes.]

\section{\$. 93 .}

Die Schwimmblase steht entweder durch eincu Duclus pneumalicus mit eincm vorderen Abschnitte des Tractus intestinalis in Höhlenverbindung oder ermangelt eines Luftganges und ist geschlossen. Sie besilzt einen Duclus preumalicus bei allen Ganoüdei und bei den Physostomi; sie ermangelt eines solehen und ist geschlossen bei allen Acanthopteri, bei den Anacanthini, den Pharyngognathi und den Lophobranchii.

Der Luftgang mündet selten in den Blindsack des Magens, wie bei manchen Clupeidlac, z. B. bei Clupea, Alosa, Bulirinus oder in die Portio cardiaca des Magens, wie bei Aceipenser. Seine gewöhnliche Ausmündungsstelle ist der Oesophregus und zwar senkt er sich gerö̈hnlich in des. sen dorsale Wand; nur bei cingen Arten der Gallung Erythrinus tritt er seitwänts ein ${ }^{1}$ ); das einzige Beispiel vom Vorkommen eines Orificium oesophageum ventrale bictet. Polypterus bichir ${ }^{2}$ ) dar, wo die Schrvimmblase aus zwei ungleich langen Säclien besteht, welche vorne zu ciner kurzen gemeinsamen Höhle zusammenfliessen.

1) S. Jacobi de vesica aërea pisc. Berol. 1840, c. tab. u. Nïlller's Archiv 1841. S. 233.

2) Abbildungen ihrer wesentlichsten Verhältnisse bei Il üller, Ganoìden. Tb, 6 . 


\section{S. 94 .}

Die mit einem Luftgange versehenen Schwimmblasen sind entreder einfach oder bestehen aus zwei hinter einauder liegenden Höh. lungen. Nicht ganz selien sind sie mit blinden Aussackungen oder Blinddiirmchen versehen. - Die einfachen Blasen bicten eine grosse Mannichfaltigkeit der Verhälnnisse dar. Ihre Höhle ist inwendig bald glatıwandig, bald zellig. In der Familie der Clupeidac ist eine zellige Bildung beobachtet bei Chirocentrus dorab ${ }^{1}$ ), in der der Siluroïdei bei Platystoma fasciatum 2); unter den Ganoïdei bei Amia ${ }^{3}$ ) und Lepidosteus ${ }^{4}$ ). Anordnung und Texturrerhälnisse dieser Zellen sind aber bei den einzelnen genannten Fischen wieder sehr mannichfaltig. - Die glattwandigen Schrimmblasen bieten manehe Verschiedenheiten dar; der Ausgangspunkt ihres Duchus pneumalicus variirt, indem er bald im vordersten Theile der Blase liegt, wie bei Esos, bald hinter dem ersten Dritheile ihrer Länge, wie bei Silurus glanis, bald etwa in ihres. Mitte, wie bcim Aal, beim Häring; dabei ist er bald ganz kurz und weit, wic z. B. bei Accipenser, bei manchen Salmones, oder lang und elwas gewunden, wie bei Silurus glanis, mehr aber noch bei einigen Aalen, z. B. bei Ophisurus serpens, Muraenophis helena. Beispicle vom Vorkommen der sogenannten rothen Körper zwischen den Häuten der Blase liefern die Aale. Ein isolirt dastehendes Beispiel rom Vorkommen eines Flimmerepithelium an ihrer Inmenwand bietet die Gattung Accipenser ${ }^{5}$ ).

Ein Zerfallen der langen Schwimmblase in drei hinter einander licgende, durch Verengerungen zusammenhangende Höhlen ist bei Bagrus emphysetus ${ }^{6}$ ) beobachtet.

Doppelte Schwimmblasen, welche, hinter einander liegend, durch eine Oeffnung mit einander communiciren und zugleich rücksichtlich der Textur ihrer Häute vou einander verschieden sich verhalten, besitzen die Familien der Cyprinoïdei, Characini und Gymnotini ${ }^{7}$ ). Die vordere

1) S. Valenciennes in d. Hist. nat. d. poiss. Vol. XIX. p. 161.

2) Nach J. slüller.

3) Beschreibung der Zellen von Amia s. bei Franque 1.c. p. 8.; auch bei Valenciennes. T. XIX. p. 408. 418.

4) S. Nähercs bei Müller, Bau und Grenzen d. Ganoìden. S. 32. Zwischen den Zellenabtheilungen kommen Trabeculae carneae vor, die aber nicht jene begründen.

5) S. Leydig in Müller's Archiv 1852. Ich kann diese Beobachtung bestätigen. - S. wuch Leydig, Anatomisch-histologische Untersuchungen. S. 29. Meine Beobachlungen in Folge der Anzeige in Muller's Archiv ron Leydig betreffen A. sturio.

6) S. Müller, Eingew. d. Fische. S. 49.

7) S. die interessante Abhandhung von J. Reinhardt. $0 \mathrm{~m}$ Swömmeblacrer hos Familien Gymnotini. Kiübenharn. November, 1852, Alle Gymnotini besitzen, wie be- 
Schwimmblase der Cyprinoïden und Characinen besitzt eine mittlere elastische Haut, deren die hintere ermangelt. Beide Blasen sind mit. Muskeln rersehco, deren isolirte Wirkung bald die vordere, bald die hintere Blase comprimiren zu liönnen scheint. Der Ductus pneumalicus trilt an der Grenze beider von der hinteren Blase ab. Die hintere Blase kann, wenigslens in ihrer vorderen Streclie, einen zelligen Bau zeigen, wie er bei Ery. thrinns salvus und taeniatus beobachtet ist. - Die hintere Blase kann auch wieder in zwei mit einander communicirende Höhlen zerfallen, wie dies bei Catastomus Sueurii und macrolepidotus vorkömmt.

Ein eigenthümlicher Apparat, durch den die Luft dor Blase willkürlich entleert werden kann, ist bei mehren Siluroülei ${ }^{8}$ ) angetroffen, namentlich bei den Gatdungen Auchenipterus, Synodontis, Doras, Malapterurus, Eusmemus. Hier findet sich jederseits am ersten Wirbel ein anfangs dünney sehmaler Fortsaiz, der zulelzt in eine grosse, runde Platte sich ansdehnt, welche die Schwimmblase rindrückt. Die Platte kamn durch einen vom Schedel entspringenden, starken Muskel gehoben werden, wobei denn die Linft durch den Duclus preumalicus austritt.

Bei den lamilien der Cyprinoïlei, Characini, Silurödei und Gymnotini steht die Schwimmblase durch eine von E. H. Weber entdeckte Ketle rerschiebbarer Knochen miłtelbar mit dem Gehörorgane in Verbindung 9). Eine andere Art indirecter Verbindung mit den Gehörorganen, wobei intessen die crwähnte Kuochenhelle mangelt, wird bei cinigen Clupeïden, namentlich den Gatlungen: Clupea, Alosa, Engraulis, und einfacher bei Notopteris ind Hyodon beobachtet.

\section{\$. 95 .}

Die geschlossenen Schwimmblasen bieten nicht minder grosse Verschiedenheiten dar, als die mit Luftgang versehenen. Sic besitzen entweder eine einfache Ilöhlung oder sind durch Einsehnürungen in zwei mil pinander communicirende IHöhlen zerfallen; ja, bei Phycis mediterranea ksommen durch solche Einschü̈rungen drei hinter einander gelegene Ab.

reits Cuvier ausgesprochen hatte, zyci Schwimmblasen: eine vordere kleinere und eine-lintere längere und oft sehr lange. Von dem hinteren Ende der vorderen Schwimmblasc entspringt ein feiner Canal, der die Länge der Blase hat und sie mit dem vorderen Ende der hinteren Schwimmblase verbindet. Yon diesem Canale, jedoch ganz nahe an der Stelle, wo er in die hintere Blase einmündet, geht der feine Ductus pneumaticus ab, der in die Räcliwand des Oesophagus, nahe an seinem Uebergange in den Magen sich öfnet. Reinhardt hat die Gathugen Carapus, Sternopygus und Sternarchus untersucht.

8) S. darüber Müller, Eingew. d. Fische, S. 39.

9) Vergl. \$. 73 . 
theilungen zu Staude: - Eine Theilung in zwei hinter cinander liegende Blasen ist namentlich bei einer kleinen Gruppe der Percoüdei beobachtet ${ }^{1}$ ). Verschieden von dieser Theilung in hinter cinander liegende Blasen ist die unvollkommene, meist anf die vordere Iäfte beschränkle Längstheilung, welche der Blase oft cine hufeisenförmige Gestall verleihet ${ }^{2}$ ). - Sehr hänfig besitzt die Schwimmblase Ausstülpungen oder llërner; oft sind un zwei vordere vorhanden, wie z. B. hei fpllyraena rulgaris, Garlus callarias u. A.; zwei hinlere Aussacknngen sler Blase kommen cben so hänfig vor, als die vorderen mnd überschreiten häulig die Grenzen der Rumpfhöhle nach hinten (s. $\$$. 92.). Bisweilen erscheint die Schwimmblase durch seitliche Eunschnürungen glcichlalls schappt oder mil Raustra versehen, wic bei Gadus acylefinus, callarias und morrhua. - Bei manchen Fischen ist die Schwimmblase durch den Besitz ciner grossen Zahl ron Ansstülpangen ausgezeichne!, dic riederum in mehr oder minder zahlreichle Tarästelungen zerfallen können. Am häufigsten kömmt diese Bildung in der Familic der Sciaenoüdei vor ${ }^{3}$ ). - Vorne künnen Ausstïlpungen der Schwimmblase an häutig geschlossene Stellen des Schedels sich anlehnen, welche ihrerseits das Gehörorgan auswendig begrenzen und abschliessen, wie bei den Gattungen Myripristis, Holocentrum, bei Priacanlius macrophthalmus und bei einigen Sparoïdei.

Im Iunern der Schwimmblase einger Arten der Gattung Hemiranphus

1) Hierher gehören namentlich die Gattungen: Therapon, Datnia, Ilelotes, Myripristis, Pelates. Die beiden hinter cinander liegenden blasen sind aber nicht, wie bei den Cyprinoïdei und Characini durch die Texturverhiltnisse ihrer lläute von einander verschieden.

2) So z. B. bei den meisten Arten der Gattung Batraclus, z, B. B. surinamensis, grunniens, Dussumieri. Verwandt sind die Verhältnisse bei Dactylopterus volitans, Prionotus, Apistus; desgleichen bei vielen Plectognathi, z. B. Diodon, Tetrodon. - Bei einigen Triglae, z. B. bei T. hirundo zerfallt die Blase unvolikommen in drei Ilühlen: eine mittlere und zwei seitliche.

3) Bei Sciaena umbra (s. Cuvier u. Valenciennes. Vol. V. p. 50.) gehen von jedem Seitenrande 36 solcher Ansstulpungen aus, deren jede, mil Ausnahme der hintersten, wieder in zahlreiche Aeste sich theilt. Diese secundären Verästelungen sind in ein dickes röthliches Gevebe gehiilt. Nach demselben Plane ist die Schwimmblase gebildet bei Johnius coïtor (Cuv. et Val. V. p. 118.), bei Johnius lobatus (ibid. p. 205.). - Zahlreiche kurze, stumpfe, ungetheilte seitliche Ausstülpungen besitzt, nach Cuvier (ibid. Vol. VI. p. 112. 113.), die Schwimmblase auch bei dem Sparoiden, Chrysophrys cocruleo-sticta. - Bei Sciacna pama hesitzt die lilase zwei hintere Ausstülpungen, welche von hinten nach vorne aufsteigen und vorne unter der Niere in drei oder vier Aeste sich theilen, die dann von Neuem sich verästeln. S. Nähieres bei Cuvier u. Val. Vol. V. p. 57.58, - S, auch über Otolithus regalis, Micropogon lineatus u. undulatus (ib. V. p. 216. 220.). Abbihduneren d. Swhimmblase von Scianoiden. s. bei Cuvier u, Val, Tb, 138, 139. 
sind zellige Bildungen, vergleichbar deuen der Froschlungen, angetroffen worden ${ }^{4}$ ).

Sehr eigenthimliche Vorrichlungen - welke bei den cinzolnen Arten jedoch mamichfache Modificationen erfuhru - funden sich bei den Ophidini ${ }^{5}$ ), nit Einschluss der Gattung Encheliophis. nu cien vorleren Theil der von dünnen Näulen mmschioss:nen Schrimmblase zn rerlïngern. Bei vinigen Ophidim-Arten wirkt ein narh rorne bereglicher und durch Muskeln anzichbarer hallmondfürniger ofler lieilförniger Knophen als Stopfon, dessen Bewesnng nach rorne den lufthaltigen Ramm der Sehwimmblase vorwärts vergrössert. Bei ciner anderen Art setzen sich zu Ereichung des

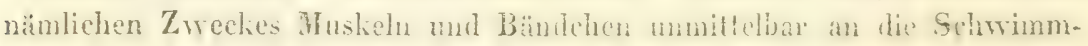

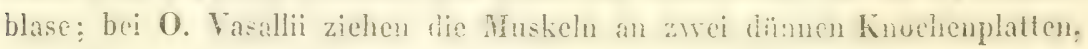
die rorne in der Haut der Schwimmblase liegen, in. Zustande der Ruhe

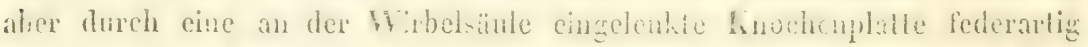
zurückgehalten werden.

Eigene quergestreifte Muskelir, durch deren Wirkung dic Tuft der

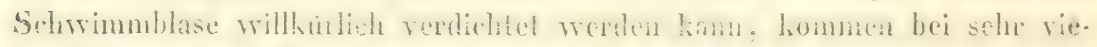

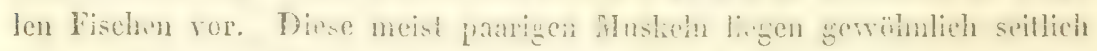
über der fibrösen Maut der Schwimmblase. So bei vielen Triglae, wo sie

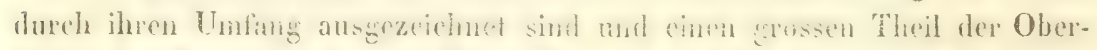

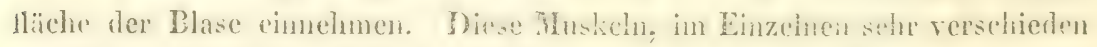
angeordnet, finden sich z. B. bei Batrachus surinamensis und grumniens,

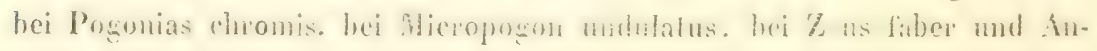
deren. Verschieden you diesen Miskeh sud anderc, die von der Vorderfläche der Wirbelsänle an die Schwimmblase trefen und cinen ähnlichen Zweek erfüllen, wie z. B. bei Gadus morrhua, bei den Arlen der Gatlung Diodon und Tetrodou und bei Anderen.

\section{\$. 96 .}

Während es physiologischer Charakter der Lungen-ist, dass ihmen rom Herzen aus venöses Blut zugeführt wird, welches, in arterielles umgevan-

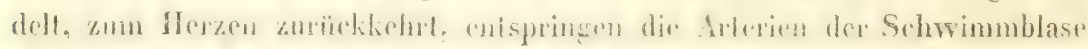

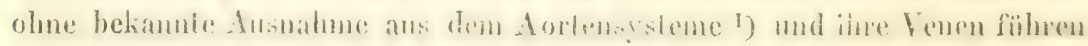

4) Valencienues (Hist. nat. d. poiss. XIX, p. 18.) hat diesen Bau bei llemiramphus Brownii, Pleii und Commersonii angetroffen. Der zellige Bau soll nur am Rücken fehlen.

5) S. darüber Broussonuet in d. Philos. transact. Vol. Lxxi. p. 437. - de la Roche in den. Annal, d. Musée d'hist. nat. d: Paris. T. XIV. p. 275 sq. J. Müller Eingew. d. Fïrche. S. 93. mil Ah, Abhildungen d. Schwimmblate vun Fierasfer Fontantsii u.von Ophidium barbatum s. auch bei Costa, Fauna del regno di Napoli. Tb. XX.

1) Es gilt dies auch von den Schwimmblasen der Ganoïden, wie J. Müller in Betreff von Polypterus gezeigt hat, wo die Arterie als Ast der letzten Kiemenvene, ron der Mitte der leizteren zu dem Schwimmblasensaclie ihrer Seite ibgeht. (Ban u. 
das Blut entweder in die l'fortader oder in das Körpervencusystem zurïck. - Näher bezeichnct, nehmen die Arterien bald aus der letzten Kiemenrenc. bahl ats dem Stamme der forla, bald ans der Art, coeliaca ihren Ursprumg mad die Venen münden bald in die Pforialer, bald in dic Venue vertebrales; bald in dic Lebervenen, wie bei Polypterus.

Die Art der Verlueilung dieser, bei einigen Fischen schr reichlich, bei anderen. wie z. B. beim Lachs, bei Belone. bein IÏring, bex Accipensel sparlich vorhandenen, zwischen der mitheren und inneren Haut der Schrimm. blase sich vertheilcuden Gefisse ist bei vielen Fischen in so ferne cigenthitmlich, als sie it undernetze ${ }^{2}$ ) bildon, in welehe sowol Arterien als Venen sich anlösen, die also einen artericllen und cinen venösen Theil besitzen. D)as nihhere Verhalten dieser Wundernetze bietel wieder mancherlei Verschiedenheilen dar. Bei viclen Fiscluen lösen die cinzelnen Gefässstämme strahlenformig, schwcifförnig, wedelfönmig, quastförmig in viele feine Röhren, nach Analogie der Wundernetze, sich auf, wclche zuletat in baumförmig sich rertheilende kleine Zweige ïhergehen. Sobald dieses Zerfallen der einzelnen Arterienstimmchen über den ganzen Zwischenraum der fibrösen Haul und der inneren Hant sich fortsetzt, wie bei den Cyprineu, so kömmt es zı heiner localen Anhäufung der feinen Gefässröhren. Sobald dieses Zerfallen der Arterien in diffuse Wundernetze aber blos aul bestimmte Stallen der Schrrimmblase sich beschnälit. cine Einnchtumg: zu weleirer die bein Hecht rolhandene den Uehergang bildel. constituiren sie die sogenamblen rol hen Kärper. Diese polhen Körper kommen am häufgigten nud fasb allemen in gesehlossenen Sebwimmblasm vor, werden aber atuch in solchen angelrollen, die cinen Ductus pneumeticus besilzen, wie z. B. bei den Muranoüden. Es verzreigen sich nun dir aus der Masse des Wundernetzes anstretenden arteriellen Gefïse culweder sosleich weiter in dessen nächster Vingebung, odier sie sammeln sich in viele libine Zweige, welche in einem eigenen Saume oder Ilofe der Wundernetzmassen sich rectheileu, während die übrige Flidhe der Schrimmblase ihr Blut nicht aus den Wundernetzen, sondern aus einfach reizweigten Gofiissen crhäll, wie bei Gadus. Lota, Perca. -. Verschieden ron dissen diflusen Wundemetzen sind die localen amphicentrischen Wundernctze. Brim Aal z. B. zerfällt der Arterienstamm in zrvei Büschel uncnllich zinhtreicher Rihrchen. welche wieder zu grossen Arterienstämmon zusammentrelen. die dam erst an der immeren Hant der

Grenzen d. Ganoülen S. 34.); hiermit stimmen die Beobachtungen von Franque über Amia (l. c. p. 8.) und von II yrtl über Lepidosteus (Sitzungsb. d. Wiener Acad. der Wissensch, 155\%. VIII. p. 71.) in Wesentichen üherein. Bei Lepidosteus entspringen die Arterien aus der Aorta und die Vence münden in die Venae vertebrales.

2) S. über diese Verhältnisse d. Gefässe bes. J. Müller, Vergl. Anat. d. Gefässsyst. d. Myxinoid. S. 30., wo die äteren Beobachtungen von de la Roche, Rathko und Anderen erwähnt sind. 
ganzen Schwinnblase baunförmig sich vertheilen. Diese sammelu sich in Venen, welche allmälich zu grossen Stämmen verbunden, zu den Wundernetzen zurïckkehren, und hicr den venösen Theil derschen bildend, viedes in die zahlreichsten feinen Rührchen zerfallen, um zuletzt einen neuen anstretenden Venensiamm zu bilden, der das Blut dem Kürpervenensystem zuführt.

Bei manchen Wischen sind die Wundernetze vou blassen oder gelblichen, mässig dicken, von der ungebenden Ilaut abgegrenzlen zelligen Säumen nugeben, in welchen die banmarlige Verzveigung der aus dem Wundernetze kommenden arteriellen Reiser Stalt hat, während die übrige Fläche der Schwimublase ilı Blut aus einfachen Blulgefässen crhält (Perca, Gadus). Bci anderen Fischen komnen zersheute Grübchen auf der ganzen Innenfläche der Schwimmblase (Polyplerus) vor, wihrend bei wieder anderen weder jene Sïume, noch diese Grübchen unchweisbar sind (Esox). Wahrseheinlich sind alle diese verschiedenen Verhälnisse von Einfluss auf die Absonderung der in der Schwimmblase enthaltenen Luft.

\section{Siebenter Abschnitt. \\ Vom G'efüsssysteme und den Giefüssdrüser.}

\section{Vom Blatgel'asssysteme.}

$$
\text { \$. } 97 .
$$

Das Bluigefässsystem der Fische besitut selbstständig contractile Centralgebilde und einfache Gefässbahnen. Gevisse Abschnitte des Gefisssystemes, die gew ühnlich als cinfache Gefässe erscheinen, sind bei einigen Fischen selbststandig contractil und herzartig. Dathin gehört der Pfortaderstamm, welcher; sonst gefïssartig, bei den Gattungen Branchiostoma und Myxine contractil ist und, wegen seincr selbstständigen Palsationen, die Bezcichnung cines P'ortadcrherzens rerdient ${ }^{1}$ ); ebenso sind bei Branchiostoma der ganze Kiemenarterienstamm und die Anfänge der einzelnen Kiemenarterien lrerzartig contractil ${ }^{2}$ ). - Eine andere, nur bei Branchiostoma erkannte Eigenthümlichkeit besteht in der canal-oder gefässförmigen äusseren Anordnungsveise der cinzelnen Ilerzabtheilungen ${ }^{3}$ ), velche bei den übrigen Fischen ihren ursprüngliels gefässartigen Charakter a) eingebüsst hahen und zu (in m einzigrn, verschiedene mit einander

1) S. \$. 98. u. 107 - 2) S. \$. 98. - 3) \$. \$. 98.

4) Vergl. B в er Entwickelungsges, d. Fische. S. 20. 
communicirende Höhlen besilzenden, Gebilde: dem Herzen zusammenge. drängt sind. - Dieses Herz ist gewöhnlich ein venöses Kiemenherz, in. dem es nur venöses Blut empfängt und nur in einen Kiemenarterienstanm sich fortsetzt, der ausschliesslich Kiemenarterien abgibt ${ }^{5}$ ). -- Bei den Dipnoi nimmt es jedoch auch das aus den Lungen durch die Lungenvene zurückkehrende arterielle Blut auf, enthält also gemischtes Blıt ${ }^{6}$ ), w- So. wol dann, wenn das Herz blos venöses Blut, als auch dann, wemn es gemischtes Blut enthält, können aus seiuem Kiemenarlcriensianme Gefäss: bogen abgehen, welche direct in die forla eimmünden. Die crstere ỉcdingung ist beobachtet worden bei der der Lungen entbehrenden Gattung Monopterus ${ }^{7}$ ), die zrveile bei den Dipnoi ${ }^{8}$ ). - In ersterem Falle crhält. sich eine Anordnungsweise perennirend, welche bei anderen Fischen transitorisch ist und nur ein gewisses Entwickelungsstadium charakterisirt ").

Das peripherische Gefässystem mancher Fische bietel merkwürdige Eigenthüınlichkeiten dar. Was zunächst die Arterien anbetriff, so bildet häufig die Aorta keinen freien isolirten Gefïssstamm; biswrilen strömt nämlich das arterielle Blut durch einen staren Knorpelcanal, der inwendig nur von einem Perichondrium ausgekleidet ist, wie bei Accipenser und Spatularia; bei anderen Fischen ist der Aortencanal gleichfalls nicht selbstständig und nicht allseilig von den gevöhnlichen Gefïsshänten umschlossen, soudern mil seiner Rückseite, an der ein clastisches Längsband verlänft, in Vertiefungen der Wirbelkörperreihe eingefiigl, wie bei Esox, Salmo, Silurus, Alosa u. A. - Das angebliche Vorkommen selbstständiger aces. sorischer herzartiger Erveiterungen und Muskelbeläge an cinzclnen peripherischen Arterienstïmmen scheint sich nicht zu bestätigen ${ }^{10}$ ). - Zu den merk.

5) S. $\$ .102 .-6)$ S. $\$ 100$.

7) Müller sah bei Honopterus am vierten kiemenlosen Visceralbngen jeder Scite einen Aortenbogen aus der Arteria branchialis unmitlelbar zur Aorta treten. Taylor hatte die Beobachtung gemacht, dass bei dem mit Lungensäcken versehenen Amphipnous cuchia jederseits zwischen dem kiemenlosen vierten Visceralbogen und dem Os pharyngeum inferius ein Aortenlogen aus der Arteria branchialis direct in die Aorta sich begebe. S. Müller, Gefässsyst. d. Myxinoĩd. S. 27.

8) S. IIyrtl und Peters.

9) S. Baer, Entwickelungsgesch. der Fische. S. 20. und Vogt; Embryol, des Salmones. p. 212. 213. Es entstehen aus dem Vordertheile des Herzens zwei Gefässbogen (Arcus aortici: Aortenwurzeln); diese umfassen den Schlund, setzen nach vorne als Carotiden sich fort und vereinigen sich hinter dem Schultergürtel zur Aorta. Bei Bdellostoma hat 11 üller noch Ueherreste dieser primitiven Aortenwurzeln angetroffen. Gefässsyst. d. Myxinoïd. S. 19.

10) Duvernoy hatte zuerst im Jahre 1835 (Ann. d. sc. nat. T. III. p. 280.), dann ausführlicher im Jahre $183 \%$ (Ann. d. sc. nat. T. VIII. p. 36.) an den Arteriat arillares der Chimaera arclica ein accessorisches llerz beschrieben in ciner, der Arteriu aufliegenden Masse ,qui enveloppe évidemment les parois artirielles d'un anneac musculaire. (S. die Abb. Tb. 3. lïg. 1 a.). Ob von Müller der sie (Archiv 184?. 
würdigsten physiologischen Verhältnissen gehört die Bildung amphicentrischer Wundernetze durch manche Arterien, die also nicht direct, sondern

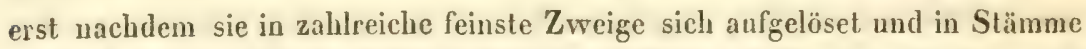
wieder sich gesammelt haben, an die ron ihnen mit Blut zu versorgenden Gebilde sich vertheilen; ja das arterielle Blut der Chorioüdea der meisten Fische muss zweimal durch solche capillare Systeme hindurchtreten, bevor es an jener Gefässhaut sich vertheilt. - Nicht minder merkwürdig erscheint die Anordnungsweise des venösen Gefässsystemes vicler Fische. Es sind nämlich nicht nur die zur Leber tretenden Venen, deren Stämme in Capillaren sich auflösen, um allmälich in einen oder mchre Stämme wiederum gesanmelt, zum Herzen sich zu begeben, sondern bei vielen Fischen wiederholt sich dieses Verhalten in Betreff der meisten Venen des Körpers. Die das Blut aus der Chorioïdea zurückführenden Venen lösen häufig wundernetzartig sich auf, ehe sie in diejenigen Aeste sich sammeln, welche in die dem Herzen zustrebenden grösseren Venen sich ergiessen. Der Schwanzvenenstamm, die Venae intercoslales zerfallen sehr häufig in oft

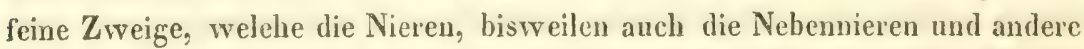
Blutgefässdrüsen erst durchsetzen, ehe sie in die das Blut direct zum Herzen führenden Venenstämme einmünden. Manche Venen der Rumpfivandungen, der Schwimmblase, der Geschlechtsorgane erscheinen als Wurzeln des Pfortadersystemes der Leber. Diese auatomischen Anordnungen un̈ssen die Rückkehr des Blutes zum Ilerzen verzögern und die Strömung des Blutes verlangsamen. Stockungen des venösen Blutstromes in den intermediären Gefässen, namentlich der Nieren, gehören zu den häufigeren Erscheinungen; blinde Ausstülpungen einzelner feiner peripherischer Gefässe kommen vor; intermediäre venöse Gefässe obliteriren, wenigstens bei manchen Fischen und in gewissen Jidreszeiteu, sehr oft; sogenannte blutkörperhaltige Zel-

S. 484.) aufführt, Contractionen gesehen wurden, weiss ich nicht. - J. Davy, (Researches, 1839. Vol. I. p. 43. Plate 1. Fig. 3.) beschrieb Aehnliches an den Arteriae axillares von Torpedo, anscheinend unabhängig von Duvernoy. ,It has very much the appearance of a nervous ganglion, but is in reality a blood-vessel, enlarged into a little bulb, lined with a reddish substance, like muscular fibre, giving the idea of a small heart." Leydig (1l üller's Archiv 1851. S. 256.) hat sowol bei Chimaera, als auch (Beiträge z. mikroskop. Anat. d. Rochen und Haie S. 15.) bei Torpedo jede Spur von Muskelfasern in den den Axillararterien aufliegenden Wülsten vermisst und ist wegen des mikroskopischen Befundes geneigt, sie als sympathischen Ganglien angehörig anzusprechen, und statuirt sie als eigenthümliche Nebenorgane des sympathischen Nervensystemes, die die Structur der Blutgefässdriisen haben. - Meine Untersuchungen an Rochen (R. clavata), wo hinter der Art. axillaris ein solcher Körper vorkömmt, der indessen ihr selbst nicht anliegt, sind der Auffassungsweise derselben, als Blasteme oder Keimlager des Sympathicus durchaus günstig. - Ein pulsirendes Organ, das Davy (Researches. Yol. II. p. 451.) bei Raja an den accessorischen männlichen Geschlechtstheilen beobachtete, ist seiner Natur nach noch nicht aufgeklärt. 
len und Schläuche werden sehr gewöhnlich, namentlich in den Nieren, angetroffen; die Blutkörper findet man oft in Untergang und in Umwandlung begriffen. Die Bildung von Exsudationen ereignet sich nicht selten; die Umwandelung von Blutkörpern in Pigmenlzelleu lässt sich häufg ver. folgen "1).

[Man vergl. über das Gefässsystem der Fische, ausser den in den Anmerkungen angeführten Schriften von II yril, Müller u. Anderen noch: du Verney, Oeuvres anatomiques. T. II. Paris, 1761. p. 470. - Tiede mann, Anatomie des Fischherzens. Landsh. 1809. 4. - Ueber die Arterien des Lepidostens s. II y rtl in den Sitzungsber. d. Wiener Acad. 1852. Bd. 8. S. 234. - Ueber Lepirlosiren vergl. die Arbeiten von II yrtl u. Peters; über Petromyzon: Rathke; über Raja: Monro.

\$. 98.

Bei dem durch den Besil chiostom a ${ }^{1}$ ) ist das Gefässsystem eigenthümlich charakterisirl durch das Vorkommen zahlreicher selbststädig contractiler herzartiger Gebilde. Das Lebervenenblut sammelt sich in ein an der Riickseite des Blinddarmes gelegenes Venenherz, dessen Contractionen vom Ende des Bliurldarmes aus beginucu, um nach vorne forlzuschreiten. Dasselbe biegt sich vorne knieförmig in das Kiemenarlerieuherz um und nimmt auscheinend an dieser Umbiegungsstelle die Körperveneustämme auf. Dies Kiemenarterienherz liegt, als gleichmässigg dicke Röhre, olue unschliessenden Herzbentel, in der Mittellinic unterhalb der ganzen Längc des Kiemenschlauches, von hinten nach vorne rasch sich zusammenziehend. Von ihm aus treten, regelmässig alteruirend, als Anfänge der Kiemenarlerien, kleine contractile Bulbillen in die Zwischenriume je zweier Spitzbogen der Kiemen, aus welchen das Blut durch Kiemenvenen in die Lorla übergeführt wird. Absgeschen von diesem die Kiemen durchströmenden Blute gelangt durch einen jederseits am Ende der Mundhöhle gelegeneu, vom Kiemenarterienherzen ausgeheuden contractilen $A$ ortenbogeu ein Theil des Blutes direct in die Iorta. -- Das Darmyenenblut

11) Alle diese anatomischen und physiologischen Dispositionen scheinen nicht allein Umwandlungen des Blutes, sondern auch Verjüngungen der Organsubstanz und Neubildungen besonders zu begünstigen. Es sind die grossen periodischen Veränderungen, welche der Organismus der Fische durch die jahrlich sich wiederholende Ausbildung des Inhaltes der Geschlechtstheile erfährt, der ausserordentliche Körperumfang, den viele derselben allmälich unter Erreichung hohen Jebensalters zu crlangen fähıg sind, so wie selbst die Zerstürungen und Perforationen der Organsuhstanz, welche durch Parasiten bewirkt werden und eine Restitution erfordern, noch nicht genurg gewurdigt worden. - Blinde Endigungen von caprillaren Gefïssen habe ich ungetroffen in den Fetthöhlen des Schedelknorpels von Accipenser; die Umwanllung von Blutkürpern in Pigmentzellen wurde verfolgt in den Nieren von Coltus und Pleuronectes.

1) Man vergl. vorzüglich die von J. Ml üller gegebene Darstellung. Ueber Bau v. Lebensersch. d, Branchiostoma, S. 103. 
sammelt sich in eine lange, an der Bauchseite des Darmes verlaufende contractile Röhre, welche, als Pfortaderherz, am Blinddame auf diesen sich begibt und, allmälich sich verengend, bis an sein Ende sich erstreckt. Das zugeführte Blut gelangt auf dem Blinddarme zur capillaren Vertheilung und wird dann in das Venenherz übergeführt.

\section{\$. 99.}

Das Herz der Marsipobranchii, Teleostei, Ganoüdei und Elasmobranchii - dessen Fleisch stets dem Systeme der quergestreiften Muskelbündel angehört - bietet eine grosse Uebereinstimmung seiner Verbältuisse dar. In dasselbe münden die vereinigten Venenstämme und aus ihm geht der Kiemenarterienstamm hervor; dasselbe ist demnach ein venöses Kie. menherz. Es besitzt drei Abtheilungen. Diese sind: 1. die zur Aufnahme der in einen Sinus venosus vereinten Venen bestimmite Vorkammer; 2. die mittelst einer, oft engen, Einschnürung mil dieser zusammen. haugende Kammer und 3. der ron dieser letzteren abgesetzte, in den Kiemenarterienstamm übergehende Hohlraum: der Bulbus arteriosus ${ }^{1}$ ). Klappen zwischen dem Sinus venosus und der Vorkammer, zwischen letzterer und der Kammer, zwischen dieser und dem Bulbus arteriosus, so wic auch, bei einigen Gruppen, in diesem letzteren angebrachte Klappen hindern den Rücktritt des Blutes.

Die Versehiedenheiten, welche das IIerz bei den einzelnen Gruppen darbietet, erstrecken sich wesentlich auf die histologische Besehaffenheit des Bulbus arteriosus und auf dic Klappen-Eimichtungen in Herzen ${ }^{2}$ ). Von untergeorlneterer Bedenlung sind die Formverschiedenheiten desselben und einige andere Verhältnisse.

Bei den Marsipobranchii liegt an der Eintrittsstelle des venösen Sinus in die Vorkammer, welche geräumiger ist als der Vcutrikel, eive häutige Doppelklappe; das Ostium venosum, so wic das Ostium arteriosum der Kammer sind gleichfalls jede durch zwei läulige Klappen verschliessbar. Die des Ostium arteriosum liegen genau an der Grenze der Kammer. Aus dieser geht vorue der Kiemenarterienstamm hervor, der an seinem Ursprunge etwas bauchig ist, jedoch veder cinon Muskelbelag, noch eine eigentliche Verdickung besitzt.

Das Herz der Elasmobranchii und Ganoüdei besitzt einen gemeinsamen Charakter in dem Umstande, dass der aus der Kammer hervortretende Bulbus arteriosus mit einer ringförmigen Schicht quergestreifter Muskel-

1) S. über denselben die Bemerkungen von E. Brïcke in dessen Beiträgen zur Anatomie u. Physiolog. d. Gefässsystemes. S. 31. Brüclse setzt seine physiologische Bedeutung darin, dass er die Kiemen-Capillaren vor dem Stosse der Blutwelle schütze und gibt zugleich eine nähere Beschreibung seincr Einrichtungen bei mehren T'clcostei.

2) S. über diese Verhältnisse besonders J. Müller, Bau U. Grenzen der Ganoiden. $S, 9$, 
bündel auswendig belegt ist, welche rome an der Greuze der eigentlichen Kiemenarterien scharf umschrieben aufhörl, und dass dieser Bulbus in seiner Höhle mit mehr oder minder zahlreichen, in mehren Reihen hinter einander gelegenen, durch Fäden angehefteten Klappen verschen ist. ${ }^{3}$ ). Diese Charaktere unterscheiden ihr Herz ron dem der Telcostei. Bei leizteren mangelt eine solche Belegung des Bulbus arleriosus mit quergestreiften Muskelfasern gänzlich. Derselbe ist zwar cbenfalls angeschwollen, doch nicht durch äusserliche Auflagerung einer Muskelschicht, sondern vermit= telst ciner dicken, durchgehenden und an der Innenseite Balken und zwischenliegende Vertiefungen bildendeu Substanz, die aus schr elastischen Faserbündeln besteht. Den Teleostei kommen, in Gegensatze zu den vorhin genannten Gruppen, fast ganz allgemein auch nur zwei Klappen zu, welche nicht im Bulbus, sondern an der Grenze des letzteren und der Herzkammer gelegen sind. Zwischen ihnen finden sich bisweilen eine oder zwei kleinere Nebenklappen. Die einzigen Knochenfische, die von diesem Typus abweichen, sind die Arten der Gattung Butyrinus, bei welehen, statt zweier, vicr in zwei Reihen angeorduete Klappen, jedoch ohne muskulösen Bulbus, vorhanden sind.

In Uebrigen ähnelt die allgemeine anatomische Anordunung des Herzeus der Teleostei derjenigen, die den Elasmobranchii und Ganoïdei zukümmt. In die Vorkammer mündet allgemein mit weiler Oeffnung der Sinus venosus; eine häutige Doppelklappe, oft an Sehnenfïdchen befestigl, hindert bei den meisten Fischen den Rücktritt des Blutes in das Venensystem. Eigenthümlich ist die Klappeneiurichtung bei Accipenser, wo an dieser Stelle ein Klappenring vorkömmt, bestehend aus zwei Hälften, von welchen die eine 4, die andere 5 Taschen besitzt, die durch starke Fäden befestigt sind ${ }^{4}$ ). - Die weite, sehr ausdehnbare, dümnvandige Vorkammer bildet gewöhnlich beiderseitig orler einseitig eine Auricula. An der Innenfläche der Vorkammer zeigen sich zahleeiche, in verschicdenes Richtung

3) Diese in Querreihen gestellten Klappen bieten, ihrer Zahl nach, grosse Verschiedenheiten dar. Zwei Querreihen besitzen, nach Hüller, Chimaera, Carcharias, Scyllium, Galeus; drei: Sphyrna, Nustelus, Acanthias, Alopias, Lamna, Rhinobatus, Torpedo; vier: Hexanchus, Ileptanchus, Centrophorus, Trygon; vier bis fünf: Raja; fünf: Scymnas, Myliobatis, Pteroplatea, Squatina. - Was die Ganoïden anbetrifft, so besitzt Arcipenser zwei Reihen von Klappen im Anfange des Bulbus und eine dritte an seinem Ënde. Polypterus hat neun Querreihen, deren jede drei ausgebildete und neben ilnen noch abortive Klappen besitzt; Lepidosteus hat noch mehr Klappen. Bei Lepidosteus bison sind 54-60 vorhanden. Am geringsten ist unter den Ganoüdei die Klappenzahl bei Amia. Es sind drei Reihen vorhanden, von denen die beiden im Bulbus. liegenden je zwei grössere und zwei kleinere, die oberste jedoch nur zwei Klappen enthalten S. Abbildungen bei Müller, Ganoïden. Tb.V. und Franque, de Amia. Fig. 10.

4) Bei Spatularia finde ich hier nur zwei sehr grosse lilappen, jede in der llitte der Tasche durch eine Chorda festgehalten, 
sich durchkreuzende Trabeculae carneae. - An der ventralen Suite der Vorkammer, von ilur oben mehr oder minder vollständigg bedeckt und silwärís ïberragt, liegt der, in seinen, der allgemeinen Körpergestalt der Fische meistens angepassten Formverhïhnissen mannichfach variirende, Ventrikel. Die Vorkammer geht oben und histen in ilın über. Der Uebergang geschieht durch eine Verengerung, die bisweilen, z. B. bei Petromyzon, ziemlich lang ist. Zur Verschliessung des Orificium alrio-ventriculare sind gewöhnlich zwei Klappen bestimml; seltener steigt ihe Auzahl auf vier, wie bei Orthagoriscus mod Accipenser ${ }^{5}$ ). Der Ventrikel is! sch dickwandig und muskulös; seine Muskelmasse zeigt sich g'wöhnlich aus zwei, durch Verschiedenheit der Faserzäge ausgezeichneten Lagen: piner ¿̈usseren und einer imeren. bestehend, die unter gerrissen Umständen, namentlich bei einigermaassen vorgeschrittener Zersetzung, bei manchen Fi. sch:"n leicht sich trennen ${ }^{6}$ ). An der Innenwand seiner Höhle, welche viel weniger umfänglich ist, als die des Vorhofes, zeigen sich zwischen den vielfach sich durchkreuzenden Muskelbïndeln zahlrciche Vertiefungen.

Das Herz liegt ${ }^{7}$ ) bei den meisten Fischen zwischen den beiden sorne und unten convergirenden Schenkeln der Clavicutae, die in der Familie der Loricarinen ein eigenes transverselles knöchernes Seplum bilden. Bei den Aalen und hesonders bei den Symbranchii ist das Herz veiter nach hinten gerückt. Bei de'n Plagiostomen liegt das IIerz mit seinem Beutel unmittelbar unter der durch die Cartilago subpharyngea impar gebildeten Verlïngerung der Copulae der Kiemenbogen. - Bei Petromyzon liegt das Herz mit seinem Beutel innerhalb der, in Gestalt ciner unvollkommen geschlossencn Capsel, von vorne nach oben und elwas nach hinten gerichfeten Verlïngerung des äusseren Kiemenkorbes und wird von der Kiemenhöhle durch dic Muskulatur, welche cine Art Diaphragma bildet; geschieden.

Bei allen Fischen, mit Ausnahme von Branchiostoma. vird das Herz. nebst dem ihm angehörigen $\boldsymbol{B}$ ulbus arteriosus, lose eingeschlossen von einem fibrösen IIerzbeutel ${ }^{6}$ ), der an der vorderen Grenze des Bulbus fixirt ist. Von ihm erstrecken sich bisweilen faltenförmige Fortsätze an die Oberfläche des Herzens. Ob der Herzbentel wirklich allgemein auch einen unmittelbaren Ueberzug der Herzsubstanz bildet. ist noch nicht nit Sicher-

5) Meckel zählte nur drei.

(6) S. viber diesen Gegenstand, neben anderen yon Döllinger gegebenen Mittheilungen, die Bemerkungen von Rathke in Meckel's Archiv f. Anat. u. Physiol. 1826. S. 144. und Meckel's System d. vgl. Anatomie. Thl. V. S. 153.

7) Vgl. \$. 77, wo auch die Communication des Herzbeutels mit der Bauchhöhle erwähint ist.

8) S. über den Herabeutel der Myxinoïden die interessanten. Mittheilungen von M üller, Vergl. Anat. d. Gefässsyst. d, Myxinoïden. S. 1. 
heit feslgestellt. Ziemlich häufig sieht man, von dem fibrösen Herzbeutel aus, Füden zum Herzen selbst, und namentlich zum Ventrikel, hinübertreten. Diese Füden bestehen freilich bei einigen Fischen aus Bindegerrebe und sind tendiü̈s ${ }^{9}$ ); zwisehen ihuen konmen aber auch zur Oberfläche des Herzens tretende Blutgefïsse vor; wie z. B. beim Aal, oder man hat blos Blułgefässe für tendinöse Fäden genommen, wie beim Stör.

\$. 100 .

Bei den Dipnoi besilzt das Ilerz eine äusserlich einfache Vorkammer, die aber dureh eine unvollkonmene Scheidewand in eine rechte und linke Abtheilung zerfällt. In die linke mündet dic Lnngenvene, an deren Eintrittsstelle eine halbmondförmige Klappe sich befindet. In die rechte geht der venöse Simus über, der an seiner Einmündungsstelle einer Klappe ermangelt. Ein gemeinsanes Ostium venosum, an dessen vorderen Umkreise cine mit der Muskulatur des Ventrikels zusammenhangende fleischige Klappe sich befindet, führt ans beiden Vorhöfen in den Ventrikel. Dieser besitzl cinen Papillarmuskel, der mit cinem Faserknorpel sich verbindet, welcher bri Lefidosiren das Oslium renosum während der Systole schliesst. Der muskulöse Bulbus arteriosus, ohne Klappenvorrichtungen an seinem $\mathrm{U}_{1}$ sprunge, bildet aufsteigend eine Krümmung. Er besilzt inwendig zwei spirale, sciiliche, longitudinale Falien verschiedener Lünge, die gegen sein vorderes Ende hin versehmelzen. So ist eine Scheidung in zwei Arteriensysteme angedeutet ${ }^{1}$ ).

\section{\$. 101.}

Bei den Ganoïdei choudrostei $\left.{ }^{1}\right)$ fällt die Figenthümlichkeit, dass arterielles Aortenblut in einem ron dem Wirbelsysteme ausgehenden und un-

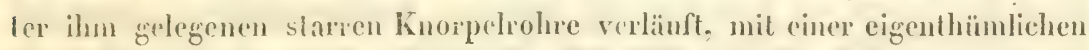
Beschaffenheit ihrer Ilerzoherdïehe zusammen. Bei Accipenser wird folgendes Verhalten wahrgenommen: die äussere Oberflïhe der Herzammer und des Bulbus ar/eriosus ist mit zahlreichen Erhabenheiten bedeckt. Diese Erhabenheiten, in ihrer allgemeinsten Form wie ein bullöser oder vesienlïser Haulaussehlag erscheinend, sind, näher betrachtet, nicht nur bei demselben Thiere, sondern auch bei verschiedenen Thieren sehr versehieden. An einzehnen Stellen der Herzoberfliche sind sie bisweilen sehr stark und mächtig, an anderen ganz klein oder fast völlig verschwunden. Eine verschiedene Anzaht arterieller Gefïsse, ans den Arleriae subclaviae und mam-

9) S. über dieselben Meckel, Syst. d. vgl. Anat. Thl. V. S. 17\%. Auffallend ist, dass Meckel sie bei Myxine an stärksten fand, wo Müller sie vermisste. - Bei den Dipnoi sind sie von Ilyrtl u. Peters beobachtet. - Bei Petromyzon, Accipenser, Spatularia, Anguilla, Cobitis sah ich Blutgefässe zur Oberfläche des Herzens treten:

1) Hyrtl, Lepidosiren. S. 35. u. Peters in Müller's Arch. 1845. S. 3.

1) Wenigstens bei Accipenser u. Spatularia. 
marice stammend, durchbohit den Herzbentel, tritt frei zu der Herzoberfläche und vertheilt sich in diese Erhabenheiten. Letztere zeigen sich in sehr verschiedenen Zuständen; ein häufig vorkommeuder ist der, dass sie allseitig geschlossen, mit ihrer Basis der Ilerzoberfläche fest aufsitzende Blasen darsiellen, deren ciutretende Arterie in ein rothes, schwammiges, aus einem Aggregale von Kernen, kernhaltigen Zellen und maschenbildenden Fasem bestehendes Gewehe sich vertheilen, von dessen Basis wieder Blutgefïsse in die IIerzsubstanz eintreten. Dieser Gewebskuchen ist oft von klarer, Körnchen-halliger Lymphe umspült. In einer solchen Erhabenheit fuden sich bisweilen Bläschen, welche wieler mit Zellen, Kernen und Flüssigkeit gefüllt sind, und mit dem Gewebskuchen durch Stiele in Verbindung stehen. I) as sehr wechsclnde, alsbald kurz zu schildernde Verhalten dieser Gebilde dentet auf Neubildung und Untergang derselben hin. Einige Erfahrungen sprechen für Beziehungen derselben zur Neubildung der Mnskelsubstanz des Herzens.

[Dieser Ueberzug des Herzens gehört zu den variabelsten Gebilden des Fischkürpers, die ich kenne; rr erheischt ein fortgesetzles Studium während verschiedener Jahreszeiten. Hier sei Folgendes kurz bemerkt: Der Reichthum der Blasen an lymphatischer Flüssigkeit ist sehr verschieden. Neben letzterer erscheint oft Fett als Inhalt. Dies liett kann ausschliesslich statt der Iymphe vorkommen. Es umgibt dann oft eine röthliche rundliche Gewebsmasse, die der eigentlichen Huskelsubstanz des IIerzens unmittelbar aufliegt oder durch kurze Gefisse mit ihr zusammenhangt. Die genannte Gewebsmasse enthält verschiedene klemente: pfiasterförmig oder reihenfürmig aggregirte Zellen, netzförmig und maschenfürmig verwirlite Fasern; Blättchen mit liürnigem Anlługe und zarter Längsstreifung, Fasern von der Breite der Muskelfasern des Iferzens mit Pünktchen oder Kürnchen; Bindegewebsfasern, untermengt mit breiteren Fasern, welche Spuren ciner Querstreifung zeigen. Letztere gehen, in Fällen, wo die bezeichnete Gewebsmasse ohne zwischenliegende Membran, der Ilerzsubstanz auflicgt, ganz allmälich in wirkliche Iluskelsubstanz mit deutlich quergestreiflen Primitivbündeln über. - Gleich der Lymphe, kann das Feft in der Umgebung der Gewebskuchen mangeln; ein solcher ist oft sehr breit und geht dann bisweilen unmerklich in die Ilerzsubstanz über, wo dam wieder Uebergangsformen zu Muskelbündeln vorkommen künnen; oder einzelne kleinere Gewebskuchen, die vom Grunde eines grösseren ausgehen, stchen ausschliesslich mit der Iterzsubstanz in Uebergangsverbindung; oder es kommen blasse, derbere finötchen ohne Fett und ohne Lymphe vor, die der Ilerzsubstanz dicht aufliegen. - Bisweilen sieht man, nach Wegnahme des ganzen Belages, Rauhigkeiten an der Oherlliche des Herzens zurüclbbleiben, in denen man mit Körnchen gefüllte Muskelfasern, punktirte, zum Theil auch quergestreifte Primitivhundel findet. Ferner gewahrt man, dass nach Entfernung des Ueberzuges die oherflählichen Schichten der flerzmuskeln auf jode äussere Reizung leicht und oft und ohne Theilnahme des ganzen Ilerzens sich zusammenziehen. - IVenn ich in einer friheren Mitheilung die Neubildung von Muskelfasern am Störherzen mit der am Herzen eines frosches zur Winterzeit beobachteten verglichen habe, so sollte damit durchaııs keine Identität der Verhältnisse ausgedrücht sein, denn Muskelfasern, 
die von Lymphe unmittelbar umspült wurden, wie dies bein Frosch vorkömmt, habe ich beim Stör nie gesehen. - Nicht minder verschieden zeigt sich das Verhalten der von aussen zur Herzoberfläche tretenden Gefässe; ich habe sie bei einem jungen Stör spurlos vermisst; während bei einem untersuchten grossen Stör 7 Gefässstämme gefunden wurden. Diese Gefässe sind die tendinösen Fäden älterer Anatomen. S. Meckel, Syst. d. vgl. Anat. Thl. V. S. 180. und über die äussere Beschaffenheit des Störherzens ibid. S. 159. Bei Spatularia treten zwei Gefässe durch den Herzbeutel zum Ventrikel. - In Betreff des Störs s. auch Leydig, Anat. histol. Untersuchungen. S. 22.]

\section{\$. 102 。}

Mit Ausnahme von Branchiostoma, dessen eigenthümliche Verhältnisse bereits angegeben sind, setzt allgemein das vordere Ende des Bulbus arteriosus sich fort in den ausserhalb des Herzbeutels liegenden, niemals mehr herzarlig contractilen Kiemenarterienstamm, aus welchem jederseits die Kiemenarterien, sei es millelbar durch mehre gemeinsame Stämme, oder unmittelbar hervorgehen.

Ter Kiemenarterienstamm der Myxinoüden, in seinem speciellen Verhalten, selbst bei Thicren der gleichen Art, variabel, verlïuft in einer häutigen Höhle, welche schon das vorderste Ende der IJerzkammer umschliesst und anch in die die Kiemensäcke umhüllenden häuligen Bentel sich fortsetzt. Jeder Kiemensack erhält seine eigene Arterie, die an seiner hinteren, wie an seiner vorderen Fliche sich vertheilt, indem sie am Eingange des äusseren Kiemenganges einen Cirkel bildel, ans dem die einzelnen Kiemengefässe radial hervorgehen.

Bei Petromyzon verläuft der Kiemenarterienstamm vor dem Bronchus vorwärts, gibt jederseits vier Kiemenarterien ab und spaltet sich weiter vorwärts gabelförmig in zwei Aeste, ans denen drei Kirmenarterien hervorgehen, wïhrend noch ein vorderer Zweig für die vorderste Kiemenblattreihe bestimmt ist. Die einzelnen Kiemenarterien treten mit Ausnahme der vordersten und hintersten, zwischen je zwei Kiemenbeutel und geben, von deren Interstitien aus, ihre Zweige zu den beirlen dureh ein Diaphragma getrenuten Kiemenblattreihen.

Bei den Plagiostomen entspringen aus jeder Seite des Kiemenarierienstammes ein ${ }^{1}$ ) orler zrvei primäre Aeste, worauf or zulelzt gabelförmig sich theilt. Die cinzelnen, aus den cben genannten Aesten hervorgehenden, Kiemenarterien Ireten zwischen je zwei, verschedenen Säcken

1) Einer, der in drei Aesle sich spaltet z. B. bei Raja, wo dann jeder Endast des Stammes ebenfalls in zwei Aeste zerfillt. S. d. Abb. bei Monro, Vergl. des Baues d. Fische. Tb. 1. - Bei Pristis analog; der erste primäre Ast tritt zu jeder Seite neben dem Stamm in der Knorpelcapsel, die jenen aufnimmt, vorwärts. 
angehörige Kiemenblattreihen; die vorderste Zungenbeinkieme erhält ihre eigene Arterie.

Bei mehren Ganoüden ${ }^{2}$ ) besitzt die Verthcilung des Kiemenarterienstammes darin eine Eigenthümlichkeit, dass die vordersten Kiemen die ersten Aeste und die dom Ilerzen zmü̈chst gelegenen Kiemenblattreihen die letzlen Aeste aus demselben empfangen. Das specielle Verhalten bei den einzelnen Gattungen bietet wieder Verschiedenheiten dar.

Bei den Teleostei tritt der Kiemenarlerienstamm oft in einem unlerhalb der Copulae der Kiemenbogen gelegenen, oben von jenen Copulae, seillich ron absteigenden Forlsätzen der untersten Glieder eines oder zweicr Kiemeubogen eingesehlossenen, unten durch fibröse IIaut ergänzten Canale vorwärts, der indessen bei manchen. z. B. bei den Aalen anch ganz fehlen kam. Oft, z. B. bei Salmo, gibt der Stamm zuerst einen gemeinsehaftlichen Ast für die Arterien des vierten und dritten Kiemenbogens, dam die Arterie für den zweiten und endlich die durch Spaltung des Stammes entstehende für den ersten Bogen ab. Aber, statt jenes gemeinsamen Asles. können auch, wie z. B. bei Muraenophis punchata, zwei gefrennte Kiemenarterien fïr die beiden hinterst'n Kirmenblathrihen rom Stamme selbst abgehen.

Was die Dipnoi anbetriflt, deren 11 crz gemischtes Blut enthält, so citspringen z. B. bei Rhinocryptis ${ }^{3}$ ) zwei Arterienäste aus jeder Seite des Kiemenarterienstammes; 1. ‘in gemeinsamer Ast für die halbe Kieme und die beiden liemenlosen Visceralbogen und 2. ein gemeinsamer Ast für die hinteren Kiemen. - Der erste gremeinsane Ast spaltet sich in zwei Arterien, welehe als Aortenbogen micr dem Sehedel zur Bildung der Aortenwurzel ihrer Seile sich rereinigen. Der erste Aortenbogen gibt zuerst eine $\Lambda \mathrm{r}$ lerie für die IIalbkieme und diese letzlere vor ihrem Ilerantreten an die genanute Kieme cine Kopfarterie ab. Aus dem ersten Aortenbogen entsteht ferner, vor seiner Vereinigung mit dem zweiten, eine Art. carotis posterior. Aus dem zweiten Aortenbogen entsteht eine Arterie zu den äusseren Kiemenfiden. - Der zweite gemeinsame Ast spaltet sich in zwei Kiemenarterien fïr den vierten ind fünften liementragenden Bogen; beider

2) So nach II yrtl, (Sitzungsber. d. Acad. d. Wissensch. z. Wien. 1852. Bd. 8. S. 133.). Bei Lepidostcus, Accipenser erhält die vorderste Kieme den ersten Ast aus dem Kiemenaterienstamm, welcher nach hinten sich umbiegend, successive von vorne nach hinten den übrigen Kienen ihre Aeste gibt. - Die Anordnung ist variabel bei den einzelnen Ganoïden, wie ich finde. Bei Spatularia tritt der erste Ast zum zweiten Kiemenbogen, der nächste zum ersten und dann folgen die Aeste für die dem Herzen näher gelegenen Bogen. Amia verhält sich ähnlich, wie Knochenfische, Ob Ilyrtl's Angaben für alle Lepidostei zutrefiend sind, ist zweifelhaft, da sie mit der von Nïller gelieferten. Abbildung (Ganoiden. 'Tb. V.) nicht in Einklang stehen.

3) S. Peters in Müller's Arch. 1845. S. 6. Tb. 1. Ueber Lepidosiren vergl. HyrtI. 
Fuden werden zu Arterien für die äusseren Kiemenfäden; die letzte Kiemenarterie gibt noch aus ihrem oberen Ende der Ast für die letzte Halb. kieme ab. - Die Lungenarterie entsteht aus der linken Aorteuvurzel.

$$
\text { \$. } 103 .
$$

Die das Blut aus den Kiemen abführenden Kiemenvenen vereinigen sich, unter Mangel eines zwisehengesehobenen Arterienherzens, zur Bildung der grösseren Arterienstämme des Körpers; sehr oft gehen aber schon aus einzelnen Kiemenvenen Körperarlerien ab. - Die Weise des Zusammentretens der Kiemenvenen zur Bildung der Aorla und der, aus den vordersten derselben hervorgehenden, Arteriae carolides zeigt sich bei den einzelnen Gruppen der Fische verschieden.

Bei den Myxinoïden treten die meisten Kiemenvenen, nachdem jede ihren Kiemensack verlassen, zur Bildung eines unter der Axe des Wirbelsystemes gelegenen, unpaaren Längsstammes zusammen, der nicht blos hinterwärts als Aorta descendens, sondern auch vorwärts, als Arleria verlebralis impar sich fortsetzt. Ausserdem hangen alle oder die meisten Kiemenvenen jeder Seite durch eine, dem unpaaren Längsstamme parallele, Längsanastomose zusammen, die nach vorne als Arleria carolis communis sich fortsetzt. Die beiden Carolides begleiten die Speiseröhre nach vorne, unter Abgabe ron Speiseröhren- und Zungenmuskelzweigen. Hinter dem Kopfe theilt sich jede Carotis communis in zwei Aeste: eine A. carot.externa für Kopfmuskeln und Zunge und eine $A$. carol. interna. Die beiderscitigen Carotides internae verbinden sich bogenförmig unter dem Anfange des Wirbelsystemes. In diesen Bogen mündet das Ende der A. vertebralis impar. Aus ihm entsteht ein: unpaare Kopfarterie, welche, nach vorne sich erstreckend, Zweige für Nase, Nasengaumengang u. s. w. abgibt.

Bei Petromyzon kümmt, mit Ausnahme der ersten und letzten, jede Kiemenvene aus dem Interstitium zweier auf einander folgender Kiemensäcke. Die Kiemenvenen treten zur Bildung eines unpaaren Längsstammes zusammen, der nach hinten als Aorla sich fortsetzt, aber vorne keine $A$. vertebralis impar bildet. Die Carohs communis wird gebildet durch die erste Kiemenvene, welche mit einem zweiten Aste in den Anfang des unpaaren Längsstammes sich fortsetzt. Jede A. carotis communis theilt sich in einen äusseren und inneren Ast. Die Verbindung der beiden Carolides internae zur Bildung einer unpaaren Kopfarterie bleibt aus.

Bei den höheren Fischen entspricht eine Kiemenvene, mil Ausnahne derjenigen der beiden halben Kiemen, jedesmal zweien einander zunächst gelegenen Kiemenblattreihen. Bei den Elasmobranchii treten sämmtliche oder die meisten Kiemenvenen, entweder unmittelbar oder nachdem eine Vereinigung cinzelner derselben zu $\Lambda$ ortenwurzh zu Stande gekommen, zur Bildung der Aorla zusammen. Die Bildung der Carotiden geschicht in rersehiedener Weise. Bei Chimaera selzt die crste Kiemen- 
vene jeder Seite (dic der halben Kieme) als Carolis posterior in die Schedelhöhle sich fort und die zweite, welche, gleich den folgenden, zur Bildung der Aorla beiträgt, gibt eine in die Augenhöhle tretende Carotis anterior ab. Bei den Plagiostomen (Raja) entsteht die Carotis posterior aus einer Aortenwurzel, die durch den Zusammenfluss der beiden ersten Kie. menvenen zu Stande kömmt; sie dringt bei Raja in den Canalis spinalis. Die Carotis anterior entsteht aus den Gefässen der Pseudobranchie des Spritzloches. (S. \$. 105.) - Während bei den Chimären und Rochen die beiden Carolides posteriores unter einander unvereinigt bleiben und demnach kein vorne geschlossener Circulus cephalicus zu Stande kömmt, fliessen sie bei den Haien unter der Schedelbasis zusammen und geben der Hirnarterie Ursprung.

Bei den Ganoïden, wo die Kiemeuvenen, indem sie die Bildung der Aorla besorgen, wiederum manche eigenthümliche Verhälthisse zeigen, geschieht die Bildung der Carotiden auf ähnliche Weise, wic bei den Plagiostomen. Bei Lepidosteus kömmt noch eine dritte Hirnarterie aus dem Aorten-Anfange.

Bei den bisher untersuchten 'T eleostei hat durch die Kiemenvenen die Bildung eines ausserhalb der Schedelhöhle gelegenen arteriellen, vorne und hinten geschlossenen Gefïsskreises (Circulus cephalicus) Stalt. Es treten hier nämlich Kiemenvenen jeder Seite zur Bildung des Aorten-Anfanges zusammen und gehen auch vorne über dem Os sphenoïdeum durch eine auf Kosien der vordersten Kiemenvene jeder Seite gebildete Queranastomose in cinander über. Der so entstandene Kreis kann weiter oder enger sein. Weit ist er da, wo die sümmtlichen Kiemenvenen jeder Seite zu einem Bogen zusammentreten, und wo beide Bogen vorn durch einen Querast, hinten durch ihre Verenigung zum Aorten-Anfange sich verbinden, wie \%. B. bei Gadus, Lota; enger ist er da, wo jeder der zur Bildung der Aorla zusammenstossenden Bogen nur aus den beiden vordersten Kiemenvenen seiner Seite gebildet wird und wo die letzten Kiemenvenen erst in den Anfang der Aorla sich einsenken, wie bei Scomber, Salmo u. A.

S. 104.

Die Aorta erscheint bald als selbstständiger, freier, ron eigenen IIäulen allseitig und vollständig umgebener Gefiissstamm - und dies ist, mil A usnahme ciniger Fanilien, das gewöhnlichste Verhalten bei den Teleostei ${ }^{1}$ ) -, bald strömt das arterielle Blul, ohne überhaupt von den gevöhmlichen discrelen Gefiisshäuten umgeben zu sein, in einem von absteigenden Fortsïlzen des Wirbelsystemes gebildeten Canale; bald endlich findet gewis-

1) Z. B. Lei Perca, Cottus, Cyclopterus, Gadus, Belone, den Aalen, Lophius u. A.; hei letzlerem Fische tritt die Aorfn sehr hald in die an der Basis des Rumpftheiles der Wirbelsünle befindlicho Rinne. 
sermaassen eine Fusion dieser beiden Verhältnisse Statt, indem die Aorta einer selbststïndigen dorsalen Wand ermangelnd, blos abwärts von freien Gefässhäuten umschlossen wird, welche ciner ventraleu Aushöhlung der Wirbelkörper, die die obere Begrenzung der hier ganz diunnhäutigen Acrta bildet, angefügt sind.

In einem von absteigenden und unten geschlossenen Fortseizungen des Wirbelgerüstes gebildeten Canalc strömt das Blut bei Accipenser und Spatularia. Der Anfang des Aortencanales, in den die Kiemenvenen münden, liegt unter dem Schedel, zuersi abwärls durch den Basilarknochen geschlossen. Dann bildet eine kurze Strecke weit eine fibröse Membran seine untere Begrenzung; bald aber sind es die durch Schaltknorpel ergänzten abwärts gebogenen und völlig verbundenen unteren Wirbelbogenelemente, die ihn unten schiliessen. Luings der ganzen Ausdehnung des Aortencanales ragt in seine Höhle hincin ein dorsales, vorn von der Schedelbasis ausgehendes elastisches längsband, das oben an Hautfalten haftet, deren Fortselzung, als sehr dïnıes, aus elastischen Fasern, Bindegewebsfibrillen nud Zellen gebildetes Perichondrium, die Innenwand des Knorpelcanales, dem sie dicht anliegt, überzicht.

Bei manchen Squalidae und mehren Teleostei, z. B. bei Esox, Alosa, Clupea, Silurus 1. A. liegt die Aorla eingebeltet in einer Vertiefung der Wirbelkörper. Zu den Seiten dieser Vertiefung finden sich z. B. bei Esox fibröse Lüingleisten. Die Aorka besilzt bei diesem Fische nur abrärts eine eigene äussere Ilaut. Sie erscheint von Stelle zu Stelle angeschwollen, ausgebuchtet, sinuös. Jede solche Lrweiterung wird von der nächstfolgenden durch eine seichte Einschnürung gelrennt. Solche Einschnürung kömmt dadurch zu Stande, dass von der fibrösen Leiste der cinen Seile zu der der anderen eine schmale Querbrücke von faserigem Gewebe sich hinüberzieht. Der zwischen je zwei solchen Brücken gelegene Abschnitt der Aorla ist also durch das Blut ausdehubarer, als der von ihnen umspannte. Inuerhalb des Canales der Aorta findet sich bei Esox, Clupea, Alosa, Coregonus, Salmo, Silurus u. A. ein ganz ähnliches fibröses, clastisches Längsband, wie beim Stör. Es beginnt am Schedel unter der vorderen Grenze des Os occipilale basilare und erstreekt sich längs des ganzen Wirbelstammes nach hinten. Als eine ummittelbare Fortsetzung der Basis dieses Bandes erscheint die elastische Arterienhaut ${ }^{2}$ ). - Obschon bei den Cyprinen die Aorka von den Wirbelkörpern mehr isolirt ist und das fibröse Jängsband fehll, bildet sie doch von Stelle zu Stelle Sinnositälen; der ventralen Seite cines Wirbelkörpers entspricht dir Verengenum der Verbindungsstelle zweier Wirbel die Erweiterung.

2) Besonders gecignet zur Erkenntniss dieses Verhïlnisses sind grosse Exemplare von Silurus glanis. 
Wenn die Aorla frei liegt, verläuft sie nicht immer genau längs der Mitte der Wirbelsäule; denn z. B. bei Belone ist sie ganz nach der linken Seite hinübergetreten.

\section{S. 105.}

Was dic peripherischen Arterienäste anbelangt, so treten dieselben theils aus einzelnen Kiemenvenen vor ihrer Vereinigung zu einem gemeinsanen Stamme (der Aorla), theils aus diesem letzteren hervor. Der Arleriae carolides posteriores ist bereits kurze Erwähnung geschehen 1). - Eine der wichtigsten Kopfarterien ist die aus dem ventralen Ende der ersten Kiemenvene hervorgehende Arleria hyoidea ${ }^{2}$ ). Sie durchbohrt bei den Teleostei (z. B. bei Gadus, Esox) zuerst das untere Ende des Zungenbeines, folgt dem oberen Rande seines Bogens, durchbohrt das os temporale, erscheint an der inneren Seite des Kiemendeckels, gibt hier Rami operculares ab und tritt zu der gewöhnlich vorhandenen Nebenkieme, nachdem sie Verbindungszweige aus dem Circulus cephalicus oder der $\boldsymbol{A}$. carotis posterior erhalten. Nun vertheilt sie sich, analog einer Kiemenarterie, in den Federchen oder Blättchen der Nebenkieme. Aus diesen letzteren führen Arteriae revehentes das Blut ab und sammeln sich in einen Stamm, welcher durch einen über dem Os sphenö̈deum basilare gelegenen $\boldsymbol{R}$. communicans mit dem der entgegengesetzlen Seite in Verbindung steht. Jede Arleria revehens wird jetzt zu einer Arteria oplıhalmica magna, welche, ohne Abgabe von Nebenzweigen, neben dem $\boldsymbol{N}$. opticus, in den Augapfel tritt. Hier löset sie sich wiederum ganz wundernetzartig auf in den arteriellen Theil des merkwürdigen hier gelegenen Gefässkörpers: der sogenamnten Glandula chorioïdalis; diese gibt die arteriellen Gefüsse für die Chorioidea ab, während der Iris Blut aus anderen Arterien (des Circulus cephalicus der Carolis posterior) zugeführt wird. Die aus der Chorioidea kommeuden venösen Gefässe lösen sich wiederum in der Chorioïdealdrüse wrundernetzartig in Reiser auf, welche deren venösen Theil bilden. Dies venöse Blut der Chorioüdea sammelt sich endlich in eine Vena ophthalmica magna, die die Vene der Iris und später auch die der Augenmuskeln aufnimmt und das Blut durch die Vena jugularis zum Herzen zurückführt. Beim Słör und bei den Plagiostomen beschränkt sich die peripherische Vertheilung der ans der Pseudobranchie kommenden Arteria revehens nicht blos auf die Chorioüdea, sondern sie zerfällt in eine $A$. ophthalmica und in eine

1) In Bezug auf ihr näheres Verhalten verweise ich auf Mülle r, Gefässsyst. d. Myxinoid.; bei Inochenfischen schildert es Hyrtl, I. c. S. 88.

2) S. über dieselbe IIyrtl, Med. Jahrb. d. Oesterr. Staates. Bd. 15. 1838; über das Verhalten der Arteriue Ophthalmicae und die Chorioïdealdrïse aber die genannte Schrift von Müller und die daselbst gegebenen Abbildungen. 
Hirnarterie (A. carotis anterior). Jene vertheilt sich auch in den Umgebungen des Auges.

Andere, aus einzelnen Kiemenvenen hervorgehende, Aeste sind z. B. gerarle nach vorne sich erstreckende oberflichliche Kopfarterien bei Raja ${ }^{3}$ ); eine Arteria epigastrica bei Lucioperea und Aspro ${ }^{4}$ ).

Die Arterien der Extremitaten (A. subclaviae) sind in ihrem Ursprunge unbeständig. Sie entspringen z. B. bei Esox aus cinem gemeinsamen Stamme der beiden vorderen Kiemenvenen einer Seile; bei Gadus aus jeder Aortenwurzel; bei Perca, bei Raja aus dem ersten Aufange der Aorta selbst, oft unsymmetrisch und so, dass die der linken Extremität rechterseits entspringt, wie bei Perea, beim Aal u. s. w. Ein merkwürdiges Verhalten zeigt die vorderste, aus jeder. Seite der Aorta entspringende Arterie bei Lophius piseatorius, indem sie nach Abgabe cines dorsalen aufsteigenden Zweiges in zwei Hauptäste sich spaltet: eine Arteria brachialis und eine in Begleitung des tiefen Astes des Seitennerven liuggs den Rumpfmuskeln bis zum Schwanzende sich erstreckende und zahlreiche Seitenzweige ahgebende Arteria laleralis ${ }^{5}$ ).

Aus dem Stamme der Aorla entspringen innerhalb der Rumpfhöhle gewöhnlich folgende Arterienstämme: 1. Arteriae subclaviae; 2. eine Arteria coeliaco-mesenterica, welche aber z. B. bei Lota, Gadus callarias u. A. auch aus der rechten Aortenwurzel hervorkommen kann. Sie vertritt bei Accipenser und bei den bisher untersuchten Teleostei die Arleria coeliacas und mesenterica anterior zugleich, während bei Raja eine cigene A. mesenterica anterior neben ihr vorkömmt; 3. eine Art. mesenterica posterior. Ausser diesen grösseren Arterien, entstehen aus ihr, meistens sehr unregelmässig, einzelne Arterien für den Kopf, für die Wandungen des Schlundes, für die Nieren, so wie auch die Arteriae intercostales, welche aber, eben so wenig, als die übrigen Arterien, regelmässig angeorduct sind odcr einem bestimmten Intercostalraume folgen. Sehr bedeutend sind endlich temporär zur Zeit der 'Trächtigkeit die, cbenfalls rücksichtlich ihres Ursprunges variirenden, Arterien der Geschlechtstheile. - Der Schwanztheil der Aorla, welcher als Art. cuudalis in den Canal Jer absteigenden Wir-

3) S. Monro, Tb. 1. Fig. 5. B. - 4) Beschrieben von Hyrtl, I. c.

5) Als ich zuerst auf die Existenz dieser Arteric hinwies, habe ich ihren Ursprung nur ungenau nach Untersuchung eines ganz verstümmelten Exemplares des Lophius schildern können. Müller's Archiv 1848. Der weite Aortenanfang dieses Fisches entsteht durch die Vereinigung zweier Bogen; jeder ist hauptsächlich gebildet durch die zweite Kiemenvene, die indessen einen starken $\boldsymbol{R}$. communicans der vordersten Kiemenvene aufgenommien hat. Das dritte Kiemenvenenpaar senkt sich streng genommen, nicht in den Anfang der Aorta, sondern in den Anfang der von dieser sogleich ausgehenden Art. coeliaco-mesenterica. Jederseits ron dem weiten Aortenanfange entspringt die oben erwähnte Arterie; sie ist fast so weit, als die hintere Fortsetzung der Aorta. 
belbogenschenkel sich fortsetzt, gibt die den Körpervandungen bestimmten Arterien ab.

Eigenthümlich sind die an cinzelnen Arterien beobachteten Wundernetzbildungen. - Bei Lamna cormubica ${ }^{6}$ ) sind zwei linkerseits entspringende Arteriae intestinales (coeliaca und mesenterica anterior) vorhanden, velche durch zwei Rumpfarterien verstärkt werden. Diese arteriellen Gefässe lösen in zwei beträchtliche, dicht unter dem Diaphragma, vor dem Schlunde liegende Wundernetze sich auf, aus welchen zwei Arterienstämme hervorgehen, die das Blut sofort zu Leber, Magen, Darm, Milz und Pancreas führen.

Bei Thynnus vulgaris ${ }^{\top}$ ) trilt die Arteria coeliaco-mesenterica 'ur concaven Fläche der Leber und theilt sich in zwei Hauptäste, welche theils Arteriae hepalicae abgeben, zum grössten Theile aber in subhepalische Wundernetze sich begeben, dereu arleriösen Theil sie billen. Aus diesen Wundernetzen sammeln sich wieder arterielle Stämme von viel dünneren Wandungen, die, in Begleitung der Venen, am Magen, Darm, an der Milz und an den Appendices pyloricae sich vertheilen.

\section{\$. 106 .}

Die das venöse Blut zu dem Ilerzen zurückfühenden Körpervenenstämme sammeln sich in zwei liure, weite Quergefïsse, welche mit den Lebervenen und bisweilen auch mit anderen selbstständig bleibenden Venen in den Sinus venosus communis sich vereinigen, der umnittelbar mit dem Vorhofe des Herzens communicirt. Jene Quergefässe sind die Trunci transversi oder Duclus Cuvieri, von denen jeder meist symmetrische, seltener unpaare Venenstämme aufnimmt.

Bei symmetrischer Entwickelung des Venensystemes tritt in jeden Truncus transversus cine vom Kopfe absteigende Vena verlebralis anterior $s$. jugularis und eine aus der Rumpfgegend anfsteigende Vena verlcbralis posterior. Beide sind meist subvertebral, selten, wie bei Petromyzon und Ammococtes, supravertrebral. - Bisweilen ist aber die symmetrische Entwickelung der Trunci transversi gestört, indem die vordere und hintere Vertebralvene nur an ciner Seite zusammentreten, wie dies z. B. bei den Myxinoiden linkerseits geschicht.

Jede Vena vertebralis anterior nimmt das Blut auf aus dem Hirne, dem Schedel, der Augenhöhle, der Zungenbeingegend, oft auch von den Kiemenbogen und dem Schlundkopfe. - Verstärkt wird sie häufig,

6) S. Müller, Gefässsyst. d. Myx. S. 99.

7) Aehnlich bei Th. brachypterus. S. Eschricht u. Müller in d. Abh. d. Berl. Acad, d. Wissensch. A. d. J. 1S35. Aus den Hauptästen der Art. coeliaco-mesenterica gehen in stumpfen Winkeln unzählige dünne Röhrchen hervor, welche, mit ähnlichen Wundernetzröhren der Pfortaderstämme, schwammige Kegel bilden, aus deren Spitze die Arterienäste wieder hervorgehen. 
doch bei weitem nicht immer, durch die in sie cinmündende Vena subclavia, welche wieder verschiedene untergeordnete Venen aufzunehmen pflegt und auch selbstständig in den Truncus transversus cinmünden kamn. - Bisweilen stehen die beiden Venae vertebrales anteriores durch eine Queranastomose mit einander in Verbindung.

Das System der Venae vertebrales posteriores nimmt das Blut aus den Nieren, oft auch numittelbar aus den Rumpfwandungen, ferner meistens die Venen der Geschlechtstheile und der Schwimmblase auf. Bisweilen, wie bei Petromyzon, bei den Plagiostomen, bei Accipenser, bei Dioilon sind die beiden Venae vertebrales posteriores von etwa gleicher Stäke; bei den meisten Teleostei z. B. Gadus, Lota ist die rechte ${ }^{1}$ ) umfä̈rlicher als die linkc. Idetztere stellt oft nur einen ganz untergeordncten

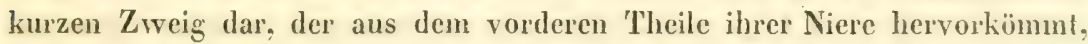
wie bei Salmo salar, beim Häring, bei Alosa, bei Esox, bei Anguilla, oder ist fast ganz durch die rechte seln starke Vene verdrängt, wie bei Belone, bei Silurus, bei Amnodyles. In diesen Fällen ergiesst sich das Blut der linken Körperhälfte durch untergeordnete Gefïsse zumeist oder fast ausschliesslich in die Vena vertebralis posterior dextra. Lelztere ist aber, wie z. B. bei Belone, anfangs nicht rechterseits gelegen, sondern nimmt die Mitte beider Nieren ein und wendet sich erst spïter nach rechts.

Die beiden Venae vertebrales posteriores oder die rechte Vene führen dem Ilerzen zugleich das aus der Vena caudalis stammende Blut zu. Bei manchen Fischen, z. B. bei den Cyclostomen und den Plagiostomen erscheinen die beiden Vertebralvenen als unmittelbare Fortsetzungen der Schwanzvene. Bei vielen anderen Fischen, namentlich vielen Teleostei löset sich jedoch der Stamm der Vena candalis bei seinem Austritle ans dem Canale der unteren Bogenschenkel, als Vence renalis advehens, pfort-

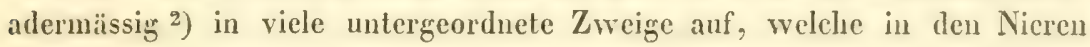

1) Nach den Beocachtungen von B a er (Eutwickelungsges. d. Fische. S. 2\&.) sind bei Cyprinus blicca die beiden hinteren Vertebralvenen ursprünglich symmetrisch; aber schon am vierten Tage ist die linke aufallend kleiner, als die rechte.

2) Dieses Verhalten der Venen ist zuerst kurz geschildert worden durch L. J a cobson, de systemate venoso peculiari in permultis animalibus observato. IJafn. 1521. Abgedruckt in d. Isis. 1522. S. 114. - Er fand eine Bestätigung durch die Untersuchungen von Nicolai, Isis. 1826. S. 411, der bei Lota und Silurus die vollständige Vertheilung der Vena caudalis in die Nierensubstanz beobachtete, bei Esox zugleich den unnittelbaren Uebergang eines Astes der $\boldsymbol{V}$. caudalis in die $\boldsymbol{V}$. vertebralis und beim Karpfen den Mangel einer Auflösung des Schwanzvenenstammes in Nicrenvenenzweige wahrnahm. - Cnvier u. Meckel bezweifelten die Richtigkeit der Angaben und auch ich konnte mich von derselben Anfangs nicht überzeugen, labe indessen bereits in der vorigen Auflage dieses Buches S. 479. meine veründerten Ansichten ausgesprochen und beispielsweise Cyclopterus und Diodon als solche Fische genannt, bei denen die Untersuchung leicht zu dem aflirmativen Ergebnisse führt, auch dic von 
sich vertheilen, um in kleinere oder grössere Stämme (Venae renales re. vehentes) wieder gesammelt, die Wurzeln der Venae verlebrales posteriores und namentlich der rechten Vene zu bilden. Unter den einheimischen Teleostei sind es besonders die Gattungen Lota, Silurus, Cyclopterns, Cottus, bei denen unan dies im Einzelnen wieder selır variabele Verhalten studiren kanu. Viele ausländische Teleostei zeigen wesentlich dieselbe Anordnung. Aber die ausserordentliche Mannichfaltigkeit der Bildungsverhältnisse der Fische offenbart sich auch in manchen weiter abwcichenden Verhältnissen, wie sie z. B. bei Lepidosiren ${ }^{3}$ ) beobachtet sind.

Die Vena caudalis und die Venae vertebrales nehmen successive Venen der Rumpfwandungen auf. Aber keinesweges tritt aus jedem Intercostalraume cine entsprechende Vene immer einzeln in die Nierenmasse, um später in cine Vena vertebralis sich zu ergiessen, sondern sehr gewöhnlich, z. B. bei Salmo salar, vereinigen sich zvvei bis vier einzelne Intercostalvenen zu einem in die Nierensubstanz eintretenden Stamme. Bei vielen Fischen, namentlich bei den Plagiostomen, bei Esox, bei Belone, bei Alosa u. A. durchsetzen diese Aeste die Nicren jedoch nicht einfach, um in die Venenstämme sich zu ergiessen, sondern lösen zuvor in untergeordnete Zweige sich auf, welche dann als solche, oder wieder in dickere Aestchen (Vence renales revehenles) gesammelt, in die Stämme eintreten ${ }^{4}$ ). Auch bei Accipenser treten in die Venae vertebrales nicht sowol stärkere venöse Stämme, sondern die Lumina der letzteren sind, selbst in der Gegend, wo die $\boldsymbol{V}$. verlebralis posterior die vordere Grenze der Niere bereits weit überschritten hat, von sehr zahlreichen feinen und engen Oeffuungen durchbrochien. Ueberhaupt hat man an sehr vielen Theilen des Fischkörpers Gelegenheit sich zu überzeugen, dass die za Stämmchen vereinten Venen abermals zerfallen, che sie in grössere rückführende Venen übergehen.

den gewöhnlichen, abweichenden VerhäItnisse der Nieren dieser Fische nicht unerwähnt gelassen. - Hyrtl ist gleichfalls zu dem Resultate gelangt, dass bei Diodon, Tetrodon, Triacanthus, Muraena, Pterois, Cepola, den Pediculati und einigen Siluroïden alles Blut des Schwanzes durch das Capillargefässsystem der Nieren strömen muss. (S. Hyrtl das uropoëtische System der Knochenfische. S. 11.) Hyrtl's Schrift enthält noch ein zahlreiches und treffliches Detail. - Bonsdorff, Act. soc. fennic. 1851. hat seitdem eine Untersuchung von Lota gegeben, wo die ganze Caudalvene in dic Niere pfortadermässig sich vertheilt. Ich kann nicht nur dieses Factum bestátigen, sondern auch für Silurus glanis, gleich $\mathrm{Nicolai}$, dasselbe angeben. - Auch in dieser Hinsicht scheint mir die Zahl der individuellen und temporären Abweichungen nicht gering zu sein; bei Esox z. B. ist es mir bisher nur gelungen, die Vertheilung von Rumpfvenen in die Nicrensubstanz zu finden. A gassiz und Vogt sprechen sich für Coregonus sehr bedenklich über dies Verhältniss aus. - Ueber das Nierenpfortadersystem von Lepidosiren s. II yril, S. 43.

3) S. die nähere Schilderung bei Hyrtl Lepidosiren, S. 39,

4) S. Analoge Angaben 1, bei Jacobson U. Hyrtl. 
Eine solche sogenannte pfortadermässige Vertheilung kleinerer Venen gewahrt man z. B. in den Nebennieren der Rochen, in der schwammigen Drüsenmasse, welche dic Venue vertebrales des Störes begleitet, in der Schwimmblase vicler Teleostei und in manchen anderen Körpertheilen.

Untergeordnetere Venen, die bei einzelnen Fischen eine grössere Selbststïndigkeit erlangen, sind die Venae epigastricue und die Venae jugulares inferiores.

Die Vena jugularis inferior ${ }^{5}$ ), welche das Blut vom Zungenbeine, vom unteren Theile des Kiemendeckels, von den Muskeln der Kiemengegend, aus den Venae bronchiales und aus den Venae nutriliae der Kiemenbogen aufnimmt, ist entweder paarig oder cinfach. In ersterem Falle ergiesst sie sich in die Trunci transversi, wie z. B. ,bei Esox, bei Perca u. A., in letzterem in den Sinus communis venarum, wie z. B. bei deu Cyclostomen, bei Thynnus, bei Cottus.

Venae epigastricae erlangen bisweilen cine bedentende Stärke; z. B. bei Loricaria ${ }^{6}$ ).

Dic Venen der keimbereitenden Geschlechtstheile, welche zur Zeit der Reife der Zeugungsstoffe gewöhnlich rine ausserordentliche Stärke besitzen, münden häufig ein in dic Venae vertebrales, wie z. B. bei Belone, Salmo, zeigen aber bei anderen Fischen, wie z. B. bei Petromyzon und bei manchen Knochenfisehen in Bezug auf ihre Einmündungsstelle ein abweichendes Verhalten.

Die Lebervenen, welche das System der Vena cava inferior höherer Wirbelthiere repräsentiren, senken sich selbstständig und zwar gewöhnlich mit zwei oder drei Aesten, deren jeder das. Blut aus einem Leberlappen sammelt ${ }^{7}$ ), seltener zu einem einfachen Stamme verbunden, in den Sinus communis venarum, der also, indem er sowol dem Wirbelsysteme, als auch dem Visceralsysteme angehörige Venen aufnimmt, einen gemeinsamen, indifferenten Sammelpunkt des venösen Blutes darstellt.

Bemerkenswerth sind die Wundernetzbildungen an den Lebervenen einiger Fische.

Bei Lamna cornubica löset sich der grösste Theil des aus der Leber zurückkehrenden venösen Blutes vor dem Erguss in das Herz wieder pfortadermässig in ein Wundernetz auf, das dem oberen Ende der Leber dicht aufsitzt. Inclessen geht cine Vene an diesem Netze vorüber, olne zu zerfallen. - Bei Thynnus haben die feineren Lebervenen einen gestreckten

5) Es ist dies die sogenannte du Verney'sche Vene. S. llist. de l'Acad. roy. de Paris 1699. p. 300. Müller, Gefässsyst, d. Myx. S. 28. Agassiz u. Vogt, Anatom. des Salmon. p. 128. Mt. Abb. Ueber die Yenae bronchiales s. ebenfalls genauere Angaben bei Alüller u. A gassiz.

6) Auch bei Belone, wo sie in den linken Truncus transversus sich ergiesst.

7) S. Näheres b. Rathko.in Neckel's Archiv 1827. S. 150. 


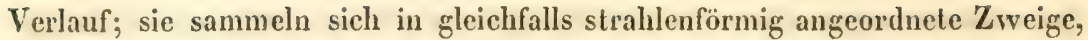
welche in beträchıliche sinuöse Erweiterungen der Lebervenenstämme übergehen ${ }^{8}$ ).

Eine Eigenthümlichkeit der Gattung Petromyzon ist der Besitz eines weiten Sackes ${ }^{9}$ ), welcher unter der Aorta und den Venae vertebrales posteriores liegl, von dessen Wänden zugleich das Suspensorium des Hoden und Eierstockes ausgeht. Mit den Venenstämmen communicirt er durch zahlreiche Oeffnungen, scheint auch Blut aus den Nieren und Geschlechtstheilen aufzunehmen. Verwandt ist ein gleichfalls mit den Venae verlebrales posteriores communicirender, inwendig zelliger Blutbehälter bei der Gattung Raja ${ }^{10}$ ), der über den Geschlechtstheilen liegt.

[Ueber das Venensystem der Fische vgl, man, ausser den Schriften von Cuvier, J a cobson, Müller, Agassiz u. Vogt, IIyrtl, dessen Alhandlung über das uropoëtische System der Knochenfische auch in die Verhältnisse des Venensystemes eingeht. - Interessante Beobachtungen über Entivickelungsverhältnisse des Venensystemes theilt Bacr (Entwickelungsgesch. d. Fische. S. 24. u. 28.) mit. Bei Güstern beobachtete er anfangs, statt einer im Canale der unteren Bogenschenkel gelegenen Schwanzvene, eine tiefer abwärts an der Basis der unteren Dornen gelegene tiefe Schwanzvene. Die in sie eintretenden Venen bilden ein reiches Gefässnetz. In der fünften und sechsten Woche erst ist die tiefe Schwanzvene viel blutärmer geworden. S. auch Baer, Ueber Entwickelungsgesch. d. Thiere. Thl. II. S. 300.]

\$. 107.

Das Leberpfortadersystem ${ }^{1}$ ) wird gebildet aus den venösen Gefässen des Oesophagus, des Magens, des Darmcanales und seiner Auhänge, der Gallenblase, der Milz; nicht selten werden aber die Wurzeln des Pfortadersystemes verstärist durch Venen der Schwimmblase ${ }^{2}$ ), der Genitalien ${ }^{3}$ ), der Bauchwandungen ${ }^{4}$ ). - Bei viclen Fischen vereinigen sich diese Ge.

S) S. Müller u. Eschricht I. c. S. 6. S. ebendaselbst Angaben über die Gefässverhältnisse des Alopias vulpes.

9) Vgl. Rathke, Bau der Pricke. S. 48. u. S. 70. Abb. Fig. 53.

10) S. Monro, Vergleichg. d. Baues d. Fische. T'b. 2. - N. Guillot in den Comptes rendus. XXI. p. 1179.

1) Ueber das Leberpfortadersystem der linochenfische $s$. vorzüglich $\mathbf{R}$ athke in Meckel's Archiv f. Anat. u. Physiol. 1826. S. $126 \mathrm{ff}$. u. Bonsdorff, in den Act. societ. fennic. Helsingf. 1851. über das Pfortadersystem bei Lota.

2) Z. B. beim Dorsch, bei Lota.

3) Bei Myxine; bei Perca, Blennius, Cobitis, Cyprinus, Osmerus nach Rathke. - Bei Silurus sah Nicolai, Isis. 1826. S. 413. einen Ast aus der $\boldsymbol{V}$. caudalis zur Pfortaderwurzel werden.

4) Müller hebt dies als eine Eigenthümlichkeit der Myxinoüden hervor; ich finde dies Verhalten aber sehr häufig bei unseren einheimischen Teleostei. So z. B. treten bei Salmo, Alosa, Clupea, Venen aus der Beckengegend und der zwischen ihr und dem After gelegenen Regio epigustrica in die Darmvene; dazu kommen bei Alosa noch 
fässe zu einem gemeinsamen Pforladerstamme ${ }^{5}$ ), che sie in die Lebru treten. Bei anderen Fischen, und zwar namentlich bei vielen Teleostei, treten die zur Bildung des Pfortadersystemes beitragenden Venen eimzeln oder in wenige Stämme gesammelt ${ }^{6}$ ), zur Leber. - Besondere Eigenthïmlich. keiten des Pfortadersystemes cinzelner Fische sind Folgende: Bei Myxine ist der Pfortaderstamm herzartig contractil. Er liegt hiuter der Banchfellfalte, muter weleher der Eingang aus der Bauchhöhle in den IIerzbeulel sich befindet. Der Stamm der Pfortader bildet eine sacliförmige Erweiterung und setat dam als Gefäss für die Iseber sich fort. Bei der Contraction zieht zucrst der Stamm der Pfortader gegen dic sackförmige Erweiterung hin sich zusammen; dam erfolgt sogleich cine Zusammenzichung der letzteren in der Richtung gegen die Leber hin. 1)ie der Leber zugewendete gefässfömige Verlängerung hat keinen Theil an der Contraction. Nerkwürdigerweise ermangelt der contractile Pfortarlerstamm quergestreifter Muskelfasern und besitzt nur gelbliche gebogene Faserbündel ${ }^{7}$ ). - Bei einigen Arten von Thunfischen ${ }^{8}$ ) gehen die vom Magen, von der Milz, vom Darme, von den Appendices pyloricae kommenden Venen einzeln über in grosse Pfortaderwundernetze die, an der nnteren Seite der Leber gelegen, acht Gefässkegel bilden.

Einen eigenthümlichen Verlauf hat die Darnvene bei Petromyzon und einigen Squalidae ${ }^{9}$ ); bei jenem liegt sie in der der Laingsrichtung des Darmes folgenden Falte, bei diesen in der cigenthümlich gerollten Spiralklappe des Darmes.

Venen aus der vorderen Regio epigastrica, welche 'in dic Venen der Appendices pyloricue einmünden; zahireiche Venen aus beiden Gegenden münden bei Alramis brama direct in die cinzelnen Pfortaderzweige der Leber. - Instalt dass also bei Amphibien dic ganze $\boldsymbol{C}$ ena abdominalis inferior sopigastrica eine Wurzel des Pfortadersystemes alogibt, treten bei Fischen viele einzelne kleine Bauchdeckenvenen in die Pfortader. Ich mache ausdrücklich auf diese wiederholt und sehr sicher beobachteten Thatsachen aufmerksam.

5) Z. B. bei Petromyzon, Raja, Acerina, Lota, Anguilla.

6) Am weitesten ist die Isolirung gediehen bei den Cyprinen, wo die Leber vielfach getheilt und gleichsam zerrissen ist. Nähere Angaben s. bei Rathke l. c.

7) S. M üller, Eingeweide d. Fische. S. 6. u. Gefässsyst. d. Myxinoĭd. S. 18.

8) Bei Thynnus vulgaris und Th. brachypterus. S. Muller u. Eschricht in d. Abhandl. d. Acad. d. Wissensch. z. Berlin. 1835.

9) Duvernoy, der, wie Meclsel, diese Bildung bei Carcharias, Galeoccrdo, Zygaena und einigen anderen Haien beobachtete, glaubt cine Belegung der Vene mit longitudinalen oder etwas spiralfürmig gekrümmten Muskelfasern erkannt zu haben. S. Ann. des scienc, nat, 1835. T. III. p. 274. 


\section{Vom Iymphgefässsysteme.}

S. 108.

Mit Ausnahme des durch Besitz hellen farblosen Blutes ansgezeichneten Branchiostoma sind bei allen bisher untersuchten Fischen Lympligefiisse aufgefunden worden und bei manchen Fischen hat das Lymphgefässsystem selbst eine vorwaltend grosse Ausbildung. - Ob und in wie ferne manche locale $\Lambda$ nhäufungen eines hellen dünnflüssigen oder gallertarligen Blastemes, wie sie z. B. in der Augenhöhle vieler Fische (von Gadus, von Lota, von Esox), oder unterhalb der läutigen Bedeckungen des Schedels, (bei Lota), oder in der. Umgebung des Herzens (wie bei Accipenser, Spatularia) oder in den Umgebungen des Gehirues (wie bei viclen Telcostei) u. s. w. vorkommen, zum lymphatischen Gefässsysteme in Beziehung stehen, bedarf weiterer Untersuchungen. Eben so wenig ist es bisher aufgeklärt, ob der sogenanute Blutbehälter in der Rumpfhöhle von Petromyzon, eih Jymphsack sei oder nicht. - Bei einigen Fischen ungeben Lymphbehäller grössere und kleinere arterielle Gefässe scheidenarlig. - Was die Ilauptstämme aubetriflt, so ist bei den Myxinoïden ${ }^{1}$ ) ein unter der Chorda dorsalis, über der Aorla gelegener Lymphgefïssstamm beobachtel, der vorne in zwei bis zum Kopfe vordringende Zweige sich spaltet, die Gefässe abgeben, welche den Ligamenta intermuscularia folgen. - Bei den übrigen Fischen sind die Stämme der Körperhöhlen von den an der Körperoberfläche gelegenen zu unterscheiden. Was jene anbetrift ${ }^{2}$ ), so kommen zahlreiche lymphatische Gefässe von den verschiedenen Theilen des Darmcanales, welche längs der Art. coeliaco-mesenterica, vielfache Verbindungen mit einander eingehend, sich erstrecken und unter dem Schlunde zu einem Behälter sich vereinigen, aus welchem paarige Aeste zu den Trunci transversi venarum herantreten. Andere lymphatische Längsgefässe verlaufen innerhalb des Canalis spinalis ${ }^{3}$ ). - Die peripherischen Stämme zerfallen in die des Rumpfes und die des Kopfes. Unter den ersteren sind am bemerkenswerthesten: 1. zwei Seitenlängsstämme ${ }^{4}$ ). Jeder derselben liegt bei der Mehrzahl der Knochenfische in dem Spalt zwischen

1) S. Müller, Gefässsyst. 'd. Myxinoïd. S. 18.

2) Zahlreiche Abbildungen dieser Gefässe finden sich bei Mo n ro (Vgl. d. Baues d. Fische.), so wie auch bei Fohmann. Etwa gleichzeitig mit Monro beschrieb sie ähnlich Hewson (Philos. Transact. Vol. LIX.)

3) Diese sind abgeb. bei Hyrt, M̈̈ller's Archiv. 1843. Tb. 10. Fig. 2.

4) Diese Seitenlängsstämme sind von Monro u. II ewson mit grosser Sorgfalt beschricben. Beiden genannten Anatomen waren die eintretenden Quergefässe bekannt. Auf letztere hat neuerlich wieder Hyrtl hingewiesen, der zugleich peripherische Geflechte derselben im Umkreise der Schuppenbasis schildert. - Agassiz und Vogt (Anat. d. Salm. p. 136.) haben sich von der Existenz der Quergefässe nicht über- 
der dorsalen und ventralen Hälfte des Seiteninuskels, begleitet demnach den Truncus lateralis $\boldsymbol{N}$. vagi. Jeder Seitenlängsstamm empfängt zahlreiche Quergefässe, welche genau den Ligamenla intermuscularia in ihrem Verlaufe folgen. Letztere Quergefässe bewirken eine Communication mehrer mehr dorsal gelegenen Längsgefässe mil dem Seitenlängsstamme.

2. ein unparer epigastrischer Längstamm ${ }^{5}$ ), welcher, von dem After aus, zwischen den ventralen Hälften der beiden Seitenmuskeln nach vorne verläuft und bis zum Schultergürtel sich erstreckt. Hinten münden Gefässe der Afterflosse in ihn ein; in der Rumpfgegend nimmt er Quergefässe auf, welche dem Verlaufe der Ligamenta intermuscularia folgen.

Ausser den genannten Hauptlängsstämmen kommen 3. unterge ordnetere oberflächliche Längsstämme 6) vor. Thre Lagenverhältnisse fallen zusammen mit gewissen Verhältnissen der Muskeln. Zunächst liegt ein Längsstamm da, wo die Ligamenta intermuscularia der dorsalen, wie auch der ventralen Hälfte des Seitenmuskels in Winkeln sich umbiegen und folgt der Reihe dieser Winkel; ein anderer liegt zwischen der oberen Grenze des Seitenmuskels uud dem Längsmuskel der Rückenflosse; oder längs der Basis der Rückenflosse. In alle diese Lüngsgefässe münden Quergefïsse eln, welche dem Verlaufe der Ligamenta inlermuscularia, oder den Interstitien der Muskeln, an der Rückenflosse auch dem Verlaufe der Strahlen derselben, folgen. Es stehen also die verschiedenen subcutanen Längsstämme durch Systeme von Quergefüssen in sorgsam angeordneter Verbindung.

4. Längs der Basis der Brustflossen liegt ein weiter, ihre ganze Breite eimmehmender Sinus, in welchen zahlreiche zwischen, den Flossenstrahlenmuskeln verlaufende, Gefässe einmünden.

Was den peripherischen $\mathbf{K}$ opftheil anbelrift, so würde derselbe, nach neueren Untersuchungen ${ }^{7}$ ), genau dem Verlaufe des peripherischen Nervenskeletes folgen. Nach denselben Untersuchungen ${ }^{8}$ ) scheint eine Communication zwischen den Lymphgefüssen und den Höhlen oder Röhren dieses Nervenskeletes Statt zu finden, in denen die Nervenknäuel allerdings von lympha-

zeugen künnen, während ich sie bei gelungenen Injectionen, z. B. bei Cottus, Silurus $u$. A. nie vermisste.

5) Diesen unpaaren Längsstamm haben sowol Hewson, als Monro gekannt, was ich nicht wusste, als ich ihn als bisher übersehen beschrieb. Weder II y rtl noch Agassiz haben ihn erwähnt. Er möchte wohl allen Knochenfischen zukommen. Die Salmones, Clupeĩdae, Gadoĩdei, Cataphracti u. A. besitzen ihn und zwar habe ich sowol in - als ausländische Fische untersucht.

6) Dies scheinen die beiden Stämme zu sein, die II yrtl bei Silurus erwähnt. Ich habe meine Untersuchungen an Silurus und, selir oft wiederholt, an Cottus angestellt. - 7) So nach C. Vogt in der Anat, des Salmon, p. 137.

8) S. Agassiz et Vogt, I. c. p. 139. 
tischen Bläschen umschlossen liegen. - Andere tiefe lymphatische Gefäs se kommen von den Kiemenbogen und münden in einen längs der Kiemenhöhle verlaufenden Canal ${ }^{9}$ ). - Die Verbindungen des Kopftheiles mit dem Rumpftheile sind noch nicht völlig aufgeklärt. - Was die Einmündung des Iuymphgefässsystemes in das Venensystem anbetrifft, so ist sie eine mehrfache. Eine Communication des Seitenlïngsstammes und des Längsstammes des Canalis spinalis mit der Vena caudalis hat Statt durch Vermittelung eines Caudalsinus ${ }^{10}$ ), der am Schwanzende der Wirbelsäule unter dem liefen mittleren Schwanzflossenmuskel jeder Seile gelegen, mit dem der entgegengesetzten Seite dureh einen kurzen, einen Träger der Schwanzflosse durchbohrenden Quercanal zusammenhangt. Dieser Caudalsinus, welcher contractil zu sein scheint, öfnet sich in die Vena caudalis. An der Eimmündungsstelle findet sich eine Klappe, welche den Rücktritt des Inhaltes der Vene hindert. - Vielleicht entspricht dieser Caudalsinus dem pulsirenden Herzen, das in derselben Gegend beim Aale ${ }^{11}$ ) sich findet. Eine andere vordere Verbindung ist nicht minder beständig. Sie findet sich an der Uebergangsstelle der Vena vertebralis anterior in den Truncus transversus, wo die vom Kopfe, von den Kiemen und vom Rumpfe kommenden Stïmme in cinen Sinus sich vereinigen, der in den Truncus venosus transversus, mündet ${ }^{12}$ ). Klappen sind im Verlanfe der Lymphgefiisse nicht wahrgenommen, kommen jedoch an Uebergangsstellen von grösseren Gefïsen in Sinus und dem Eingange dieser in Venen vor. Dic Lymphgefissstimme scheinen anch nicht conlractil zu sein ${ }^{13}$ ).

9) Agassiz et Vogt. p. 138.

10) Diese Communication des Lymphgefïs - und Venensystemes wurde gleichzeitig von Hyrtl und von Agassiz und Vogt aufgefunden. Beide haben sie abgebildet. Vogt hat unregelmässige Contractionen des Simus walurgenommea.

11) S. darüber II arshall Hall, A critical and experimental essay on the circulation of the blood. Lond. 1831. 8. p. 170. Tb. X. Es ist dies ein pulsirender blasser Sack, der mit kleineren Gefüssen und mit einem Schwanzenenstamme in Verbindung steht. Bereits Leeuwenhook hatte ihn gekannt. Müller hat ihn auch bei Muraenophis bcobaclitet.

12) Diese Communication mit dem Venensysteme haben Monro u. Hewson selrr gut gekannt. S. M o n ro l. c. p. 36. Tb-19. der Uebers. XXVII. des Originales. Aehnlich, obschon im Einzelnen nicht ganz übercinstimmend, schildern sie die Neueren. - Dass dieser Simus contractil wäre, möchte ich in Abrede nehmen. - Agassiz u. Vogt gedenken auch noch einer Communication mit der Vena jugularis inferior. - Ueber die Fohmann'schen Ansichten betreffend das lymphatische System der Kiemen s. dessen Schrift: Das Saugadersystem der Wirbehthiere. 1. Ileft. Ileidelb. 1827. Mt. Abb. - Rïcksichtich aller feincren Verhailtnisse muss auf die Schriften von II ewson, Monro und Fohmann verwiesen werden.

13) Ich habe namenllich die grossen Seitenstämme und das epigastrische Gefäss bei Knochenfischen of galvanisch gereizt, olne eine Spur von Contraction hemerkt zu haben. 
Ein eigenthümliches Verhältniss ist dies, dass bei Plagiostomen zahlreiche kleine einfache Blutgefässknäuel in das Lumen von Lymphgefässen vorspringend gesehen sind ${ }^{14}$ ).

\section{Von den Gefässdrüsen und Fettkörpern.}

\$. 109.

Den Blutgefässdrüsen höherer Wirbelthiere vergleichbare Gebilde treten schon bei den meisten Fischen, verschiedentlich ausgebildet, auf. Abgesehen von der dem Gehirne adjungirten Hypophysis und der Milz, kommen hier zunächst Gebilde in Betracht, welche, ihrer Lage und ihrem Baue uach, als Thyreoidea und Thymus anzusprechen sind.

Die Schilddrüse (Thyreoidea) ist bisher nur bei den Elasmobranchii, Ganoïdei und Teleostei beobachtet worden. Sie liegt bei den Elasmobranchii, als ziemlich grosser, röthlicher, gefïssreicher Drüsenkörper, hinter dem Unterkiefer, unterhalb des Musculus geniohyoüleus, am vorderen Eude des Kiemenarterienstammes. Der rundliche oder ovale Driisenkörper besteht aus gelblichen, etwas durchscheinenden Läppchen. Jedes Läppchen besteht aus einem von einer Bindegewebshülle umschlossenen Aggregate von rundlichen Bläschen, welche cine klare Flüssigkeit enthalten. Ein in Bezug auf Lage und Bau ganz analoges Gebilde ist bei den Ganoïlei und vielen Teleostei, in Gestalt von agglomerirten Bläschen angetroffen, welche, unterhalb der Copulae der Kiemenbogen gelegen, den Kiemenarterienstamm an seinem vorderen Ende umgeben. Es ist beim Stör bisweilen von ausnehmender Grösse und kömmt hier biswcilen selbst in der Circumferenz des Ursprunges der Kiemenarterienäste vor. Bei den Teleostei ist es im Ganzen viel kleiner, scheint aber bei derselben Species nicht zn jeder Zeit vorhanden zu sein. Es besteht aus geschlossenen, leicht zu iso-

14) Nach Leydig Anat. histol. Beobachtungen. S. 24. Mt. Abbild. Tb. 1. Fig. V.

1) Die Thyreoïdea von Raja war schon Stenson hekannt: De musculis et glandulis. Lugd. Bat. 1683. p. 86. Später hat Retzius (Observat. in anat. chondropt. p. 30.) sie bei anderen Plagiostomen beschrieben. Beim Stör und bei den línochenfischen wurde sie gleichzeitig von mir (s. die erste Auflage dieses Buches S. ¿5. u. S. 450. und von Simon (Philosophical transactions. 184. T. II. p. 295.) aufgefunden. Simon fand sie beim Aal, während ich sie bei Lophins, Belone, Gadus, Lota, Pleuronectes, Salmo, Esox, Silurus antraf. Wenn ich sie zuerst als Thymus deutete, so ward diese Deutung schon im Jahre 1848, bei Erwähnung ihres Vorkommens bei Lophius modificirt. Wenn ein ausgezeichneter Wiener Anatom sie den von mir bezeichneten Fischen abspricht, und zugleich mich sie noch als Thymus deuten lässt, so liegt ein doppelter Irrthum vor. Dass sie temporär schwinden kann, ist mir nach eigenen $\mathrm{Be}-$ obachtungen am Hechte und einigen anderen Knochenfischen, sehr wahrscheinlich, da ich sie bisweilen z. B. beim Hechte nicht aufzufinden vermochte. 
lirenden Bläschen, die in einem oft gefässreichen Stroma liegen. Der feinere Bau bietet manche kleine Differenzen dar.

\section{S. 110 .}

Die parige Thymus ist bisher bei den Mysinoïden, bei allen untersuchten Plagiostomen und bei einigen Teleostei beobachtet worden. Bei den Myxinoïden liegt sie hinter den Kiemen zu jeder Seite der Cardia. Die rechte liegt hinter der Bauchfellfalte, rechts von der Leber; die linke kömmt in dem Theile des Herzbeutels, worin der Vorhof gelegen ist, über diesem zum Vorschein. Beide bestehen aus Büscheln sehr kleiner länglicher Lobuli, welche an Blutgefässen hangen und durch lockeres Bindegewebe zusammengehalten werden. Jeder Lobulus besteht aus einer doppelten Reihe von cylindrischen, kernhaltigen Zellen, welehe Reihen am Ende des zoltenförnigen Lobulus in einander umbiegen. Zwischen diesen beiden Reihen verlaufeu die Gefässe und ein Strang von Bindegewebe.

Bei den Plagiostomen liegt oberhalb des dorsalen Endes der Kiemenbogen eine vorne breitere, nach hinten sich verschmälernde, grosse, grauliche, weiche, gelappte Drüsenmasse. Jedes Läppchen besteht aus mehren durch Bindegewebe zusammengehaltenen Blasen. Die Blasen sind von ciner structurlosen Membran umschlossen und von einer Bindegewebshülle, in welcher dic Gefässe verlaufen, umgeben. Der Inhalt der Blasen besteht in einer milchweissen Flüssigkeit, welche eine feinkörnige Masse, Kerne und Zellen enthält.

Ein entsprechendes Gebilde kömmt bei einigen Teleostei an der hinteren Grenze der Kiemenhöhle längs dem oberen Theile des Schnltergürtels vor. Es wurde bisher nur bei Lophius, Gadus, Lota, Pleuronectes beobachtet. Es liegt lïngs der Scapula auf dem Truncus lateralis $\boldsymbol{N}$. vagi, von einer eigenen häutigen Hülle eingeschlossen. Das Organ ist von granröthlicher Farbe, hat eine durch vorragende Acini oder rundliche Ausstïlpungen bewirkte höckerige Obertläche und enthält eine zähe, klebrige Flüssigkeit, in welcher Zellenkerne, Pigmentzellen, Fettkugeln und Zellen vorkommell.

[Bei den Myxinoiden ist dies Gebilde aufgefunden und beschrieben von J. M üller, der es zuerst als Nebenniere, später als Thymus deutete. (S. Eingeweide d. Fische. S. 8. u. Archiv 1850. S.507.). Bei den Plagiostomen (Raja) wurde es zuerst erwähnt und der Thymus verglichen von Fohmann. (Saugadersystem d. Wirbelthiere S. 44.) Später ist es wieder beobachtet von Robin (Annal. des sc. nat. T. VII. 1847.) uud gleichzeitig von Eclier im Ilandwörterbuch d. Physiologie. Bd. 4., der es auch wieder als Thymus deutete. Letzterer Forscher erkannte dieses Gebilde bei Mustelus, Galeus, Squatina, Raja, Myliobatis, Torpedo; ich kenne es auch bei Trygon, Aëtobatis, Pristis und Narcine.

Bei den genannten Teleostei habe ich es aufgefunden und beschrieben (II üler's Archiv. 1850. S. 502.). Auch dies Organ scheint seine Evolutions- und Involutionszeiten zu haben. Bei einem im Winter untersuchten, sehr grossen Gadus morrhua 
(einem weiter entwickelten Dorsch) fand ich es kleiner als beim Dorsch, als cylindrischen Strang, voll Pigment, fast ohne Höhle. Bei Accipenser habe ich es immer spurios vermisst. Während es bei Lophius sehr gross ist, fehlt es bei Batrachus tau; hier liegen wieder, wie bei Accipenser, an der Stelle des Thymus zahlreiche, weite Ostia besitzende, Folliculi branchiales, aus denen eine klebrige, etwas transparente Masse hervorkömmt. Es erweckt dies die Vermuthung, dass die absondernde Drüse die Stelle des Thymus vertreten könne. Leydig, dem ebenfalls dies Verhältniss nicht entgangen ist, braucht nicht an der Existenz der offenen Mündungen zu zweifeln.]

\section{\$. 111 .}

-Andere Gebilde erscheinen den Nebennieren vergleichbar. Es sind in diese Kategorie folgende Körper gebracht worden: 1. schmale okergelbe oder etwas hellere Streifen, die an der Rücken- oder Innenseite der Nieren, oder in den Wandungen der Schwanzvene liegen und nicht in discrete Körper zerfallen sind. Unter dieser Form erscheinen sie bei den bisher untersuchten Squalidae und bei Chimaera; 2. an der Innenseite der Nieren gelegene oder etwas an ihre Rückentläche tretende Gebilde, meist in vier bis fünf discrete, zwei Reihen bildende Körper zerfallend, die hinten bisweilen durch einen verhältnissmässig sehr grossen mittleren unparen, über dem Reclum gelegenen Körper verbunden werden. 3. Rundliche gelbe, fettreiche Körper, die bei Accipenser in grosser, jedoch unbeständiger Zahl in einer einwärls von den Nieren gelegenen schwammigen Blutgefässdrüse eingebettet liegen 1). 4. Weissliche, mehr oder minder runde, oder ovale, bald mehr kugelförmige, bald mehr platte Körperchen, die bei vielen Teleostei innerhalb der Nicrensubstanz vorkommen; sie finden sich bald mehr oberflächlich, bald in die Tiefe eingesenkt, bald mehr einwärts, bald answïrts, bald symmetrisch, bald asymmetrisch gelagert. Bei vielen Teleostei liegen sie im Schwanzende der Nieren, an der vorderen Grenze des durch die unteren Wirbelbogen gebildeten Gefässcanales; bei anderen weiter vorwärts, etwa in der Milte der Nieren. Dic zuerst genannte Iage haben sie z. B. bei den cinheimischen Acanthopteri, Anacanthini, Pharyngognathi, so wie bei den Cyprinen und bei Silurus; etwa in der Mitte der Nieren liegen sie bei Esox, bei den Salmones, beim Aal. Die Zahl dieser Körper beläuft sich bei Fischen, welche den zuerst namhaft gemachlen Gruppen angehören, gewöhnlich auf zwei bis drei. Bei Salmo und bei Esox dagegen findet man sie in der Regel in beträchtlicherer Anzahl, meist zu fünf bis acht; bei einzelnen Hechten ist aber die ganze Niere, von der Mille an bis zum Schwanzende hin, mil solchen Körpern versehen, gefunden worden.

1) Ob sie morphologisch und physiologisch Nebennieren repräsentiren, hatte ich für zweifelhaft Vgl. übrigens auch Leydig, Anat. histol. Beobachtungen über Fische und Reptilien: Berl. 1853. 
Nicht minder verschieden, als ihre Anzahl, erscheint ihr übriges Verhalten, das selbst bei Thieren gleicher Species nicht geringe Abweichungen darbietet. Bald erscheinen diese Körper weich, gefässreich und bluthaltig, bald hart, gefässarm, ganz gefässlos und wie vertrocknet. Häufig erblickt man sie eingekapselt von einer aus Bindegewebsfibrillen bestehenden Membran; mit dieser zusammenhangende, nach innen gerichtete, Septa können das Gebilde in mehr oder minder zahlreiche Läppchen theilen. In letzteren beobachtet man oft zarte dünnwandige Bläschen, deren Inhalt variabel ist, bestehend aus feinkörniger Masse, Fettkörnchen, Zellenkernen und kernhaltigen Zellen. Bisweilen sind die Gebilde weich, zerfliessend und sehr gefässreich. Bei Gadus callarias stehen sie in engster Verbindung mit denjenigen sympathischen Strängen, welche zu den Geschlechtstheilen sich begeben. Aus ihrer Masse gehen Fäden hervor, welche diese letzteren verstärken. Diese Fäden gehören, ihrer Textur nach, den Remak'schen Fasern an. Im Inneren der Bläschen der Nebennieren finden sich sehr gewöhnlich den Ganglienkörpern rücksichtlich ihres Aussehens entsprechende Gebilde.

[Bei den Plagiostomi scheint Retzius (Observationes in anatomiam chondropterygiorum. Lund. 1819.) zuerst auf ihr Vorkommen aufmerksam gemacht zu haben; bei Chimaera beobachtete sie Leydig. Sie scheinen nie zu fehlen; ich habe sie schon beim Fötus von Acanthias angetroffen. Jedoch sind ihre näheren Verhältnisse selbst bei verschiedenen Individuen wechselnd. So z B. traf ich bei einer sehr grossen Raja clavata im Winter, ausser den beiden Seitenreihen, einen mittleren hinteren Kürper von mehr als $2 \frac{1}{2}$ Zoll Querdurchmesser an, der bei einem viel kleineren, so eben (im Mai) untersuchten Exemplare spurlos fehlt. Jener mittlere Körper hatte Venue advehentes und revehentes. An jeder Seite desselben lagen, halb eingebettet in die Substanz der Nebenniere, runde flache Körper, zahlreiche Bläschen einschliessend, deren jedes einen Ganglienkörper enthielt. - Die bekannten Körper des Störes stimmen in den allgemeinsten Verhältnissen ihrer Anordnung mit den Nebennieren anderer Fische überein, sind aber äusserst fettreich. - Die Nebennieren der Teleostei sind von mir nachgewiesen (Müller's Archiv. 1839. S. 97 ff.), Hyrtl, (das uropoëtische System der Knochenfische. Wien, 1850. 4.) hat sie noch bei vielen Teleostei beobachtet. Ecker (der feinere Bau der Nebennieren. Braunschw. 1846. S. 31. Abb. Tb. 2.) hat über ihren feineren Bau gehandelt. Derselbe geschätzte Beobachter sah bei mehren jungen Ilechten die ganze Niere mit äusserst kleinen weissen Körperchen besetzt, welche vollkommen den Nebennieren glichen und in die Nierensubstanz eingesenkt waren, auch in ihrem Baue mit denselben übereinstimmten. Ich habe im April, nach vielen vergeblichen Bemühungen, zwei ähnliche Beobachtungen gemacht; in der rechten Niere eines jungen Hechtes traf ich 49, in der linken 35 solcher lö̈per; ein anderes Exemplar enthielt eine wol mehr als doppelt so grosse Anzahl. In beiden Fällen nahmen sie nur die hintere Hälfte der Nieren, von der Mitte bis zum Schwanzende ein. Das Ergebniss lange fortgesetzter Studien über die Nelrennieren des Dorsch ist Folgendes: 1 Sie fehlen sehr selten vollständig; 2. sie künnen als halbllüssige, sehr gefäss- und blutreiche, noch nicht eingckapselte, unförmliche llassen vorkommen, in welchen Falle Blutkörperchen klümpchenweise zusammengeballt und in mannichfa- 


\section{Siebenter Abschnitt. Vom Gefiisssysteme u, d. Gefissdrüsen. 259}

chen Formen der Zersetzung in ihnen vorkommen oder Exsudatkörper (Eiterkörper), mit Blutkörpern vermischt, auf ähnliche Weise zu Klümpchen vereint sind; 3. sie können eingekapselt, weich und dabei mehr oder minder gefässreich sein. In diesem Falle begegnet man oft dem von Ecker als charakteristisch geschilderten Bau; 4. sie können als gefässarme, oder gefässlose, eingetrocknete Massen sich zeigen; 5. nicht selten lkömmt die Anwesenheit von Schläuchen und Bläschen nur in einem Theile der Masse einer Nebenniere vor, deren übriger Theil eine unförmliche Masse von Exsudatkörperchen, Fettkörnern u. s. w. darstellt; 6. fast ausnahmslos begegnet man beim Dorsch dem oben erwähnten Verhälnisse der Nebennieren zu den genannten sympathischen Strängen. Die Nebennieren-artigen Körper der Teleostei möchte ich in gewisser Beziehurig vergleichen mit pathologischen Exsudationen, deren Masse theilweise typisch zu Nervenelementen organisirt wird, während sie theilweise resorbirt werden oder abgelagert bleiben kann und zwar bald als trockenes Exsudat, bald in Gestalt von Feltcysten, bald in Gestalt mehr lymphatischer Cysten. Jene Bildungen beim IIechte möchte ich als rein pathologisch bezeichnen. - 0 b die Nebennicren constant bei allen Teleostei vorkommen, möchte ich um so mehr bezweifeln, als ich sie bei Clupea harengus und bei Ammodytes tolianus, dort bei zahlreichen, hier bei sparsamen Nachforschungen, immer vermisst habe.]

\section{\$. 112.}

Bei ziemlich vielen Fischen knmmen längs der Venae vertebrales verlaufende oder sie umgebende eigenthümliche fett-oder blut- und gefïssreiche Körper vor. Innerhalb ihrer ist bisweilen der Grenzstrang des $\boldsymbol{N}$. sympathicus eingebettet oder sie scheinen zur Entwickelung sympathischer Ganglien in Beziehung zu stehen. Solche Körper sind beobachtet worden bei Ammocoetes ${ }^{1}$ ), bei Petromyzon ${ }^{2}$ ) marinus und fluviatilis, wo sie sehr feltreich sind. In den Körpern von Petromyzon, die längs der Venae vertebrales, von den Nieren getrennt, sich hinziehen, kommen den Nebennierenläppchen analog gebildete Körperchen vor und von ihnen aus entwikkeln sich Fasern, die die Blulgefïsse ungeben und auch zu den Geschlechtstheilen treten; wahrscheinlich Elemente cines $\boldsymbol{N}$. sympathicus. - Bei Accipenser ${ }^{3}$ ) erstreckt sich vom hintersten Theile der Schedelbasis aus, answärts vom knorpeligen Aortencanale, linten einvärts von jeder Nicre

1) S. Rathke, Anatomie des Querders. S. 92. Mit ihnen sind die Nieren eng verbunden.

2) Diese Körper von Petromyzon sind aber nicht zu verwechseln mit den von Rathke (Anat. d. Pricke. S. 52.) beschriebenen Verlängerungen des Vorderrandes der Nieren, die allerdings auch ein fettreiches Blasten enthalten.

3) Ich hatte in meiner Schrift über das peripherische Nervensystem der Fische diese Masse mit den Nieren confundirt, die von ihr jedoch vollständig getrennt sind. Der Kopftheil der Nasse ist dasellbst abgebildet Tfl. IV. Fig. 8. Sie ist in ihren wesentlichsten Theilen ein Gefüssconvolut; doch kommen sehr zahlreiche zellenartige Gebilde, ahnlich Exsudat- und Eiterkörpern darin vor. Blutkrystalle wurden einen Tag nach dem Tode in ungeheurer Quantität im Winter darin wahrgenommen. 
in der Ungebung jeder Vena verlebralis anterior und posterior, oberhalb der die Rumpfliöle auskleidenden und anch die Nieren abwïrts bedeckenden Fascia eine sehr gefüssieiche, schwammige, vorme dickere und compacte, hinten mehr sich verdïmuende Masse. Sie besteht grossentheils aus venösen Blutgefässen; ferner gehen in ihre Zusammensetzung ein : Bindegewebe, Fett, 'Lellen und Zellenkerne versehiedener Art. In ihs eingebettet liegen die als Nebennieren angesprochenen fettreichen Körper. In ihr verborgen liegt ferner der Grenzstrang des $\boldsymbol{N}$. sympalhicus. Die von ihr umschlossenen dünnwandigen Venenstämme sind in ihrer ganzen Circumferenz gewissermassen siebförmig durchlöchert, inden die Venen nicht in weitere Zweige gesammelt, sondern als ganz enge Gefïsse in sie eintreten. - Bei vielen Teleostei ${ }^{4}$ ) scheint die schwammige gefässreiche Grundmasse der Nieren, in welcher die Harncanälchen oft so sparsam eingebettet liegen, ihre Stelle zu vertreten. - Bei Acanthias vulgaris ${ }^{5}$ ) kömmt längs den Venae vertebrales posteriores, auswäıts von jeder, aber ihr eng angeheflet, cine Reihe runder, mit lymphatischer Flüssigkeit, Zellenkernen und Fett gefüllter Bläschen vor; in jedes derselben ragt von der. Vene aus ein einfacher Blutgefïssknäuel hinein. -- Morphologiseh betrachtet scheinen alle diese verschiedenen Gebilde den Glandulae lumbarss und thoracicae der Såugethiere zu entsprechen.

Verschieden von diesen Grbilden ist eine Reihe von Kürpern, welche bei den Elasmobrauchii ${ }^{6}$ ), von der Arteria axillaris aus, lïngs jeder Seile der Aorta sich herabzieht. Sie scheinen den Glandulae mediastinae posteriores zu entsprechen.

Endich finden sich bei vielen Teleostei ') eigenthümliche Körper in

4) Meine Untersuchungen über diesen Giegenstand sind noch nicht geschlossen, doch stimme ich im Wesentlichen mit Rathke überein. Vergl. \$. 114.

5) Ich fand in Januar bei einem Acanthias Folgendes: In die Wand der Schwanzvene, so weit sie zwischen den Nieren liegt, cingebettet, sieht man einen einfachen, gelben, fettreichen, der Nebenniere ganz analogen Körper. An der Vena vertebralis jeder Seite hangen 10 runde Lürper; in jeden ragt ein Blutgefass von der Vene ausgehend, quastartig hinein. Die Körper scheinen zwischen den Iläuten der Vene sich zu befinden; wenigstens geht ihre Aussenwand in die der Vene über; dass diese von einem Lymphgefässe umschlossen gewesen, habe ich nicht gesehen.

6) Von der Untersuchung der fälschlich sogenannten Nebenherzen der Chimaera ausgehend, hat L eydig diese líörper entdeckt und beschriehen. S. seine Abhandlung über Chimaera in 11 ïller's Archiv 1851, und seine Schrift über Rochen und Haien. S. 15. 16. Rücksichtlich seiner Schlüsse, dass sie dem Nervensysteme angehörige Nebenorgane vom Bane der Blutgefässılrüsen sind, kann ich ihm nur beistimmen. Sie sind meiner Ueberzeugung nach Blasteme sympathischer Elemente, zunächst der Ganglienkugeln, dann der Remak'schen Fasern. Im Einzelnen bietet ihr Verlauf bei verschiedenen Plagiostomen, sogar dersellen species, mannichfache kleine Verschiedenheiten dar.

7) Diese liorper habe icls schon im Jahre 1839 beschrieben und in der vorigen 
der Bauchhöhle. - Bald ist cin einziger vorhanden, wie bei Collus, Cyclopterus, oberhalb der Milz, bald zwei, wie bei Zoares, wo der zweite an der Leberarterie gelegen ist. Bei Cyclopterus z. B. liegr zwischen den Platten des Mesenterium, an der Theilungsstelle der Arteria coelinco-mesenterica in ihre beiden Ilaupläste, an einer zur Leber tretenden Milzvene, in der Nühe der Mliz und der Appendices pyloricae, an einem Truncus splanchnicus des Sympalhicus, ein milchweisser, rundicher Körper, der feine Arterien erhält und von dem eine kleine Vene in die Milzvene übergeht. Er besitzl, von einer gemeinsamen Membran unschlossen, einen milchweissen Inhalt, der von Fortsetzungen jener Membran durchzogen wird. Sein nicht immer ganz gleicher, sondern variabler Inhalt besteht in Fettkörnchen, in runden, kleinen kernhaltigen Zellen (Zellenkernen), analog denen der grauen Hirnsubstanz, elıas grësser, oder ungefähr so gross oder kleiner als Blutkörperehen, die dureh Essigsïure nicht aufgelöset werden, und in sparsamer vorkommenden grösseren, Ganglienkörpern ähnlichen Zellen, in deren feinkörniger Grundsubstanz ein meistens heller eccentriseher Kern mit dunklem Kernkörper sich findet. - Threr Lage nach entsprechen diese Körper der Teleostei Mesenterialdrüsen.

\section{Achter Abschnitt. \\ Von den Uro-Genital-Organen.}

\section{Von den Harnorganen.}

\section{\$. 113.}

Die Fischnicren liegen immer im dorsalen Theile der humpfhöhle, ansserhalb des Sackes des Periloneum. Ein Gegensalz vou Rinden- und Marksubstanz fehlt. Die äussere II ̈̈udung der Il aruwerkzeuge liegt nicmals vor dem After, sondern meist hinter, selten seitwärts von ihm. Während die Nieren bei Branchiostoma noch kaum erkannt wor-

Auflage dieses Buches S. 111 erwähnt und als llesenterialdrüsen gedeulet. Die Körper von Gadus und Cobitis gehören vielleicht gar nicht, die von Belone nur theilweise hicrher. - Die von Cyclopterus und Cottus wurden fiegenstand anhaltender Nachforschungen; minder oft die von Zoarces. Nit ihnen stimmen die nur wenige Nale untersuchten Körper von Gobius, Spinachia, Scomber. - Nicht zu verwechseln sind diese Körper mit Fettanhäufungen an der Gallenblase, die z. B. bei den Pleuronectes constant vorkommen. - Jene Körper erscheincn mir gleichfalls als Blasteme des Sympathicus. 
den sind 1), erscheinen sie bei den Myxinoïden von einfachster Bildung. Von einem langen oben fadenförmig werdenden Harnleiter gehen von Stelle zu Stelle, als Repräsentanten der IIarucanälchen, kurze sackartige Canälehen ab, deren jedes durch cine Verengerung in ein zweites Säckchen führt, in dessen Grunde frei ein blos mit Gefïssen in Verbindung stehender Glomerulus langt. Die Membrana propria der Harncanälchen und Säckchen wird von ciner Fortselzung der äusseren Haul des Harnleiters überzogen. Aus den Glomeruli hervorgehende Gefässe verzweigen sich in dem Säckchen und im harnleitenden Apparate. Die Ureteren öfnen sich, ohme zu cincr Harnblase sich zu erweitern, in den Porus, welcher auch die zur Ausführung der Geschlechtsproducte bestimmten Bauchöfnungen aufnimmt ${ }^{2}$ ).

Bei Petromyzon nehmen dic Nieren das hintere Drittheil der Rumpflı̈hle ein, ohne deren hinterstes Ende ganz zu erreichen. Sie bilden, wenigstens in dem grössten Theile ihres Verlaufes, eiue zusammenhangende compacte Masse; im hinteren Theile der Rumpfhöhle findet man oft eiuzelue von der übrigen Niere abgesonderte Renculi.

Längs des ganzen Aussemrandes jeder Niere erstreckt sich ein verhältnissmässig sehr weiter, inwendig von Epithelium ausgeklcideter IIarnleiter. Die Harnleiter beider Seiten vereinigen sich hinter dem Eude der Nieren zu cinem kurzen und weiten Canale, welcher durch dic röhrenförmig ausgezogene Papilla urogenitalis ausmündet. - Bemerkenswerth ist der Umstand, dass jeder Harnleiter vorn über das Ende seiner Niere hinaus sich, oft nicht unbeträchtlich, verlängert. Zur Seite dieser zuletzt blind geschlossenen Verlängerung findet sich ein Streifen Fett-haltigen Blastemes.

Bei den Elasmobranchii liegen die Nieren im dorsalen Theile der Rumpfhöhle, von der eigentlichen Bauchhöhle gesondert durch eine straffe fibröse Membran, die, vou der Wirbelsäule ausgehend, ihre ventrale Fläche überzieht. Bei den Squalidae sind die Nieren im Allgemeinen von etwas gestreckterer Form; bei den Rajidae ${ }^{3}$ ) und bei Chimaera kürzer; bei den meisten oder allen auf die hintere Hälfte oder die hinteren zwei Dritttheile der Rumpfhöhle beschränkt. Jede Niere ist ziemlich compact und besteht aus einer verschiedenen Anzahl von Lappen, die durch Querfurchen unvollkommen von einander gesondert sind. Von der Rïckseite betrachtet,

1) Am hintersten Theile der respiratorischen Bauchhöhle, in der Nähe des Porus abdominalis sah Müller bei Branchiostoma mehre von einander getrennte drüsige Körperchen, ohne Ausführungsgänge wahrzunchmen. S.M üll e r, Branchiostoma. S. 101.

2) S. Müller, Eingeweide der Fische. S. 10 u. 57. Abb. Tb. I. Fig. 2-7.

3) In den IIarncanälchen der Rochen und Haie kömmt Flimmerbewegung vor. Die Wimpern sind lang und stehen einreihig in Kreisen. So nach Simon's mehrfach bestätigter Angabe. S. II üll er's Archiv. 1845. S. 520. und v. H ess ling, Histol. Beiträge. S.47. 
erscheinen diese Lappen als spiralig gewundene, an den Seiten in einander übergehende Substanzmassen. Von jedem Lappen verlïuft bei Raja ein dickwaudiger Ilarneanal zum Innenrande der Niere. Zwei oder drei solcher, aus der Nierensubstanz hervorgetretener Canäle vereinigen sich immer zu einem Stamme. Indem diese Stämme vom vorderen Theile der Niere aus absteigen, von ihrem hintersten Theile aus aufsteigen, convergiren sie und fliessen jederseits zu einem sehr kurzen Ureter zusammen. Der Harnleiter jeder Seite mündet in eine blasenartige Erweiterung; beide Blasen öfrnen sich in eine kurze Urethra, die beim münnlichen Geschlechte auch die Vasa deferentia aufnimmt, und in die Rückwand der Kloake, hinter der Einmündung des Rectum, ausmündet ${ }^{4}$ ).

Die Nicren des Störes liegen, dureh einen kician Theil der ersten und die ganze zweite IIälfte des Rumpfhöhle sich erstreckend, bedeckt von einer tendinösen, Querbrücken bildenden Membran, auswärts von der Wirbelsäule, als anfangs schmalere, später breitere, compacte Massen. An ihrer Aussenseite und zuletzt mehr an ihrer Vorderseite, verlaufen die contractilen Harnleiter, ausserhalb der tendinösen Brücken. Durch die Interstitien der letzteren hindurch münden die IIarncanäle in den IIarnleiter. Dieser verliert scine Selbstständigkeit im hintersten Dritttheile der Rumpfhöhle, indem ein anscheinend zu den Geschlechtsorganen in Beziehung stehender Banchfelltrichter, dessen dorsale Wand schon eine Strecke weit die ventrale Begrenzung des IIarnleiter's gebildet hatte, in letzteren sich einsenkt. Die beiden Harnleiter münden, in eine gemeinsame Ilöhle sich vereinigend, hinter dem After aus.

\section{\$. 114 .}

Die Ausdehung der ansserhalb der Peritonealhöhle gelegenen Nieren '), die an ihrer unteren der Peritonealhöhle zugewendeten Fläche sehr gewöhulich von einer fibrösen Membran überzogen sind, ist bei den Teleostei sehr verschieden.

4) Diese blasenartigen Erweiterungen kommen nicht allen Rajidae zu; sie fehlen z. B. bei Torpedo.

1) S. über die Nieren der Teleostei, besonders Gottsche in Frorieps Notizen. 1834. Nr. 838. - Steenstra-Toussaint, Commentatio de systemate uropoëtico piscium. Lugd. Bat. 1835. - Hyrtl, das uropoêtische System der Knochenfische in den Denkschriften der Wiener Acad. d. Wissensch. Bd. 1. - Th, v. Hessling, Histol. Beiträge zur Lehre von der Harnabsonderung. Jena 1851. 8. - Die Nieren der Fische und besonders diejenigen der Teleostei, sind vielfach nicht sowol den bleibenden Nieren höherer Wirbelthiere, als vielmehr den Wolff'schen Körpern verglichen worden; jedoch mangelt solcher Auffassungsweise, meiner Ansicht nach die üherzeugende Beweiskraft. Die Nicren vieler Teleostei scheinen mir zwei bei Accipenser getrennte Körper zu repräsentiren : eine schwammige, blut- und gefässreiche Masse und die eigentlich harnbereitenden Gebilde. - Ueber die listologischen Verhältnisse handelt II essling, J. co, der auch bei Knochenfischen Cilien beobachtet hat. 
Bei vielen erstrecken sie sich von der Schedelbasis bis zum Ende der Rumpflöhle oder selbst hinter die hintere Grenze der letzteren hinaus, intem sie in den durch Schliessung der unteren Bogen der Schwanzwirbel gebildeten Canal sich verlängern können, wie letzteres z. B. bei vielen Gadoïdei und Salmones der Fall ist. Diese Ausdehnung kömmt ihnen bei weitem nicht immer zu. Bisweilen nämlich ist nur ihr vorderster Theil entwickelt, so dass sie nach hinten die Grenze des Diaphragma der Kiemenhöhle nicht überschreiten, wie dies z. B. bei den Pediculati, bei mehren Plectognathi Gymnodontes, bei Pterois der Fall ist. Bei anderen, (wie z. B. hei Fistularia) crstrecken sie sich vom Kopfe aus nur über einen kurzen Raum der Rumpfgegend, oder sie crreichen wenigstens deren hinteres Ende nicht, wie z. B. bei Thynnus vulgaris, bei Cyclopterus lumpus, bei Clupea harengus, Fischen, bei denen ihre Ausdehnung wieder gradweise verschieden ist. Auf der anderen Seite fehlt es auch nicht an Beispielen von Mangel ihres Kopftheiles, so dass sie wesentlich auf die Rumpfhöhle beschränkt, nach vorn die Grenze des Diaphragma der Kiencnhöhle nicht überschreiten.

Die speciellen Formverhältnisse des vordersten oder Kopftheiles der Nieren sind sehr grossen Verschiedenheiten unterworfen. Während in der Regel die Kopftheile beider Nieren von einauder getrennt sind, können sie auch eng an einander sich legen und wirklich verschmolzen oder durch Brücken mit einander verbunden sein. An Bejspielen asymmetrischer Anordnung dieser vordersten Abschnitte der Nieren fehlt es ebenfalls nicht.

Ihr Verhalten innerhalb der Rumpfhöhle gestaltet sich verschieden. Wenn die unteren Bogenschenkel der Rumpfgegend oberhalb der Bauchgegend sich schliessen, können die Nieren innerhalb oder ausserhalb des von ihnen gebildeten Canales liegen. Ein Beispiel des erstgenannten Verhaltens bietet Blennius gunnellus dar; das letztere hat z. B. Statt bei Liparis, bei Cybium regale, bei Alosa vulgaris u. A. - Die Form der Nieren accommodirt sich im Ganzen derjenigen der sie aufnehmenden und begrenzenden Theile. Bei solchen Fischen, deren erster Flošsenträger eine ab- und vorwärts gerichtete Krümmung macht, folgt das Ende der Nieren hïufig seiner Richtung, wie z. B. bei mehren einheimischen Pleuronectes. Die Form der Nieren und ihre Dicke an verschiedenen Stellen ihrer Gesammtausdehnung sind eben so oft bedingt durch die Verhältnisse der vor oder unter ilnen liegenden Schwimmblase. So sind bei Gadus callarias der Kopf- und Schwanzheil der Nieren sehr dick, während ihr hinter dem Körper der Schwimmblase gelegener Iängster $\Lambda$ bschnitt sehr schmal und platt ist. Bei Cyprinus und Silurus verbreitern und verflachen sie sich in den zwischen den beiden Schwimmblasen gelegenen Regionen, wo sie nicht durch diese Gebilde beengt werden und senken sich namentlich auch in die von den Rippen gebildeten Vertiefunger. Bei Belone, wo die Aorta 
linkerseits verläuft, trennt sie die linke Niere, wenigstens vorne, in einen inneren und äusseren Streifen. An ihrem hinteren Ende verschmelzen die beiden Nieren nicht selten.

Die Nieren bestehen meistens aus einer weichen, schr gefäss- und blutreichen Iasse; innerhalb derselben findet man die Harncanälchen stellenweise reichlicher, stellenweise sparsamer; namentlich zcichnet sich das obere Ende der Nieren mancher einheimischer Fische, z. B. Cyprinen, Belone u. A. so wie auch der flache Theil der Nieren von Silurus u.s. w. durch Armuth an Iarncanälchen aus, ${ }^{2}$ ) Wirkliche runde, Blutkörperchenhaltige Zellen und grösscre eingecapselte Blutextravasate kommen in der Nierensubstanz sehr häufig vor. In die blinden Anfänge und Aussackungen der Harncanälchen ragen die Glomeruli hineiv.

Die IIarnleiter, meist in der Nierensubstanz eingebettet und bald allmälich an Weite zunehmend, bald plötzlich wreit erscheinend, münden anscheinend immer in eine Harnblase. Ihr specielles Verhalten bietet manches Bemerkenswerthe dar. Bei einigen (aber nicht allen) Gadoïden, z. B. bei Gadus pollachius, liegen die Harnleiter in der Höhle der Schwimmblase. Bei einigen Fischen, z. B. bei Spinachia vulgaris ${ }^{3}$ ), senken sich, ansser den beiden Iauptharnleitern, vier bis fünf Gänge, vom Ende der Nieren getrenut, in die Blase ein. Es kömmt vor, dass bei grosser Kürze der Nieren, die beiden. Harnleiter zu einem langen einfachen Stamm ${ }^{4}$ ) sich vereinigen, der in die Blase und zwar bald in den Körper, bald in den IIals derselben sich einsenkt. Die Blase selbst bietet Verschiedenheiten ihrer Form dar. Bei manchen Teleostei erscheint sie als eine spindelförmige Erweiterung des Harnleiters, wie z. B. beim Häring, bei Alosa. Am häufigsten finden sich elliptische und ovale Formen, welche bald mehr sphärisch (Zoarces viviparus, Cyclopterus lumpus), bald mehr cylindrisch (Esox) werden. Dic Blasenaxe ist oft lang, wurstförmig (Pleuronectes). Lange Blasen zerfallen bisweilen durch Einschnürungen in hinter einander liegende Abtheilungen. Auch Ausbachtungen oder Cornua der Blase kommen vor, wie bei mehren cinheimischen Gadoüdei (G. callarias, aeglefinus) und bei Cottus. Die Iarnblase liegt meistens in der Mittellinie und wird dann durch eine von der Wirbelsäule ausgehende Bauchfellfalte suspendirt,

2) Ilierauf hat bereits Rathke in Burdach's Physiologie, Thl. 2. S. 601, kurz hingewiesen. In so ferne gewisse Partieen des $\boldsymbol{N}$. sympathicus in der Nierenmasse cingebettet liegen und Ganglien desselben in ihnen gebildet werden, kann man sie zugleich als Blasteme für diese auffassen. - In ihrer Substanz entwickeln sich bei vielen Teleostei die Nebennieren.

3) Diese Thatsache ist von Cuvier, Steenstra-Toussaint, Gottsche u. A. mit allem Rechte hervorgehoben. Hyrtl machte analoge Beobachtungen bei cinigen Aalen.

4) So z. B. bei Thynnus vulgaris. Abgebildet bei Mäller und Eschricht über die Wundernetze des Thunfisches, Tb. III. Fig. 6. Auch bei Alosa vulgaris, nur kïrzer. 
weicht jedoch auch nicht selten nach einer Scite hin ab. Gewöhnlich hat sie ihre Lage zwischen den Geschlechtstheilen und der Schwimmblase, hinter dem Rectum ${ }^{5}$ ). Sie ist oft von einem Cylinderepithelium aus. gekleidet.

Das kurze Endrohr der Blase (die sogenannte Urethra) mündet in der Regel hinter dem After, ein Gesetz, das dadurch eine Ausnahme crfährt, dass bei cinigen Symbranchii, manchen Plectognathi und den Pediculati, nach $\mathrm{Hy}^{\mathrm{t}} \mathrm{l}$, Harn- und Geschlechtsöffnung schon in die hintere Dickdarmwand cimmünden. Ferner liegt bei allen Pleuronectides, mit Ausnahme von Hippoglossus, die Harnöhrenöfnung - abgesondert vou der hinter dem After ausmündenden Genitalöfnung — als röthliche Papille nicht hinter dem After und dem Porus genilalis, sondern asymmelrisch an der gefärbten Seite des Körpers. Sonst besitzen die Harnund Geschlechlsöfnumgen eutweder getrennte Ostia oder es findet sich ein cinfacher Porus urogenitalis. - In ersterem Falle, welcher als der häufigere zu betrachten ist, mündet die Harnröhre gewöhnlich mit einfachem Ostium hinter dem Porus genilalis, welcher seinerseits hinter dem After gelegen ist; selten liegt, wie bei männlichen Blennii, ihr Ostium zwischen den paarigen Pori genilales.

Haru- und Geschlechts-Oeffnungen, mögen sie getreunt oder verschmolzen sein, münden sehr häufig an einer bald höheren, bald niedrigeren Papilla urogenitalis, die bei einigen Fischen, namentlich den Blennioïden, Gobiö̈den, Cyclopoden, z. B. unter den einheimischen bei Liparis und bei Cyclopterus lumpus, eine ziemliche Lïnge erreicht. Die an ihrer Spitze sich zeigende Oeflnung ist gewöhnlich ausschliesslich die Mündung der Ilamröhre, während die Genitalöffnung etwas mehr an der Basis zu liegen pflegt. Seltener liegen die Uro-Genital-Oeffungen, unter Mangel der Papille, blos in einer spaltartigen Grube. - Die Uro-Genital-Papillen stehen entweder frei hinter dem After, oder gehen von einer mehr oder minder tiefen Grube aus, welche zugleich den After enthält.

Bei Lepidosiren ${ }^{6}$ ) besitzen die nur durch den hinteren Theil der Rumpfhöhle sich erstreckenden Nieren gewundene Lappen. Jeder Ureter liegt nur eine kurze Strecke am änsseren Nierenrande frei und mündet auf einer kleinen Papille, seitlich vom Ostium der verbundenen Eileiter, in die Cloake. Eine dünnwandige Blase hat ihre besondere Oeffnung hinter dem Rectum : und nimmt die Ureteren nicht auf.

5) Bei Solea rückt die Blase mit dem Endtheile der Nieren in die zur Aufnahme des Ovarium bestimmte Verlängerung der Bauchhöhle zwischen Schwanzmuskeln und Knochen.

6) Vgl. II yrtl S. 42. Abb. Tb. V. 


\section{Von den Geschlechtstheilen ${ }^{1}$ ).}

\$. 115.

Die meisten und vielleicht alle Fische, sind getrennten Geschlechtes. Hoden und Eierstöcke sind oft nur durch die Verschiedenheit ihres Inhaltes zu unterscheideu. Besondere Ausführungsorgane fïr die Geschlechtsproducte fehlen manchen Fischen sanz. Bei viclen sind die Keimbildenden Organe von den ausfühenden Theilen durchaus nicht getreunt. Bei anderen findet beim weiblichen Geschlechte eine Trenuung der Ovarien von den Eileitern Statt und bein männlichen Geschlechte kommen neben den Iloden eigene Nebenhoden vor. Die meisten Fische sind Eierlegend, verhältnissmässig wenige lebendig gebärend. Die Entwickelung der Embryonen geschieht bei letzteren nicht selten in der IIöhle des Eierstockes; bei an. deren in bestimmten Regionen des leitenden Apparates, die als wirkliche Uteri anzusprechen sind. Bei wenigen Eierlegern geschicht sie in BrutLaschen an der Oberfläche des Körpers der Männchen. Die ausführenden Geschlechtstheile münden an ihren Enden meistens mit den harnausführenden Organen zusammen aus; bei einigen Fischen kömmt eine Fusion der Ausführungsgänge von Geschlechtstheilen und Harnorganen schon früher zu Stande. - Als äussere Copulationsorgane mit Wahrscheinlichkeit anzusprechende Theile, kommen nur wenigen unter den lebendig gebärenden Fischen zu.

Bei Branchiostoma ${ }^{2}$ ) liegen Eierstöcke und IIodeu, durch ihren Inhalt von cinander unterschieden, an der Bauchseite der Unterleibshöhle, einerseits an die Bauchwände angervachsen, übrigens von einer Bauchhaut bedeckt. Da Eileiter und Samenleiter fehlen, können die Geschlechtsproducte nur in die Bauchhöhle fallen und werden wahrscheinlich durch den Porus externus ausgeführt.

Die Cyclostomen ermangeln gleichfalls eigener ausführender Canäle der Geschlechtsorgane. Bei den Myxinoïden ${ }^{3}$ ) hangt das unpaare Geschlechtsorgan in einer langen Bauchfellfalte an der rechten Seite des Darmgekröses. Die beiden Geschlechter sind nur durch den verschicdenen Inhalt ihres keimbereitenden Geschlechtsorganes verschieden. Eier und Samen gelangen in die Bauchhöhle. Am Ende derselben findet sich zu jeder Seite des Darmendes ein kurzer Canal, welcher in den hinter dem After, zwischen zwei Hautlippen gelegenen einfachen Porus genilalis führt.

1) Vgl. über dieselben auch Cuvier et Duvernoy, Leçons d'Anatomic comparée. Tome VIII. Paris 1846, 8.

2) Vgl. Müller, l. c. S. 102; Kölliker in Müller's Archiv. 1843. S. 32.

3) S. Ml üller, Eingeweide d, Fische. S. 4. 
Bei Petromyzon 4) hangt jeder Geschlechtstheil, unter Mangel eines Bauchfelles an der Rückwand der Eingerveidehöhle, deren gauze Iänge cr eiunimmt, durch zahlıciche Fäden angeheftet an der Axe derselben und an dem über ihm liegendeu, oft mit Blut angefüllten Hohlraume. Das Słroma enthält reichlich Fasern und bildet zeitweise etwas gekräuselte PJatten. Im Frühjahre sind die beiden Geschlechter durch den verseliedenen Inhalt ihres Geschlechtsapparates sehr deutlich unterscheidbar. Rücksichtlich der übrigen Verhältuisse weicht Petromyzon von den Myxinoïden nur darin ab, dass der Porus genitalis in eine ziemlich lange Papille ausmündet. In Mai erkennt man bei beiden Geschlechtern Flimmerbewegung in der Bauchhöhle, namentlich am Ende derselbes. Zugleich ist die Umgebung des Ausganges lebhaft geröthet und geschwollen; eine lymphatische Flüssigkeit hat in dem Gewebe der Basis der Rückenflosse und in der Umgebung des After's sich angesammelt.

\section{§. 116.}

Was dic Ganoïden anbelangt, so ist Aceipenser ${ }^{1}$ ) am häufigsteu Gegenstand der. Untersuchung gewesen. Jeder der beiden langen, schmaIen, gelblichen Hoden erstreckt sich, an einer Peritonealduplicatur befestigt, vom Oesophagus bis zum Rectum. In seinem letzten Drittheile erscheint er gelappt. In dieser Strecke zieht sich, von den Bauchfellplat ten umhüllt, an der angehefteten Seite des Hodens über seine hintere Grenze hinaus, von seiner. Hauptmasse etwas abgegrenzt, ein Convolut von wenig weiteren Hohlräumen hin, das mit jener durch mehr querlaufende Gefiisse zusammenhangt. An der Innenseite des Hodens liegt, ihm eng verbunden, ein gelbes, äusserst fettreiches Blastem. Eine Einmündung des Hodens oder von ihm ausgehender Gefässe in einen ausführenden Canal

4) S. Rathke, Pricke; Schluesser, de petromyzontum et anguillarum sexu. Dorp. 1848. 8. Ich habe beide Geschlechter häufig im Mai untersucht, lange Zeit nur Weibchen erhalten, während später oft nur Männchen anlangten. Bei P. fluviatilis habe ich frei in der Bauchhöhle Spermatozoìden beovachtet. Ihre Bewegungen traten erst ein, sobald sie in einen Wassertropfen gebracht wurden; nie sah ich sie in ihrer umgebenden Flüssigkeit selbst sich bewegen. Es ist dies auch sonst eine sehr gewöhnliche Erscheinung. - Vergl. auch Panizza, sulla Lampreda marina; in den Nemorie dell' Istituto Lombardo di scienze lettere ed arti. Milano 184.

1) Die Bildung der Samenbestandtheile ist noch nicht aufgeklärt. Ebenso wenig die Art, wie die Ausführung des Samens geschieht. - Rathke hat beim llausen Quergefässe gesehen, die durch das Mesurchium in den Ilarnleiter übergingen (1. c. S. 129). Beim Stör habe ich mit Sicherheit mich hiervon nicht überacugen künnen. Rathke lässt das Convolut weiterer Hohlräume auch nicht über die Grenze des Hodens hinausgehen. - Was den durch C. E. v. Baer entdeckten Trichter anbelangt, so hat Ml üller ihn öfter verschlossen als offen gefunden, und zwar bei beiden Geschlechtern; damit stimmen meine Beobachtungen nicht, indem sie fast dis entgegengesetzte Ergebniss lieferten, in so ferne ich den Tricbter viel üfter offen, als geschlussen antraf, 
wird nicht wahrgenomnien. Jedoch findet sich cin Bauchfelltrichter, dessen äussere Apertur der Mitte der Länge des Hodens entspricht, und der in den über ihm gelegenen IIarnleiter hineinragt. Das Ende dieses Trichters wird bald geschlossen, bald offen gefunden. Die Höhle des Trichters ist, wenn auch nicht beständig, doch temporär, mit einem Flimmerepithelium ausgekleidet ${ }^{2}$ ).

Nach demselben Typus sind die Lagenverhältnisse der weiblichen Geschlechtstheile angeordnet. Der in den Harnleiter führende Trichter und das Flimmerepithelium kehren ebenfalls wieder ${ }^{3}$ ).

\section{\$. 117.}

1)ic Geschlechtsverhältnisse ${ }^{1}$ ) sind noch nicht bei allen Teleostei vollständig aufgekłärt. Während die meisten ganz entschieden getrennten Geschlechtes sind, sind vom Aale ${ }^{2}$ ) bisher noch keine mänuliche Individuen mit gehöriger Sicherheit erkannt worden. - Andererscils bieten Arten der Gattung Serranus ${ }^{3}$ ) des Räthselhaften noch viel dar, indem sie Hermaphodriten zu sein scheinen.

2) Auch zur Seite des Ilodens, und des Ovarium, ist die Bauchhaut mit Flimmerepithelium ausgekleidet, worauf ich zuerst, hinsichtlich des weiblichen Geschlechtes, in der ersten Auflage dieses Buches, S. 125, aufmerksam machte. Seitdem habe ich die Flimmerbewegung auch beim männlichen Geschlechte ötier wahrgenommen; dass sie zu allen Zeiten vorhanden sei, lässt sich aber nicht behaupten, da ich sie, wie bereits früher erwähnt, auch entschieden vermisst habe. Auch Leydig hat sie bei männlichen Stören anderer Art gesehen.

3) Polypterus (s. M̈̈ller, Ganoïden) S. 20. und Amia (s. Franque, p. 8) verhalten sich in den wesentlichsten Verhältnissen analog. Die mit weitem, querem Schlitz in die Bauchhöhle geöffneten Eileiter liegen bei Polypterus vor den langen und weiten Harnleitern. Beide verfolgen ihren Weg getrennt bis nahe vor dem gemeinschaftlichen Ausgang im Porus urogenitalis. Aehnlich verhält sich Amia.

1) Man vgl. über die Geschlechtstheile der Teleostei die Abhandlung von Rathke: Ueber den Darmcanal und die Geschlechtstheile d. Fische in dessen Beiträgen zur Geschichte der Thierwelt. S. auch Treviranus in Tiedemann's Zeitschrift f. Physiologie. Bd. II. S. 12. J. M üller, de glandul. secernent. struct. p. 105. Hyr॥, Beiträge zur Morphologie der Urogenital-Organe der Fische in den Denkschriften d. Wiener Acad. d. Wissenschaften. Bd. I.

2) Rathke, der so anhaltend mit den Geschlechtsverhältnissen des Aales sich beschäftigt hat (s. Beiträge zur Gesch. d. Thierwelt. 2. Aufi. Ialle, 1524. 4.; Wiegmann's Archiv f. Naturgesch. 1838. S. 299; Muller's Archiv. 1850) scheint noch nicht zu einem befriedigenden Resultate gelangt zu sein; eben so wenig ist es Hohnb) aum-Il ornschuch (de Anguillarum sexu et generatione Gryph. 1842. 4.) geIungen, einen sicher männlichen $\Lambda$ al aufzufinden. Nach wiederholter eigener Prüfung der Frage muss ich demnach Schluesser (de petromyzontum et anguillarum sexu. Dorp. 1848. 8. p. 33.) dahin beistimmen, dass sie noch nicht gelöset ist und dass männliche Aale noch nicht nachgewiesen sind。

3) Cavolini (Abhandlung üher die Erzeugung der Fische und Krebse. Uebers. v. Z immermann. Berl. 1792. 8. S. 84 fl. Tb. I. Fig. 16-18.) hat das schon den Alten räthselhafte Verhalten des Serranus scriba einer sorgfältigen Untersuchung un- 


\section{S. 118 .}

Die weiblichen Geschlechtsorgane der Teleostei sind nach zwiefachem Typus gebildet. Bald sind Eierstöcke vorhanden, welche ausführender Fortsetzungen zu ermangeln scheinen, so dass die an ihnen gebildeten Eier in die Bauchhöhle fallen und durch einen hinter dem After gelegenen Porus der letzteren ausgeführt werden, bald stellen die Ovarien ununterbrochene Schläuche dar, welche frei nach, aussen mündend, sowol Bildungs-, als auch Ausführungsorgane der Eier sind.

Mangel deutlich schlauchförmiger Bildung der Eierstöcke charakterisirt die Familie der Salmones ${ }^{1}$ ), die Galaxiae und anscheinend einige zu den Clupeïdae gezählte Gattungen, so wie endlich die Muraenoïdei. - Die Bildung der Eierstöcke bei den Lachsen ist Folgende: Das Ovarium stellt bei Salmo eine häutige Platte dar, von welcher zahlreiche, aus sehr gefässreichem Bindegewebe bestehende runde Blätter sich erheben. Dies Gewebe der Blätter des Ovarium bildet das Stroma für die Entwickelung der Eier. Haben dieselben einen gewissen Grad der Reife erlangt, so ragt das Ei, von einer Theca umgeben, die durch einen Stiel mit der Eierstocksplatte verbunden ist, hervor. Seine Lösung geschieht

terworfen, die zu dem Ergebniss führte, dass am unteren Theile der Ovarien, in Gestalt einer weissen drüsigen Masse, anscheinend ein Hode haftet. Cuvier (Hist. nat. d. poiss. Vol. 2. p. 221.), der die anatomischen Thatsachen C avolini's bestätigt, schliesst aus seinen Untersuchungen, dass die Entwickelung des hodenähnlichen Organes mit derjenigen der Eiersäcke gleichen Schritt hält. Nur anhaltend fortgesetzte mikroskopische Beobachtungen werden zu einer Entscheidung der Frage führen.

1) Die Verhältnisse der weiblichen Geschlechtsorgane der Salmones sind zuerst von $\mathbf{C a r u s}$ in ihren Eigenthümlichkeiten erkannt, dann von Rathke und später von Agassiz und Vogt ausführlich geschildert. J. Müller hat sie als Grundlage zur Charakteristik der durch ihn begrenzten Familie der Salmones benutzt und seinen Galaxiae denselben Bau vindicirt. Valenciennes gibt von Notopterus an, dass die Eier in die Bauchhöhle fallen und an dem einzigen weiblichen Hyodon claudulus, den ich untersuchen ksonnte, schien es mir auch für dieses Thier der Fall zu sein. Bei Osmerus fallen aber nach Rathke (I. c. S. 159.) die Eier nicht unmittelbar in die Bauchhöhle, vielmehr geht, dem genannten hochgeschätzten Beobachter zufolge, vom Ende jedes Eierstocks ein zarter hautartiger Fortsatz, eigentlich nur eine Duplicatur des Bauchfelles, nach hinten ab, deren oberer Rand sich an die Nierenmasse, der untere aber an die Bauchdecken ansetzt. Auf diese Weise liegt hinter jedem Eierstocke eine IJöhle, deren äussere Seite von der Seitenwand des Bauches, die innere von jenem Bande gebildet wird. Lösen sich die Eier, so fallen sie in diese, nach hinten sich verschmãlernde Ilöhlen und gehen endlich durch den gemeinsamen Porus genitalis aus dem Körper. - Aehnliche Beobachtungen scheinen IIyrtl bestimmt zu haben, den Salmones, gleich wie auch den Aalen, wirkliche Tubae zuzuschreiben. Es bedarf also jedenfalls neuer Untersuchungen zu geeigneter Jahreszeit. - Ueber die durch $R$ athke als nach dem Typus der Salmones gebildeten weiblichen Geschlechtstheile von Acanthopsis taenia vgl. Müller, Ganoiden. S. 71 und II yrtl, I. c. p. 14. 
durch Bersten jener Theca. Dic Eier fallen nach ihrer Lösung in dic Bauchhöhle, deren Gefässe un diese Zeit sehr blutreich sind. Gleichzeitig erscheint das Gewebe der Eierstocksplatten erweicht und in einem Zustande der Auflösung begriffen. Jede Eierstocksplatte ist an einer Bauchfellplatte befestigt, welche einen zarten Ueberzng derselben zu bilden scheint und jenseits derselben bis zum Porus genilalis zu verfolgen ist.

Was die weiblichen Generationsorgane der übrigen Teleostei anbelangt, so stellen dieselben Hohlschläuche dar, welche ohne. Unterbrechung der Continuitäl durch den Porus genilalis ${ }^{2}$ ) nach aussen münden. Diese Schläuche sind gewöhnlich in doppelter', selten in einfacher Zahl ${ }^{3}$ ) vorhanden. In ersterem Falle vereinigen sie sich zuletzt zu einem einfachen kurzen Gange, der zwischen After und Harnröhrenmündung nach aussen geöffuet zu sein pflegt. Sie liegen innerhalb der Bauchhöhle, gewöhnlich seillich an den Eingeveiden derselben, meist nach aussen von der Schwimmblase, gewöhnlich frei, selten hinten angewachsen, wie bei Cobitis fossilis. Bei vielen Pleuronectes liegen sie eingesenkt in einen Raum zwischen den Flossenträgern und den Muskeln der Schwanzgegend. - Dic Eierstocksschläuche besitzen einen Bauchfellsüberzug, dessen Platten zur Seite des Rückens in ein Mesoarium sich fortsetzen, welches die zur Zeit der Geschlechtsreife meist sehr starken Gefässe, so wie auch die Nerven einzuschliessen pflegt. Bei beträchtlicher Anfüllung des Eierstockes drängt sich dieser zwischen die Platten des Mesoarium und gelangt so hart an die Rückseile der Bauchhöhle, wie z. B. bei Esox. - Die Dicke der Wandungen der Eierschläuche zeigt sich nicht nur, je nach Verschiedenheit der Fische verschieden, sondern nimmt auch, bisweilen wenigstens, um die

2) Nach Cavolini (1. c. S. 72.) ist bei Julis der Porus genitalis bis zur Ausleerung der Eier hăutig verschlossen.

3) Dahin gehüren z. B. Perca fluviatilis, Zoarces viviparus, Blennius gunnellus, Ophidium barbatum und Vassalli, Ophicephalus striatus. Iy rtl hat gezeigt, dass die Ovarien mancher Fische, welche bisher für einfach galten, eigentlich doppelt sind. Dahin gehören Anableps tetrophthalmus und Ammodytes tobianus, wo freilich die Scheidewand schon lange bekannt war. Derselhe Beobachter findet bei Trachypterus iris, hei Cobitis barbatula, bei Balistes tomentosus in einer oberen Einkerbung oder Spaltung des sonst einfachen Eierstockes eine Andeutung beginnender Duplicität. Er fand bei Poecilia Schneideri den anscheinend einfachen Eierstock mittelst eines Septum in eine obere und untere IIälfte getheilt. Angesichts dieser Angaben ist nicht ausser Acht zu lassen, dass die Summe der individuellen Schwankungen bei Fischen sehr gross ist. So habe ich bei Petromyzon fluviatilis, ausser dem normal angehefteten Ovarium, eine von diesem vollständig getrennte Masse gesehen, die wie ein kleiner Eierstock mit reifen Eiern gefült war und einen Theil des Darmcanales eng umhülte. Desgleichen sah ich bei Lota vulgaris den Eierstock der einen Seite durch ein vollständiges Septum in zwei ilälften getheilt: eine grosse und eine etwa sechsmal keinere. - Ueber das Detail muss auf $\mathrm{Hyr} t \mathrm{l}$ verwiesen werden. 
Zeít der Reife der Eier beträchtlich ab. Dicker erscheinen die Wände immer beil Zoarces, Pleuronectes, als bei Cyclopterus, Belone, Gadus und bei diesen wieder dicker, als bei Clupea, Esox; bei letztgenanntem Fische ist der ganze Peritonealüberzug des Ovarium, mit Einschluss des Mesoarium, auswendig mit Flimmerepithelium bekleidet 4). Die Form der Eierstöcke wrechselt; bei Belone sind sie z. B. lang und wurstförmig, bei Cyclopterus stellen sie weite Schläuche dar, die kürzer und breiter sind. Umfang und Ausdehnung der Eiersäcke sind, je nach dem Stande der Entwickelung der Eier, grossen Verschiedenheiten unterworfen. Wenn letztere ihre Reife erlangt haben, füllen ihre Behälter oft die ganze Bauchhöhle aus und bringen die übrigen Eingeweide mehr oder minder aus ihrer Lage. -

Innerhalb der Eierstockshöhle bildet die Schleimhaut häufig Längsfalten oder Querfalten, welche oft aus an einander gereiheten blattartigen Vorsprüngen bestehen; seltener kommen zoltenartige Formen vor; doch können beide auch neben eiuander erscheinen. Alle diese Vorragungen sind sehr gefässreich. Zwischen ihren Häuten geht die Ausbildung der Eier vor sich. Bei Zoarces viviparus ${ }^{5}$ ) hangt z. B. das reife Ei an einem dünnen Stiele, der in eine sehr gefïssreiche Capsel (Theca) sich fortsetzt, welche das Ei lose umhüllt und nur an einer helleren Stelle (der Narbe), wo die Blutgefässe ganz fehlen, seiner Oberfläche eng angewachsen ist. Jener Stiel ist eine Fortsetzung der Gewebstheile und Blutgefässe der Eierstockshäute. Zwischen dem Eie und dem grössten Theile seiner gefässreichen Theca findet sich, von Fäden durchzogen, oft, obschon nicht immer, cine klare lymphatische Flüssigkeit. Die Lösung des Eies geschicht durch Platzen des gefässlosen angewachsenen Theiles der Theca und so gelangt das Ei in die Höhle des Eierstockes.

Das Ovarium der Teleostei ist bald blos Bildungsstatte und Ausführungsorgan der Eier, die ausserhalb des Körpers ihre fernere Entwickelung erfahren, bald fungirt es als Uterus, indem die Entwickelung der Embryonen in seiner Höhle vor sich geht. Die Zahl der lebendig gebärenden Teleostei ist verhältnissmässig gering. Es gehört dahin unter den einheimischen Fischen: Zoarces viviparus; aber auch aus anderen Familien sind lebendig gebärende Fische bekannt, z. B. Sebastes viviparus, manche Cyprinodontes, z. B. Anableps tetrophthalmus u. A.

Bei manchen Fischen, z. B. bei Fundulus unter den Cyprinodontes, verlängert sich der Oviduct längs dem vorderen Rande der Afterflosse.

4) So habe ich es bei zwanzig Hechten in den Monaten April und Nai gefunden. Ich kenno dies Flimmerepithelium bei keinem anderen Knochenfisch.

5) Zu anderen Zeiten ragen kolhenartige Fortsätze in das Ovarium hinein, in deren Substanz die Eier sich entwickeln. Diese hahen anfangs ein Keimbläschen. 
\$. 119 .

Die männlichen Geschlechtstheile der Teleostei bestehen aus den Hoden, deren Secret durch ihnen verbundene und mit ihnen in unuterbrochenem Zusammenhange stehende Schläuche oder Canäle ausgefïhrt wird. Die Hoden sind in der Regel, und vielleicht ausnahunslos, paarig. Jeder Hode pflegt seitlich in der Bauchhöhle zu liegen, befestigt an einer Peritoncalduplicatur, welche zugleich seinen äusseren Ueberzug bildet. In dieser verlaufen die ihm bestimmten Gefïsse und Nerven. Die Ausdehmung der IIoden und die Beschaffeuheit ihres Inhaltes sind, je nach Verschiedenheil der Geschlechtsreife und der Jahreszeit, grossen Verschiedenheiten unterworfen. Sehr gewöhnlich sieht man mit dem Hoden in innigem Zusammenhange ciuen durch eine Furche mehr oder minder scharf abgesetzten Körper, der später in den über den IIorlen hinaus reichenden ausführenden Canal sich fortsetzt. Es repräsentirt dieser Körper ein Rete testis. Fr ist bisweilen, wie bei Cottus, wenigstens um die Zeit der Reife der Geschlechtsproducte, wenig schmaler, als der Hode selbst und überragt letzteren nach oben; bei anderen Fischen, z. B. dem Hecht, dem Lachs, dem IIäring, ist er viel sehmaler und folgt der Iö̈ngenrichtung des Hodens. Dies Rete testis besteht hïufig, z. B. beim Lachs, aus zahlreicheu, anfangs mehr quer und schräge, später mehr gerade verlaufenden, aber doch netzartig unter einander verbundenen, von der Fortsetzung der Membrana propria des Hodens aus, nach innen rorspringenden Scheidervänden und Canälen. Diese werden allmälich weiter und verschwinden zuletzt in dem hinterwärts über den Iloden hinaus verlängerten $\boldsymbol{V}$ as deferens. Von diesem aus crstrecken sich bisweilen -- und das kömmt z. B. bei Esox häufig vor - blind endende Divertikel zwischen die als Mesorchium dienenden Bauchfellplatten himein. Am Eude der Bauchhöhle verbinden sich die beiderseitigen Vasa deferentia und münden, gevöhnlich mit der Urethra, in die Papilla urogenitalis. Das eigentliche Gerüst des Hodens besteht, wenigstens häufig, aus feinen, blind endenden Röhren, deren Nachweis allerdings nicht immer mit gleicher Dentlichkeit gelingt. Die Entwickelung der Spermatozoïden geht anch bei manchen Teleostei, z. B. bei Salmo salar, bei Cottus scorpius ${ }^{1}$ ), in Zellen ror sich, ist aber noch nicht anhaltend genug verfolgt worden. - Uebrigens bieten die Hoden, in Betreff ihres äusserlichen Verhaltens, ihrer Ausdehunug, ihres Zerfallens in mehre an dem Ausfïhrungscanale

1) Bei Cottus scorpius finden sich im Januar in einem felt- und körnerreichen Blasteme zahlreiche Bläschen; jedes derselben schliesst zahlreiche Zellen ein; heim Lachs (Salmo hamatus) sieht man im November zahlreiche (6-- 6 ) aggregirte Zellen, ohne dass eine eigene umhüllende Blase immer zu erkennen wäre. Die Spermatozoiden, die rund erscheinen und deren Schwanz nicht mit wünschenswerther Genauigkeit erkannt werden kann, sind im Rete testis in lebhafter Bewegung. 
hangende grössere Lappen, mannichfache Verschiedenheilen dar. Grössere Lappen kommen z. B. bei Tinca vor; vielfach gekräuselte längliche Körpeı bilden die Iloden beim Dorsch. Bei den Plenronectes treten sie nicht, gleich den Ovarien, in Verlängerungen der Bauchhöhle, welche zwischen den Muskeln und Knochen der Schwanzgegend liegen.

Bei einigen Knochenfischen sind, neben den eigentlichen keimbereilenden männlichen Gesehlechtstheilen, accessorischc drüsige Gebilde beobachtel worden, deren Secret mit demjenigen der Hoden gemischt zu werden scheint. Am bekanntesten sind dieselben bei den Gobii ${ }^{2}$ ).

Wie die Spermatozoïden in die weiblichen Geschlechtstheile solcher Fische gelangen, die lebendig gebärend sind, ist noch nicht aufgeklärt. Zwar besitzen z. B. die männlichen Blennii eine Papilla urethralis, aber diese kömmt auch den Weibchen zı und in ihr münden nicht cinmal die Vasa deferentia ans. - Bei Anableps tetrophthalmus ${ }^{3}$ ), wo die beideu Vasa deferentia verbunden in die Harnblase münden, verläuft die Urethra in einer Rime, welche durch die Strahlen der Afterflosse gebildet wird, die eine Art von Penis darstellt.

Eine merkwürdige Eigenthümlichkeil besitzen die Lophobranchii ${ }^{4}$ ). Eine unterhalb der iusseren Bauchdecken und der ventralen Seite der vorderen Schwanzgegend, durch zwei der Iänge nach sich erstreckende Falten begrenzte Rinne, bildet beim Mämuchen einen Hohlraum, in welchen die vom Weibchen gelegten Eier aufgenommen werden, um bis zum Ausschlüpfen der Jungen beherbergt zu werlen. Durch ïbereinstimmende Beobachtungen neucrer Forscher hat es sich herausgestellt, dass es die Mïnnehen sind, die diese Brïttasche besitzen. Bei der ostindischen Gattung Solenostomus, wird durch die Bauchflossen ein Sack gebildet, der die nämliche Bestimmung hat.

Intercssant sind die Verïnderungen in der Färbung der Hautbedeckungen, welehe bei den Männchen vieler Fische, 11 die Zeit der Begattung, vor sich gehen. Man hat Gelegenheit, dieses Hochzeitskleid z. B. bei Cottus scorpius, bei Labrus viridis, so wie auch bei man-

2) Vgl. über dieselben Kathke, I. c. p. 201. und IIyrtl, I. c. p. \%. Sic bestehen aus parigen Körpern; jeder ist ein Agglomerat von Bläschen, die durch Canäle miı dem $V$ as deferens zusammenhangen. Auch bei llullus barbatus und bei Cobitis fossilis hat $1 \mathrm{yrtl}$ analoge blasenförmige Gebilde angetrolfen; desgleichen bei Blennius gattorugine.

3) S. die genaue Beschreibung und die Abb. bei IIyrtl, I. c. S. 9.

4) Vgl. Cavolini, 1. c. S. 32, und dagegen die neueren Beobachtungen von Eckstroem, die Fische in den Scheeren von Morkö, übers. von Creplin. S. 133; Retzius, Isis, 1835; Krohn in Wiegmann's Archiv, 1840. I. S. 16.; v. Sicbold in Wiegmann's Archiv, 1842. S. 292. Abbildungen dieser Brüttasche s. z. B. bei Carus, Erläuterungstafeln zur vgl. Anatomie, Ileft V. Tfl. 6. 
chen Cyprinoïden wahrzunchmen. - Aeussere Geschlechtsunterschiede kommen bei den Fischen häufig vor; bekannt ist z. B. der Haken am Oberkiefer mämnlicher Lachse, der in eine tiefe Grube der Unterkiefergegend aufgenommen wird.

\section{\$. 120 .}

Bei den Elasmobranchii sind die Eileiter von den Orarien gesondert. Was die Ovarien anbelangt, so sind sie meist doppelt und parig; nur bei den Familien der Scyllii und Nictitantes ist ein unpaares und zugleich asymmetrisches Ovarium vorhanden.

Die Ovarien liegen, wenn sic doppelt sind, jedes an der Innenseite seines Eileiters; angeheftet durch eine Verdoppelung des Banchfelles (Mesoarintm); der uupare Eierstock der Scyllii und Nictitantes liegt zwar bei alteren Thieren ungefähr in der Mitte beider Eileiter, an einer mittleren Bauchfellfalte zwischen ihnen herabhangend; aber bei jungen Thieren ist er nicht in der Mitte, sondern einseitig und zwar gewöhnlich rechts, seltener linkerseits, angetroffen worden.

Die leitenden Organe sind immer doppelt, mögen die Ovarien doppelt oder cinfach sein. Sie besitzen unmiltelbar unter dem Diaphragma der Kiemeuhöhle über der Leber, an deren Ligamentum suspensorium angeheftet, eine gemeinsame mittlere Abdominalöfluung. Jeder Eileiter zerfüllt in einen eigentlich sogenannten Oviduchus und in den erweiterten Uterus, welcher von jenem durch cine cirkelförmige Klappe abgesondert ist. - Die Schleimhantanordnnng des Eileiter's weicht von der des Uterus ab; an der Innenfläche der ersteren, welche gewöhnlich Lïngsfalten besitzt, ist ein Flimmerepithelium beobachlet worden. - Zwischen den Membranen des Eileiters liegt bei den meisten Elasmobranchii eine absondernde Drüse: die Eileiterdrüse, bestimmt zur Absonderung des zur Eischale erstarrenden Stoffes. Sie ist kaum spurweise vorhanden bei der Gattung Torpedo, wo das Ei keine Schale erhält. Die Form dieser Drüse variirt. Bei Acanthias vulgaris und Scymnus lichia ist sie ringförförmig; bei den Nictitantes besteht sie aus zwei hohlen schneckenartig gebogenen Hörnern; bei Rhinobatus ist sie herzförmig. Am grössten ist sie bei den cierlegenden Elasmobranchii, wo sie aus zwei convexen, dem Eileiter aufgesclzten, drüsigen Massen besleht, welehe an den Seitenwänden, wo sie sich berühen, efwas zusammenfliessen. Sic besteht aus zahlreichen Röhrchen, die an der Innenfläche des Eileiters münden ${ }^{1}$ ).

Die Innenfläche des Uterus, an welcher Flimmerepithelium vermisst ist, zeigt sich glatt bei den Seyllii und Niclitanles, mit Zotten versehen bei Spinax niger, mit Längsfalten, welche mit dreiseitigen Blätteru beselzt

1) Abb. b. Müller de Struct. glandul. Tb. II. Fig. 14. 15. 
sind bei Acauthias vulgaris ${ }^{2}$ ) u. A. Nahe verwandte Arten, wie Torpedo ocellata und T. marmorata ${ }^{3}$ ) bieten Verschiedenheiten der Anordnung dar. Es scheint selbsi, dass die Formen in verschiedenen Lebensstadien der gleichen Species variiren. Die Enden beider Uteri münden, mit gemeinsamer Oeffnung, etwas hinter dem Ausgange der Ureteren in die Cloake ${ }^{4}$ ).

In den Eileitern wird die Eischalenhaut abgesondert, welehe letztere bei den Eierlegenden dick, bei den Vivipara dagegen dünne ist oder fehlt ${ }^{5}$ ). Bei letzteren erfolgt die Entwickelung der Frucht innerhalb des Uterus. Die Zahl der lebendig gebärenden Fische ist in dieser Abtheilung grösser, als die der Eierlegenden. Unter den IIaien sind eierlegend die Scyllii, unter den Rochen die Rajae, gleich wic auch die Chimären es sind. Die Eier der eierlegenden Elasmobranchii crhalten eine feste, platte, meist länglich viereckige, oft an den Winkeln zugespitzte und spiraligg gewundene hornige Schale, deren Form nach den Gattungen verschieden ist; ihre Eier verweilen im Uterus nur bis zu vollendeter Bildung der Schale und verlassen ihn vielleicht immer vor begonnener Eutwickelung des Embryo. - Was die lebendig gebärenden Plagiostomen anbetriff, so ist ihr Dottersack gewöhnlich frei und ohne Verbindung mit dem Uterus ${ }^{6}$ ). Bei einigen jedoch, wie Mustelus laevis ${ }^{7}$ ): dem glatten Hai des Aristoteles, so wie bei den Carcharias, ist er an eine wirkliche Placenta uterina angeheftet und zwar so, dass seine Falten und Runzeln in entsprechende Vertiefungen der Schleimhaut des Uterus cingreifen.

Ein eigenthümliches Gebilde ${ }^{8}$ ), immer symmetrisch doppelt, liegt bei den Nictitantes je in einer Bauchfellfalte, dic vor der Wirbelsäule und

2) Abb. bei Treviranus in Tiedemann's Zeitschr. für Physiologie. Bd. 2. Tab. II. Fig. 3.

3) S. Dary, Researches. Tab. II. Fig. 1. 2.

4) Es war mir auffallend das in die Cloake führende Ostium der ausführenden weiblichen Geschlechtstheile bei einem sehr grossen Exemplare von Raja clavata in Januar verschlossen zu finden; bei Acanthias mit zwei Fötus war das um die gleiche Zeit nicht der Fall.

5) Sie fehlt, nach Davy, bei Torpedo und bei Squatina; dagegen ist sie z. B. bei Acanthias vorhanden.

6) Vivipara acotyledona sind unter den Ilaien: Sphyrna, Galeus, Thalassorhinus, Mustelus vulgaris, Alopias vulpes, IIexanchus griseus, Acanthias vulgaris, Spinax niger, Centroscyllium Fabricii, Scymnus Lichia und Squatina vulgaris; ferner die bisher beobachteten Rajidae, mit Ausnahme von Raja und Platyrhina,

7) Mustelus vulgaris besitzt diese Eigenthümlichkeit nicht und es ist eine merkwürdige Thatsache, dass zwei einander so nahe stehende Arten hinsichtlich der Ausbildung der Frucht so abweichend sich verhalten. - Der Nabelstrang der Squali cotylophori ist sehr lang; die äussere Haut, eine Fortsetzung der Baachhaut, ist bei Mustelus laevis und bei Prionodon ganz glatt, bei Scoliodon aber dicht mit Zotten besetzt.

8) Il üller bezeichnet es als epigonales Organ der weiblichen Geschlechtstheile. 
vor den Nieren sich lıcrabzicht. Es ist cine weissı̈̈thliche drüsige, aus Körnchen bestehende, Substanz. An der Seite, wo der Eierstock liegl, reicht es bis zu diesem; an der anderen Seite ist es kürzer.

[In Betreff der weiblichen Geschlechtstheile ist fast ganz auf J. Müller's Arbeiten, in denen auch die älteren Beobachtungen kritisch zusammengestellt sind, zu verweisen: Eingeweide der Fische, S. 19, und die classische Abhandlung: Ueber den glatten Ilai des Aristoteles in den Abhandl. d. Acad. d. Wissensch. zu Berlin. A. d. J. 1840. - Man vergl. auch Leydig (Rochen und IIaie, S. 86.), der die Flimmerbewegung in den Oviducten beobachtete.]

\section{\$. 121 .}

Die mänlichen Geschlechtstheile der Elasmobranchii bestehen aus den anscheinend immer parigen Hoden, den mit ihmen dureh Vasa efferentia verbundenen Nebenhoden, den Vasa deferentia, in welche liese sich fortsetzen und in paarigen, äusseren IÏ̈lfsorganen, deren rigenlliche Bestimmung noch dunkel ist.

Der rumdliche, ovale oder scheibenförmige II ode, in seinen Gestallungsverhiltnissen selbst bei Thieren der gleichen Species variirend, wird durch eine Peritonealduplicatur befestigt, welche von der Mitte des Wirbelstammes ausgeht und später auch den Nebenhoden äberzicht. Er liegl. im vordersten Theile der Bauchhöhle, bedeckt von der Leber. Seine Substanz besteht aus einem fettreichen Blasteme $\left.{ }^{1}\right)$ und aus zahlreichen erbsengrossen Blasen oder Capseh. Jede dieser Blaseu enthält bei Raja cine Menge zum Theil gestielter, zum Theil geschlossener kleiner Bläschen. In Zellen, welche diese enthalten, bilden sich Bündel von Spermatozoüden. Diese gelangen durch zarte Vasa efferentia in den Nebenhoden. Derselbe liegt einwärts vom IIoden, beginnt dicht unter dem Diaphragma, und erstreckt sich dann längs der Wirbelsänle nach hinten. Er besteht aus einem Systeme vielfach gewundener Canäle, welche (bei Raja vor dem Vorderende der Nicren) in das Vas deferens übergehen, das anfangs cinen spiral gewumdenen, allmälich mehr geraden und sich erweiternden Canal darstellt, der invendig kreisformig gestelle Falten besilzt ${ }^{2}$ ). Das $\boldsymbol{V} a s$ deferens verläuft einvärts vou der Niere, dicht neben dem Wirbelstamm. Es wird, gleich der Niere, durch eine fibröse Fascia von der Bauchhöhle abgegrenzt. Es mündet nebst der kurzen Urethra mit einer Papille in die

1) Monro, Tb. IX. der Uebers. Fig. $1 \mathrm{k}$. A white matter like the milk. Diese Masse ist nicht ganz beständig vorhanden. Davy hat sie bei den Torpedines durchaus vermisst. - Die Entwickelung der Spermatozoiden ist durch mich, durch I) a vy und durch Hallmann gleichzeitig verfolgt worden. S. Hallmann's Ablındlung in M̈̈̈ller's Archiv 1840.

2) Z. B. bei Raja clavata, Acanthias vulgaris; analog, nach Leydig, bei Chimaera. 
Rückenvand der Cloake ${ }^{3}$ ). - An der Rückseite des Nebenhodens und des spiral gewundeneu Theiles des Vas deferens liegt wenigstens bei mehren Plagiostomen, eine Masse ${ }^{4}$ ) von der Farbe hellen Muskelfleisches, die aus vielfach gewundenen Canilen besteht, welche in die Höhle des Vas deferens cinmünden.

Die äussercu II ülfsorgane ${ }^{5}$ ), welehe allen mänulichen Elasmobranchii zukommen, bielen freilich bei den einzelnen Gruppen mannichfache Versehiedenheiten dar, haben aher viel Gemeinsames. Sie stellen am Ende des Beckenknochens seh. frei beweglich befestigle -- durch an- und abziehende, theils vom Bechen, theils von den Seilen des Körpers ausgehende, theils eigenc Muskehn beherrschte - ausgehöhlte Anhänge dar. Hhre Grundlage wird gebildet durch zahl'eiche Knochen- und Knorpelstïiclic, welche zum Theil blattartig umgerollt auch eine kurze Strecke weit durch laxe Hautbrücken verbunden sind und einen von Schlcimhant ausgekleideten, schlüpfrigen, durch Abziehen der sie bedechenden Knorpel erweiterungsfähigen, unvollkommen gesehlossenen Canal bilden. In den blinden Anfang dieser IÖ̈hle münden, wenn auch vielleicht nicht immer, doch meistens, die Ausfülrungsgänge einer absondernden Drüse. Diese Drüse ist z. B. bei Torpedo von einer quergestreiften Muslicllage umhüllt und besteht aus weiten geraden Schliuchen, welche mit zahlreichen Oeffnungen in die Rinne des Organes münden.

\section{\$. 122 .}

Analog der Bildung der weiblichen Geschlechtstheile bei den Elasmobrauchii verhält sich dieselbe unter den Dipnoi bei Lepidosiren ${ }^{1}$ ). Die Ovarien sind parig, an Bauchfellfalten befestigt, mit einem

3) Bei Chimaera verbinden sich dic I'asa deferentia beider Seiten vor ihrer Ausmündung zu einem kurzen Canale nach Leydig.

4) Monro, Tab. IX. der Uebers. Fig. 1.0. J. Müller, De Struct. Glandul. secernent. Tb. XV. Fig. 8. c. Die Mündung dieser Canäle in das Vas deferens ist durch Leydig (Rochen und Ilaie, S. S6.) beobachtet; es fehlte mir an Gelegenheit mich durch Autopsic davon zu überzeugen. Leydig hat auch bei Chimaera die Drüse beobachtet, in welcher das Vas deferens gelegen ist. Die Verhältnisse dieses Gebildes deuten auf einc Analogic desselhen mit einem Wolff'schen Körper. Ein Beutel, gefüllt mit grüner Flüssigkeit, den Mo n ro Tab. XI. abbildet, ist mir ganz unklar, da ich ihn sellsst nie gefunden und auch spätere Beobachter seiner nicht gedenken.

5) Bei Raja wird die Grundlage eines jeden durch dreizehn solide Stïcke gebildet. - Die Art der physiologischen Verwendung dieser merkwürdigen Anhänge ist durch Beobachtungen noch nicht sicher gestellt. Am wahrscheinlichsten bleibt immer die schon vielfach ausgesprochene Ansicht, wonach sie in die weiblichen Geschlechtstheile eingeführt werden, um das Sperma in dieselben zu übertragen. -S. die Beschreibungen in Cuvier (Lecons d'Anat. compar. T. VIII. p. 305.), von Nayer (Froriep's Notizen. 1834. Nr. 876.), von Davy (Researches. Vol. 2. p. 450.). Davy und Leydig (1. c. 86.) haben auch die Drüse näher beschrieben.

1) S. Hyrtl, Lepidosiren. S. 41. Abb. Th. V. 
Bauchfellüberzuge versehen. Am Inncurande des Ovarium verläuft ein dicker, muskulöser, stark gewundener, mit trichterförmiger Erweiterung beginnender Eilciter. Gegen sein hinteres Ende hin geht cr, allmälich sich erweiternd, über in einen dïmwandigen Uterus, weleher an seinem Ende mit dem der anderen Seite sich verbindel. Beide münden hinter der IIarnblase mit einer gemeinsamen Oeffnung aus. Die Schleimhant des Eileiters bildet Längsfalten. In der Mitte seiner Länge besilzt der Eileiter eine starke Drüsenschicht. 



